USP - UNIVERSIDADE DE SÃO PAULO

ESCOLA DE ENGENHARIA DE SÃO CARLOS

JOSÉ HUMBERTO LOPES

\title{
MATERIAIS DIELÉTRICOS DE COMPOSTOS HÍBRIDOS DE MICA E HIDROXIURETANAS OBTIDAS \\ VIA ROTA DE FIXAÇÃO DE CO2.
}

São Carlos, 2020 



\section{JOSÉ HUMBERTO LOPES}

\section{MATERIAIS DIELÉTRICOS DE COMPOSTOS HÍBRIDOS DE MICA E HIDROXIURETANAS OBTIDAS \\ VIA ROTA DE FIXAÇÃO DE $\mathrm{CO}_{2}$. \\ Versão Corrigida.}

Tese apresentada ao programa de PósGraduação em Ciência e Engenharia de Materiais da Universidade de São Paulo, como parte dos requisitos para obtenção do título de Doutor em Ciências.

Área de concentração:

Desenvolvimento, Caracterização e Aplicação de Materiais.

Orientador (a): Ubirajara Pereira Rodrigues Filho.

São Carlos

2020 
AUTORIZO A REPRODUÇÃO E DIVULGAÇÃO TOTAL OU PARCIAL DESTE TRABALHO, POR QUALQUER MEIO CONVENCIONAL OU ELETRO̊NICO, PARA FINS DE ESTUDO E PESQUISA, DESDE QUE CITADA A FONTE. hidroxiuretanas nas obtidas via rota de fixaçăo de $\mathrm{CO}_{2} /$ José Humberto Lopes; orientador Ubirajara Pereira Rodrigues Filho. -- Săo Carlos, 2020.

Tese (Doutorado) - Programa de Pós-Graduação em Ciência e Engenharia de Materiais e Área de Concentração em Desenvolvimento, Caracterizaçăo e Aplicaçăo de Materiais. -- Escola de Engenharia de Săo Carlos da Universidade de Sảo Paulo, 2020.

1. Hidroxiuretanas. 2. Mica. 3. Fixaçăo de $\mathrm{CO}_{2} \cdot 4$. HNIPU. I. Título.

Elaborado por Edusardo Grazlosi SIVa- CRB-S/8907 


\section{FOLHA DE JULGAMENTO}

Candidato: Químico JOSÉ HUMBERTO LOPES.

Título da tese: "Materiais dielétricos de compostos híbridos de mica e hidroxiuretanas obtidas via rota de fixação de $\mathrm{CO} 2 "$.

Data da defesa: $26 / 11 / 2020$.

\section{Comissão Julgadora}

Prof. Associado Ubirajara Pereira Rodrigues Filho (Orientador)

(Instituto de Química de São Carlos/IQSC-USP)

Prof. Dr. Jean Claude MPeko

(Instituto de Física de São Carlos/IFSC-USP)

Dr. Fábio Augusto de Souza Ferreira

(Serviço Nacional de Aprendizagem Industrial/SENAI)

Prof. Titular Bem Hur Viana Borges

(Escola de Engenharia de São Carlos/EESC-USP)

Prof. Dr. Fabio Simões de Vicente

(Universidade Estadual Paulista "Júlio de Mesquita Filho"/UNESP - Rio Claro)
Resultado

-aprovado aprovado

aprovado

_ aprovado

Coordenador do Programa de Pós-Graduação em Ciência e Engenharia de Materiais:

Prof. Associado Marcelo Falcão de Oliveira

Presidente da Comissão de Pós-Graduação:

Prof. Titular Murilo Araujo Romero 



\section{AGRADECIMENTOS}

Ao Professor Ubirajara, meu orientador e principalmente amigo, pessoa que admiro muito e que nesses 18 anos de contato sempre teve a paciência para me mostrar o caminho correto. Sem sua ajuda seria impossível chegar a esse ponto.

Ao Professor Hidetaki pela orientação e pelas discussões sempre no sentido de aprimorar o meu trabalho. Ao Professor Paulo Sérgio da UFSCar, o qual humildemente colaborou para o sucesso da etapa de análise térmica desse projeto. Ao Professor Peko e seu Grupo de alunos do Instituto de Física, em especial a Angélica, pela disponibilidade em ajudar e colaborar para o sucesso do meu projeto.

Aos funcionários do Departamento de Química no Campus 2 que quando necessário estavam prontos a colaborar, não posso deixar de mencionar principalmente o Guto que quando precisei estava à disposição, o Benedito que não colocou obstáculos para a utilização da capela do seu laboratório, o Fabiano por cuidar muito bem dos documentos que eu precisava obter e o João pela ajuda no emprego das técnicas de RMN.

A todos os colegas do Grupo de Materiais Híbridos do IQSC, companheiros de jornada, não podendo deixar de citar alguns que marcaram essa etapa. $\mathrm{O}$ amigo Mateus que foi meu tutor desde o primeiro momento, sempre paciente para ensinar e mostrar a melhor maneira de fazer. A amiga Kellen pela ajuda e compreensão da estratégia na tomada de decisão, o Atila pela ajuda na questão de metodologias de teste, o Elias pelas discussões, o Elton pela ajuda no Origin, a Amanda pelas trocas de ideias e discussões políticas e o Caio por sempre estar pegando no meu pé com as questões de organização do laboratório.

A amiga Glenda da UNESP de Araraquara, ex colega da $3 \mathrm{M}$ a qual me ajudou muito na etapa de correções e ajustes do modelo da minha TESE.

Aos meus familiares, em especial a Raissa, minha filha tão querida e que sempre que precisei nas questões de formatação e computador estava ali para ajudar. Ao meu filho Lucas pelo incentivo e principalmente por me chamar atenção para manter o nível do trabalho e minha parceira de 40 anos de jornada, a companheira do coração, Neusa. Uma pessoa que escolhi e tive a felicidade de estar ao meu lado todo esse tempo, sempre segurando a barra em casa para eu poder encarar esse desafio.

A USP, através do Departamento de Engenharia de Materiais pela oportunidade de realização do Doutorado e o Departamento de Materiais Híbridos pelo suporte na execução do projeto. Ao CNPQ, CAPES e FAPESP pelo financiamento dos Laboratórios utilizados.

A DEUS, sempre me fortalecendo diante dos desafios. 



\section{RESUMO}

LOPES, J. H. MATERIAIS DIELÉTRICOS DE COMPOSTOS HÍBRIDOS DE MICA E HIDROXIURETANAS OBTIDAS VIA ROTA DE FIXAÇÃO DE $\mathrm{CO}_{2 ., 2015}$. X.f Tese (Doutorado) - Escola de Engenharia de São Carlos, Departamento de Engenharia de Materiais Universidade de São Paulo, São Carlos, 2020.

O sistema de isolamento elétrico em Hidrogeradores usados atualmente, são compostos de dois itens principais, o isolamento feito por resina epóxi curada com aminas ou anidridos e pelo uso de uma fita de papel de mica como elemento de proteção térmica e efeito corona. Esse modelo apresenta dois desafios ainda sem solução e que acarretam problemas de confiabilidade de equipamentos de alta responsabilidade, a falha causada pelo excesso de reticulação gerada pelo sistema epóxi, o que provoca ao longo do tempo fraturas, trincas e outros defeitos mecânicos que afetam o sistema de isolamento elétrico e as perdas elétricas geradas pelo uso da fita de mica no formato de papel, que cria uma interface propicia para geração de descargas parciais que comprometem o isolamento elétrico do sistema e o tempo de vida do equipamento.

A Tese aqui apresentada buscou uma nova rota para solucionar esses dois principais problemas, a substituição da fita de mica, pelo uso de uma mica sililada com o aminossilano (3-aminopropiltrimetóxissilano, APTS) dispersa na matriz polimérica e a melhoria da resistência à fratura via aumento das propriedades elásticas ao substituir o sistema epóxi pelo uso da hidroxiuretana, NIPU e HNIPU, de bisfenol A. Na obtenção dessas hidroxiuretanas utilizou-se como monômero o bisfenol A diciclocarbonato, DGEBA, obtido pela rota de $\mathrm{CO}_{2}$. Esse monômero reagiu com os grupos amino da mica sililada e com a isoforenodiamina para formar os diversos compostos testados.

As matérias-primas e os protótipos preparados foram caracterizados quanto à sua estrutura química por técnicas espectroscópicas (Espectroscopia de Ressonância Magnética Nuclear, 
Espectroscopia de Absorção na Região do Infravermelho, Espectroscopia de Fotoelétrons Excitados por Raios X) e ensaios físico-químicos como molhabilidade, absorção de água, \% de gel e estabilidade em THF. As propriedades elétricas foram caracterizadas por espectroscopia de impedância e ensaio de rigidez dielétrica. A análise morfológica foi feita por Microscopia Eletrônica de Varredura e microanálise por espectroscopia dispersiva em energia (EDS). As propriedades mecânicas e térmicas foram obtidas por Análise Termogravimétrica, Calorimetria Exploratória Diferencial (DSC), Análise Dinâmico Mecânica (DMA) e Nanoindentação e suas propriedades químicas.

Os protótipos de HNIPU mostraram resultados extremamente positivos do ponto de vista químico, mecânico (componente elástica) e principalmente em relação às solicitações elétricas, sendo os valores de Fator de dissipação, uma medida indireta de descargas parciais, superior inclusive ao sistema atual com fita de papel de Mica. Do ponto de vista térmico um dos protótipos atendem a $\mathrm{Tg}$ (Transição vítrea) da aplicação, $70^{\circ} \mathrm{C}$, porém novos esforços deverão ser enveredados para que o material atinja o limite de $130{ }^{\circ} \mathrm{C}$.

Quanto aos protótipos NIPU, não se mostraram adequados para serem um substituto ao sistema atual, além da questão térmica inferior, mostraram-se frágeis do ponto de vista mecânico. Contudo, podem ser uma opção para locais onde a solicitação mecânica e térmica seja de natureza inferior.

Um avanço nessa TESE foi o uso da mica sililada, a mesma trouxe a inovação de uso desse conceito para melhorar as propriedades térmicas de sistemas como NIPU, HNIPU e também ao próprio sistema atual, Epóxi. A mesma mostrou que pode ser uma opção para melhoria das características elásticas do sistema atual, além de comprovar que seu uso pode ser uma opção a fita de Papel de Mica usada atualmente no sistema epóxi/anidrido.

Palavras-chave: hidroxiuretanas, Mica, fixação de $\mathrm{CO}_{2}$, HNIPU 


\begin{abstract}
LOPES, J. H. New Dielectric Composite of Mica and hydroxyurethane obtained by $\mathrm{CO}_{2}$ fixation Route. 2015. X.f. Thesis (PhD) - Escola de Engenharia de São Carlos, Departamento de Engenharia de Materiais Universidade de São Paulo, São Carlos, 2020.

The electrical insulation system in Hydrogenerators used today are composed of two main items, the insulation made by epoxy resin cured with amines or anhydrides and the use of a mica paper tape as an element of thermal protection and corona effect. This model presents two challenges that are still unsolved and that cause reliability problems in high responsibility equipment, the failure caused by the excess of crosslinking generated by the epoxy system, which causes fractures, cracks and other mechanical defects that affect the system over time. of electrical insulation and the electrical losses generated by the use of mica tape in paper format, which creates an interface conducive to the generation of partial discharges that compromise the electrical insulation of the system and the life of the equipment.
\end{abstract}

The Thesis presented here sought a new route to solve these two main problems, the replacement of the mica tape, by the use of a silylated mica with the aminosilane dispersed in the polymeric matrix and the improvement of fracture resistance via more suitable elastic properties once replacing the epoxy system with the use of hydroxyurethane, NIPU and HNIPU. The bisphenol A dicyclocarbonate, DGEBA, obtain by $\mathrm{CO} 2$ fixation reacts by amylolysis with amino groups in the sylilated micas as well as with isophorenediamine, IPDA, to for the NIPU and HNIPU composites with mica powder.

The raw materials and composites were characterized in terms of their chemical structure by spectroscopic techniques such as Nuclear Magnetic Resonance, Mid Infrared Spectroscopy, X-ray Photoelectron Spectroscopy, and physico-chemical methods such as water static contact angle (wettability), water absorption, $\%$ gel and THF stability. The electrical properties were characterized by impedance spectroscopy and dielectric strength test. Scanning Electron Microscopy performed the morphological analysis with microanalysis by 
energy dispersive spectroscopy (EDS). The thermal and mechanical properties were probed by Thermogravimetric Analysis, Differential Scanning Calorimetry (DSC), Dynamic Mechanical Analysis (DMA) and nanoindentation.

Within the premises of being an alternative for isolation in Hydrogenerators, the HNIPU prototypes showed extremely positive results from the chemical, mechanical (elastic component) point of view and mainly the electrical demands, being the dissipation factor values, an indirect measure of discharges partial, even higher than the current system with Mica paper tape. From the thermal point of view, one of the prototypes meet the application's $\mathrm{Tg}$ (glass transition), $70^{\circ} \mathrm{C}$, but this parameter will need to be improved to meet emergency requests, $130{ }^{\circ} \mathrm{C}$.

As for the NIPU prototypes, they have not been shown to be a substitute for the current system, in addition to the lower thermal issue; they have shown themselves to be mechanically fragile. They can be an option for places where the mechanical and thermal stress is of a lower requirement.

A breakthrough in this THESIS was the use of silylated mica; it brought the innovation of using this concept to improve the thermal properties of systems like NIPU, HNIPU and to the current system, Epoxy. It showed that it could be an option to improve the elastic characteristics of the current system, in addition to proving that its use can be an option to Mica Paper tape currently used in the epoxy / anhydride system.

Keywords: hydroxyurethanes, Mica, $\mathrm{CO}_{2}$ fixation, HNIPU. 


\section{LISTA DE FIGURAS}

Figura 1 - Processo Atual de Preparação da Isolação no hidrogerador usando o sistema epóxi curado com anidrido

Figura 2 -Processo Resultante das Premissas usadas nesse Projeto de TESE com a substituição da fita de Papel de Mica 36

Figura 3 -Hidrogerador de Itaipu com o esquema de funcionamento e as partes de Isolação 37

Figura 4 - Corte de um estator com identificação de suas partes principais onde para efeito dessa TESE o item 1 (enfitamento com fita de Mica) 38

Figura 5 - Dados Estatísticos do Modo de Falha de um Hidrogerador, na cor vermelha o percentual correspondente a falha por isolação

Figura 6 - Fenômeno de polarização de um liquido polar, representado por um dipolo elétrico, como substância dielétrica em um capacitor

Figura. 7- Representação esquemática dos dipolos elétricos em um material dielétrico polar submetido a um campo elétrico externo horizontal.

Figura 8 -Representação esquemática de um compósito resina epóxi/mica, importante para efeito dessa TESE é representar a formação de fratura causada pela componente .46

Figura 9- Micrografia de um material isolante envelhecido apresentando as delaminações na fita de mica e formação de falha na interface. .48

Figura 10- Grupo funcional Epóxi ou Oxirano, ponto de reticulação no processo de cura. 50

Figura 11 - Mecanismo de reação de um sistema epóxido com "endurecedor" do tipo diamina

Figura 12 - Estrutura Molecular do Éter Diglicidilico do Bisfenol A (DGEBA) 51

Figura 13 - Representação da Estrutura molecular do DGEBA 51

Figura 14 - Etapas de cura em polímeros termorrígidos 53 
Figura 15. Esquema simplificado do processo de cura e gelatinização da resina epóxi......53

Figura 16 - Reação iniciada por sistema não catalítico..................................................57

Figura 17 - Reação iniciada por sistema catalítico.......................................................... 57

Figura 18 - Perfil das transições em cura em função do tempo........................................ 58

Figura 19 - Fórmula e Nome Químico das Aminas Alifáticas Usadas em Sistema epóxi. 58

Figura 20- Fórmula e nome químico das aminas cicloalifáticas usadas em sistema epóxi. 59

Figura 21- Fórmula e nome químico, aminas aromáticas usadas em sistema epóxi........... 59

Figura 22 - Estrutura química dos endurecedores, a) TETA, b) DDS e c) DDM................63

Figura 23- Estrutura do POSS funcionalizado.....................................................................66

Figura 24- Arranjo de silicatos $\left(\mathrm{Si}_{2} \mathrm{O}_{5}\right)^{2-}$ formando anéis hexagonais interligados.............67

Figura 25- Placa formada por íons metálicos em sítio octaédrico.......................................68

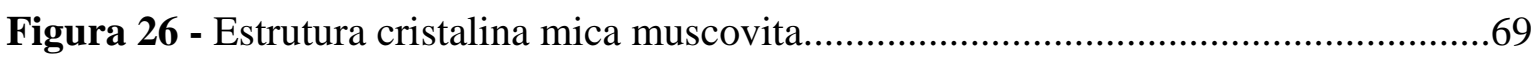

Figura 27 - Mica, Fita de papel de mica e barra impregnada .......................................... 71

Figura 28 - Comparação do fator de dissipação entre sistema com nanoparticula e sistema

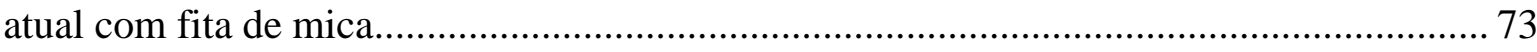

Figura 29 - Esquema de reação do silano com a argila...................................................... 76

Figura 30- Relação entre concentração e tempo de reação.................................................. 78

Figura 31 - Imagem MEV do quartzo/Silano/Polímero....................................................... 80

Figura 32- Imagem MEV do quartzo/polímero sem tratamento de silano......................... 80

Figura 33 - Representação dos compostos híbridos classe II ......................................... 83

Figura 34 - Reação de funcionalização de um óxido metálico............................................ 83

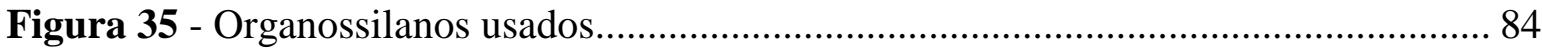

Figura 36 - a) Ciclocarbonato reagindo com amina via híbrido e formando uretana e b) epóxi reagindo com amina do híbrido e fazendo a reticulação....................................................84

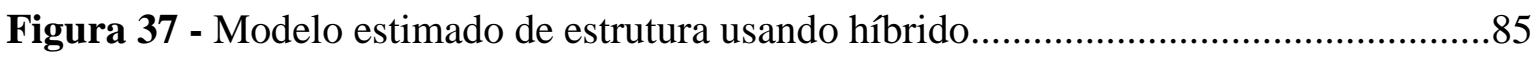

Figura 38 - Mecanismos de reação epóxi silicone a) grupamento epóxi b) silicone............87

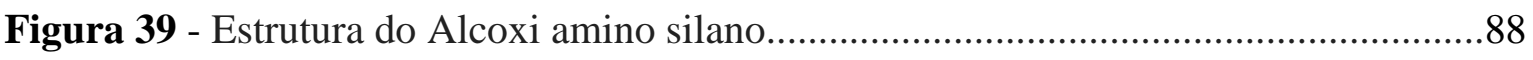


Figura 40 - Possíveis reações usando o usando $\mathrm{CO}_{2}$ como reagente. 91

Figura 41 - Esquema da reação do $\mathrm{CO}_{2}$ com oxiranos (epóxi)

Figura 42 - Esquema evidenciando a obtenção de ciclocarbonato pela ação do catalisador brometo de tetraetilamônio (TEBA) 93

Figura 43 - Formação de um ciclocarbonato....................................................................... 93

Figura 44 - a) reação padrão para formação de poli (uretana) b) e estrutura típica............ 94

Figura 45 - Rota de síntese do TDI, evidenciando a liberação de ácidos e fosgênio.......... 94

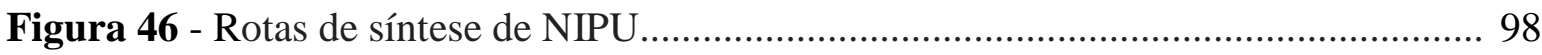

Figura 47 - Modelo de síntese de poli (uretana) s a partir de um bis (ciclocarbonato) e monoamina. 99

Figura 48 - Síntese de Prepolímeros funcionalizados e reação posterior com epóxi ........102

Figura 49- Estrutura do Aminohidroxiuretano proposto por Figovsky..............................103

Figura 50 - Fluxograma para Preparação da Mistura Para teste DSC (cura) .............. 107

Figura 51 - Fluxograma da Síntese da Mistura Para a teste DSC (epóxi) ..................... 108

Figura 52- Fluxograma para obter os protótipos epóxi Para testes Térmicos, elétricos e Imagem 109

Figura 53 - Esquema de preparação da NIPU usando TETA...........................................110

Figura 54 - Método usado para preparação NIPU diferentes razões equivalente .............112

Figura 55 - Método usado para preparação da HNIPU (NIPU terminação amina) ............113

Figura 56 - Fluxograma de Testes com os Insumos usados na TESE ..............................113

Figura 57- Reação para obter o ciclocarbonato (CCGEBA) e técnicas usadas na análise. 114 Figura 58 - Fluxograma para visualização da temperatura de cura de epóxi e NIPU....... 114 Figura 59 - Fluxograma de análise para caracterização do pré polímero NIPU terminação

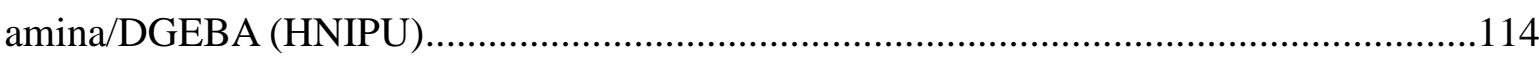

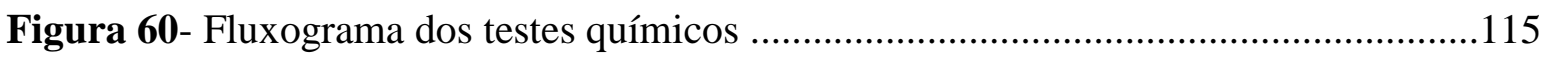

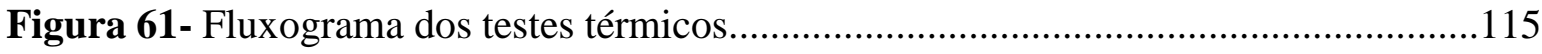

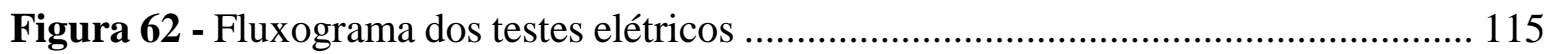


Figura 63 - Fluxograma da caracterização mecânica dos protótipos Epóxi, NIPU e HNIPU.

Figura 64- Fluxograma da caracterização morfológica por micrografia dos protótipos Epóxi, NIPU e HNIPU 116

Figura 65- Reação na titulação com ácido perclórico. .117

Figura 66 - Frasco com amostra solubilizada e equipamento usado na RMN .118

Figura 67 - RMN Agilent Modelo 500/54. 120

Figura 68 - Tensiomêtro ATTENSION 124

Figura 69 - Gota de Água superpura sendo aplicada. 125

Figura 70- Imagem do equipamento para rigidez dielétrica, placa suporte 126

Figura 71 - Gráfico da Impedância em função da Frequência 126

Figura 72 - Corpos de prova submetido a análise de impedância 127

Figura 73 - TGA 50 Shimadzu. 131

Figura 74 - Sinais Gerados e Medidos no DMA 133

Figura 75 - Relações das componentes através do uso do ângulo de fase. 133

Figura 76 - Diagrama esquemático da geometria de medida "Single Cantilever". 134

Figura 77 - Amostra inserida no equipamento DMA (single Cantilever). .134

Figura 78 - Eventos Observados em uma análise de DSC 135

Figura 79 - Indentador Berkovich 136

Figura 80-Representação esquemática de uma indentação com uma ponta piramidal 137

Figura 81 -Curvas de carga e descarga em materiais a) totalmente plásticos, b) elasto plásticos e c) totalmente elásticos 138

Figura 82 - Típica curva de nanoidentação com carga e recuperação. 138

Figura 83-Grupos Funcionais de aminossilano na superfície tratada com APTS 141

Figura 84 - Comparativo de concentração das espécies presentes na superfície. 143

Figura 85- Espectros de fotoemissão em baixa resolução de energia obtida XPS. 144

Figura 86 - Espectro de absorção na região do Infravermelho médio 145 
Figura 87-Espectro de absorção na região de Infravermelho médio protocolo 2 ................ 146

Figura 88 - Espectro de absorção na região de Infravermelho protocolo 3 e 4 ................. 147

Figura 89 - Espectro de RMN H${ }^{1}$ e evidências da formação de ciclocarbonato................. 148

Figura 90- Espectro de $\mathrm{RMN} \mathrm{H}{ }^{1}$ para confirmação da formação de ciclocarbonato..........150

Figura 91 - Reator usado para síntese de Ciclocarbonato.............................................. 151

Figura 92 - FTIR amostra síntese para protótipos de NIPU......................................... 152

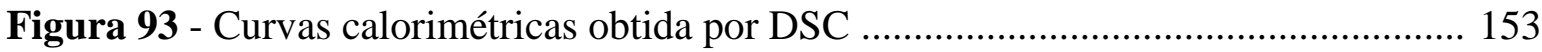

Figura 94- Ampliação da Curva calorimétrica da Figura 93 com a finalidade de mostrar a região da transição vítrea e estimar a Tg......................................................................... 154

Figura 95- Curvas DSC para o sistema Epóxi/TETA/Mica........................................ 155

Figura 96-Parametro de Cura, segundo ciclo do sistema DGEB/Teta/Mica ............... 155

Figura 97-Curva DSC (NIPU CCGEBA e TETA em pasta)....................................... 156

Figura.98-Curva calorimétrica diferencial para a mistura CCGEBA fundido +TETA) ....157

Figura 99 - Estrutura química do TETA e IPDA....................................................... 158

Figura 100 -Espectros de absorção na região do Infravermelho Médio do Ciclocarbonato e

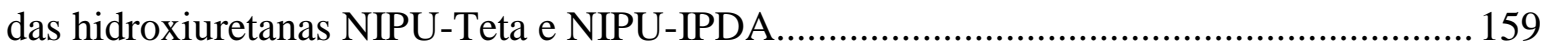

Figura 101- Espectro e absorção na região do Infravermelho médio do ciclocarbonato

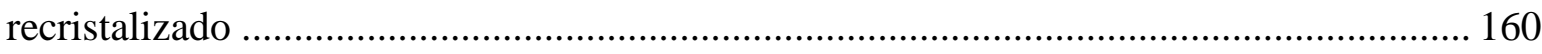

Figura 102- Espectro e Absorção na região do Infravermelho médio do DGEBA..............160

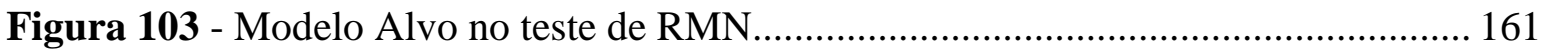

Figura 104 - Estrutura evidenciada pela análise de RMN.......................................... 162

Figura 105 - Espectro de Infravermelho Pré polímero de NIPU com excesso de Amina. 162

Figura 106 - Espectro da HNIPU (cura do pré-polimero com DGEBA............................163

Figura 107 - Gráficos de \% de Absorção de Água.............................................................. 165

Figura 108 - Representação Gráfica da percentagem de gelificação em THF.................. 168

Figura 109 - Fotografia das amostras dos Protótipos após 24 horas imersos em THF...... 168

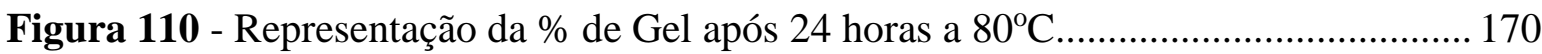


Figura 111 - Medidas de ângulo de Contato.

Figura 112 - Curvas Termogravimétricas dos materiais base NIPU, formulaçães 1 a $3 \ldots 175$

Figura 113 - Comportamento Perda de Massa no Protótipo NIPU 3............................. 176

Figura 114 - Comportamento Perda de Massa Protótipo NIPU 4 .................................. 176

Figura 115 - Comportamento Perda de Massa Protótipo NIPU 2 ................................... 177

Figura 116 - Representação Gráfica do \% de Perda de Massa (NIPU) ........................... 177

Figura 117-Comportamento Termogravimétrico para os materiais Epóxi, .................... 178

Figura 118 - Comportamento Perda de Massa (Epóxi 2) ............................ 179

Figura 119- Comportamento Perda de Massa (Epóxi 3) ............................................ 179

Figura 120 - Comportamento Perda de Massa (Epóxi 1) ......................................... 180

Figura 121-Representação gráfica \% Perda de Massa em função da Temperatura ............180

Figura 122- Comportamento Perda de Massa Amostras HNIPU..................... 181

Figura 123 - Comportamento Perda de Massa Protótipo HNIPU 4 com TETA. 182

Figura 124 - Comportamento Perda de Massa Protótipo HNIPU 2

Figura 125 - Comportamento Perda de Massa Protótipo HNIPU 3. 185

Figura 126 - Comportamento Perda de Massa Protótipo HNIPU $1 \quad 184$

Figura 127 - Representação Gráfica das Perdas nas HNIPUs................................... 185

Figura128 -Gráfico obtido no DSC para (NIPU4). (Segundo aquecimento) ...................187

Figura129 -Gráfico obtido no DSC NIPU 2. (Segundo aquecimento) ..............................187

Figura. 130-Gráfico obtido no DSC para Epóxi 2 (Segundo aquecimento). ....................188

Figura. 131 -Gráfico obtido no DSC para Epóxi 3. (Segundo aquecimento) ..................189

Figura132-Gráfico obtido no DSC para HNIPU 4. (Segundo aquecimento) 189

Figura. 133-Gráfico obtido no DSC para HNIPU 2 (Segundo aquecimento) .................. 190

Figura 134 - Gráfico obtido no DSC para HNIPU 3(Segundo aquecimento) ................. 190

Figura 135 - Representação Gráfica dos dados de Tg (segundo aquecimento) ..................191

Figura 136- Ilustração da Formação de Volume livre devido introdução de partículas......193 
Figura 137- Dependência do módulo de armazenamento (E') em função da temperatura para cada amostra em estudo.

Figura 138 -Dependência do módulo de perda (E') em função da temperatura para as diferentes amostras em estudo.

Figura 139- Curvas de $\operatorname{tg} \delta$ em função da temperatura para as amostras em estudo 196

Figura140-Gráfico mostrando a comparação entre valores de $\mathrm{Tg}$ obtidos por DMA 198

Figura 141 - Comparação entre as curvas de Tg em função temperatura HNIPU 4 199

Figura142 - Comparação entre as curvas de Tg em função temperatura HNIPU 3..........200

Figura 143 - Comparação entre as curvas de Tg em função temperatura HNIPU 2.........201

Figura 144- Comparação entre as curvas de Tg em função temperatura todas as amostras.201 Figura 145 - Módulo de armazenamento (E') em função da temperatura para amostra HNIPU

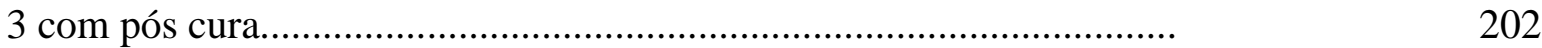

Figura 146- Módulo de armazenamento (E') em função da temperatura para amostra HNIPU 2 com pós cura.

Figura 147 - Módulo de armazenamento (E’) em função da temperatura para amostra HNIPU 4 é pós cura.

Figura 148- Comparação da resposta do módulo de perda (E'’) em função da temperatura para HNIPU 3 e pós cura................................................................... 204

Figura 149 - Dependência do módulo de perda (E') em função da temperatura para HNIPU 2 e pós cura.

Figura 150 - Dependência do módulo de perda (E') em função da temperatura para HNIPU 4 e pós cura

Figura 151 - Gráfico com Valores de Rigidez Dielétrica................................................. 207

Figura 152 - Comportamento Protótipos Epóxi Constante Dielétrica ASTM D 150...... 210

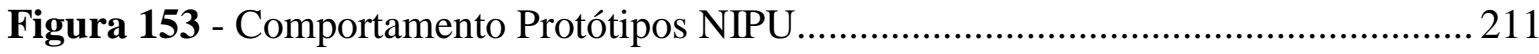

Figura 154 - Comportamento Protótipos HNIPU (NIPU/DGEBA) .................................. 212 
Figura 155- Comportamento Protótipos Epóxi Fator de Dissipação. ASTM D150......... 214

Figura 156 - Comportamento Protótipos NIPU Fator de Dissipação ASTM D150.......... 214

Figura 157 - Comportamento Protótipos HNIPU Fator de Dissipação ASTM D150....... 215

Figura 158 - Comportamento do Fator de Perda em sistema usando Fita de Mica............216

Figura 159 Comportamento da dureza obtida via Nanoindentação..............................219

Figura 160- Dados médios de módulo elástico (GPa) via nanoidentação......................... 219

Figura 161 - Esquema do protótipo para teste de imagem............................................ 220

Figura 162- Imagem fractográfica da superfície fraturada Epóxi 3. (2000 X)............... 221

Figura 163 - Imagem fractográfica da superfície fraturada Epóxi 2. $(2000$ X)............ 221

Figura 164 - Imagem fractográfica da superfície HNIPU 2. $(200 \mathrm{X})$............................ 222

Figura 165- Imagem fractográfica da superfície fraturada HNIPU 3. (200 X)................ 223

Figura 166 - Imagem fractográfica da superfície fraturada HNIPU 2. (2000 X)............. 224

Figura 167 - Imagem fractográfica da superfície fraturada HNIPU 3. (2160 X)............. 224

Figura 168- Mapeamento EDS da superfície do epóxi 2 (2000 X) ............................... 226

Figura 169 Mapeamento EDS da superfície do epóxi $3(2000$ X) .................................226

Figura 170 - Mapeamento EDS da superfície da HNIPU 2 (2000 X) .................................. 227

Figura 171 - Mapeamento EDS da superfície da HNIPU3 (2000 X) .............................. 227

Figura 172 - Representação da estrutura atual com diciclocarbonato..............................231

Figura 173 - Representação Gráfica do pré-polímero com terminação IPDA....................232

Figura 174 - Representação Gráfica do novo pré-polímero com triamina.........................232

Figura 175 - Representação do novo monômero proposto................................................233 


\section{LISTA DE TABELAS}

Tabela 1-Condutividade Elétrica de alguns materiais relevantes para esse projeto de TESE

Tabela 2-Principais materiais de isolamento, classe de isolamento e temperatura de uso.

Tabela 3-Propriedades da resina Bisfenol A Diglicidil éter (DGEBA) .51

Tabela 4 -_Resumo de propriedades das moléculas usadas como endurecedores para resinas epóxi...... 54

Tabela 5 - Propriedades Elétricas das micas usadas em aplicação elétrica 69

Tabela 6 - Pressão de vapor dos isocianatos utilizados em poli(uretana)s. .95

Tabela 7 - Constante Dielétrica de solventes e taxa de Conversão da reação do Etileno carbonato com Ciclohexilamina 101

Tabela 8 - Parametros de Formulação e Processos nas Diversas sínteses de ciclocarbonato sob pressurização. 106

Tabela 9 - Parametros de Formulação e Processos nas diversas sínteses a pressão atmosférica.

Tabela 10 - Estequiometria sistema epóxi sem mica. 107

Tabela 11 - Estequiometria sistema epóxi utilizando mica 108.

Tabela 12 - Balanço de formulação para testes térmicos, elétricos e imagem. 108

Tabela 13 -Massa molar, número de grupos reativos por molécula(funcionalidade) e equivalentes dos reagentes (gramas/mol) 110

Tabela 14 - Estequiometria usada para obter a NIPU razão molar 1/1 111

Tabela 15- Estequiometria usada para obter a NIPU razão molar 1,5 /1

Tabela 16 - Estequiometria usada para obter a NIPU razão molar 2,0 /1

Tabela 17 - Estequiometria usada para obter a NIPU razão molar 1,0 /2 
Tabela 18 - Formulação para obtenção do Pré Polímero CCGEBA/IPDA $(1: 1,5)$ e NIPU

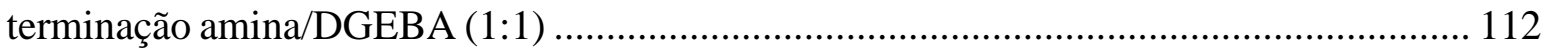

Tabela 19 -_Parâmetros de aquisição dos espectros de XPS......................................... 121

Tabela 20 - Relação entre os Formalismos da Impedância..............................................129

Tabela 21 - Resultado com os materiais alvo (principalmente Nitrogênio).......................141

Tabela 22 - Composição Superficial em percentagem atômica obtidos por meio de XPS..142

Tabela 23 - Sínteses usando co-catalisador.................................................................... 149

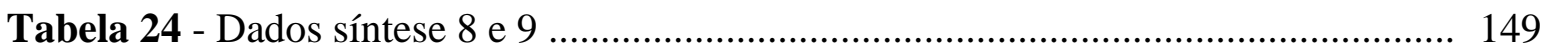

Tabela 25 - Síntese para Obtenção dos Protótipos para os testes finais...............................151

Tabela 26 - Fómulas usadas para o teste de absorção de água ......................................... 164

Tabela 27 -Dados com resultado final \% absorção de água ...............................................165

Tabela 28 - Composição dos protótipos usados para Grau de Gelificaçãa .........................166

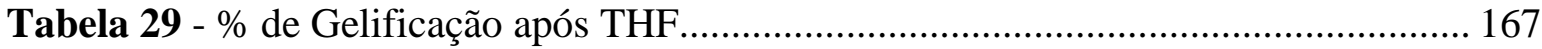

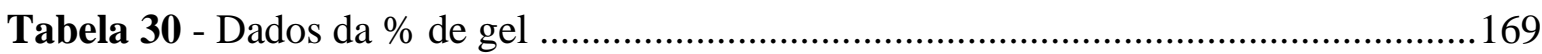

Tabela 31 -_Composição dos protótipos para teste do ângulo de contato....................... 171

Tabela 32 -_Dados obtidos no teste de molhabilidade via medida de ângulo de contato. 172

Tabela 33 -_Descrição das amostras usadas na avaliação via TGA ............................... 174

Tabela 34 - Quadro Resumo da \% de Perdas de massa em faixa de temperatura........... 177

Tabela 35 -Quadro Resumo da \% de Perdas de massa protótipos epóxi em faixa de

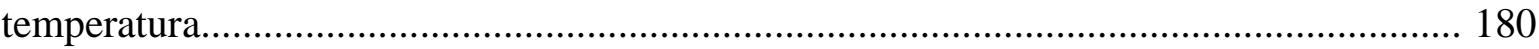

Tabela 36 -Resumo \% de Perdas de massa das HNIPU em faixa de temperatura ............184

Tabela 37 - Composição dos protótipos avaliados via DSC ...........................................186

Tabela 38 - Resumo dos dados gerais de $\mathrm{Tg}$, das amostras testadas.................................191

Tabela 39 - Fórmulas dos Protótipos Usados para DMA............................................. 193

Tabela 40 - Medidas das amostras avaliadas no DMA ….................................................194

Tabela 41 - Dados de Tg obtidos por DMA com aqueles obtidos por DSC................... 198

Tabela 42 - Protótipos de HNIPU que sofreram a pós cura .............................. 199 
Tabela 43 - Valores Tg obtidos dos primeiros centroides para HNIPU .202

Tabela 44 - Formulação usada nos testes elétricos 206

Tabela 45 - Dados obtidos nos testes de rigidez dielétrica ........................................... 206

Tabela 46 -_Medidas dos corpos de prova usados na impedância ................................. 208

Tabela 47 - Dados de capacitância Real obtida no teste de impedância ........................ 209

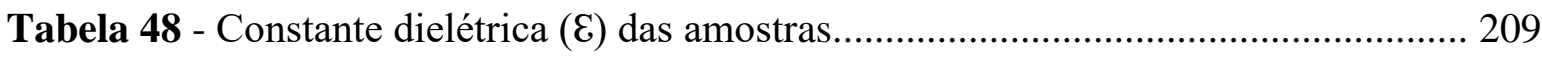

Tabela 49 - Dados obtidos do fator de dissipação............................................................ 213

Tabela 50 - Identificação dos Protótipos avaliados na Nanoindentação........................ 217

Tabela 51 - Lista das propriedades Mecânicas obtidas por nanoidentação .......................218

Tabela 52 - Identificação dos Materiais avaliados por Fractografia............................ 220 



\section{LISTA DE ABREVIATURAS E SIGLAS}

AC - Corrente alternada

APTS - 3- aminopropil (trietóxissilano),

ASTM - Sociedade Americana de Métodos e Testes.

ATPB - poli (butadieno) terminado com grupo amino

ATR - Refletância total atenuada ou reflectância externa

BDGE - 1,4 butanodioldiglicidiléter ou 1,4-Bis (2,3-epoxipropiloxi) butano

CCGEBA- Ciclocarbonato do Diglicidil éter de Bisfenol A.

$\mathrm{CO}_{2}$ - Dióxido de carbono ou gás carbônico

COZY - Espectroscopia de Correlação homonuclear.

CTBN - poli (butadieno-co-acrilonitrila) terminado com grupo carboxila ou Copolímero de butadienoacrilonitrila com grupo carboxila terminal

DBU - 1,8-diazobiciclo[5.4.0]undec-7-eno

DC- Corrente Contínua (do inglês Direct current).

DDS - 4,4 - diaminodifenilsulfona

DDM - 4,4-diaminodifenilmetano

DEPT 135 - Intensificação sem distorção por Transferência de Polarização.

DETA - DietilenoTriamina ou 2,2'-Diaminodietilamina

DGEBA - Bis Glicidil éter de Bisfenol A ou 2-[[4-[2-[4-(Oxiran-2-ilmetoxi) fenil]propan-2-

il]fenoxi]metil]oxirane

DMTA ou DMA - Análise Dinâmico Mecânico ou Termodinâmico Mecânico.

DRIFT - Espectroscopia de Absorção no Infravermelho Médio em modo interferométrico por refletância difusa

DSC - Calorimetria Exploratória Diferencial

EDA - 1,2-etileno diamina ou 1,2-diaminopropano

FTIR - Espectroscopia de absorção na região do infravermelho médio em modo interferométrico 
GPa. - Giga Pascal.

GPTS - Glicidoxipropiltrimetóxissilano

HNIPU - Hybrid Non-Isocyanate Polyurethane.

HSQC - Heteronuclear Single Quantum Coherence

IUPAC - União Internacional de Química Pura e Aplicada.

IPDA - mistura de isômeros cis e trans da Isoforeno Diamina ou 5-Amino-1,3,3trimetiylciclohexanemetilamina

KV - Quilo Volt.

MDI - 1-isocianato-4-[(4-fenilisocianato) metil] benzeno

MEV - Microscopia Eletrônica de Varredura

MMA - Metilmetacrilato

Mmol - Milimol.

MPS - [3-(Methacriloiloxi) propil] trimetoxissilano ou 3-(Trimetoisilil)propil metacrilato NIPU - Non Isocyanate Polyurethane ou Poli (uretana) obtida sem o uso de isocianatos nm - nanômetro (medida que equivale a $10^{-9} \mathrm{~m}$ ).

OC - Octakis[[2-(3,4-epoxiciclohexil) etil] dimetilsiloxi]octasilsesquioxane

OG - Octa [ (3-Propilglicidiléer) Dimetilsiloxi] Silsesquioxane

Pf - Pico Farad.

PHUs - poli (hidroxiuretanas)

PMMA - poli (metil metacrilato) ou poliéster metílico de ácido metacrílico 
POSS - OctaSilsesquioxane oligomérico poliédrico

Ppm: Partes por milhão.

PPO - Poli (óxido de Fenileno)

PU - Poli(uretana)

PVC - Poli(cloreto de vinila)

RMN - Ressonância magnética nuclear

RPI - Rede polimérica Interpenetrante

TEBA - Brometo de Tetraetilamônio

TBD - 1,5,7-triazabiciclo [4.4.0] dec-5-eno

TDI - 2,4-Diisocianato-1-metilbenzeno ou 2,4-Diisocianato-1-metilbenzeno

TETA - Trietileno Tetra Amina ou N, N'-Bis (2-aminoetil) etano-1,2-diamina.

$\mathrm{T}_{\mathrm{g}}$ - Temperatura de transição vítrea

TGA - Análise termogravimétrica

TGDDM - N, N'-tetraglicidil diaminodifenilmetano.

XPS - Espectroscopia de Fotoelétrons Excitados por Raios X 



\section{SUMÁRIO}

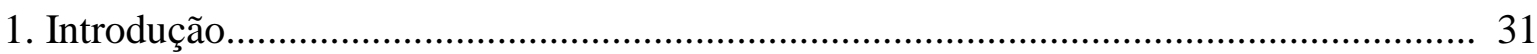

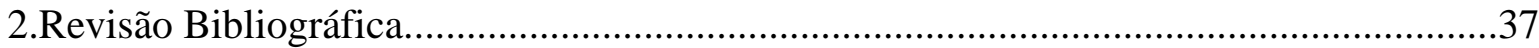

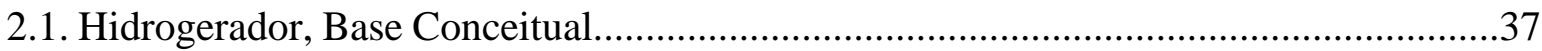

2.2. Isolamento Elétrico e Uso de Sistema epóxi ................................................................ 40

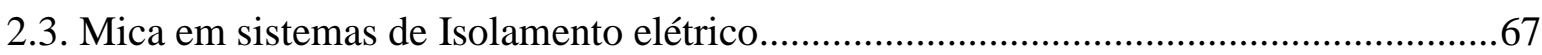

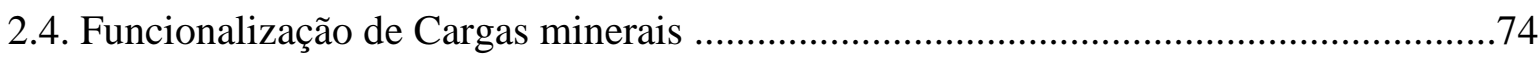

2.5. Obtenção de compósitos híbridos ......................................................................... 82

2.6. Produção de Ciclocarbonatos a partir do Dióxido de Carbono......................................... 89

2.7. Hidroxiuretanas livres de isocianato obtida via ciclocarbonatos .................................. 93

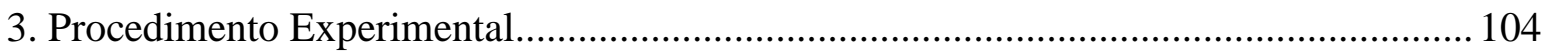

3.1. Materiais utilizados na Síntese do Bis(ciclocarbonato) de DGEBA …………….........104

3.2. Materiais utilizados fase protótipos Sistema Epóxi.................................................... 105

3.3. Materiais Utilizados Fase Protótipos Sistema NIPU/HNIPU.......... 106

3.4. Síntese do Bis(ciclocarbonato) de DGEBA............................................................. 106

3.5. Preparação dos protótipos do sistema epóxi............................................................... 107

3.6. Preparação dos protótipos NIPU para cura via DSC …………………………... 109

3.7. Protótipos HNIPU para Testes Térmicos/Elétricos, Imagem e Químicos................... 112

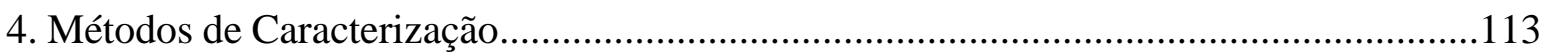

4.1. Fluxograma das metodologias de caracterização usadas............................................ 113

4.2. Espectroscopia de Absorção na região do Infravermelho...............................................116

4.3. Titulação Volumétrica Para cálculo do Equivalente Epóxi .......................................... 117

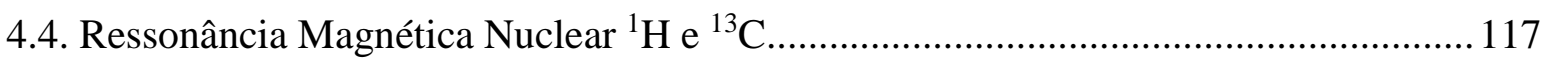

4.5. Espectroscopia de Fotoelétrons excitados por Raio X (XPS) ........................................ 121

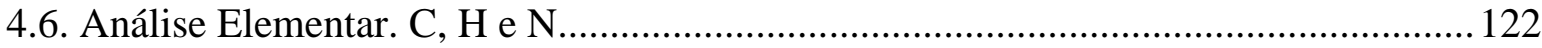

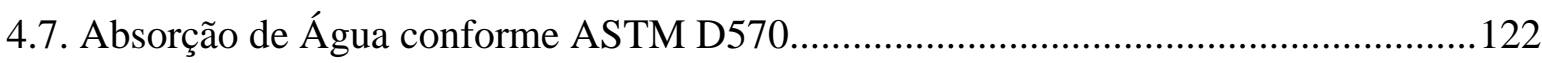

4.8. Análise do Grau de Gelificação emTHF e teor de Gel .............................................. 122 


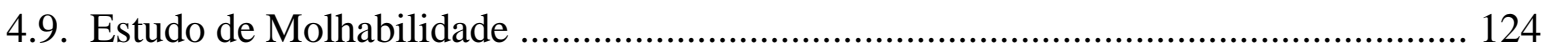

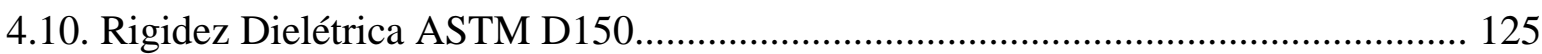

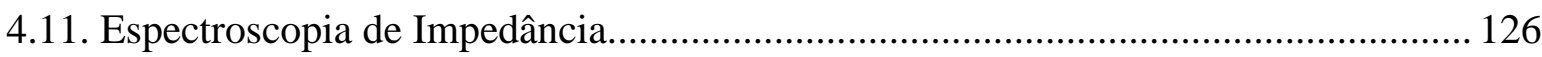

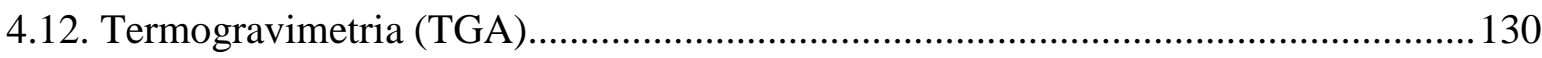

4.13. Análise Dinâmico-Mecânico (DMA)......................................................................131

4.14. Análise térmica de Calorimetria Exploratória Diferencial (DSC)............................. 136

4.15. Análise de Nanoindentação............................................................................. 135

4.16. Fractografia via Microscopia eletrônica de varredura (MEV)................................ 139

4.17. Espectroscopia de Emissão de Raios X com Detecção Dispersiva (EDS)................. 140

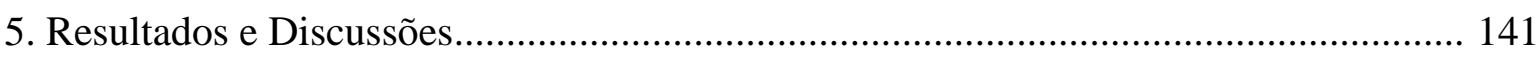

5.1. Avaliação da Mica sem tratamento superficial e tratada superficialmente....................141

5.2. Avaliação dos protocolos de Síntese de Ciclocarbonato ............................................ 145

5.3. Avaliação Protótipos Epóxi/NIPU Parametros de Cura..................................... 153

5.3.1. Obtenção dos Parametros de cura via DSC …………………………………...... 153

5.4. RMN da síntese para obtenção da HNIPU......................................................... 161

5.4.1. Espectroscopia infravermelho protótipos HNIPU ………………………………....162

5.5. Avaliação Absorção de água conforme ASTM D570............................................ 164

5.6. Determinação grau de gelificação em THF e teor de gel............................................. 166

5.7. Avaliação de Molhabilidade via Ângulo de Contato...................................................... 171

5.8. Estabilidade Térmica avaliada por Termogravimetria ( TGA).................................... 174

5.9 Avaliação DSC para os Protótipos............................................................................... 186

5.10. Avaliação DMA Protótipos sem Pós Cura.................................................................. 193

5.11. Avaliação DMA Protótipos com Pós Cura...................................................................198

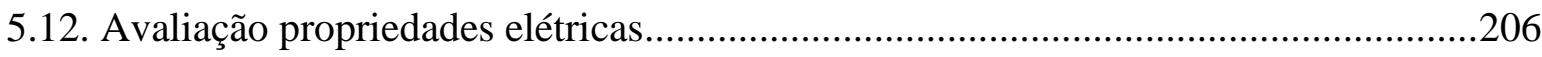

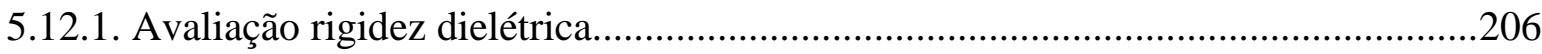

5.12.2. Comportamento Dielétrico por Espectroscopia de Impedância................................208

5.13. Propriedades mecânicas, via nanoindentação............................................................ 217 
5.14. Fractografia por Microscopia Eletrônica de Varredura..............................................220

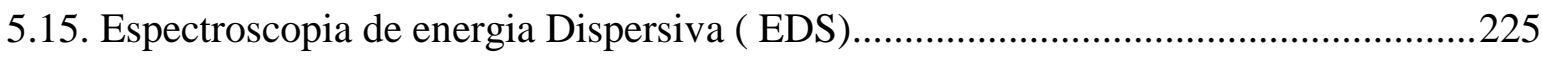

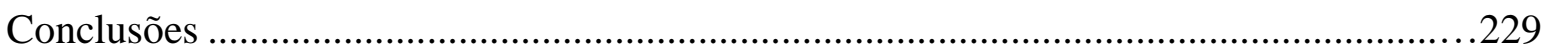

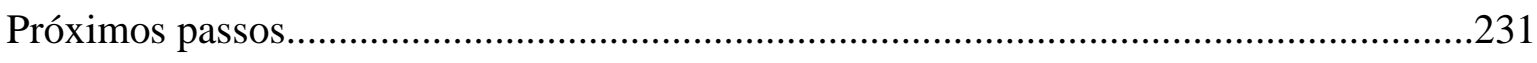

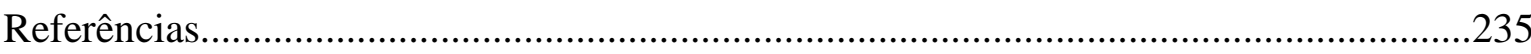

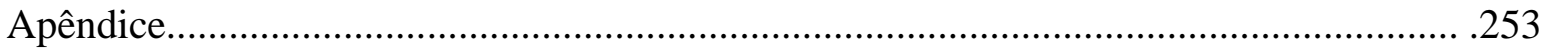





\section{INTRODUÇÃO}

Um dos setores com grande reestruturação em consonância com as tendências globais das necessidades ambientais são os novos equipamentos energéticos que buscam melhorar os materiais isolantes já existentes ou produzir novos materiais com maior durabilidade para um intervalo de uso igualmente maior. Atualmente o fornecimento de energia elétrica tem sido questão estratégica de segurança nacional, sendo que nesse contexto os grandes equipamentos que fazem parte dos parques geradores, tem merecido uma atenção especial. [1]

Deste 1960, a totalidade do sistema de isolamento usados nos equipamentos de geração elétrica como Hidrogeradores, usam o conceito de isolamento obtido com um composto de resina epóxi e mica. [2]

Esse sistema apesar está em uso por mais de 60 anos, portanto, uma tecnologia madura, sendo hoje fornecida sob a forma de fitas de mica, a qual consiste de um papel com mica depositada sobre uma gaze de fibra de vidro, com as partículas aderidas entre si por meio de uma resina epóxi. Esse compósito apresenta uma composição clássica de $30 \%$ de resina epóxi (ou poliéster) e 70\% do pó de mica, formando uma estrutura termofixa monolítica. Ocorre que justamente devido sua estrutura molecular na forma de escamas, esse conceito de isolação apresenta seu "calcanhar de Aquiles", essas microescamas são uma das responsáveis pelo modo de falha de um hidrogerador [2].

Esse material composto altamente reticulado proveniente do uso do epóxi e da fita de mica com escamas e a presença de um suporte (fibra de vidro ou poliéster) é responsável por $56 \%$ dos defeitos em equipamentos do tipo Hidrogeradores. [3 ].

A associação desses dois sistemas acaba gerando as chamadas descargas parciais, essas podem ter sua definição como "faíscas" envolvidas em um fluxo de elétrons e íons em pequenos volumes de ar encapsulados em cavidades que se configuram como defeitos no sistema de isolamento que se caracteriza como um espaço não impregnado por material isolante e que pode enclausurar gases provenientes do material isolante [1]. Assim, se houver uma cavidade, no interior ou superfície de uma isolação, essa pode facilitar o aparecimento de descargas, resultando ao longo do tempo na retirada do equipamento de operação. [ 4]

Os sistemas epóxi (mistura do monômero com endurecedores e ou aceleradores) combinam propriedades interessantes como alta resistência mecânica e boa estabilidade 
térmica nas condições de uso dos hidrogeradores. Esse sistema além da questão mecânica apresenta excelente estabilidade e durabilidade como isolante elétrico. A principal desvantagem associada com a aplicação como isolante elétrico é o fato do epóxi ser um polímero termorrígido, aumentado sua fragilidade através do aumento da densidade de reticulação. Essa característica leva a uma perda de resistência ao impacto, assim como, a capacidade de suportar os esforços resultantes da utilização do sistema como isolante elétrico sujeito as condições dos estresses térmicos e mecânicos. [5, 6]

Essa situação tem levado junto com avanços científicos de novas tecnologias para geração de energia elétrica, a busca de novos materiais no sentido de melhorar a confiabilidade dos sistemas atuais. Um dos desafios desse sistema é ter uma alternativa ao uso do conjunto resina epóxi com mica. Aparentemente existe um esgotamento no estado da arte dos compósitos isolantes disponíveis para uso na isolação das barras estatóricas presentes nos Hidrogeradores, quer sejam para melhorar isolação ou mesmo reduzir os custos. Essa busca motiva pesquisadores a desenvolverem alternativas que possam suportar uma rigidez dielétrica acima de $3 \mathrm{KV} / \mathrm{mm}$ encontrados atualmente neste equipamento e uma temperatura acima de $70^{\circ} \mathrm{C}$ com picos até $130^{\circ} \mathrm{C}$ para equipamentos classe $\mathrm{B}$ e $155^{\circ} \mathrm{C}$ para equipamentos classe F. [ 7 ].

Um dos caminhos para melhorar a flexibilidade é utilizar um poli (uretano) como agente de modificação. A reação de isocianato com os grupos hidroxila presentes na resina epóxi, bem como uma cura usando resina epóxi de baixa massa molecular com isocianato e poliaminas, tem sido empregada com esse objetivo [8,9]. Essa abordagem apesar de melhorar a flexibilidade apresenta um sério problema devido a reação do isocianato com água ou umidade do meio, resultando na formação de uréia com a liberação de $\mathrm{CO}_{2}$ na forma de bolhas ou microbolhas, situação que coloca em risco a camada isolante e por consequência pode levar a falha elétrica do componente que contém esse polímero. A presença de microbolhas e a grande absorção de água durante a formação do poli (uretano) convencional, é uma das barreiras ao uso de poli (uretana) em máquinas elétricas. Esses problemas, somados à toxicidade do isocianato, levaram pesquisadores a criar poli (uretana) sem o uso de isocianato, NIPU do inglês Non-isocyanate polyurethanes, obtendo materiais com menor permeabilidade à água e maior resistência química e térmica quando comparados ao poliuretano clássico via uso de Isocianato. [10, 11$]$. 
Outro fator limitante ao uso de poliuretana convencional em sistemas elétricos, se deve ao fato das poliuretanas possuírem muitos grupos polares que tendem a se orientarem com aplicação de um campo elétrico, sendo que a flexibilidade da cadeia facilita essa orientação. De outro lado essa flexibilidade é muito sensível a frequência aplicada e temperatura de operação, gerando com isso elevação nas constantes dielétricas e considerável perdas dissipativas. [12]

As NIPU têm um processo de síntese altamente controlado no aspecto de segurança, com menor risco ao operador e usuário, assim como, menor impacto ambiental comparado às rotas sintéticas convencionais. Para a obtenção da NIPU utilizam o dióxido de carbono $\left(\mathrm{CO}_{2}\right)$ como matéria prima, rota esta que se tornou uma das mais promissoras dentro da Química Verde. A produção de NIPU pode colaborar com a fixação (parcial) no médio prazo de um dos gases do chamado efeito estufa, portanto, seu uso para aplicação elétrica passou a ser uma possibilidade a ser buscada, principalmente devido sua estrutura central ser proveniente do DGEBA, o que pode ter uma característica polar diferenciada. [13,14]

Portanto, o objetivo desse trabalho foi desenvolver um sistema inovador que produza compósito de hidroxiuretanas e mica para isolamento elétrico usando duas premissas básicas, a obtenção da NIPU tradicional pela síntese de um ciclocarbonato pela adição de $\mathrm{CO}_{2} \mathrm{e}$ usando Mica tratada com aminossilano como precursor para obtenção de um hibrido. Foi sintetizado também a HNIPU, que consiste da obtenção de um ciclocarbonato com terminação amina e sua posterior reação com o DGEBA com o objetivo de aumentar a. densidade de reticulação, sem perder a flexibilidade do sistema poliuretano. Na HNIPU também foi usado a micas organomodificada com aminossilano com o objetivo de aumentar a reticulação, considerado até hoje o grande problema do uso de ciclocarbonato isoladamente em reação com poliaminas [13,14,15]. Importante, não foi utilizado a folha de papel de mica e em seu lugar o próprio hibrido de pó de mica organofuncionalizada, dessa forma ter-se-á a presença de mica como elemento de dissipação térmica e também como agente reticulador,

A versatilidade do trabalho com ciclocarbonato, o uso da mica tratada com aminossilano e principalmente o uso da HNIPU mostrou nesta TESE como algo extremamente promissor para ser uma nova opção ao uso do sistema epóxi/mica em geradores de energia. Abre-se uma nova fronteira para ser explorada nesse segmento extremamente conservador. 


\section{OBJETIVOS}

\section{Objetivo geral}

O objetivo geral desta tese é produzir e avaliar um material compósito dielétrico para resinas epóxi com papel poroso de mica, solucionando os modos de falhas atuais desse sistema. Será um compósito que tenha as propriedades Químicas, físicas, térmicas e elétricas do conjunto epóxi/mica no formato de fita, porém endereçando uma solução para os modos de falhas atuais, alto módulo elástico e problema de interface na fita de mica gerando descargas parciais.

\section{Objetivos específicos}

Obtenção e caracterização de um ciclocarbonato de DGEBA (Bis-Glicidil éter de Bisfenol A) com rendimento de conversão acima de $80 \%$ usando a rota de fixação de $\mathrm{CO}_{2}$.;

Comprovar a presença de grupos $-\mathrm{NH}_{2}$ na Mica sililada fornecida pela empresa Imerys do Brasil e utilizá-la como substituta do papel poroso de mica.

Produção de hidroxiuretanas a partir de reação de adição do precursor ciclocarbonato oligomérico e endurecedores a base de aminas primárias (NIPU) com o uso da mica sililada,

Preparação dos compostos de referência usando resina epóxi e aminas com mica sililada e sem silililação em substituição à fita porosa de papel de mica.

Preparação dos compostos HNIPU (síntese de um pré-polímero proveniente da reação da NIPU com excesso de terminação amina e DGEBA) com Mica sililada e sem silililação em substituição à fita porosa de papel de mica.

- Caracterizar os materiais obtidos (Epóxi, NIPU e HNIPU) do ponto de vista mecânico, elétrico, químico e térmico tendo em vista sua comparação com o sistema atual composto de resina epóxi, reticulada com anidrido ou amina, com papel poroso de mica. 
Figura 1 - Processo atual de Preparação da Isolação no Hidrogerador usando o sistema Epóxi curado com endurecedor do tipo anidrido e usando o sistema de impregnação sob vácuo (VPI).

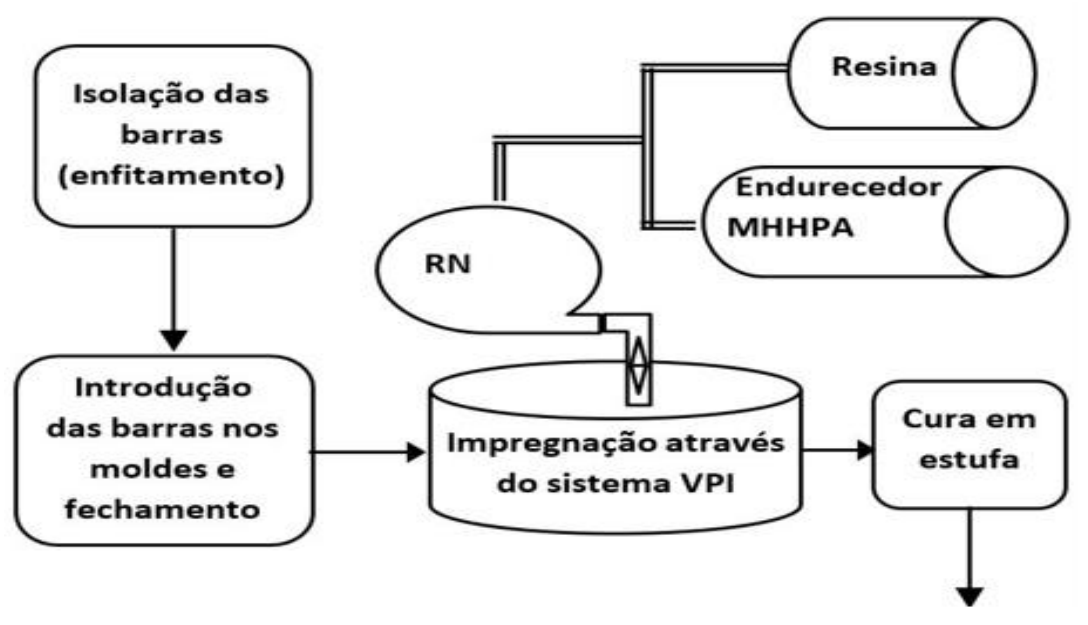

Fonte: Autoria Própria

Figura 2 - Processo Resultante das premissas usadas nesse Projeto de TESE com a substituição da fita de papel de mica pelo uso da mica tratada com aminossilano e o uso do sistema polimérico a base de NIPU ou HNIPU obtida via rota do $\mathrm{CO}_{2}$

\section{SISTEMA PROPOSTO}

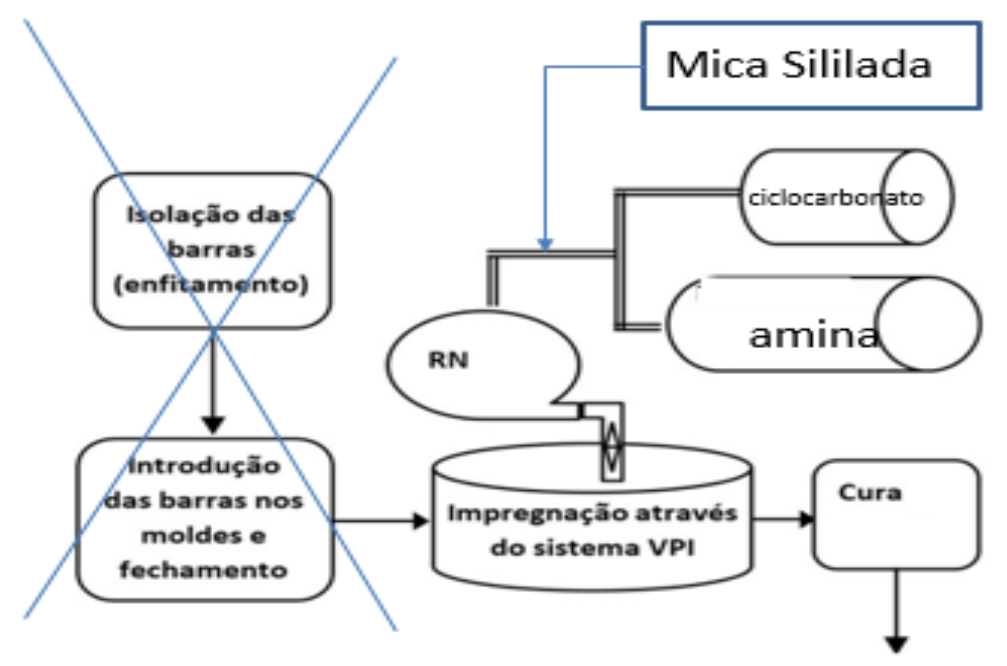

Fonte: Autoria Própria.

Onde temos: VPI como sendo processo de impregnação a vácuo, resina (DGEBA) e endurecedor MHHPA (anidrido metil hexa-hidroftálico) 


\section{REVISÃO BIBLIOGRÁFICA}

\subsection{Hidrogerador, Base Conceitual.}

Trata-se de um equipamento que converte energia mecânica, química, eólica ou de outra forma em energia elétrica. Atualmente $75 \%$ da matriz energética brasileira se dá por esse sistema através das hidrelétricas. [1]

Na figura 3, temos o esquema simplificado de um hidrogerador,

Figura 3 - Hidrogerador de Itaipu com esquema de funcionamento e as partes da isolação e onde se usa a resina epóxi curada com anidrido e o enfitamento com fita porosa de mica. [ 7 ]

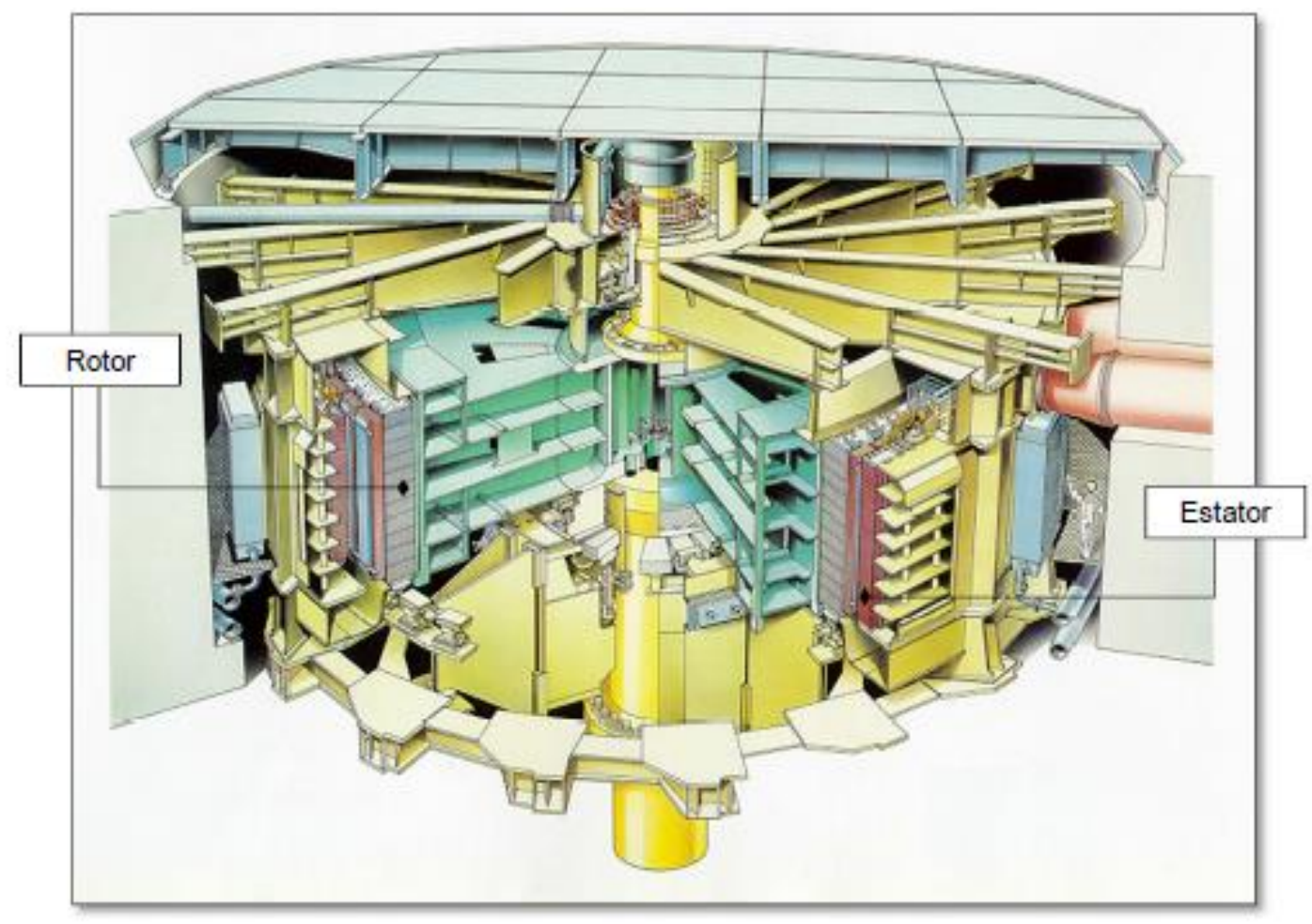

Figura esquemática do hidrogerador de Itaipú (Cortesia Voith Hydro Ltda).

Fonte: Figura extraída de NOVAES, R. D.; et al, Avaliação das propriedades elétricas de barras estatóricas fabricadas com resina do tipo éter diglicidílico do bisfenol $F$ (DGEBF) contendo nano partículas de sílica; Faculdade de Engenharia Química, Universidade Estadual de Campinas UNICAMP, Campinas, SP, Brasil.

O rotor possui polos do tipo coroa por onde circulam correntes contínuas que induzem o campo elétrico. Esse campo gerado induz uma corrente no enrolamento do estator 
(composto por barras), posicionado nas ranhuras do núcleo do estator. Esse núcleo é composto de chapas de material ferromagnético (aço silício) isoladas individualmente. Deste modo, permitindo a indução de correntes elétricas no enrolamento estatórico ao longo das ranhuras do núcleo. [16].

O enrolamento do estator é composto por barras ou bobinas de acordo com o projeto. A Figura 4, ilustra de maneira simplificada um corte feito em um enrolamento estatórico, sendo possível ver os principais materiais usados na sua montagem.

Figura 4 - Corte de um estator com a identificação das suas partes principais, para efeito dessa TESA o item 1 (enfitamento com fita de Mica e o item 1, conjunto com resina epóxi e fita de mica. [ 7 ].

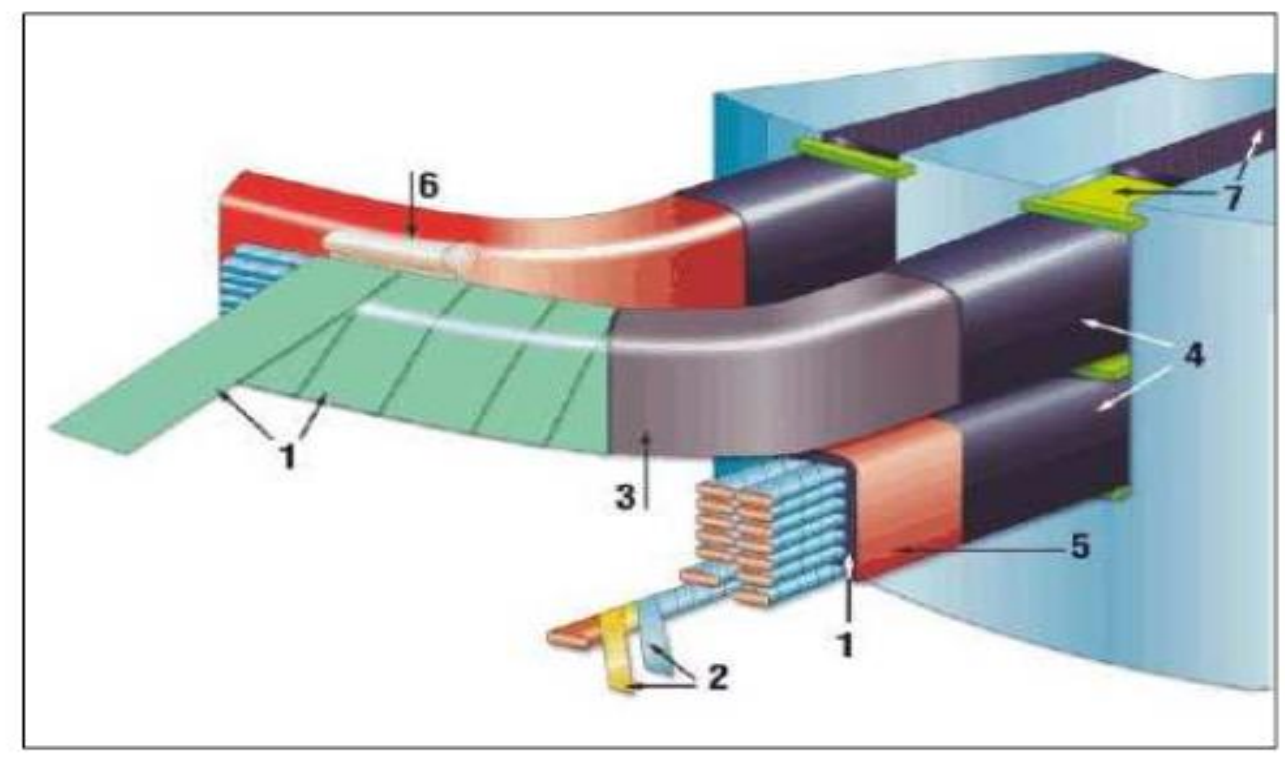

Fonte: Figura extraída de NOVAES, R. D.; et al, Avaliação das propriedades elétricas de barras estatóricas fabricadas com resina do tipo éter diglicidílico do bisfenol $F$ (DGEBF) contendo nano partículas de sílica; Faculdade de Engenharia Química, Universidade Estadual de Campinas UNICAMP, Campinas, SP, Brasil.

Onde temos:

1) Isolamento principal composto de fita de mica e resina epóxi.

2) Condutores de cobre

3) Sistemas anti corona semicondutivos.

4) Sistemas anticorona semicondutivos no formato de pintura.

5) Revestimento no formato de fita ou pintura.

6) Calço distanciador tangencial a base de laminados.

7) Cunhas de fixação. 
A montagem desse sistema de isolação exige materiais que suportem as condições de operação (partidas e paradas do acionamento) e a exigência da operação continua que gera estresses elétricos, térmicos etc. Isso faz com que sistemas para fazerem parte desse conjunto tenham que suportar as solicitações de origem elétricas, mecânicas (vibrações, tensões), térmicas (partidas e paradas do equipamento) e ambiental (umidade, altitude, ozônio, etc..). [17]

Segundo Bruetsch (2008) et al [3], a principal causa das falhas das em hidrogeradores está relacionado a danos na isolação, o que representa $56 \%$ da estatística quando se faz essa análise. Conforme pode se ver na Figura 5, temos os dados de falha nesse equipamento.

Figura 5-Dados Estatísticos do Modo de Falha de um Hidrogerador, na cor vermelha o percentual correspondendo a falha por isolação e onde será o foco desse projeto de TESE. [3]

\section{\% DE FALHA NO EQUIPAMENTO}

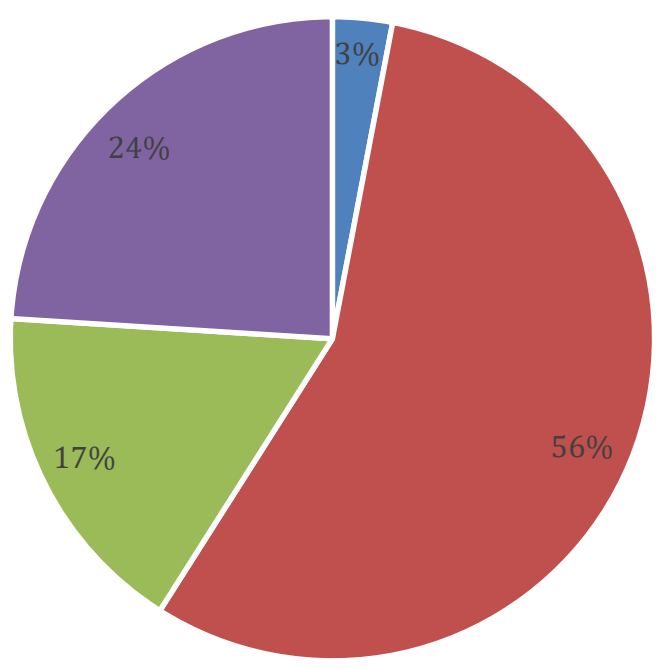

- Rotor

- Isolação

- Térmicos

- Mecânicos

Fonte: Figura própria, adaptada de Bruetsch et al [3].

Os defeitos que ocasionam as paradas dos equipamentos de modo não planejado causados por falhas na isolação elétrica são um grande problema, pois contabilizam elevadas perdas para a planta e comprometem os indicadores de desempenho devido longos períodos de parada da unidade geradora para restauração da função geração. [18] 
Hoje de maneira preditiva, tem sido usado ferramentas para antecipar esses defeitos, os quais são na totalidade relacionado com o aumento do nível de descargas parciais (DP) da isolação elétrica do equipamento. As ocorrências de DP (Descargas parciais) são sintomas de fragilidade no isolamento elétrico cuja evolução pode acarretar graves consequências para o equipamento. [4]

Considerações Iniciais: Pode se extrair do Hidrogerador como modelo de utilidade para aplicação da tecnologia aqui trabalhada, que a solução inovadora usando NIPU ou HNIPU terá que atender as questões elétricas (rigidez dielétrica acima de $3 \mathrm{KV} / \mathrm{mm}$ ), os requisitos térmicos para uso continuo acima de $70^{\circ} \mathrm{C}$ com os picos de intermitência até $130{ }^{\circ} \mathrm{C}$ para sistemas classe B e para até $155^{\circ} \mathrm{C}$ para equipamentos classe F. Quanto ao principal modo de falha do ponto de vista elétrico, que são medidos pelas descargas parciais, as medidas de fator de Dissipação terão uma importância muito grande na etapa de escolha do sistema, principalmente devido as descargas parciais serem provenientes da ionização de defeitos intrínsecos do isolante.

\subsection{Isolamento elétrico e uso de sistemas epóxi}

A palavra "dielétrico" vem da junção das palavras gregas "dia” (entre) e a palavra “elétrico" (âmbar). Em 1836 Faraday descobriu que cargas elétricas criadas por gerador de alta voltagem não cria um campo elétrico dentro de uma sala lacrada por paredes metálicas (denominada gaiola de Faraday). Na prática, as linhas do campo elétrico passam pelo condutor elétrico, em oposição ao que aconteceria com qualquer material que não transportasse eletricidade como vidro ou ar. Faraday então viu a necessidade de criar um novo termo para definir os materiais não condutores (condutividade elétrica) que permitem a passagem de um campo elétrico através de sua estrutura. Em 1836, William Whewell criou o termo " dielétrico, para definir essa característica [19].

Um sistema isolante consiste de materiais que fornecem uma resistência elevada à passagem de uma corrente elétrica através dele, e que é usado para confinar uma corrente elétrica em um determinado circuito. Em vários dos casos, o isolante usado também realiza a função adicional de servir como: a) suporte mecânico do condutor, b) de proteção a entrada de umidade [20].

Materiais que apresentam baixa condutividade elétrica (menor que $10^{-9} \mathrm{~S} . \mathrm{m}-^{1}$ ) são denominados dielétricos ou isolantes. O termo dielétrico é mais utilizado para aplicação em capacitores, enquanto que isolante é mais apropriado quando o material tem a função de isolar 
eletricamente componentes em um circuito elétrico [21]. Segundo o Dicionário Brasileiro de Eletricidade, um isolante é definido como um material onde sua banda de valência é cheia, separada da banda de condução por uma banda proibida, de largura tal que para os elétrons passarem da banda de valência para a banda de condução é necessária uma energia tão grande que é capaz de causar a ruptura do material [21].

Um isolante perfeito oferece uma resistência infinita à passagem da corrente elétrica, enquanto um condutor perfeito não oferece nenhuma resistência. Infelizmente, na prática, não existem isolantes ou condutores perfeitos [22], mas os melhores isolantes tais como ar, vidro, mica, porcelana, borracha, óleo, dentre outros demonstrados na Tabela 1, possuem nas temperaturas ordinárias, resistência elétrica da ordem de bilhão de vezes maior do que a do cobre ou a do alumínio, conforme pode ser visto na Tabela 1 [ 20 ].

Tabela 1 - Condutividade elétrica de alguns materiais, importante para esse projeto de TESE o valor da mica

\begin{tabular}{|l|l|}
\hline \multicolumn{1}{|c|}{ Semicondutores } & Condutibilidade elétrica $(\mathbf{S} / \mathbf{m})$ \\
\hline Silício & $(0,02-10) \times 10^{5}$ \\
\hline Germânio & $(0,0002-0,01) \times 10^{5}$ \\
\hline \multicolumn{1}{|c|}{ Dielétrico (Isolantes) } & \\
\hline Vidro & $(0,0000001) \times 10^{5}$ \\
\hline Mica & $(0,0000001) \times 10^{5}$ \\
\hline Borracha & $(0,00000001) \times 10^{5}$ \\
\hline
\end{tabular}

\begin{tabular}{|l|l|}
\hline \multicolumn{1}{|c|}{ Condutores } & Condutibilidade elétrica (S/m) \\
\hline Prata & $630 \times 10^{5}$ \\
\hline Cobre & $580 \times 10^{5}$ \\
\hline Aluminio & $350 \times 10^{5}$ \\
\hline Platina & $100 \times 10^{5}$ \\
\hline Ferro & $80 \times 10^{5}$ \\
\hline Grafite & $001 \times 10^{5}$ \\
\hline
\end{tabular}

Fonte: modificado pelo autor do site www.rc.unesp.br , acesso em 01/11/2018

Tabela 2 - Principais materiais de isolamento, classe de isolamento e temperatura máxima de uso.

\begin{tabular}{|c|c|c|}
\hline Classe de Temperatura & Materiais & $\begin{array}{c}\text { Máxima Temperatura } \\
{ }^{\circ} \mathbf{C}\end{array}$ \\
\hline Y & Celulose ou seda pura & 90 \\
\hline A & Celulose ou seda impregnados & 105 \\
\hline E & Fibras Sintéticas & 120 \\
\hline B & Poliéster & 130 \\
\hline F & Mica/Amianto/epóxi & 155 \\
\hline H & Fibra de Vidro/Silicones & 180 \\
\hline C & Vidro/Cerâmica & 180 \\
\hline
\end{tabular}

Fonte: elaborado pelo próprio autor, 2019. 
A interpretação da Tabela 2 se dá da seguinte forma, se há necessidade de um material isolante para trabalho contínuo em determinada temperatura, a escolha é baseada na máxima temperatura que o mesmo pode suportar. Um exemplo, no caso de o isolante ter que trabalhar até $155^{\circ} \mathrm{C}$, a escolha recai sobre a Mica, Amianto ou um Epóxi. [20]. Para essa aplicação não poderá se usar um material como poliéster, esse material suporta até $130{ }^{\circ} \mathrm{C}$.

As resinas epóxi que são classificadas como matrizes poliméricas termorrígidas são as mais versáteis do mercado pela gama de possibilidades que as mesmas oferecem. $\mathrm{O}$ volume das transações com estes materiais no mercado global gira em torno de 1,8 milhões de toneladas/ano (dados de 2016), e a demanda tem crescido em média 5\% ao ano no segmento de isolamento elétrico como material de enchimento ou matriz polimérica para equipamentos elétricos de potência ou transmissão de energia elétrica. É possível adequar sua formulação com diferentes aceleradores para ajustá-los às diferentes condições de trabalho em função das diversas aplicações [ 6,7, 23,24, ].

Suas principais características para uso em equipamentos elétricos são:

1. Facilidade de processamento e manuseio;

Inerte a reação com umidade em sistemas abertos (pode ser aplicada em equipamentos sem necessidade de proteção externa);

2. Possibilidade de controlar seu tempo de gelificação;

3. Possibilidade de projetar diferentes propriedades mecânicas.;

4. Versatilidade do sistema epóxi, pois, é possível usar diferentes composições e, portanto, obter diferentes reatividades e consequentemente tempos de cura;

5. Disponível na forma líquida, sólida ou em pó.

6. Elevada rigidez dielétrica e constante dielétrica (uso como isolante elétrico para acima de $\left.10 \mathrm{kV} \cdot \mathrm{mm}^{-1}\right)$.

Uma propriedade fundamental dos materiais dielétricos é a polarização de suas partículas elementares quando sujeitas à ação de um campo elétrico externo. Define-se por polarização um deslocamento dos centros das cargas positivas e negativas na direção dos eletrodos responsáveis pelo campo elétrico aplicado. Esta direção da polarização acompanha, ou pelo menos tende a acompanhar a própria orientação do campo elétrico aplicado e é reversível. Essa polarização pode ser classificada como: 
a) Polarização eletrônica: neste caso, a polarização é resultante da deformação dos orbitais em relação a sua forma original o que leva a um deslocamento das cargas ao redor das moléculas ou átomos constituintes do material [5]. Este tipo de polarização é similar àquela que observamos quando dois átomos ou moléculas se aproximam gerando um dipolo elétrico.

b) Polarização iônica: esta polarização resulta do deslocamento dos átomos de suas coordenadas internas originais levando a deformações axiais, angulares ou torsões nas ligações químicas entre átomos ou íons. Este tipo de polarização é similar ao que observamos em espectroscopia vibracional, exemplo no FTIR [5,25 ].

c) Polarização dipolar: similar à anterior, esta polarização também leva ao deslocamento de átomos e íons de sua posição original, porém é característica de ligações polares onde há a presença de um dipolo permanente que em função destes deslocamentos leva a uma mudança na orientação ou intensidade do dipolo. A exemplo do que foi citado para a polarização atômica, este fenômeno é similar ao que ocorre na espectroscopia vibracional.

d) Polarização interfacial ou de separação espacial de cargas: O deslocamento iônico é comum em materiais que possuem rede cristalina ocupada por cátions e ânions. Sob a influência de um campo elétrico, os momentos de dipolo são gerados pela migração dos íons. O deslocamento iônico pode ser relativamente grande em comparação ao deslocamento elétrico e por esta razão pode induzir altas constantes dielétricas em alguns materiais (cerâmicas).

A característica de isolante deve ser mantida até determinados valores de diferença de potencial aplicado ao material, acima deste limite o material irá tornar-se um condutor de eletricidade. Um dielétrico submetido a uma diferença de potencial será polarizado devido a presença do campo elétrico, comportando se de forma semelhante a um capacitor de placas paralelas conforme Figura 6. A polarização do dielétrico leva a um aumento de temperatura, resultante do consumo de energia [5 ]. 
Figura 6 - Fenômeno de polarização de um líquido polar, representado por um dipolo elétrico, como substância dielétrica em um capacitor desligado (esquerda) e ligado (direita) (a) capacitor sem carga, (b) capacitor com carga aplicada.

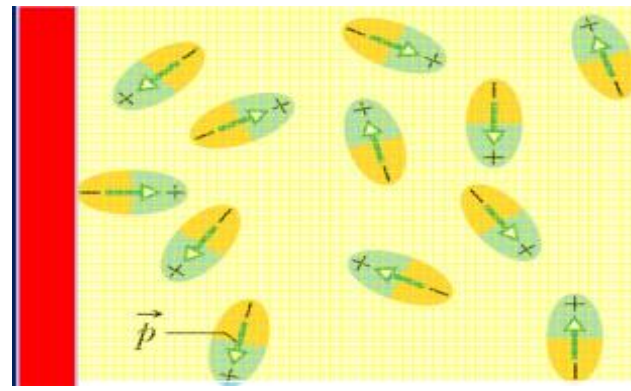

(a)

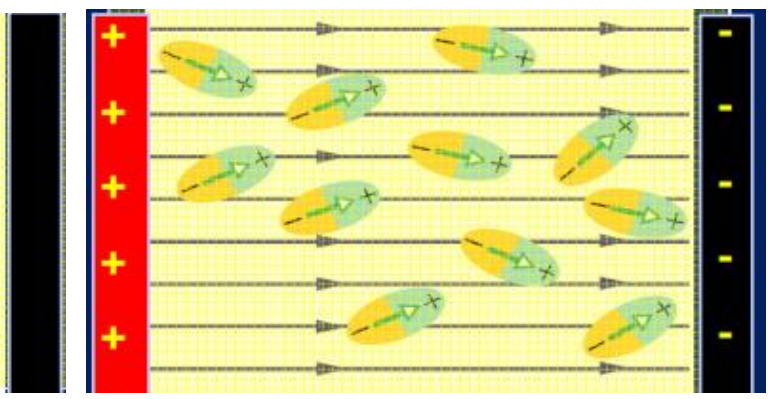

(b)

Fonte: http://coral.ufsm.br/cograca/graca4_2.pdf acesso 04/03/2019

Os dielétricos são classificados em função ao tipo de polarização, apresentando os materiais dielétricos características bastante diversas. Quando o dielétrico é submetido a uma tensão, uma pequena corrente circula em um circuito fechado as quais são denominadas de cargas de polarização conforme podemos observar na Figura 7, que deverá ser estudada dependendo da aplicação em questão. As condições de resposta como temperatura, rigidez e envelhecimento são de particular importância.

Figura 7 - Representação esquemática dos dipolos elétricos em um material dielétrico polar submetido a um campo elétrico externo horizontal.

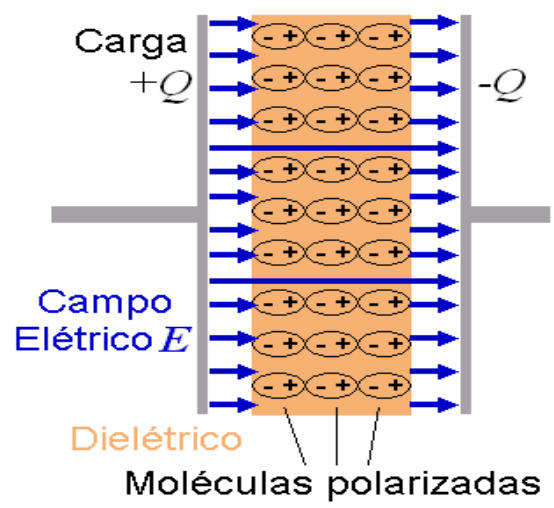

Fonte: Materiais Elétricos 2, Prof.: Carlos Pedroso (http://www.eletrica.ufpr.br)

A ruptura dielétrica nos isolantes ocorre quando a tensão aplicada é suficiente para promover a passagem da corrente elétrica pelo material, e o valor da tensão por área do material submetida à tensão é definida como Rigidez Dielétrica segundo Herbert Fröhlich.

O trabalho de revisão "Dielectric Breakdown in solids" de 1939 ainda permanece como base devido ao mérito científico e pela clareza na definição [26]. 
Os dois tipos fundamentais da ruptura mencionada por Fröhlich são:

- Ruptura eletrônica: a energia acumulada é suficiente para que os elétrons passem da banda de valência ou de níveis de energia na banda proibida (GAP) para a banda de condução, eventualmente produzindo colisões com outros elétrons e gerando a ruptura [26].

- Ruptura tipo avalanche: este é um fenômeno de geração secundária de portadores de carga, ou seja, com o material sendo submetido a campos elétricos suficientemente intensos, os elétrons portadores de carga podem por transferência parcial de energia causar uma segunda ionização. Estes elétrons gerados na segunda ionização, segundo por sua vez, podem causar outra ionização e assim por diante, daí o nome de efeito avalanche [26].

Nos dois casos a ruptura modifica permanentemente o material levando a sua falha enquanto isolante elétrico. Na prática a ruptura dielétrica aparece muitas vezes abaixo do limite intrínseco do material. Os parâmetros e fenômenos que afetam a resistência elétrica são:

- Tipo do material e suas características:

Como a resistividade é considerada o inverso da condutividade, e o fator mais importante na condutividade é a composição do material e sua densidade, pode-se concluir que esses sejam os parâmetros mais importantes para essa propriedade. Quanto menor a condutividade de um material, maior a tensão ou força eletromotriz necessária para passar um fluxo de elétrons através dele [3 ]. Outros parâmetros igualmente importantes são:

- O tipo e a duração do campo elétrico aplicado:

- Integridade mecânica: em muitos casos a falha do ponto de vista mecânico vem de defeitos do material como por exemplo uma trinca.

- Danos radioativos: estes podem alterar a composição ou criar um defeito eletrônico ou mecânico e assim mudar as propriedades dielétricas.

- Ação Química: uma oxidação por exemplo pode levar a uma perda de eficiência de isolamento elétrico.

- Hidrólise: Dentre as ações químicas, a hidrólise, em particular pode levar à criação de contaminação que afetará a resistência elétrica. Normalmente, durante o processo de hidrólise podem ser formados compostos ácidos os quais afetam diretamente o isolamento 
por serem elementos condutores. Esse modo de falha ocorre muito em sistemas de transformadores isolados com papel e óleo vegetal [27].

- Interfaces: Em muitas circunstâncias existe um perfil favorável para a ruptura dielétrica. As descargas internas ocorrem por causa das cavidades internas inerentes do processo de fabricação ou a delaminações em função da cura imperfeita ou estresse térmico. $\mathrm{Na}$ interface o campo elétrico pode ser aumentado pela variação da constante dielétrica. Por exemplo, se houver um vazio ou cavidade de ar interna ao isolamento, o alto valor de campo elétrico pode levar à ocorrência de descargas parciais, as quais irão degradar o isolamento principal da máquina e caso não houver correções, a repetição destas descargas poderá aumentar o tamanho da cavidade levando à falha do isolamento [4, 18, 28].

Figura 8 - Representação esquemática de um compósito resina epóxi/mica, importante para efeito dessa TESE é representar a formação de fratura causada pela componente rígida e no caso da fita de mica a formação de interface com a formação de vazios que levarão a formação de descargas parciais. [29 ].

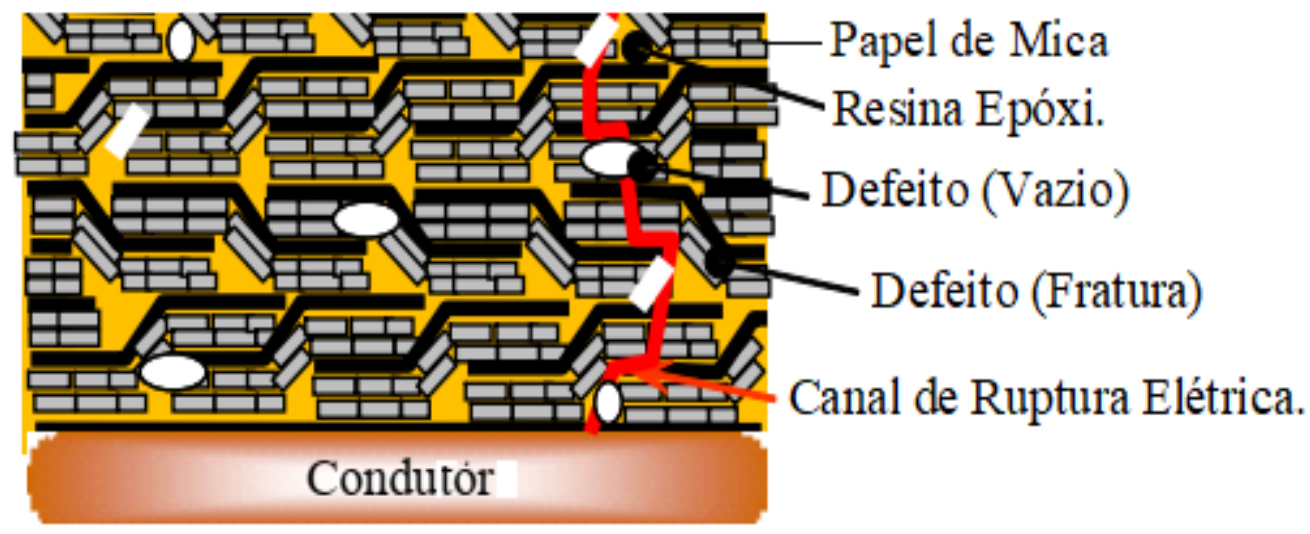

Fonte: Figura extraída de TANAKA K. et al; EEE Transactions on Dielectrics and Electrical Insulation Vol. 22, No. 2; 2015.

Na Figura 8, em amarelo está a matriz epóxi, em cinza estão as folhas de mica, as elipses brancas representam defeitos por ausência de material, enquanto os defeitos por quebra do papel de mica (Crack) são representados por retângulos cinzas partidos. Em vermelho está representado o trilhamento elétrico. [29]

- Erosão progressiva: essa característica cria comportamento favorável à ruptura, tendo diferentes formas, trilhamento elétrico e ou descargas parciais. O fenômeno de erosão leva ao dano denominado envelhecimento, uma transformação progressiva ao longo do tempo [28]. 
As tensões dos sistemas de isolamento das máquinas elétricas em operação podem ser acidentais (de curto prazo) ou permanentes (de longo prazo) e estão diretamente relacionadas aos seus regimes de operação:

a) regime de operação contínua (usado para determinação das estruturas e dimensões dos sistemas de isolamento);

b) regimes de sobrecarga (que determinam, por um período limitado de tempo, um importante aumento do estresse de isolamentos (térmico, mecânico);

c) condições anormais de operação, que consistem no surgimento de tensões de sobrecarga ou curto-circuito e geram estresse súbito intenso (choque elétrico, térmico, mecânico) [30].

Estresses elétricos (normais, acidentais) levam ao início e ao desenvolvimento de descargas parciais, piorando as características elétricas dos isolantes e sua degradação até a ocorrência das falhas elétricas. A falha, por definição, é quando o isolante perde a sua capacidade de suportar a tensão elétrica aplicada. Quando o isolante recebe essa grande quantidade de energia, torna-se condutor e os elétrons libertados podem causar a queima, fundir ou vaporizar uma região localizada do material, portanto, provocar nele danos irreversíveis [30].

Estresses mecânicos como por exemplo vibrações, impactos e outros que ocorrem entre condutores, condutores e núcleos magnéticos, etc., podem levar a formação de trincas e até os descolamentos do sistema de isolamento favorecendo o aparecimento da perda de isolação. Outro fator de estresse são os gerados pelas intempéries $\left(\mathrm{O}_{2}\right.$ do ar, umidade, exposição aos raios solares, etc.), esses fenômenos podem favorecer a ocorrência das reações químicas nos sistemas poliméricos da isolação que levam às reações de degradação do isolamento. [2,3,4,6,16,18]

Analisando as ações de estresse no tempo sobre os sistemas de isolamento, podese observar o início e o desenvolvimento de três fenômenos, mais ou menos distintos: envelhecimento, degradação e seu fracasso.

A falha de isolamento (elétrica, térmica e eletromecânica) é manifestada pelo início de alguns canais macroscópicos com alta condutividade elétrica [31]. Estes canais atravessam o isolamento entre os condutores separados por eles e levam à perda do isolamento e, consequentemente faz-se necessário a troca do equipamento elétrico. Degradação e envelhecimento do isolamento são fenômenos que facilitam a falha do isolamento, mas que nem sempre são claramente separados. [3] 
A Figura 9 mostra um evento causador de uma falha no isolamento.

Figura 9 - Micrografia de material isolante envelhecido apresentando as delaminações na fita de Mica e formação da falha na interface que levará a perda da isolação através da geração de descargas parciais [32].

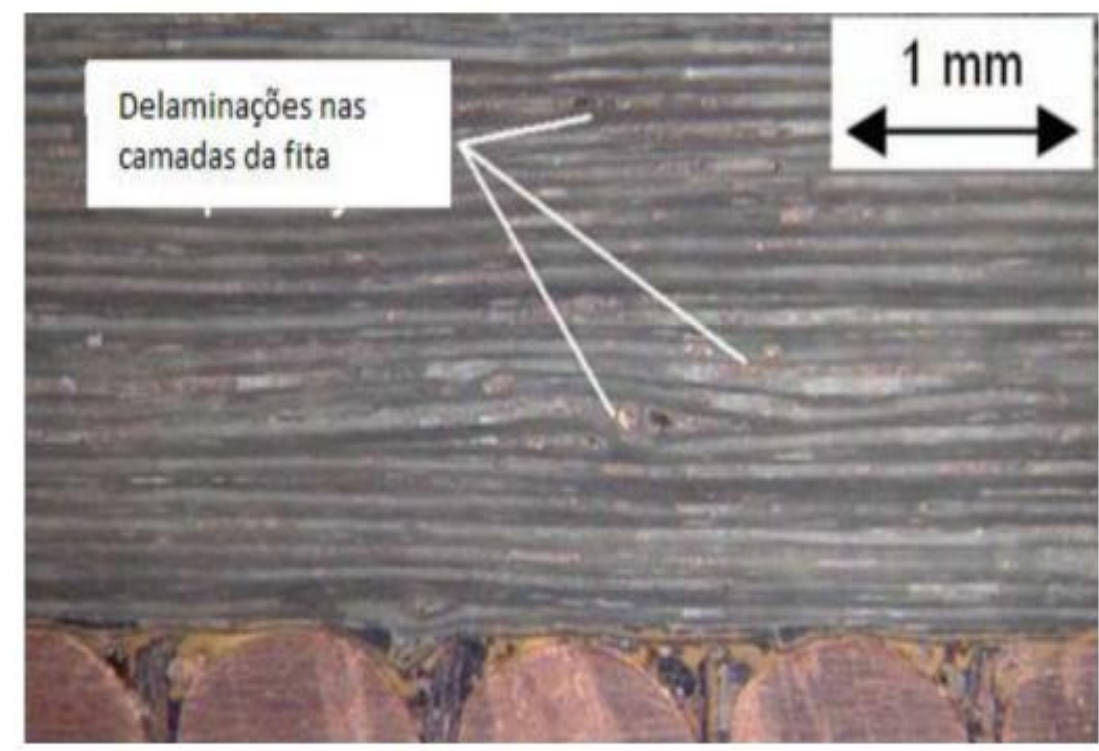

Micrografia do isolamento envelhecido por tempo de serviço.

Fonte: Figura extraída de: Thermochimica Acta, 291, p.73-79, 1997.

A diferença essencial entre os fenômenos de degradação e decomposição consiste no fato de que a degradação é um processo que ocorre em um longo período de tempo, enquanto a falha de decomposição é um processo que ocorre repentinamente e é catastrófico, sendo o isolamento incapaz de suportar o valor nominal da tensão gerada após a sua falha. Por exemplo, a degradação causada pelo desenvolvimento de trilhamento elétrico pode levar horas, dias, meses ou mesmo anos até o dano de isolamento (sua falha) [30,31,33]. A respeito do trilhamento elétrico em polímeros isolantes, Silva [34] estabeleceu:

O fenômeno de trilhamento elétrico é um mecanismo de degradação superficial dos materiais dielétricos que produz trilhas visíveis, como resultado da ação de descargas elétricas próximas, ou na superfície do material isolante. $\mathrm{O}$ trilhamento elétrico pode causar a erosão do material isolante, que é a perda localizada e gradual de massa que ocorre pela ação de descargas superficiais. $\mathrm{O}$ alto valor de resistividade superficial dos polímeros isolantes normalmente empregados em redes protegidas limita a circulação de correntes superficiais responsáveis pelo fenômeno de trilhamento [34 ]. 
Mecanismos de falha

Um isolamento dielétrico é estressado por vários fatores, entre outros: elétrico (intensidade e tipo de tensão aplicada), térmico, mecânico, químico (incluindo oxidação), radiação e, claro, contaminação. Esses fatores podem produzir degradação de curto e ou longo prazo. Em aplicações como isolante elétrico, as causas de falhas dielétricas (curtocircuito elétrico) podem ser basicamente esquematizadas em três grupos principais:

- propriedades dielétricas insuficientes (design errado)

- falhas mecânicas que quebram a integridade dielétrica

- modificação das propriedades dielétricas da massa (interior do componente) ou da superfície

Os eventos citados por causa de uma modificação irreversível e progressiva das propriedades do sistema dielétrico em consequência de tensões externas, chamamos de envelhecimento $[28,35]$.

Comentários Iniciais: Do ponto de vista elétrico e principalmente dos modos de falha, a rota desenhada nesta TESE de usar a mica no formato de pó, sem a presença de uma nova interface pode ser um ponto positivo principalmente para o não aparecimento de descargas parciais. Aqui torna-se importante a questão da dispersão da mica na matriz polimérica para evitar a criação de aglomerações de materiais e formação de pontos de interface. Em relação ao sistema polimérico, as propriedades elétricas também terão um peso extremamente importante, no caso do Hidrogerador, principalmente a medida de Fator de Perda ou Fator de Dissipação.

\subsubsection{Resinas Epóxi}

As resinas epóxi são polímeros termorrígidos e têm como principais características de aplicação, o alto módulo de Young, a baixa fluência, a boa resistência à corrosão, a estabilidade dimensional e a boa adesão em diversos substratos. A formação de materiais frágeis depois de curados, com baixa resistência à propagação de trincas é um dos principais problemas que limitam as aplicações de resinas epoxídicas e fazem com que seu uso na aplicação como isolante elétrico tenha que ser executada com o máximo cuidado. Estas 
características são influenciadas por vários fatores, como o agente de cura utilizado, condições de cura e a presença ou não de modificadores [36].

Uma resina epóxi pode ser um produto monocomponente ou bicomponente. No caso de sistemas com um único componente, há uma reação de homocondensação entre os grupos epóxi terminais denominado oxiranos (Figura 10).

Figura 10 - Grupo funcional Epóxido ou Oxirano ponto de reticulação no processo de cura [37 ].

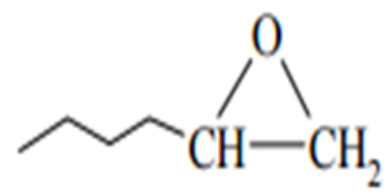

Fonte: elaborado pelo próprio autor, 2019.

A presença de pré-polímeros contendo dois grupos oxirano na presença de catalisadores do tipo bases de Lewis, por exemplo, aminas terciárias ou imidazol acelera o processo de formação da resina. No caso de sistemas de dois componentes, além do prépolímero com terminação oxirano, há também um "agente de cura" ou "endurecedor", por exemplo, uma diamina ou triamina, um fenol, um tiol ou um anidrido cíclico [37 ]. Este reagente reage com os grupos oxirano levando a uma reação de heterocondensação conforme a Figura 11.

Figura 11 - Mecanismo de reação de um sistema epoxido com "endurecedor" do tipo diamina.

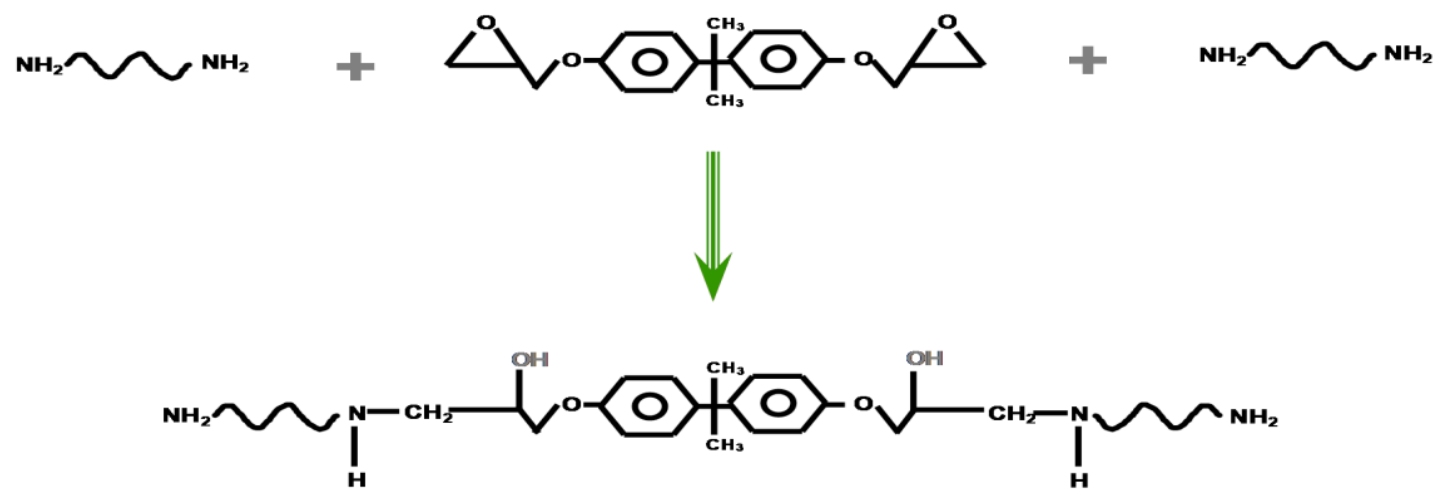

Fonte: autor desconhecido licenciado em CCBY-SA. 
A resina epóxi mais comum, inclusive foco desse trabalho é o DGEBA, cuja estrutura molecular é mostrada nas Figuras 12 e 13 e suas propriedades na Tabela 3.

Figura 12 - Estrutura Molecular do Diglicidil éter de Bisfenol A (DGEBA), com a representação do oxirano na extremidade o que vai caracterizar o material como sendo um epóxi com duas funcionalidades[37 ].<smiles>Cc1ccc(OCC(O)COc2ccc(C(C)(C)C)cc2)cc1CCOc1ccc(OCC2CO2)cc1</smiles>

Fonte: Autoria própria.

Tabela 3 - Propriedades da Resina do DGEBA [37,38].

\begin{tabular}{r|c|l}
\hline $\begin{array}{r}\text { Peso Molecular Médio } \\
\mathrm{Mw}(\mathrm{g} / \mathrm{mol})\end{array}$ & $\begin{array}{c}\text { Equivalente Epóxi } \\
\text { EEW }\end{array}$ & $\begin{array}{l}\text { Faixa de Viscosidade (Mpa.s). } \\
25^{\circ} \mathrm{C}\end{array}$ \\
\hline 340 & 172 a 178 & 4000 a 6000 \\
350 & 178 a 186 & 6500 a 9500 \\
370 & 186 a 192 & 11.000 a 15.000 \\
\hline
\end{tabular}

Fonte: Autoria própria.

Figura 13- Representação da Estrutura molecular do DGEBA a) cadeia polimérica e b) oxirano [37]

a)

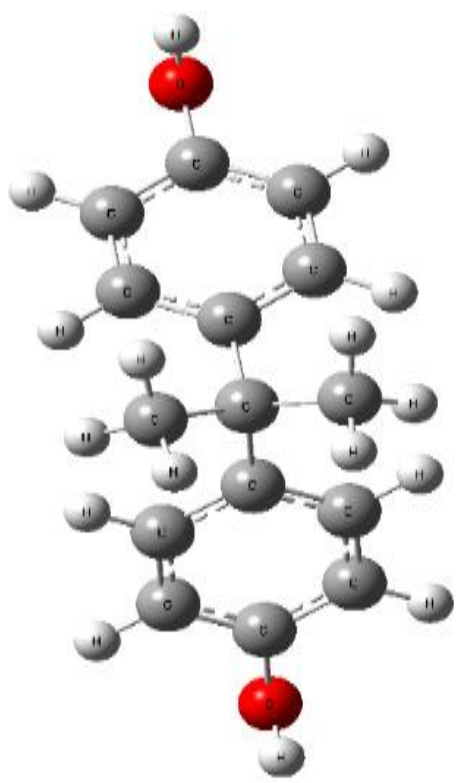

b)

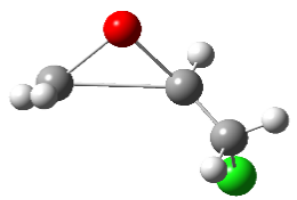

Fonte: Figura extraída de MORALES, A. R. 1989. 204f. Dissertação (Mestrado em Ciência e Engenharia de Materiais) - Faculdade de Engenharia de Materiais, Universidade Federal de São Carlos, São Carlos, 1989. 
Na Figura 13 tem se a) o bisfenol A (esquerda) e b) epicloridrina ou 1-cloro-2,3epoxipropano (direita). Esferas brancas para átomos de $\mathrm{H}$, cinzas para átomos de $\mathrm{C}$, vermelhas para átomos de $\mathrm{O}$ e verdes para o átomo de $\mathrm{Cl}$.

A síntese dos diglicidiléter de bisfenol A se dá pelo ataque intermolecular de um grupo fenóxido, gerada por desprotonação em meio básico, à extremidade do grupo oxirano da epicloridrina [ 39 ]. Em ciência de polímeros, o termo cura é o processo de endurecimento do polímero por meio de reação de polimerização e formação de grande número de ligações entrecruzadas. A formação das ligações entrecruzadas é responsável pelo aumento de rigidez mecânica. A cura é considerada completa após todos os grupos reativos, como epóxi, serem consumidos. A cura de resinas epóxi pode ser dividida entre cura com endurecedores e cura com aceleradores onde a diferença entre elas e devido ao papel na reação, os endurecedores participam estequiometricamente do balanço, enquanto os aceleradores promovem uma auto polimerização da própria resina e atuam como catalisadores [ 23, 40 ]. Em termos da estrutura formada a cinética de reticulação de sistemas epóxi, tem três etapas bem definidas [23,40 ] e são mostradas nas Figuras 14 e 15. As etapas podem então ser assim descritas:

1- Na Figura 14 (a) temos a fase de mistura dos componentes por convecção ou simples difusão, não ocorre reação propriamente dita. Esta etapa é chamada de indução,

2- Na Figura 14 (b) temos a reação entre as moléculas após a fase de indução com formação de oligômeros e polímeros ramificados com o consequente aumento de viscosidade,

3- Na Figura 14 (c) temos a etapa de reação entre estas cadeias poliméricas levando a formação de uma rede de cadeias interconectadas, Figura 14d.

4- Estas redes se sobrepõem e se entrelaçam via ligações entrecruzadas formando aglomerados coloidais em suspensão, o gel (Figura 15). Neste estado a suspensão ainda se comporta como um fluído Não-Newtoniano de viscosidade crescente em função do tempo.

5- Próximo à transição sol-gel, ou seja, do tempo de gelificação ocorre a aglomeração das partículas do sol seguindo um modelo de Percolação. [41,42,43] 
6- Quando as partículas estão completamente interconectadas temos o estado gel, ou seja, um sólido formado pela rede de partículas aprisionando um líquido como mostrado na Figura 15. O gel apresenta um comportamento viscoelástico.

Figura 14 - Etapas de cura em polímeros termorrígidos (a) Indução, (b) Crescimento e indução, (c) Gelificação e (d) Vitrificação. [ 23]

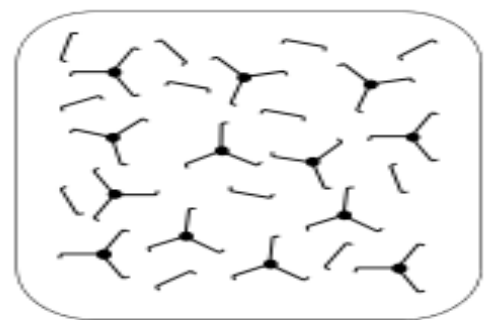

(a)

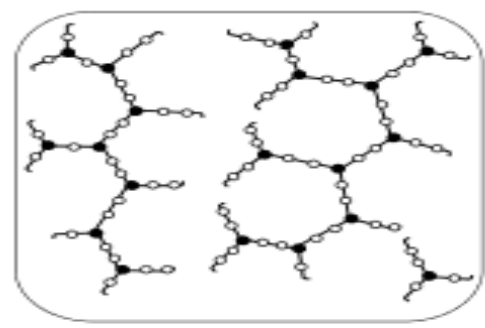

(c)

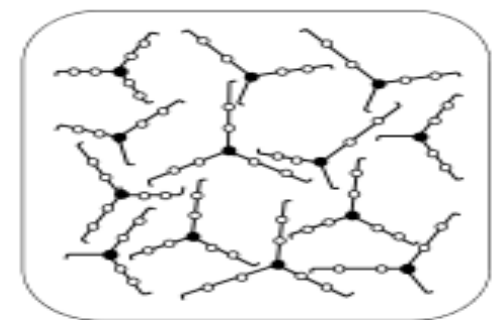

(b)

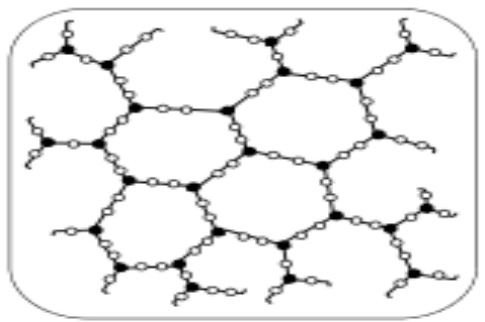

(d)

Fonte: Figura extraída de HADAD, D. K. Physical and chemical characterization of epoxy resins. Epoxy Resins: chemistry and technology. 2nd Ed. New York: Marcel Dekker, p. 1089-1172, 1988.

Figura 15- Esquema simplificado do processo de cura de gelificação da resina epóxi.

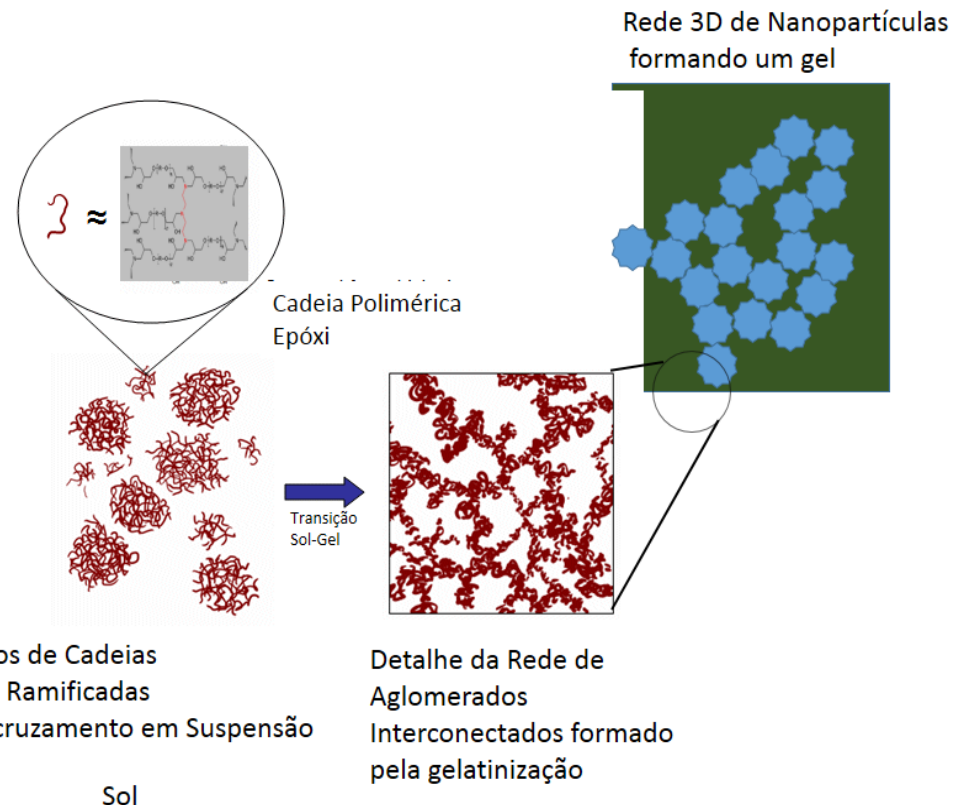

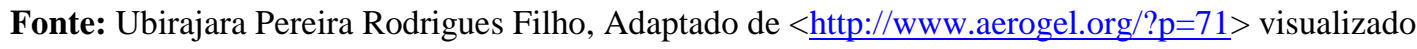
em 03/08/2019. 
Os sistemas epóxi para aplicação elétrica na maioria dos casos consistem de um sistema bicomponente, ou seja, há adição de endurecedor. Pode ocorrer, ainda, a adição de aceleradores e aditivos que vão influenciar suas características físicas finais [23,45]

Existem três tipos principais de agentes de cura para as resinas epóxis: a) aminas (as mais comuns) conforme podemos ver nas Figura 19, 20 e 21, b) anidridos e c) sistemas catalisados por ácidos de Lewis, tipicamente os trifluoretos de boro e os imidazóis. Cada grupo de endurecedor induz textura e morfologias distintas às resinas, resultando em características distintas de isolamento elétrico conforme pode ser visto na Tabela 4. Estes são considerados abaixo em conjunto com seus parâmetros de processamento e manuseio. Historicamente e funcionalmente, uma das classes mais proeminentes são as aminas alifáticas. Eles são de viscosidade mais baixa, curam prontamente à temperatura ambiente e outros são úteis para temperaturas de operação contínua de até $130^{\circ} \mathrm{C}$.

Tabela 4 - Resumo de propriedades dos endurecedores usados em epóxi [45 ].

\begin{tabular}{|l|c|c|c|c|}
\hline $\begin{array}{l}\text { Propriedades das Resinas } \\
\text { Obtidas com os endurecedores } \\
\text { à direita }\end{array}$ & Aminas & Aminas & Aminas & \\
\hline & Alifáticas & $\begin{array}{c}\text { alifáticas } \\
\text { cíclicas }\end{array}$ & Aromáticas & Anidridos \\
\hline Cura & $25^{\circ} \mathrm{C}$ & 70 a $100^{\circ} \mathrm{C}$ & 120 a $150^{\circ} \mathrm{C}$ & 120 a $150^{\circ} \mathrm{C}$ \\
\hline Máx. Temperatura uso & $130^{\circ} \mathrm{C}$ & $150^{\circ} \mathrm{C}$ & $200^{\circ} \mathrm{C}$ & $200^{\circ} \mathrm{C}$ \\
\hline Resistência Química & Boa & muito boa & excelente & boa \\
\hline Resistência Mecânica & muito boa & Excelente & muito boa & boa \\
\hline Constante Dielétrica- $60 \mathrm{~Hz}$ & 3,22 & 3,42 & 4 & 3,13 \\
\hline Fator Dissipação $60 \mathrm{~Hz}$ & 0,034 & 0,027 & 0,03 & 0,004 \\
\hline
\end{tabular}

Nota: ${ }^{\mathrm{a}} \mathrm{e}^{\mathrm{b}}$, quanto menor melhor propriedade

Fonte: Autoria própria extraída de MASTERBOND, Evaluation Electrically Insulating Epoxies (www.masterbond.com).

Estas resinas epóxi curadas com aminas alifáticas são amplamente utilizadas em vários equipamentos graças às excelentes propriedades de isolamento elétrico, resistência química e resistência mecânica. A relação de mistura para estas aminas alifáticas tende a ser desigual (por exemplo: 100: 12). Embora estes sistemas com aminas alifáticas curem bem em seções finas, a reação altamente exotérmica faz como que usualmente estes não sejam 
curados além de $0,5 \mathrm{~mm}$ de espessura. Uma segunda categoria de aminas são os adutos de amina, ou seja, os oligômeros de epóxi com diaminas com massa molar pouco elevada (comercialmente chamados de amido aminas). Outra classe são oligômeros do tipo oligo (amida) de ácidos graxos com poliaminas, se constituindo no sistema amina-epóxi mais comum. Estes agentes de cura, curam prontamente à temperatura ambiente, mas tendem a formar resinas mais viscosas. As proporções entre grupos epóxi e agentes de cura de mistura são muito tolerante s (uma proporção de mistura de 1: 1 bastante comum para esta classe). Eles estão entre os melhores sistemas de cura em temperatura ambiente resultando em bons materiais isolantes. No entanto, a resistência à temperatura conferida ao sistema não é tão alta quanto aos materiais resinosos obtidos usando aminas alifáticas. Eles geralmente são úteis para usos entre a temperatura ambiente até cerca de $100{ }^{\circ} \mathrm{C}$ em uma base contínua. As poliamidas têm constantes dielétricas muito baixas, juntamente com outros valores de isolamento elétrico em temperaturas ambientes. As reações das poliamidas com os grupos epóxi normalmente não são tão exotérmicas e podem ser curadas prontamente para espessuras de até $50 \mathrm{~mm}$. De fato, existe um subgrupo nesta classe com uma exotermia tão baixa que pode ser curada em espessuras de 10 a $15 \mathrm{~cm}[45,46]$.

Outro grupo importante de aminas são as aminas alifáticas cíclicas. Como outras aminas, elas possuem boas propriedades de isolamento elétrico. Apresentando uma viscosidade baixa a moderada e cura em temperatura ambiente, um tratamento térmico póscura é realizado para aprimorar suas propriedades pós-cura. No entanto, o calor requerido não é particularmente alto $\left(70-100^{\circ} \mathrm{C}\right)$. Estas superam as poliamidas e as aminas alifáticas em termos de resistência química, com alguns sistemas que podem ser usados continuamente até $150{ }^{\circ} \mathrm{C}$. As aminas alifáticas cíclicas têm razões de mistura mais tolerantes do que as aminas alifáticas, contudo apresentam uma desvantagem em relação as poliaminas, em razão das reações mais exotérmicas. Aminas aromáticas são a base para aplicações de alta temperatura e resistência química. Eles exigem uma temperatura mais alta para a cura do que as outras aminas discutidas até agora, pois, estas curam entre 120 e $150^{\circ} \mathrm{C}$ com tratamento térmico pós-cura entre 150 e $200^{\circ} \mathrm{C}$ e têm uma viscosidade baixa a moderada à temperatura ambiente. Enquanto algumas das aminas aromáticas podem ter valores de isolamento elétrico ligeiramente mais baixos do que outras aminas à temperatura ambiente, estas ainda são muito robustas, portanto, são amplamente utilizadas sem função da resistência química e térmica. A maioria destas pode ser utilizada até temperaturas de cerca de $200^{\circ} \mathrm{C}$ em uma base 
contínua. A reação dos epoxidos com estas têm uma exotermia muito baixa, uma vida útil de vários dias e são adequados para obtenção de peças de tamanho maiores [45].

Cada grupo amina primária $\left(-\mathrm{NH}_{2}\right)$ é capaz de reagir com dois grupos epóxi, pois apresenta dois átomos de hidrogênio ativos ligados ao nitrogênio. Por outro lado, a reatividade dos átomos de hidrogênio, das aminas primárias $\left(-\mathrm{NH}_{2}\right)$ e aminas secundárias ($\mathrm{NH}$ ), tende a ser diferente. Resulta que os átomos de hidrogênio dos grupos amina participam sucessivamente da reação de adição entre o grupo epóxi conforme sua reatividade $[47,48]$.

Além das reações epóxi discutidas, outras reações também podem ocorrer por autocatálise ou pela adição de catalisadores, como, por exemplo, as reações de esterificação que podem ocorrer na presença de amina terciária estericamente sem impedimento.

O mecanismo de reação do sistema composto por uma resina epóxi do tipo éter de diglicidil de bisfenol A (DGEBA) e diaminas tem sido extensivamente estudado por diferentes grupos de investigadores. Os mecanismos de reação deste sistema químico são bem conhecidos, sendo um não catalítico e outro auto catalítico, de acordo com as equações a seguir:

$$
\begin{aligned}
& \mathrm{E}+\mathrm{A}_{1} \rightarrow \mathrm{A}_{2}+(\mathrm{OH}) \\
& \mathrm{E}+\mathrm{A}_{2} \rightarrow \mathrm{A}_{3}+(\mathrm{OH}) \\
& \mathrm{E}+\mathrm{A}_{1}+(\mathrm{OH}) \rightarrow \mathrm{A}_{2}+2(\mathrm{OH}) \\
& \mathrm{E}+\mathrm{A}_{2}+(\mathrm{OH}) \rightarrow \mathrm{A}_{3}+2(\mathrm{OH})
\end{aligned}
$$

Onde: E é o grupo epóxi; OH é o grupo hidroxila inicial formado pela reação entre os grupos epóxi e amina; $A_{1}, A_{2}$, e $A_{3}$ correspondem ao grupo amina primária, secundária e terciária respectivamente. As reações 1 e 2 correspondem ao mecanismo não catalítico, o iniciador participa da reação como monômero, conforme visto na Figura 15. Enquanto isso, as reações 3 e 4, correspondem ao mecanismo catalítico, a amina é regenerada terminada a reação, portanto, funciona como iniciador para promover a homopolimerização conforme as Figuras 16 e 17 [37, 38]. 
Figura 16 - Reação iniciada por sistema não catalítico [38].

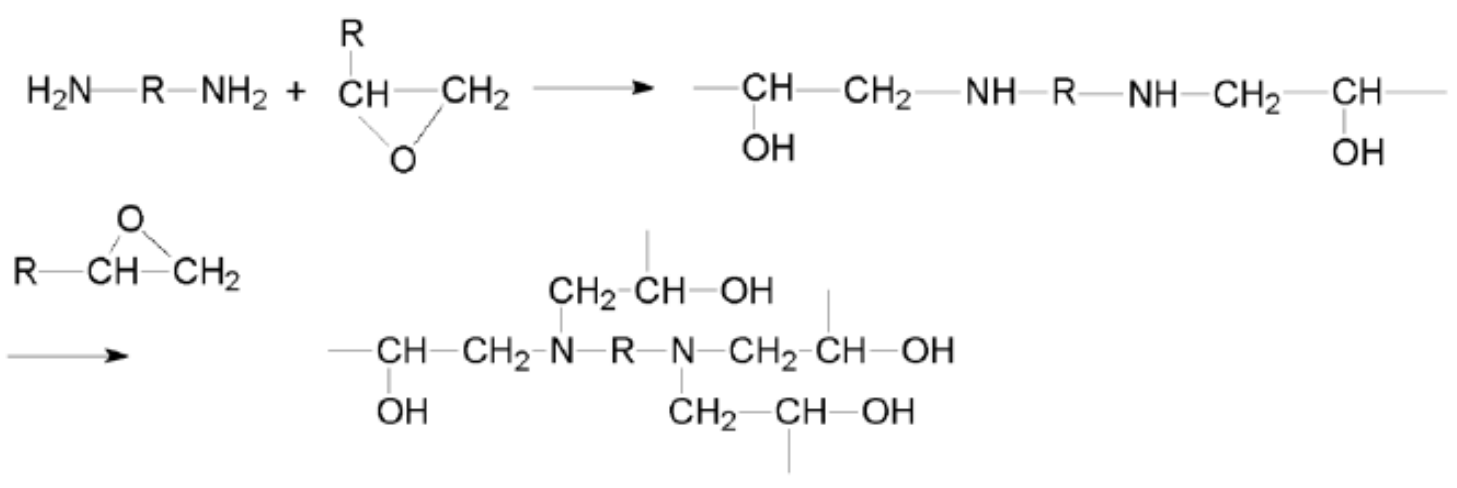

Fonte: elaborado pelo próprio autor, 2019.

Figura 17 - Reação iniciada por sistema catalítico [ 38].<smiles>[R]C1OC1CCC(O)C(C)OCC(O)C(C)(O)[N+]#[R16]</smiles>

Fonte: elaborado pelo próprio autor, 2019.

A extensão da reação depende da reatividade da amina, temperatura de reação, e da razão entre o equivalente molar de epóxi e o equivalente molar de amina. A reações 1 e 2 ocorrem sob condições normais de cura. A reação 3 é uma reação de esterificação que pode não obedecer às condições de estequiometria molar e quando a temperatura de cura está abaixo de $150^{\circ} \mathrm{C}$. Isto é especialmente verdadeiro para DGEBA curado com aminas alifáticas (tais como DETA) [ $37,38,48]$.

$\mathrm{Na}$ reação deste sistema químico ocorrem simultaneamente ambos os mecanismos, sendo que a predominância de um sobre o outro depende da temperatura de cura. A reação também está caracterizada pela gelificação e a vitrificação conforme demonstrado na Figura 18. Enquanto, por um lado, a gelificação ocorre quando o grau de reticulação alcança um determinado valor, dependendo unicamente da funcionalidade, a estequiometria e a reatividade entre os grupos funcionais. A vitrificação ocorre quando a temperatura de cura é inferior à temperatura de transição vítrea $T_{g}$ máxima para a resina totalmente curado. Ou seja, 
durante a cura isotérmica, a medida que aumenta a temperatura de reticulação, aumenta a $\mathrm{T}_{\mathrm{g}}$ até igualar a temperatura de cura, a partir deste instante a $\mathrm{T}_{\mathrm{g}}$ aumenta lentamente já que o composto se encontra em estado vítreo ilustrado na Figura 17 [37,38 47,49,50 ].

Figura 18 - Perfil das transições em cura em função do tempo. [ 50]

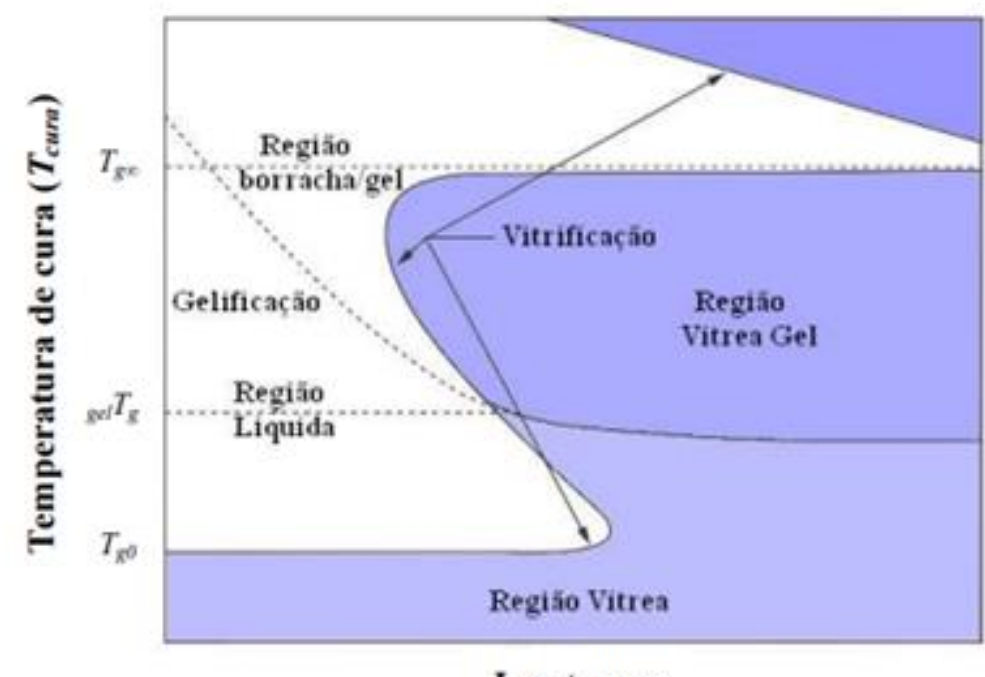

Log tempo

Fonte: Figura extraída de : MENCZEL J.D., PRIME R.B., Thermal analysis of polymers, fundamentals and applications, 1 ed., New York, Wiley, 2009

Nas Figuras 19, 20 e 21 são mostradas as principais aminas que são usadas como endurecedores para sistema epóxi.

Figura 19 - Formula e nome químico das aminas alifáticas usadas em sistema epóxi [37, 45,46].

tificaticas

Fonte: elaborado pelo próprio autor, 2019. 
Figura 20 - Formula e nome químico das aminas cicloalifáticas usadas em sistema epóxi [ 37,45,46].

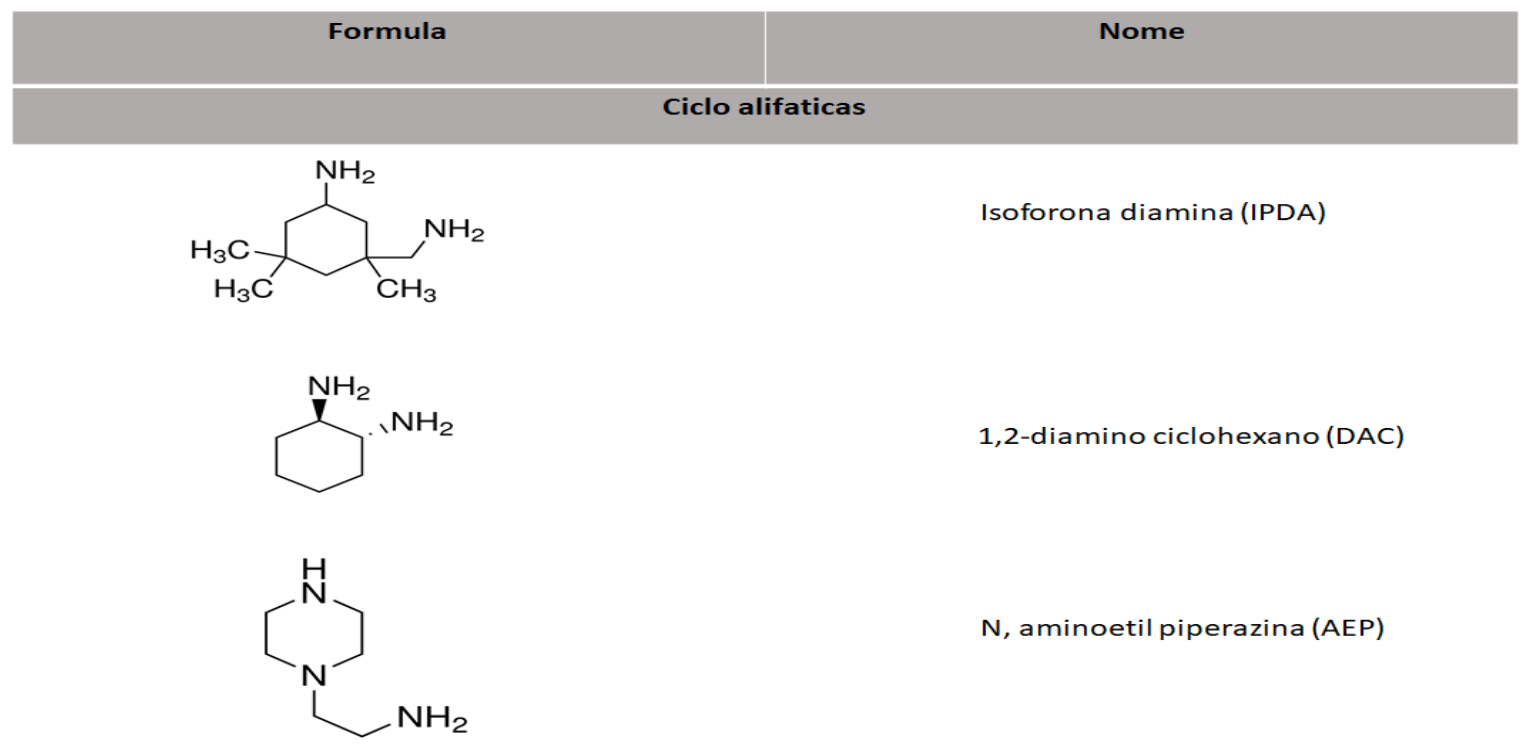

Fonte: elaborado pelo próprio autor, 2019.

Figura 21 - Formula e nome químico das aminas aromáticas usadas em sistema epóxi [37, 45,46].

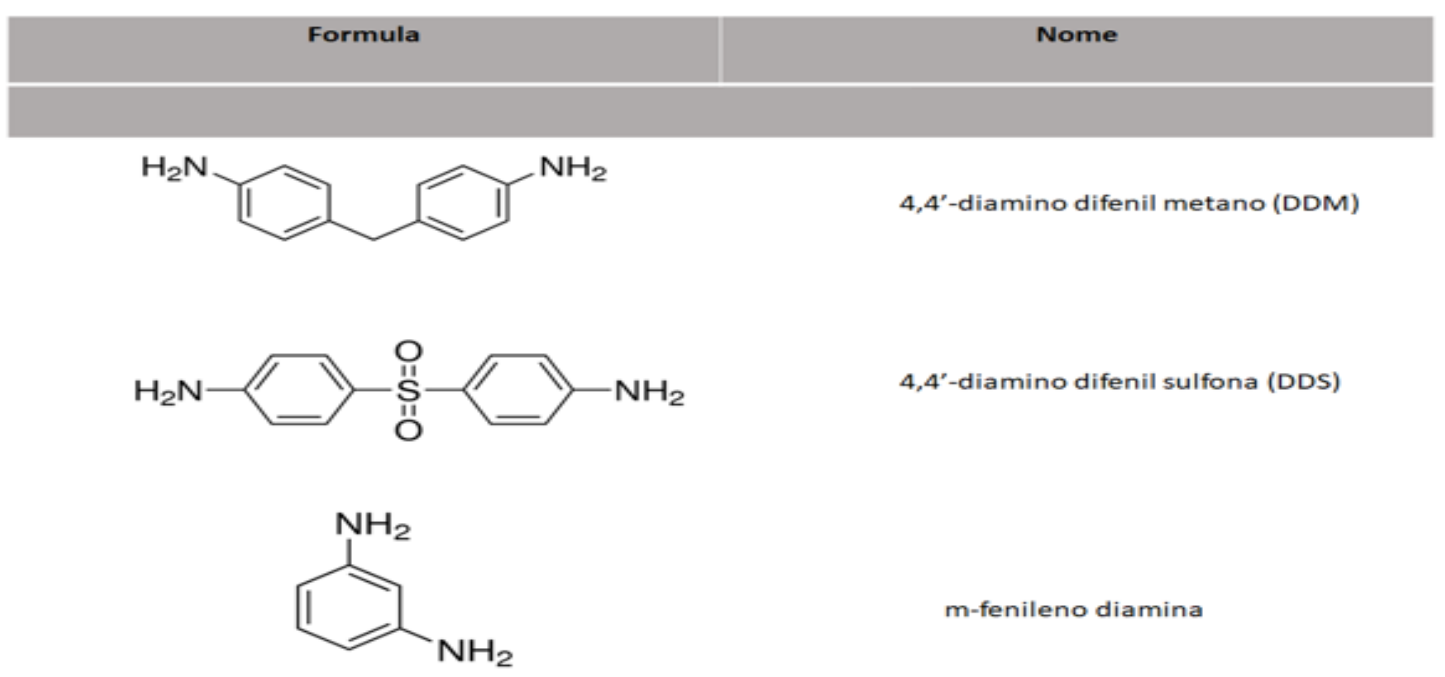

Fonte: elaborado pelo próprio autor, 2019.

A segunda categoria principal de agentes de cura são os anidridos, às vezes chamados de anidridos ácidos. Suas principais aplicações são para envasamento e 
encapsulamento. Estes são usados principalmente por causa de suas propriedades insuperáveis de isolamento elétrico. Realisticamente, no entanto, os anidridos requerem calor intenso para reticulação com parâmetros de cura de $120^{\circ} \mathrm{C}$ por $8-12$ horas, seguidos por tratamento térmico pós-cura para otimizar algumas dessas propriedades. Eles são de baixa viscosidade, têm uma exotermia extremamente baixa com a vida útil estendendo-se em muitos casos por semanas à temperatura ambiente. Esses sistemas são os mais usados por fornecer uma resina bem reticulada e com $\mathrm{Tg}$ acima de $100{ }^{\circ} \mathrm{C}$ [51].

A formação das ligações entrecruzadas durante a cura leva à mudança de dimensão o que provoca tensões internas que geram à formação de trincas. $\mathrm{O}$ crescimento destas trincas leva ao aparecimento de fraturas reduzindo o tempo de vida dos isoladores elétricos com epóxi. A propagação das trincas das resinas epóxi pode ser evitada pela adição de uma porcentagem alta em volume de cargas minerais inertes, a fim de reduzir o coeficiente de expansão térmica e melhorar a condutividade térmica em comparação com a resina epóxi não preenchida. No entanto, o compósito epóxi torna-se cada vez mais difícil de processar com o aumento do nível de carga mineral, limitando o avanço das propriedades do material. Com o aumento da fração com carga mineral, temos o aumento da viscosidade do composto, o qual além de tornar mais difícil sua aplicação, gera a necessidade de melhores sistemas para desaeração dos gases que são incorporados durante o processo de mistura [52 ].

Almeida e Monteiro (1998) estudaram a influência do número de moles de agente de cura no sistema epoxidos DGEBA/TETA sobre a resistência mecânica por meio do ensaio de tensão de ruptura. Com a adição de excesso molar do agente de cura, ou seja, em quantidades superiores ao ditado pela estequiometria. Os resultados mostraram uma abrupta mudança nos valores de E' (módulo elástico), resultando em uma transição do comportamento de frágil para o dúctil com os valores de módulo passando de 3,67 $\pm 0,6 \mathrm{GPa}$ para 3,84 $\pm 0,6 \mathrm{GPa}$ ao se variar a percentagem de diamina de 7 para $13 \%$ de N, N'-Bis (2aminoetil) etano-1,2-diamina (TETA). Conquanto, os valores de módulo elástico passaram de 2,40 $\pm 0,4 \mathrm{GPa}$ para 2,87 $\pm 0,4 \mathrm{GPa}$ para composições que passaram de $15 \%$ para $21 \%$ de TETA, respectivamente. Adicionalmente, o acréscimo de endurecedor levou a um crescente aumento nos valores de tensão de ruptura e deformação até a ruptura. Este comportamento foi associado a uma mudança no comprimento dos segmentos de cadeias do polímero. Formulações ricas em grupos epoxidicos, portanto, com apenas 7 e $9 \%$ de diamina, seriam mais frágeis devido à total reação dos grupos funcionais das moléculas de amina e deixando os grupos epoxidos reagirem entre si o que favoreceria o aumento da densidade de ligações 
entrecruzadas. O comportamento dúctil, em formulações ricas em amina (15 a 21\%), está associado à presença de grupos aminos que não reagiram (aminas secundárias são menos reativas que aminas primárias), nesse ponto teremos um excesso molar de amina em detrimento do grupamento epóxi o que devido a maior disponibilidade das aminas primárias, acarreta uma maior mobilidade dos segmentos de cadeia no polímero formado. [52]

Morales (1989) investigou a adição do elastômero CTBN (copolímero de butadienoacrilonitrila com grupo carboxila terminal) ao sistema epoxídico de DGEBA com TETA como agente de cura. Este é um caso típico de uso de oligômero de poliamida como agente de cura, pois os grupos carboxila reagem com as aminas formando amidas. A adição de CTBN promoveu um significativo aumento na resistência ao impacto, queda no módulo elástico (parte elástica do módulo de armazenamento (E’)) e no Módulo de Young (no modo de tensão com tração uniaxial) em menor intensidade, conferindo menor rigidez ao material. Através de análise de DMTA, a curva de tan $\delta$ da blenda mostra um único pico atribuído à $\mathrm{T}_{\mathrm{g}}$ deslocado e alargado em relação à resina sem CTBN. Isto indica que a resina e a CTBN nas proporções usadas são miscíveis [37 ].

Kar e Banthia (2005), estudaram um compósito formado pela modificação do sistema epoxídico DGEBA/TETA com o elastômero polibutadieno com grupo amino terminal (ATPB). O material foi caracterizado por FTIR, RMN de próton e análise elementar. O ATPB foi misturado à resina epoxídica com agitação à $200^{\circ} \mathrm{C}$ durante $5 \mathrm{~h}$ e depois TETA foi adicionado em quantidade estequiométrica. $\mathrm{O}$ sistema com 0 a 20 partes de borracha por cada 100 partes de ATPB foi curado a $25{ }^{\circ} \mathrm{C}$ por $24 \mathrm{~h}$ e depois a $50{ }^{\circ} \mathrm{C}$ por $2 \mathrm{~h}$. Os ensaios de resistência ao impacto foram realizados segundo a norma ASTM D 4812-93. Os resultados mostraram acréscimo de resistência ao impacto de $\sim 100 \mathrm{~J} / \mathrm{m}$ no material DGEBA/TETA até $\sim 360 \mathrm{~J} / \mathrm{m}$ com adição de $15 \%$ de ATPB, em massa [53].

Alcântara (2003) et al, estudaram um sistema de redes poliméricas interpenetradas (pseudo-RPIs) formado pelo epóxi tetrafuncional TGDDM e poli metil metacrilato (PMMA), sintetizados simultaneamente. Metil metacrilato (MMA) foi polimerizado com peróxido de benzoila (polímero linear) enquanto a resina epóxi TGDDM foi polimerizada com quantidade estequiométrica do agente de cura TETA ou do agente de cura EDA. Coeficiente de expansão térmica aumentou em função do aumento na quantidade de MMA, porém foi observada maior densidade de ligações cruzadas e menor expansão térmica no sistema de pseudo-RPIs preparado com TETA se comparado ao sistema preparado com EDA [54 ]. 
Lee e Lichtenhan (1998), realizaram estudos sobre o sistema epoxídico formado pelas resinas epóxi DGEBA e BDGE (1,4-butanodiol diglicidil éter) e o agente de cura poli oxipropilenodiamina modificado com um silsesquioxano cúbico multifuncionalizado com grupos epoxidos. $\mathrm{O}$ material foi curado a $100^{\circ} \mathrm{C}$ por 24 horas, com adição de 5 e $9 \%$ em massa do modificador. A presença do cubo de silsesquioxano retardou o envelhecimento do material polimerizado. Através de análise de DSC foi observado ganho na Tg devido ao aumento da densidade de ligações cruzadas. Concluíram que os POSS ocupavam pontos terminais na rede de ligações cruzadas, impedindo a movimentação molecular nas junções da rede. Não houve alteração do módulo na região plástica na análise de DMTA, indicando que o material tem influência sobre a movimentação molecular, porém, sem modificar o processo de deformação global das cadeias [55].

Stroganov (2018) et al, estudaram uma maneira de melhorar a atual fragilidade do sistema epóxi-amina através do uso da modificação da resina epóxi na forma de oligômero. Via carbonização com $\mathrm{CO}_{2}$ e sua conversão a um ciclocarbonato a qual criou uma estrutura. A formação da hidroxiuretana linear além de melhorar a questão da fragilidade, aumentou as características adesivas do composto obtido, tornando-se um campo promissor para pesquisas [56].

Sistemas epoxidos, mesmo sendo o material isolante preferido é altamente utilizado por apresentar alta coesividade, propriedade dielétrica superior, pequeno encolhimento, boa estabilidade química e fácil processamento, no entanto, podem falhar em várias aplicações. Recentemente, muitas pesquisas se concentram em aplicações de nanocompósitos de polímeros em isolamento elétrico, e a incorporação de nanopartículas demonstra melhorias elétricas, mecânicas e térmicas progressivas combinadas em relação aos sistemas de microfilme convencionais $[57,58]$.

Nanocompósitos poliméricos baseados em nanoargilas [59,60], nanofibras [61,62], partículas de metal e nanopartículas de óxido de metal $[63,64]$, mesmo com uma pequena fração de nanopartículas inorgânicas, podem melhorar seu desempenho, como propriedades mecânicas. A melhoria dos desempenhos de isolamento, como a rigidez dielétrica $[57,65,66]$, a resistividade volumétrica [67] e a resistência à erosão elétrica [68 ] também foram relatadas.

Tanaka (2005) et al propôs um modelo multi-core intimamente relacionado a uma "zona de interação" com uma espessura de 10-30 nm entre matriz polimérica e nanopartículas. O volume da zona de interação do nanocompósito polimérico pode ser ainda maior que o das 
nanopartículas, o que afeta diretamente as propriedades elétricas e mecânicas dos compósitos [69].

Shengtao (2011) et al, também consideraram que existe uma barreira potencial na zona de interação que restringe os portadores e melhora o desempenho de isolamento dos nanocompósitos [70].

Nanopartículas de alumina têm sido amplamente utilizadas como nanocargas em nanocompósitos de epóxi. No entanto, a pesquisa recente concentrou-se principalmente em boehmite [64] ou $\gamma$-alumina [ 57,68, ] que pode não ser estável em campos elétricos altos ou em outros ambientes críticos. E a maioria dessas partículas precisa ser modificada na superfície para melhorar a resistividade do volume, a força de ruptura ou outro desempenho elétrico do nanocompósito de epóxi.

McIntyre (2004) et al estudaram os nanocompósitos baseados na dispersão de nanopartículas da argila montmorilonita organomodificada com sal de amônio quaternário, Cloisite 30B (antiga Southern Clay Products e atualmente BYK Additives), nos sistemas epoxidos formados por DGEBA curado com os agentes de cura TETA, DDS (4,4 diaminodifenilsulfona) ou DDM (4,4-diaminodifenilmetano) em razões molares estequiométricos. Na Figura 22, temos a estrutura química desses agentes de cura.

Figura 22 - Estrutura química dos endurecedores, a) TETA, b) DDS e c) DDM.
a) TETA
b) DDS
c) DDM

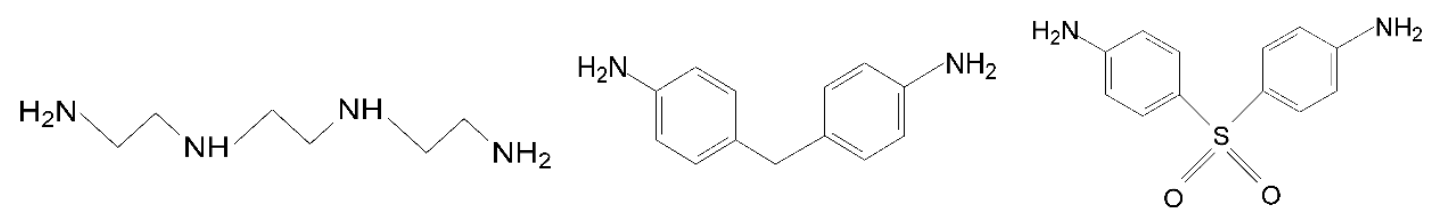

Fonte: Autoria própria 2019.

Observando a estrutura dos três endurecedores ilustrados na Figura 22, podemos esperar que o uso do TETA dará um composto mais flexível, mesmo sendo uma amina com quatro grupos reativos com epóxi, a sua estrutura linear favorece o comportamento flexível. Enquanto o DDS e o DDM pela presença de grupamentos aromáticos, mesmo possuindo menor número de grupamentos reativos com epóxi, dará compostos mais rígidos [71].

O difratograma das amostras de DGEBA/TETA curadas a $100{ }^{\circ} \mathrm{C}$ durante 6 h e póscurada a $160{ }^{\circ} \mathrm{C}$ por $4 \mathrm{~h}$ não apresentou o pico de difração associado à Cloisite $30 \mathrm{~B}$, o que 
foi interpretado como função da exfoliação da mesma e, portanto, alto grau de dispersão de Cloisite 30B na resina e orientação aleatória das lamelas isoladas. Contudo, a substituição da TETA pela DDS e DDM só ocasionaram exfoliação até percentagem em massa de 10 e $6 \%$, respectivamente. Altas concentrações de argila poderiam levar a arranjos pseudonemáticos. Arranjos pseudonemáticos são domínios em escala multinanométrica dentro de sistemas isotrópicos nematogênicos [71].

Através da técnica de DMTA observou-se que a adição de $5 \%$ Cloisite 30B (em massa), ao sistema DGEBA/TETA, provocou um aumento da $\mathrm{Tg}$ de 113 para $125{ }^{\circ} \mathrm{C}$. Enquanto o aumento do módulo elástico na região viscosa ou plástica está associado à ação da argila como reforço e ao aumento da densidade de ligações cruzadas. A degradação térmica característica em análise de TGA, não alterou pela presença do modificador em nenhum dos sistemas epoxidos. A adição de 12\% Cloisite $30 \mathrm{~B}$ no sistema mais rígido DGEBA/DDM, curado a $180{ }^{\circ} \mathrm{C}$ por $16 \mathrm{~h}$, resultou em elevação da Tg de 114 para $140{ }^{\circ} \mathrm{C}$. No sistema DGEBA/DDS, a adição de $15 \%$ de Cloisite 30B provocou decréscimo da Tg de $256{ }^{\circ} \mathrm{C}$ para $245{ }^{\circ} \mathrm{C}$ [123]. Uma análise em função da estrutura do endurecedor (número de grupos reativos) e a quantidade de argila utilizada, pode se concluir que em sistemas altamente reticulados (DGEBA/DDS), o aumento do teor de argila pode impactar negativamente ao criar barreira para a reticulação [71].

Brown (2004) et al, estudaram a preparação e propriedades de uma série de nanocompósitos baseados na adição de argilas montmorilonita ao sistema epoxídico DGEBA/TETA em formulação estequiométrica. Foram comparadas quatro montmorilonitas diferentes: a argila natural Cloisite $\mathrm{Na}+$ (montmorilonita sódica) e três argilas com modificadores orgânicos, Cloisite 6A, Cloisite 30B, em quantidades de 1 a $25 \%$, em massa e a Cloisite 25A adicionada de 1 a 20\%, em massa. As amostras foram curadas, inicialmente, a $60{ }^{\circ} \mathrm{C}$ por $20 \mathrm{~h}$, posteriormente submetidas a tratamento térmico a $100{ }^{\circ} \mathrm{C}$ por $24 \mathrm{~h}$ e por último a $160{ }^{\circ} \mathrm{C}$. A análise de DMTA foi usada para estudar o efeito da incorporação de camadas do modificador intercaladas na matriz polimérica. $\mathrm{O}$ material foi uniformemente dispersado na matriz através de agitação em ultrassom a $80^{\circ} \mathrm{C}$ por $30 \mathrm{~min}$. O uso do TETA como amina para o sistema, devido sua baixa viscosidade, fez com que para todas as argilas utilizadas houvesse um abaixamento da viscosidade do sistema, mesmo com o aumento da concentração das mesmas. Como se a presença do TETA houvesse o efeito de neutralização dos sítios da argila que seriam responsáveis pelo espessamento. 
Cloisite $\mathrm{Na}+$ é uma forma natural da argila, sem nenhum tratamento orgânico, observou no seu uso o efeito normal da adição de carga mineral em uma matriz polimérica, em testes de DMTA a redução do módulo de perda (E').

Cloisite 25A é uma argila com modificação usando o dimethyl, hydrogenated tallow, 2- ethylhexyl, quaternary ammonium chloride. Essa molécula orgânica tem uma cadeia hidrocarbônica longa o que ajuda a facilitar a dispersão da argila na matriz polimérica. Em módulos de alta e baixa temperatura obteve se aumento em sistemas com esse aditivo. $\mathrm{O}$ resultado indica que não houve alteração na $\mathrm{Tg}$ com o aumento da concentração da Cloisite 25A.[72]

Cloisite 6 A e uma argila modificada com Dimethyl, dihydrogenated tallow, quaternary ammonium chloride. As duas cadeias hidrocarbônicas longas estão hábeis para interagir com as moléculas da vizinhança estabilizando o material formado. Resultados indicaram que a Tg diminui com a adição da Cloisite 6A sugerindo dois efeitos possíveis. Adição de pequena quantidade de argila diminuiu a Tg, enquanto haverá aumento com a maior concentração da argila. [72]

Cloisite 30B é uma argila modificada com methyl hydrogenated tallow bishydroxyethyl ammonium chloride. A cadeia longa tem um potencial de estabilização da argila sendo que os dois grupamentos hidroxilas tem a capacidade de ancorar firmemente na superfície da argila. Esse material nos testes mostrou-se como o mais efetivo. $\mathrm{O}$ aumento da concentração da Cloisite $30 \mathrm{~B}$, gradualmente aumenta os módulos elástico (E’) e o módulo de perda (E'), porém tem pequeno efeito na Tg comparada ao padrão sem o uso de argila. Em resumo, Brown concluiu que a argila age como uma carga mineral e que o polímero interage com as placas da argila. A falta de melhoria da Tg foi inesperada, mas pode se concluir que não está ocorrendo uma densificação da maneira esperada, podendo ser atribuído a um efeito de plastificação, não houve um efeito nas propriedades físicas do composto final [72].

Laine (2001) et al, estudaram dois sistemas com polioctasesquisiloxanos, POSS, octafuncionalisados com grupos octadimetilsiloxilglicidil, OG, curados com os agentes de cura DDM e comparados com a resina epóxi convencional DGEBA, também curada com DDM. Na Figura 23 temos a estrutura do hibrido obtido. 


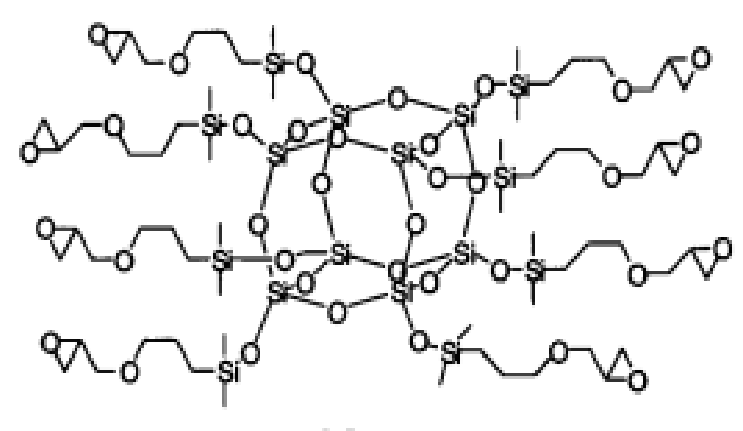

$\underline{O G}$

Fonte: Autoria própria 2019.

Os protótipos curados foram balanceados estequiométrica em função da razão molar entre o número de amina do DDM com o número de grupamentos epoxidos no OG. Usou se o fator $\mathrm{N}=$ número de aminas do DDM /número de grupamento oxirano no OG.

$\mathrm{Na}$ análise de DMTA foram observados picos de $\mathrm{Tg}$ em $110^{\circ}$ e $60^{\circ} \mathrm{C}$ para os sistemas DGEBA/DDM e OG/DDM (em N=1,00), respectivamente, e elevação do módulo viscoso na composição estequiométrica $(\mathrm{N}=0,5)$ para os dois sistemas, indicando maior densidade de ligação cruzadas nesta composição. O sistema $\mathrm{OC} / \mathrm{DDM}(\mathrm{N}=1,00)$, curado a $150{ }^{\circ} \mathrm{C}$ por $10 \mathrm{~h}$, apresentou E' de 2,3GPa e $\mathrm{K} 1 \mathrm{C}$ (dureza) de 0,6 MPa e o mesmo valor de $\mathrm{Tg}\left(110{ }^{\circ} \mathrm{C}\right)$ que o sistema DGEBA/DDM. Os maiores valores de E' exibidos pelos sistemas DGEBA/DDM e

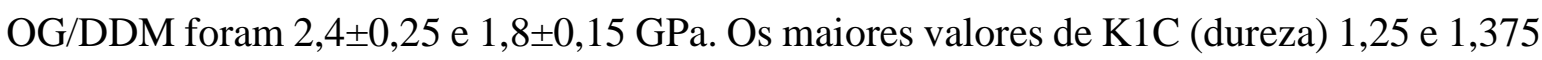
$\mathrm{MPa}$ foram encontrados nas composições com excesso de amina para os sistemas DGEBA/DDM e OG/DDM, respectivamente [73].

Comentários Iniciais: Vê se que através do uso de borrachas, cargas funcionalizadas, materiais nanométricos é possível alterar o módulo elástico do sistema epoxido. Em relação a premissa dessa TESE de usar uma carga mineral (mica) funcionalizada tem fundamentação teórica o suficiente para comprovar-se acertada. No caso a fundamentação básica será sem perder a questão elástica, ter o reforço mecânico que a NIPU e HNIPU precisam. 


\subsection{Mica em sistemas isolantes elétricos}

Mica é um termo geral para um grupo mineralógico com estrutura e propriedades químicas similares. Sob o ponto de vista mineral, o termo não é bem definido. O princípio da classificação das micas está baseado na sua composição química e na estrutura cristalina, sendo normalmente sua classificação baseada apenas na composição química, uma vez que suas propriedades físicas não são muito diferenciadas de outros silicatos lamelares [74]. A família de aluminossilicatos da classe da Mica possuem características similares com a representação da fórmula geral [75,76] como: $\mathrm{XY}_{2-3}$. $\mathrm{T}_{4} \mathrm{O}_{10} \mathrm{X}_{2}$. Onde:

$\mathrm{X}=$ são cátions com número de coordenação doze como $\mathrm{K}^{+}, \mathrm{Na}^{+}, \mathrm{NH}_{4}{ }^{+}, \mathrm{Rb}^{+}, \mathrm{Cs}^{+}$, $\mathrm{Ca}^{+2} \mathrm{e} \mathrm{Ba}^{+2}$ ou uma vacância parcial.

$\mathrm{Y}=$ um cátion ocupando um sítio octaédrico, por exemplo o $\mathrm{Al}^{3+}, \mathrm{Fe}^{3+}, \mathrm{Cr}^{3+}, \mathrm{Mn}^{3+}$, $\mathrm{V}^{3+}, \mathrm{Ti}^{3+}, \mathrm{Mg}^{+2}, \mathrm{Zn}^{+2}, \mathrm{Fe}^{2+/+3}, \mathrm{~V}^{3+}, \mathrm{Mn}^{2+/ 3+} \mathrm{e} / \mathrm{ou} \mathrm{Li}^{+}$;

$\mathrm{T}=$ um cátion ocupando sítio tetraédrico, frequentemente $\mathrm{Si}^{4+}$, além do $\mathrm{Al}^{3+} \mathrm{e} \mathrm{B}^{+3}$, podendo eventualmente ser o $\mathrm{Fe}^{3+}, \mathrm{Mn}^{3+} \mathrm{e} \mathrm{Ti}^{3+}$.

$\mathrm{X}=$ ânions como $\mathrm{OH}^{-}, \mathrm{O}^{2-}, \mathrm{F}^{-}$e raramente o $\mathrm{S}^{2-}$.

Segundo a classificação de Liebeau (1985), [77], as micas pertencem ao grupo de filossilicatos (silicatos lamelares) de dimensionalidade (D) igual a 2, mas na literatura também tem sido chamado de hidrosilicatos [78].

Como em todos os filosilicatos as placas de silicatos em arranjo tetraédrico podem ser visualizadas como sendo resultado da união de unidades $\left(\mathrm{Si}_{2} \mathrm{O}_{5}\right)^{2-}$ como mostrado na Figura 24.

Figura 24 - Arranjo de silicatos $\left(\mathrm{Si}_{2} \mathrm{O}_{5}\right)^{2-}$ formando anéis hexagonais interligados.

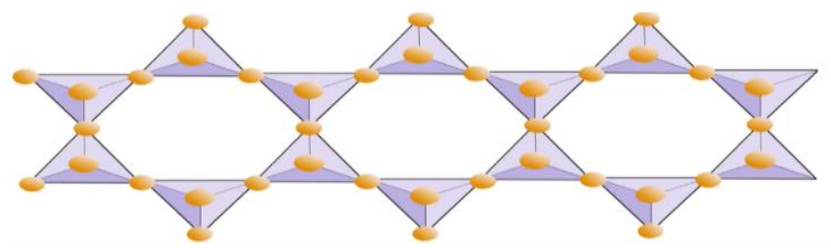

Fonte: Autoria desconhecida, Licença Creative Commons BC CA.

Na Figura 24 os anéis interligados dão origem a uma placa de poliânion de silicatos característica de filossilicatos. As esferas em amarelo representam íons $\mathrm{O}^{2-}$. 
Entre duas placas de tetraédricas de silicatos, os filossilicatos possuem uma placa octaédrica (o) como ilustrado na Figura 25 onde as esferas azuis são $\mathrm{O}^{2}$.

Figura 25 - Placa formada por íons metálicos em sítio octaédrico.

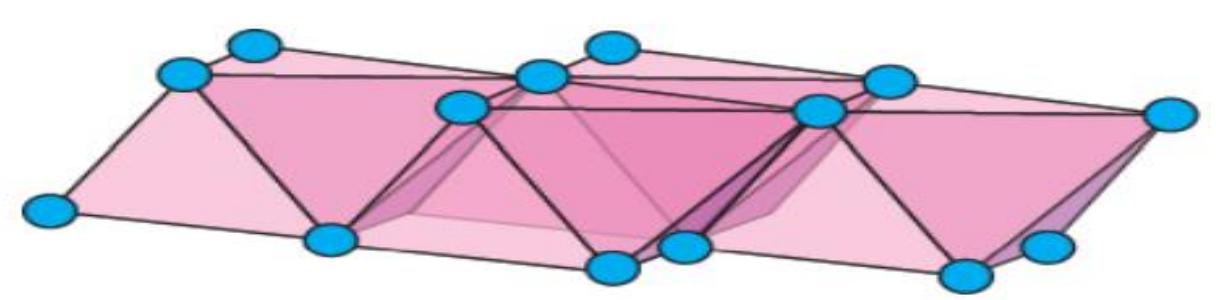

Fonte: Extraído de <http://www.geo.umass.edu/courses/geo311/phyllosilicates.pdf $>$ visualizado em $\underline{03 / 08 / 2019}$

A junção destas camadas t e o forma a espinha dorsal da rede cristalina das Micas é baseada num arranjo do t-o-t, ou seja, camada de poliânions com metais em sítios tetraédricos (t) e sítios octaédricos (o) alternados, também chamada de camada 2:1. A substituição parcial dos íons $\mathrm{Si}^{+4}$ por íons $\mathrm{Al}^{+3}$ resulta numa carga negativa líquida destas camadas $2: 1$. Esta carga líquida negativa é compensada pela presença de cátions X. Os sítios octaédricos podem estar completamente ocupados para dar micas trioctaédricas ou parcialmente ocupadas $(2 / 3 \mathrm{de}$ grau de ocupação) nas dioctaédricas.

As micas são extremamente abundantes na natureza, mas apenas alguns tipos atendem os requisitos necessários para a utilização em aplicações com grau técnico. No caso das aplicações em engenharia elétrica, existem apenas três tipos de mica em uso, são elas: muscovita, a flogopita e em menor quantidade a biotita [79].

Muscovita é a mais importante mica natural existente, sendo representada pela fórmula: $\mathrm{KAl}_{2}\left(\mathrm{AlSi}_{3} \mathrm{O}_{10}\right)(\mathrm{OH})_{2}$. Na estrutura lamelar os íons alumínio ocupam sítios octaédricos. Esse tipo de mica é classificado como um aluminosilicato de Potássio. A Figura 26 ilustra uma seção da rede cristalina desse tipo de material. Flogopita ou mica carbonatada difere da muscovita pela troca do $\mathrm{Al}^{+3}$ pelo $\mathrm{Mg}^{+2}$, representada pela fórmula: $\mathrm{KMg}_{3}\left(\mathrm{AlSi}_{3} \mathrm{O}_{10}\right)(\mathrm{OH})_{2}$ Tanto os íons magnésio quanto alumínio ocupam sítios octaédricos. Biotita ou mica férrica é um nome comercial. Este conjunto de micas estão distribuídas nas classes chamadas de Fluorofogopita e Fluorotetraferriflogopita, ou seja, micas ricas em $\mathrm{Fe}^{+2}$. Exemplos destas micas são a Annita, a Fluorannita, a Tetra-ferri-annita e a Siderofilita onde o íon ferro substituem parte dos íons magnésio na fórmula final e cujas fórmulas 
estequiométricas são respectivamente: $\mathrm{KFe}_{3}{ }^{2+}\left(\mathrm{AlSi}_{3} \mathrm{O}_{10}\right)(\mathrm{OH})_{2}, \mathrm{KFe}_{3}{ }^{2+}\left(\mathrm{AlSi}_{3} \mathrm{O}_{10}\right)(\mathrm{F}, \mathrm{OH})_{2}$, $\mathrm{KFe}_{3}{ }^{2+}\left(\left(\mathrm{Fe}^{3+}, \mathrm{Al}\right) \mathrm{Si}_{3} \mathrm{O}_{10}\right)(\mathrm{OH})_{2}$ e $\mathrm{KFe}_{2}{ }^{2+} \mathrm{Al}\left(\mathrm{Al}_{2} \mathrm{Si}_{2} \mathrm{O}_{10}\right)(\mathrm{OH})_{2}$.

Reforçando, a exemplo das outras micas, neste caso os íons $\mathrm{Al}^{+3}, \mathrm{Mg}^{+2}$ e $\mathrm{Fe}^{+2}$ estão em sítios octaédricos [79].

Figura 26 - Estrutura cristalina mica muscovita [80].

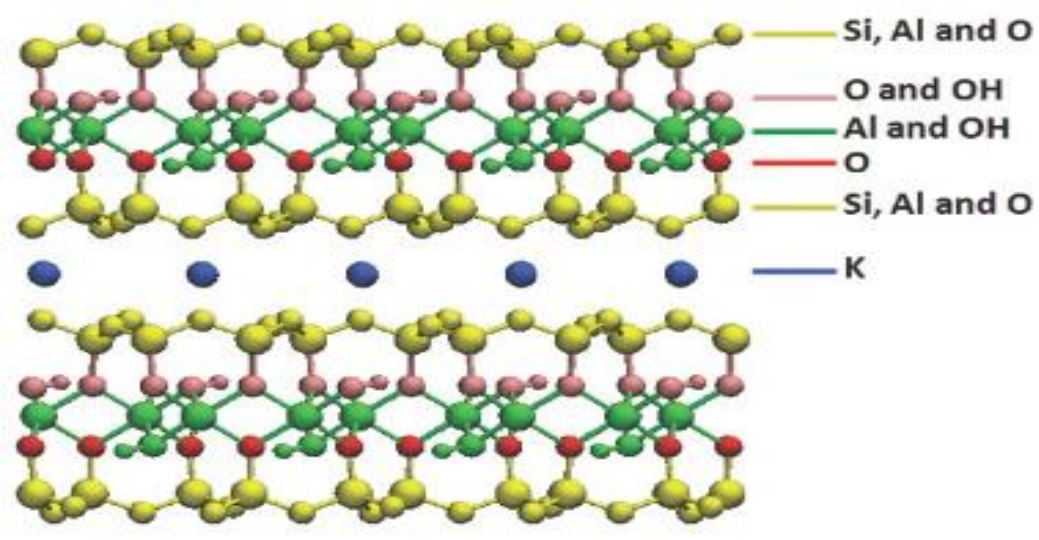

Fonte: Figura obtida em: KLEIN, H. H. Some thoughts regarding mica and mica paper. Von Roll Isola course information, 2012.

Diferente das duas micas principais, a biotita não tem grande interesse em aplicações especiais como o caso de uso em sistemas elétricos. A Tabela 5 compara as micas do ponto de vista elétrico e térmico.

Tabela 5 - Propriedades Físicas das Micas para Aplicação Elétrica [79].

\begin{tabular}{|l|l|l|l|}
\hline Propriedade Física & Unidade & Muscovita & Flogopita \\
\hline Temperatura de Fusão & ${ }^{\circ} \mathrm{C}$ & $1200-1300$ & $1200-1300$ \\
\hline Início da Calcinação & ${ }^{\circ} \mathrm{C}$ & 550 a 650 & 750 a 900 \\
\hline Estabilidade Térmica & ${ }^{\circ} \mathrm{C}$ & 500 & 700 \\
\hline Condutividade Térmica & $\mathrm{W} / \mathrm{m} . \mathrm{K}$ & 0,25 a 0,70 & Acima 1.7 \\
\hline Coeficiente Expansão Térmica & $\mathrm{K}^{-1}$ & $90.10^{-7}$ & $135.10^{-7}$ \\
\hline Constante Dielétrica & & 6 a 8 & 5 a 6 \\
\hline Fator de Dissipação (tan. Delta) & & $3 \times 10^{-4}$ & 10 a $100 \times 10^{-4}$ \\
\hline Rigidez Dielétrica & $\mathrm{KV} / \mathrm{mm}$ & 60 a 70 & 50 \\
\hline Resistência ao efeito Corona & & Passa & Passa \\
\hline
\end{tabular}

Fonte: Dados da tabela 4 extraídos de ROTTER, H, W., 1985.

As propriedades acima corroboram a escolha da mica como um material ideal para o uso em isolamento elétrico. Elas possuem alta estabilidade térmica, não são inflamáveis, possuem baixa expansão térmica, apresentam muito boa rigidez dielétrica sendo a melhor escolha quando se pensa em aplicações de isolamento elétrico para alta tensão [79]. Sua 
participação em compósitos para uso elétrico providencia além da melhora nas propriedades mecânicas, um aumento da resistência ao efeito corona, tendo sido usadas desde de 1960. Até os dias de hoje, com pequenas alterações, é o sistema que está em uso normalmente $[2,3,7]$.

Nas aplicações na área de isolamento de alta e média tensão, uma das formas mais comuns é o papel de mica. A fabricação do papel de mica pode ocorrer por diferentes processos. De uma maneira simplificada o mesmo se dá a partir de diversas etapas de fragmentação do mineral até a obtenção de pequenos flocos. Estes fragmentos são transformados em uma polpa que posteriormente é seca e reagrupada onde se obtém um papel poroso de gramatura definida. O comprometimento entre rigidez mecânica e elétrica, porosidade e controle do tamanho de partículas são os pontos fundamentais na produção do papel de mica [2,3,7,81]. A rigidez mecânica elevada pode fragilizar o papel tornando-o mais suscetível a proporcionar o aparecimento de trilhamento elétrico (arborescência) através das camadas.

A porosidade é um parâmetro importante para que se tenha uma rápida e efetiva penetração de resina em todas as camadas da fita de mica e de seus pequenos poros durante o processo de impregnação. Os papéis de mica fabricados atualmente apresentaram valores relativos em volume de até $50 \%$ de porosidade, tornando-os uma espécie de papel mata borrão para absorver resina. O papel de mica foi desenvolvido nos Estados Unidos durante o período da $2^{\mathrm{a}}$ guerra mundial como uma alternativa a importação da mica em escamas. A solução encontrada foi a fabricação do papel de mica fina a partir de um dos subprodutos da fabricação da mica prensada para aplicação eletrônica. Este papel atualmente é majoritariamente utilizado em relação ao tipo em escamas por sua facilidade de impregnação e por sua espessura uniforme resultando em uma significativa melhora na tolerância a espessura comparada com o tipo em escamas. Assim, possibilitando menores espessuras de isolação para suportar um mesmo valor de tensão com a mesma fração de mineral $[2,3,7,16]$.

A composição final do papel de mica é constituída de um reforço mecânico de tecido de fibra de vidro (usado devido a fragilidade do papel). A união entre o papel e o tecido se dá através do uso de aglutinantes (resina epóxi curada com anidrido). Isso garante a continuidade do material ao longo do processo de enfitamento sob tração contínua. Dependendo da tecnologia de fabricação pode ser acrescido um catalisador (normalmente se usa o nafetanato de zinco) à fita e um tecido de poliéster na construção do papel em 
substituição ao tecido de fibra de vidro. Após a conclusão dos estágios de fabricação do papel o mesmo é cortado em larguras determinadas de acordo com seu tipo de aplicação e tecnologia do fabricante. Este corte permite a confecção em rolos de diâmetros menores para posterior aplicação manual ou automatizada em máquinas de enfitamento [16]. Na Figura 26 temos o fluxo de uso da mica, o mineral, o papel de mica e já o seu uso em um equipamento elétrico. Na Figura 27 (a) temos a Mica muscovita em formato de flocos, na Figura 27 (b) papel de mica impregnado com resina epóxi e na Figura 27 (c) temos a barra elétrica enfitada com papel de mica e impregnada com resina.

Figura 27 - (a) Mica, (b) Fita de papel de mica e (c) barra impregnada [81].
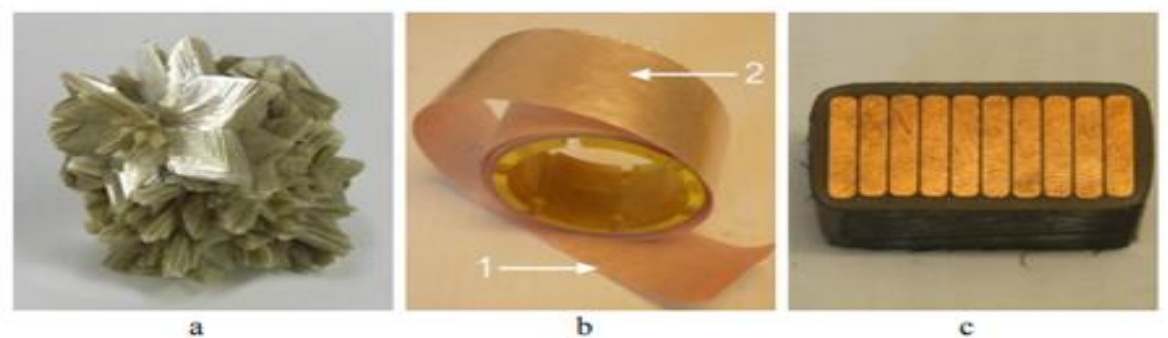

Fonte: SAXÉN, C; A $\mu$ - CT Investigation of the electrical breakdown mechanisms in Mica/Epoxy Machine Insulation; Examensarbete 30 hp; Julho 2017.

Abu (2006) et al [82], estudaram o efeito do uso de mica em poliestireno. A condutividade elétrica e o comportamento dielétrico foram estudados em função da concentração de mica e da frequência de campo elétrico aplicada. De acordo com os autores pode-se concluir que:

1. A condutividade $\mathrm{AC}$ e as constantes dielétricas dos compósitos se mostraram dependente do conteúdo de mica;

2. Os efeitos observados de relaxação e polarização do compósito são principalmente atribuídos ao comportamento dielétrico da mica. [82]

Hailin Mo (2016) et al, verificaram que sistemas epóxi-mica especialmente usados como isolamento elétrico em média ou alta tensão, eram sujeitos a estresse do tipo, térmico, elétrico e mecânico durante sua operação. A aplicação simultânea dessas tensões resultava em envelhecimento com concomitantes mudanças nas propriedades dos materiais. A delaminação de camadas de mica, rachadura entre os grãos de mica e vazios dentro do isolante eram as principais causas para a deterioração do isolante elétrico. Como os materiais de isolamento epóxi-mica são uma parte essencial de todo o sistema de trabalho com energia elétrica, sua falha afeta severamente sua confiabilidade e determina sua vida na maioria dos 
casos. Com isso seu trabalho foi na direção de melhorar a condutividade térmica do isolamento epóxi-mica e sua interface com a matriz epóxi. [83]

Um dos caminhos foi utilizar a mica sintética, um silicato em camadas expansível com alta cristalinidade, pureza e reprodutibilidade e com esse material fazer sua esfoliação, porém o alto custo inviabilizou a aplicação. Pesquisas anteriores demostraram que uma solução aquosa de dopamina em um $\mathrm{pH}$ alcalino fraco pode formar uma fina camada aderente na superfície da mica, tornando possível uma reatividade secundária com vários grupos funcionais. Com isso houve uma ligação de hidrogênio entre a matriz epóxi e mica, melhorando as propriedades elétricas e mecânicas. O tratamento epóxi-mica-dopamina pode aumentar em $42 \%$ a condutividade térmica quando comparada a um sistema epóxi-mica. Em outro importante estudo mostrou que a perda dielétrica e a constante dielétrica são menos dependentes da frequência, sendo que a resistência ao impacto aumentou em $72 \%$. Portanto, as propriedades mecânicas e elétricas são melhoradas com o tratamento superficial da mica e a sua melhoria na interface com o sistema epóxi. Sendo um trabalho para a próxima geração de equipamentos eletroeletrônicos [83].

Tripathi (1990) et al, estudaram o efeito do Tamanho de Partículas e da Concentração das mesmas nas Propriedades Mecânicas e Elétricas do PVC carregado com Mica. Eles descobriram que a adição de mica nestes compósitos poliméricos melhora significativamente as propriedades dielétricas dos plásticos. Essas alterações nas propriedades elétricas dos compósitos poliméricos preenchidos com mica os tornam adequados para uso em aplicações de isolamento elétrico [84].

Gupta (1994) et al, descobriram em seus estudos que as microfissuras resultantes de tensões internas de compósitos preenchidos com mica perdem suas propriedades elétricas. Quando o compósito sofre o processo de resfriamento, sua baixa resistência a deformação pode levar a formação de rachaduras ou microfissuras o que acarreta as perdas elétricas durante sua utilização. Essas microfissuras em materiais compósitos decorrem principalmente da falha adesiva na interface entre mica e resina [85].

Sahai (2017) et al, concluíram que o uso de agente de acoplagem como por exemplo o N- (2-Aminoethyl) -3-aminopropyltrimethoxysilane em mica é um excelente agente para trabalhar com PPO (polyphenilene oxide) compósitos. A adição de mica sililada com o agente de acoplamento como carga no PPO melhora as propriedades mecânicas, tais como, a resistência ao impacto e à flexão quando comparadas com o compósito com mica não tratada [86]. 
Vogelsang (2006) et al, estudaram o comportamento de sistemas epoxidos em aplicação elétrica, tendo analisado a formação de trilhamento elétrico em função do tipo de interface entre a resina e os outros materiais no compósito. De acordo com eles, o trilhamento dependerá da ligação química e a resistência ao cisalhamento entre a resina epóxi e o aditivo. Quanto maior for a presença de grupos funcionais na superfície da matriz menor será o efeito de falha causado pelo trilhamento elétrico. No caso específico do uso de mica como barreira, como esse material tem muito pouco grupamento $\mathrm{OH}$ (hidroxila) na superfície, a iteração entre a resina epóxi e a mesma mostrou-se como frágil, facilitando a propagação do trilhamento elétrico [87].

Novaes da Conceição (2015), estudou o sistema de obtenção de sistemas isolantes para alta tensão, onde mantendo o procedimento padrão de uso de uma fita de mica composta de mica fina $\left(160 \mathrm{~g} / \mathrm{m}^{2}\right)$, muscovita não calcinada, depositada sobre uma fita de vidro impregnada com DGEBA/anidrido, substitui esse sistema pelo uso de uma resina epóxi (DGEBF) usando Nano partículas de sílica (RN) e sem o uso da fita de Mica. Sua abordagem seria o de eliminar eventuais falhas na isolação, como por exemplo, vazios na isolação, de modo a melhorar a isolação elétrica e reduzir as perdas por transporte de energia. Apesar dos resultados satisfatórios obtidos, para as barras fabricadas com resina RN contendo nanopartículas de sílica, não se observa uma melhora significativa dos resultados para o fator de dissipação, sendo possível que as propriedades dielétricas características da mica de impedimento à propagação de descargas elétricas preponderam em relação às propriedades das nanopartículas conforme pode ser visto na Figura 28 [7].

Figura 28 - Comparação do Fator de dissipação entre sistema com Nanopartícula e sistema atual com fita de Mica [7].

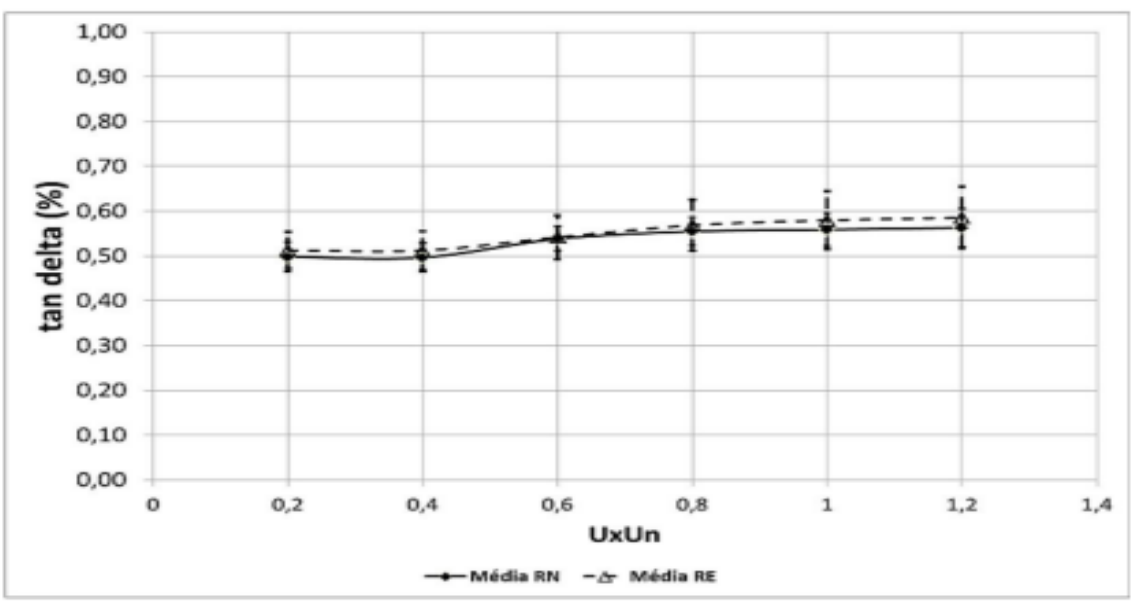

Fonte: Figura extraída do trabalho de Novaes da Conceição [7]. 
Comentários Iniciais: Tem se nessa fase da revisão bibliográfica, que o tratamento da mica pode ser um diferencial para melhorar suas propriedades. Nos artigos revisados não se viu o enfoque dado nesse projeto de uso da mica em pó com o polímero na substituição do conjunto de isolação. Busca-se melhorar as características da mica, porém não se faz referência a substituição da fita de papel de mica. Dessa forma, o abordado por essa TESE é um fato científico inédito nessa linha de pesquisa para substituição do sistema epóxi/fita de mica nos hidrogeradores.

\subsection{Funcionalização de cargas minerais}

Cargas minerais é o nome que se dá comercialmente às substâncias inorgânicas compostas por materiais inorgânicos (ou minerais) muito pouco flexíveis, cerâmicas, que são incorporados à massa de polímeros [88].

Os polímeros, quando puros, apresentam propriedades que muitas vezes não atendem às especificações técnicas que as peças finais fabricadas a partir deles devem possuir. As propriedades dos polímeros tais como resistência à tração, resistência química a ataques ácidos e básicos, resistências à deformação ao calor, etc., são aprimoradas através da adição de cargas minerais, tratadas superficialmente, em quantidades adequadas [89].

A melhora das propriedades mecânicas dos polímeros pela adição de cargas inorgânicas depende de aspectos mecânicos e químicos da interface entre eles que permitam uma intensa força de adesão entre os dois tipos de compostos químicos. Do ponto de vista químico, a energia de superfície dos dois componentes (polímero e carga) direciona o tipo de interação entre eles, ou seja, interações físicas do tipo forças intermoleculares ou eletrostáticas, em oposição às ligações químicas covalentes. Um exemplo interessante ocorre quando o polímero tem baixa energia de superfície caracterizado quimicamente por grupos apolares ao longo da cadeia polimérica e a carga possui alta energia de superfície. Esta diferença de energia de superfície resulta numa incompatibilidade. Ou seja, faz com que a carga mineral tenha dificuldades em ser "molhada" pelo polímero, comprometendo assim a sua adequada dispersão e as propriedades elétricas, óticas e mecânicas do composto formado pela dispersão da carga mineral no polímero. Para compatibilizar esses dois materiais, são utilizados produtos químicos que atuam modificando a energia de superfície por modificação química dos grupos superficiais da carga mineral. Este tipo de estratégia se convencionou 
chamar de tratamentos de superfícies da carga mineral e os compostos utilizados são chamados de agentes de acoplagem [90,91].

A partícula de carga mineral possui uma energia superficial muito superior à energia superficial do polímero. A alta energia de superfície das cargas minerais (componentes estruturais) é função da presença de grupos funcionais polares como por exemplo, o grupo silanol, Si-OH, nas sílicas não-cristalinas e cristalinas, sendo que os mesmos podem estar isolados, vicinais ou geminados como demonstrado por Maciel et al (1997). [92].

As diferentes densidades destes grupos polares afetam intrinsecamente a capacidade de adsorção destes materiais, bem como a força de adesão entre estes e outros componentes dos compósitos [93]. Assim, se a carga mineral for misturada ao polímero sem que a primeira houvesse sido tratada superficialmente, a mesma tenderia a se aglomerar porque a variação de energia livre de interação partícula-partícula seria mais negativa do que a variação de energia livre de interação partícula-polímero. Com o tratamento superficial a energia superficial da carga mineral é diminuída a valores próximo daquele da energia superficial do polímero; então a variação de energia livre partícula-partícula torna-se menos favorável do que a variação de energia livre de interação partícula-polímero permite que a carga se disperse facilmente na matriz do polímero [94]. Dependendo do agente de tratamento empregado, a partícula será apenas dispersa na matriz do polímero sem que haja forte interação entre ela e o polímero. Esse processo é usado por exemplo quando se quer melhorar o processamento de um polímero, usa-se ácidos graxos como lubrificante para melhorar seu fluxo, não ocorrendo com esse uso iteração interna com o polímero. Em outras situações o agente que promove a dispersão também favorece, por algum meio, forte interação partículapolímero (por exemplo, os organossilanos). Os organossilanos são compostos organometálicos contendo o silício como átomo central e ligações C-Si. Os grupos orgânicos em torno do silício podem conter grupos funcionais passivos como alquilas e arilas ou grupos ativos que reagem com a cadeia lateral do polímero ou que se polimerizam junto com o monômero do polímero formando ligações interfaciais entrecruzadas, grupos acrílicos, epoxidos ou vinílicos. [95]

Estes agentes de acoplamento têm amplo uso por sua habilidade de interligar quimicamente com os polímeros orgânicos e os materiais inorgânicos, como as cargas minerais [95]. Quando os organossilanos são adicionados nestes sistemas eles via de regra 
melhoram suas propriedades físicas e químicas, mesmo quando submetidos a severas condições de fadiga ambiental.

$\mathrm{O}(\mathrm{Y})$ da fórmula representa a parte do organosilano que reagirá com o polímero, podendo conter grupos alquil, aril, vinil, amina, epóxi, metacrilato e outros. Já $\mathrm{O}(\mathrm{X})$ na fórmula representa os grupos hidrolisáveis ligados ao silício $(\mathrm{Si})$. Esses grupos são representados pelo cloro, alcóxi ou acetóxi. Em determinadas condições de temperatura/umidade estes grupos são deslocados e dão origem a ligações covalentes interfaciais para formar ligações Si-O-carga mineral. Alternativamente, na presença de umidade estes grupos $\mathrm{X}$ sofrem hidrólise formando hidroxisilanos e HX conforme representado na equação 5 .

$$
\mathrm{YRSiX}_{3} \stackrel{\mathrm{H}_{2} \mathrm{O}}{\longrightarrow} \mathrm{YRSi}(\mathrm{OH})_{3}+3 \mathrm{HX}
$$

Estes por sua vez podem aderir sobre a carga mineral via ligações de hidrogênio e/ou formar ligações interfaciais Si-O-carga mineral liberando água. A Figura 29 ilustra a reação entre um silano com um mineral.

Figura 29 - Esquema de reação do silano com a argila [96].

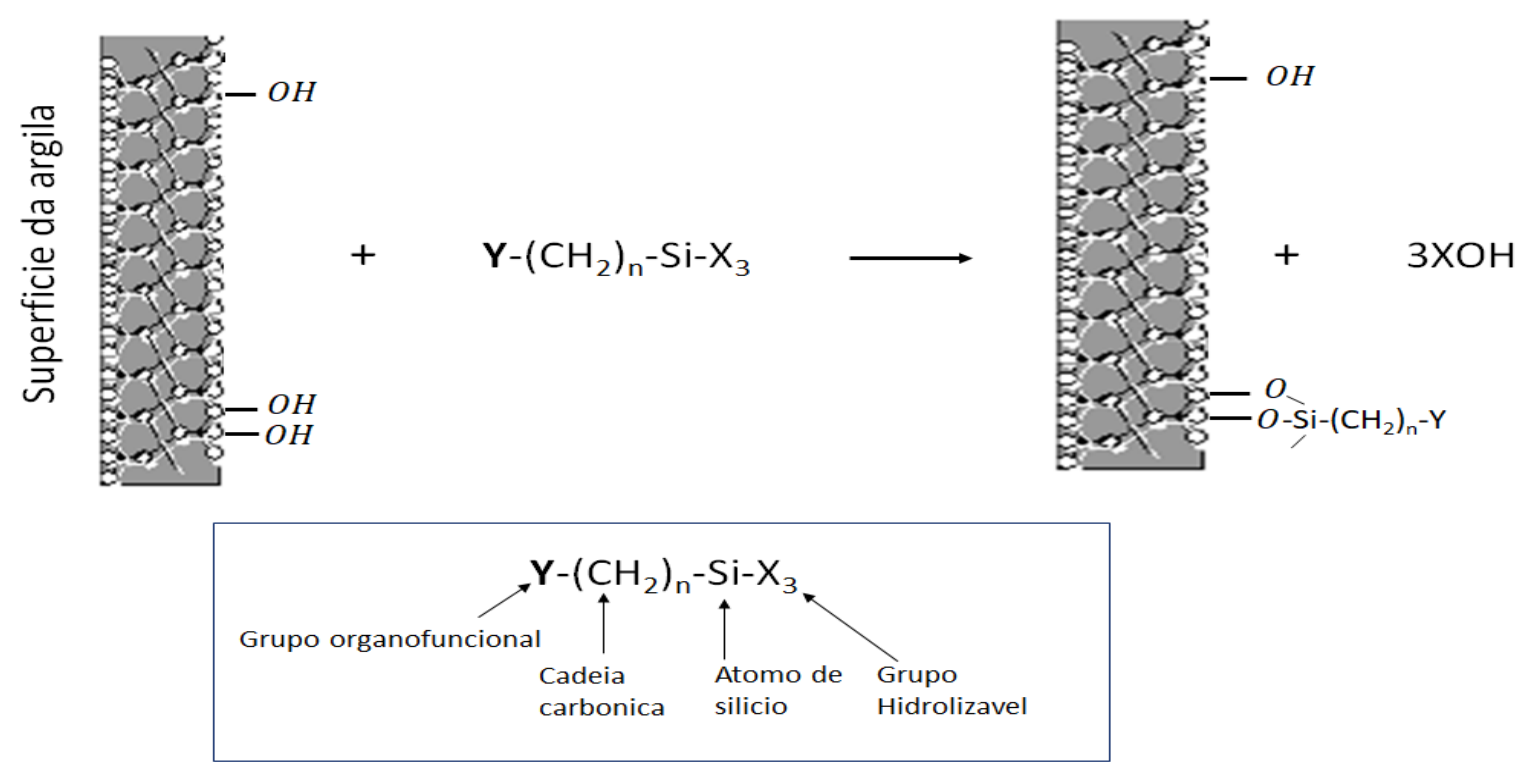

Fonte: elaborado pelo próprio autor, 2019. 
Vários estudos na literatura tratam da compreensão da reação de sililação de superfícies hidroxiladas usando as mais variadas abordagens. Um dos primeiros estudos de sililação de superfícies hidroxiladas foi realizado por Michalska (1981) et al em sílica gel com o objetivo de obter catalisadores heterogeneizados de compostos de coordenação de ródio [97].

Kang (1991) et al, utilizaram RMN de estado sólido para estudar as estruturas e o comportamento de camadas de silanos com grupo funcional amino sobre a superfície de sílica. Os espectros de RMN de ${ }^{29} \mathrm{Si}$ da sílica tratada, mostraram que as moléculas de silano estavam quimicamente ligadas à superfície por meio de ligações covalentes do tipo siloxanos, estas seriam formadas na reação dos grupos silanol da superfície com os grupos hidrolisáveis dos silanos. Houve um aumento da densidade de grupos aminossilanos adsorvidos em função do aumento da concentração destes em sílica que foi tratada com uma solução aquosa contendo de 2 a 10\% de DABES (aminobutil-trietoxissilano) [98].

Ishida (1980) et al encontrou que há a formação de monocamadas até uma concentração de $2 \%$ de silano em solução aquosa com pH 3,5 que foi ajustado com ácido acético, sendo que multicamadas foram obtidas em concentrações acima desse percentual [99].

Okabayashi (1997) et al estudaram a formação de camadas de APTS (3aminopropiltrietoxisilano) sobre sílica gel por DRIFT. Eles encontraram evidências de que a estrutura da camada de APTS formada a partir de solução em tolueno era dependente de dois fatores, a concentração e o tempo de adsorção do aminossilano conforme pode ser visto pela evolução da razão entre as áreas das bandas em 1597 e $1867 \mathrm{~cm}^{-1}$ com o tempo obtido por Espectroscopia de Absorção no Infravermelho usando o acessório de Reflectância Difusa na Figura 30 [100]. 
Figura 30 - Razão da área das bandas em 1597 e 1867 cm-1 com o tempo obtido por Espectroscopia de Absorção no Infravermelho usando acessório de Reflectância Difusa em função do tempo de adsorção do aminossilano.

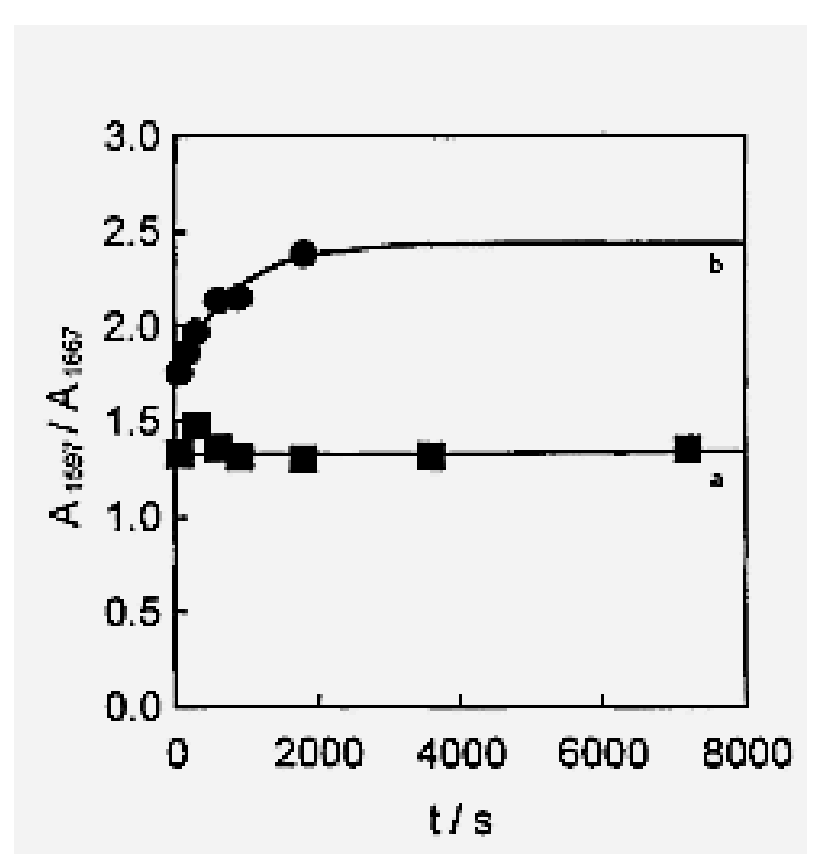

Fonte: extraída da publicação de Okabayashi et al com licença para uso sob número 4991381383647 [100].

Foram utilizadas partículas de nanosílicas, sendo as diferenças entre elas o diâmetro médio. Amostra A $(5,5 \mathrm{~nm})$, B e C $(6,6 \mathrm{~nm})$ e D $(8,1 \mathrm{~nm})$. A cadeia orgânica do grupo Y também é um fator importante a ser considerado na formação e organização de camadas de silanos sobre superfícies inorgânicas. Ishida et al [99] observaram que quando Y é a cicloexila são obtidas camadas cristalinas de silanotriol na interface da fibra de vidro tratada, demonstrando assim a ocorrência de auto-organização dos silanos quimissorvidos. Dois fatores introduzem desordem na camada de silanos, eles são a magnitude da agregação de silanos em solução e as irregularidades da superfície da estrutura tratada [99].

De Haan (1986) et al, comprovaram que a natureza da ligação era dependente do tipo do solvente usado e também do tratamento térmico usados na aplicação. O uso de tolueno na deposição de APTS resultava principalmente em ligações mono e bidentada, enquanto o uso de água como solvente forma apenas ligações bi e tridentada. $\mathrm{O}$ aumento da temperatura em ambos os casos resultou no aumento de ligações tridentada [101]. 
Caravajal (1988) et al usando sílica gel como material base e tratadas com APTS, encontraram evidências que a quantidade de cobertura e da estrutura de silano usando tolueno seco era dependente da disponibilidade de água na superfície [102].

Ondus (1988) et al estudaram o processo de sililação sobre materiais metálicos como o titânio e ferro metálico além de ligas de alumínio (1100 e 2024). No estudo realizado foi possível observar que a natureza da ligação do silano com a superfície destes metais e ligas era influenciada pelo pós-tratamento térmico destes materiais sililados. Na análise de FTIR observou-se um aumento na homopolicondensação horizontal dos grupos alcóxi e silanol laterais, contudo na superfície com alumínio a amina foi oxidada para imina e a homopolicondensação foi baixa ou não foi detectada [103].

Embora a Figura 29 ilustre um panorama simples para a reação de silanos com superfícies hidroxiladas, Hyacinth (2000) et al demonstraram que pode ocorrer a formação de nanofitas na superfície de vidro aluminossilicato tratados com APTS usando Microscopia de Força Atômica. Em paralelo, eles encontraram por Espectroscopia de Fotoelétrons Excitados por Raios X (XPS) uma segregação superficial de $\mathrm{Na}^{+}$, formação de carbamatos pela quimissorção de $\mathrm{CO}_{2}$ do ar e depleção superficial da concentração de $\mathrm{N}$ em função do tempo de exposição ao ar atmosférico. Assim, mesmo silanos simples como o APTS podem levar a padrões de auto-organização complexos como as nanofibras em função do substrato e exposição ao ar [104].

Em sistemas compósitos o silano presente na carga, terá uma função de compatibilizar o componente estrutural (carga) com o componente matricial (polímero), ou seja, funciona como uma ponte entre os dois materiais, melhorando as características do composto final. As imagens de fractografia por microscopia eletrônica de varredura a seguir ilustram na Figura 31 o quartzo (carga mineral) tratado com um silano contendo grupo acrilato inserido numa matriz de resina de poliéster, enquanto na Figura 32 temos o quartzo sem tratamento de silano inserido na mesma resina. Na Figura 31 não é possível observar uma interface abrupta entre os dois materiais pela presença do agente compatibilizante, na figura 32 é nítida o contorno de grão do quartzo evidenciando a ausência de interação entre a matriz polimérica é a carga mineral, ou seja, uma interface abrupta. 
Figura 31 - Imagem MEV (Microscopia eletrônica varredura) do quartzo/Silano/Polímero. Imagem capturada do catálogo da Dynasilan. Não consta no catálogo informações da escala é condições que foi obtida essa imagem.

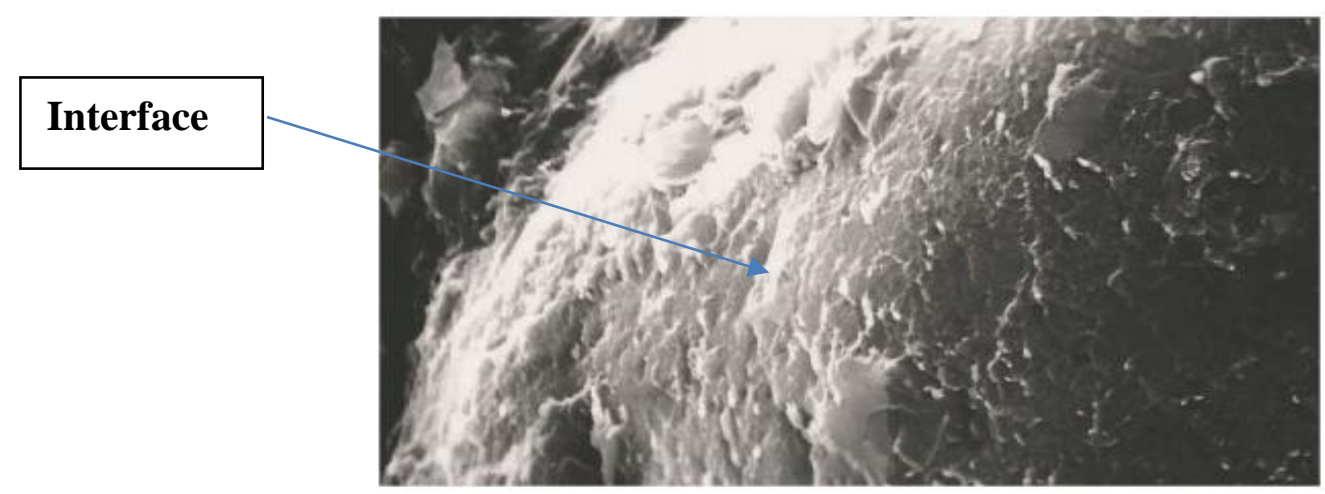

Fonte: Catálogo da Dynasilan.

Figura 32- Imagem MEV (Microscopia eletrônica varredura) do mesmo sistema sem tratamento de silano. Imagem capturada do catálogo de silanos Dynasilan. Não consta no catálogo informações da escala e condições de obtenção da imagem.

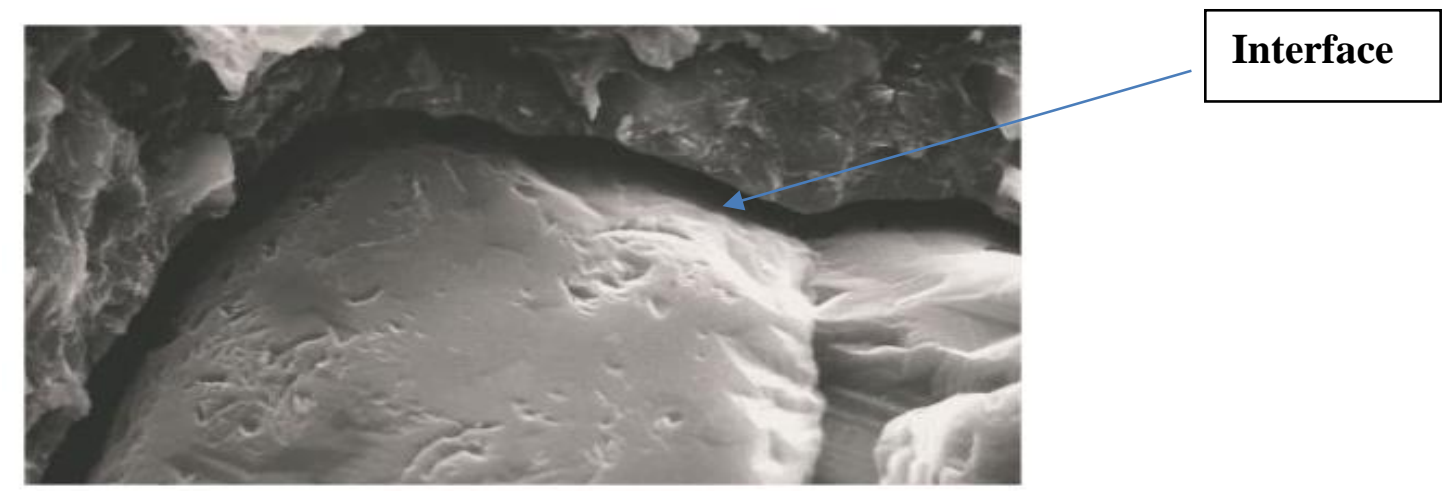

Fonte: Catálogo da Dynasilan.

\subsubsection{Efeito da Sililação de Componentes Estruturais em Compósitos de Resina}

\section{Epóxi}

Wong (2005) et al documentaram que a adição de silano aos sistemas epóxi pode modificar sua reologia, molhabilidade e também adesão sobre vários substratos. Eles utilizaram como substrato amostras de Silício metálico, liga de SiN além de microesferas de vidro. O estudo mostrou que em média, a adesão de epóxi não modificado quando comparado com epóxi modificado com silano diminui em 90\% sua adesão após imersão em água quente. 
Verificaram também que a viscosidade do polímero pode ser reduzida com o uso de silano [105].

Dharmalingan (2015) et al comprovaram que o uso de aluminossilicato como carga em sistemas epóxi pode reduzir as propriedades mecânicas em razão da pobre dispersão e falta de ligação interfacial com a matriz polimérica. Para melhorar essa interface, tratou a superfície da carga mineral com surfactantes do tipo Lauril Sulfato de sódio e com silanos do tipo GPTS (glycidoxi propil trimetoxi silano). Estudos morfológicos, térmicos e mecânicos comprovaram que a carga mineral tratada com GPTS mostrou boa dispersão melhorando as propriedades mecânicas, em especial a resistência ao impacto [106 ].

Torkildsen (2018) observou que as interações entre uma matriz epóxi e a superfície da carga mineral sem tratamento (Sulfato de Bário, Mica e Wollastonita) não puderam ser observadas por FTIR e XPS. Entretanto, nos ensaios de tração e flexão houve uma indicação de interação fraca entre a matriz e a carga mineral. Com o tratamento da carga mineral com APTS, estudos de XPS revelaram a presença de carbono, silício e nitrogênio em todas as superfícies, contudo os estudos de FTIR e do XPS não mostraram as interações químicas entre a carga e o sistema epóxi após a cura. Não obstante, a fractografia mostrou que a carga modificada com silano estava mais ancorada na matriz polimérica [107].

Chiang (1980) et al, estudaram o tipo de reação que ocorre na interface entre um sistema epóxi curado com anidrido e uma fibra tratada com aminossilano. Usando técnicas de FT-IR, encontrou evidências que ligações químicas são formadas na região interfacial entre a matriz e os agentes de acoplamento. A quantidade de ligação interfacial depende da composição e das condições de processamento. A principal ligação química entre a matriz e o agente de acoplamento de amina ocorre entre os grupos epóxi e amina. Uma pequena quantidade de ligação amida também foi encontrada [108].

Tianhao (2017) et al investigaram três agentes de acoplamento baseados em silanos para modificação da superfície de uma nanosílica, sendo preparado posteriormente sistemas baseados em sílica/epóxi. Silano epóxi e aminossilano com um grupo amina primária e um grupo amina secundária na posição propílica tanto na forma linear como na forma cíclica é um diazo silano foram testados. A primeira intenção era que dois grupos amina formassem uma rede mais densa, no entanto, os grupos amina reagem com a resina epóxi e levam à diminuição da reticulação da própria resina com o anidrido. A temperatura de transição vítrea dos compósitos com sílica tratada com aminossilano foi surpreendentemente baixa e as 
propriedades térmicas e mecânicas também foram danificadas. A solução foi aplicar sobre a camada de sílica que recebeu o diazo silano uma camada de anidrido (Metil hidroxi hidroftálico), dessa forma os resultados foram superiores [109].

Comentários Iniciais: De uma maneira geral pode se concluir que o tratamento superficial de cargas minerais com silano deve ser executado considerando o grupamento acoplado como participante da reticulação, no caso desta TESE, onde o grupamento será o mesmo do sistema reacional, verá se que essa questão de interferência na velocidade de reação não terá impacto significativo.

\subsection{Obtenção de compósitos híbridos}

Os termos compósitos e híbridos orgânico-inorgânicos são de forma inadvertidamente usados como sinônimos. Compósitos são materiais constituídos pela mistura de dois ou mais componentes ou fases separadas, normalmente em escala macroscópica, os quais são apresentados em proporções razoáveis (> 5\%) [110]. Uma outra definição mais abrangente para compósitos foi dada por Mano (1991), [111] como sendo: "Classe de materiais heterogêneos, multifásicos, podendo ser ou não poliméricos, em que um dos componentes, descontínuo, dá a principal resistência ao esforço (componente estrutural), e o outro, contínuo, é o meio de transferência desse esforço (componente matricial). Esses componentes não se dissolvem ou se descaracterizam completamente; apesar disto atuam corretamente, e as propriedades do conjunto são superiores à de cada componente individual ". O componente estrutural pode ser fibroso ou pulverulento, enquanto o componente matricial pode ser termoplástico ou termorrígido. Um dos caminhos usados hoje para compatibilizar os componentes estruturais e matriciais através é por meio da funcionalização da partícula inorgânica. Uma das rotas possíveis é a sililação, onde temos a modificação da superfície através da reação dos grupos hidroxilas com clorosilanos e alcóxisilanos reagindo entre si e formando uma ligação interfacial covalente X-O-Si-Y; onde X é um átomo metálico ou semi metálicos da superfície, Y é um grupo funcional orgânico. As Figuras 33 e 34 ilustram uma reação genérica de um processo de funcionalização [111]. A sililação permite que se altere a energia da superfície a fim de aumentar o trabalho de adesão e/ou formar uma ligação entrecruzada ou interfacial com o componente matricial, por exemplo no caso de Y conter grupos vinila, acrilato ou tiol. 
Os materiais híbridos são compósitos onde há componentes estruturais inorgânicos (metais ou cerâmicas) e componentes orgânicos (matricial), sendo que um deles foi formado a partir de precursores moleculares durante a formação do compósito [112]. Estes compósitos ditos híbridos são arranjados em duas classes, conforme abaixo:

(a) Classe I, onde a interação entre os componentes se dá por meio de interações fracas, por exemplo, a forças de Van der Wall, as ligações de hidrogênio ou interação eletrostática [113].

(b) Classe II, onde os domínios orgânicos são ligados quimicamente aos inorgânicos por ligações iônicas ou covalentes [65]. Conforme ilustrado na Figura 33.

Figura 33- Representação dos compostos híbridos classe II.

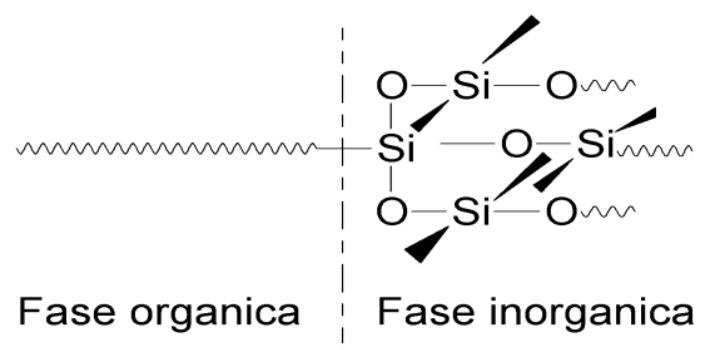

Fonte: Autoria própria 2019.

Figura 34 - reação de funcionalização de um óxido metálico.

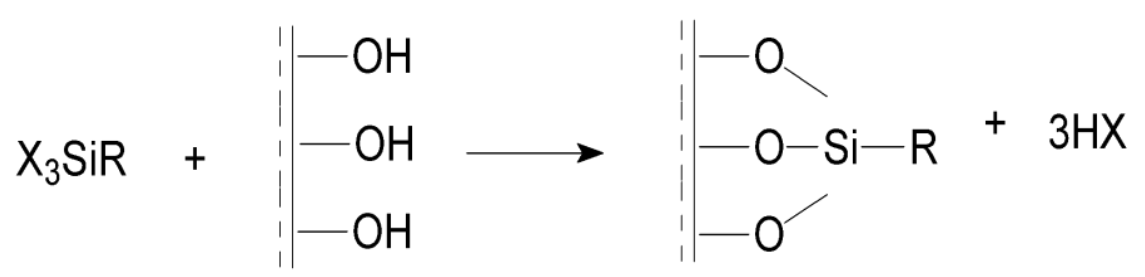

Fonte: Autoria própria 2019.

A figura 35 mostra os principais grupos funcionais de organosilanos usados nas reações de obtenção de materiais híbridos [110]. 
Figura 35 - Organossilanos usados, a) Metacriloxipropiltrimetoxilano (MPS); b) n-propriltrimetoxilano; c) viniltrimetoxisilano; d) 3-glicidiloxipropiltrimetoxisilano (GPTS); e) 3-aminopropiltrietoxilano (APTS).<smiles>C=C(C)C(=O)OCCC[Si](OC)(OC)OC</smiles>

(a)<smiles>CO[Si](CCCOCC1CO1)(OC)OC</smiles>

(d)<smiles>CCC[Si](OC)(OC)OC</smiles>

(b)<smiles>C=C[Si](OC)(OC)OC</smiles>

(c)

Fonte: Autoria própria 2019.

No caso dos híbridos produzidos com aminossilano (APTS), o grupo amina atua como nucleófilo na reação com os grupos epóxi, assim como, com os policarbonatos conforme ilustrado abaixo na Figura 36 (a) e Figura 36 (b).

Figura 36- a) Ciclocarbonato reagindo com amina via híbrido e formando uretana e b) epóxi reagindo com amina do híbrido e fazendo a reticulação. [110]<smiles>NCCC[Si](O)(O)OC1CC1CNCNNCO[C@H](CO)C(CO)OC(N)=O</smiles><smiles>[R]C(O)CNNCC(O)CCN</smiles>

Fonte: Autoria própria 2019. 
A Figura 37 ilustra o modelo final esperado de um híbrido tratado com aminossilano e sua interação com o sistema polimérico e que será uma das metas desse projeto.

Figura 37 - Modelo estimado de estrutura usando híbrido [110].

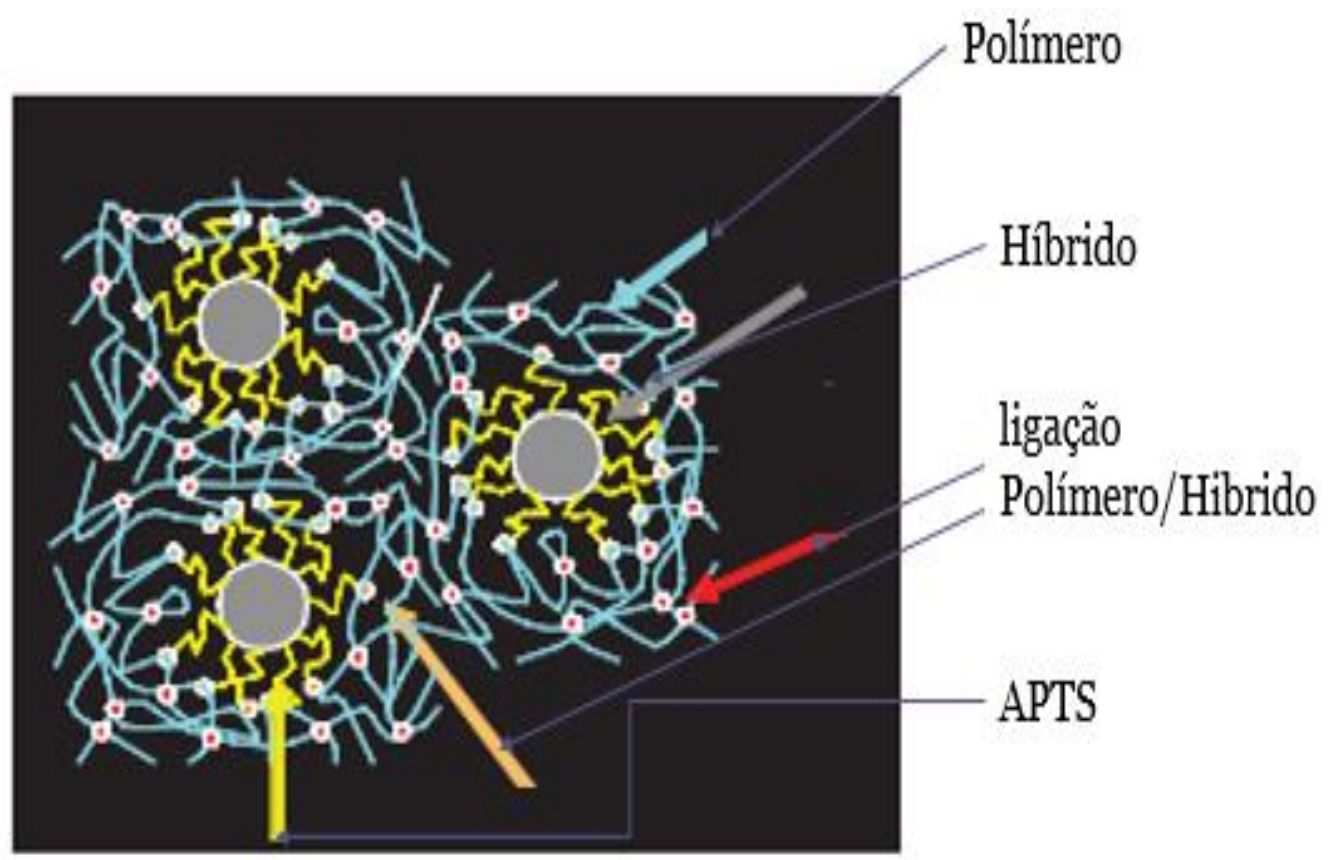

Fonte: Autoria própria 2019, com modificação a partir de ARROYO, M; 2013.

Kartal (2014) et al, buscaram através de uso de materiais híbridos melhorar a tenacidade de polímeros frágeis usando o conceito de rede interpenetrante. Para tal finalidade usou resinas de poliuretano com terminação tipo silano. Com este objetivo, materiais híbridos à base de epóxi com várias concentrações foram preparados a partir de resina epóxi tipo bisfenol A e um uretano terminado por silano. Onde a presença do uretano com terminação silano produziu excelente endurecimento do sistema epóxi. As imagens de microscopia eletrônica de varredura confirmaram em escala micro e sub-micron uma segunda fase dispersa. Encontrou que resistência a tração, valores de módulos elástico foram reduzidos com adição do híbrido, sendo que o valor de resistência ao impacto foi $60 \%$ maior que no sistema epóxi convencional [114].

Macan (2004) et al fizeram um Sistema híbrido usando GLIMO,3glicidiloxipropiltrimetoxissilano obtido após uma hidrólise controlada, com epóxi, reticulando posteriormente com polioxipropileno diamina (Jeffamine D230). Os grupos epóxi permaneceram estáveis durante a hidrólise, e os grupos silanol hidrolisados atuam como catalisadores para a reação epóxi-amina. A condensação inorgânica precoce em 
sistemas catalisados por base pode impedir estericamente a reticulação completa da fase orgânica, enquanto a presença de íons cloreto do catalisador ácido (ácido clorídrico) influencia adversamente a estabilidade térmica desses materiais híbridos, conforme determinado por análise termogravimétrica (TGA). As propriedades mecânicas dos materiais híbridos totalmente curados foram determinadas por Nanoindentação e a temperatura de transição vítrea foi determinada por DSC. Sistemas hidrolisados com maiores quantidades de água apresentam propriedades mecânicas mais pobres, enquanto a melhoria mais significativa nas propriedades mecânicas foi alcançada para um sistema catalisado por ácido [115].

Gonzáles (2011) et al, pesquisaram o uso de um sistema híbrido não convencional, uma poliamina organo-inorgânica obtida através da reação entre PAMS (Poliaminopropil methoxi silano) com Rhodamine B sulphonyl chloride para curar um sistema epóxi cicloalifático o qual apresenta uma reatividade reduzida quando comparado com o DGEBA. Analisou o comportamento dessa cura via espectroscopia no infravermelho próximo, e as transições térmicas foram medidas por análise térmica dinâmica. Os materiais obtidos apresentaram altos valores de $\mathrm{T}_{\mathrm{g}}\left(\mathrm{em}\right.$ torno de 125 a $164{ }^{\circ} \mathrm{C}$ ), sendo que do ponto de vista de análise usando microscopia de varredura mostrou se homogêneos [116].

Prezzi (2005) et al, compararam os efeitos da introdução de grupos funcionais trialcoxisilano na extremidade da cadeia (utilizando amina e mercapto-silanos) com tipos semelhantes enxertados no meio da cadeia da resina constituinte (utilizando um silano isocianato). O uso de agentes de acoplamento com um caráter básico (tipo amina silano) promove a formação de redes mais densas em ambas as fases constituintes do híbrido epóxisílica resultante, que se manifesta através de um grande aumento na Tg e uma supressão mais extensa da relaxação molecular dentro das regiões de transição vítrea. $\mathrm{O}$ aumento do número de grupos funcionais alcoxi-silano na extremidade da cadeia, com a utilização de um bisaminossilano, tem um efeito relativamente menor na morfologia e nos espectros mecânicos dinâmicos dos híbridos epóxi-sílica resultantes. Verificou-se também que, a incorporação de pequenas quantidades de uma resina epóxi de alto peso molecular causa uma plastificação considerável da fase orgânica e uma redução sensível na Tg [117].

Selimov (2018) et al, pesquisaram sobre compósitos poliméricos reforçados com fibras de carbono, uma geração de materiais que é atualmente usada para aplicações aeroespaciais. Por meio da introdução de agentes de reforço secundários, como nanopartículas de alumina, 
se obtiveram melhorias nas propriedades mecânicas, tais como resistência à fratura. No entanto, problemas com o processo de fabricação podem surgir pela variabilidade inerente das técnicas de fabricação, assim como, com a tendência de aglomeração das nanopartículas. A espectroscopia de fotoluminescência foi utilizada para investigar o impacto dos parâmetros de processamento, bem como o impacto do parâmetro de formulação agente de acoplamento baseado em silano na dispersão das partículas e uniformidade em amostras do mesmo tipo. Segundo os autores, o acréscimo dos silanos na formulação com o intuito de modificar a superfície das nanopartículas melhorou sua dispersão, com o tratamento reativo proporcionando a maior uniformidade entre as amostras [118].

Aicha (1991) et. al, estudaram a reações de um pré-polímero de epóxi a base de DGEBA com APTS. Diferentes técnicas, como por exemplo cromatografia de exclusão, DSC, titulação química e FTIR foram usadas para caracterizar quimicamente o material obtido e estudar o impacto nas suas propriedades. A conclusão foi que a reação direta entre um epóxi e uma amina é mais rápida que uma reação de um epóxi com um pré-polímero com terminação tipo APTS [119].

Hassanein (2015) et al, exploraram e avaliaram reações químicas e cinéticas no processo de cura da resina híbrida epoxisiloxano. Esta resina híbrida tem dois reagentes principais: um anel de epóxi e o grupamento silicone. Portanto, há reações concorrentes quando o anel epóxi reage na cura entre epóxi-amina e o silicone reage via condensação conforme a Figura 38.

Figura 38 - Mecanismo de reação epóxi silicone a) grupamento epóxi e b) silicone.

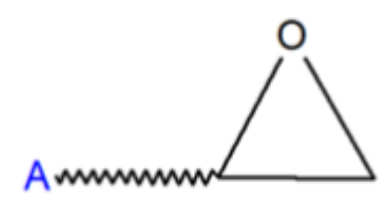

(a)

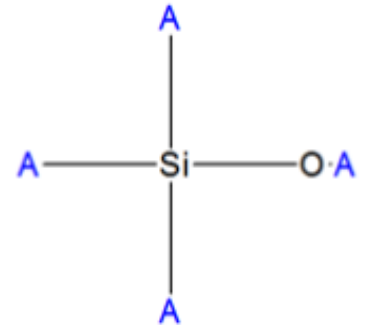

(b)

Fonte: Autoria própria 2019 a partir de Hassanein et al 2015.

Como endurecedor para o sistema em questão, foi usado um amino silano, o qual pode reagir com o grupamento epóxi e também via condensação com o silicone. Conforme a Figura 39, o material terá o mecanismo dual de ação sobre as duas estruturas [120]. 
Figura 39 - Estrutura do Alcoxi aminossilano. [120]

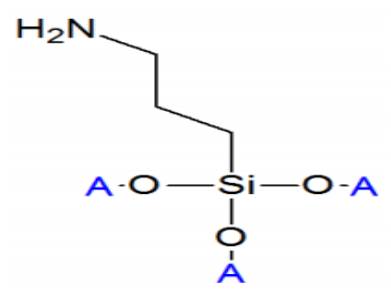

Fonte: Autoria própria 2019 a partir de Hassanein et all 2015.

Os resultados não só apoiaram a hipótese sobre as reações, mas também deram algumas novas informações sobre a cinética. $O$ processo de cura teve uma duração diferente no tempo, dependendo da camada e das reações. O procedimento consistiu de misturar os componentes em fase líquida, via pipeta foi retirado gotas da mistura e aplicada sobre uma superfície de teflon, sendo levada posteriormente para uma câmara climática para controle de temperatura e análise periódicas das reações. Concluíram que a reação da amina com o grupamento epóxi ocorre imediatamente, enquanto que a fase silicone levou vários dias [120].

Filomena Pisciteli (2010) estudou nanocompósitos de resina epóxi/montemorilonita (MMT) sódica sililada. Três diferentes tipos de aminossilanos foram usados como agentes de acoplamento entre a MMT e a resina epóxi, foram eles: a) 3-aminopropiltrietoxisilano, b) $\mathrm{N}$-(2-aminoethil) -3-aminopropiltrimetoxisilano e c)3-[2-(2-aminoethilamino) etilamino]propil-trimethoxisilano, assim como, amostras usando o $\gamma$-glicidoxypropiltrimetoxisilano foram testadas. Os resultados mostraram a formação de ligações covalentes entre a MMT sililada, assim como, formação de ligações de hidrogênio. A existência desta interface química entre a argila e a resina epóxi, como esperado resultou em aumento de até 8,5 \% na $\mathrm{T}_{\mathrm{g}}$ (medida por DMTA) em relação à amostra de nanocompósito com MMT não sililada, enquanto, uma queda foi notada em relação ao módulo de elasticidade em flexão que ficou em torno de 2,3 GPa. Já o módulo elástico a $150{ }^{\circ} \mathrm{C}$ dobrou com a carga sililada com aminossilanos. O esforço de tração dos nanocompositos sofreu queda para baixos teores de MMT, $1 \%$, enquanto foram aumentados em 4\% para amostras com 3\% de MMT [ 121].

Oleksy (2014) et al , realizaram um estudo envolvendo o preenchimento de resina epóxi com bentonita e sílica modificada com silsesquioxano oligomérico poliédrico (POSS). 
Verificou-se que as propriedades mecânicas básicas dos compósitos híbridos melhoraram e em particular houve um ganho na resistência à tração de $44 \%$ e na resistência ao impacto usando o método charpy de $93 \%$ [122].

Abdolahhi (2018) et al, pesquisaram a melhoria da estabilidade térmica das resinas epóxi fazendo modificações químicas (uso de resina novolaca epoxidada) e sua incorporação em redes de sílica/siloxano além da incorporação de óxido de grafeno e nanotubo de carbono obtendo redes hibridas. Sua conclusão foi que a introdução dos sistemas híbridos melhora a estabilidade térmica do sistema quando comparado com sistemas sem a presença dos compostos híbridos a base de sílica/siloxano. Essa medida foi obtida via análise de decomposição térmica via TGA onde no composto híbrido obteve um rendimento de cinzas em torno de $10 \%$ mais que o protótipo sem o uso do híbrido [123].

Comentários Iniciais: O uso de agente de acoplamento e formação de híbridos mostra como coerente com a premissa inicial desta TESE de ter a reticulação favorecida através da inserção de grupos reativos. A única questão a ser analisada será o efeito da reatividade do grupamento com os sistemas poliméricos e também o efeito da fixação da quantidade de híbrido e seu balanço estequiométrico.

\subsection{Produção de ciclocarbonatos a partir de dióxido de carbono}

$\mathrm{Na}$ natureza, o ciclo de carbono tem a habilidade de reciclar em torno de 200 giga toneladas (Gt) de Dióxido de carbono por ano. Embora o $\mathrm{CO}_{2}$ gerado pelo homem (antropogênico), seja em torno de $7 \mathrm{Gt}$ por ano, representando aproximadamente 3,4\% do total convertido no ciclo natural, o acumulado por anos na atmosfera tem, segundo alguns autores, afetado e criado o chamado efeito estufa, o que potencialmente tem afetado a mudança climática. A questão do Aquecimento Global é relevante para a sobrevivência de todas as formas de vida no nosso planeta. Assim, é vital estabelecer estratégias para limitar o acúmulo de $\mathrm{CO}_{2}$ na atmosfera. Para além dos esforços de desenvolvimento de metodologias confiáveis de monitoramento ambiental e de modelos que permitam aumentar nossa capacidade de previsão dos cenários é necessário investir em tecnologias de Captura e 
Armazenamento de $\mathrm{CO}_{2}$ que se tornam mais atrativas com o posterior uso deste $\mathrm{CO}_{2}$ armazenado [ 124,125,126, 127, 128, 129].

$\mathrm{O}$ uso de $\mathrm{CO}_{2}$ como um fluido tecnológico ou uma matéria prima para processos químicos, providencia um potencial para redução desse acúmulo na atmosfera, falando não em termos de um processo de estocagem, mas sim de sua eficiência. $\mathrm{O}$ uso por exemplo de $\mathrm{CO}_{2}$ como um co-monômero para síntese de policarbonatos e poli (uretana) s, que podem persistir por décadas e, portanto, representa uma opção inteligente para fixação de $\mathrm{CO}_{2} \cdot[10,11,130]$

Um ponto importante, seria irreal pensar que a conversão de $\mathrm{CO}_{2}$, resolverá o acúmulo na atmosfera, pois fatores cinéticos e também de termodinâmica, trabalham contra essa possibilidade. Pensando de modo positivo em termos de tempo, é possível converter uma limitada fração do $\mathrm{CO}_{2}$ antropogênico, em torno de $7 \%$ dessa fração poderá ser mitigada na forma de materiais obtidos com o $\mathrm{CO}_{2} \mathrm{em}$ sua rota produtiva. Hoje a grande concentração de geração de $\mathrm{CO}_{2}$ vem da produção de energia (carvão, gás, combustíveis fósseis para automóveis). A limitação ou mudança nesse processo, pode ajudar a questão do acúmulo na atmosfera [130], além do que pode evitar o gasto energético do sistema que tem sido proposto de purificar e estocar o $\mathrm{CO}_{2}$ como tem sido discutido. Essa ideia de estocagem tem um gasto enérgico de $30 \%$ do custo do combustível do qual o gás foi gerado [131].

$\mathrm{O}$ paradigma da questão, reside no fato de que o $\mathrm{CO}_{2}$ é tanto termodinamicamente quanto cineticamente estável, desta forma, o seu completo potencial raramente é utilizado, devido a deficiência em elétrons do grupo carbonila, $\mathrm{o} \mathrm{CO}_{2}$ tem uma forte afinidade pelos nucleófilos e reagentes doadores de elétrons [ 132, 133,134]. Água, alcóxidos e aminas são exemplos de nucleófilos potenciais que se adicionam ao $\mathrm{CO}_{2}$ para produzir compostos com grupos carboxilados. Essas reações convenientemente produzem carbonatos e carbamatos [135].

A Figura 40 sumariza exemplos de síntese orgânica usando dióxido de carbono como reagente. 
Figura 40 - Possíveis reações usando o usando $\mathrm{CO}_{2}$ como reagente [135].

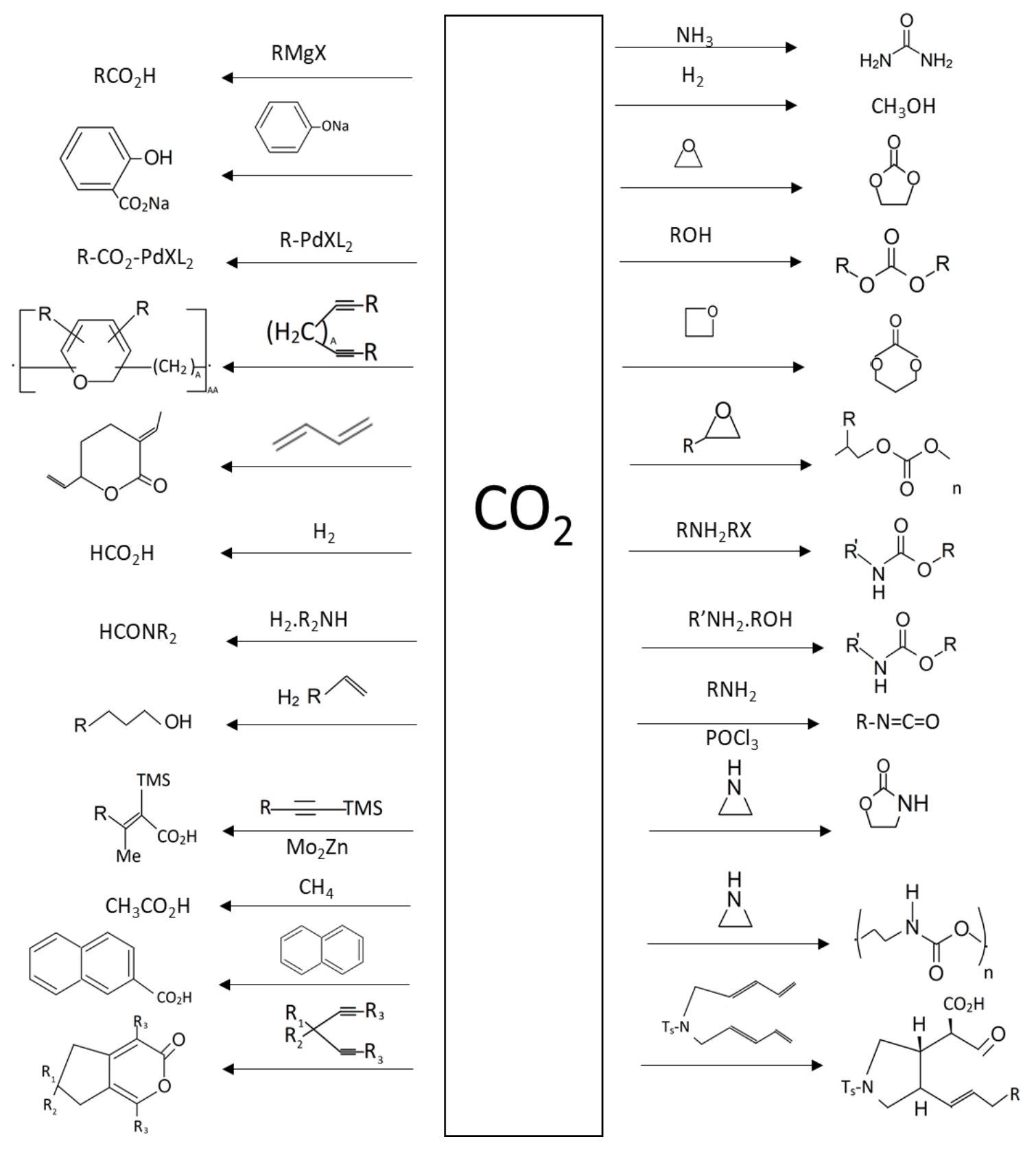

Fonte: elaborado pelo próprio autor, 2019.

A formação de carbonatos a partir de oxiranos e $\mathrm{CO}_{2}$, catalisados por Dietil Zinco e água $\left(\mathrm{ZnEt}_{2} / \mathrm{H}_{2} \mathrm{O}\right)$, foi descoberta por Inoue (1969) et al, Figura 41 [136]. Após o trabalho de Inoue, Kuran (1976) et al, desenvolveu um sistema de copolimerização usando Dietil Zinco e fenóis, incluindo o 4-Bromopirogalol produziram policarbonatos em temperatura até $35^{\circ} \mathrm{C}$ e 60 bar de pressão de $\mathrm{CO}_{2}$ [137]. Em um esforço para desenvolver catalisadores mais ativos, Jacobsen (2004) et al, sintetizaram um catalisador heterogêneo a partir de $\mathrm{Zn}(\mathrm{OH}) 2$ e ácido glutárico. A $60{ }^{\circ} \mathrm{C}$ e 30 Bar de pressão de $\mathrm{CO}_{2}$, a mistura de $\mathrm{Zn}(\mathrm{OH})_{2}$ / ácido glutárico 
produziu policarbonatos com um TOF de 1,1 e um peso molecular de $12.000 \mathrm{~g} / \mathrm{mol}$ [99]. Além disso, Jacobsen relata vários estudos nos quais a derivatização de epoxidos é descrita com compostos de metal macrociclo nos quais vários centros estão trabalhando em conjunto [138].

Darensbourg e Holtcamp (1996) revisaram os diversos tipos de catalisadores utilizados na conversão de epóxi em policarbonatos usando $\mathrm{CO}_{2}$ [139], sendo que os mais comuns são líquidos iônicos, sais quaternários de amônio, óxidos metálicos além de complexos com bases de Schiff (Salen) e principalmente os sais de zinco. Coates também interpretou seus resultados com os derivados de zinco como catalisadores para a copolimerização de $\mathrm{CHO} / \mathrm{CO}_{2}$ e de óxido de limoneno / $\mathrm{CO}_{2}$ em termos de um mecanismo de catálise multi-local $[140,141,142]$. Isto está em contraste por exemplo com os trabalhos anteriores do grupo de Darensbourg (2003) [143] num sistema catalisador Tmtaa e crômio anidro (crômio III) cloreto, sendo o Tmtaa um tetrametiltetraaza-anuleno, ou ao trabalho de Chisholm (2004) et al com complexos de tetrafenilporfirina de alumínio (III) [135]. Um grande número de mecanismos tem sido reportado no esforço de ter catalisadores eficientes para a produção de carbonatos cíclicos [139,144,145].

Figura 41 - Esquema da reação do $\mathrm{CO}_{2}$ com oxiranos (epóxi).
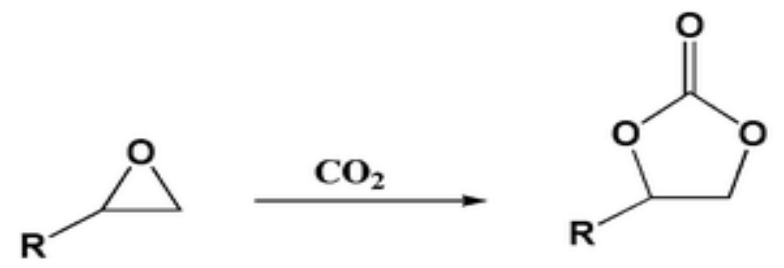

Fonte: elaborado pelo próprio autor, 2019.

Atualmente os ciclocarbonatos tem sido alvo de atenção por utilizar dióxido de carbono na sua formação, em virtude da busca por processos de fixação de $\mathrm{CO}_{2}$ em produtos orgânicos de utilização industrial. Lopes (2004), abordou esse assunto, sendo que com o uso de co-catalisador de zinco, o resinato de Zinco, foi possível obter ciclocarbonatos com alta taxa de conversão à baixa temperatura e sem o uso de pressão no reator. [10]

Um dos mecanismos que teve grande sucesso para obtenção de ciclocarbonato foi o uso de um catalisador a base de brometo de tetraetilamônio (TEBA) cujas etapas de reação são descritas na Figura 42 [146]. 
Figura 42 - Esquema evidenciando a obtenção de ciclocarbonato pela ação do catalisador brometo de tetraetilamônio (TEBA). [146]

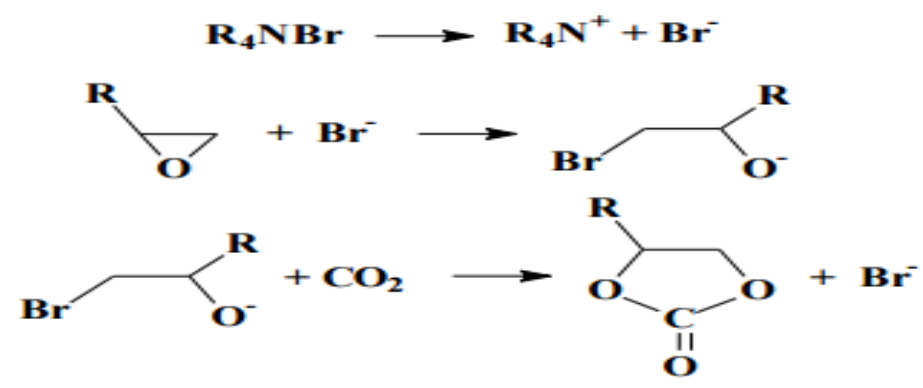

Fonte: elaborado pelo próprio autor, 2019.

O mecanismo para essa finalidade consiste no ataque nucleofílico do ânion do catalisador ao carbono com carga positiva parcial do oxirano havendo a adição do dióxido de carbono com a formação do ciclocarbonato intramolecular e a reformação do ânion (Figura 43). A ciclização tem sido a proposta mais aceita, devido sua maior estabilidade termodinâmica [144,147].

Figura 43 - Formação de um ciclocarbonato [147].

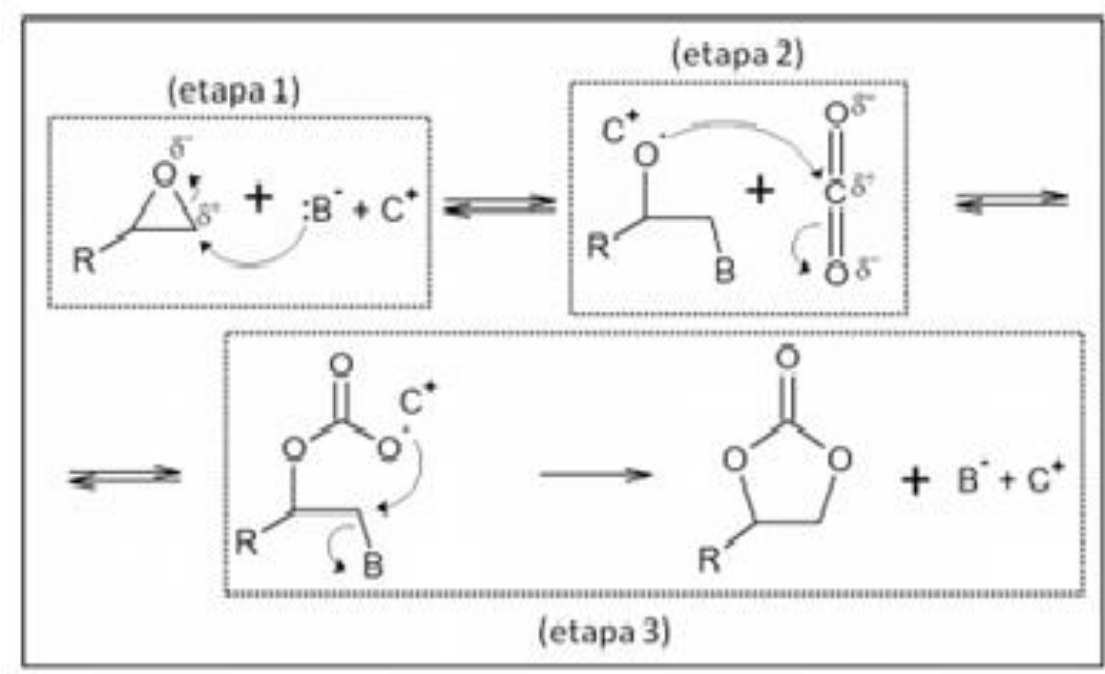

Fonte: Extraída de LEITE, D, F, Dissertação de Mestrado em Química IQSC, 2015.

\subsection{Hidroxiuretanas livres do uso de isocianato obtida via ciclocarbonatos}

As poli (uretana) s, figura 42 a e 42 b, foram desenvolvidas em 1937 por Otto Bayer et al, sendo produzidas pela reação de um isocianato (di ou poli funcional) com um poliol ou outros reagentes contendo dois ou mais grupos reativos conforme vistos na Figura 44. 
Figura 44 - a) reação padrão para formação de poli (uretana) b) e estrutura típica [10, 148].

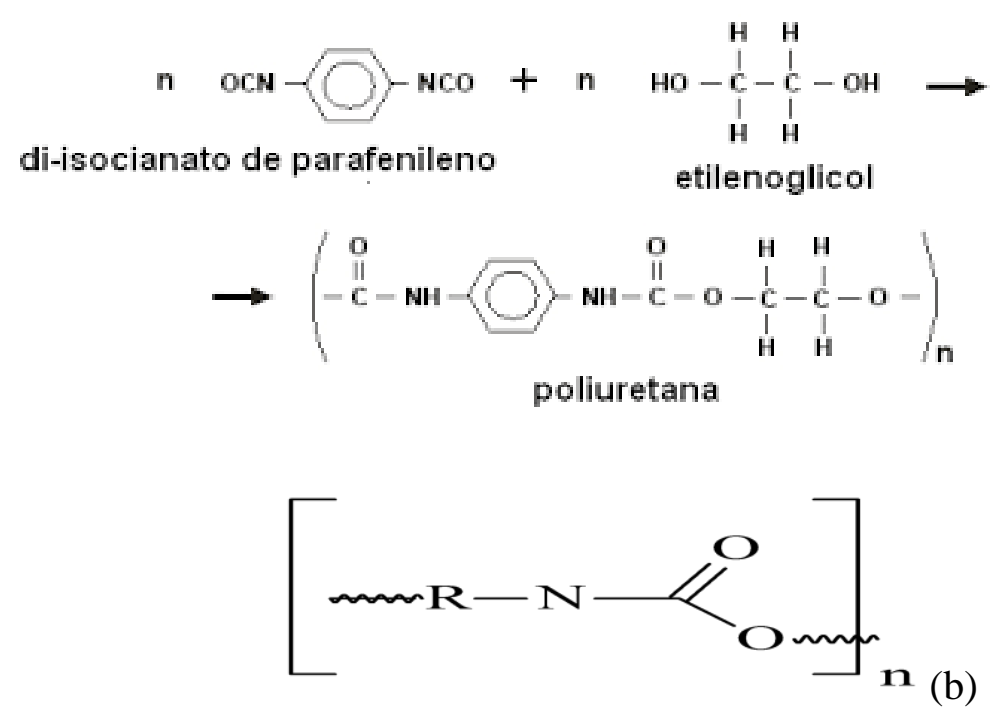

Fonte: elaborado pelo próprio autor, 2019.

Os compostos podem ser aromáticos ou alifáticos, sendo que essa flexibilidade na escolha dos reagentes permite obter uma grande variedade de compostos com diferentes propriedades físicas e químicas, conferindo a esse polímero uma função extremamente importante no mercado mundial $[148,149]$. As duas principais matérias-primas usadas na fabricação das poli (uretana) s são os isocianatos e os polióis de baixo peso molecular.

Os isocianatos utilizados como reagentes na obtenção de poliuretanos apresentam grandes desvantagens quanto a sua toxicidade no manuseio, que é considerada, uma vez no seu processo de obtenção usam-se insumos tóxicos, o cloreto de carbonila (denominado fosgênio) e ácido nítrico. Na Figura 45 vemos a reação para obtenção de um isocianato (TDI). Outrossim dos cuidados na manipulação do isocianato utilizado na polimerização, havendo grande preocupação com o isocianato residual presente no polímero formado após a reação.

Figura 45 - Rota de síntese do TDI, evidenciando a liberação de ácidos e fosgênio [10,148.149].

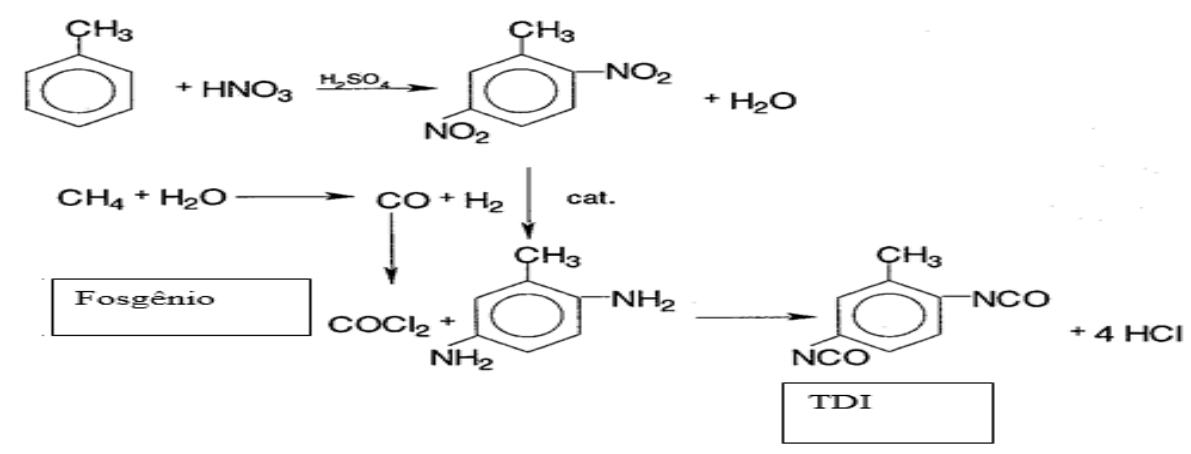

Fonte: elaborado pelo próprio autor, 2019. 
Os aerossóis ou vapores de isocianatos podem irritar as membranas e mucosas do sistema respiratório, causando irritação nasal, dor de garganta, tosse, desconforto no peito, falta de ar e redução da função pulmonar. Pessoas com hipersensibilidade brônquica podem responder a concentrações extremamente baixas com sintomas semelhantes ao ataque de asma [10,148,149 ]. Exposições em altas concentrações podem levar à bronquite, a espasmos e até edema pulmonar. Como resultado de repetidas pequenas exposições ou dose forte única, certos indivíduos podem desenvolver sensibilidade aos isocianatos (asma química), que podem causar reação alérgica em concentrações muito baixas. Esses sintomas, que podem incluir aperto no peito, respiração ofegante, tosse, falta de ar ou ataque asmáticos, podem ser imediatos ou acontecerem diversas horas após o contato [10,148,149]. Exposições frequentes aos isocianatos podem causar danos permanentes ao pulmão, incluindo o decréscimo dessa função $[10,148,149]$. Devido a esses efeitos adversos à saúde, o valor limite de tolerância é 0,005 ppm. Agora, para exposição superior a 8 horas, o limite diminui para 0,002 ppm. O efeito tóxico do manuseio dos diferentes tipos de isocianatos é similar, e as diferenças ficam por conta de suas pressões de vapor conforme visto na Tabela $6[10,148,149]$.

Tabela 6 - Pressão de Vapor dos Isocianatos utilizados em Poli (uretana) s.[10,148,149]

Pressão de Vapor dos Isocianatos mais comuns usados na produção de PUs tradicionais $(\mathrm{mm} \mathrm{Hg}) 25^{\circ} \mathrm{C}$.

\begin{tabular}{l|l}
\hline MDI & 0,000016 \\
TDI & 0,025 \\
IPDI & 0,003 \\
NDI & 0,003 \\
HDI & 0,003 \\
\hline
\end{tabular}

Fonte: elaborado pelo próprio autor, 2019. 
Atualmente os dois isocianatos mais usados na produção de poli (uretana) são o Etileno Difenil 4,4 Diisocianato (MDI) e o 2,4-Diisocianato-1-metilbenzeno (TDI), ambos são classificados como CMR (carcinogênico, mutagênicos e reprotóxico [150].

Por conta da altíssima toxicidade do fosgênio (cloreto de carbonila), muitos estudos vêm sendo feitos com a intenção de substituir a rota tradicional de síntese de PU usando isocianatos, que se dá por meio da fosgenação de aminas primárias. Além da questão tóxica, o fosgênio por ser um gás altamente tóxico e inflamável tem sido alvo de constante preocupação com o meio ambiente e a saúde ocupacional das pessoas envolvidas no processo de produção das poli (uretana) s. Isso tem levado a um aumento no interesse em desenvolver métodos de preparação alternativas de poli (uretana) s com a eliminação das variáveis tóxicas do processo. [148,149]

A fim de projetar uma poli (uretana) sem isocianato (NIPU: Non Isocyanate PolyUrethane), uma alternativa interessante consiste principalmente em fazer a polimerização via reação de policondensação entre bis-ciclocarbonatos e diaminas. Os materiais resultantes são chamados polihidroxiuretanas (PHUs), uma vez que contêm também grupos hidroxila ao longo da cadeia macromolecular. Estas hidroxilas criam ligações de hidrogênio inter e intramoleculares com o grupo do uretano que confere ao produto melhores propriedades $[10,151]$.

Além disso, essas PHUs também apresentam excelente estabilidade térmica principalmente quando se usa diamina aromática na síntese [ 152,153]. Ademais, estudos mostraram que as PHUs eram menos sensíveis à umidade do que as poli (uretana) $\mathrm{s}$ convencionais obtidas usando isocianatos $[10,154]$.

Nos últimos anos, as NIPUs ganharam muita atenção na comunidade científica com 245 artigos na base de dados Web of Science (palavra-chave Non-isocyanate Polyurethane) e 4767 citações até agosto de 2019. Em tempo, nesta base de dados a publicação mais antiga data de 1992. A literatura relata quatro rotas de síntese: policondensação, rearranjo, polimerização por abertura de anel e poliadição sendo que essas rotas estão resumidas na Figura 40 [142].

Recentemente, algumas revisões dedicadas à síntese da NIPU foram publicadas $[142,155]$, podendo ser vista na Figura 46 as quais forneceram uma visão geral completa de todos esses métodos. Entre as vias de policondensação, podemos encontrar as reações entre policloroformato e poliamina, policarbamato e poliol por transuretanização, cloreto de 
policarbonila e poliol, e policarbonato e poliamina. No entanto, essas rotas requerem o uso de cloreto de carbonila (fosgênio) ou derivados para a síntese de precursores. Além disso, durante a policondensação, produtos secundários, como ácido clorídrico $(\mathrm{HCl})$ ou álcoois, são liberados, o que é uma limitação significativa para aplicações industriais.

Outra via de policondensação consiste na reação entre policarbamato e polialdeído. Essa reação parece interessante, mas essa via, ainda pouco estudada, implica também a liberação de água durante a polimerização [156].

A terceira via para a síntese de NIPUs é a polimerização por abertura de anel de carbamatos cíclicos alifáticos [157] ou aziridinas [158,159]. Embora estas NIPUs sejam sintetizadas sem qualquer libertação de produtos secundários, estas reações são frequentemente realizadas à alta temperatura e os carbamatos cíclicos são geralmente produzidos a partir de fosgênio. A toxicidade das aziridinas continua sendo também um problema significativo.

Finalmente, a última via de síntese que conduz à NIPU é a poliadição de carbonatos e aminas cíclicos. Esta reação parece a melhor rota para a síntese de NIPU, uma vez que evita o uso de isocianato e cloreto de carbonila (fosgênio). Além disso, os carbonatos cíclicos não são tóxicos, não são sensíveis à umidade, como os isocianatos, que levam a produtos secundários, como a ureia e o $\mathrm{CO}_{2}$. Portanto, seu armazenamento não requer qualquer cuidado especial [160]. Além disso, a reação entre ciclocarbonatos e diaminas não libera qualquer composto orgânico volátil que impeça o uso desta rota para aplicações de revestimento [142]. Portanto, essa rota é a que será alvo desse projeto de pesquisa em questão, obter um ciclocarbonato por meio da polimerização por adição usando $\mathrm{CO}_{2}$. 
Figura 46 - Rotas de síntese de NIPU onde pode ser visto os processos de obtenção desse polímero, o destaque se deve ao tipo de reação, com material tóxico ou amigável, pode se concluir que apenas a rota de adição de $\mathrm{CO}_{2}$ a única que não usa materiais tóxicos [142]

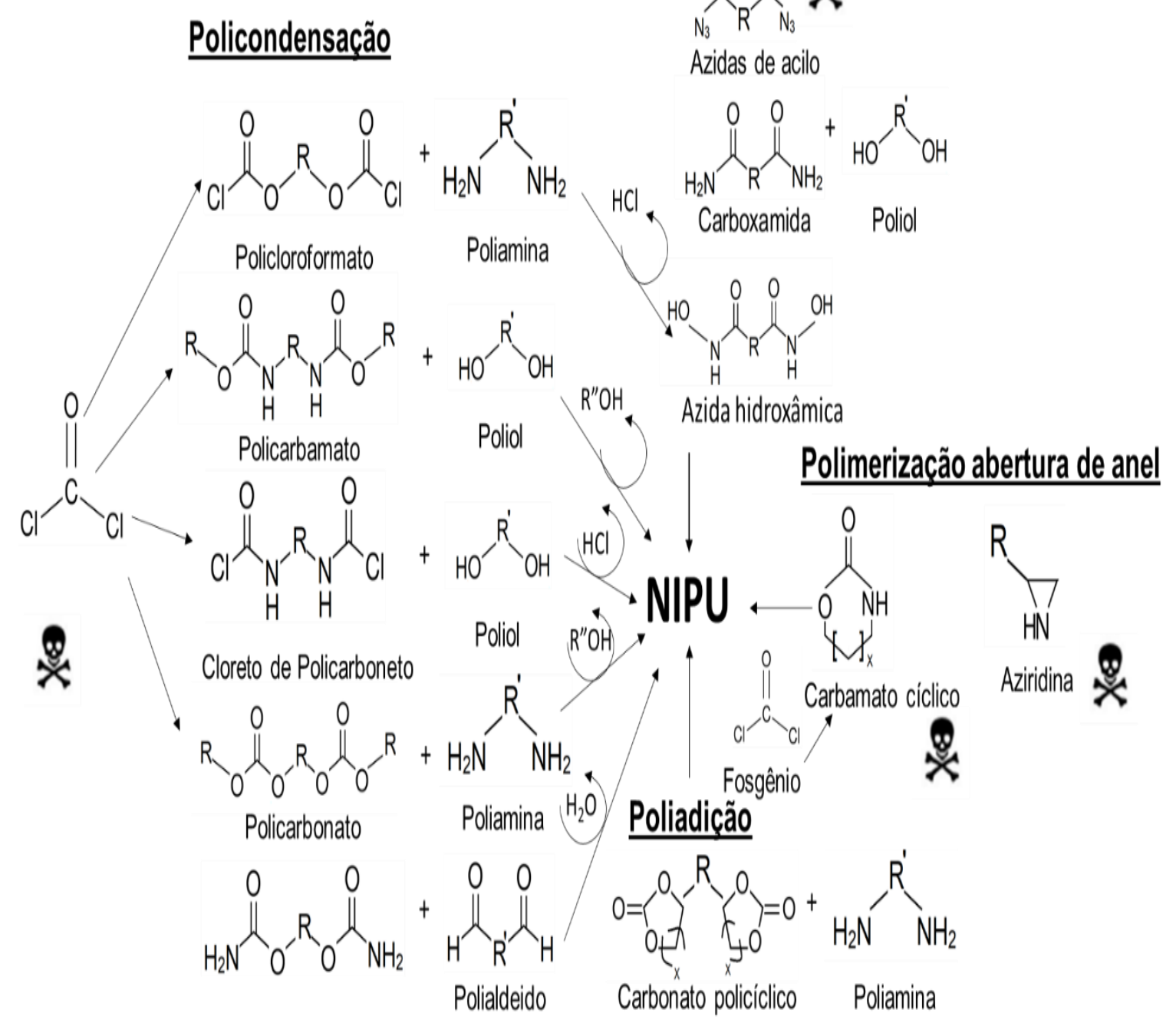

\section{Rearranjo}

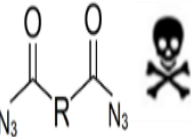

Azidas de acilo 
entre suas partículas. Recorrendo a tabelas e dados de termodinâmica e estabelecido que o $\mathrm{CO}_{2}$ usando a equação de Van Der Wall (equação 6), teria o seguinte:

a) Como gás Real: v=0,366 litros/mol.

b) Como gás ideal: v= 0,41 litros/mol (usando PV=nRT).

1 mol de $\mathrm{CO}_{2}$ possui 44 gramas, e para produzir $1 \mathrm{Kg}$ de ciclocarbonato consumimos 68 gramas, teremos mitigado 1,54 moles ou o equivalente a 0,56 litros.

Em volume considerando como gás real (equação de Van Der Walls): 1 tonelada de Ciclocarbonato mitigará 560 litros de $\mathrm{CO}_{2}$.

Diante disso, com o uso das NIPUs além de contribuirmos com o meio ambiente pela substituição do fosgênio e isocianato, ainda utilizamos como matéria-prima uma quantidade considerável de um dos maiores vilões para o meio ambiente e considerado por muitos como o responsável pelo aquecimento global, ou seja, o dióxido de carbono. Não menos importante, o $\mathrm{CO}_{2}$ tem um custo bem mais competitivo que o fosgênio. O preço médio do fosgênio no mercado (dados importação China) está hoje em torno de $\mathrm{R} \$ 12,00 / \mathrm{Kg}$ (preço agosto 2019), enquanto o $\mathrm{CO}_{2}$ pode ter apenas o custo de captação, além do que pode se receber crédito em venda de carbono [161].

Figovsky (1999) e Whelan (1963) et al [162, 163] e Ried (1969) et al [164] foram os primeiros pesquisadores a prestarem atenção para a reação entre ciclocarbonatos de cinco membros e diaminas. O trabalho consistiu de uma polimerização por meio da abertura do anel do ciclocarbonato [165], conforme ilustrado na Figura 47.

Figura 47 - Ilustração da síntese de poli (uretana) s a partir de um bis (ciclocarbonato) e uma monoamina [162].

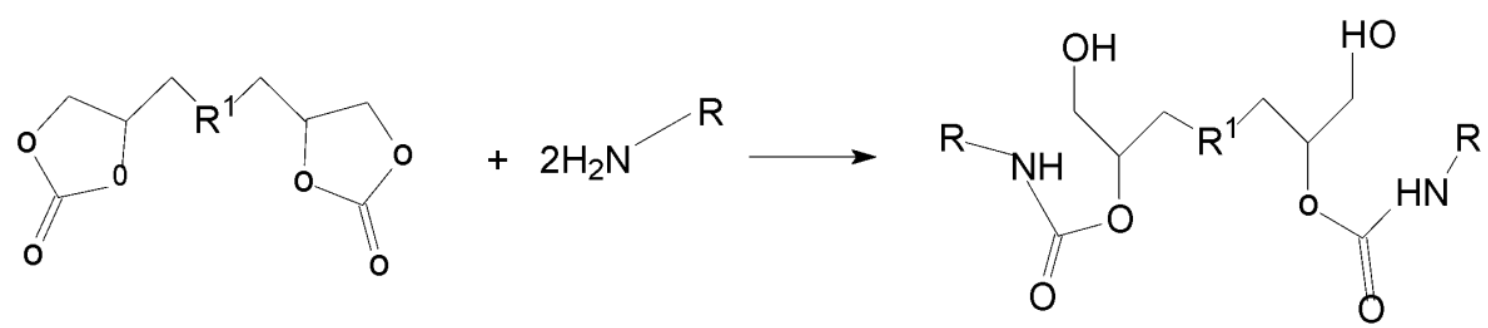

Fonte: elaborado pelo próprio autor, 2019.

Desde esta data, esta reação tem sido fortemente estudada e vários métodos de síntese foram descritos posteriormente [166,167], particularmente por Endo (1993 e 2001) et al [168,169]. Rokicki (2015) et al [170] e Maisonneuve (2015) et al [155] publicaram revisões 
sobre NIPUs, sua síntese, propriedades e aplicações. Além disso, recentemente Carré (2015) et al [171] descreveram as sínteses de novas NIPU totalmente de base natural, através de um processo inspirado na química verde, sem solvente e catalisadores além de usar bisepóxidos obtidos a partir de óleos vegetais. No entanto, esta reação tem dois grandes inconvenientes: a baixa reatividade da reação carbonato / amina à temperatura ambiente [165] quando comparado ao isocianato / álcool e as baixas massas molares de PHUs obtidas (Mn entre 1.800 e $28.000 \mathrm{~g} \mathrm{~mol}^{-1}$ ) [168,169,172,173,174]. Para resolver esses problemas, muitos estudos na literatura foram realizados para projetar PHUs a partir de ciclocarbonatos contendo substituintes que tornem os ciclocarbonatos mais reativos $[168,169,172,174,175,176]$ ou usando ciclocarbonatos de seis e sete membros ou tio-cíclico $[60,169,170,172,178]$. Porém a preparação desses compostos envolve fosgênio ou seus derivados para carbonatos de seis membros ou dissulfuretos de carbono para tiocarbonatos, $[169,175,178$,$] .$

Uma vez que as PHUs não exibem altas massas molares a partir de ciclocarbonatos de cinco membros e aminas, a reticulação de PHUs através da cura de ciclocarbonatos com di- e poliaminas pode ser considerada para fornecer borrachas termorrígidas de PHU. Nessa linha Figovsky desenvolveu materiais híbridos (PHU/Epóxi) [162,179]. Esses híbridos são comercializados com o nome comercial Green PolyurethaneTM e representam a primeira aplicação bem-sucedida de PHUs na vida cotidiana. Estes poliuretanos híbridos oferecem várias vantagens em relação aos poliuretanos convencionais: baixo ou nulo teor de compostos orgânicos voláteis, eliminação da necessidade do uso de solvente, 30 a 50\% mais resistentes à degradação química, 10 a 30\% mais adesivo (dependendo do substrato), 20\% mais resistente ao desgaste.

No entanto, estes materiais híbridos não resolvem a questão principal das PHUs, que é a baixa reatividade da reação entre o ciclocarbonato e aminas. Essa baixa reatividade implica conversão incompleta, o que dificulta o desenvolvimento de PHUs para aplicações onde se exige materiais de alta $\mathrm{T}_{\mathrm{g}}$ e mecanicamente resistentes. A fim de melhorar a cinética da reação carbonato / amina, muitas pesquisas foram dedicadas ao desenvolvimento de novos catalisadores.

Lambeth (2013) et al demonstraram que o 1,5,7-triazabiciclo [4.4.0] dec-5-eno (TBD) e o ciclohexilfenilo tioureia são os melhores catalisadores para promover a reação ciclocarbonato / amina [180]. 
No grupo de Química de Materiais Híbridos da USP-São Carlos, Aguiar (2014) obteve um híbrido usando bis (ciclocarbonato) derivado de polidimetilsiloxano o qual foi polimerizado com diferentes aminas primárias alifáticas, obtendo um polímero de polidimetilsiloxano ligado por pontes uretanas, fazendo com que importantes propriedades químicas e físicas, tal como boa resistência a altas temperaturas e agentes oxidantes fossem incorporadas ao híbrido obtido [11].

Garipov (2003) et al buscaram entender o mecanismo de reação entre o ciclocarbonato e aminas para descobrir uma maneira de aprimorar o método sintético e encontraram em solventes apróticos a reação de segunda ordem, acelerada com o aumento da polaridade do meio conforme ilustra-se na Tabela 7 [181].

Tabela 7 -Constante Dielétrica de solventes e taxa de Conversão da reação do Etileno carbonato com Ciclohexilamina. [181]

\begin{tabular}{l|c|c}
\hline Solvente Aprótico & Constante Dielétrica $(\varepsilon)$ & Taxa Conversão $\left(\mathrm{K}_{3} \times 10^{4} \mathrm{~L}^{2} \mathrm{~mol}^{-1} \mathrm{~S}^{-1}\right.$ \\
\hline Tolueno & 2,4 & 0,067 \\
Dimetil formamida & 31,7 & 0,45 \\
Dimetil Sulfóxido & 49 & 0,8 \\
2-Butoxietanol & 15 & 1,89 \\
1 Butanol & 17 & 1,46 \\
\hline
\end{tabular}

Fonte: Tabela de autoria própria extraída de GARIPOV R. Doklady Physical Chemistry; 393, 2003.

Cornille (2016) et al, desenvolveram outra estratégia para oferecer novas PHUs híbridas com alta conversão. O processo inovador consistia em duas etapas, na primeira a síntese de pré-polímeros de PHU funcionalizados com aminas primárias os quais poderiam facilmente reagir como co-monômeros com vários grupos epóxi, em uma segunda etapa produzia-se uma gama de novas PHUs, conforme pode ser visto na Figura 48 [182]. Temos aí o exemplo da chamada HNIPU, que será uma das formas trabalhadas nesse projeto de TESE. 
Figura 48 - Síntese de Pre-polimeros funcionalizados e reação posterior com epóxi.

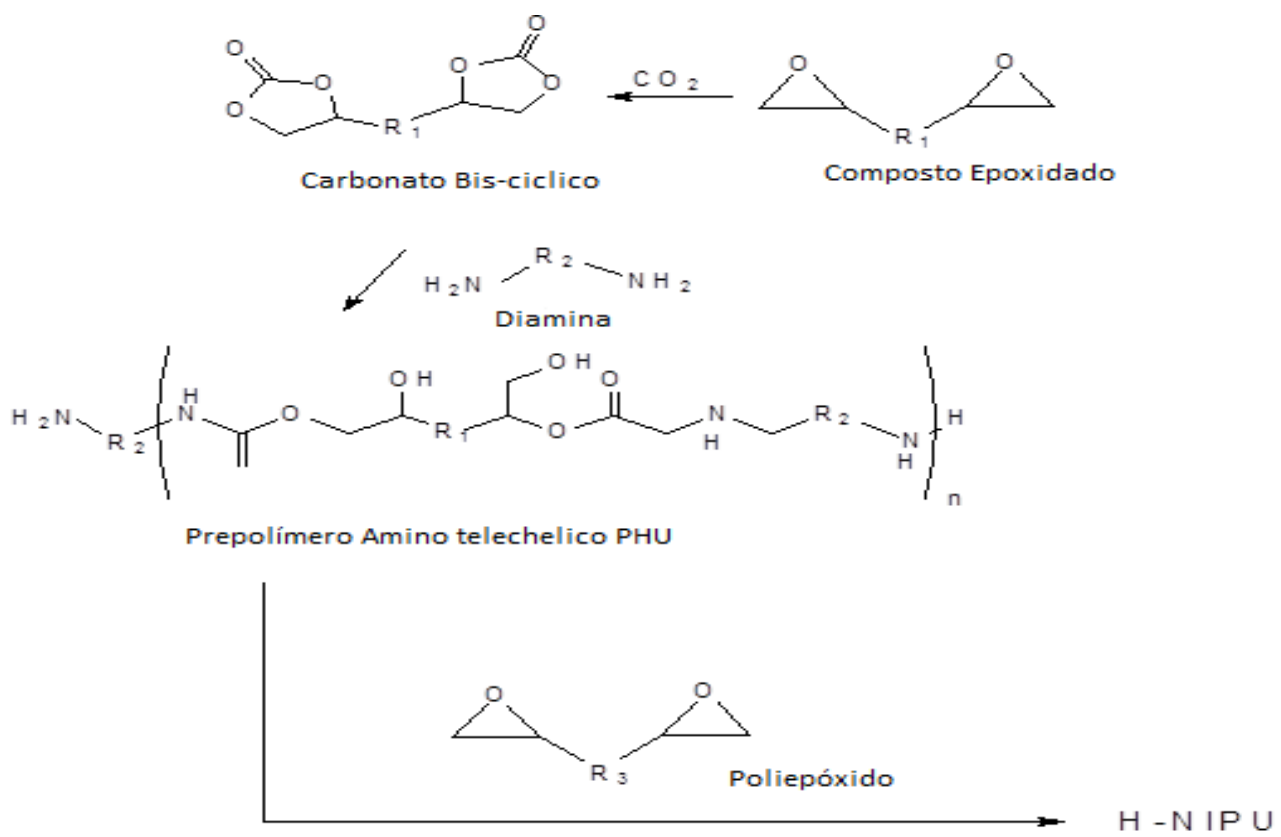

Fonte: Modificado de Cornille et al; Eur Polym J; 2016. [182]

Estes pré-polímeros de PHU foram sintetizados pela reação entre espécies com bisciclocarbonato e as diaminas em excesso. Estes oligômeros PHU com terminação com aminas reagem com epoxidos usados como modificador de cadeia para produzir blendas de PHU/epóxi. Esta abordagem fornece oligômeros de diferentes massas molares em função do tipo de amina e do excesso destas na reação ciclocarbonato / amina. Então, variando os reagentes epóxi, foi possível produzir PHUs híbridas com várias propriedades. Os epoxidos usados como extensores de cadeia foram o Éter diglicidílico de bisfenol A (DGEBA) e também dois epóxidos de base natural: o di-epóxi cardanol (NC-514) da Cardolite Company e o tri-epóxi-fluoroglucinol (PGTE) da Specific Polymers Company. Os materiais obtidos apresentaram propriedades superiores aos poliuretanos convencionais usando isocianato, apresentando 30 a 50\% melhor resistência a degradação química, 10 a 30\% superior em adesão e $20 \%$ melhor resistência à abrasão [183].

Ke (2017) et al trabalharam com as HNIPU a partir da reação da NIPU com terminação amina no sentido de melhorar as propriedades mecânicas do sistema. Sua síntese partiu de obtenção de um ciclocarbonato com a rota de $\mathrm{CO}_{2}$ usando o DGEBA como precursor, sendo posteriormente colocado em reação com aminas alifáticas como EDA (1,2 etilenodiamina), TETA e DETA em diferentes temperaturas e excesso molar de aminas. 
Sua conclusão foi que altos teores de triaminas levam a melhor desempenho mecânico quando curados com o próprio DGEBA [184].

Rokicki (1990) et al, modificaram sistemas epóxi curados com TETA usando ciclocarbonato como flexibilizante. Essas composições exibiram baixo efeito exotérmico, e alta densidade de reticulação. As composições curadas de ciclocarbonato epoxídico exibiram uma resistência ao impacto consideravelmente maior e resistência à tração superior em comparação com resinas epóxi tradicionais e principalmente uma melhora na taxa de deformação mecânica. Importante conclusão e que a presença do anel epóxi favorece inclusive a reação das aminas com o grupamento ciclocarbonato. Observaram que a presença de grupamentos polares como a carbonila e as hidroxilas permitem a formação de ligações de hidrogênio com os ciclocarbonatos que não reagiram e os grupos de uretano formados. Essa interação pode ter causado um aumento no aparente grau de reticulação [185].

Figovsky (2016) et al no seu projeto de pesquisa para síntese e aplicação de NIPU, usando ciclocarbonato cíclico de 5 membros, foi descrito uma composição de epóxi com amina modificada com o hidroxi Alquil uretano obtido pela reação de uma amina primária com um monociclocarbonato. Na Figura 49, R1 é o resíduo da amina primária enquanto R 2 e R3 são provenientes de grupos selecionados consistindo de $\mathrm{H}$, alquil, hidroxialquil e outros. O uso desse Hidroxialquil uretano, melhorar características como tempo de vida/secagem, tensão de ruptura, adesividade, aparência e superior resistência a abrasão e solventes de uso como material protetivo (recobrimento). [186].

Figura 49- Estrutura do aminohidroxiuretano propostos por Figovsky [186].

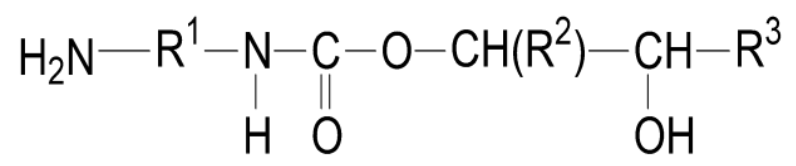

Fonte: elaborado pelo próprio autor a partir de Figovsky et all;

Um exemplo de nanocompósito de NIPU foi introduzido pelo grupo de Katlawear (2013) et al, o grupo explorou o uso de $\mathrm{ZnO}$ (oxido de zinco) funcionalizado com alkyl silano com terminação ciclocarbonato para aplicação anticorrosiva em metais. Sua rota consistiu de tratar ZnO com GPTS (silano com terminação epóxi) e posteriormente via rota do $\mathrm{CO}_{2}$ obteve um $\mathrm{ZnO}$ com terminação ciclocarbonato, a qual foi incorporada a NIPU obtida através da síntese usando epóxi como precursor. O material final foi curado usando o 4,9 dioxidodecano 1,12 diamina. $\mathrm{O}$ uso do $\mathrm{ZnO}$ organomodificado com ciclocarbonato na formulação do 
nanocompósito conferiu melhor resistência a abrasão e esforço para remoção do cobrimento, quando comparado com o uso de $\mathrm{ZnO}$ sem o grupamento ciclocarbonato [187].

Comentários Iniciais: A síntese da NIPU já é procedimento bem sedimentado no Grupo de Materiais Híbridos da USP São Carlos, com isso a premissa de ter-se a NIPU possui um forte embasamento técnico. A novidade será a incorporação da mica tratada com aminossilano para obtenção de um híbrido e sua reação posterior com o ciclocarbonato. Isso é uma novidade e poderá dar fundamentação para solucionar um dos desafios da NIPU, a obtenção de materiais estruturados. Do mesmo modo, a obtenção da HNIPU com a presença do mesmo híbrido será uma nova rota para o laboratório e também para todo o histórico de trabalho com HNIPU. O trabalho foi baseado na pesquisa de Ke et al [184] e Cornille et al [182 e 183] porém com a inovadora utilização do híbrido de mica para aumentar as características mecânicas e térmicas como uma opção ao sistema epóxi/mica no hidrogerador.

\section{PROCEDIMENTO EXPERIMENTAL}

\subsection{Materiais Utilizados na Síntese do Bis (Ciclocarbonato) de DGEBA}

- Epon 828: Éter Diglicidílico de Bisfenol A (DGEBA), possui o nome oficial de 2,2-bis (4-glicidiloxifenil) -propano (IUPAC), material produzido pela HEXION. É uma resina líquida com viscosidade de 11.000 a $15.000 \mathrm{mPa} \mathrm{s}^{-1}$ (Brookfield) a $25^{\circ} \mathrm{C}$. Material bifuncional e apresenta uma massa equivalente epóxi (EEW- equivalente epoxy weight) de 185 a $192 \mathrm{~g}$ $\mathrm{eq}^{-1}$.

- Epon 826: Éter Diglicidilico de Bisfenol A (DGEBA), possui o nome oficial de 2,2-bis (4glicidiloxifenil) -propano (IUPAC), material produzido pela HEXION. Resina similar a EPON 828, porém de menor viscosidade, 6500 a $9500 \mathrm{mPa} \mathrm{s}^{-1}\left(\right.$ Brookfield) a $25^{\circ} \mathrm{C}$. Material bifuncional e apresenta uma massa equivalente epóxi (EEW-equivalente epoxy weight) de 178 a $186 \mathrm{~g} \mathrm{eq}^{-1}$.

- Brometo de tetraetilamônio (TEBA), 98\% Sigma Aldrich.

- Dióxido de carbono $\left(\mathrm{CO}_{2}\right), 99,99 \%$ Linde Gás. 
- 2-etóxietanol 99\%, Sigma Aldrich.

- Resinato de Zinco (Zincograal Zn 9). Material de grau de pureza técnica produzido pela Parchem com um teor médio de 7 a $8 \%$ de $\mathrm{Zn}$ em massa.

- Pentacloreto de Nióbio (V) ( $\left.\mathrm{NbCl}_{5}\right)$, 99\% Sigma Aldrich.

- Cloreto de Zinco (II) anidro $\left(\mathrm{ZnCl}_{2}\right), 98 \%$ Merck.

- Trietanolamina (TEA), 99\% Sigma Aldrich.

- 1-Metil-2-Pirrolidona, 99\% VETEC.

\subsection{Materiais Utilizados- Fase Protótipos Sistema Epóxi}

- Aradur HY 956, (TETA), possui o nome IUPAC (N, N'-bis (2-aminoetil) -1,2etanodiamina), amina alifática produzido pela HUNTSMAN. Líquido com viscosidade de 370 a $470 \mathrm{mPa} \mathrm{s}^{-1}$ (Brookfield) a $25^{\circ} \mathrm{C}$.Possui equivalente ativo de $\mathrm{H}^{+}$de $47 \mathrm{~g} \mathrm{eq}^{-1}$.

- Epon 828 éter diglicidílico de bisfenol A (DGEBA), possui nome oficial de 2,2-bis (4-glicidiloxifenil) -propano (IUPAC), material produzido pela HEXION. É uma resina líquida com viscosidade de 11.000 a $15000 \mathrm{mPa} \mathrm{s}^{-1}$ (Brookfield) a $25^{\circ} \mathrm{C}$. Material bifuncional apresentando um peso equivalente epóxi (EEW- equivalente epoxy weight) de 185 a $192 \mathrm{~g}$ $\mathrm{eq}^{-1}$.

-Isoforenodiamina (IPDA), possui o nome oficial 5-Amino-1,3,3trimetilciclohexanometilamino; 99\% Sigma Aldrich.

- Mica muscovita protótipo 452015, muscovita pura com malha granulométrica 325 produzido pela IMERYS Brasil. Possui uma densidade de 2,6 a 2,9 g/ $/ \mathrm{cm}^{3}$ é uma composição média de $67 \%$ de $\mathrm{SiO}_{2}, 24 \%$ de $\mathrm{Al}_{2} \mathrm{O}_{3}$ em torno de $2,5 \%$ de $\mathrm{K}_{2} \mathrm{O}$.

- Mica muscovita tratada com aminossilano protótipo 462015, definida como Mica sililada com malha granulométrica 325 produzido pela IMERYS BRASIL. Possui uma densidade de 2,6 a 2,9 g/cm' é uma composição média de 67\% de $\mathrm{SiO} 2,24 \%$ de $\mathrm{Al}_{2} \mathrm{O}_{3}$ em torno de 2,5\% de $\mathrm{K}_{2} \mathrm{O}$. O tratamento feito por método de aspersão em misturador intensivo tipo "ribbon blender" sendo usando 0,8 a $1,0 \%$ em peso de aminossilano (SILQUEST A1100- Momentive). 


\subsection{Materiais Utilizados- Fase Protótipos Sistema NIPU/HNIPU}

- Bis (ciclocarbonato) de DGEBA.

- Acetona: 99\% (CG): Vetec Química.

- Aradur HY 956, (TETA), possui o nome IUPAC (N, N'-bis (2-aminoetil) -1,2etanodiamina), amina alifática produzido pela HUNTSMAN. Resina líquida com viscosidade de 370 a $470 \mathrm{mPa} \mathrm{s}^{-1}$ (Brookfield) a $25^{\circ} \mathrm{C}$. Possui equivalente ativo de $\mathrm{H}^{+}$de 47 $\mathrm{g} \mathrm{eq}^{-1}$.

- Isoforenodiamina (IPDA), 99\% Sigma Aldrich.

- Mica sililada, código Imerys 462015.

- Mica não sililada, código Imerys 452015.

- DBU (1, 8-Diazabiciclo[5.4.0]undec-7-eno), 98\% Sigma Aldrich.

\subsection{Síntese do Bis (ciclocarbonato) de DGEBA}

A síntese se efetivou com duas rotas principais, sob pressão atmosférica e sob alta pressão $[153,155]$. Abaixo temos as Tabelas 8 e 9 com a descrição dos dois procedimentos.

Tabela 8 - Parâmetros de Formulação e Processo usados nas diversas sínteses de ciclocarbonato sob pressurização.

\begin{tabular}{|c|c|c|c|}
\hline Condições/ Experimento & Síntese 1 & Síntese 8 & Síntese 9 \\
\hline $\begin{array}{c}\text { Epóxi } \\
\end{array}$ & Epon 826 & Epon 826 & Epon 828 \\
\hline Catalisador & TEBA $1 \%$ & TEBA $1 \%$ & TEBA $1 \%$ \\
\hline Co-Catalisador & Sem & $\mathrm{ZnCl}_{2} 0,1 \%$ & $\mathrm{ZnCl}_{2} 0,1 \%$ \\
\hline solvente & Sem & Etoxietanol & Etoxietanol \\
\hline Temperatura ${ }^{\circ} \mathrm{C}$ & 150 & 120 & 120 \\
\hline Pressão $\mathrm{CO}_{2}$ (atm.) & 10 & 7 & 7 \\
\hline Fluxo $\mathrm{CO}_{2}\left(\mathrm{~mL} \cdot \mathrm{min}^{-1}\right)$ & 15 & 15 & 15 \\
\hline
\end{tabular}

Fonte: elaborado pelo próprio autor, 2019.

Nota: O fluxo de $\mathrm{CO}_{2}$ é contínuo durante toda a síntese. 
Tabela 9 - Parâmetros de Formulação e processo usados nas diversas sínteses de ciclocarbonato à pressão atmosférica.

\begin{tabular}{|c|c|c|c|c|c|c|}
\hline Condições & Síntese 2 & Síntese 3 & Síntese 4 & Síntese 5 & Síntese 6 & Síntese 7 \\
\hline Epóxi & Epon 826 & Epon 826 & Epon 826 & Epon 826 & Epon 826 & Epon 826 \\
\hline Catalisador $1 \%$ & TEBA & TEBA & TEBA & TEBA & TEBA & TEBA \\
\hline Co Catalisador $0,1 \%$ & Sem & Res. Zinco & Res. Zinco & $\mathrm{NbCl}_{5}$ & $\mathrm{NbCl}_{5}$ & TEA \\
\hline Uso solvente & Sem & Sem & Sem & Sem & Sem & Sem \\
\hline Temperatura ${ }^{\circ} \mathbf{C}$ & 100 & 120 & 150 & 150 & 120 & 120 \\
\hline Pressão $\mathrm{CO}_{2}$ (Atm.) & Atmosf. & Atmosf. & Atmosf. & Atmosf. & Atmosf. & Atmosf. \\
\hline Fluxo $\mathrm{CO}_{2}\left(\mathrm{ml} \cdot \mathrm{min}^{-1}\right)$ & 15 & 15 & 15 & 15 & 15 & 15 \\
\hline
\end{tabular}

Fonte: elaborado pelo próprio autor, 2019.

Nota: O fluxo de $\mathrm{CO}_{2}$ é contínuo durante toda a síntese.

\subsection{Preparação dos Protótipos do Sistema Epóxi}

\subsubsection{Preparação para os Testes Curva temperatura de cura (Epóxi)}

Todos os experimentos foram realizados no Instituto de Química de São Carlos, Grupo de Materiais Híbridos e Inorgânicos IQSC-USP. A Tabela 10 e 11 mostra o balanço estequiométrico usado para obter esse protótipo e a Figura 50 e 51 o processo de síntese.

Tabela 10 - Estequiometria usada para obter o sistema epóxi sem Mica.

\begin{tabular}{|l|r|l|}
\hline Insumo & \% em Peso & Equivalente \\
\hline DGEBA & $80 \%$ & 1 \\
TETA & $20 \%$ & 1 \\
\hline
\end{tabular}

Fonte: elaborado pelo próprio autor, 2019.

Figura 50 - Fluxograma da formulação para teste DSC (CURA).

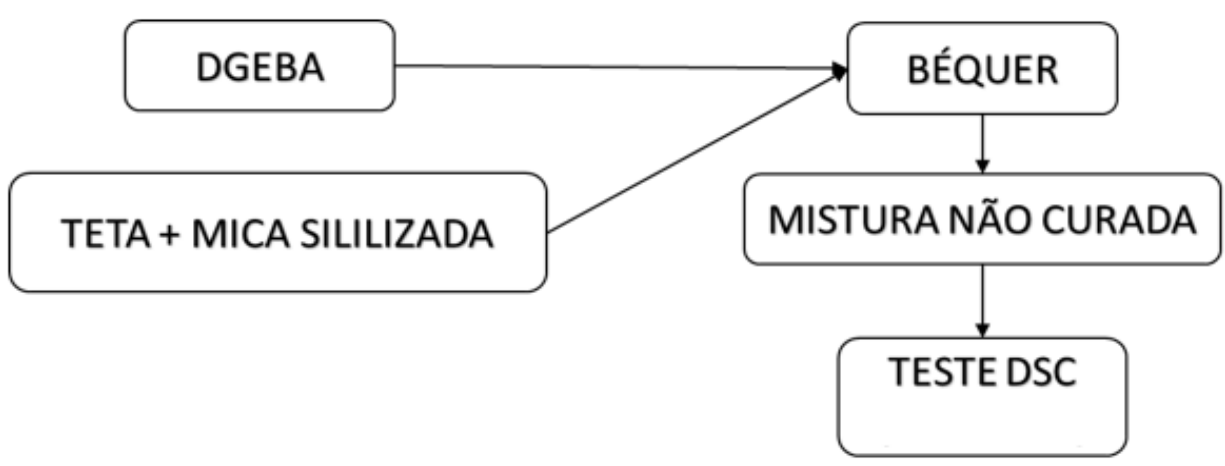

Fonte: elaborado pelo próprio autor, 2019. 
Tabela 11 - Estequiometria usada para obter o sistema epóxi na presença de Mica.

\begin{tabular}{|c|c|c|}
\hline Insumo & $\%$ em Peso & Equivalente \\
\hline DGEBA & $48 \%$ & 1 \\
TETA & $12 \%$ & 1 \\
MICA SILILIZADA & $40 \%$ & 0,0025 \\
\hline
\end{tabular}

Fonte: elaborado pelo próprio autor, 2019.

Figura 51 - Fluxograma da Síntese da Mistura Para teste DSC, epóxi com Mica

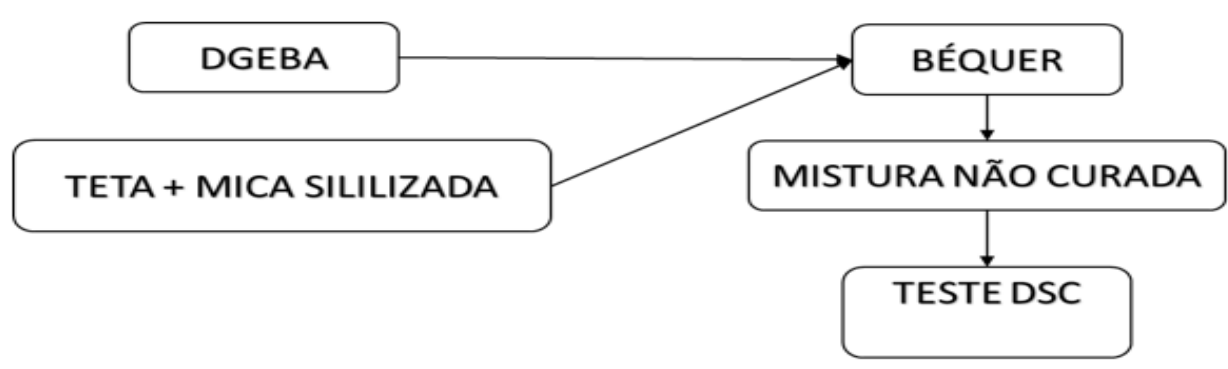

Fonte: elaborado pelo próprio autor, 2019.

\subsubsection{Preparação para os Testes Térmicos/Elétricos/Imagem Sistema Epóxi}

Foram executados o preparo de amostras conforme balanço da tabela 12, sendo seguido o mesmo procedimento de obtenção para o compósito com a mica sililada para aquele com a mica não sililada, figura 52. Todos os experimentos foram realizados no Instituto de Química de São Carlos, Grupo de Materiais Híbridos e Inorgânicos IQSC-USP

Tabela 12 - Balanço de formulação para ensaios térmicos, elétricos e de micrografia (sendo identificados posteriormente nos testes como Epóxi 1, Epóxi 2 e Epoxi3

Prototipo Epoxi
\begin{tabular}{|c|c|c|c|}
\hline Monomero & Formula 1 & Formula 2 & Formula 3 \\
\hline DGEBA & $1 \mathrm{eq}$ & $1 \mathrm{eq}$ & $1 \mathrm{eq}$ \\
IPDA & $1 \mathrm{eq}$ & $1 \mathrm{eq}$ & $1 \mathrm{eq}$ \\
MICA Pura & 0 & $40 \%$ peso & 0 \\
Mica Silada & 0 & & $40 \%$ peso \\
\hline
\end{tabular}

Fonte: elaborado pelo próprio autor, 2019. 
Figura 52 - Fluxograma para obter os protótipos epóxi para testes térmicos, elétricos e de micrografia.

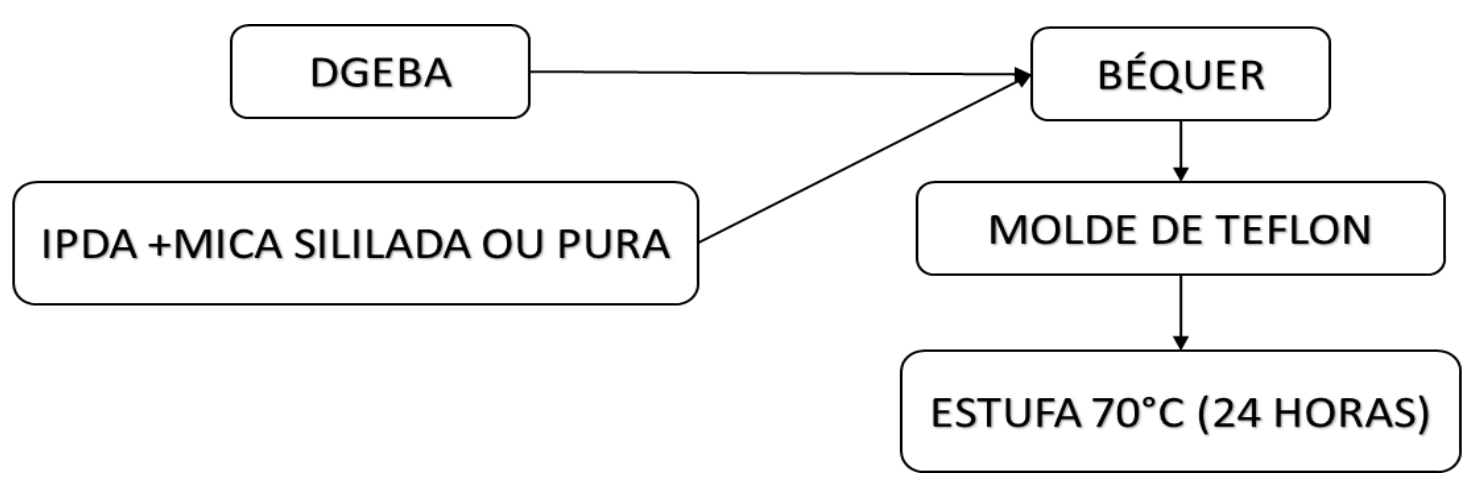

Fonte: elaborado pelo próprio autor, 2019.

\subsection{Preparação dos Protótipos do Sistema NIPU Cura via Calorimetria} Exploratória Diferencial (DSC)

Todos os experimentos foram realizados no Instituto de Química de São Carlos, Grupo de Materiais Híbridos e Inorgânicos IQSC-USP.

\subsubsection{NIPU obtida do Ciclocarbonato + TETA. (Método usando ciclocarbonato} sólido)

Método Utilizado: Tendo em vista que o Ciclocarbonato de DGEBA é um material sólido, buscou-se misturar o ciclocarbonato com a amina com a finalidade de obter uma pasta para o DSC. A ideia seria buscar a fusão do ciclocarbonato e ao mesmo tempo registrar a temperatura de início da cura e na segunda curva do DSC observar a Tg do sistema.

\subsubsection{NIPU obtida do Ciclocarbonato + TETA. (Usando ciclocarbonato}

\section{fundido)}

Método Utilizado: O ciclocarbonato foi fundido a $110^{\circ} \mathrm{C}$, informação obtida do DSC deste composto, e na sequência adicionou-se o TETA até a obtenção de uma pasta. Com o resfriamento se formou uma pastilha que foi posteriormente levado para o DSC, esta análise foi executada com as mesmas condições usadas para o sistema epóxi.

\subsubsection{Protótipos de ciclocarbonato com TETA curados por 24 horas}

Método de preparação conforme Figura 53. O ciclocarbonato foi fundido a $110{ }^{\circ} \mathrm{C}$, em seguida foi incorporado o TETA; a mistura foi deixada por 24 horas em estufa a $80{ }^{\circ} \mathrm{C}$. 
Em paralelo foram produzidos protótipos com a mica sililada com a concentração de $40 \%$ em peso. Em ambos os casos foram preparados protótipos com razão molar entre ciclocarbonato e TETA de 1:1, sendo considerando no TETA para fim de formulação apenas os grupamentos de amina primária. Usou -se $0,1 \%$ de DBU como catalisador.

Figura 53 - Esquema de preparação da NIPU usando TETA.

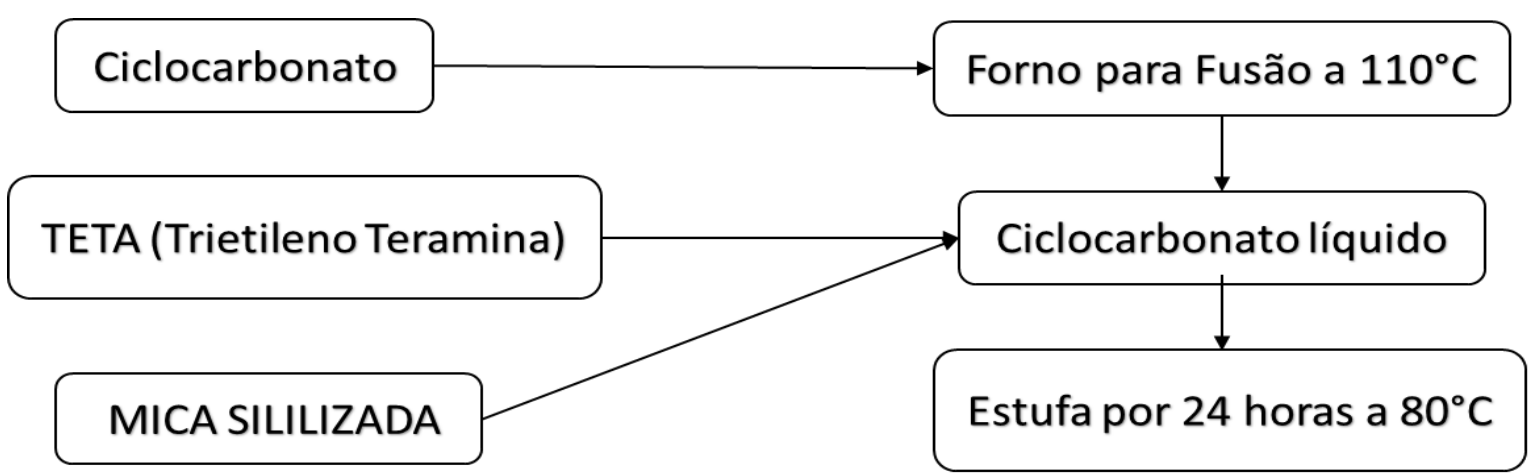

Fonte: elaborado pelo próprio autor, 2019.

\subsubsection{Protótipos de NIPU Para testes Térmicos/Elétricos e Imagem/Químicos}

Tabela 13 - Massa molar, número de grupos reativos por molécula (funcionalidade) e equivalentes dos reagentes (gramas.mol ${ }^{-1}$ ).

\begin{tabular}{|l|r|r|r|}
\hline Insumo & Massa Molar & Funcionalidade & Equivalente \\
\hline EPON 828 & 380 & 2 & 190 \\
TETA & 146 & 2 & 73 \\
IPDA & 170 & 2 & 85 \\
CCBA & 480 & 2 & 240 \\
MICA Sililada a 1\% & 134 & 1 & 0,0745 \\
\hline
\end{tabular}

Fonte: elaborado pelo próprio autor, 2019.

\section{Metodologia para Cálculo do Equivalente da Mica Sililada.}

Peso Molecular da Mica: 400,30 g/mol

Peso Molecular do APTS: 134,186 g/mol 
Considerando que em 100 gramas de mica usa-se 1 grama de APTS, teremos 7,45 m.mol de APTS por grama de mica. Em todos os experimentos feitos fixou-se o teor de 40 $\%$ em peso de Mica (sililada ou sem tratamento).

Tabela14 - Estequiometria usada para obter a NIPU razão Equivalente 1:1.

\begin{tabular}{|c|c|c|}
\hline Insumo & \% em Peso & Número de Equivalentes \\
\hline CICLOCARBONATO & $43,9 \%$ & 1 \\
IPDA & $16 \%$ & 1 \\
MICA SILILADA & $40 \%$ & 0,03 \\
DBU & $0,1 \%$ & \\
\hline
\end{tabular}

Fonte: elaborado pelo próprio autor, 2019.

Tabela 15 - Estequiometria usada para obter a NIPU razão Equivalentes1,5 :1.

\begin{tabular}{|c|c|c|}
\hline Formulação & \% em Peso & número de Equivalentes \\
\hline CICLOCARBONATO & $47,9 \%$ & 1,5 \\
IPDA & $12 \%$ & 1 \\
MICA SILILADA & $40 \%$ & 0,03 \\
DBU & $0,1 \%$ & \\
\hline
\end{tabular}

Fonte: elaborado pelo próprio autor, 2019.

Tabela 16 - Estequiometria usada para obter o NIPU razão Equivalente $2,0: 1$.

\begin{tabular}{|c|c|c|}
\hline Formulação & \% em Peso & número de Equivalentes \\
\hline CICLOCARBONATO & $50,9 \%$ & 2 \\
IPDA & $9 \%$ & 1 \\
MICA SILILADA & $40 \%$ & 0,03 \\
DBU & $0,1 \%$ & \\
\hline
\end{tabular}

Fonte: elaborado pelo próprio autor, 2019.

Tabela 17 - Estequiometria usada para obter o NIPU razão Equivalentes 1,0: 2,0.

\begin{tabular}{|c|c|c|}
\hline Formulação & \% em Peso & número de Equivalentes \\
\hline CICLOCARBONATO & $34,9 \%$ & 1 \\
IPDA & $25 \%$ & 2 \\
MICA SILILADA & $40 \%$ & 0,03 \\
DBU & $0,1 \%$ & \\
\hline
\end{tabular}

Fonte: elaborado pelo próprio autor, 2019. 
Figura 54 - Método usado para preparação NIPU diferentes razões molares.

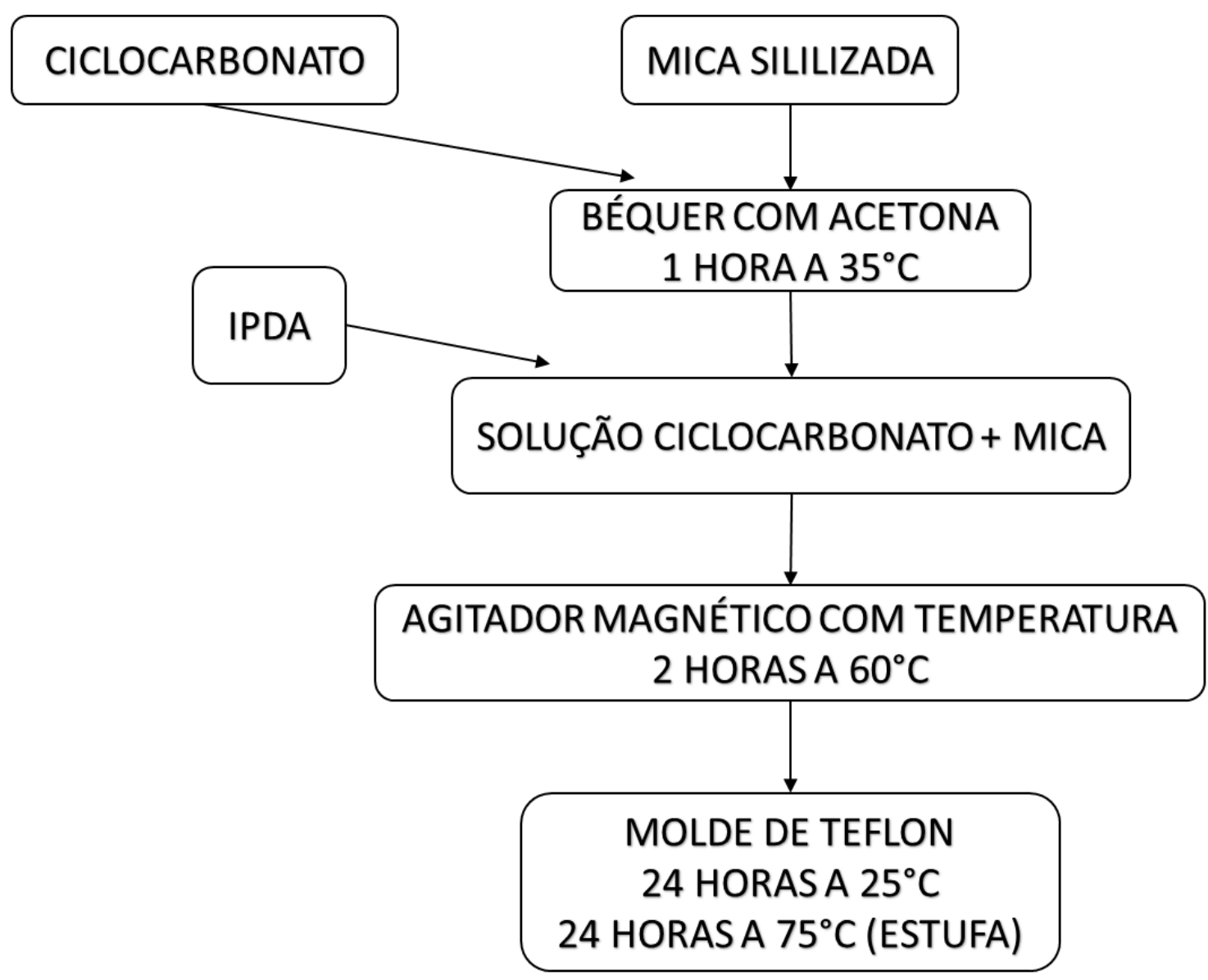

Fonte: Elaborado pelo próprio autor, 2019.

\subsection{Protótipos HNIPU Para testes Térmicos/Elétricos, Imagem e Químicos}

Todos os experimentos foram realizados no Instituto de Química de São Carlos, Grupo de Materiais Híbridos e Inorgânicos IQSC-USP

Tabela18 - Formulação para obtenção do Pré-Polímero CCGEBA/IPDA $(1: 1,5)$ e NIPU terminação Amina/DGEBA (1:1).

\begin{tabular}{|c|c|}
\hline Formulação Pré-polímero & Equivalentes \\
\hline CICLOCARBONATO & 1 \\
IPDA/ ou TETA & 1,5 \\
MICA SILILADA & 0,03 \\
DBU & 0 \\
\hline FORMULAÇÃO Final & Equivalentes \\
\hline Pré Polímero H-NIPU & 1,0 \\
DGEBA ( EPON 828) & 1,0 \\
\hline
\end{tabular}

Fonte: elaborado pelo próprio autor, 2019. 
Figura 55 - Método usado para preparação da HNIPU (NIPU Terminação Amina/DGEBA)

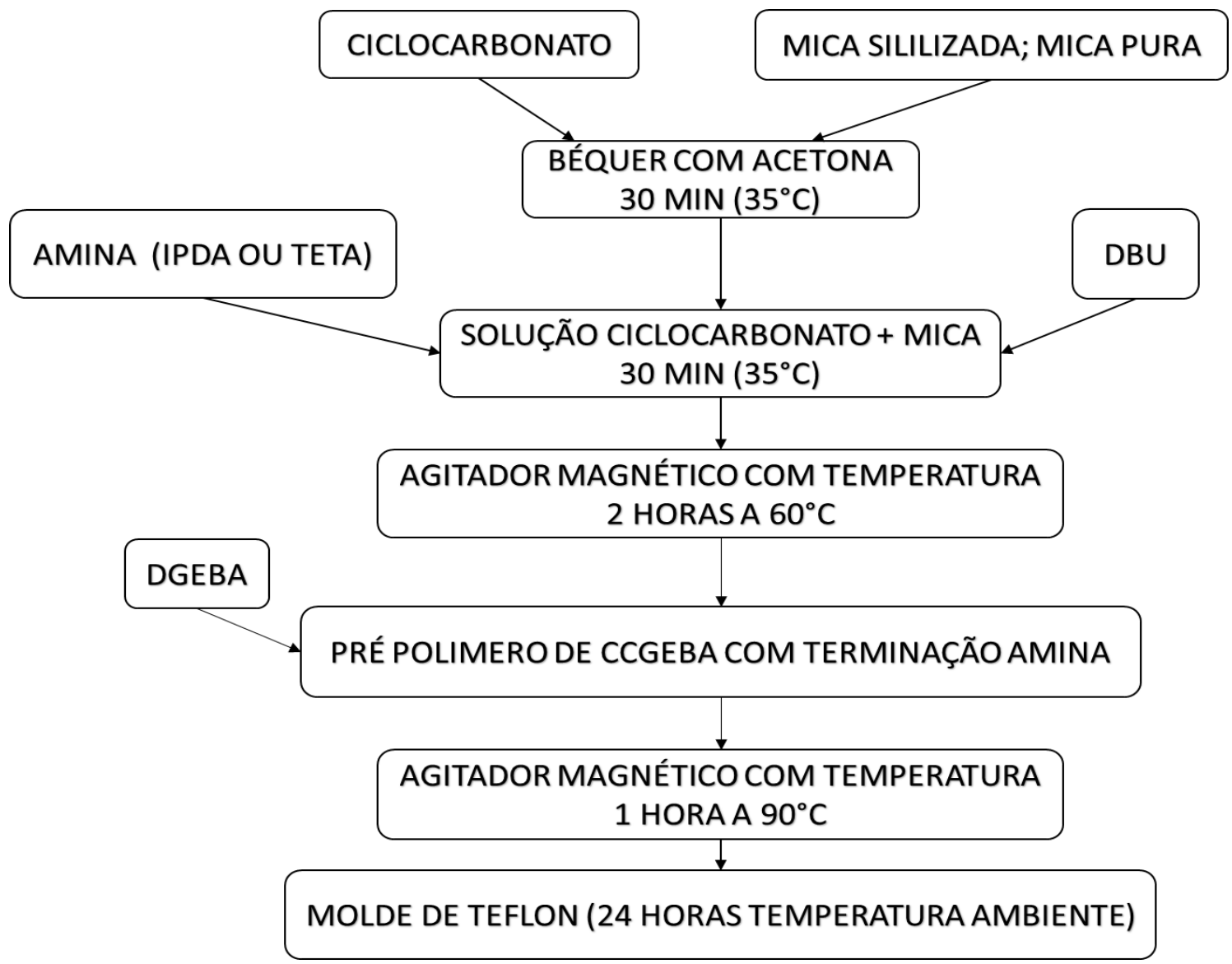

Fonte: elaborado pelo próprio autor, 2019.

\section{MÉTODOS DE CARACTERIZAÇÃO}

\subsection{Fluxograma das metodologias de Caracterização usadas}

a) Caracterização dos Insumos usados na TESE, figura 56.

Figura 56 - Fluxograma de Testes com os Insumos usados na TESE.
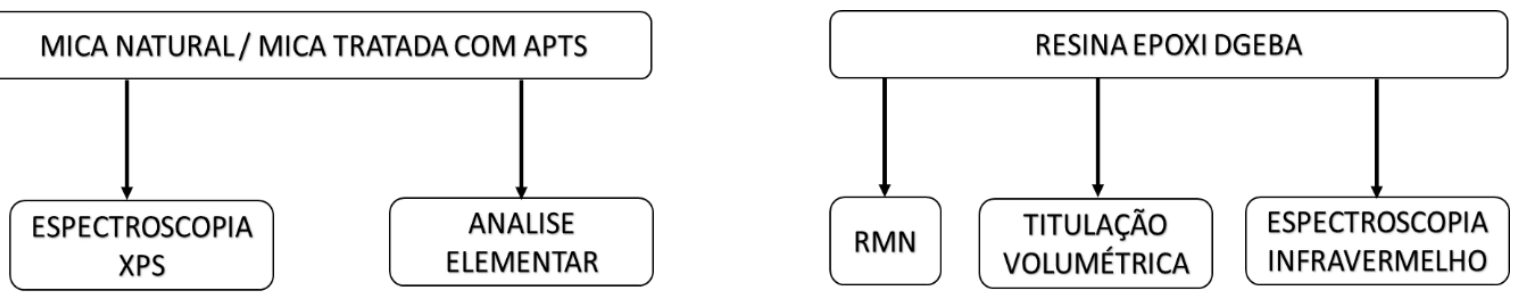

Fonte: elaborado pelo próprio autor, 2019. 
b) Caracterização dos produtos obtidos na síntese do ciclocarbonato (CCGEBA). Figura 57.

Figura 57 - Reação para obter o ciclocarbonatos (CCGEBA) e técnicas usadas na análise.

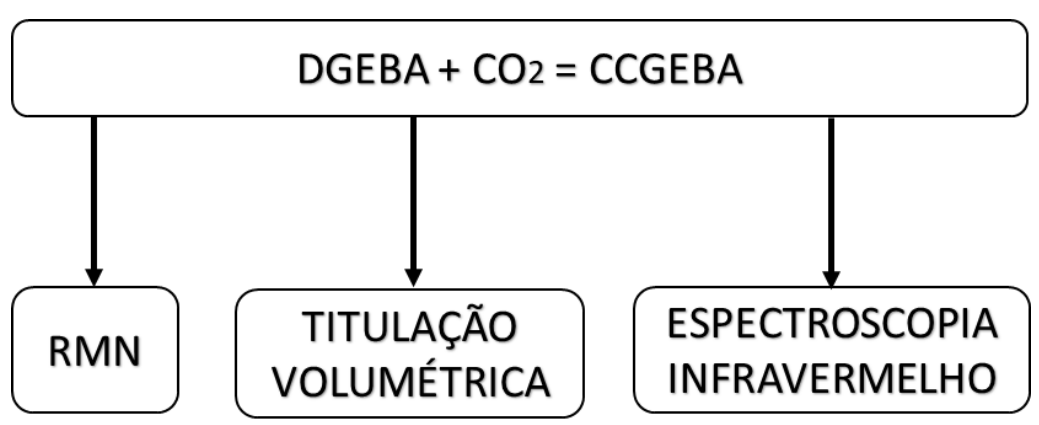

Fonte: elaborado pelo próprio autor, 2019.

c) Caracterização Protótipos para obtenção da temperatura de Cura (Epóxi e NIPU).

Figura 58- Fluxograma para visualização da temperatura de cura epóxi e NIPU.
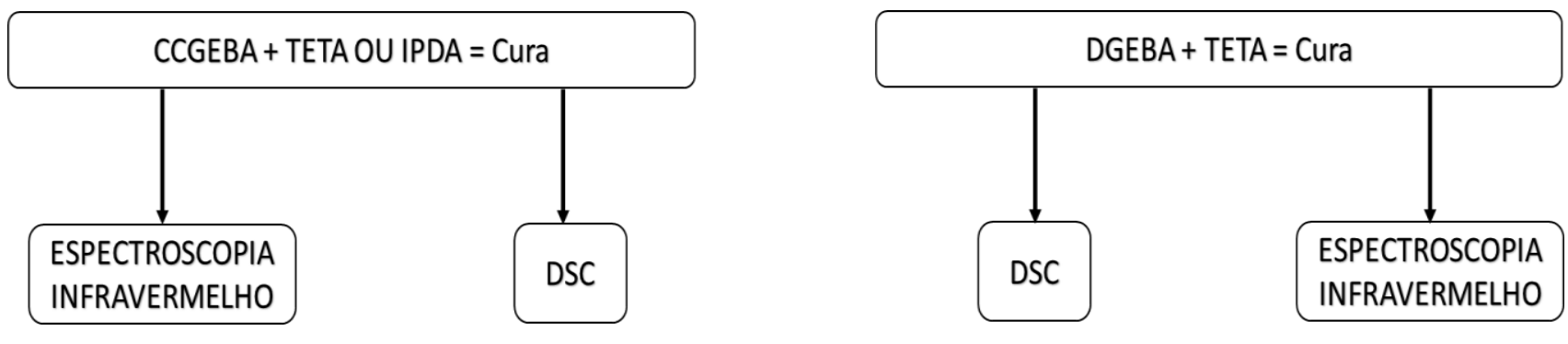

Fonte: elaborado pelo próprio autor, 2019.

d) Caracterização do Pré-Polímero (NIPU com Terminação amina) usado na síntese do protótipo (NIPU terminação amina/DGEBA) HNIPU (Blenda).

Figura 59 - Fluxograma de análise para caracterização do pré polímero base do protótipo NIPU terminação amina/DGEBA (HNIPU).

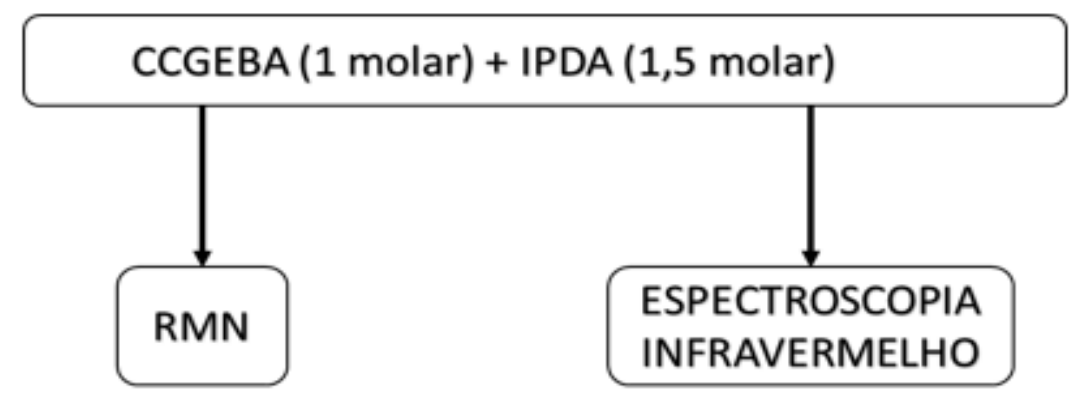

Fonte: elaborado pelo próprio autor, 2019. 
e) Caracterização Química dos Protótipos epóxi, NIPU, HNIPU (Blenda)

Figura 60 - Fluxograma dos testes Químicos.

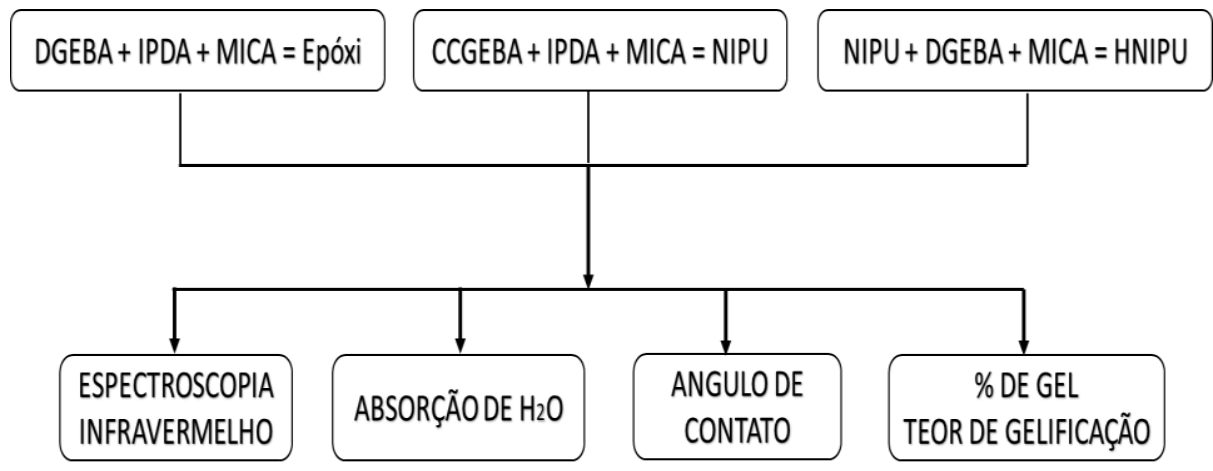

Fonte: elaborado pelo próprio autor, 2019.

f) Caracterização Térmica dos Protótipos epóxi, NIPU e HNIPU (Blenda).

Figura 61 - Fluxograma dos testes Térmicos.

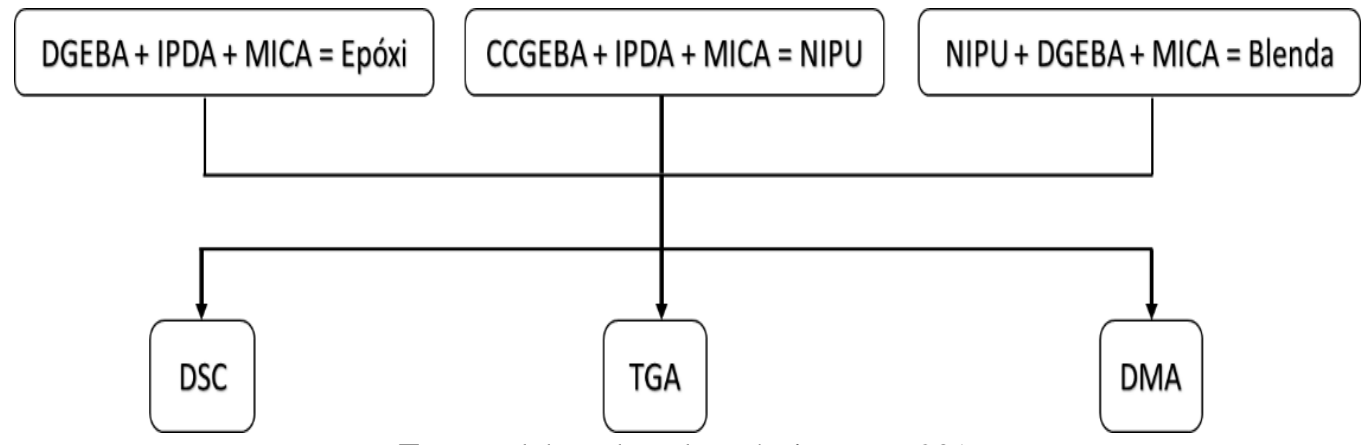

Fonte: elaborado pelo próprio autor, 2019.

g) Caracterização dos Testes Elétricos dos Protótipos epóxi, NIPU e HNIPU (Blenda)

Figura 62 - Fluxograma dos testes elétricos.

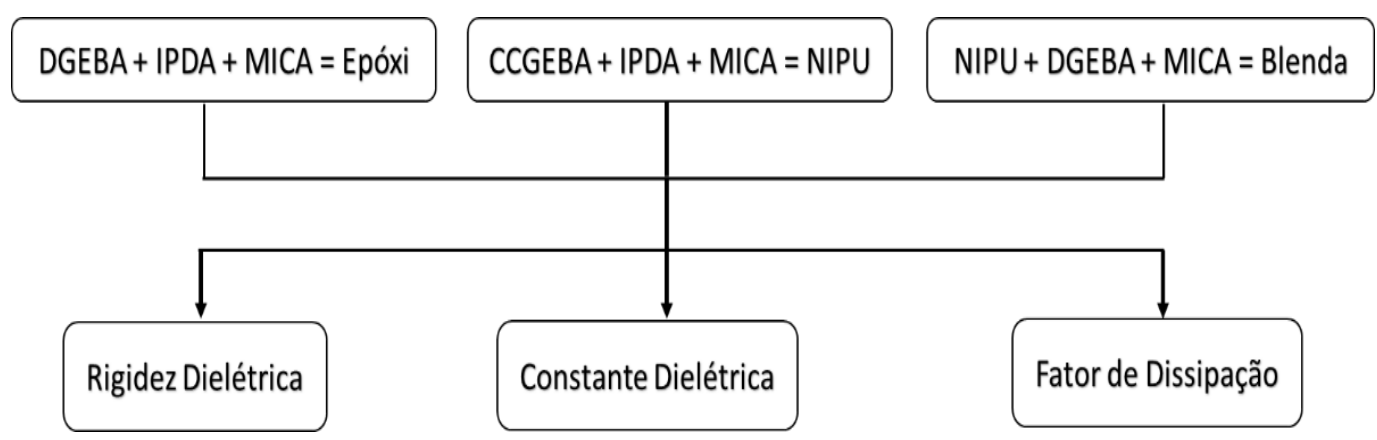

Fonte: elaborado pelo próprio autor, 2019. 
h) Caracterização Mecânica via Nanoindentação.

Figura 63 - Fluxograma da caracterização mecânica dos protótipos Epóxi, NIPU e HNIPU (Blenda).

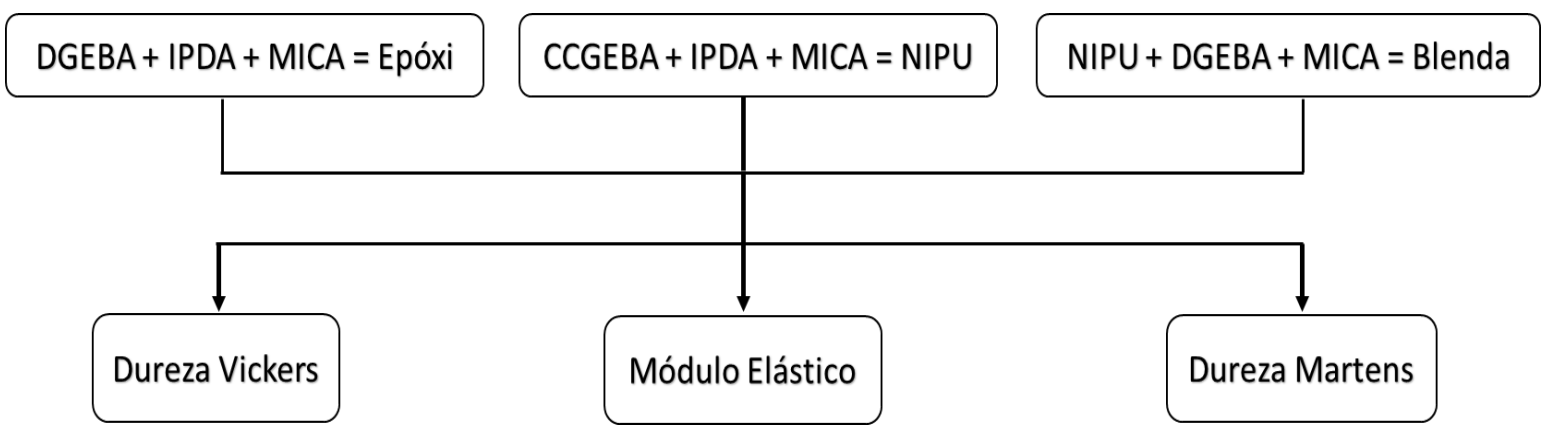

Fonte: elaborado pelo próprio autor, 2019.

i) Caracterização por Imagem.

Figura 64 - Fluxograma da caracterização morfológica por micrografia dos protótipos Epóxi, NIPU e HNIPU

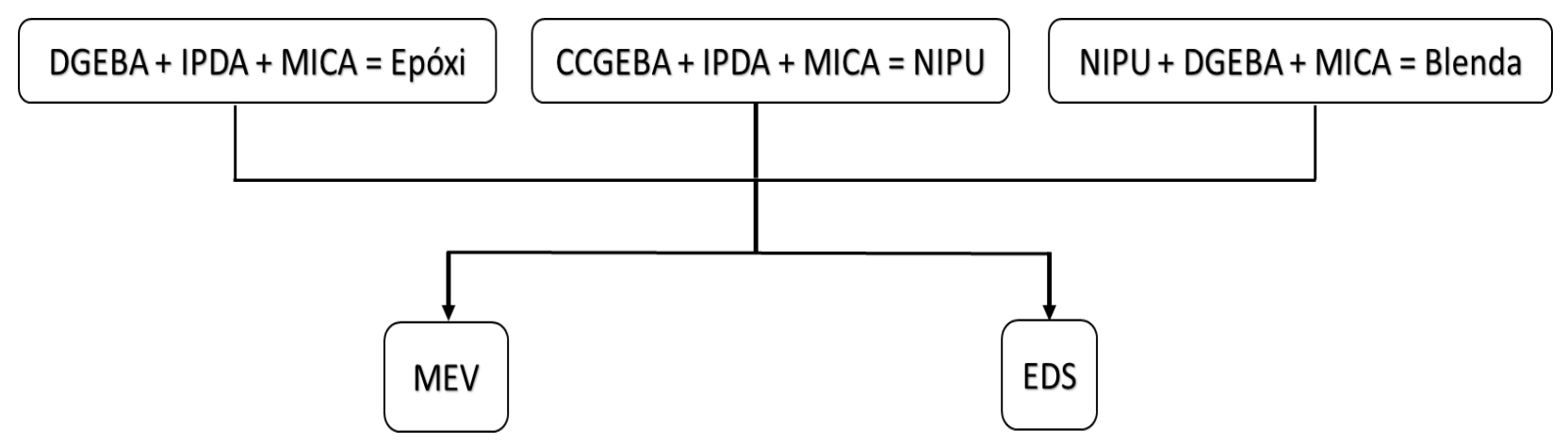

Fonte: elaborado pelo próprio autor, 2019.

* Importante: A denominação Blenda se refere ao protótipo HNIPU.

\subsection{Espectroscopia de Absorção na Região do Infravermelho}

Os espectros foram adquiridos com um espectrômetro Bruker Equinox 55 operando em uma faixa entre $650 \mathrm{~cm}^{-1}-4000 \mathrm{~cm}^{-1}$ e resolução em energia de $4 \mathrm{~cm}^{-1}$ na Central Analítica do Instituto de Química da USP São Carlos. Os espectros mostrados nestas Tese são resultado da soma de 32 espectros acumulados. Todos os espectros foram obtidos em 
modo de reflexão total atenuada (ATR) usando o cristal de ZnSe (Seleneto de Zinco). No caso do teste com ciclocarbonato sólido, utilizou-se a técnica de pastilha de $\mathrm{KBr}$.

\subsection{Titulação Volumétrica para cálculo do equivalente epóxi}

O teste de obtenção do equivalente epóxi for realizado no Instituto de Química de São Carlos, Grupo de Materiais Híbridos e Inorgânicos IQSC-USP, sendo feito pela titulação de ácido perclórico sobre a mistura do ciclocarbonato obtido das reações de cicloadição de $\mathrm{CO}_{2}$, o qual foi dissolvido em cloreto de metileno e com presença de uma solução de TEBA (brometo de tetraetilamônio) em ácido acético. O ponto final da titulação ocorre com a mudança da cor violeta para verde. Os grupos epóxi reagem com o ácido bromídrico formado in situ por adição do ácido perclórico sobre o brometo de tetraetilamônio. A reação é estequiométrica, cada equivalente de epóxi consome 1 equivalente de ácido bromídrico conforme Figura 65 [188].

Figura 65 - reação na titulação com ácido perclórico para análise do teor de oxirano. [188]

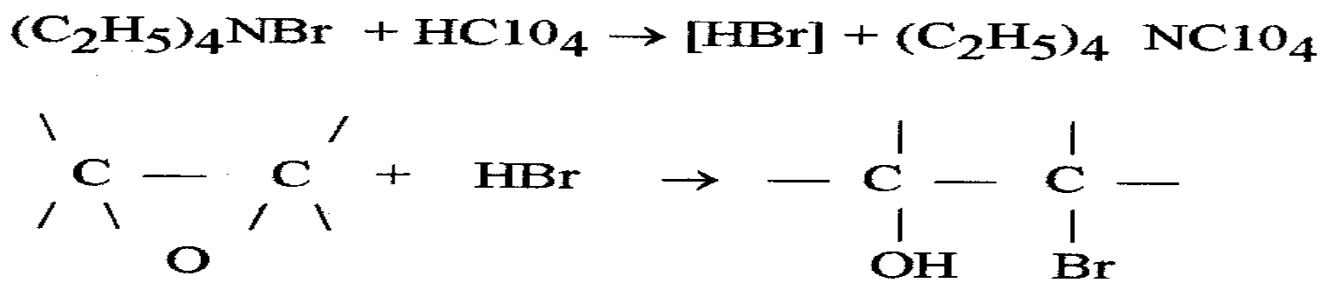

Fonte: elaborado pelo próprio autor, 2019.

\subsection{Ressonância Magnética Nuclear de ${ }^{1} \mathrm{H}$ e ${ }^{13} \mathrm{C}$}

\subsubsection{Teste de $\mathrm{RMN}$ de ${ }^{1} \mathrm{H}$ no ciclocarbonato}

As amostras analisadas $(30 \mathrm{mg}$ ) foram solubilizadas em clorofórmio deuterado contendo tetrametilsilano (TMS) como padrão de deslocamento químico. Os espectros foram coletados usando o espectrômetro Bruker Avance $500 \mathrm{MHz}$ no Laboratório Analítico da 3M em St. Paul-MN (Estados Unidos) equipado com ponta criogenicamente resfriada, conforme 
Figura 66. Dados 2D (homo e hetero nuclear) foram coletados para confirmar o sinal encontrado. Um pico de ressonância do solvente foi usado como referência de escala de deslocamento químico na dimensão do próton ( $ð=7,27$ ppm). Os parâmetros utilizados nas medidas foram: Número de espectros acumulados NS (32), tempo entre as sequências de pulso (delay time) D1 (5 s), tempo de aquisição AT (3 s), intervalo de tempo para relaxamento (intervalo de tempo entre cada sequência de pulso) D1 (0.1 s).

Figura 66 - Frasco com amostra solubilizada e equipamento usado na RMN.
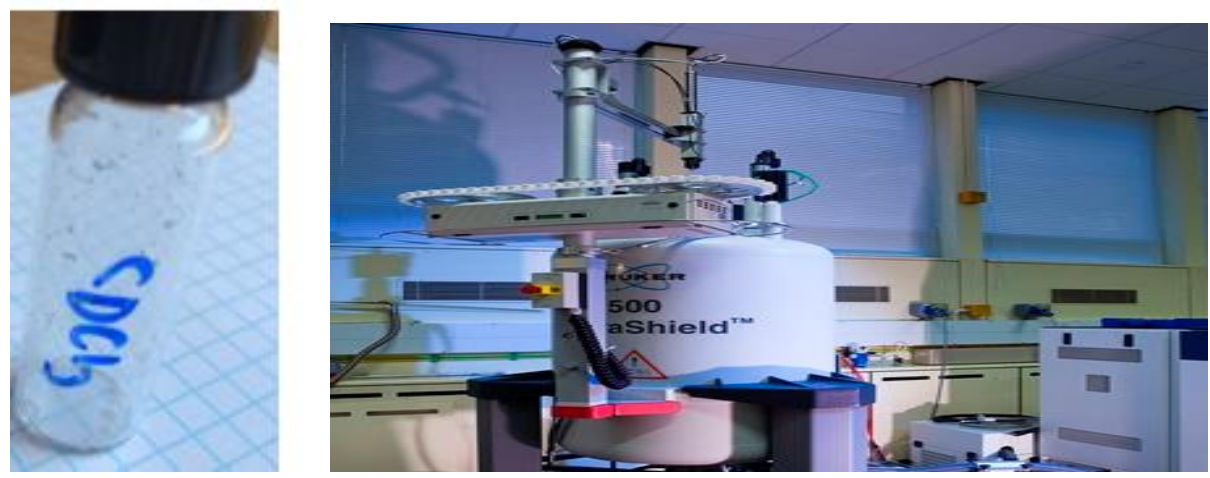

Fonte: elaborado pelo próprio autor, 2019.

\subsubsection{Teste de RMN de ${ }^{1} \mathrm{H} \mathrm{e}^{13} \mathrm{C}$ na NIPU com terminação amina}

O ensaio de RMN foi realizado na Central Analítica do Instituto de Química da USP São Carlos. Utilizou-se o RMN Agilent modelo 500/54 (conforme Figura 67). Os espectros de $\mathrm{RMN}$ de ${ }^{1} \mathrm{He} \mathrm{e}^{13} \mathrm{C}$ da amostra foram adquiridos em um Agilent $500 \mathrm{MHz}$ com os seguintes parâmetros de aquisição: $\left({ }^{1} \mathrm{H}\right)$ número de scans $(\mathrm{NS})=16$, largura do pulso $(\mathrm{P} 1)=3,95 \mu \mathrm{s}$, tempo entre cada sequência de pulsos $(\mathrm{D} 1)=1 \mathrm{~s} ;\left({ }^{13} \mathrm{C}\right) \mathrm{NS}=4096, \mathrm{P} 1=6,6 \mu \mathrm{s}$ e D1=3s. Todos os espectros foram referenciados ao $\mathrm{CDCl}_{3}$ em 7,26 ppm. Devido a complexidade da estrutura alvo, principalmente pelo prépolímero (NIPU com terminação amina) ser proveniente da reação do DGEBA com $\mathrm{CO}_{2}$ e com excesso de amina para posterior reação com o próprio DGEBA, a presença de vários grupos similares poderiam via RMN monodimensional não ser possível determinar com exatidão a estrutura alvo da NIPU com terminação amina. Diante disso optou por além de fazer o RMN monodimensional, realizar novas sequências de pulso para elucidar com maior exatidão a estrutura alvo. Além do RMN de ${ }^{1} \mathrm{H}$ e ${ }^{13} \mathrm{C}$ foi executado o Distortionless Enhancement by Polarization Transfer (DEPT) 
135, e as técnicas bidimensionais de Espectroscopia de Correlação (COSY do inglês Correlation Spectroscopy) a $90^{\circ}$ e Heteronuclear Single Quantum Coherence (HSQC).

DEPT135 - Este experimento de DEPT utiliza um ângulo de $135^{\circ}$ para que sinais de $\mathrm{CH}_{2}$ tenham fase diferente dos sinais de $\mathrm{CH}_{3}$ e $\mathrm{CH}$. Neste experimento não são observados sinais de carbonos quaternários. DEPT-135 mostra carbonos ligados a hidrogênios, não mostra o sinal do $\mathrm{CDCl}_{3}$ e dos carbonos quaternários, enquanto, os sinais do $\mathrm{CH}$ e do $\mathrm{CH}_{3}$ são positivos e os doCH $\mathrm{CH}_{2}$ são negativos.

Os experimentos de RMN em duas dimensões (RMN 2D) não são tão difundidos quanto aqueles em $1 \mathrm{D}$, os experimentos em $2 \mathrm{D}$ podem ser homo- $\left({ }^{1} \mathrm{H},{ }^{1} \mathrm{H}\right)$ ou heteronucleares $\left({ }^{1} \mathrm{H},{ }^{13} \mathrm{C}\right)$. As técnicas 2D permitem correlacionar hidrogênios e/ou carbonos que possuam alguma relação escalar $\left({ }^{\mathrm{n}} \mathrm{J}_{\mathrm{H}, \mathrm{H}},{ }^{\mathrm{n}} \mathrm{J}_{\mathrm{C}, \mathrm{H}},{ }^{\mathrm{n}} \mathrm{J}_{\mathrm{C}, \mathrm{C}}\right)$ ou espacial (H, H- ou H,C) entre si. Desta forma é possível fazer um mapeamento estrutural mais preciso do que utilizando somente as técnicas $1 \mathrm{D}$ e dados de possíveis compostos similares da literatura, principalmente na análise de estruturas mais complexas. Não obstante, é sempre recomendável que o usuário de RMN 2D esteja familiarizado com a influência de fatores como eletronegatividade ou anisotropia magnética ou compressão estérica sobre os deslocamentos químicos e/ou constantes de acoplamentos [189, 190].

COSY (homonuclear Correlation Spectroscopy) - com esta sequência de pulsos pode-se estabelecer as correlações entre os hidrogênios que estão acoplados por $\mathbf{J}_{\mathrm{H}, \mathrm{H}}$ (acoplamentos geminais e vicinais, mensuráveis no espectro 1D) e assim discernir a multiplicidade dos sinais observados no espectro de $\mathrm{RMN}{ }^{1} \mathrm{H}$. Eventualmente, sinais devidos a $J_{H, H}$ são também visíveis (acoplamentos a longa distância, raramente mensuráveis no espectro 1D). [189,190]

COSY 90 é o procedimento mais comum dessa técnica, nela, o pulso de radiofrequência p1 magnetiza o sistema de spins nucleares de ${ }^{1} \mathrm{H}$ de forma que estejam alinhados a $90^{\circ}$, seguido de um tempo $t 1$ de espera e na sequência um novo pulso (p2) de radiofrequência igualmente alinha os spins a $90^{\circ}$ provocando transferência de polarização (magnetização) entre os spins nucleares acoplados via interação dipolar magnética. Outra possibilidade de COSY é o COSY 45, onde p2 alinha os spins a $45^{\circ}$. A vantagem do COSY 45 e que os picos diagonais são menos pronunciados, fazendo mais fácil achar o cruzamento da diagonal em polímeros de alta massa molecular. Adicionalmente os sinais de constantes 
de acoplamento podem ser elucidados mais facilmente. O COSY 45 oferece um espectro mais limpo enquanto o COSY 90 é mais sensível [190].

HSQC (Heteronuclear single Quantum correlation Spectroscopy) detecta correlações entre núcleos de dois tipos diferentes que são separados por uma ligação química. Esse método fornece um pico por par de núcleos acoplados, cujas coordenadas são as mudanças químicas dos dois átomos acoplados. O HSQC funciona transferindo a magnetização do núcleo I (geralmente o próton) para o núcleo $\mathrm{S}$ (um heteroátomo) usando a sequência de pulsos INEPT (Insensitive nuclei enhanced by polarization transfer); esse primeiro passo é realizado porque o próton tem uma magnetização de equilíbrio maior e, portanto, resulta em um sinal mais forte. A magnetização evolui e depois é transferida de volta ao núcleo I para observação. Opcionalmente, uma etapa extra de rotação de magnetização pode ser usada para desacoplar o sinal, simplificando o espectro ao recolher multipletos em um único pico. Os sinais desacoplados indesejados são removidos executando a experiência duas vezes com a fase de um pulso específico invertido; isso reverte os sinais dos picos desejados, mas não os indesejados; portanto, subtrair os dois espectros fornecerá apenas o pico desejado [190].

Figura 67 - RMN Agilent Modelo 500/5 4.

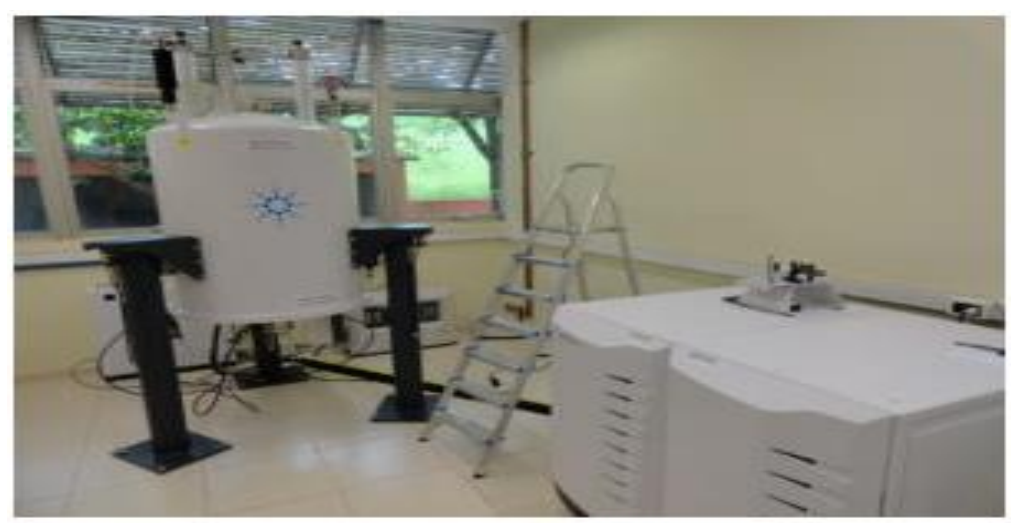

Fonte: elaborado pelo próprio autor, 2019.

Preparação para Teste: O pré-polímero foi sintetizado conforme o protocolo normal de obtenção dos protótipos, a diferença foi após a evaporação da acetona e antes de se fazer o processo de cura para obter do protótipo rígido, fez se, a dissolução em clorofórmio deuterado de forma a se ter cerca de $30 \mathrm{mmol}$ de pré polímero dissolvido. 


\subsection{Espectroscopia de fotoelétrons excitados por Raios X (XPS)}

As amostras de mica sem tratamento e com tratamento à base de aminossilano foram analisadas usando Espectroscopia de Fotoelétrons Excitados por Raios X conforme os parâmetros da Tabela 19, no Laboratório Analítico da 3M-St Paul nos Estados Unidos Os dados foram tratados pelo software PHI Multi Park.

Para o cálculo da percentagem atômica, são assumidas várias simplificações, ou seja, assumir que o material será uma camada homogênea sobre toda a superfície e que esta é de baixa rugosidade. A partir disso para obter a percentagem atômica (A) é aplicada a seguinte equação (7) para um sistema com dois elementos:

$$
\mathrm{A}=\% \text { atômica de } \mathrm{A}=(\mathrm{IA} / \mathrm{FA}) /[(\mathrm{IA} / \mathrm{FA})+(\mathrm{IB} / \mathrm{FB})]
$$

Onde F é chamado de fator de sensibilidade atômica que é associado com a ótica do equipamento (analisador de elétrons, detector, ângulo de coleta dos fotoelétrons, área de irradiação da amostra e a intensidade do feixe de raios X [191] e o elemento químico a ser analisada e I: é a intensidade do pico fotoelétrico de interesse nos espectros de fotoemissão, geralmente aqueles com maior seção de choque.

Tabela 19 - Parâmetros de aquisição dos espectros de XPS.

\begin{tabular}{|c|c|}
\hline Espectrômetro & Physical Electronics Versa Probe 5000 \\
\hline Área de Análise & $\approx 500 \mu \mathrm{m} \times 1500 \mu \mathrm{m}$ \\
\hline $\begin{array}{l}\text { Ângulo de coleta dos } \\
\text { fotoelétrons }\end{array}$ & $45^{\circ} \pm 20^{\circ}$ \\
\hline Fonte de Raios X & Monocromática Al Ka $(1486,6 \mathrm{eV}) 85 \mathrm{~W}$ \\
\hline $\begin{array}{l}\text { Calibração da Escala de } \\
\text { Energia de Ligação em } \\
\text { função de carregamento } \\
\text { residual }\end{array}$ & $\begin{array}{l}\text { Energia de Ligação do fotoelétron ionizado do orbital 1s do } \\
\mathrm{C} \text { contendo como vizinhos apenas C ou H (C-C/C-H) } \\
\text { acertada para } 284,8 \mathrm{eV} \text {. Este carbono foi assumido como } \\
\text { proveniente de contaminação espúria na câmera de análise } \\
\text { [192] }\end{array}$ \\
\hline $\begin{array}{c}\text { Pressão na Câmara de } \\
\text { Análise }\end{array}$ & $\sim 5.10^{-8}$ Torr \\
\hline
\end{tabular}

Fonte: elaborado pelo próprio autor, 2019. 


\subsection{Análise elementar C, H, N}

Análise elementar de carbono, hidrogênio e nitrogênio (CHN) foi realizada em um analisador elementar CHN2400 series II (Perkin-Elmer) na Central Analítica da Universidade de São Paulo IQ-USP. Os elementos foram quantificados pelo método de Pregl-Dumas, no qual as amostras são submetidas à combustão em atmosfera de oxigênio e os gases liberados são detectados em um detector de condutividade térmica (TCD).

\subsection{Absorção de água, conforme ASTM D 570}

Análise de Absorção de água, conforme ASTM D 570 [193] (adaptada) foi realizada no Instituto de Química de São Carlos, Grupo de Materiais Híbridos e Inorgânicos IQSCUSP.

O objetivo dessa técnica é de maneira comparativa quantificar a capacidade de absorção de água dos diferentes compósitos [194]. Essa absorção mede a afinidade da água pelos grupamentos polares presentes na estrutura do polímero em avaliação. Devido a essência do projeto ser uma aplicação elétrica, essa propriedade afetará diretamente o comportamento final do produto [195].

Os materiais obtidos na fase protótipos com $2 \mathrm{~mm}$ de espessura foram recortados em quadrados com cerca de $20 \mathrm{~mm}$ x $20 \mathrm{~mm}$ (sempre em triplicatas). Esses corpos de prova foram pesados inicialmente e deixados por 24 horas imersos em um béquer com água destilada em temperatura ambiente $\left(25^{\circ} \mathrm{C}\right)$. Após o tempo, as amostras foram removidas e secas em papel toalha absorvente e pesadas novamente. $\mathrm{O}$ teor de absorção de água e calculado conforme equação 8 abaixo:

$$
\% \text { de Absorção de água }=\frac{(m 1-m 0)}{m 0}
$$

Onde $\mathrm{m}_{1}$ : massa após 24 horas em água.

m 0: massa inicial da amostra.

\subsection{Análise do Grau de Gelificação em THF e teor de gel}

Análise do Grau de Gelificação em THF e seu posterior cálculo do grau de teor de GEL foi realizada no Instituto de Química de São Carlos, Grupo de Materiais Híbridos e Inorgânicos do IQSC-USP. 
A partir dessa avaliação podemos estimar o grau de reticulação que os sistemas apresentam e dessa forma inferir sobre o seu grau de conversão e formação de uma estrutura tridimensional rígida. O princípio dessa metodologia se baseia nas propriedades de solvência do tetrahidrofurano em relação aos monômeros usados (DGEBA e CCGEBA), sendo assim, ao imergirmos os blocos ou placas do material compósito em THF, ocorrerá o inchamento do material e solubilização de todos os componentes não reticulados, monômeros e oligômeros. Portanto, é uma medida tanto do grau de inchamento causado pela absorção do solvente quanto do grau de reticulação e formação de gel $[183,184]$.

Os materiais obtidos na fase protótipos com $2 \mathrm{~mm}$ de espessura foram recortados em quadrado com cerca de $20 \mathrm{~mm}$ x $20 \mathrm{~mm}$ (triplicata). Esses corpos de prova foram pesados inicialmente e deixados por 24 horas imersos em um béquer com THF à temperatura ambiente $\left(25^{\circ} \mathrm{C}\right)$. Após este tempo, as amostras foram removidas, secas em papel toalha absorvente e pesadas novamente. O grau de gelificação é calculado conforme equação 9 abaixo:

$$
\text { Grau de Gelificação } \frac{m 1-m 0}{m 0} \times 100 \%
$$

Onde temos: $\mathrm{m}_{1}=$ Peso após 24 horas em THF

$$
\mathrm{m}_{0}=\text { Peso inicial da amostra }
$$

Após a pesagem o material proveniente do teste de gelificação foi deixado em estufa com ventilação a $80{ }^{\circ} \mathrm{C}$ por 24 horas. Esse procedimento se deve a necessidade de evaporar o solvente que foi absorvido e ficou internamente aprisionado na estrutura da amostra. Removidas após esse tempo, foi pesada para se obter o teor de gel [183,184]. O teor de gel foi calculado conforme equação 10 a seguir.

$$
\text { Teor de Gel }=\frac{m 2}{m 0} \times 100 \%
$$

Onde temos: $\mathrm{m}_{2}=$ massa após a secagem

$$
\mathrm{m}_{0}=\text { massa inicial da amostra } .
$$




\subsection{Estudo de Molhabilidade}

O estudo de molhabilidade foi realizado pela medida do ângulo de contato dos líquidos com a superfície e foram realizados na Central de Análise Química (CAQUI) do Instituto de Química de São Carlos. Utilizou-se o Tensiômetro ATTENSION (Figura 68) com medidas estáticas de ângulo de contato das superfícies dos protótipos obtidos para os testes de avaliação. $\mathrm{O}$ volume da gota foi mantido constante em $3 \mu \mathrm{L}$ para cada medida e o valor final do ângulo de contato foi a média de três medidas em três regiões diferentes da amostra. As imagens foram adquiridas em uma câmera CCD e as imagens analisadas com o software SCAN 20 Data Physics, 6 imagens/segundo, com duração de 10 segundos cada imagem. Usou-se água ultrapura Milliken, conforme Figura 69.

A calibração se deu com uma esfera de Tungstênio com diâmetro de 3,9999 mm e um ângulo de contato de $143^{\circ}$ previamente padronizado.

Figura 68 - Tensiomêtro ATTENSION.

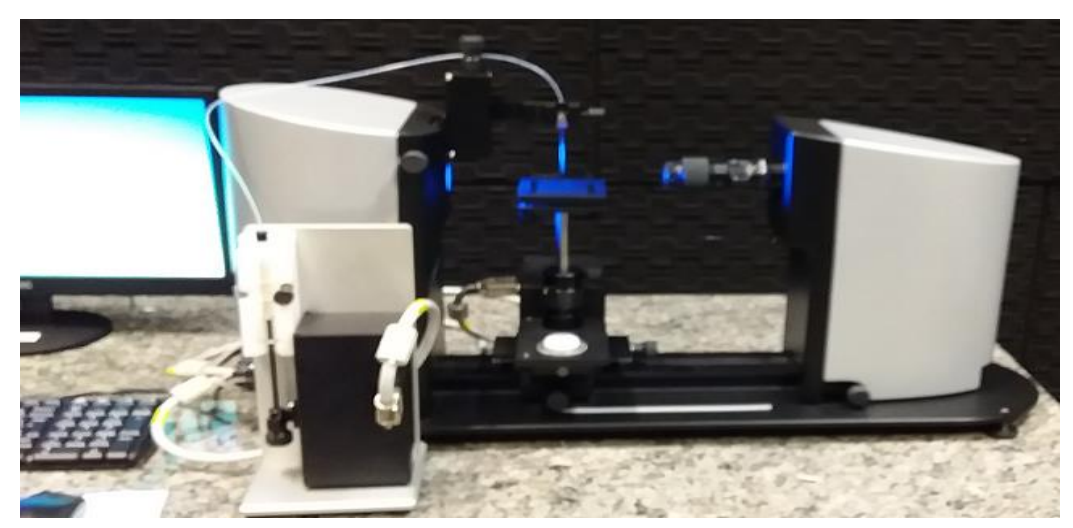

Fonte: elaborado pelo próprio autor, 2019. 
Figura 69 - Gota de Água superpura sendo aplicada.

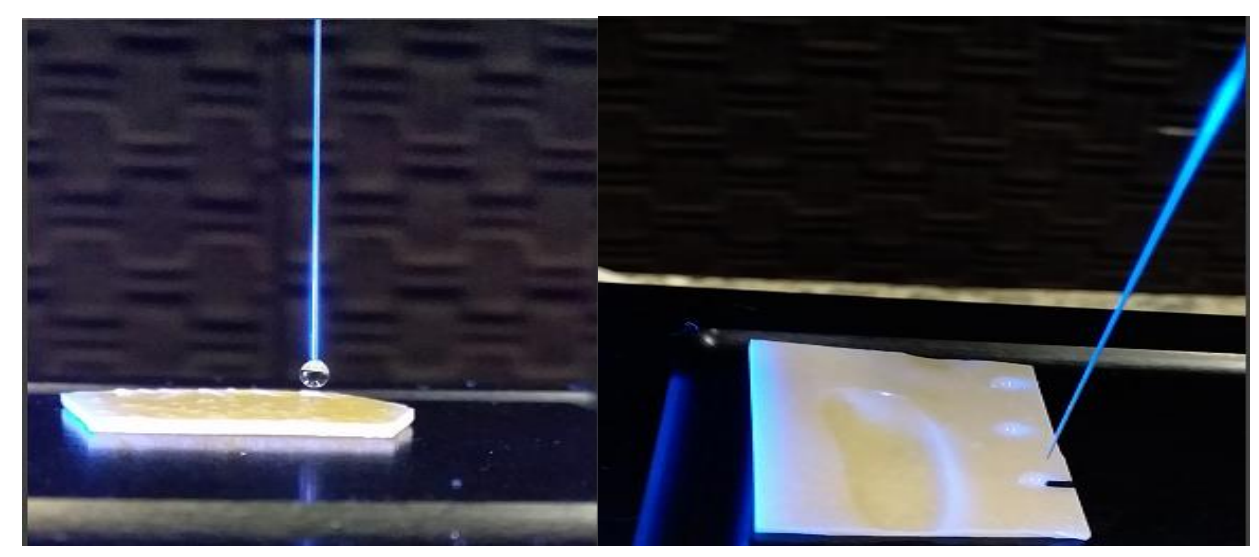

Fonte: elaborado pelo próprio autor, 2019.

\subsection{Rigidez dielétrica ASTM D 149}

A análise de rigidez dielétrica nos protótipos foi realizada no Laboratório de Controle de Qualidade da 3M do Brasil em Ribeirão Preto. Utilizou-se o equipamento ITEL com sistema em fenolite para proteção no caso de descarga elétrica. Os corpos de prova cortados foram colocados em suporte de fenolite, sendo protegido por uma fita isolante de borracha, conforme a Figura 70. O teste consiste em aplicar uma descarga elétrica sobre o corpo de prova até que haja a sua ruptura (Tensão Disruptiva), sendo que o cálculo da rigidez dielétrica se dá conforme a equação 11, fazendo a divisão entre essa tensão máxima para ruptura do corpo de prova pela espessura do protótipo.

$$
\text { Rigidez Dielétrica }\left(\frac{K V}{\mathrm{~mm}}\right)=\frac{\text { tensão disruptiva }(\text { volts })}{\text { espessura }(\mathrm{mm})}
$$


Figura 70 - Imagem do Equipamento para Rigidez Dielétrica, Placa Suporte e Protótipo Testado.
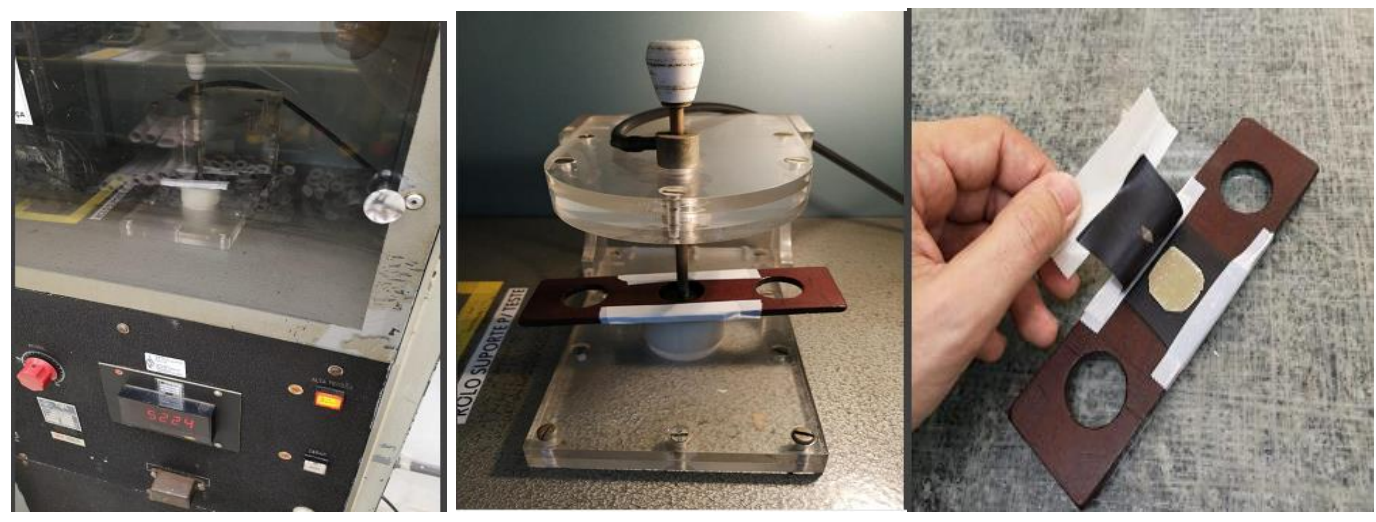

Fonte: elaborado pelo próprio autor, 2019.

\subsection{Espectroscopia de impedância}

A Espectroscopia de Impedância foi realizada no Instituto de Física de São Carlos, Grupo de Nanomateriais e Cerâmicas Avançadas (NACA), em colaboração com o professor Jean Claude M’Peko. Utilizou-se o equipamento Solartron (SI 1260 A) com o software SMaRT, utilizando tinta condutiva de carbono e prata para obter o capacitor. As medidas foram realizadas à temperatura ambiente $\left(25^{\circ} \mathrm{C}\right)$ com frequência de $0,1 \mathrm{a} 100 \mathrm{kHz}$ (Figura 71) e amplitude $300 \mathrm{mV}$ em onda senoidal. Foram executadas medidas nas temperaturas de $50{ }^{\circ} \mathrm{C}$ mantendo a variação de frequência similar a temperatura ambiente.

Figura 71 - Gráfico da Impedância em função da frequência.

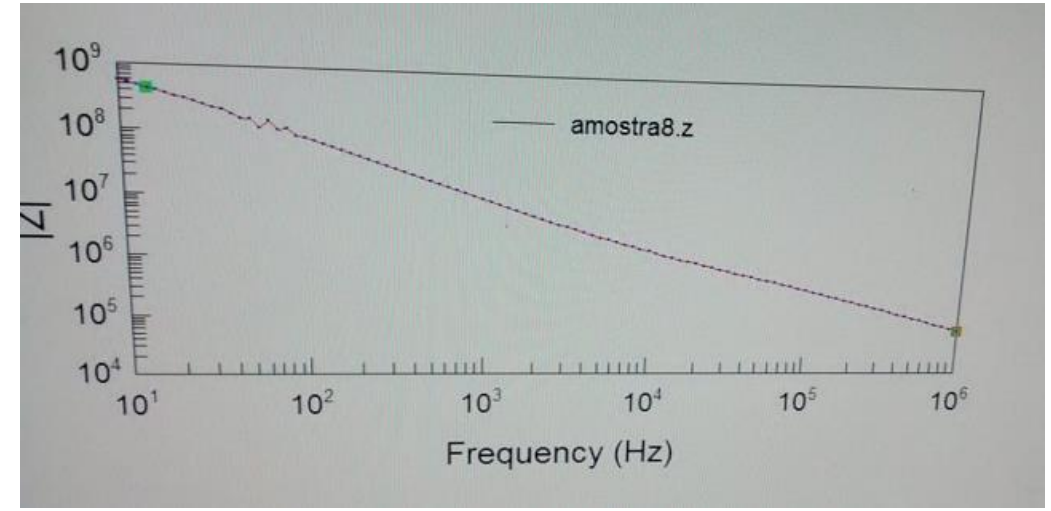

Fonte: elaborado pelo próprio autor, 2019.

Abaixo na Figura 72 tem-se os corpos de prova usados para o teste de impedância, com o depósito condutivo na superfície para promover o contato elétrico. 
Figura 72 - Corpos de prova submetido a análise de Impedância.

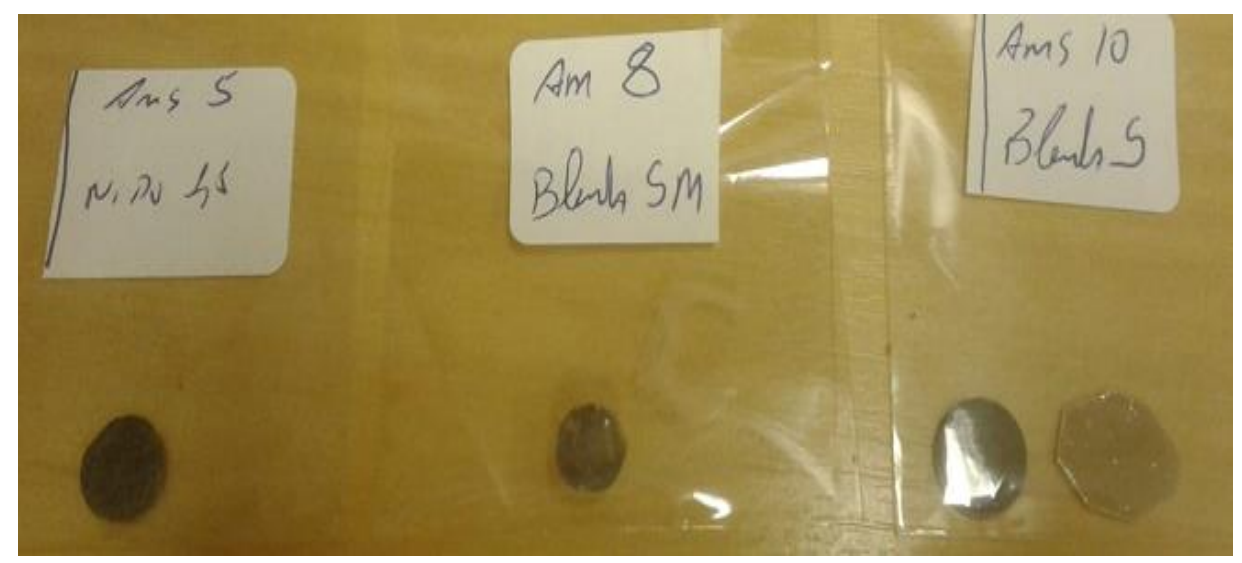

Fonte: elaborado pelo próprio autor, 2019.

O objetivo dessa análise foi obter os dados de constante dielétrica e fator de dissipação dos protótipos obtidos.

A impedância $\left(Z^{*}\right)$ é uma generalização do conceito de resistência elétrica $(\mathrm{R})$ de um material, e é por definição uma quantidade complexa expressa pela equação 12 a seguir:

$Z^{*}(\omega)=Z^{\prime}(\omega)-i Z^{\prime \prime}(\omega)=Z \exp \left(-i^{\phi}\right)=Z \cos ^{\phi}-i Z \operatorname{sen}^{\phi}$

Z'e Z" são a parte real e imaginária da impedância. Ao aplicarmos uma diferença de potencial elétrico alternado a um sólido cuja forma é dada pela equação 13:

$$
V(t)=V_{m} \operatorname{sen}(\omega t)
$$

A resposta do material se dá na forma de uma corrente elétrica conforme a equação 14.

$$
I(t)=I_{m} \operatorname{sen}(\omega t+\varphi)
$$

em que $\varphi$ é a diferença de fase entre a voltagem e a corrente elétrica; ou seja, a impedância de um material, calculada como na equação 15:

$$
Z *(\omega)=V(t) / I(t)
$$

Essa equação leva em conta a possível defasagem possível defasagem $(\varphi \neq 0)$ entre estímulo e resposta [156].

A espectroscopia de impedância (IS do Inglês, Impedance Spectroscopy) é uma ferramenta de caracterização elétrica que explora a dependência entre a resposta de um 
sistema e a frequência do estímulo aplicado, com a posterior análise desta resposta, a fim de adquirir informações sobre as propriedades físicas e químicas do sistema [196].

Os resultados obtidos podem ser relacionados com circuitos elétricos equivalentes que representam o comportamento elétrico do material. Assim por exemplo, fenômenos de polarização ideal podem ser simulados por um capacitor ideal, enquanto, fenômenos de perda de energia pela polarização do material são simulados por um resistor (R). Analisado as grandezas características destes componentes e de posse da composição e microestrutura do material é possível correlacionar o comportamento dielétrico aos efeitos de polarização, defeitos, microestrutura e condutividade em sólidos, por meio de termos que envolvem variáveis complexas. Isto é possível apenas através de medidas de condutividade em corrente alternada (ac) dentro de uma faixa de frequência entre $10^{-4} \mathrm{~Hz}$ e $10^{7} \mathrm{~Hz}$ [196].

Podendo igualmente ser obtidas informações adicionais como mecanismos de condução e de polarização dielétrica, o que não seria possível através de simples medidas da condutividade em corrente contínua (dc), pois tais medidas de 'dc' fornecem apenas o valor da condutividade total, não fornecendo informações sobre as diferentes contribuições e mecanismos de relaxação que podem ocorrer em determinados materiais [196].

Na técnica de espectroscopia de impedância, as propriedades elétricas são obtidas a partir de um conjunto de medidas de impedância complexa Z* (usa-se o símbolo ‘*' por se tratar de unidade complexa), tomadas em um intervalo de frequências $(\omega)$. Os dados experimentais de espectroscopia de impedância podem ser estudados por meio de quatro formalismos complexos:

i) impedância, $Z^{*}$;

ii) admitância, $\mathrm{Y}^{*}$;

iii) módulo elétrico, $\mathrm{M}^{*}$;

iv) permissividade dielétrica, $\varepsilon^{*}$.

Algumas vezes utilizou-se uma forma mais geral para denotar qualquer um dos 4 formalismos anteriores, chamada de imitância, que é dada como I*=I'+jI", onde I' e I' são as componentes real e imaginária da imitância, respectivamente. Esses quatro formalismos básicos estão relacionados entre si e podem ser apresentados conforme ilustrado na Tabela 20 , considerando-se o fator de inter-relação $\mu=j \omega \mathrm{C}_{0}$, sendo $\mathrm{C}_{0}$ a capacitância do vácuo [197]. 
Tabela 20 - Relação entre os Formalismos da Impedância [ 112].

\begin{tabular}{ccccc}
\hline & $M$ & $Z$ & $Y$ & $\varepsilon$ \\
\hline$M$ & $M$ & $\mu Z$ & $\mu Y^{-1}$ & $\varepsilon^{-1}$ \\
$Z$ & $\mu^{-1} M$ & $Z$ & $Y^{-1}$ & $\mu^{-1} \varepsilon^{-1}$ \\
$Y$ & $\mu M^{-1}$ & $Z^{1}$ & $Y$ & $\mu \varepsilon$ \\
$\varepsilon$ & $M^{-1}$ & $\mu^{-1} Z^{-1}$ & $\mu^{-1} Y$ & $\varepsilon$ \\
\hline
\end{tabular}

Fonte: elaborado pelo próprio autor, 2019.

Para o caso específico das medidas alvo de constante dielétrica e fator de dissipação $(\operatorname{tg} \delta)$ foram utilizadas as equações abaixo:

Considerando C': Parte real da capacitância.

C’: Parte imaginária da Capacitância temos (Equação 16 e 17)

$$
\begin{aligned}
& C(\omega)=C^{\prime}(\omega)-i C^{\prime \prime}(\omega) \\
& C^{\prime}=\varepsilon_{0} \varepsilon \mathrm{A} / \mathrm{d}
\end{aligned}
$$

Onde: \&: Constante Dielétrica ou Permissividade dielétrica.

$$
\begin{aligned}
& \mathcal{E}_{0} \text { : Constante Dielétrica do vácuo }\left(8,854 \times 10^{-12} \mathrm{~F} / \mathrm{m}\right) \\
& \text { A: área dos eletrodos e } \\
& \text { D: espessura (distância entre os eletrodos). }
\end{aligned}
$$

Assim para efeito da análise, os dados das propriedades alvo dessa TESE, Constante Dielétrica e Fator de Dissipação serão calculados conforme Equação 18 e 19 respectivamente:

$$
\begin{aligned}
& \varepsilon \text { (constante dielétrica) }: \frac{C^{\prime} \times d}{\varepsilon_{0} A} \\
& T_{g} \delta\left(\text { fator de dissipaçao ou perda: } \frac{C^{\prime \prime}}{C^{\prime}}\right.
\end{aligned}
$$


Um ponto importante para essa propriedade é correlacionar os valores de constante dielétrica e fator de dissipação com a premissa básica do trabalho, ou seja, um novo sistema isolante que substitui o papel de mica pela mica sililada para uso no hidrogerador para trabalho acima de 3000 volts $/ \mathrm{mm}$.

No caso da constante dielétrica e fator de dissipação é normatizado pela ASTM D150 [198] como metodologia para aprovação de isolantes, sendo padronizado a condição de $1000 \mathrm{Hertz}$ a $25^{\circ} \mathrm{C}$ em equipamentos de média e alta tensão e $60 \mathrm{Hertz}$ a $25^{\circ} \mathrm{C}$ para equipamentos com uso até 1000 volts. Nesse caso, será usado a frequência de 1000 Hertz para comparar os protótipos usados nesse projeto, o qual além de atender o uso em média e alta tensão evitará que medidas feitas a 60 Hertz tenham o efeito da rede elétrica que abastece o equipamento.

Em termos de especificação, para uso como isolante elétrico, é considerado como ideal que o isolante tenha no máximo um valor de 30 para a constante dielétrica [199].

Para o fator de perda, será considerado como referência o parâmetro que se tem para as medidas quando se usa a fita de mica impregnada com resina epóxi. Hoje, para máquinas elétricas que fazem uso desse sistema é encontrado um fator de perda de 0,5 a 0,6 [7, 199].

\subsection{Termogravimetria (TGA)}

O ensaio de TGA foi realizado no Laboratório da empresa AFINKO em São Carlos, utilizando o TGA 50 da Shimadzu (Figura 73), com uma faixa de temperatura de 25 a $800^{\circ} \mathrm{C}$ sob atmosfera de nitrogênio (50 ml/min) com um tempo total de aquisição de dados de 40 minutos/amostra. 
Figura 73 - TGA 50 Shimadzu.

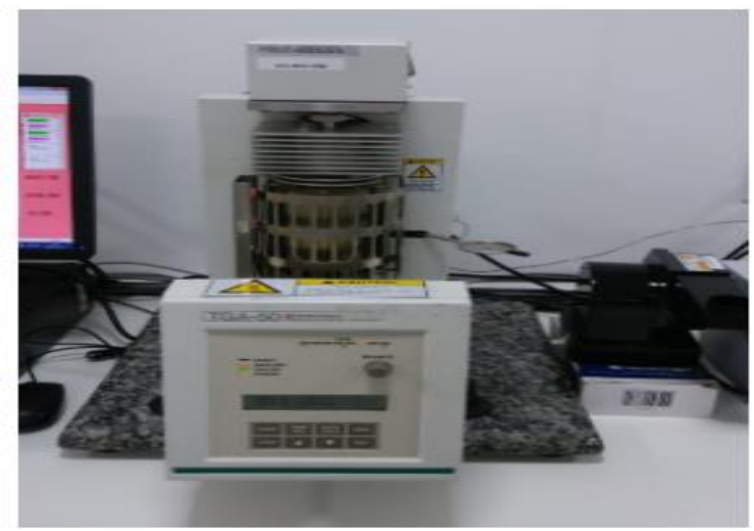

Fonte: elaborado pelo próprio autor, 2019.

Para a análise de TGA, foram confeccionadas amostras com dimensões de 2,5 x 2,5 mm, conforme recomendado por Yee e Stephens (1996) [200]. Esta técnica propicia obter dados referentes às alterações que o aquecimento pode provocar na massa de materiais em análise, permitindo com isso estabelecer a faixa de temperatura em que elas adquirem composição fixa, definida e constante. Obtém-se também a temperatura em que a amostra começa a se decompor, além de possíveis reações de desidratação, oxidação e decomposição [201].

\subsection{Análise Dinâmico-Mecânico (DMA)}

Os ensaios termomecânicos foram realizados no Grupo de Materiais Funcionais Avançados (MAFA) do Departamento de Física da Universidade Federal de São Carlos em colaboração com o professor Paulo Sergio da Silva Jr. Utilizando-se um equipamento Perkin Elmer DMA8000, operando no modo amplitude constante, para uma única frequência e geometria "single cantilever".

O objetivo desta caracterização termoanalítica foi obter as informações de viscoelasticidade dos materiais em estudo, o que permite analisar a mobilidade dos segmentos de cadeia, tais como temperatura de transição vítrea, caracterização de ligações cruzadas, comportamento de endurecimento e amolecimento e também transições de segunda ordem em geral [32, 194,202]. Para identificar a temperatura de transição vítrea de matrizes poliméricas termorrígidas com grande quantidade de ligações cruzadas, ou mesmo alta fração volumétrica em cargas, este método é o mais indicado, por apresentar maior sensibilidade de detecção quando comparado ao teste de calorimetria diferencial exploratória DSC [203]. A 
análise dinâmico-mecânica (DMA) consiste na aplicação de uma tensão mecânica oscilante de baixa amplitude que interage com o material resultando na absorção de energia mecânica resultante de processos internos. A absorção de energia mecânica pelo material em análise é caracterizada pela não instantaneidade na resposta da deformação mecânica ao estímulo aplicado, que resulta na defasagem entre a tensão aplicada e a deformação exibida pelo material [204]. A grande vantagem da análise dinâmico-mecânica sobre outras formas de testes mecânicos é o regime de carregamento periódico, de baixa amplitude, bem definido que é usado. Uma tensão periódica normalmente senoidal é aplicada na amostra e a deformação resultante é medida, esta medição considera a amplitude dos sinais e a diferença de fases entre elas [205]. Outra vantagem está relacionada a varredura de temperatura e de frequência que podem ser realizadas, permitindo a obtenção de informações mais detalhadas da dependência e que pode ser visto um valor de módulo cada vez que uma onda de seno é aplicada, permitindo fazer varredura usando faixa de temperatura ou frequência [206].

No DMA, a tensão e a deformação são resolvidas em componentes em fase e fora de fase, então definindo o módulo de armazenamento real e o módulo de perda ou imaginário [206]. A proporção de deformação que está em fase com a tensão aplicada representa a energia elástica armazenada e é recuperável (módulo de armazenamento). Enquanto a parte da deformação $90^{\circ}$ fora de fase está associada ao processo de absorção de energia (módulo de perda). Outro parâmetro de grande relevância nas caracterizações por DMA é o tan $\delta$, que é designado como a fração de energia mecânica perdida por ciclo de carga, ou seja, é a razão entre o módulo de perda e o módulo de armazenamento, também sendo este parâmetro denominado de módulo de amortecimento ou atrito interno do material, sendo uma manifestação macroscópica da absorção de energia mecânica por processos internos no material. A essência das medidas de DMA está na baixa amplitude da tensão aplicada, resultando em uma resposta não destrutiva do material, assim em ambos os casos, os módulos de Young são medidos na região linear (elástica) do material. A diferença é que pela curva Tensão deformação, se obtém o módulo de Young estático, enquanto no DMA se determina o módulo de Young dinâmico, sendo que na maioria das vezes o módulo dinâmico é mais preciso que o estático, sendo de grande relevância em aplicações que requerem esforços dinâmicos no material [206]. A Figura 74 mostra a aplicação de força no DMA é os sinais medidos. 
Figura 74 - Sinais Gerados e Medidos no DMA [206].

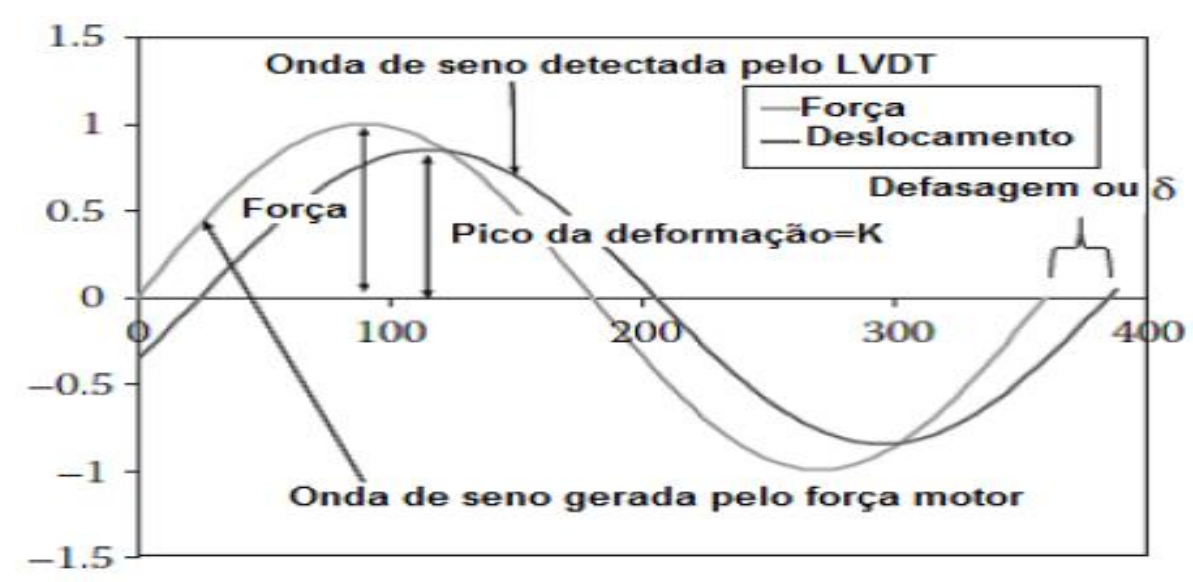

Fonte: Figura extraída de MENARD. K. P.; Dynamics Mechanical Analysis: a practical introduction. Boca Raton: 2008.

O DMA utiliza a medida de ângulo de fase e amplitude do sinal para calcular o amortecimento, $\tan \delta$, e a constante de mola, K. A partir desses valores, os módulos de armazenamento (E') e de perda (E') são calculados. As relações entre as componentes do módulo elástico de rigidez complexo $\left(\mathrm{E}^{*}\right)$ e a defasagem ( $\delta$ ) é apresentada na Figura 75.

Figura 75- Relações das componentes através do uso do ângulo de fase [206].

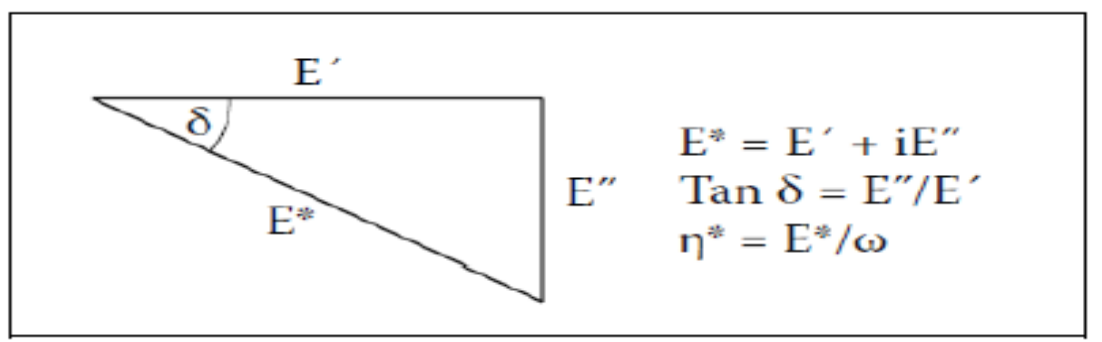

Fonte: Figura extraída de MENARD. K. P.; Dynamics Mechanical Analysis: a practical introduction. Boca Raton: 2008.

No caso específico deste projeto, utilizamos a geometria "single cantilever", representada esquematicamente pelas Figuras 76 e 77, que permite a aplicação de tensões mecânicas de flexão ao material em estudo, em razão das premissas usadas serem a de obter polímero que pudessem endereçar um melhor comportamento elástico que o sistema epóxi [5]. 
Figura 76 - Diagrama esquemático da geometria de medida "Single Cantilever".

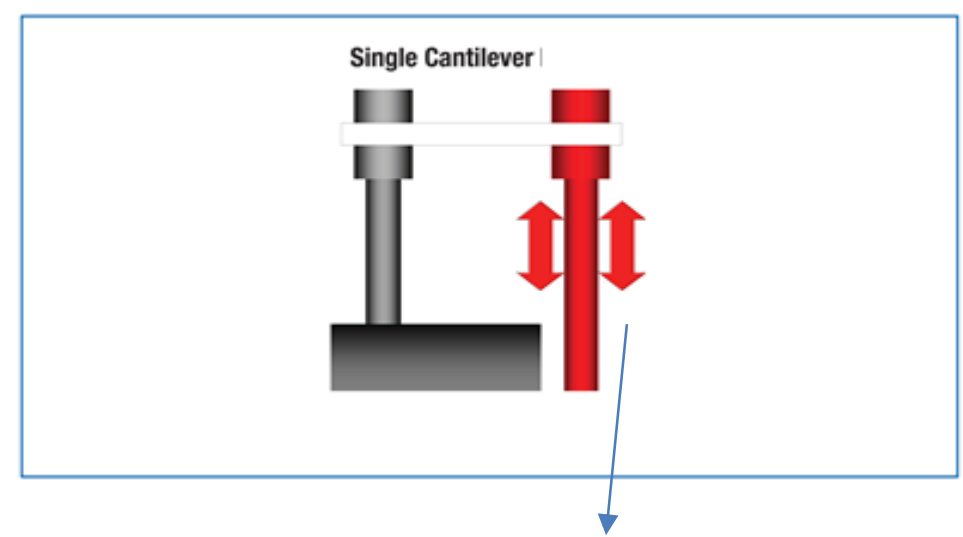

Nota: a amostra é fixada nas garras e sofre o esforço de dobramento.

Fonte: Figura extraída do catálogo DMA Perkin Elmer 8000.

As condições de teste das amostras foram:

a) Temperatura inicial: $-15^{\circ} \mathrm{C}$.

b) Temperatura final: $180^{\circ} \mathrm{C}$

c) Taxa de aquecimento: $2,0{ }^{\circ} \mathrm{C} / \mathrm{min}$.

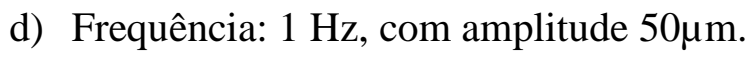

Figura 77 - Amostra inserida no equipamento de DMA (single cantlever).

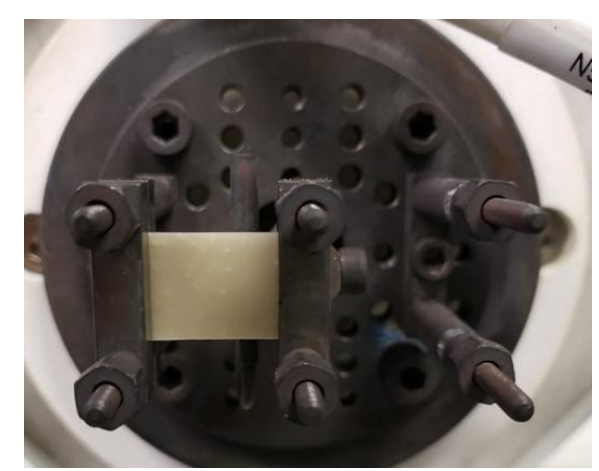

Fonte: elaborado pelo próprio autor, 2019.

\subsection{Análise térmica de Calorimetria Exploratória Diferencial (DSC)}

A calorimetria exploratória diferencial (DSC) é uma técnica utilizada para medir a diferença de energia entre uma amostra e um material de referência em função de um programa de aquecimento ou resfriamento sob atmosfera controlada. Essa técnica determina a temperatura de fusão e cristalização; entalpias de fusão e cristalização bem como na 
determinação de transição vítrea. Em resumo, o DSC mede a variação de energia em função da temperatura e/ou tempo. Esses eventos térmicos geram modificações nas curvas do DSC podendo ser transições de primeira ou de segunda ordem. As transições de primeira ordem apresentam variações de entalpia, endotérmica ou exotérmica e dão origem a formação de picos. Exemplo de eventos endotérmicos são, fusão, perda de massa, dessorção e reações de redução. Eventos exotérmicos podem ser, cristalização, reações de polimerizações ou cura. Essas transições caracterizam pela variação de capacidade calorífica, porém sem variações de entalpia. A Figura 78 ilustra os eventos que ocorrem em uma análise DSC [89].

Figura 78 - Eventos que são observados em uma análise DSC [89].

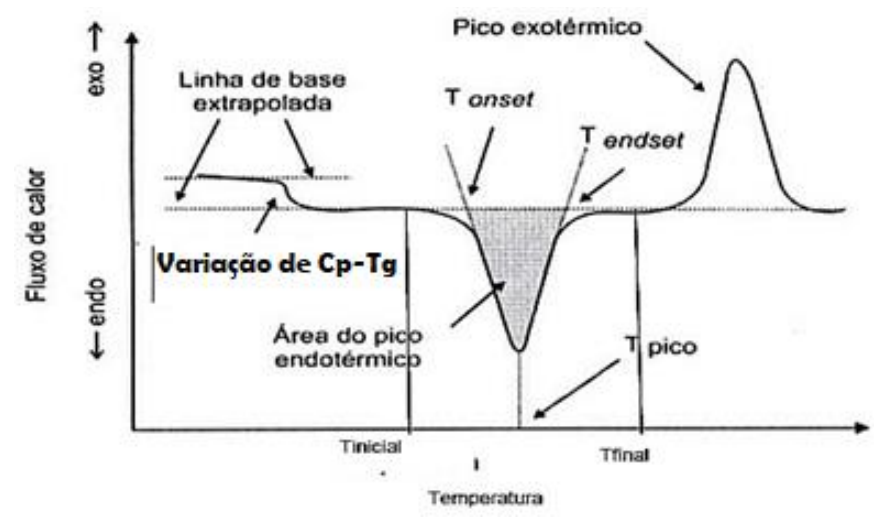

Fonte: Figura extraída CANEVAROLO JR, S, V.; Ciência dos Polímeros-Texto Básico para Tecnólogos e Engenheiros, São Paulo (2002).

\subsubsection{Uso do DSC para Determinação de Cura.}

O ensaio de DSC foi realizado no equipamento DSC8000 Tipo 8500 da Perkin Elmer do Departamento de Engenharia de Materiais da USP-São Carlos em colaboração com o Professor Antônio José Félix. Essa técnica tem como finalidade buscar a temperatura que ocorre a cura dos protótipos obtidos e na segunda curva obter com exatidão a Tg [207].

As condições de teste das amostras foram:
a) Temperatura inicial: $25^{\circ} \mathrm{C}$
b) Temperatura final: $200{ }^{\circ} \mathrm{C}$

c) Rampa de aquecimento: $10^{\circ} \mathrm{C} / \mathrm{min}$

d) Manutenção de 1 min a $200{ }^{\circ} \mathrm{C}$ e resfriamento a taxa de $10^{\circ} \mathrm{C} / \mathrm{min}$

e) Repetição da segunda curva iniciando a: $25^{\circ} \mathrm{C}$ taxa de $10^{\circ} \mathrm{C} / \mathrm{min}$ até $200^{\circ} \mathrm{C}$ 


\subsubsection{Calorimetria Exploratória Diferencial (DSC)}

O ensaio de DSC para avaliação do comportamento térmico dos protótipos foi realizado no Laboratório da empresa AFINKO em São Carlos sob contrato de prestação de serviço, com o equipamento DSC Shimadzu 60. Utilizou-se as condições abaixo com atmosfera de nitrogênio (50 $\mathrm{ml} / \mathrm{min})$ :

a) Temperatura inicial: $25^{\circ} \mathrm{C}$ (Para os protótipos epóxi e HNIPU)

b) Temperatura final: $200^{\circ} \mathrm{C}$

c) Rampa de aquecimento: $10^{\circ} \mathrm{C} / \mathrm{min}$

d) Manutenção de 1 min a $200^{\circ} \mathrm{C}$ e resfriamento a taxa de $10^{\circ} \mathrm{C} / \mathrm{min}$

e) Repetição da segunda curva iniciando a: $25^{\circ} \mathrm{C}$ taxa de $10^{\circ} \mathrm{C} / \mathrm{min}$ até $200^{\circ} \mathrm{C}$

Para os protótipos NIPU, a temperatura inicial foi $-10^{\circ} \mathrm{C}$.

\subsection{Análise de Nanoindentação}

O ensaio de Nanoindentação foi realizado no equipamento Nanovea PB 100 utilizando o nanoindentador de forma piramidal Berkovich, Figura 79, do Departamento de Engenharia de Materiais da USP-São Carlos sob contrato de prestação de serviço com o Professor Haroldo Cavalcanti Pinto.

O ensaio foi realizado com o indentador Bergovich (Pirâmide de base triangular) para a medida de dureza, conforme Figura 80. Para cada amostra, 5 pontos, separados por uma distância média de $15 \mu \mathrm{m}$ foram medidas com uma carga de $30 \mathrm{mN}$, sendo calculados a dureza média e o desvio padrão, além dos dados de módulo elástico.

Figura 79 - Indentador Berkovich.

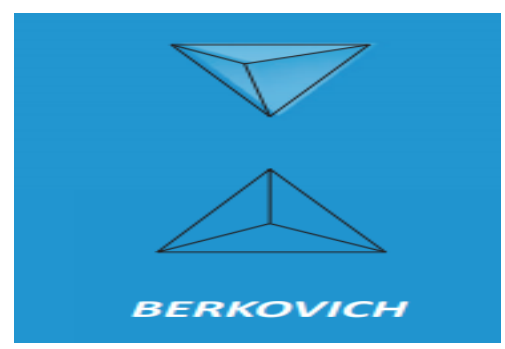

Fonte: Imagem extraída do site da Nanovea www.nanovea.com/brochures. 
O principal objetivo de medidas de Nanoindentação é a determinação da dureza $H$ e do módulo de elasticidade $E$ dos protótipos referência (epóxi) e sua comparação com aqueles obtidos utilizando a rota com NIPU e com a HNIPU (DGEBA/NIPU com terminação amina). Durante a obtenção dos protótipos os materiais utilizando a rota NIPU, o material ficou extremamente frágil, sendo facilmente fraturado com o simples contato manual. Vê se na Nanoindentação uma técnica que possibilita, mesmo para materiais com essa condição um estudo comparativo de propriedades mecânicas [208].

Para fins de medida de dureza, uma força (carga) $P$ é aplicada a um indentador (um ponta de diamante com uma determinada forma) em contato com a superfície da amostra (Fig. 80). Geralmente, isto é feito em três etapas. Inicialmente, a carga é aplicada com uma taxa pré-determinada até atingir um valor máximo $P_{\max }$. Feito isto, a força é mantida constante por um determinado intervalo de tempo permitindo assim a acomodação do material. Em uma última etapa, a carga é controladamente retirada e o indentador removido da amostra.

Figura 80 - Representação esquemática de uma indentação com uma ponta piramidal.

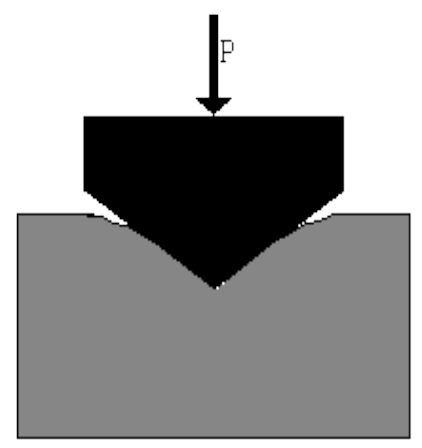

Fonte: elaborado pelo próprio autor, 2019.

Durante todo o processo de indentação a profundidade de penetração da ponta é medida em função de $P$. Quando a carga é removida do indentador, o material tende a retornar à sua forma original $($ Fig.81 c). Todavia, muitas vezes ele é impedido de fazê-lo devido a deformações plásticas sofridas durante o processo de aplicação da carga (Fig.81 a). Entretanto, devido à relaxação das tensões elásticas no material, pode ocorrer um certo grau de recuperação (Fig.81 b). A análise desta recuperação elástica após a retirada da carga fornece uma estimativa do módulo de elasticidade da amostra [209]. 
Figura 81 - Curvas de carga e descarga em materiais a) totalmente plásticos, b) elasto -plásticos e c) totalmente elásticos [209].
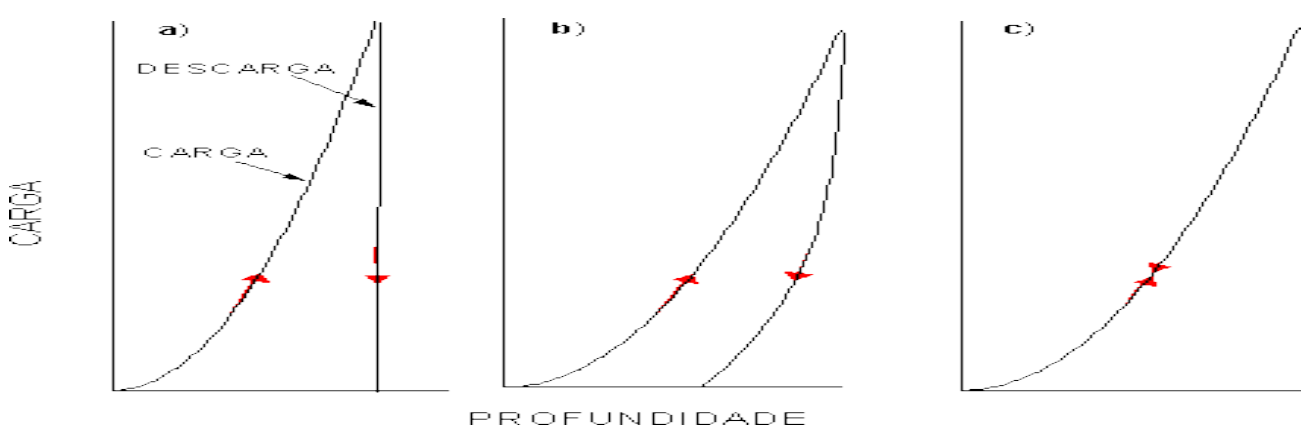

Fonte: Figura extraída de OLIVER, W.C and G.M. Pharr, J. Mat. Res. 1992.

A Dureza H do material é determinada pela divisão entre a máxima carga, Pmáx, pela área de contato A do indentador no ponto de máxima carga conforme a equação 20 abaixo.

$$
H=\frac{P \max }{A}
$$

Para um Nanoindentador de geometria ideal conforme a figura 77 a área projetada de contado pode ser determinada a parte da penetração, hc, na máxima carga Pmax conforme a equação 21 abaixo:

$$
A=C_{0} \cdot h c^{2}
$$

Onde temos que:

$\mathrm{C}_{\mathrm{o}}$ : é uma constante conforme o nanoindentador usado, no caso do modelo piramidal Berkovich, o valor será de 24,5.

H: diferente do h máx, o hc leva em consideração a deformação elástica que ocorre na região da ponta do nanoindentador conforme a Figura 82.

Figura 82 - típica curva de Nanoindentação com carga e recuperação [209].
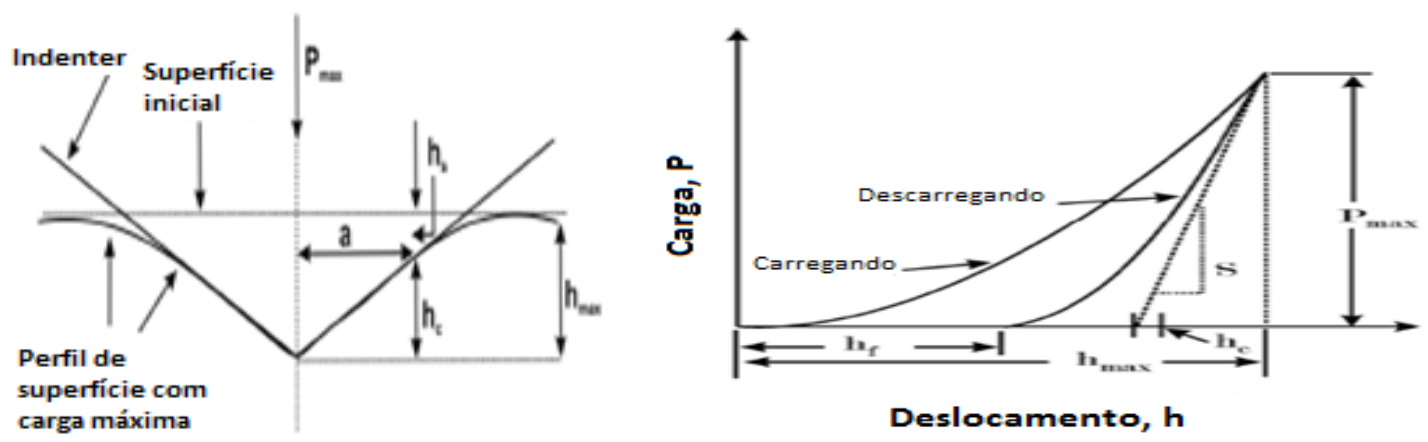

Fonte: Figura extraída de TIWARI, A.; Nanomechanical analysis of Hybrid silicones and Hybrid epoxy coatings, Advances in Chemical Engineering and Science, 2012. 
Sendo que a penetração de contato hc é dada pela equação 22:

$$
h_{c}=h_{\max }-\varepsilon \frac{P_{\max }}{S}
$$

Onde temos que:

S: representa a rigidez do material que pode ser calculada a partir da inclinação da curva de recuperação na carga máxima aplicada.

$\mathcal{E}=$ é uma constante para o nanoidentador piramidal Berkovich, equivale a 0,75 .

Para calcular o módulo elástico, basicamente se usa como parâmetro valores de uma referência, normalmente quartzo. Considerando que S máximo é obtida partir da curva carga aplicada pela penetração, assumindo que o módulo elástico do quartzo é constante, a área projetada de contato A pode ser obtida conforme a equação 23 abaixo [209].

$$
A=\left(\frac{\pi}{4}\right)\left(\frac{S_{\max }}{E_{r}}\right)^{2}
$$

Sendo o $\mathrm{E}_{\mathrm{r}}$ o módulo elástico reduzido, o qual ocorre em ambos, no nanoidentador e na amostra em avaliação. A partir desses dados pode ser obter o módulo elástico do material a ser avaliado, o equipamento possui um software que procede aos cálculos fornecendo os dados de carga, penetração, módulo elástico e dureza.

\subsection{Fractografia via Microscopia eletrônica de varredura (MEV)}

As fotomicrografias de MEV foram obtidas na Central de Análises Químicas Instrumentais do Instituto de Química de São Carlos (CAQI/IQSC/USP) em um equipamento ZEISS LEO 440 (Cambridge, England) com detector OXFORD (model 7060), operando com feixe de elétrons de $15 \mathrm{kV}$, corrente de 2,82A e I probe de $200 \mathrm{pA}$. As amostras foram recobertas com 6nm de ouro em um metalizador Coating System BAL-TEC MED 020 (BAL$T E C$, Liechtenstein) e mantidas em dessecador até o momento de análise. Condições de metalização: pressão na câmara $=2,00 \times 10^{-2} \mathrm{mbar}$; corrente $=60 \mathrm{~mA}$; taxa de deposição $0,60 \mathrm{~nm} / \mathrm{s})$. 
Uma das ideias iniciais foi o protótipo após o ensaio térmico de DMA ter uma fratura e esse material ser usado para caracterização de imagem via MEV e EDS. Não houve a fratura no DMA, com isso o material que sofreu o estresse térmico, foi colocado em uma máquina Universal de Ensaios Mecânicos (INSTRON) e fez-se o esforço até que houvesse sua ruptura, sendo esse o protótipo que foi usado para análise de imagem

\subsection{Espectroscopia de Emissão de Raios X com detecção Dispersiva em Energia} (EDS)

A espectroscopia emissão de raios X com detecção em energia dispersiva (EDS) foi realizada na Central de Análises Químicas Instrumentais do Instituto de Química de São Carlos (CAQI/IQSC/USP) em um equipamento EDX LINK ANALYTICAL, (Isis System Series 300), com detector de SiLi Pentafet, janela ultrafina ATW II (Atmosphere Thin Window), de resolução de $133 \mathrm{eV}$ à $5,9 \mathrm{keV}$ e área de $10 \mathrm{~mm}^{2}$ quadrado, acoplado a um Microscópio Eletrônico ZEISS LEO 440 (Cambridge, England). Utilizou-se padrão de Co para calibração, feixe de elétrons de $15 \mathrm{kV}$, distância focal de $25 \mathrm{~mm}$, dead time de $30 \%$, corrente de 2,82A e I probe de 2,5nA. Os mapas composicionais dos elementos químicos presentes foram adquiridos com 50 frames. 


\section{RESULTADOS E DISCUSSÕES}

\subsection{Avaliação da Mica sem tratamento superficial e Tratada superficialmente}

com APTS

Nesta etapa buscou comprovar a existência dos grupos funcionais provenientes do tratamento com aminossilano na superfície da mica conforme Figura 83, utilizando as técnicas de análise elementar e XPS.

Figura 83 - Grupos Funcionais de aminossilano presentes na superfície sililada.

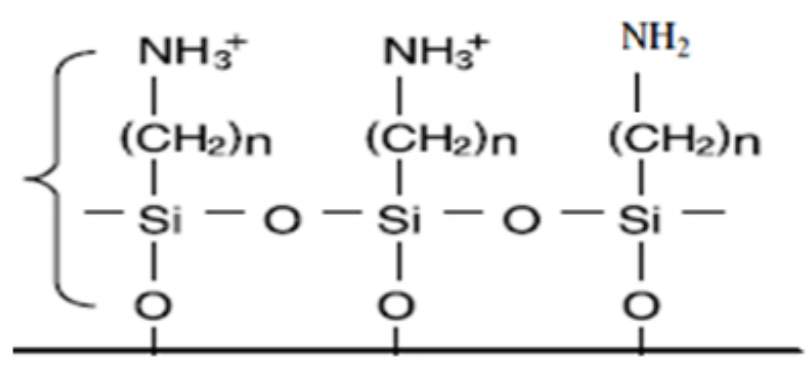

Fonte: elaborado pelo próprio autor, 2019.

a) Análise Elementar

Na Tabela 21, têm se os dados provenientes dessa técnica, onde a identificação mica pura se refere ao material sem tratamento superficial, enquanto mica sililada é o material que sofreu o tratamento com $1 \%$ de aminossilano (APTS) e sobre o qual se espera a presença de grupos nitrogenados na superfície. Uma informação importante é que ambos os materiais são provenientes do mesmo lote de produção de mica.

Tabela 21 - Resultado com os materiais alvo, principalmente Nitrogênio proveniente do grupamento amina presente no aminossilano.

\begin{tabular}{|l|r|l|l|}
\hline Amostra & \% Carbono & \% Hidrogênio & \multicolumn{2}{|l|}{ \% Nitrogênio } \\
\hline Mica Pura & 0,31 & 0,46 & 0,06 \\
\hline & 0,26 & 0,56 & 0,22 \\
\hline
\end{tabular}

Fonte: elaborado próprio autor. 2018

Média aritmética dos resultados de análise de duplicatas de cada composição. 
b) XPS. (Espectroscopia de Foto Elétrons por emissão de Raio X).

Na Tabela 22 e Figura 84 temos as percentagens obtidas nos espectros de fotoemissão em baixa resolução em energia representativa obtidos por meio de XPS para cinco áreas de cada amostra de mica pura e tratada (sililada).

Tabela 22- Composição superficial em percentagem atômica obtidos por meio de XPS (5 pontos/amostra).

\begin{tabular}{|c|c|c|c|c|c|c|c|}
\hline Samples & Al \% & C \% & Ca \% & K \% & N \% & 0 \% & Si \% \\
\hline \hline Mica Pura & 9.5 & 4.8 & 0.1 & 0.5 & 0.7 & 67.7 & 16.7 \\
\hline Mica Pura & 9.7 & 5.2 & 0.1 & 0.5 & 0.4 & 67.4 & 16.7 \\
\hline Mica Pura & 9.3 & 4.9 & 0.2 & 0.6 & 0.4 & 68.4 & 16.2 \\
\hline Mica Pura & 9.5 & 5.2 & 0.1 & 0.5 & 0.5 & 67.5 & 16.6 \\
\hline Mica Pura & 9.6 & 4.9 & 0.1 & 0.5 & 0.3 & 67.8 & 16.8 \\
\hline Mica Tratada & 8.3 & 11.6 & 0.2 & 0.5 & 2.9 & 60.6 & 15.8 \\
\hline Mica Tratada & 8.3 & 11.5 & 0.2 & 0.5 & 3.0 & 60.5 & 16.1 \\
\hline Mica Tratada & 8.8 & 10.3 & 0.1 & 0.5 & 2.9 & 61.0 & 16.4 \\
\hline Mica Tratada & 8.4 & 12.0 & 0.0 & 0.3 & 2.2 & 60.8 & 16.3 \\
\hline Mica Tratada. & 8.5 & 11.0 & 0.1 & 0.3 & 2.2 & 61.4 & 16.6 \\
\hline
\end{tabular}

Fonte: Elaborado próprio autor 2017

Pode se ver na tabela 21 e Figura 84 uma pequena queda no alumínio e no silício com o aumento no carbono e no nitrogênio, evidencia que existem grupos aminossilano na superfície da mica. 
Figura 84 Comparativo de concentração das espécies presentes na superfície da mica tratada com aminossilano e sem tratamento.
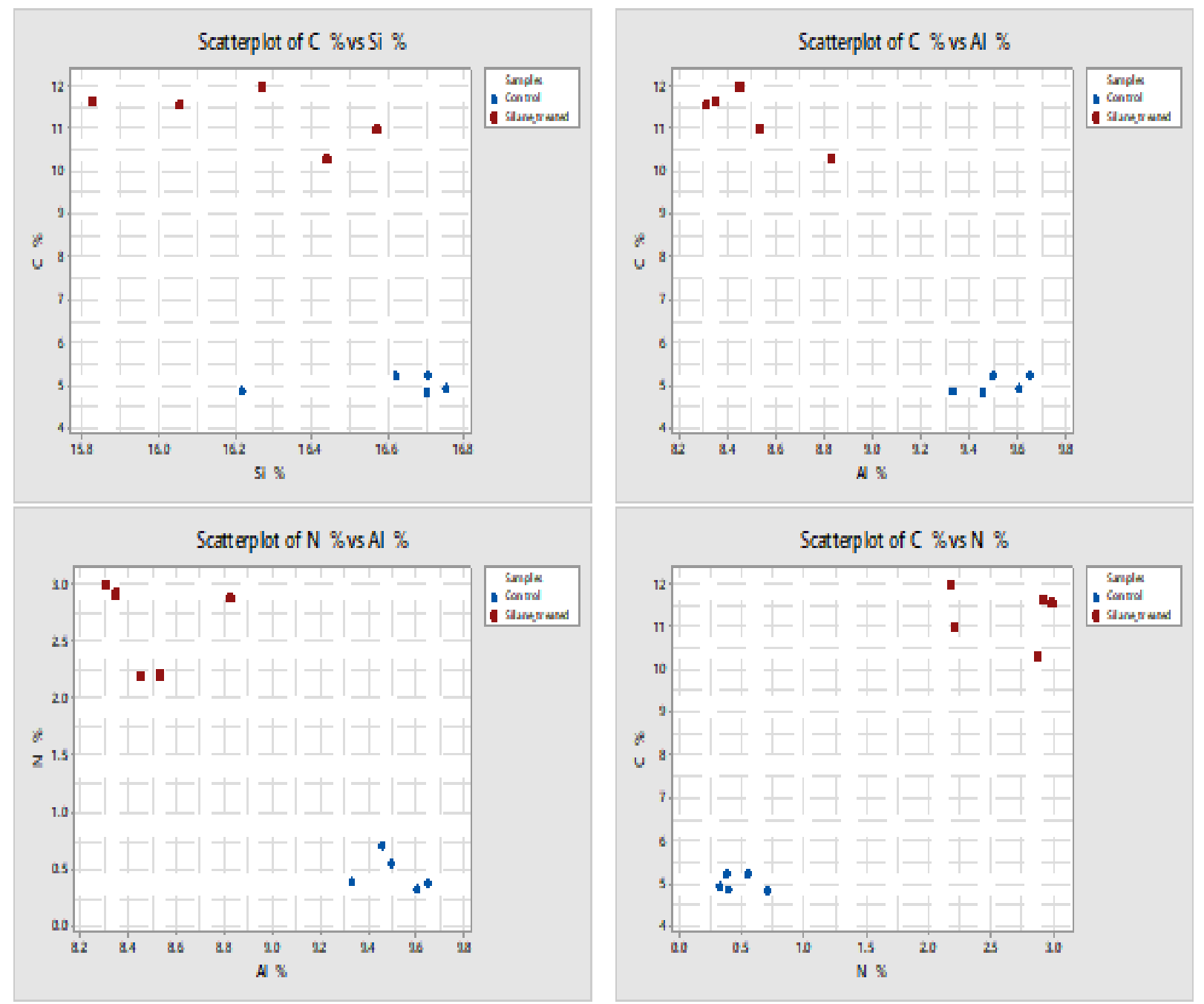

Fonte: Elaborado próprio autor 2017 
Figura 85 - Espectros de fotoemissão em baixa resolução de energia obtidos via XPS da Mica sem sililação (azul) e com sililação (vermelho). Os picos fotoelétricos mais relevantes estão marcados assim como o pico Auger O KLL.

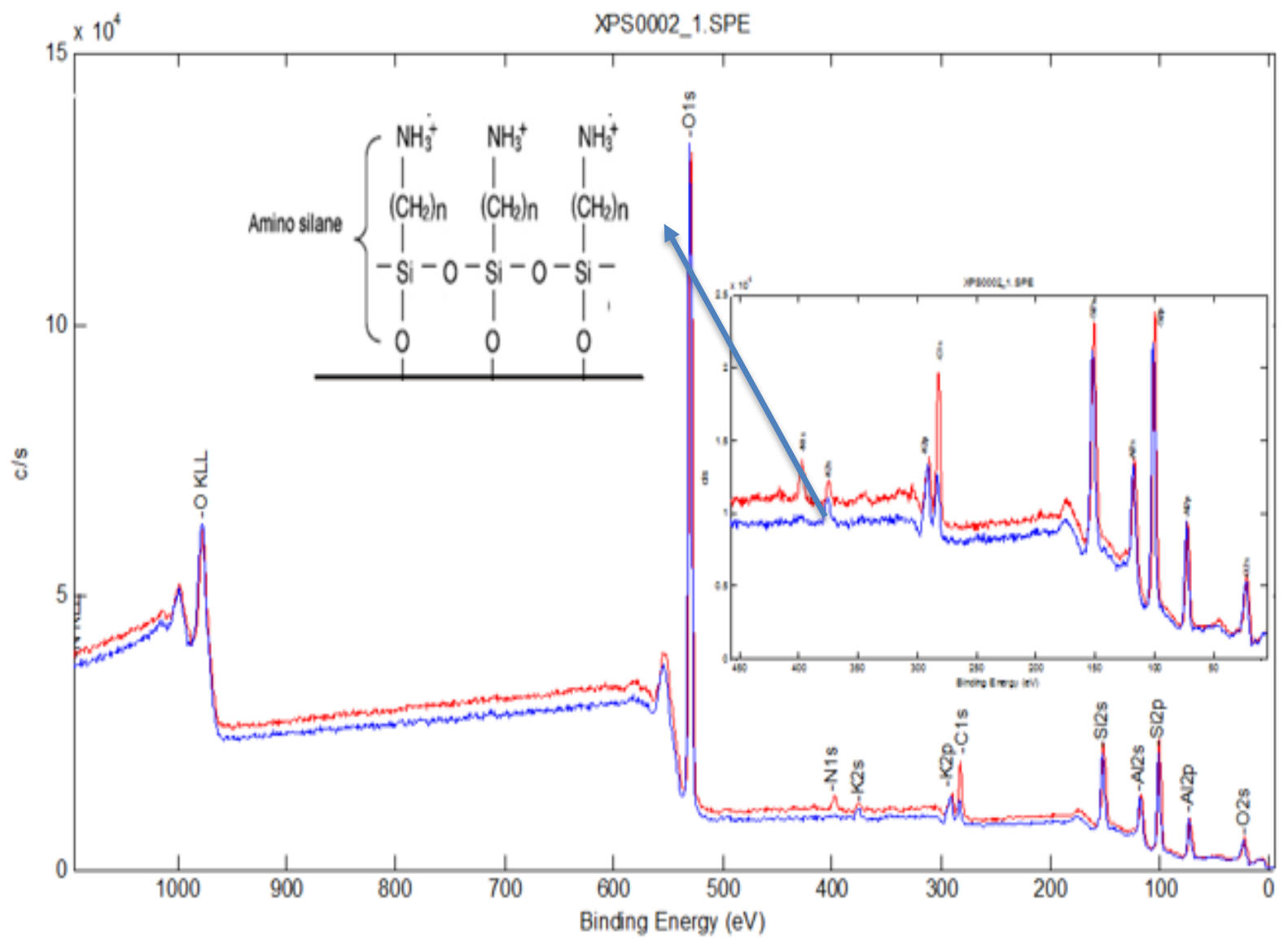

Fonte: elaborado pelo próprio autor, 2017.

A grande diferença entre os espectros de fotoelétrons excitados por Raios $\mathrm{X}$ da amostra sililada para a amostra não-sililada é a presença do pico fotoelétrico N1s na amostra sililada, Figura 85. As razões atômicas dos elementos majoritários nas duas amostras são mostradas de forma comparativa na Tabela 21. Assim como no espectro em baixa resolução em energia, a presença do grupo nitrogenado fica comprovada pela maior percentagem atômica do $\mathrm{N}$ na amostra mica sililada.

Comentários Iniciais: Vê se pelos dados obtidos que a mica usada nesse projeto apresenta evidências da presença de grupamentos amino proveniente do silano usado, um aminossilano. Para futura abordagens, uma técnica que pode ser implementada é o uso do composto Ninidrina, o qual tem a capacidade de reagir com aminas livres mudando a coloração para azul escuro ou roxo. Será uma técnica complementar àquela usada nesse projeto de TESE. [210]. 


\subsection{Avaliação dos Protocolos de Síntese de Ciclocarbonato}

Com o uso da espectroscopia de infravermelho, figura 86, pode-se confirmar a conversão das oxiranas (anel epóxi) em ciclocarbonatos com anéis de cinco membros, após reação com dióxido de carbono, pois, a banda correspondente ao modo vibracional da ligação $\mathrm{C}=\mathrm{O}$ do grupo carbonila do ciclocarbonato pode ser observada em torno de $1800 \mathrm{~cm}^{-1}$ [211] e a ausência de bandas das oxiranas com vibração de $1250 \mathrm{~cm}^{-1}$ e $910 \mathrm{~cm}^{-1}$. Além do uso do infravermelho, utilizou-se os testes de titulação via ácido perclórico e análise de RMN de ${ }^{1} \mathrm{H}$. A premissa inicial desenhada foi obter na síntese uma conversão de oxirano em ciclocarbonato acima de $80 \%$ para posterior obtenção de NIPU e HNIPU.

\section{Síntese 1}

A Figura 86 apresenta o espectro do reagente DGEBA, EPON286 (826), e do ciclocarbonato obtido a partir dele pela reação de cicloadição de $\mathrm{CO}_{2}$. O espectro do produto de cicloadição evidencia a formação de ciclocarbonato pela presença da banda em $1800 \mathrm{~cm}$ ${ }^{-1}$ atribuída ao grupo carbonila deste grupo funcional, assim como simultaneamente, pelo desaparecimento das bandas de oxirano em torno de $910 \mathrm{~cm}^{-1}[115]$

Figura 86 - Espectro de absorção na região do infravermelho médio para o protocolo da síntese de ciclocarbonato de DGEBA (EPON 826) usado apenas catalisador (TEBA) e sem solvente. Temperatura 150 ${ }^{\circ} \mathrm{C}$; Pressão $10 \mathrm{Atm}$, sem uso de solvente com 24 horas de reação.

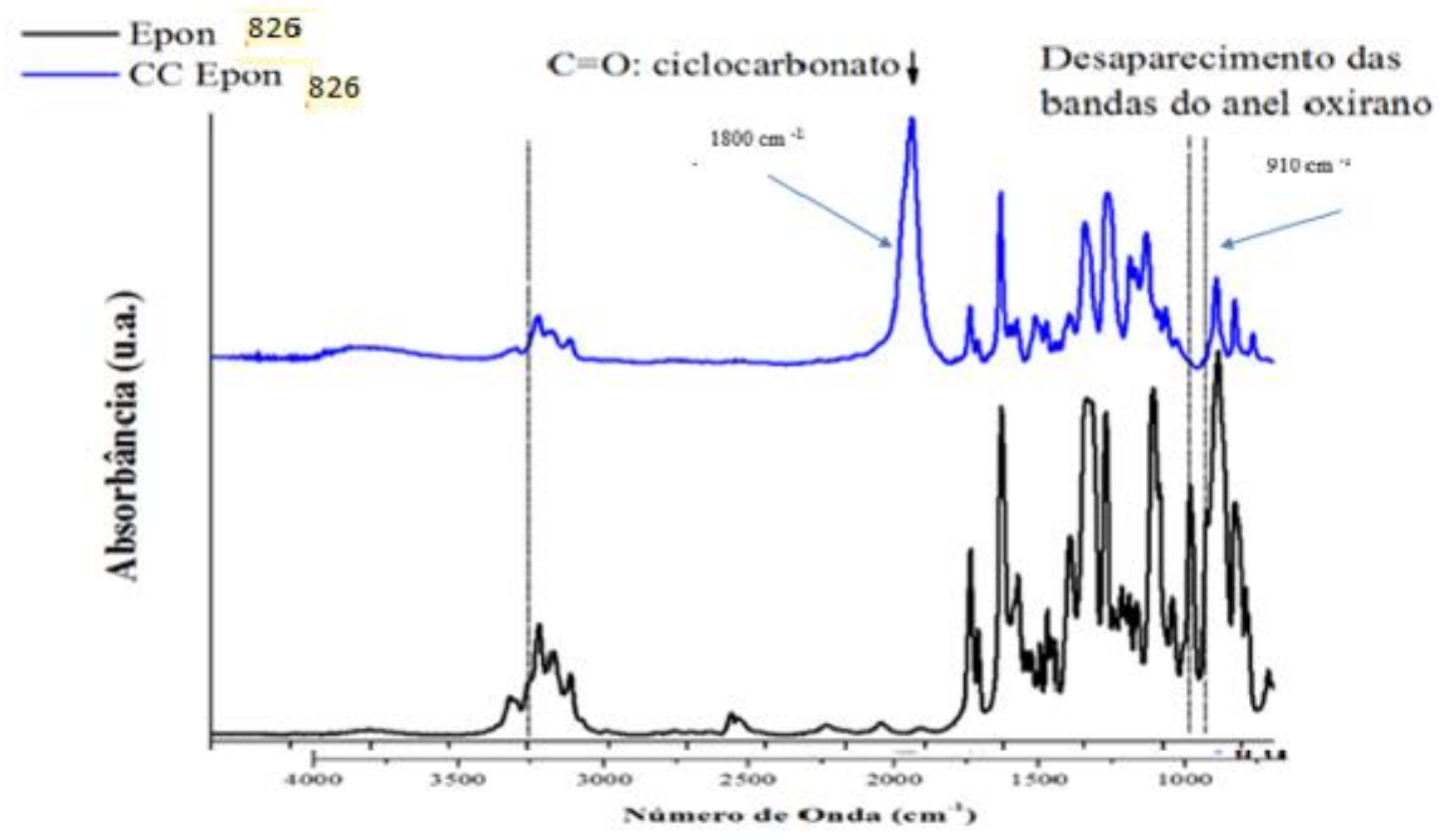

Fonte: elaborado pelo próprio autor, 2016. 
Tendo em vista que a aplicação deste protocolo, dito síntese 1, levou ao endurecimento total do ciclocarbonato dentro do reator, pois a síntese foi realizada sem o uso de solvente e com alta temperatura e pressão, adotou-se um novo protocolo sintético. Neste novo protocolo, dito síntese 2 , buscou-se reduzir a temperatura e trabalhar à pressão atmosférica.

\section{Síntese 2}

A Figura 87 apresenta o espectro do reagente DGEBA, EPON826, e do ciclocarbonato obtido a partir dele pela reação de cicloadição de $\mathrm{CO}_{2}$ em função do tempo de reação. O espectro do produto de cicloadição evidencia a formação de ciclocarbonato pela presença da banda em $1800 \mathrm{~cm}^{-1}$ atribuída ao grupo carbonila deste grupo funcional que crescem em função do tempo. Realizando o cálculo de rendimento baseado na ISO 3001 1978 [188] titulação com ácido perclórico, obteve-se após 8h de reação um rendimento de 24,3\%. Tal rendimento foi considerado insatisfatório diante da premissa básica de ter um rendimento acima de $80 \%$, portanto, novos protocolos foram planejados.

Figura 87 - espectro de absorção na região do infravermelho médio para o protocolo 2 de síntese de ciclocarbonato de DGEBA usado apenas catalisador (TEBA) com tempos de reação entre 4 e $8 \mathrm{~h}$.

Temperatura $100{ }^{\circ} \mathrm{C}$; Pressão atmosférica, sem uso de solvente com 24 horas de reação.

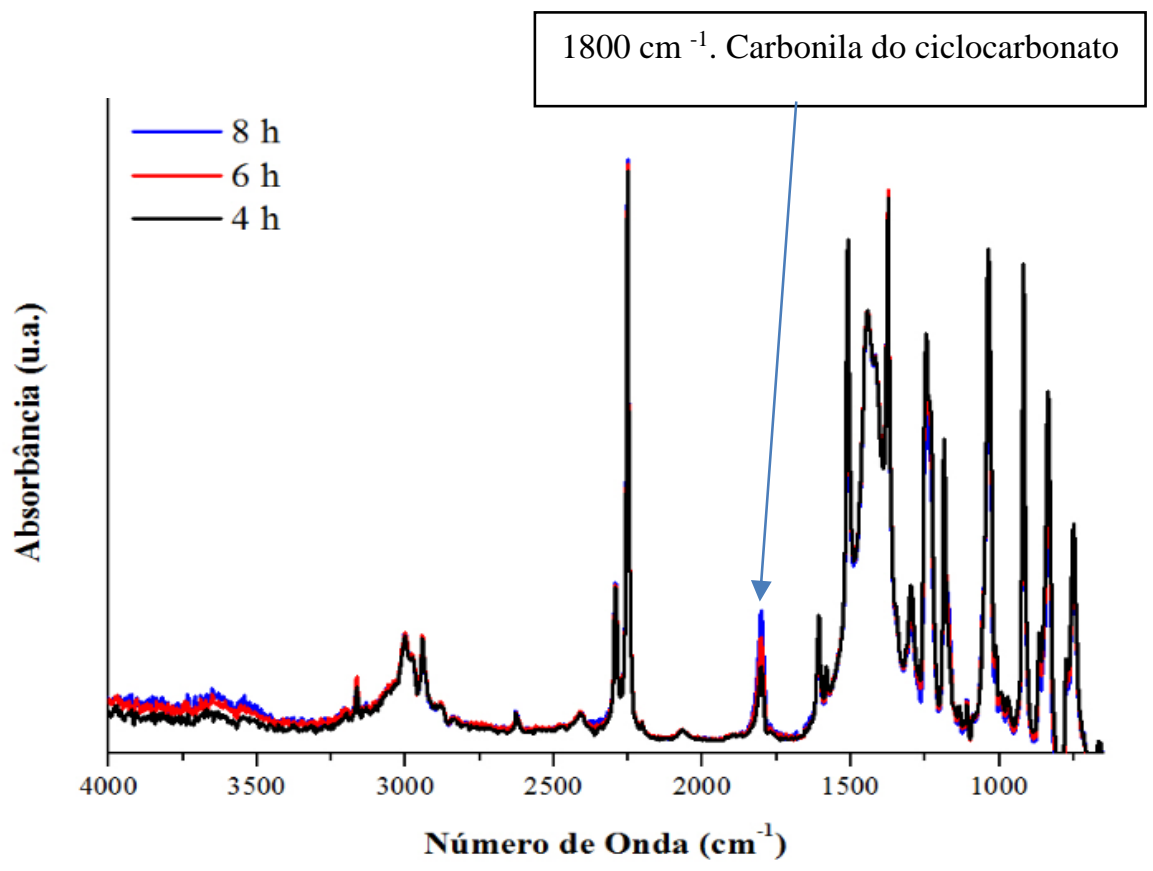

Fonte: elaborado pelo próprio autor, 2016. 
a) Síntese 3 e 4 .

Uma das formas de aumentar o rendimento no mesmo tempo de reação é a utilização de co-catalisadores de metais de transição. Baseado no executado por Lopes, utilizou-se como co-catalisador o Resinato de zinco[ 10]. A Figura 88 mostra para o mesmo tempo de reação os espectros dos ciclocarbonatos obtidos usando-se co-catalisador, traço vermelho, e sem cocatalisador, traço preto. Baseado na área da banda da carbonila do ciclocarbonato em torno de $1800 \mathrm{~cm}^{-1}$ nota-se que o uso do co-catalisador causa um aumento no rendimento da conversão. No protocolo 3, via titulação com ácido perclórico houve uma conversão de $45 \%$ enquanto no protocolo 4 uma conversão de $76 \%$ de oxirano em ciclocarbonato, próximo do alvo de $80 \%$ para a obtenção de NIPUs e HNIPUs.

Figura 88 - Espectro de absorção na região do infravermelho médio para o protocolo 3 e 4 de síntese de ciclocarbonato de DGEBA usado apenas catalisador (TEBA) e usando catalisador TEBA e co-catalisador Resinato de Zinco). Protocolo 3: Temperatura $120^{\circ} \mathrm{C}$, Pressão Atmosférica, Tempo de reação 24 horas. Protocolo 4: Temperatura $150{ }^{\circ} \mathrm{C}$, Pressão Atmosférica, Tempo de reação 24 horas.

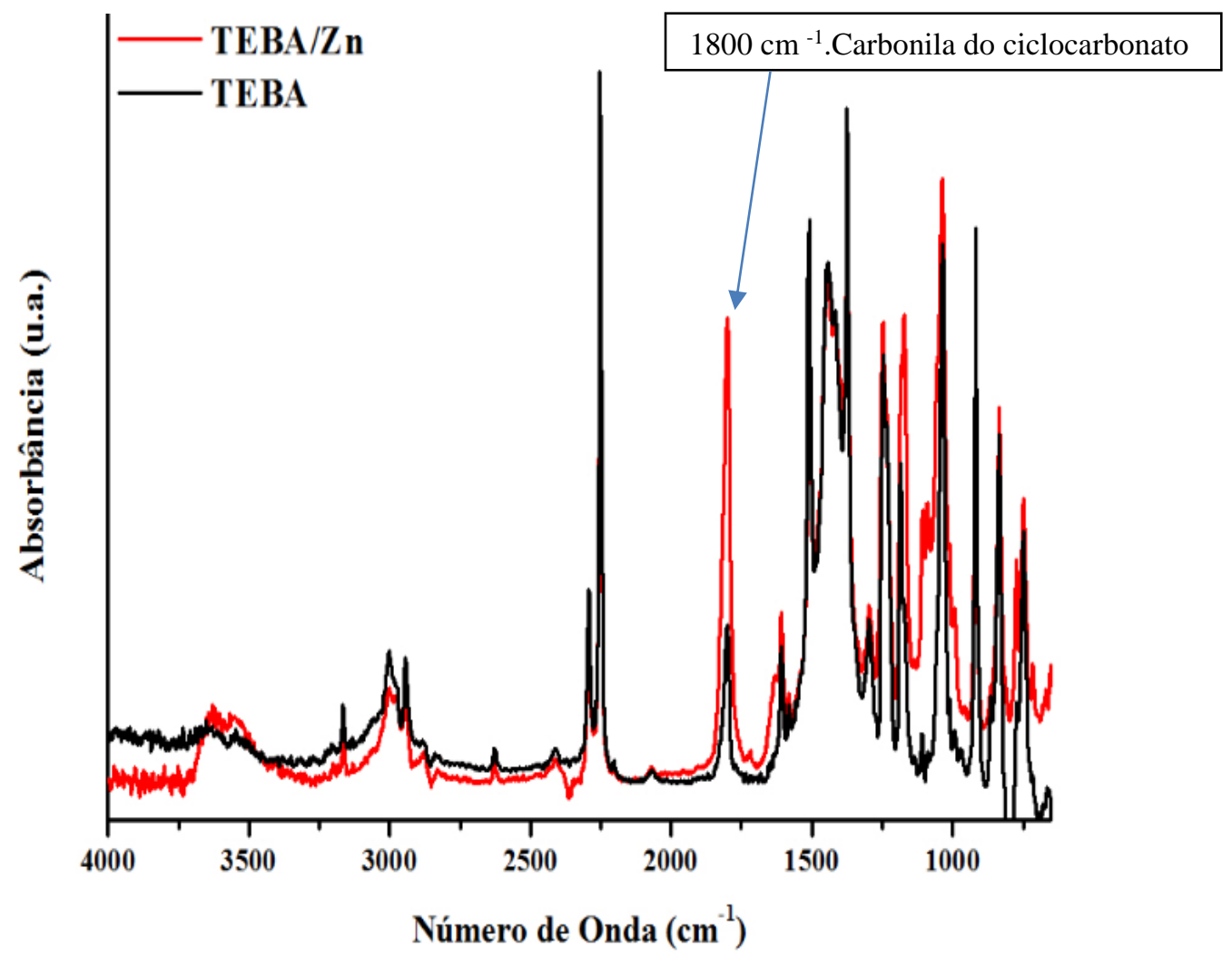

Fonte: elaborado pelo próprio autor, 2016. 
Este aumento de temperatura no processo de síntese, conjugado com o uso do cocatalisador aumentou o rendimento de reação de $45 \%$ para $76 \%$ baseado na titulação com ácido perclórico. No intuito de confirmar estes dados e a estrutura molecular do ciclocarbonato, foram obtidos espectros de RMN de $\mathrm{H}^{1}$. Os espectros de $\mathrm{RMN}$ de ${ }^{1} \mathrm{H}$, apresentados na Figura 89, mostraram sinal dos prótons $h$ e $i$ na região 4,8 a 5,05 ppm, e também analisando a região de 3,03 ppm do oxirano (grupamento característico do DGEBA), precursor da síntese.

Figura 89 - Espectro de RMN H${ }^{1}$ com evidências da formação de ciclocarbonato.

Legenda da Figura: Cor Preta DGEBA (precursor da síntese); cor verde protocolo 2 (catalisador TEBA, Pressão Atmosférica temperatura $100{ }^{\circ} \mathrm{C}$ e sem solvente com tempo de reação de 24 horas); cor vermelha protocolo 3 (catalisador TEBA, co-catalisador Resinato de Zinco, Temperatura $120^{\circ} \mathrm{C}$ Pressão Atmosférica e sem solvente com tempo de reação de 24 horas), cor lilás protocolo 4 (catalisador TEBA, co-catalisador Resinato de Zinco Temperatura $150^{\circ} \mathrm{C}$ e pressão atmosférica).
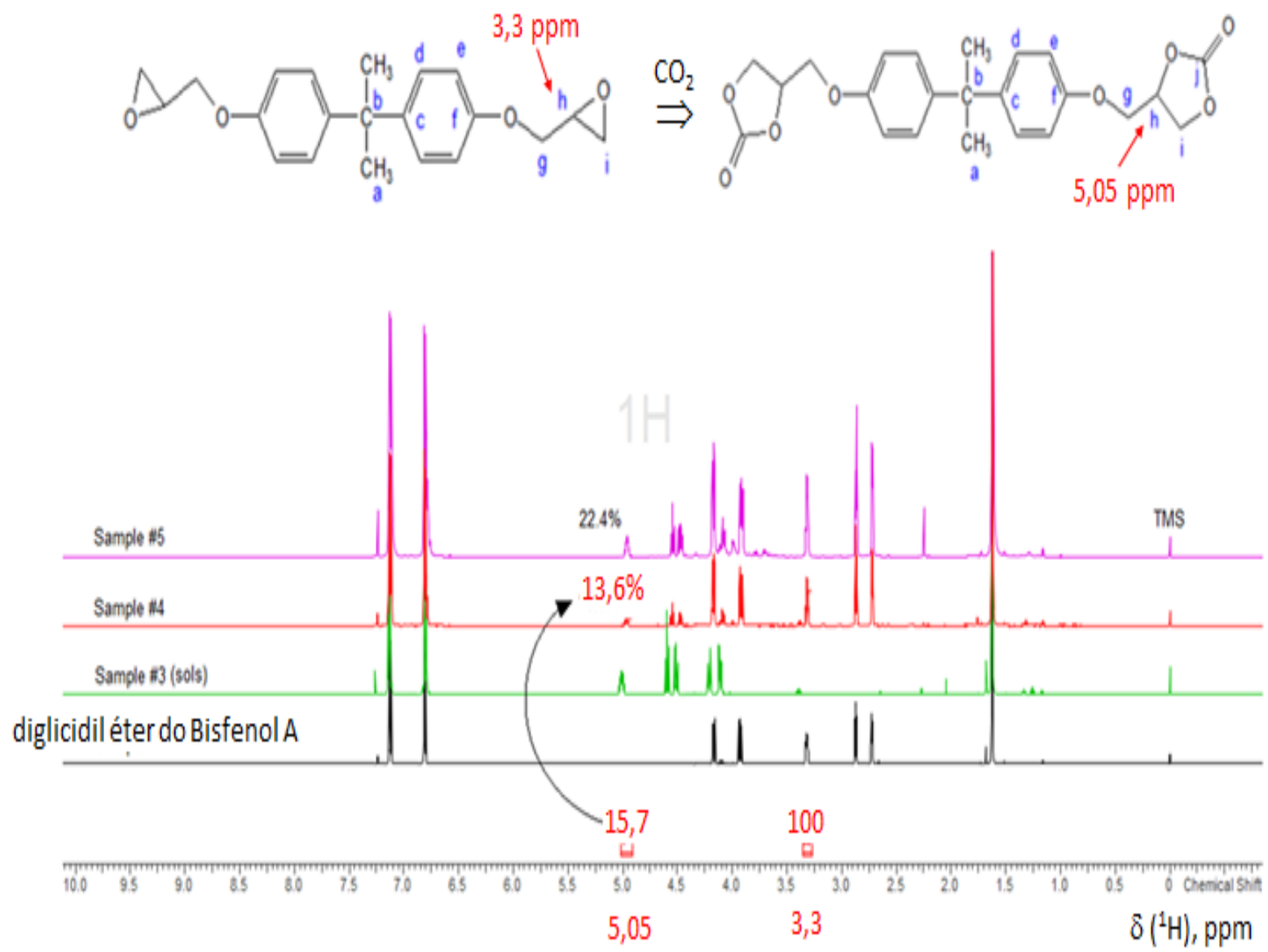

Fonte: elaborado pelo próprio autor, 2016.

Pelo RMN encontrou-se uma conversão de epóxi em ciclocarbonato de $22,45 \%$ no protocolo 4 de síntese, sendo refeito a titulação encontrou-se 30,4\% de conversão 
evidenciando a necessidade de se melhorar a síntese para atingir o objetivo de conversão em ciclocarbonato de $80 \%$.

\section{a) Síntese 5, 6 e 7.}

Nas sínteses 5 a 7, trabalhou-se com os parâmetros: a) tipo de catalisador, b) temperatura. Como podemos ver na Tabela 23 em nenhuma destas atingiu-se o objetivo de conversão acima de 80\%. Nas sínteses 5, 6 e 7 trabalhou se com Pressão Atmosférica.

Tabela 23 - Sínteses usando co-catalisador.

\begin{tabular}{|l|l|l|l|r|}
\hline Sínteses & Catalisador & Co-catalisador & Temp/tempo & Conversão via Titulação \\
\hline Síntese 05 & TEBA 1\% & $\mathrm{NbCl}_{5} 0,1 \%$ & $150^{\circ} \mathrm{C} / 4$ horas & $44 \%$ \\
\hline Síntese 06 & TEBA 1\% & $\mathrm{NbCl}_{5} 0,1 \%$ & $\begin{array}{l}120^{\circ} \mathrm{C} / 10 \\
\text { horas }\end{array}$ & $28 \%$ \\
\hline Síntese 07 & TEBA 1\% & TEA 0,1\% & $\begin{array}{l}120^{\circ} \mathrm{C} / 4 \\
\text { horas }\end{array}$ & $29 \%$ \\
\hline
\end{tabular}

Fonte: elaborado pelo próprio autor, 2016.

\section{a) Sínteses 8 e 9.}

Nessa síntese (tabela 24) a única diferença entre ambas é o tipo de Resina Epóxi utilizada. Síntese 8 usou-se Epon 826 e na síntese 9 o Epon 828, em ambas as formulações foi utilizado uma mistura de solvente ( 2 etil etanol + metil pirolidona), uma forma de evitar que houvesse com temperatura e pressão o endurecimento dentro do reator. Trabalhou se em ambas com uma pressão no reator de 7 atm.

EPON 826 (DGEBA): 178 a 186 gramas/equivalente.

EPON 828 (DGEBA): 185 a 192 gramas/equivalente

Tabela 24 - Dados síntese 8 e 9.

\begin{tabular}{|l|l|l|l|r|}
\hline Síntese & Catalisador & co-catalisador & Temp/tempo & Conversão via Titulação \\
\hline Síntese 8 (Epon 826 & TEBA 1\% & $\mathrm{ZnCl}_{2} 0,1 \%$ & $120{ }^{\circ} \mathrm{C} / 24$ horas & $97 \%$ \\
\hline Síntese 9 (EPON 828) & TEBA 1\% & $\mathrm{ZnCl}_{2} 0,1 \%$ & $120{ }^{\circ} \mathrm{C} / 24$ horas & $97, \%$ \\
\hline
\end{tabular}

Fonte: elaborado pelo próprio autor, 2016. 
Devido a excelente conversão obtida pela técnica de volumetria, realizou-se novo teste de RMN de ${ }^{1} \mathrm{H}$ como contraprova aos dados obtidos por titulação, além de verificar a estrutura química obtida da conversão do oxirano em ciclocarbonato (Figura 90).

Figura 90 - RMN para confirmação da conversão de oxirano em ciclocarbonato.

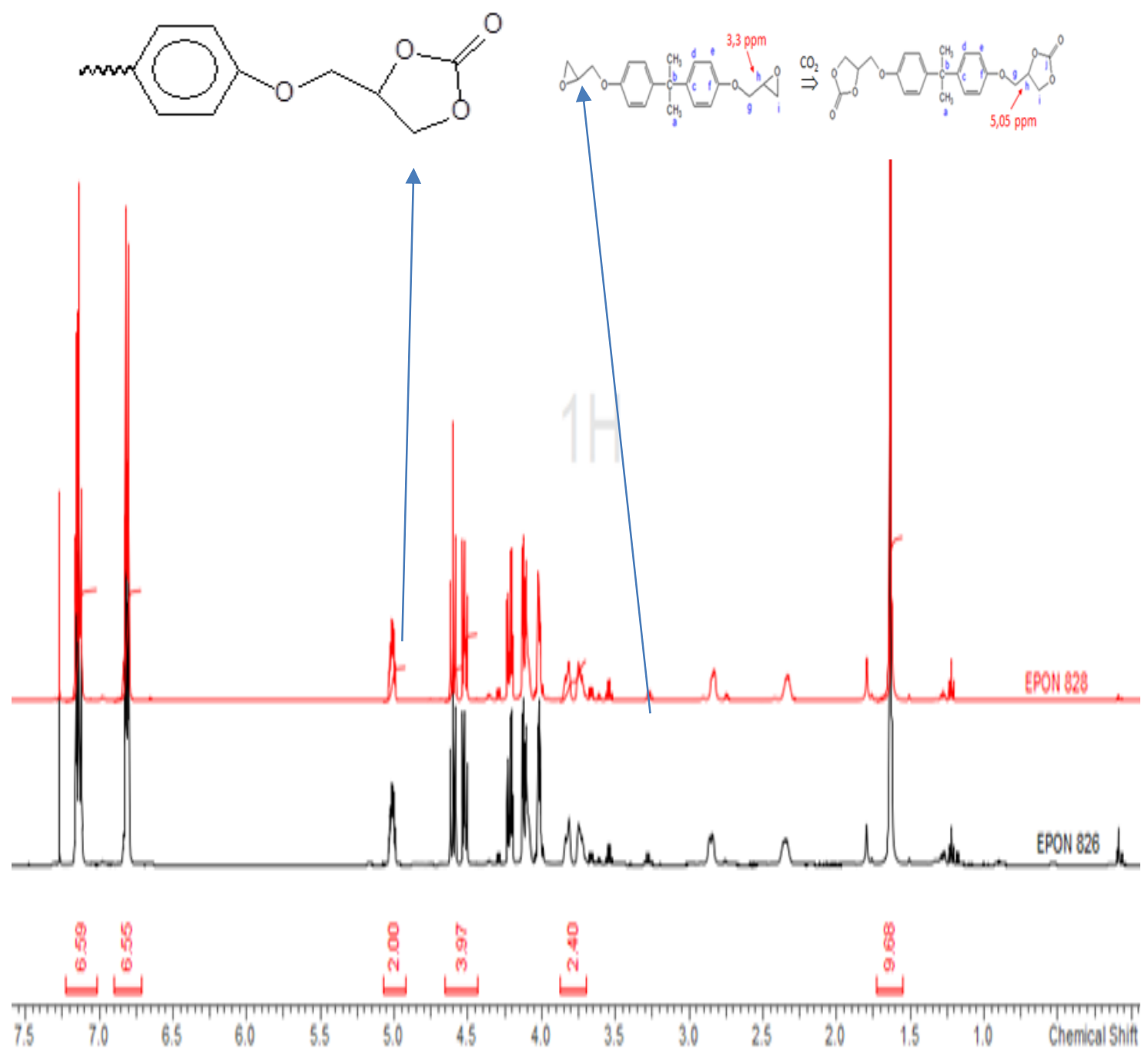

Fonte: elaborado pelo próprio autor, 2016.

Obteve-se via RMN uma conversão de 95\%, confirmando os dados já obtidos por titulação, em 4,8 a 5,05 ppm vemos o aparecimento do ciclocarbonato e praticamente desaparecimento do pico em 3,3 ppm proveniente do grupamento oxirano. Esses valores são coerentes com o teste de titulação (onde se encontrou 97\% de conversão) e com a premissa de obter ciclocarbonato com conversão acima de $80 \%$ para atender os objetivos da tese.

Optou-se pela escolha do DGEBA EPON 828, o qual tem melhor disponibilidade comercial e como a síntese se faz em meio solvente, a maior viscosidade desse monômero 
não terá impacto no meio reacional, além do que nos dados analíticos não apresentou vantagens o uso do EPON 826.

Tabela 25: Síntese para Obtenção dos Protótipos para os testes finais da NIPU e HNIPU.

\begin{tabular}{|l|l|l|l|l|}
\hline DGEBA & & & & \\
\hline & Catalisador & Co catalisador & Temp./tempo & Conversão via Titulação \\
\hline & & & & \\
EPON 828 & TEBA 1\% & $\mathrm{ZnCl}_{2} 0,1 \%$ & 120 ㅇ $/ 24$ horas & \\
\hline
\end{tabular}

A síntese final (Tabela 25$)$ foi feita usando a mistura solvente $(15 \mathrm{ml}$ de 2 etóxietanol + $10 \mathrm{ml}$ de metilvinilpirilidona para cada 20 gramas de DGEBA) no reator de aço inoxidável da PAR Instruments conforme Figura 91.

Figura 91 - Reator usado para síntese de Ciclocarbonato.

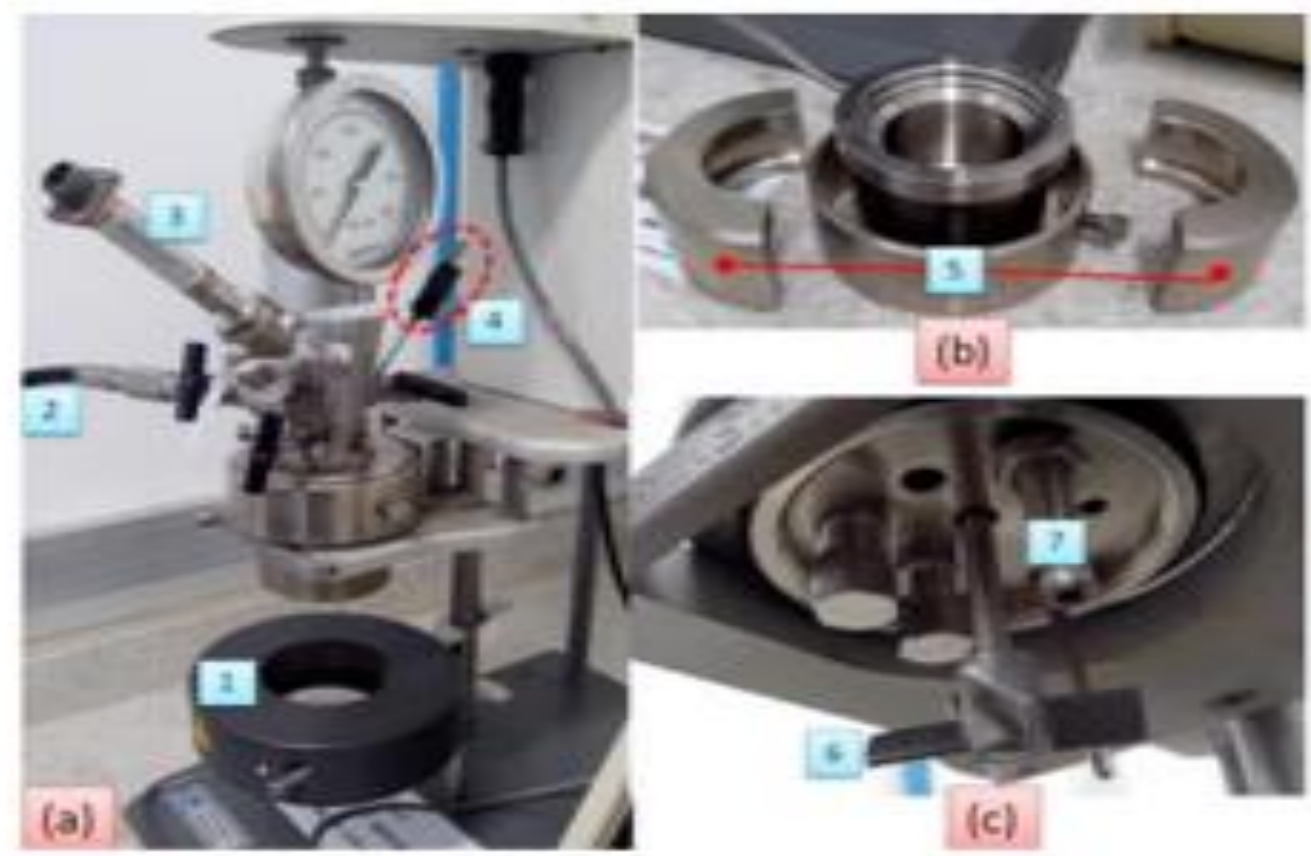

Fonte: elaborado pelo próprio autor, 2018.

Onde temos:

a) reator montado com manta de aquecimento, manômetro, mangueiras de gases e dispositivos de monitoramento.

b) reator aberto com visão interna e suporte de segurança. 
c) sistema de leitura e agitação com pás a $45^{\circ}$.

A remoção de solvente foi executada utilizando um rotaevaporador IKA modelo RV10 a $130^{\circ} \mathrm{C}$ e $200 \mathrm{~mm} \mathrm{Hg}$ de pressão. Após evaporação do solvente, o ciclocarbonato de DGEBA (CCDGEBA) obtido foi lavado com água destilada para extração do cloreto de zinco e TEBA e em seguida filtrado em filtro de papel. Sendo seco por 24 horas a $80^{\circ} \mathrm{C}$ e posteriormente usando nitrogênio sólido, foi triturado para facilitar seu uso nas sínteses de NIPU e HNIPU

Na amostra obtida, Figura 92 testou-se a conversão também por infravermelho, onde vimos o aparecimento da banda de ciclocarbonato em $1800 \mathrm{~cm}^{-1}$.

Figura 92 - Espectro de FTIR da amostra de CCDGEBA usada na síntese dos protótipos de NIPU e HNIPU que serão usados nos ensaios de propriedades Químicas, mecânicas, elétricas, térmicas e morfológicas.

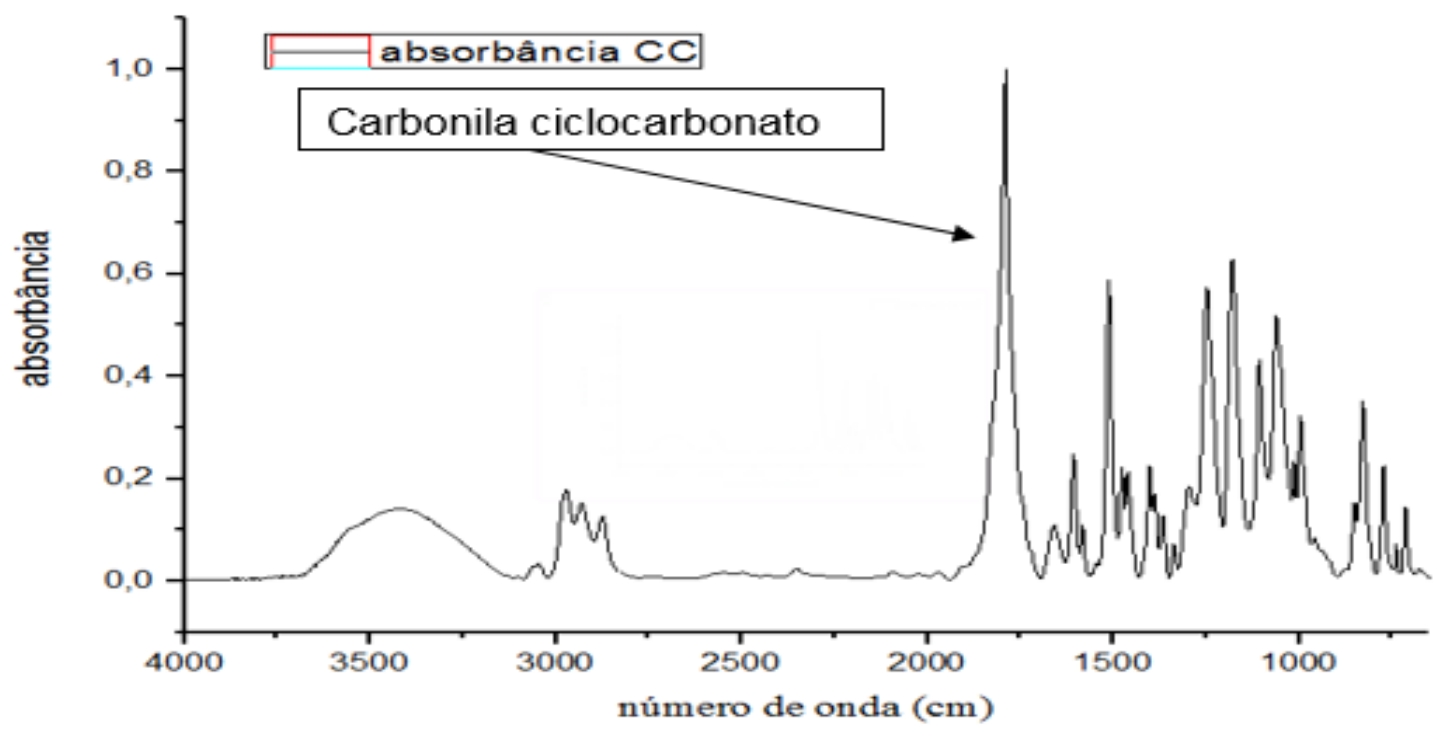

Fonte: elaborado pelo próprio autor, 2018.

Comentários Iniciais: Pode se concluir nesse ponto que o protocolo para obtenção de ciclocarbonato usando rota do $\mathrm{CO}_{2}$ atendeu totalmente os requisitos. Obteve-se uma conversão extremamente alta de oxirano (epóxi) em ciclocarbonato. A escolha do DGEBA EPON 828 foi baseado por ser o material atualmente mais usado para a finalidade alvo da TESE, a diferença de peso molecular entre a EPON 828 e a 826 e de apenas 20 gramas/mol, sendo que por ser feito em meio solvente a menor viscosidade do EPON 826 não impactaria na síntese, fato confirmado na própria conversão. 


\subsection{Avaliação dos protótipos Epóxi /NIPU Parâmetros de Cura.}

\subsubsection{Obtenção dos Parâmetros de Cura via DSC}

a) Protótipo DGEBA/TETA razão molar 1:1. (Figuras 93e 94)

No caso do sistema epóxi, foi observado que usando os parâmetros rampa $10^{\circ} \mathrm{C} / \mathrm{min}$, de 25 a $200{ }^{\circ} \mathrm{C}$ no DSC foi possível observar o início da cura pelo formato da curva. O evento corresponde a um pico exotérmico (liberação de calor). Em termos de faixa de temperatura, a cura do sistema inicia-se em torno $60{ }^{\circ} \mathrm{C}$ e finaliza em $100{ }^{\circ} \mathrm{C}$ nas condições desse experimento calorimétrico, Figuras 93 e 94. Em tempo, no segundo ciclo térmico, ou seja, após a cura foi possível observar a $\mathrm{T}_{\mathrm{g}}$ do polímero formado. As curvas equivalentes para $\mathrm{o}$ compósito com mica sililada são mostrados nas Figuras 95 e 96 . A presença da mica aumenta a temperatura de transição vítrea do sistema de $76,8^{\circ} \mathrm{C}$ (sem a mica) para $104,7^{\circ} \mathrm{C}$ com a incorporação da mica sililada. Importante, em todos os experimentos foi mantido a percentagem em massa de $40 \%$ em peso de mica. Se houve alteração significativa da $\mathrm{T}_{\mathrm{g}}$ obtida por DSC, não percebemos alteração da temperatura inicial de cura em função da presença da mica.

Figura 93 - Curvas de calorimetria exploratória diferencial da mistura DGEBA: TETA (1:1).

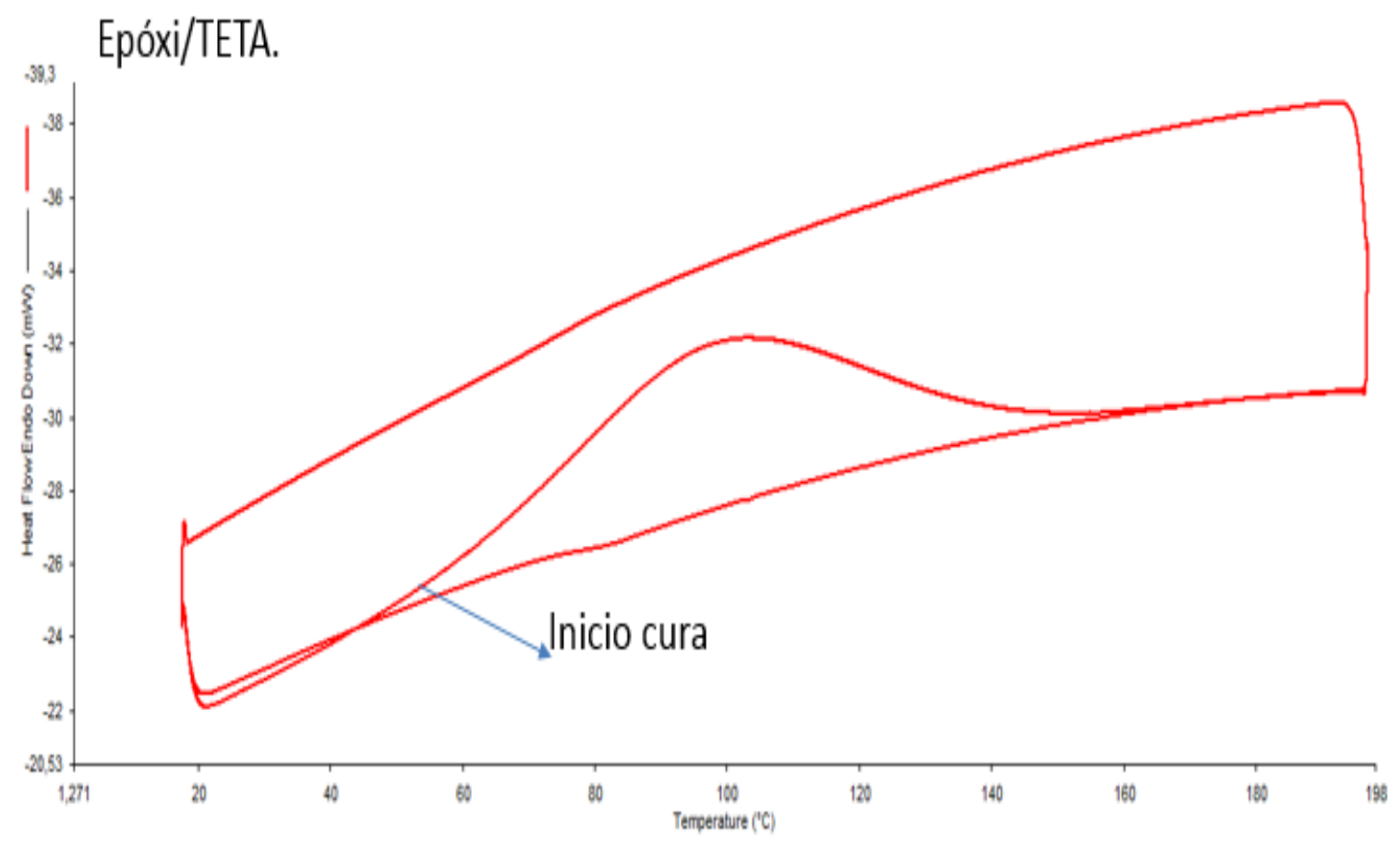

Fonte: elaborado pelo próprio autor, 2017. 
Figura 94 - Ampliação da Curva calorimétrica da Figura 93, pós-cura, com a finalidade de mostrar a região da transição vítrea e estimar a $\mathrm{T}_{\mathrm{g}}$ do sistema DGEBA: TETA (1:1).

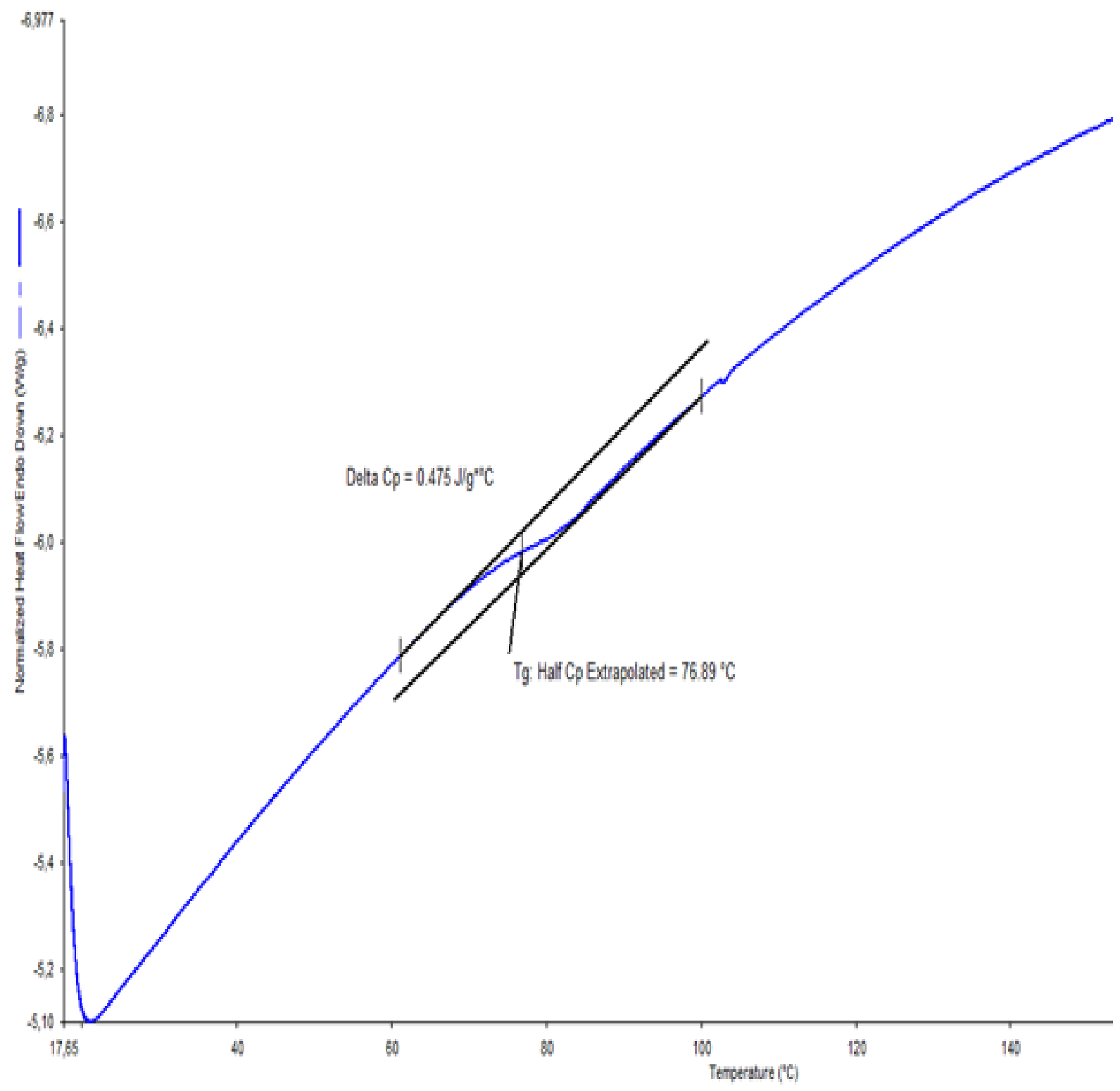

Fonte: elaborado pelo próprio autor, 2017. 
b) Protótipo DGEBA/TETA/Mica sililizada razão molar 1/1. (Figura 95 e 96).

Figura 95 - Curvas DSC para cura do sistema DGEBA/TETA/MICA

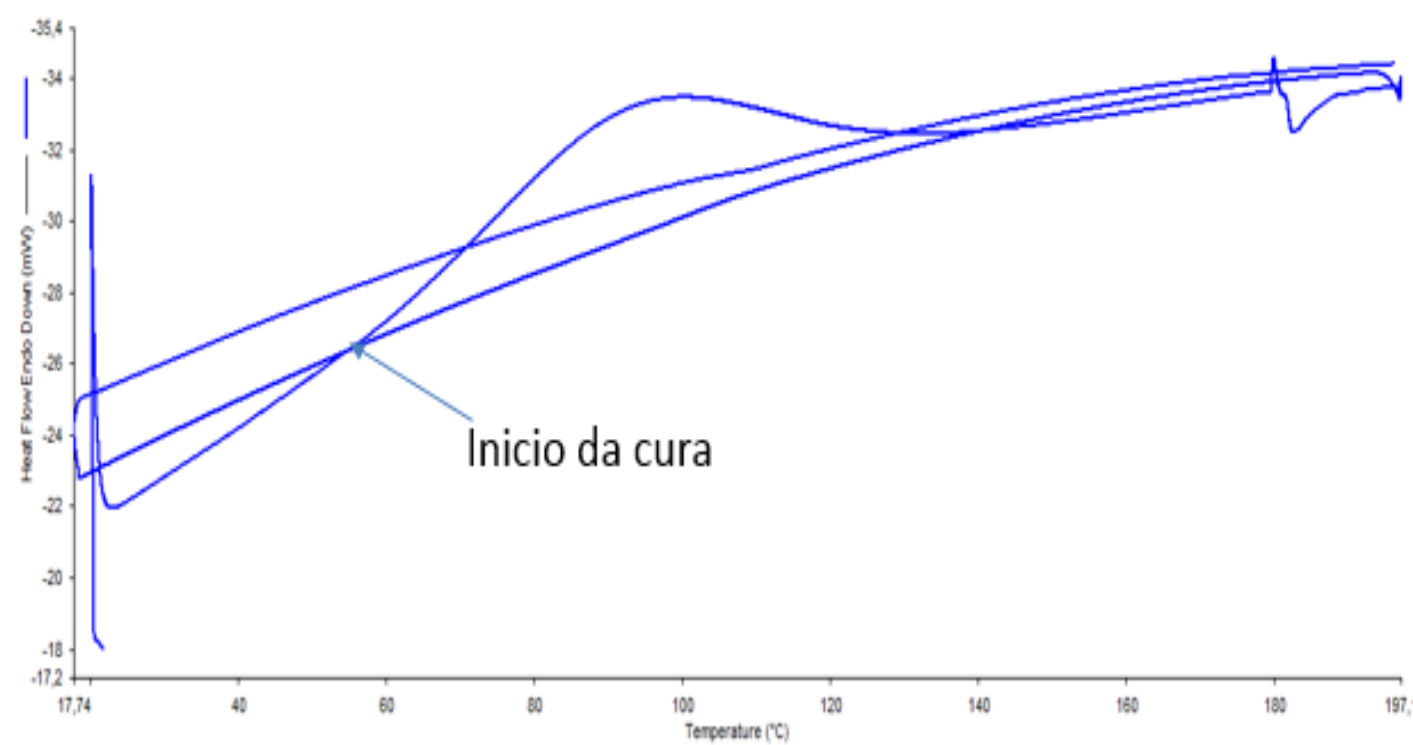

Fonte: elaborado pelo próprio autor, 2017.

Figura 96 - Parâmetro de Cura, segundo ciclo térmico, do sistema DGEBA/Teta/Mica sililizada mostrando a posição da Tg.

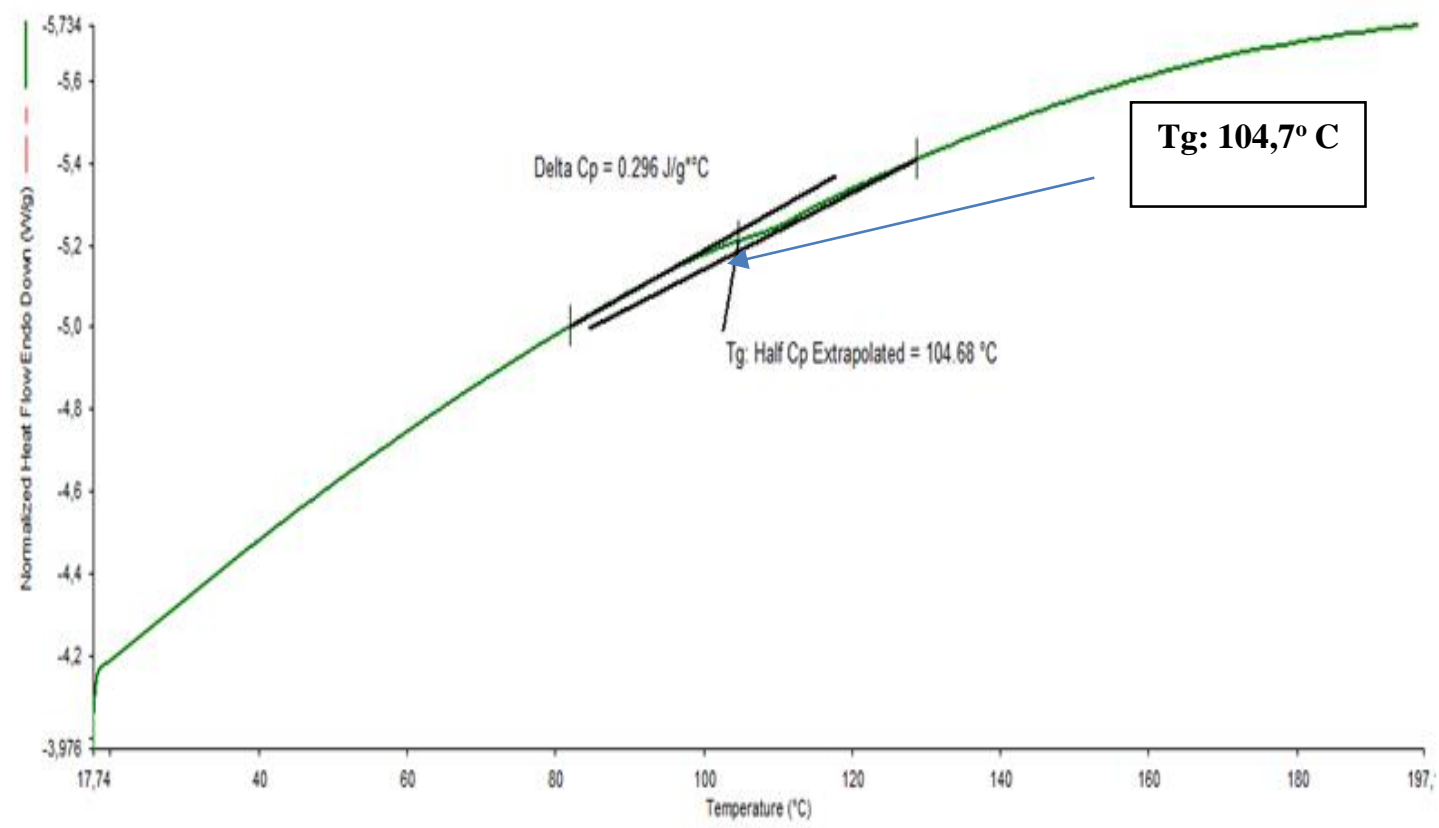

Fonte: elaborado pelo próprio autor, 2017. 
c) Parâmetro de Cura do sistema NIPU (CCGEBA + TETA) (Figuras 97,98)

Usando o mesmo procedimento feito para epóxi com o protótipo NIPU, na Figura 97, (rampa $10{ }^{\circ} \mathrm{C} / \mathrm{min}$, de 25 a $200{ }^{\circ} \mathrm{C}$ ), observou-se apenas a fusão da pasta utilizada. Portanto, não ocorre a cura do sistema nas condições usadas uma vez que na segunda curva do DSC não se observa um desvio da linha base atribuível à $\mathrm{T}_{\mathrm{g}}$.

Mudando o formato de pasta para o uso do ciclocarbonato fundido previamente, Figura 98, ocorre a mesma situação, não temos a ocorrência da cura e na segunda curva do DSC, não vemos o aparecimento da Tg.

Figura 97 - Curva de calorimetria diferencial exploratória (DSC) para o sistema NIPU a partir de CCGEBA e TETA em pasta.

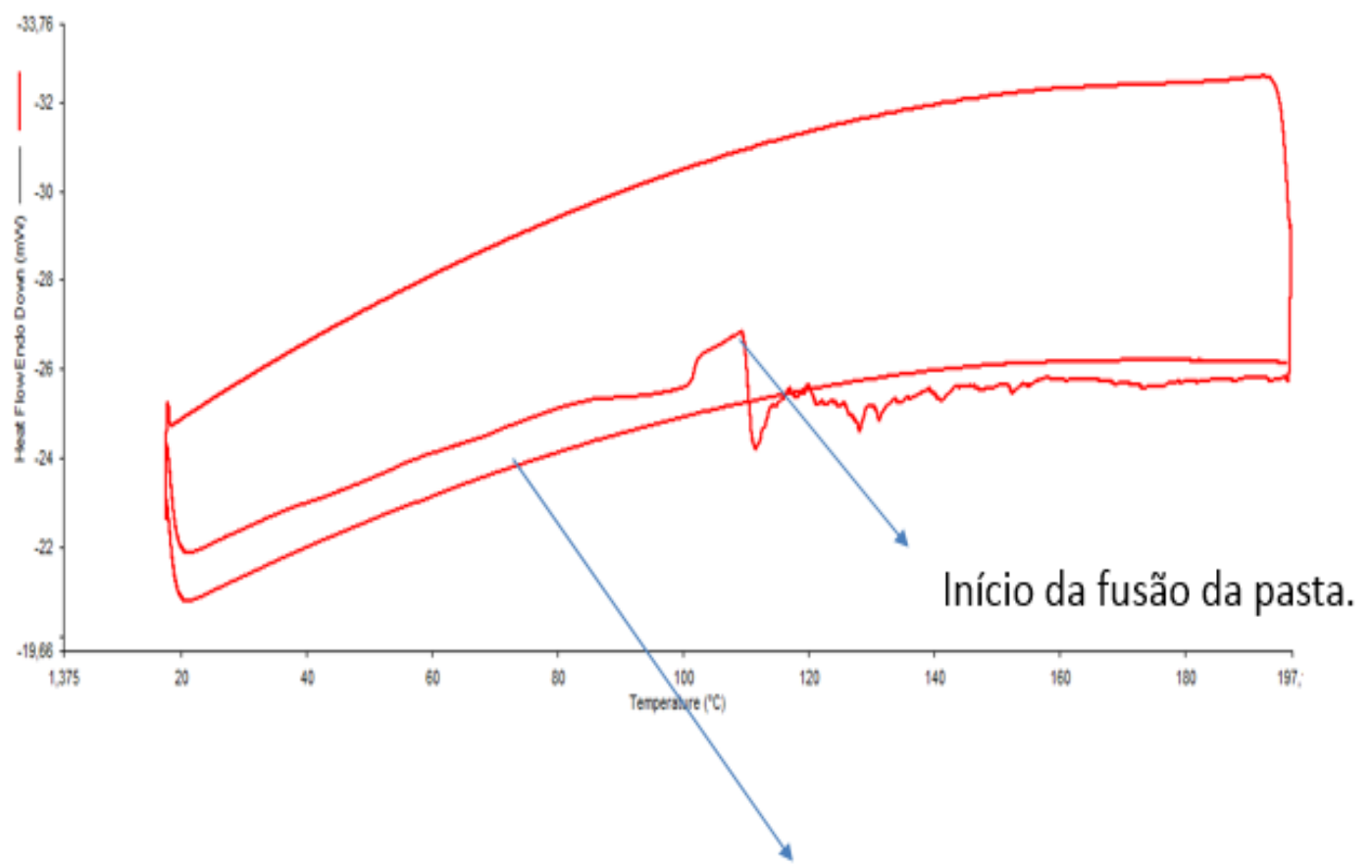

Não houve aparecimento da Tg.

Fonte: elaborado pelo próprio autor, 2017. 
Figura 98 - Curva calorimétrica diferencial para a mistura CCGEBA fundido mais TETA.

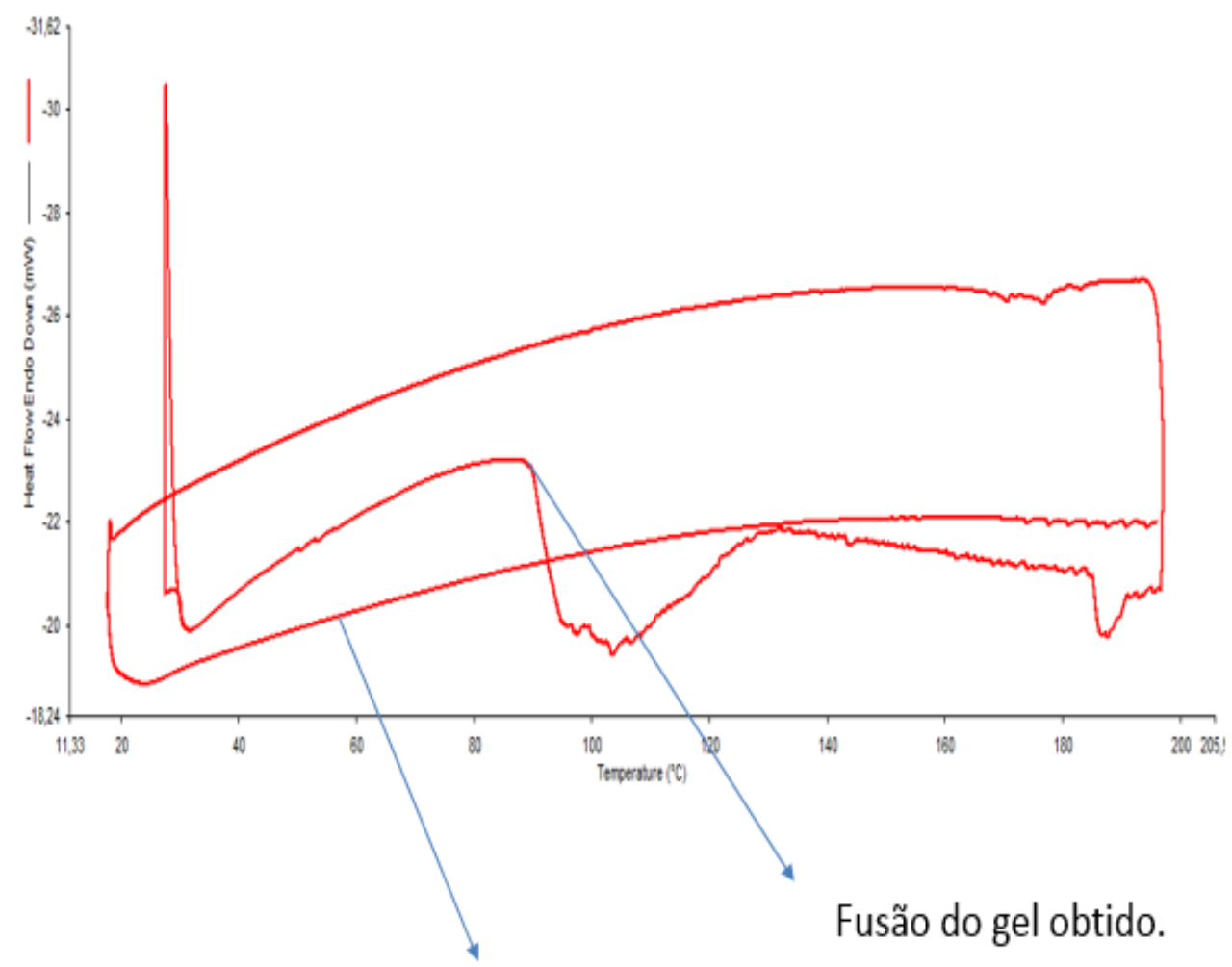

Não apresentou evidência de Tg

Fonte: elaborado pelo próprio autor, 2017.

Avaliando a curva da Figura 98, observa-se como no caso do sistema em pasta que ocorre a fusão do sistema, porém não ocorre a cura o que é evidenciado pela ausência na segunda curva da $T_{\mathrm{g}}$. Conforme Kristis (2011) et al, pode-se verificar que a reação nas condições usadas é muito lenta, normalmente ocorre acima de 18 horas; podendo ser acelerada utilizando-se catalisadores e temperatura acima de $70{ }^{\circ} \mathrm{C}$ [64]. Diante dessa observação e a não disponibilidade do equipamento para experimentos tão longos quanto 18 horas, abortou-se a busca para entender a temperatura de cura por esta metodologia. Portanto, os testes foram deste ponto em diante realizados com materiais com tempo de reação de 24 horas a $80^{\circ} \mathrm{C}$ e uso de outras técnicas para confirmar a cura e assim ter parâmetros seguros para as etapas elétricas e mecânicas da pesquisa. 
c.1) NIPU obtida do Ciclocarbonato + TETA, Pré-curada por 24 horas.

Após 24 horas de cura observou-se que o protótipo usando apenas ciclocarbonato com TETA apresentava a consistência de um gel, enquanto, o protótipo de ciclocarbonato com TETA e mica tinha uma característica de um sólido extremamente flexível, ou seja, comportamento próximo ao de um elastômero em concordância com o reportado para sistemas reacionais similares por Maisonneuve (2015) et al [155].

Para confirmar se houve a reação entre o ciclocarbonato e o TETA realizou-se o espectro de absorção na região do infravermelho. No FTIR, o desaparecimento da banda de carbonila do ciclocarbonato entre $1790-1810 \mathrm{~cm}^{-1}$ e a formação da banda carbonila da uretana em torno de 1720 e $1740 \mathrm{~cm}^{-1}$ são os parâmetros determinantes para validar o sucesso ou fracasso desta rota sintética. Na Figura 100 comprovou-se o desaparecimento da banda carbonila do ciclocarbonato e a formação da carbonila de uretana.

Diante desse resultado, para reduzir o aspecto de um protótipo extremamente mole e flexível, totalmente diferente do alvo desse projeto, substituiu TETA pela Isoforenodiamina (IPDA), uma diamina que devido a sua estrutura cíclica, conforme Figura 99, poderia conferir maior rigidez à estrutura curada, e dessa forma, obter protótipos com um aspecto físico similar ao sistema epóxi curado com o mesmo material.

Figura 99 - Estrutura química do TETA e da IPDA, evidenciando a diferença estrutural que levou aos resultados encontrados nessa fase de avaliação. [141].

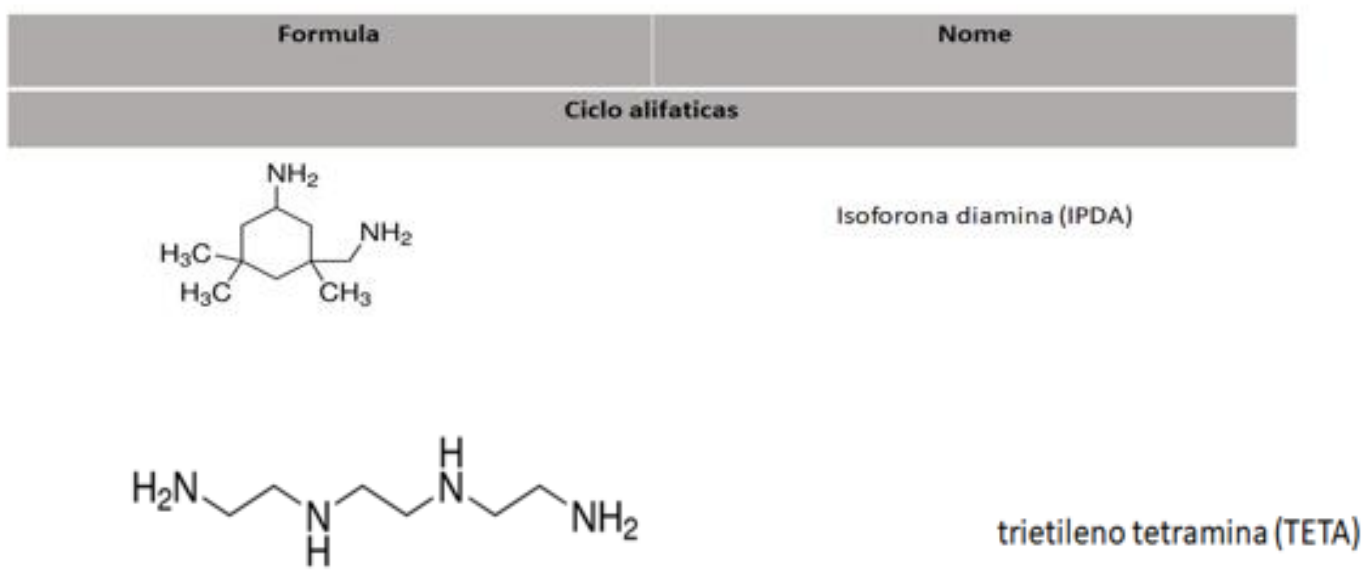

Fonte: elaborado pelo próprio autor, 2019. 
c.4) Protótipos de NIPU, usando ciclocarbonato curado com IPDA.

Como visto no trabalho realizado por Maisonneuve (2015) et al [155] o uso de solvente para dissolver o ciclocarbonato pode favorecer o processo de cura. Assim sendo, o ciclocarbonato foi solubilizado em acetona e foi adicionado o IPDA. O tempo de cura foi acertado para 1 hora a $70^{\circ} \mathrm{C}$. Na sequência evaporou-se a acetona em estufa a vácuo por 24 horas a $80^{\circ} \mathrm{C}$. Utilizando esse processo obteve-se materiais rígidos e com características visuais similares aos protótipos epóxi. Para confirmar se houve a reação, fez-se o FTIR dos protótipos obtidos, os quais podem ser vistos na Figura 100, onde buscou-se a presença de carbonila da estrutura uretana e o desaparecimento da carbonila característica do ciclocarbonato.

Figura 100 - Espectros de absorção na região do Infravermelho Médio do Ciclocarbonato e das hidroxiuretanas NIPU-TETA e NIPU-IPDA.

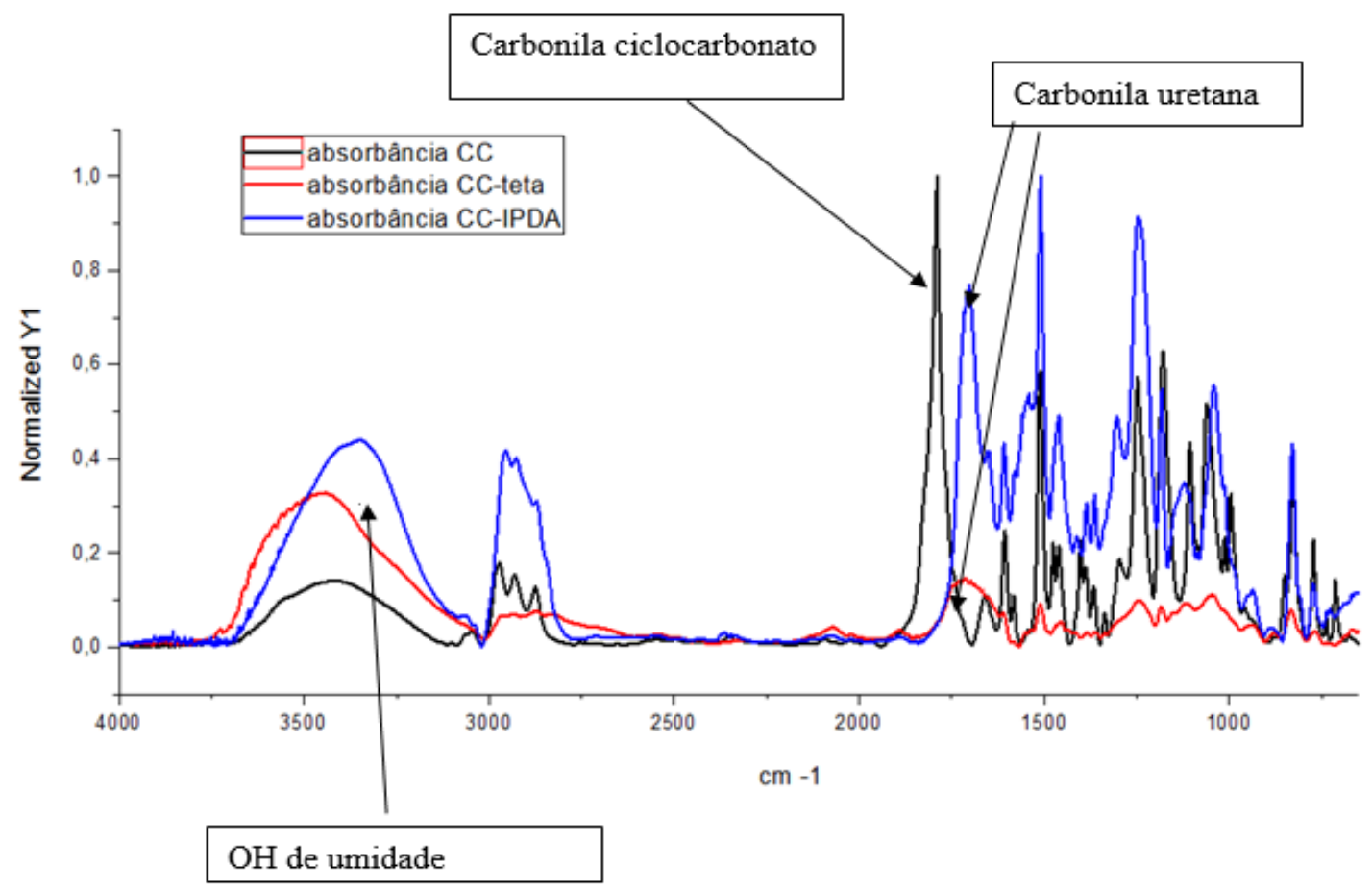

Fonte: elaborado pelo próprio autor, 2018.

Nesse espectro observa-se claramente que em ambos os casos, com o uso de TETA ou IPDA, existe o desaparecimento da carbonila do ciclocarbonato e a formação do grupo uretana, banda marcada na Figura $98 \mathrm{em} 1740 \mathrm{~cm}^{-1}$. A banda larga em $3300 \mathrm{~cm}^{-1}$ é indicativa da absorção dos grupos $-\mathrm{OH}$ da hidroxiuretana, $-\mathrm{NH}_{2}$ residual na ligação de hidrogênio ou 
água proveniente de umidade. Para se certificar que esta banda não é função de água misturada à hidroxiuretana, foi realizada uma recristalização usando ciclohexano, secagem e obtido novo espectro como vemos na Figura 101. Feito análise de umidade por Karl Fischer, vimos que a recristalização melhorou sensivelmente o teor de umidade, passando de 1200 ppm para 300 ppm com esse método. No espectro na Figura 101, continua a presença da banda de absorção em $3300 \mathrm{~cm}^{-1}$ a qual se deve não a umidade, mas sim ao grupamento - OH (hidroxila) do monômero utilizado (DGEBA) conforme pode ser visto na Figura 102

Figura 101 - Espectro e absorção na região do Infravermelho médio do ciclocarbonato recristalizado.

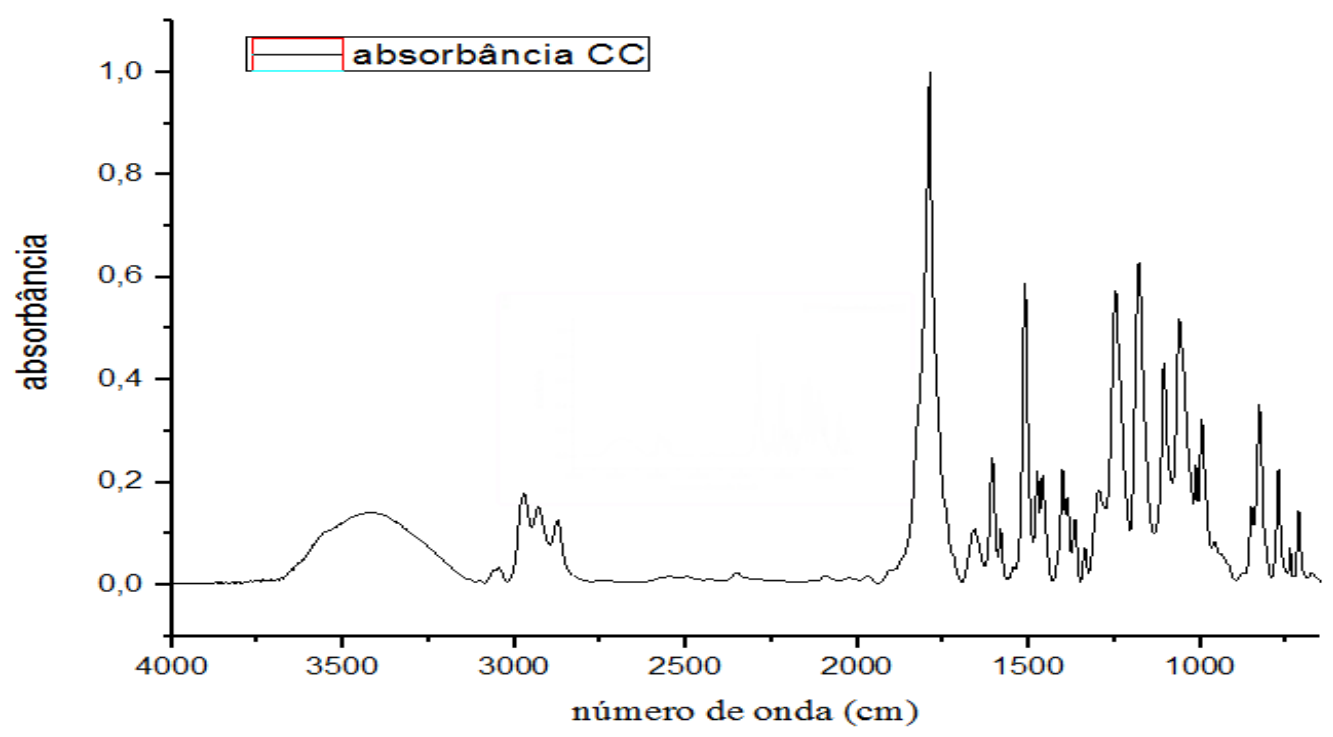

Fonte: elaborado pelo próprio autor, 2018.

Figura 102 - Espectro e absorção na região do Infravermelho médio do DGEBA.

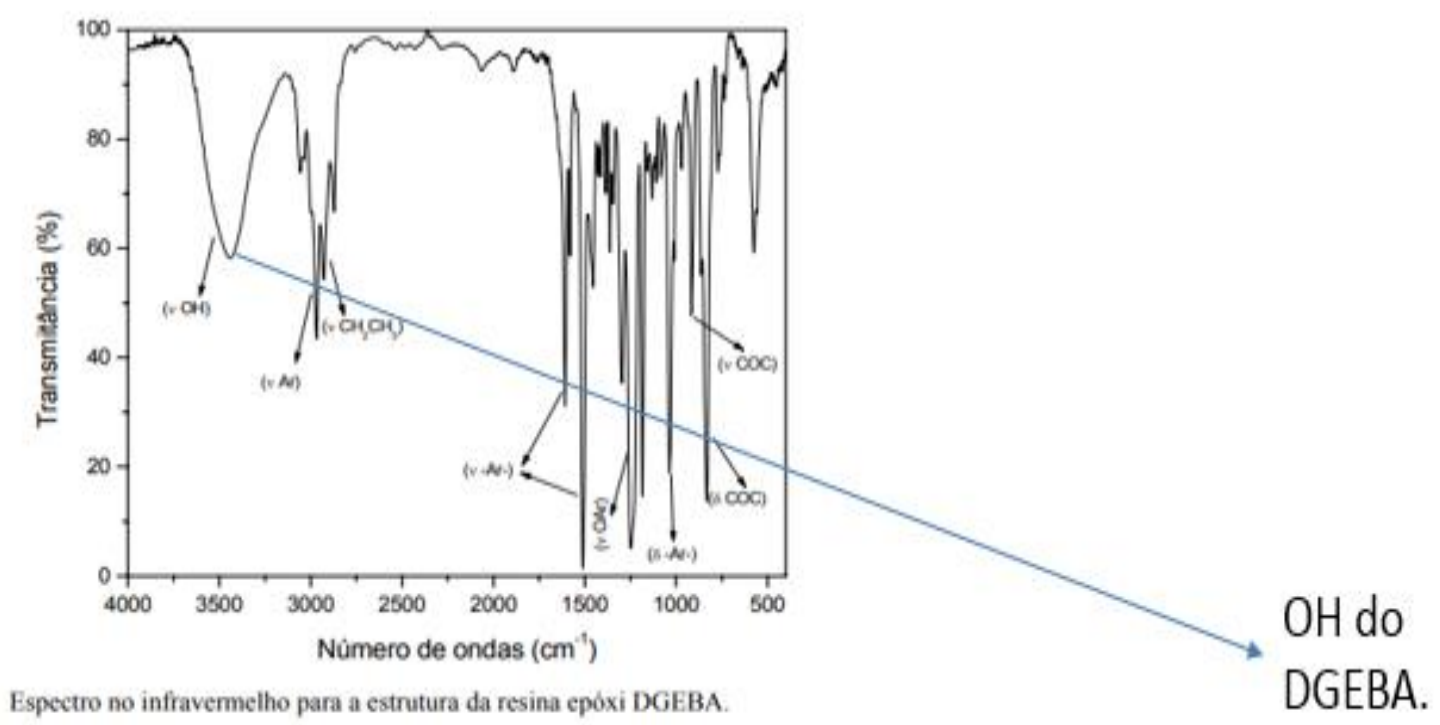

Fonte: elaborado pelo próprio autor, 2018. 
5.4 RMN da síntese para obtenção da HNIPU (NIPU COM TERMINAÇÃO AMINA -DGEBA)

Na obtenção da HNIPU produzida pela reação de oligômero NIPU com terminação amina e DGEBA, uma das formas de comprovação foi a análise de RMN do pré polímero obtido (NIPU com terminação amina) usando um modelo teórico conforme a Figura 103.

Figura 103 - Modelo Alvo no teste de RMN com a estrutura da NIPU e as terminações amina nas extremidades. [184]

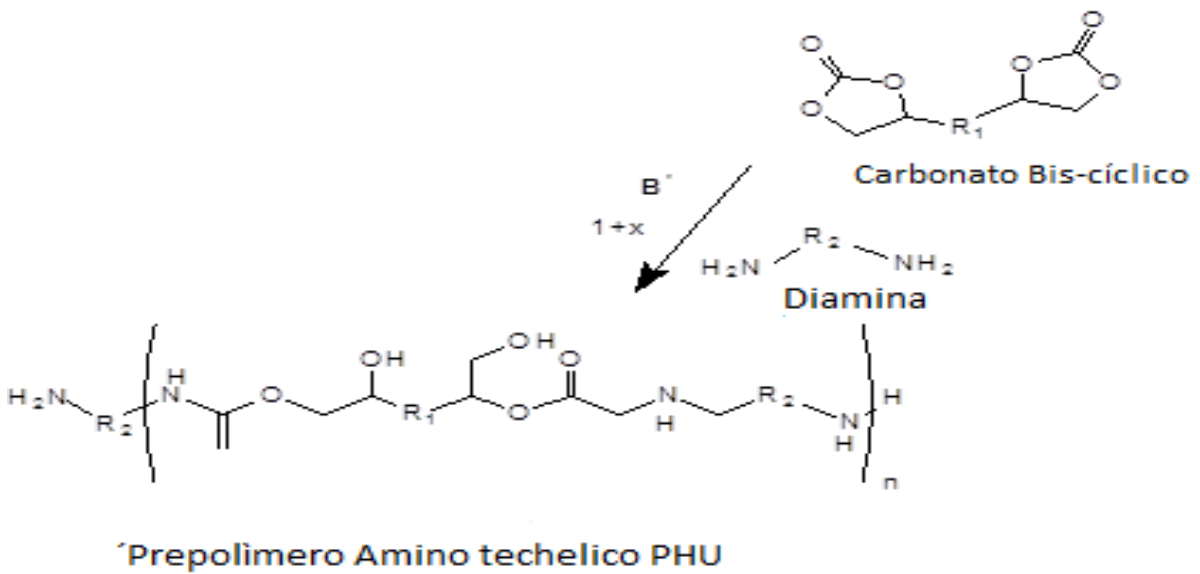

Fonte: elaborado pelo próprio autor, 2019 baseada em Ke et all [184].

1. Avaliação do pré polímero de NIPU com terminação amina.

$\mathrm{O}$ espectro de $\mathrm{RMN}$ de ${ }^{1} \mathrm{H}$, Apêndice A da página 253, permite observar o deslocamento hidrogênio $\mathbf{h} 5.05 \mathrm{ppm}$ para $4.95 \mathrm{ppm}$, o que sugere a abertura do anel pela correspondente amina;

- O espectro de RMN de COSY, Apêndice B e C da página 254 e 255, permite observar correlações deste hidrogênio com os metilênicos g e i (4.4ppm a 4.5ppm e 4.1ppm);

- O espectro de RMN de HSQC, $\mathrm{C}^{13}$, ilustrados nos Apêndices D, E e F da página 256,257 e 258 , correlacionam diretamente os hidrogênios $\mathbf{g}$ com o carbono situado em 74.2ppm e os hidrogênios h e i com os carbonos em 66.2ppm e 66.9ppm.

Estes deslocamentos químicos, associados com os dados ilustrados no Apêndice G da página 259 são condizentes com o esperado para a estrutura proposta para o pré-polímero de NIPU com terminação amina na Figura 104. 
Figura 104 - Estrutura evidenciada pela análise de RMN com a inserção do IPDA nas extremidades da NIPU.

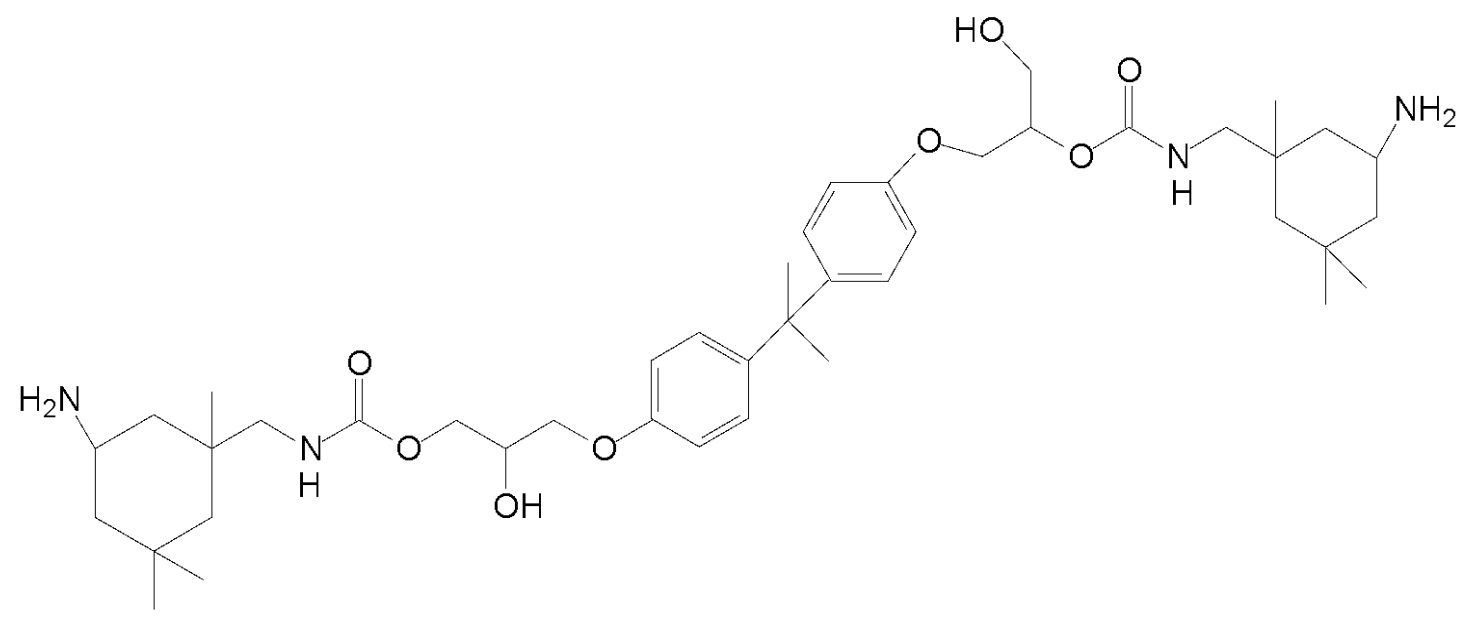

Fonte: elaborado pelo próprio autor, 2019.

\subsubsection{Espectroscopia de Infravermelho Protótipo HNIPU (NIPU com}

\section{Terminação Amina /DGEBA)}

a) Material utilizado: produto da reação entre ciclocarbonato (1,0 mol) com IPDA em excesso (1,5 mol). O material testado aqui é o mesmo avaliado pela rota usando RMN.

Figura 105 - Espectro de Infravermelho Pré-Polímero de NIPU com excesso de Aminas.

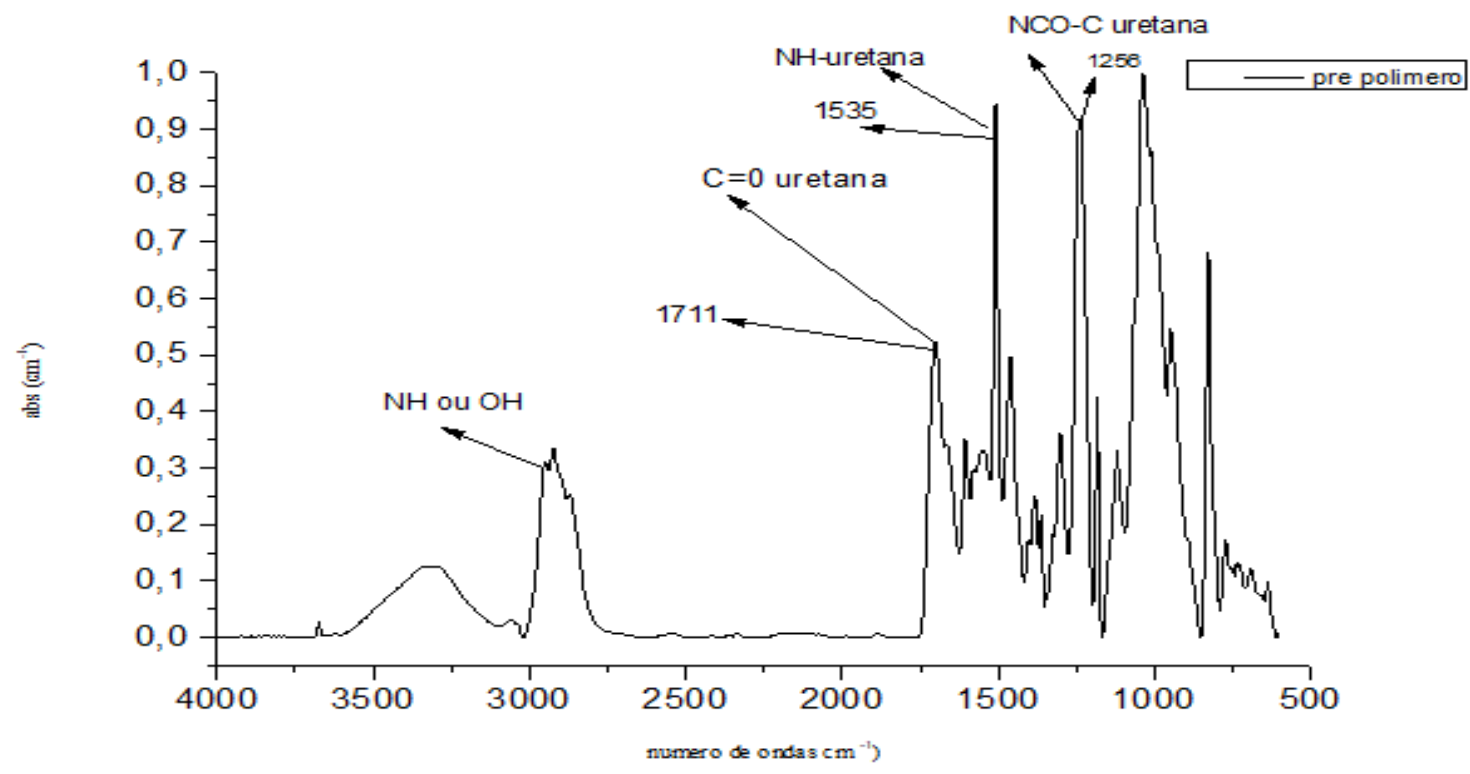

Fonte: elaborado pelo próprio autor, 2019. 
O espectro de infravermelho da Figura 105 mostra coerência com o encontrado na RMN onde temos o desaparecimento da banda do ciclocarbonato que ocorre entre 1790 a $1810 \mathrm{~cm}^{-1}$. Originando a banda da carbonila da uretana em $1711 \mathrm{~cm}^{-1} \mathrm{e}$ as bandas do $\mathrm{NH}$ da uretana em $1535 \mathrm{~cm}^{-1}$ e a banda característica da estrutura uretana (NCO-C) em $1256 \mathrm{~cm}^{-1}$. Portanto, houve a formação da NIPU com a abertura do anel do ciclocarbonato. A região de absorção de 3000 a $3500 \mathrm{~cm}^{-1}$ ' por ser uma região característica da presença de grupamentos OH de hidroxilas ou até umidade, NH de grupamentos aminas, não é possível por essa técnica assegurar que existe grupamentos $\mathrm{NH}$ em excesso.

b) Espectro de Infravermelho da HNIPU curada, Figura 106

Figura 106 - Espectro da HNIPU (cura do Pré Polímero de NIPU com DGEBA)

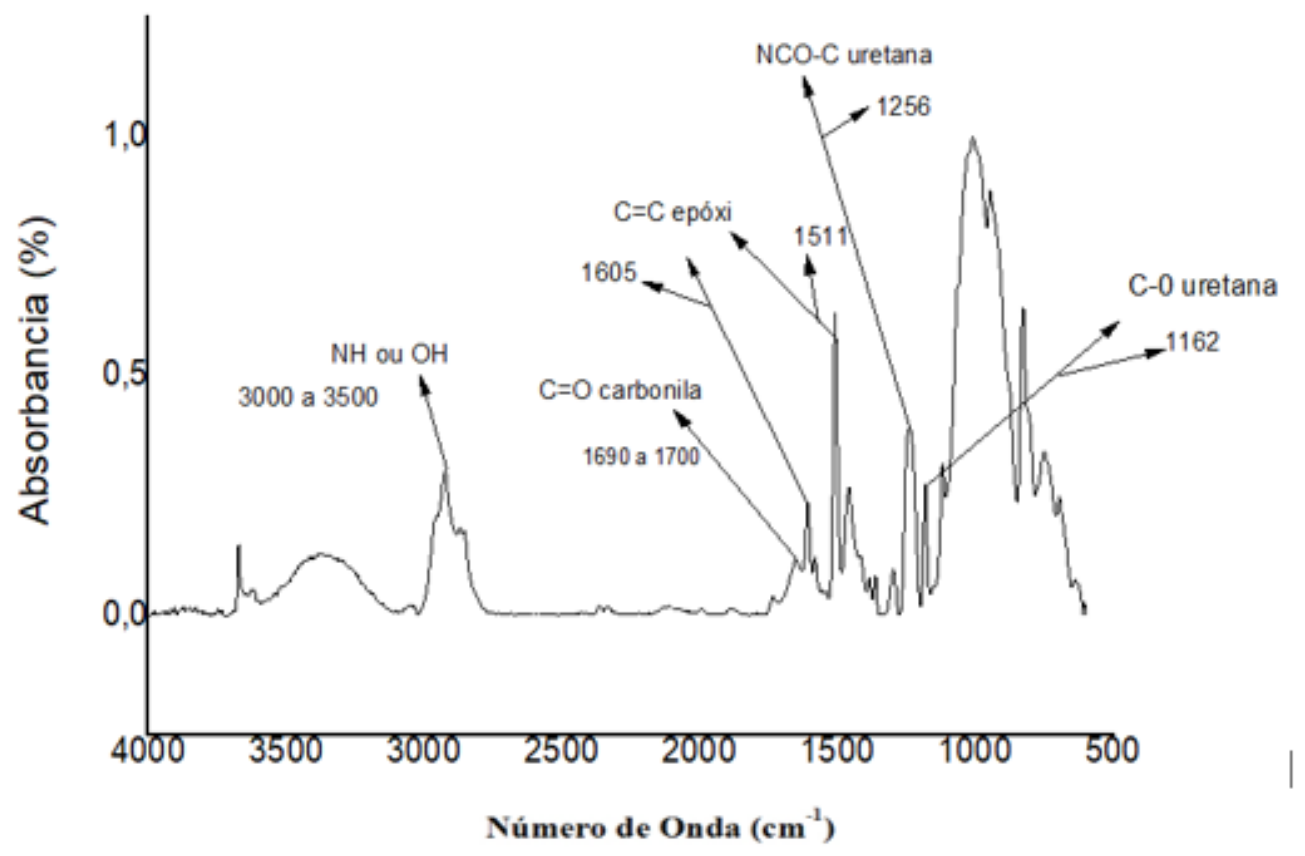

Fonte: elaborado pelo próprio autor, 2019.

O espectro de infravermelho, Figura 106, é coerente com a reação efetuada entre o Pré Polímero de NIPU com terminação amina e o DGEBA.Observa-se em 1690, 1700, 1256 e $1162 \mathrm{~cm}^{-1}$ picos atribuídos às ligações uretânicas. Da estrutura do DGEBA pode se atribuir as bandas presente em 1605 e $1511 \mathrm{~cm}^{-1}$ como sendo grupamentos $\mathrm{C}=\mathrm{C}$. Devido à similaridade de região para absorção, não é possível por essa técnica evidenciar com segurança a presença dos grupamentos $\mathrm{NH}$ da amina, os mesmos absorvem na mesma região de $\mathrm{OH}$, de 3000 a $3500 \mathrm{~cm}^{-1}$. 
5.5 Avaliação Da Absorção de Água conforme ASTM D570 dos Protótipos Epóxi, NIPU e Blenda Epóxi-NIPU da Tabela 26.

Tabela 26 - formulas usadas para o teste de Absorção de água.

\begin{tabular}{|l|l|}
\hline Formulas & Base Química Da Síntese \\
\hline Epóxi 1 & DGEBA/IPDA/Sem Mica \\
\hline Epóxi 2 & DGEBA/IPDA/Mica sililada com APTS \\
\hline Epóxi 3 & DGEBA/IPDA/MICA Sem Tratamento \\
\hline NIPU 1 & NIPU ( CCGEBA /IPDA) razão molar /1:1 \\
\hline NIPU 2 & NIPU ( CCGEBA/IPDA/Mica sililada) razão molar 1:1 \\
\hline NIPU 3 & NIPU ( CCGEBA/IPDA/Mica sililada) razão molar 1,5:1 \\
\hline NIPU 4 & NIPU ( CCGEBA/IPDA/MICA Sem tratamento) razão molar 1:1 \\
\hline HNIPU 1 & HNIPU ( CCGEBA/IPDA/DGEBA) razão molar 1:1 \\
\hline HNIPU 2 & HNIPU( CCGEBA IPDA/DGEBA) /MICA Sem tratamento razão 1:1 \\
\hline HNIPU 3 & HNIPU ( CCGEBA/IPDA/DGEBA) /Mica sililada razão molar 1:1 \\
\hline HNIPU 4 & HNIPU ( CCGEBA/TETA/ DGEBA) Mica sililada razão molar 1:1 \\
\hline
\end{tabular}

Fonte: elaborado pelo próprio autor, 2019.

As Tabelas com os dados de massa dos protótipos antes e após serem submetidos as condições exigidas pela ASTM D570 encontram-se no Apêndice H e I, respectivamente (páginas 260), com as descrições, $\mathrm{m}_{0}$ (pesagem inicial), $\mathrm{m}_{1}$ (pesagem após 24 horas), dados que foram utilizados para o cálculo da \% de absorção de água, conforme a Tabela 27 e demonstrados na Figura 107. Por meio dos resultados obtidos na Tabela 26 e na Figura 107, conclui-se como premissas verdadeiras as seguintes informações:

a) A razão de Equivalentes da NIPU tem fundamental papel na absorção de água, o pior resultado foi obtido com um aumento na razão de equivalentes, o excesso de ciclocarbonato ( 1,5 equivalentes) em relação ao IPDA, mostrou uma maior absorção de água, NIPU 3.

Outro dado que engloba tanto a NIPU como o sistema DGEBA é a utilização da Mica. Nota-se que amostras sem a carga mineral dentro de suas séries de teste, são as que apresentam a menor taxa de absorção, Epóxi 1, NIPU 1 e HNIPU 1. Por outro lado, do ponto de vista de valores obtidos, está claro também em todos os sistemas que compósito com a mica tratada com aminossilano leva a uma menor absorção de água que o compósito com a mica sem o tratamento com aminossilano (Epóxi 2 com a Epóxi 3, NIPU 2 com a NIPU 4 e 
a HNIPU 3 com a HNIPU 2). Considerando os dados com a barra de erros, podemos concluir que as únicas amostras que tem valores de aumento de absorção de água são a NIPU 3 e a NIPU 4. A explicação pode reforçar a hipótese de que a mica sililada funciona como agente de reticulação pela reação de aminólise do ciclocarbonato e consequente reticulação e no caso da NIPU a presença de grupamentos hidroxilas livres no volume e na superfície dos sólidos.

Tabela 27 - Dados com resultado Final \% Absorção de Água

\% de Absorção de água

\begin{tabular}{|l|l|r|}
\hline Síntese & Descrição & \% de Absorção de Água. \\
\hline Epóxi 1 & DGEBA/IPDA Sem Mica & 1,08000 \\
Epóxi 2 & DGEBA/IPDA Mica Sililada & 1,8600 \\
Epóxi 3 & DGEBA/IPDA Mica não Sililada & 3,2800 \\
NIPU 1 & NIPU/IPDA Sem Mica & 2,4800 \\
NIPU 2 & NIPU/IPDA Mica Sililada & 2,1100 \\
NIPU 3 & NIPU/IPDA Mica Sililada 1.5:1 & 19,0300 \\
NIPU 4 & NIPU/IPDA Mica não Sililada & 9,5600 \\
HNIPU 1 & HNIPU-IPDA Sem Mica & 0,9100 \\
HNIPU 2 & HNIPU-IPDA Mica não sililada & 1,7300 \\
HNIPU 3 & HNIPU- IPDA Mica Sililada & 1,2900 \\
HNIPU 4 & HNIPU (TETA). Mica Sililada & 1,3200 \\
\hline
\end{tabular}

Fonte: elaborado pelo próprio autor, 2019.

Figura 107 - Gráficos de \% de Absorção de Água.

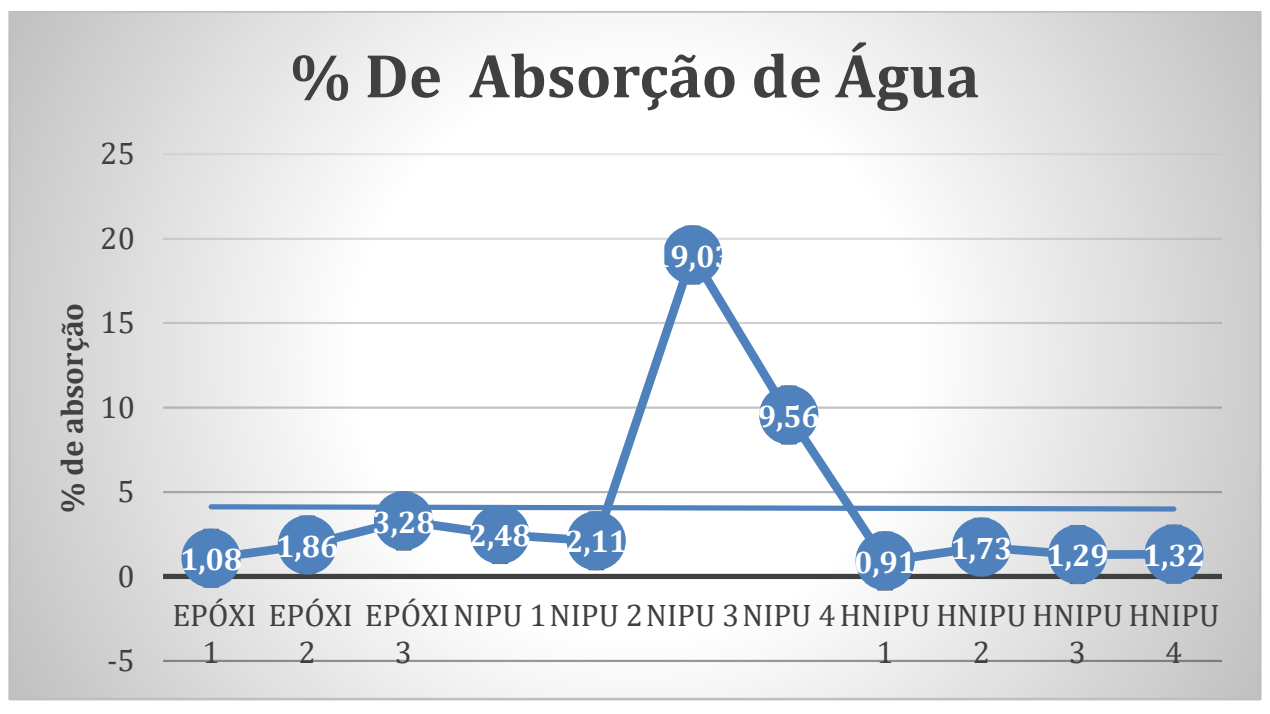

Fonte: elaborado pelo próprio autor, 2019.

Comentários Iniciais: O teste de \% de Absorção de Água, devido as premissas de um material para uso elétrico traz informações extremamente importantes. Pode se ver que o sistema HNIPU apresenta um comportamento de similaridade com a Epóxi, fato positivo 
para seu uso na aplicação elétrica. Fato a destacar é que nos protótipos vemos que o uso da mica tratada com aminossilano tem menor absorção de água, sua utilização acentua a hidrofobicidade do polímero. A NIPU se mostrou bem dependente do uso da Mica sililada e o efeito do excesso do ciclocarbonato é um fato que deve ser melhor investigado.

Em trabalho feito por Dutta (2008) [212], usando um sistema de DGEBA com TETA apresentou uma absorção de água de $2,1 \%$, bem acima dos valores encontrados por esse projeto. Seu foco foi comparar o comportamento elétrico desse sistema em função da absorção de água. Segundo o trabalho, epóxi tem esse modo de falha de alta absorção de água o que compromete sua isolação ao longo do tempo, podendo aumentar a Constante Dielétrica em mais de 10 vezes. Trazendo essa premissa para o Hidrogerador, será necessário no futuro correlacionar absorção de água com as propriedades elétricas para entender o benefício que a HNIPU ou NIPU pode conferir a esse sistema.

\subsection{Determinação Grau de Gelificação em THF e teor de Gel nos Protótipos Epóxi, NIPU e HNIPU (NIPU com terminação Amina/DGEBA) Tabela 28}

Tabela 28 - Composição dos protótipos usados para Grau de Gelificação.

\begin{tabular}{|l|l|}
\hline Fórmulas & Base Química da Síntese \\
\hline Epóxi 1 & DGEBA/IPDA/Sem Mica \\
\hline Epóxi 2 & DGEBA/IPDA/Mica sililada com APTS \\
\hline Epóxi 3 & DGEBA/IPDA/Mica Sem Tratamento \\
\hline NIPU 1 & ( CCGEBA /IPDA) razão /1:1 \\
\hline NIPU 2 & ( CCGEBA/IPDA/Mica sililada) razão equivalente $1: 1$ \\
\hline NIPU 3 & ( CCGEBA/IPDA/Mica sililada) razão equivalente $1,5: 1$ \\
\hline NIPU 4 & ( CCGEBA/IPDA/Mica Sem tratamento) razão equivalente $1: 1$ \\
\hline HNIPU 1 & ( NIPU terminação Amina /IPDA/DGEBA) sem mica, razão equivalente $1: 1$ \\
\hline HNIPU 2 & $\begin{array}{l}\text { (NIPU terminação Amina IPDA/DGEBA)/Mica não Sililada razão } \\
\text { equivalente 1:1 }\end{array}$ \\
\hline HNIPU 3 & (NIPU terminação amina /IPDA/DGEBA)/Mica sililada razão equivalente $1: 1$ \\
\hline HNIPU 4 & (NIPU terminação amina /TETA/DGEBA)/Mica sililada razão equivalente $1: 1$ \\
\hline
\end{tabular}

Fonte: elaborado pelo próprio autor, 2019.

As fórmulas Epóxi (1, 2 e 3), apresentaram intumescimento em THF, porém, não houve dissolução. Contudo, o intumescimento das mesmas levou a formação de uma estrutura gelatinosa em especial na fórmula Epóxi 1, sem mica, conforme ilustrado pela 
Figura 109. Essa característica não ocorreu nas demais amostras, exceto para a formulação NIPU 3 (CCGEBA/IPDA/Mica sililada com razão molar 1,5:1). As formulações, NIPU 1,2 e 4 sofreram completa dissolução. As fórmulas HNIPU, apresentaram baixo grau de gelificação, sendo a HNIPU 1, aquela que apresentou o menor grau de gelificação, uma evidência que deve ser analisada futuramente. A ausência de mica e o processo de obtenção via solvente pode levar a formação de poros que facilitaria a entrada do solvente e a sua consequente dissolução ou gelificação.

Cálculo do Grau de Gelificação.

Os dados para os cálculos de \% de Gelificação, encontram-se na página 261, para os dados da pesagem inicial $\left(\mathrm{m}_{\mathrm{O}}\right)$, Apêndice $\mathrm{J}$ e para os dados da pesagem final $\left(\mathrm{m}_{1}\right)$ após THF no Apêndice K.

Tabela 29. \% de Gelificação após THF.

\begin{tabular}{|c|c|}
\hline Fórmulas & \% de Gelificação \\
\hline Epóxi 1 & 85,93 \\
Epóxi 2 & 68,12 \\
Epóxi 3 & 51,13 \\
NIPU 1 & Dissolveu \\
NIPU 2 & Dissolveu \\
NIPU 3 & 92,55 \\
NIPU 4 & Dissolveu \\
HNIPU 1 & 3,00 \\
HNIPU 2 & 8,00 \\
HNIPU 3 & 6,30 \\
HNIPU 4 & 16,00 \\
\hline
\end{tabular}

Fonte: elaborado pelo próprio autor, 2019. 
Figura 108. Representação Gráfica da percentagem de gelificação das amostras em THF.

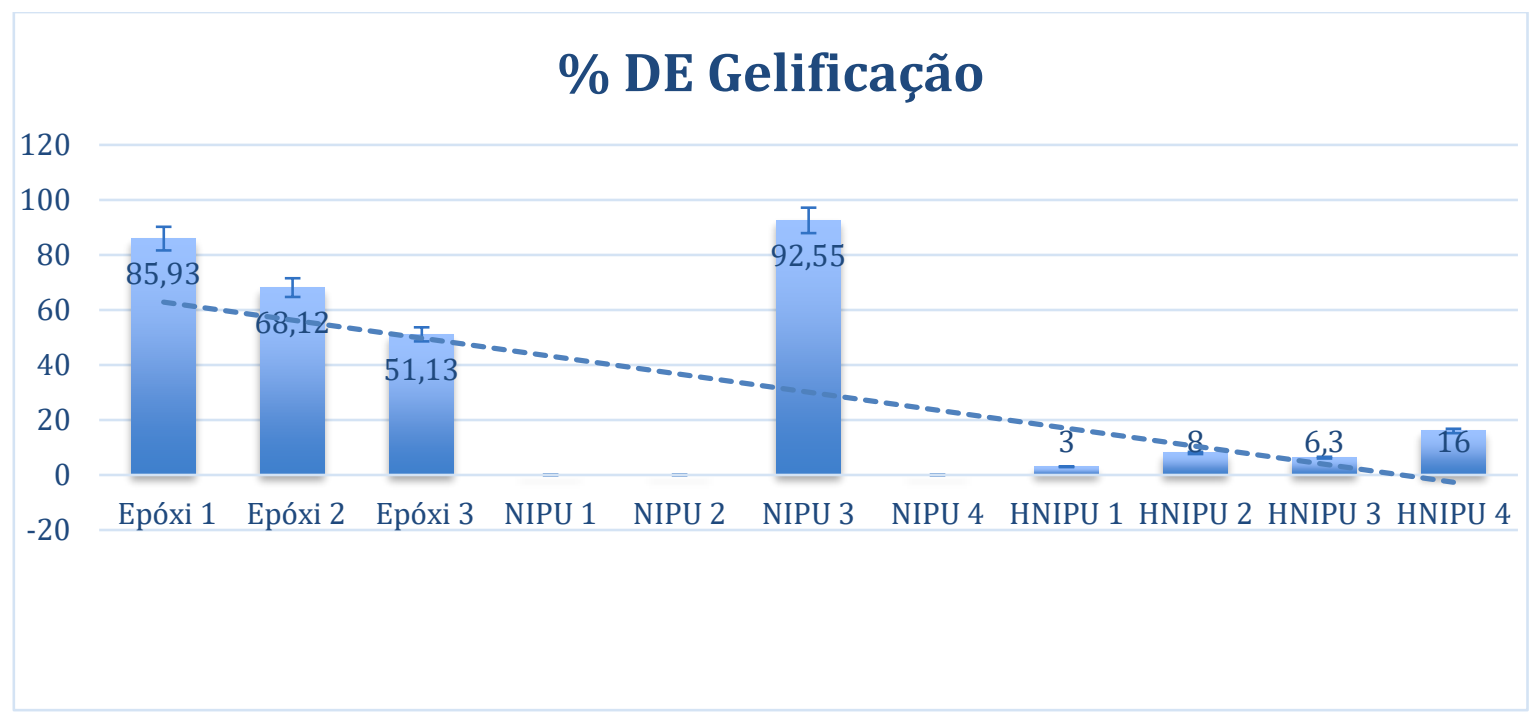

Fonte: elaborado pelo próprio autor, 2019.

Figura 109 - Fotografia das amostras dos protótipos após 24 horas imersos em THF.

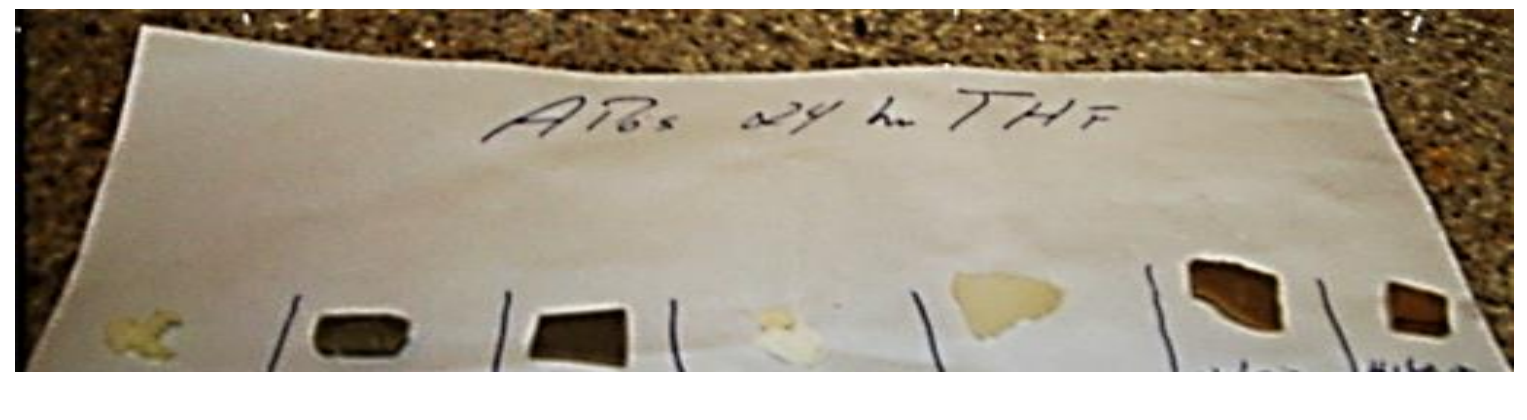

$\begin{array}{lllllll}\text { Epóxi } 1 & \text { Epóxi } 2 & \text { Epóxi } 3 & \text { NIPU } 3 & \text { HNIPU } 1 & \text { HNIPU } 3 & \text { HNIPU } 4\end{array}$

Fonte: elaborado pelo próprio autor, 2019.

Ao compararmos os resultados das amostras NIPU em relação as amostras epóxi observa-se em geral, com exceção da razão equivalente $1,5: 1$, uma baixa resistência ao THF que pode ser explicada pela baixa taxa de reticulação do sistema utilizado. Zhao (2015) et al já haviam observado comportamento similar para NIPUs [213]. A insolubilidade da amostra NIPU 3 indica um maior grau de reticulação, porém uma estrutura altamente porosa, indesejável para as aplicações almejadas nesta Tese. Possivelmente, essa baixa dissolução seja proveniente da retificação induzida pela mica tratada com aminossilano e não de uma estrutura polimérica reticulada.

As amostras HNIPU apresentaram menor intumescimento e a maior resistência ao THF, estas são as amostras contendo o pré-polímero (NIPU com terminação Amina) e sua reação posterior com o DGEBA. Este comportamento é coerente com o reportado por Ke $e t$ 
al [184], pois para um sistema similar de balanço estequiométrico encontrou valores de teor de gelificação de 10 a $30 \%$.

Os resultados de percentagem de gel, Figura 108, Figura 110, Tabela 29 e 30, refletem parâmetros do grau de gelificação reforçando a ideia de que o uso de pré-polímero com a terminação amina, leva a uma melhor reticulação quer pela menor solubilização quer pela menor taxa de intumescimento.

Esse cálculo da percentagem de gel leva em consideração a pesagem da amostra após 24 horas em estufa (m2). A secagem da amostra nessa condição faz com que tenhamos a evaporação do THF que foi absorvido durante o processo de imersão e reflete o percentual de material que resistiu, que não foi dissolvido após imersão.

Para o cálculo da \% de Gel após 24 horas em estufa a $80{ }^{\circ} \mathrm{C}$ foi usado a equação abaixo, sendo que os dados de $\mathrm{m}_{2}$ e mo estão no Apêndice K e Apêndice L das páginas 261e 262 respectivamente.

Tabela 30 - Dados da \% de gel.

\begin{tabular}{|c|c|}
\hline Fórmulas & \% de Gel \\
\hline Epóxi 1 & 42,08 \\
\hline Epóxi 2 & 84,85 \\
\hline Epóxi 3 & 80,42 \\
\hline NIPU 1 & 0 \\
\hline NIPU 2 & 0 \\
\hline NIPU 3 & 23,92 \\
\hline NIPU 4 & 0 \\
\hline HNIPU 1 & 80,02 \\
\hline HNIPU 2 & 90,53 \\
\hline HNIPU 3 & 95,95 \\
\hline HNIPU 4 & 86,48 \\
\hline
\end{tabular}

Fonte: elaborado pelo próprio autor, 2019 
Figura 110- Representação da \% de Gel após 24 horas a $80^{\circ} \mathrm{C}$.

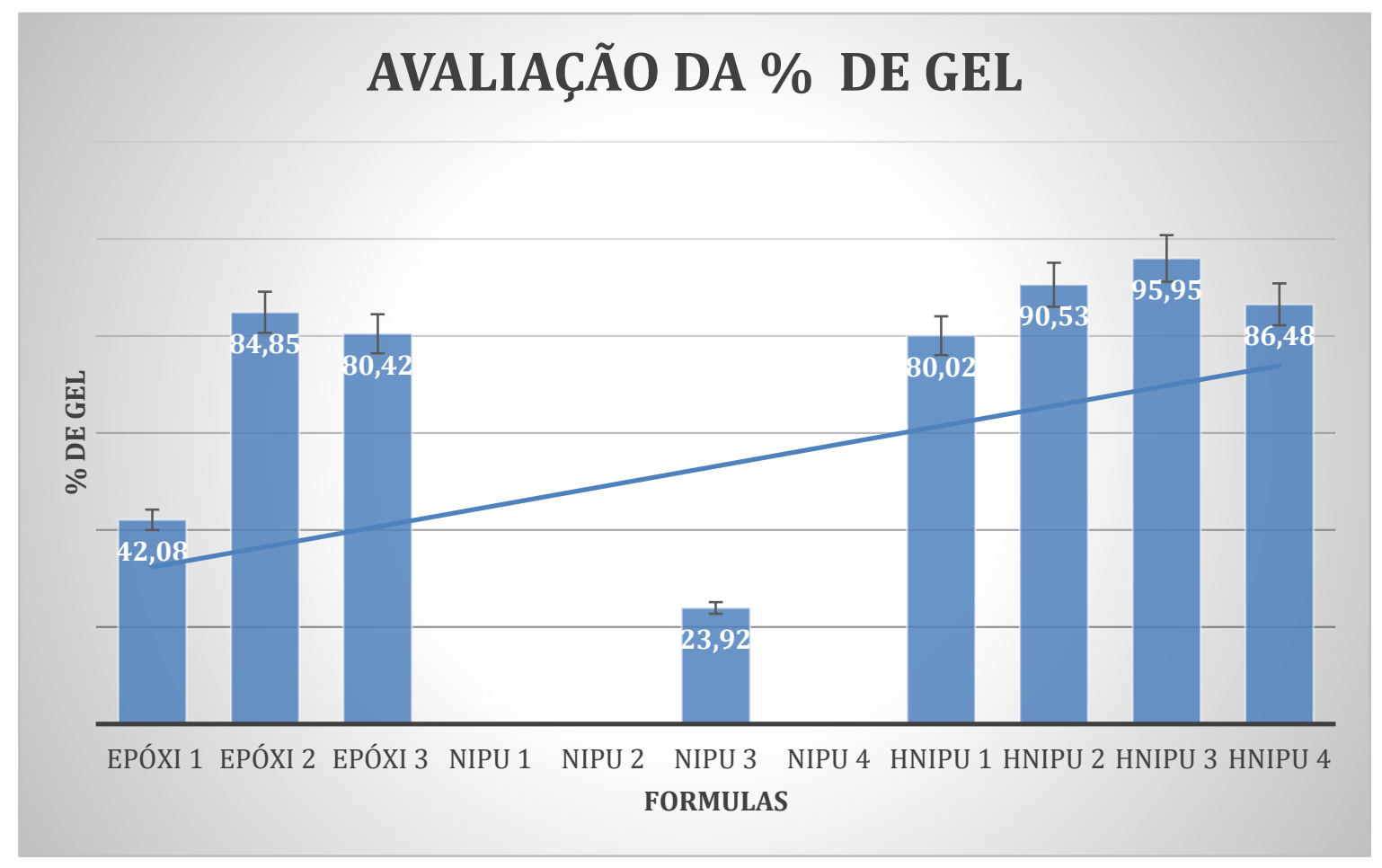

Fonte: elaborado pelo próprio autor, 2019

Comentários Iniciais: Os dados mostrados trazem uma informação extremamente positiva para a premissa do projeto, o uso da formula HNIPU mostrou-se superior a Epóxi nesse teste, evidenciando uma reticulação que impediu a solubilização pelo THF não destruísse a estrutura polimérica de rede formada. No caso da NIPU os dados comprovam que o tipo de ligação química, mesmo com a presença do híbrido de Mica não foi suficiente para assegurar uma reticulação que pudesse suportar o ataque do solvente. Existe uma dúvida ainda a ser respondida, HNIPU tem a estrutura central do DGEBA e sua reticulação se dá também pela inserção do DGEBA, era esperado que houvesse uma similaridade no teor de Gel. Conforme Ke et al, a presença de grupamentos polares e a presença de grupamentos livres favorece a dissolução via THF. Pode se atribuir a ausência de grupamentos não reagidos no HNIPU e sua presença nos protótipos Epóxi. 


\subsection{Avaliação de Molhabilidade via Ângulo de Contato}

Para os testes de Ângulo de Contato, foram utilizados os protótipos obtidos conforme a Tabela 31, proveniente da mesma placa produzida para os testes de absorção de água e gelificação.

Tabela 31 - Composição Química dos Protótipos para teste do ângulo de Contato.

\begin{tabular}{|l|l|}
\hline Formulações & Base Química Da Síntese \\
\hline Epóxi 2 & DGEBA/IPDA/ Mica sililada \\
\hline Epóxi 3 & Epóxi DGEBA/IPDA/Mica não sililada \\
\hline NIPU 2 & CCGEBA /IPDA/ / Mica Sililada com APTS ,razão equivalentes $1: 1$ \\
\hline HNIPU 2 & CCGEBA/IPDA/DGEBA/Mica não sililada, razão equivalentes $1: 1$ \\
\hline HNIPU 3 & CCGEBA/IPDA /DGEBA/Mica sililada, razão equivalentes 1:1) \\
\hline
\end{tabular}

Fonte: elaborado pelo próprio autor, 2019.

Todos os compósitos testados apresentaram baixa histerese (ver Tabela 32), ou seja, a diferença entre o ângulo direito e esquerdo da gota d'agua sobre os materiais. Isto indica que há uma homogeneidade morfológica e química na superfície na escala microscópica deste ensaio.

Fazendo a representação Gráfica dos dados, considerando o valor das médias do ângulo de contato podemos melhor visualizar na Figura 111 o comportamento dos protótipos avaliados.

As amostras de compósito com HNIPU e as amostras epóxi apresentam menor molhabilidade e menor energia de superfície que as mesmas sem o uso da mica sililada, portanto, há um forte indício que os grupos bisfenol A estejam majoritariamente ocupando a superfície dos compósitos. Essa constatação é ainda mais clara ao se observar o Apêndice M, página 262, onde pode ser visto a fotografia da gota para as formulações das HNIPU e no Apêndice $\mathrm{N}$ da página 263, a gota para as formulações do sistema epóxi, onde fica evidente essa observação. 
Tabela 32 - Dados obtidos no Teste de molhabilidade via medida do ângulo de Contato.

\begin{tabular}{|c|c|c|c|c|c|}
\hline & Dados & Tempo [s] & Âng.Esquerdo $\left[^{\circ}\right]$ & Ang.direito $\left[{ }^{\circ}\right]$ & Ang. Médio $\left[{ }^{\circ}\right]$ \\
\hline \multirow[t]{6}{*}{ HNIPU 2} & Media & 5 & 63,54 & 64,21 & 63,88 \\
\hline & Desvio Padrão & 2,96 & 5,32 & 4,94 & 5,11 \\
\hline & Pontos Usados & 61 & 29 & 29 & 29 \\
\hline & Pontos Descartados & 0 & 32 & 32 & 32 \\
\hline & & & & & \\
\hline & Dados & Tempo [s] & Âng.Esquerdo $\left[{ }^{\circ}\right]$ & Ang.direito $\left[{ }^{\circ}\right]$ & Ang. Médio $\left[{ }^{\circ}\right]$ \\
\hline \multirow[t]{6}{*}{ HNIPU 3} & Media & 4,91 & 92,4 & 89,78 & 91,1 \\
\hline & Desvio Padrão & 2,91 & 1,4 & 4,97 & 2,64 \\
\hline & Pontos Usados & 60 & 44 & 44 & 44 \\
\hline & Pontos Descartados & 0 & 16 & 16 & 16 \\
\hline & & & & & \\
\hline & Dados & Tempo [s] & Âng.Esquerdo $\left[{ }^{\circ}\right]$ & Ang.direito $\left[{ }^{\circ}\right]$ & Ang. Médio $\left[{ }^{\circ}\right]$ \\
\hline \multirow[t]{6}{*}{ EPÓXI 3} & Media & 5 & 73,08 & 72,64 & 72,86 \\
\hline & Desvio Padrão & 2,96 & 1,7 & 2,4 & 2 \\
\hline & Pontos Usados & 61 & 26 & 26 & 26 \\
\hline & Pontos Descartados & 0 & 35 & 35 & 35 \\
\hline & & & & & \\
\hline & Dados & Tempo [s] & Âng.Esquerdo [ $\left.{ }^{\circ}\right]$ & Ang.direito $\left[{ }^{\circ}\right]$ & Ang. Médio $\left[{ }^{\circ}\right]$ \\
\hline \multirow[t]{6}{*}{ EPÓXI 2} & Media & 4,92 & 95,93 & 94,84 & 95,38 \\
\hline & Desvio Padrão & 2,91 & 0,91 & 0,39 & 0,58 \\
\hline & Pontos Usados & 60 & 56 & 56 & 56 \\
\hline & Pontos Descartados & 0 & 4 & 4 & 4 \\
\hline & & & & & \\
\hline & Dados & Tempo [s] & Âng.Esquerdo [ $\left.{ }^{\circ}\right]$ & Ang.direito $\left[{ }^{\circ}\right]$ & Ang. Médio $\left[{ }^{\circ}\right]$ \\
\hline \multirow[t]{4}{*}{ NIPU 2} & Media & 4,91 & 49,96 & 46,65 & 48,31 \\
\hline & Desvio Padrão & 2,91 & 5,69 & 6,08 & 5,87 \\
\hline & Pontos Usados & 60 & 60 & 60 & 60 \\
\hline & Pontos Descartados & 0 & 0 & 0 & 0 \\
\hline
\end{tabular}

Fonte: elaborado pelo próprio autor, 2019 
Figura 111 - Medidas de ângulo de Contato.

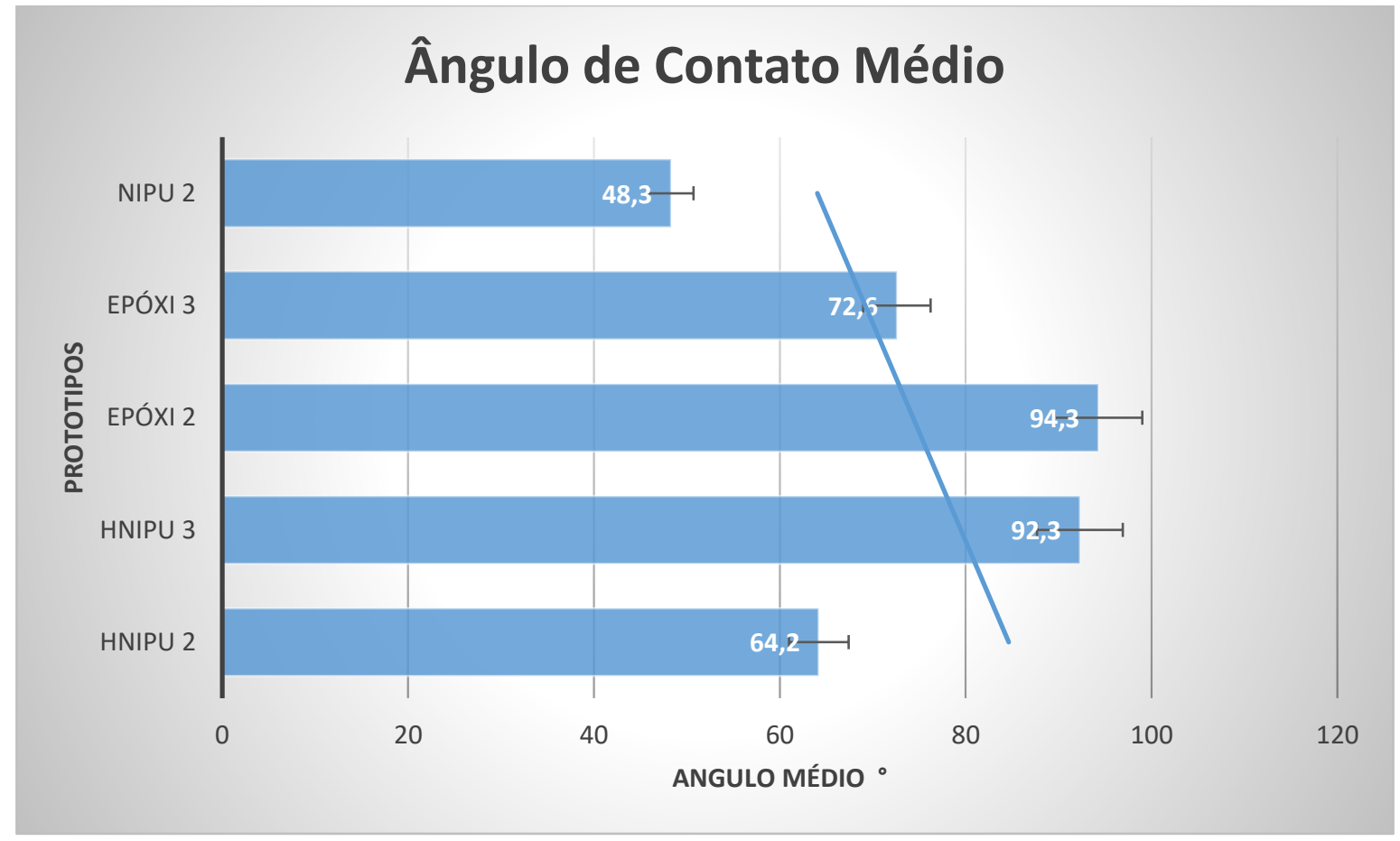

Fonte: elaborado pelo próprio autor, 2019.

No caso da NIPU podemos verificar que mesmo usando a mica sililada temos uma maior molhabilidade, portanto, estas amostras apresentam uma maior energia superficial. Esse dado é bem coerente com o visto no teste de \% de absorção de água. No Apêndice O na página 263 observa-se a fotografia da gota da NIPU, formulação 4.

Comentários Iniciais: os dados de molhabilidade dentro da premissa de um material para uso como isolante no hidrogerador, traz informações importantes, o sistema HNIPU com mica tratada com aminossilano se mostra dentro da margem de erro similar ao epóxi que utiliza mica tratada na sua composição. Os dados são coerentes com os já obtidos na absorção de água e reforça um parâmetro importante, a HNIPU, produzida com mica tratada com aminossilano pode ser direcionada para aplicações onde a hidrofobicidade se faz necessário. No caso da NIPU, mesmo com a mica tratada com aminossilano apresenta uma maior molhabilidade, pode se atribuir ao já encontrado nos testes de absorção de água e \% de gel, tem-se deficiência na reticulação. 


\subsection{Estabilidade Térmica avaliada por Termogravimetria (TGA)}

Na Tabela 33 estão as descrições dos materiais ensaiados de forma a permitir ao leitor acompanhar a discussão que se segue.

Tabela 33 - Descrição das amostras usadas na avaliação via TGA.

\begin{tabular}{|r|l|}
\hline Formulas & Base Química das Sínteses. \\
\hline NIPU 2 & CCGEBA/IPDA/Mica sililada) razão equivalente 1,0:1,0 \\
NIPU 3 & CCGEBA/IPDA/MICA sililada) razão equivalente 1,5:1,0 \\
NIPU 4 & CCGEBA/IPDA/MICA não sililada) razão equivalente 1:1,0 \\
Epóxi 1 & DGEBA/IPDA//sem mica \\
Epóxi 2 & DGEBA/IPDA/mica sililada. \\
Epóxi 3 & DGEBA/IPDA/mica não sililada \\
HNIPU 1 & CCGEBA/IPDA/ DGEBA) sem mica. \\
HNIPU 2 & CCGEBA IPDA/DGEBA)/Mica não sililada razão equivalente 1,0:1,0 \\
HNIPU 3 & CCGEBA/IPDA/DGEBA)/Mica sililada razão equivalente 1,0:1,0 \\
HNIPU 4 & CCGEBA/TETA/DGEBA) Mica sililada razão equivalente $1,0: 1,0$ \\
\hline
\end{tabular}

Fonte: elaborado pelo próprio autor, 2019.

Para facilitar o entendimento, as curvas termoanalíticas e tabelas foram agrupadas em classes de materiais, descritos a seguir: materiais base NIPU, materiais base Epóxi e os materiais base HNIPU.

Avaliação Protótipos NIPU: Observa-se na Figuras 112 a 115 que as amostras base NIPU apresentam três faixas características de perda de massa, descritas a seguir:

1) Entre $25{ }^{\circ} \mathrm{C}$ e $200{ }^{\circ} \mathrm{C}$ há uma pequena perda de massa. Neste intervalo de temperatura, as perdas certamente estariam relacionadas a liberação de solvente em conjunto com reações de desidroxilação por condensação. As reações de condensação entre grupos amina e epóxi e amina e ciclocarbonato liberam pequenas moléculas que podem ficar aprisionadas no interior do material e serem liberadas com leve aquecimento. É importante salientar que esta última contribuição não deve ser muito significativa, pois na Tabela 34 e na Figura 116 as diferenças em perda de massa nesta faixa são muito pequenas. Difícil afirmar que este fato comprovaria que a maioria dos grupos amino da superfície da mica sililada reagem com os grupos ciclocarbonato tendo em vista a baixa fração molar destes grupos. Contudo, há um aumento de cerca de 4\% entre a amostra NIPU 4 e NIPU 3 que pode indicar que na NIPU 4, amostra com mica não sililada, haveria mais grupos amino e ciclocarbonatos sem reagir. Em tempo, há de se lembrar que as amostras 4 e 3 se dissolvem completamente em THF, portanto, 
não reticulam completamente e levam a terem possibilidade de material volátil nessa faixa de temperatura.

2) Entre 240 a $450{ }^{\circ} \mathrm{C}$ ocorrem maiores perdas, que segundo Cornille (2016) et al, correspondem principalmente a degradação da ligação uretana com liberação de pequenas moléculas como $\mathrm{CO}_{2}$ e amônia [183]. Novamente, a amostra NIPU 4 apresenta menor estabilidade térmica quando comparada aos outros materiais. Esta informação tomada em conjunto com a dissolução em THF da amostra, pode indicar que neste caso há menor taxa de condensação/reticulação das amostras, sendo seus monômeros ou oligômeros de menor massa molar formados, portanto, menos estáveis termicamente. Outra possibilidade, seria de que a mica não sililada por não estar ligada a estrutura como híbrido pode aumentar o espaço livre e dessa forma facilita a degradação da parte orgânica da estrutura formada.

3) $\mathrm{Na}$ última faixa de temperatura entre 450 e $800{ }^{\circ} \mathrm{C}$ temos a decomposição do restante da cadeia carbônica dos materiais base NIPU $[182,183]$. Aqui temos a maior perda na NIPU 3 obtida com excesso de ciclocarbonato, um fato que deve ser melhor investigado por técnicas como espectroscopia de massa para qualificar o material volatizado nessa temperatura.

Figura 112 - Curvas termogravimétricas dos materiais base NIPU.

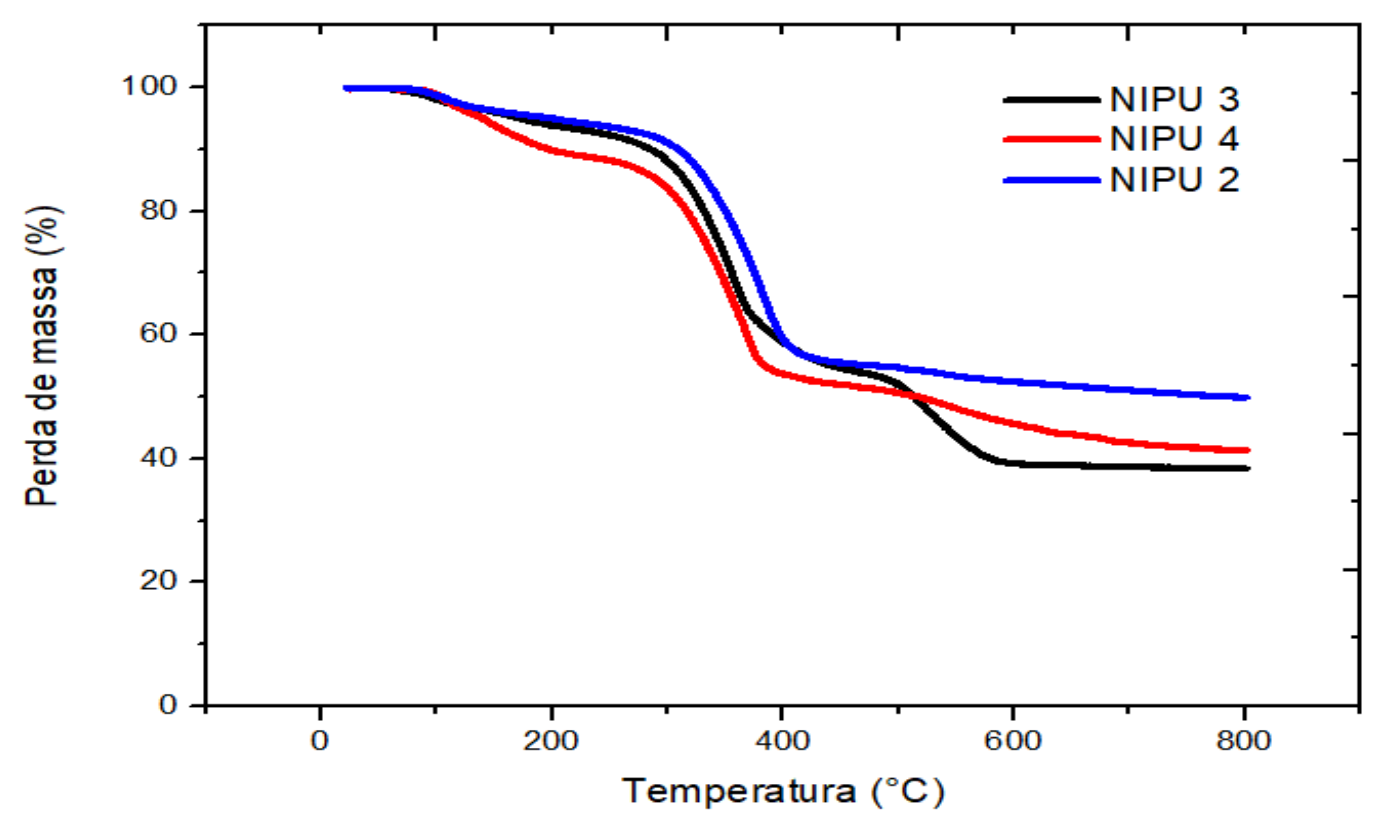

Fonte: elaborado pelo próprio autor, 2019. 
Figura 113 - Comportamento Perda de Massa no Protótipo NIPU 3.

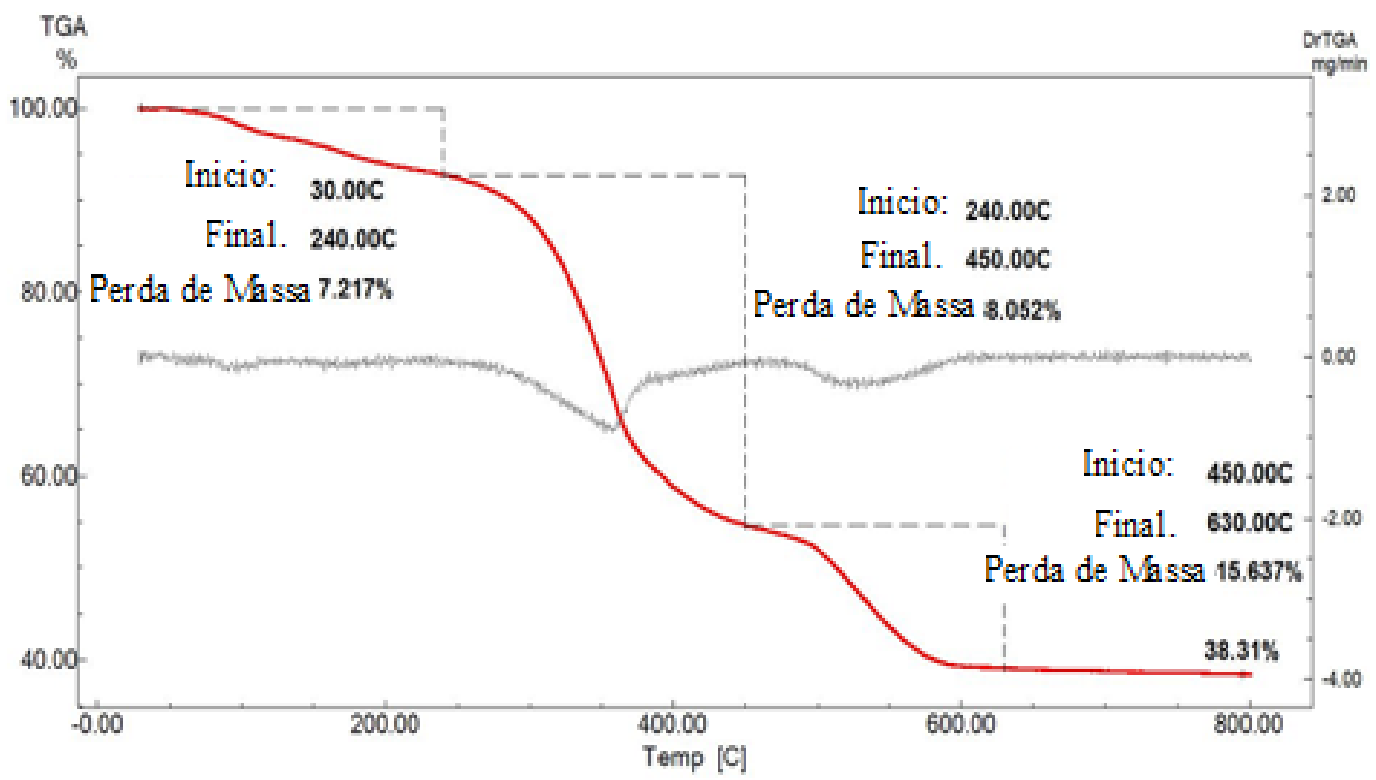

Fonte: elaborado pelo próprio autor, 2019.

Figura 114- Comportamento Perda de Massa Protótipo NIPU 4

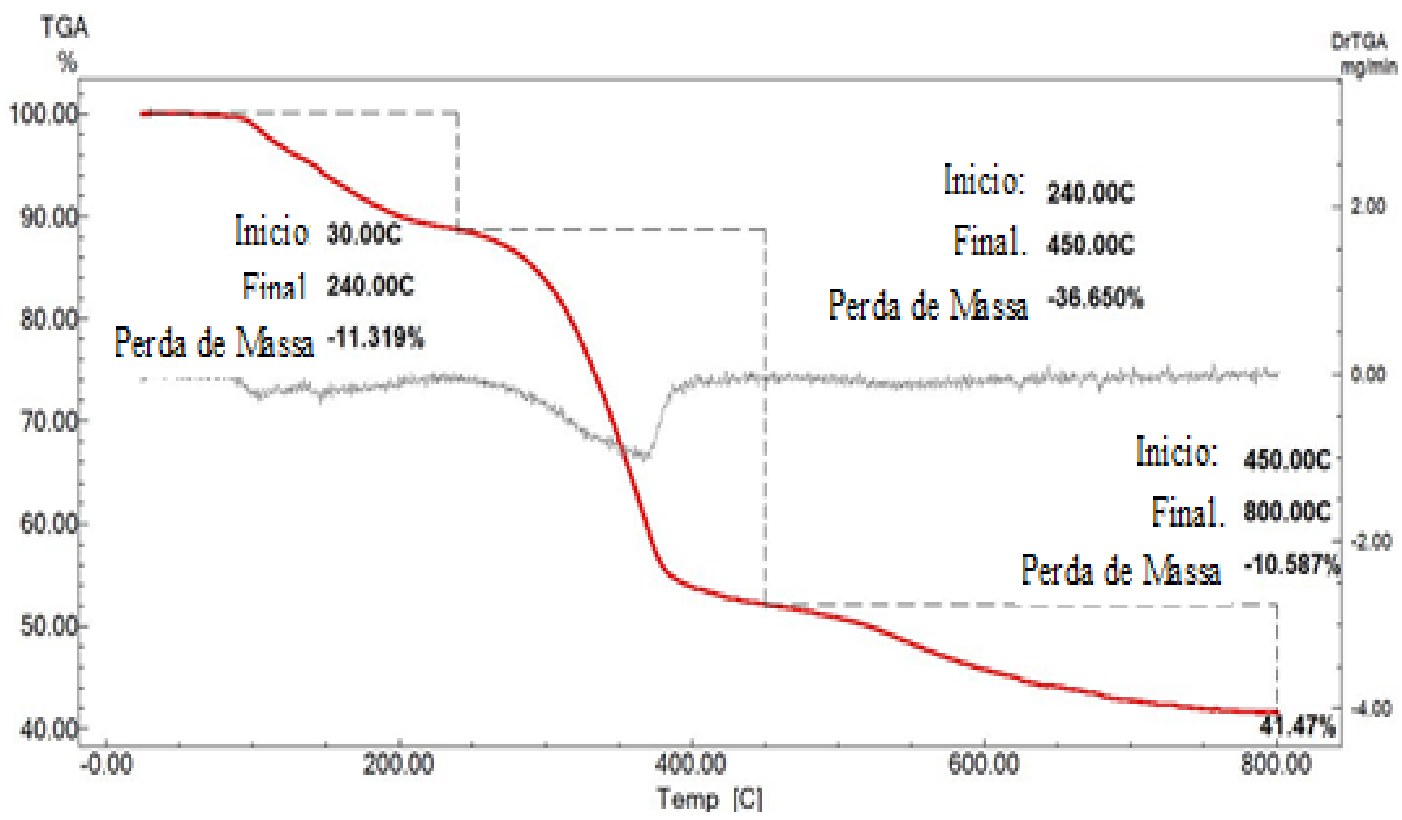

Fonte: elaborado pelo próprio autor, 2019. 
Figura 115 - Comportamento Perda de Massa Protótipo NIPU 2.

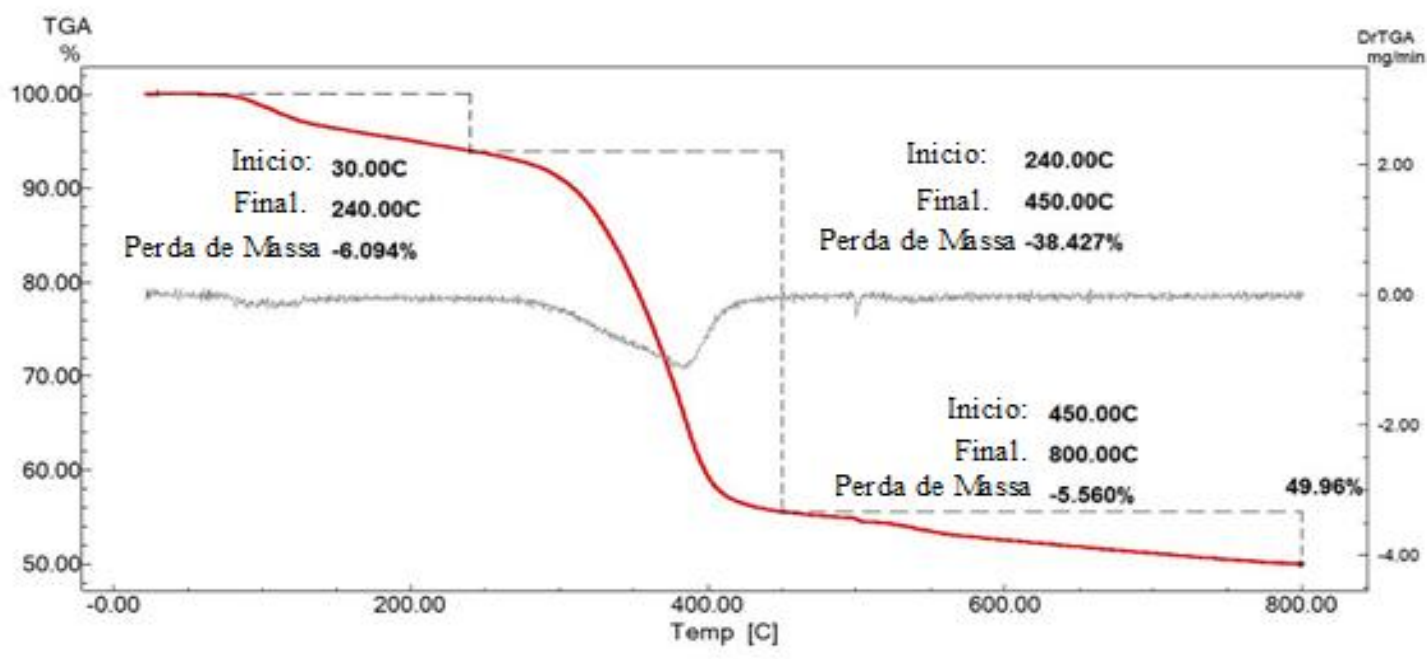

Fonte: elaborado pelo próprio autor, 2019.

Tabela 34 - Resumo da \% de Perdas de Massa por faixa de temperatura.

\begin{tabular}{l|l|l|l}
\hline \multicolumn{1}{c|}{ Temperatura $\left({ }^{\circ} \mathrm{C}\right)$} & NIPU 3 & NIPU 4 & NIPU 2 \\
\hline 30 a 240 & 7,22 & 11,32 & 6,09 \\
\hline 240 a 450 & 38,05 & 36,65 & 38,43 \\
\hline 450 a 800 & 15,637 & 10,59 & 5,56 \\
\hline \multicolumn{2}{|l}{ Fonte: elaborado pelo próprio autor, 2019. }
\end{tabular}

Fonte: elaborado pelo próprio autor, 2019.

Figura 116 - Representação Gráfica do \% de Perda de Massa (NIPU).

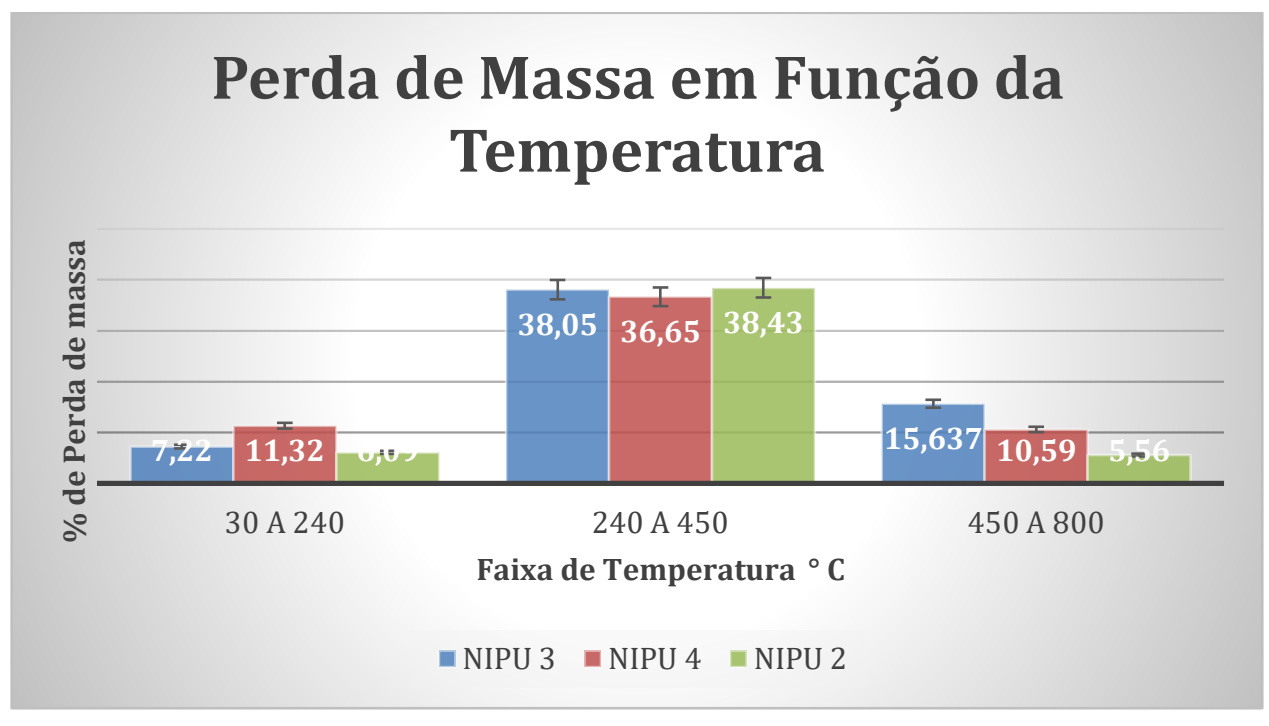

Fonte: elaborado pelo próprio autor, 2019. 


\section{b) Avaliação Protótipos Epóxi}

De uma maneira geral os resultados de TGA para o sistema epóxi, Figuras 117 a 121 e Tabela 35, ao contrário das amostras NIPU's apresentam apenas duas faixas de eventos térmicos, assim como mostram melhor estabilidade térmica que os NIPU’s.

Na primeira faixa de temperatura entre a temperatura ambiente e $240{ }^{0} \mathrm{C}$ ocorre menor perda de massa que nas amostras NIPU, evidenciando menor conteúdo de solventes e/ou melhor reticulação. Neste ponto, é útil voltar à Figura 110 e observar que o conjunto de amostras epóxi apresenta alto grau de gelificação/reticulação.

Entre 240 e $800^{\circ} \mathrm{C}$ ambas as amostras com mica perdem a mesma quantidade de massa, indicando que a quantidade de carga mineral é a mesma. Da mesma forma, o início e fim da perda causada pela aplicação do evento térmico nestas amostras é similar. Portanto, não há significante a diferença de estabilidade entre os materiais contendo a mica sem sililação e com sililação. Comparado com dados em sistemas similares, vemos que Urbaniak (2007), [207] encontrou a mesma estabilidade do sistema DGEBA/TETA com o que encontramos, para o sistema DGEBA/IPDA. Contudo, comparando este sistema epóxi com o sistema NIPU, existe uma robustez evidente do sistema epóxi.

Figura 117 - Comportamento termogravimétrico para os materiais base epóxi.

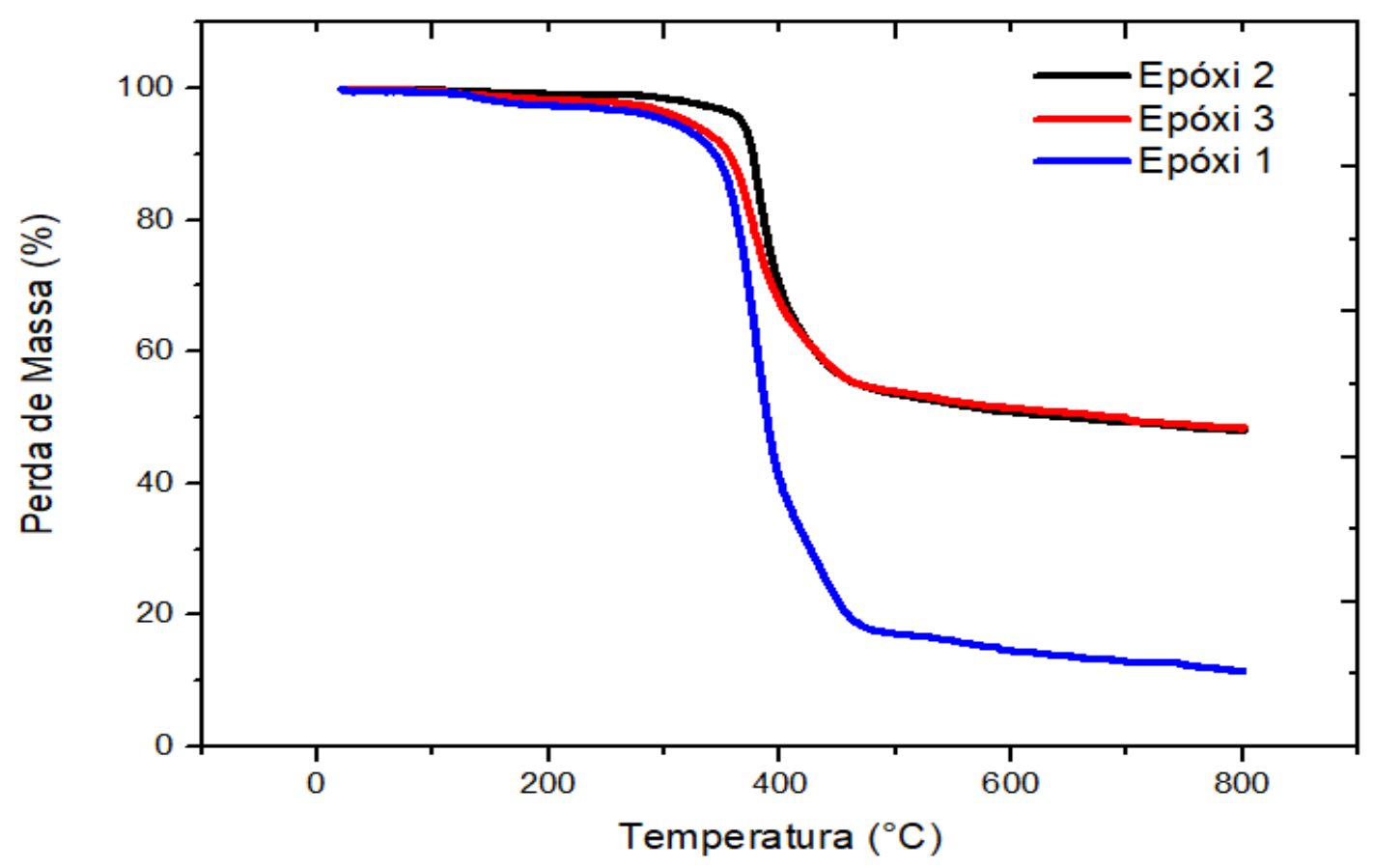

Fonte: elaborado pelo próprio autor, 2019. 
Figura 118 - Comportamento Perda de Massa formulação Epóxi 2.

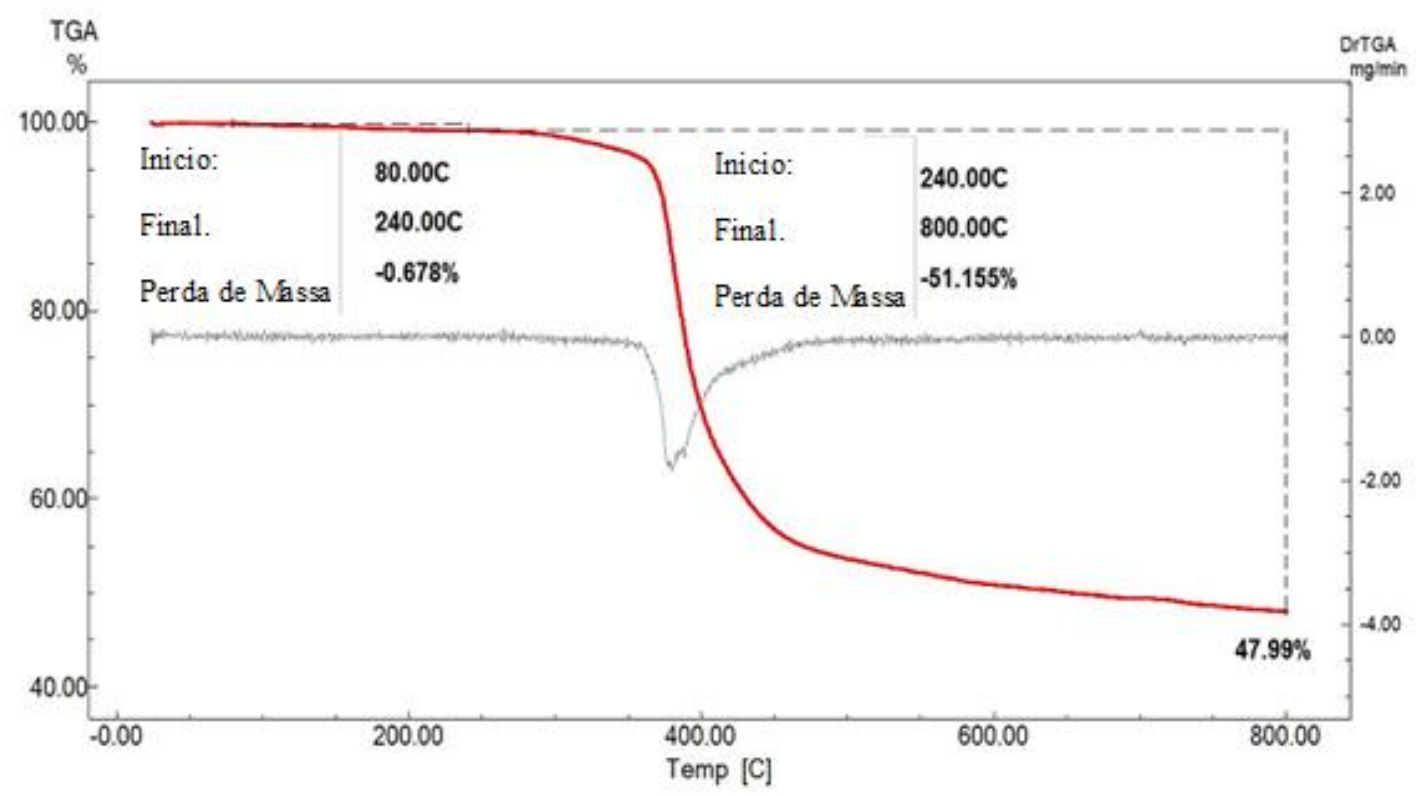

Fonte: elaborado pelo próprio autor, 2019.

Figura 119 - Comportamento Perda de Massa Epóxi 3

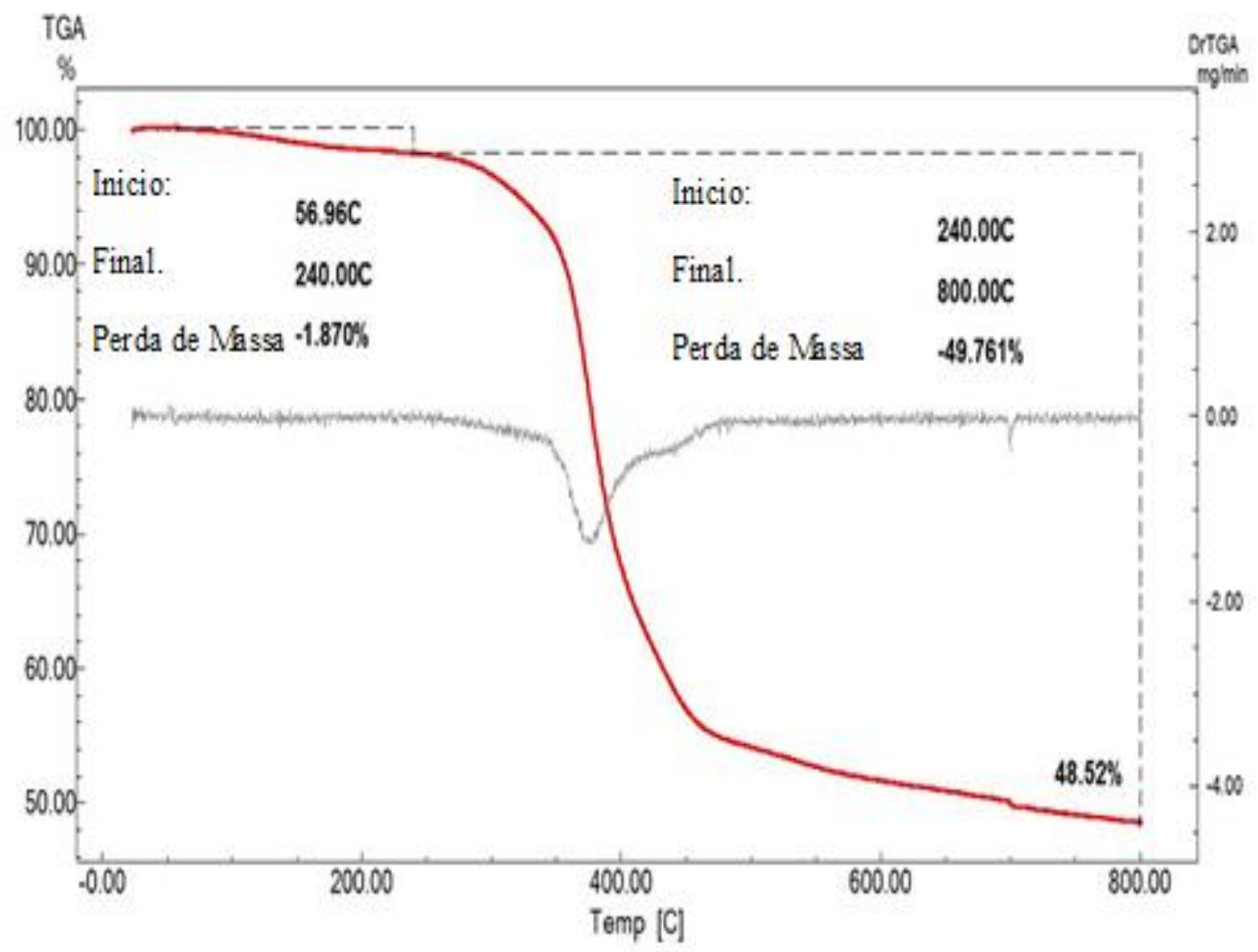

Fonte: elaborado pelo próprio autor, 2019. 
Figura 120 - Comportamento Perda de Massa formulação Epóxi 1.

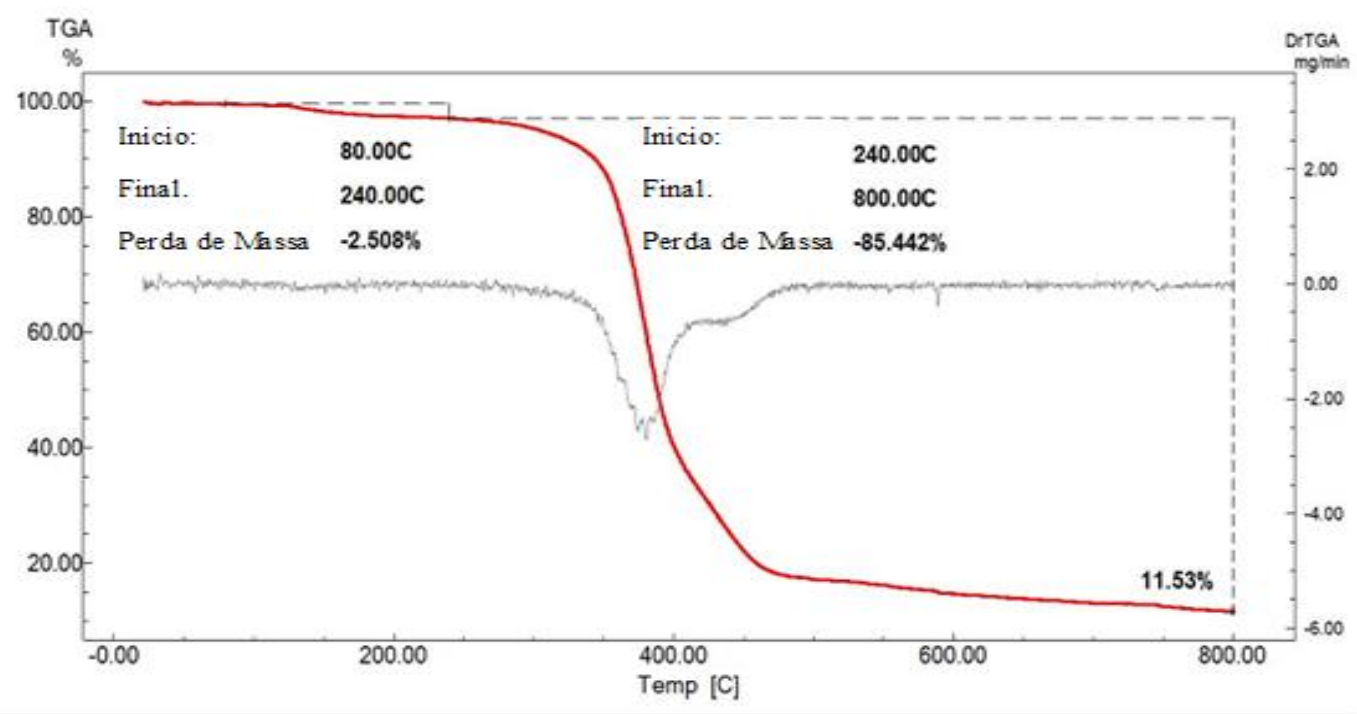

Fonte: elaborado pelo próprio autor, 2019.

Tabela 35 - Quadro resumo da \% de Perdas de massa formulações epóxi em faixa de temperatura.

\begin{tabular}{|c|c|c|c|}
\hline Temperatura $\left({ }^{\circ} \mathrm{C}\right)$ & Epóxi 2 & Epóxi 3 & Epóxi 1 \\
\hline até 240 & 0,62 & 1,87 & 2,51 \\
\hline 240 a 800 & 51,16 & 49,76 & 85,44 \\
\hline
\end{tabular}

Fonte: elaborado pelo próprio autor, 2019.

Figura 121 - Representação gráfica \% Perda de Massa em função da Temperatura.

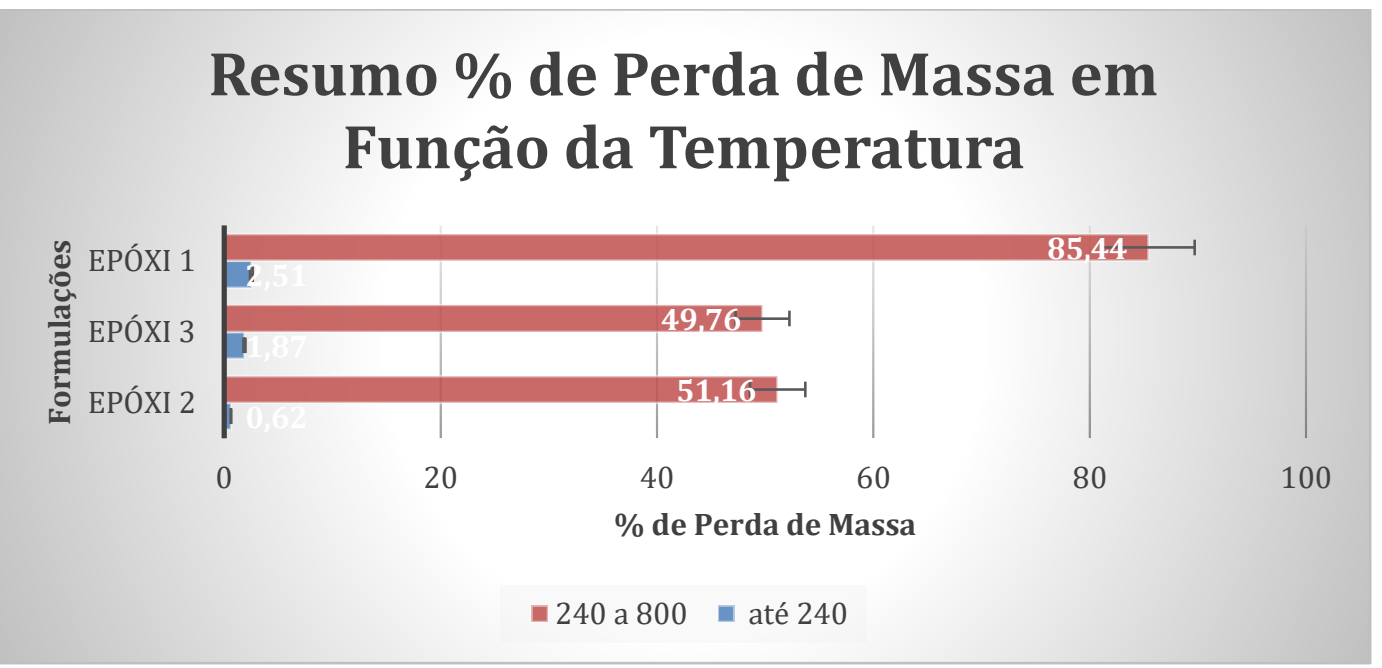

Fonte: elaborado pelo próprio autor, 2019. 


\section{b) Avaliação Protótipos HNIPU.}

Analisando o conjunto das Figuras 122 a 127 e a Tabela 36, pode-se observar dois eventos térmicos em consonância com as amostras base epóxi e em contraposição com as amostras base NIPU, exceção para a HNIPU usando TETA como amina e com mica sililada como agente de reforço (HNIPU 4) que apresenta três regiões. Assim como nos materiais base NIPU há uma maior perda de massa, entre 4 e $9 \%$, na faixa entre $25^{\circ}$ e $240^{\circ} \mathrm{C}$. Assim como no caso da NIPU, a rota de obtenção da HNIPU se faz usando solvente como meio para diluição do ciclocarbonato, pode ser atribuído essa maior perda de massa a possível solvente residual que não foi eliminado durante o processo de cura. Como medida futura, faz-se necessário usando técnicas de espectroscopia de massa, buscar qualificar que tipo de material está sendo eliminado nessa faixa de temperatura. Como será discutido posteriormente nas técnicas térmicas, a HNIPU precisa de um tratamento de pós cura. Na análise de TGA, esse procedimento para a HNIPU não foi executado, dessa forma pode haver monômeros não reticulados e que se volatilizam nessa faixa de temperatura. Como esperado, o material HNIPU sem mica apresenta a maior perda de massa, Tabela 36 e Figura 127, refletindo a diluição da matéria orgânica pela adição de carga mineral.

Figura 122 - Comportamento Perda de Massa Amostras HNIPU.

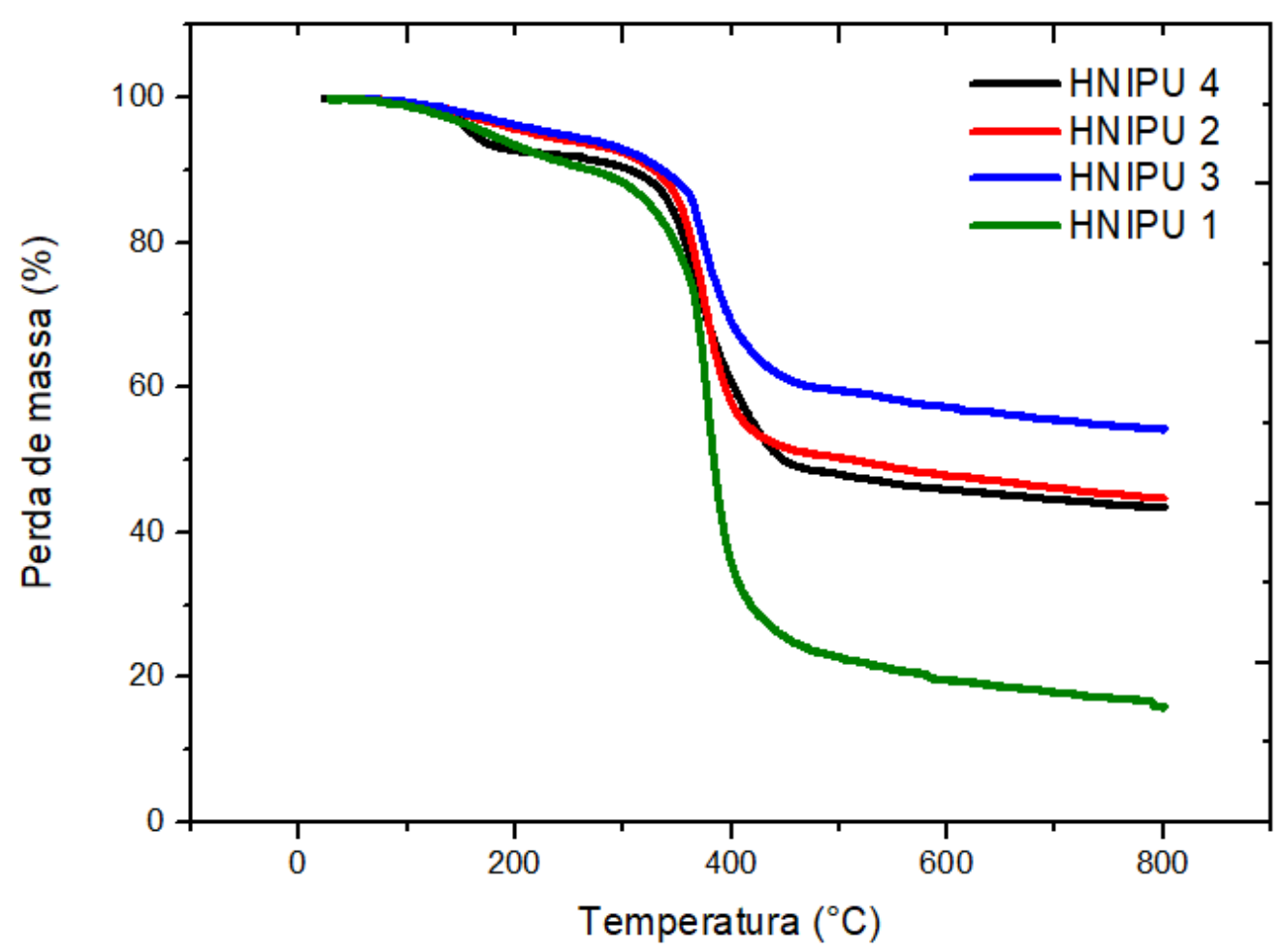

Fonte: elaborado pelo próprio autor, 2019. 
Observando a Figura 122 vê se que a curva termoanalítica para o material HNIPU com TETA (HNIPU 4 ) apresenta dois eventos térmicos entre 50 e $240^{\circ} \mathrm{C}$. Na Figura 109, é possível constatar que esta amostra tem o menor grau de reticulação, assim, os seus grupos amina em grande parte não reagiram, a existência destes grupos pode levar a um aumento na absorção de pequenas moléculas de água que seriam responsáveis pelo evento térmico na menor faixa de temperatura, enquanto, o segundo evento térmico entre $140^{\circ} \mathrm{C}$ poderia ser atribuído a evaporação de TETA [214].

Figura 123 - Comportamento Perda de Massa Protótipo HNIPU com TETA e mica sililada (HNIPU 4).

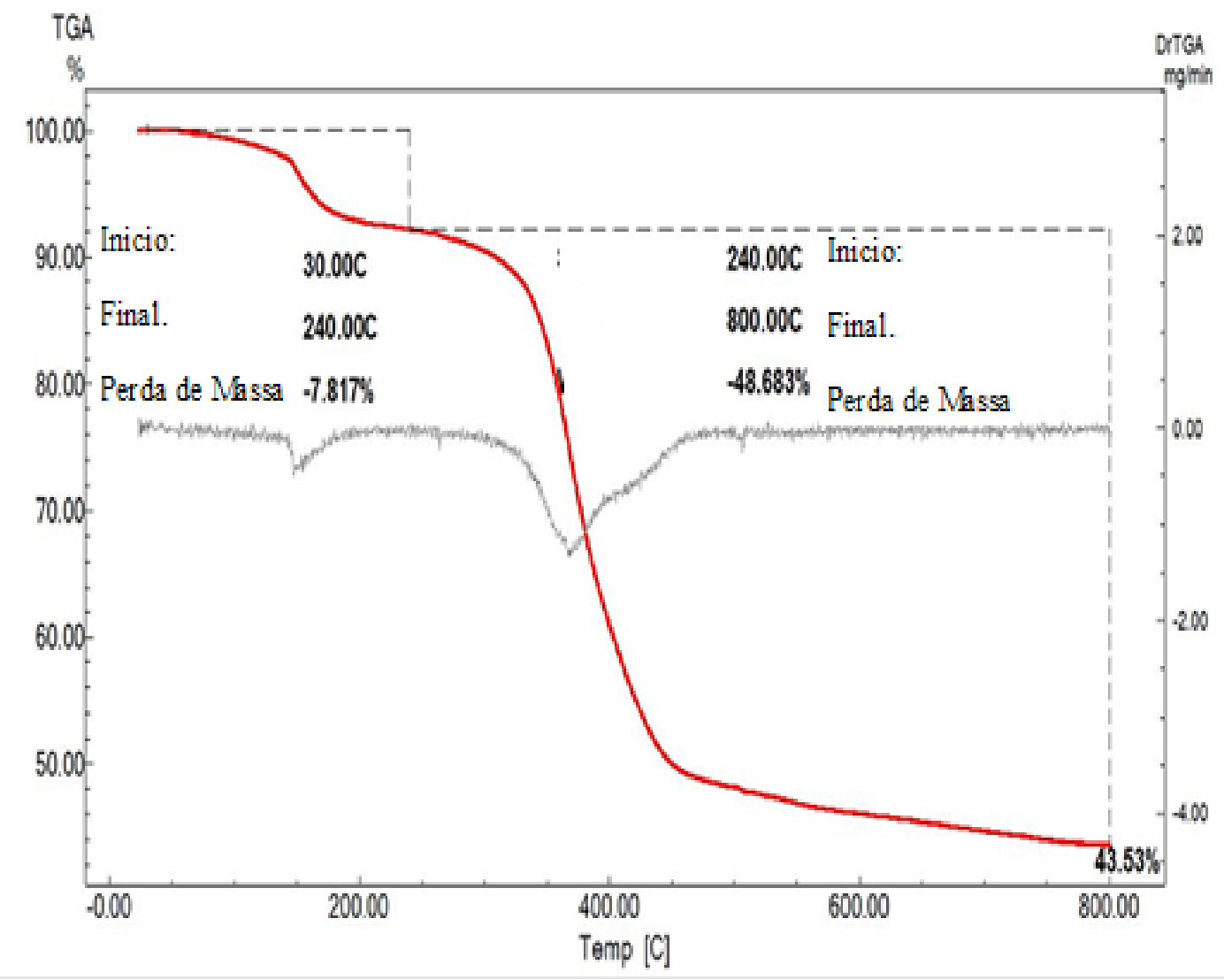

Fonte: elaborado pelo próprio autor, 2019.

Comparando-se a Figura 122 com as Figuras 123, 124 e 126, assim como, observado os valores de perda de massa na Tabela 33 fica clara a menor estabilidade da HNIPU com TETA dentre os materiais base HNIPU contendo mica, pois, este apresenta a maior perda de massa. Comparando-se com o trabalho realizado por Ke (2017) et all [184] de obtenção de HNIPU, tem se valores similares de perda de massa em função da densidade de reticulação. Da mesma forma, onde Ke et all usaram amina alifática (TETA) obteve assim como nessa 
Tese, maior perda de massa em menor temperatura, evidenciando o efeito da reticulação como fator principal para essa característica.

Figura 124 - Comportamento Perda de Massa Protótipo HNIPU com IPDA e mica não-sililada (HNIPU 2).

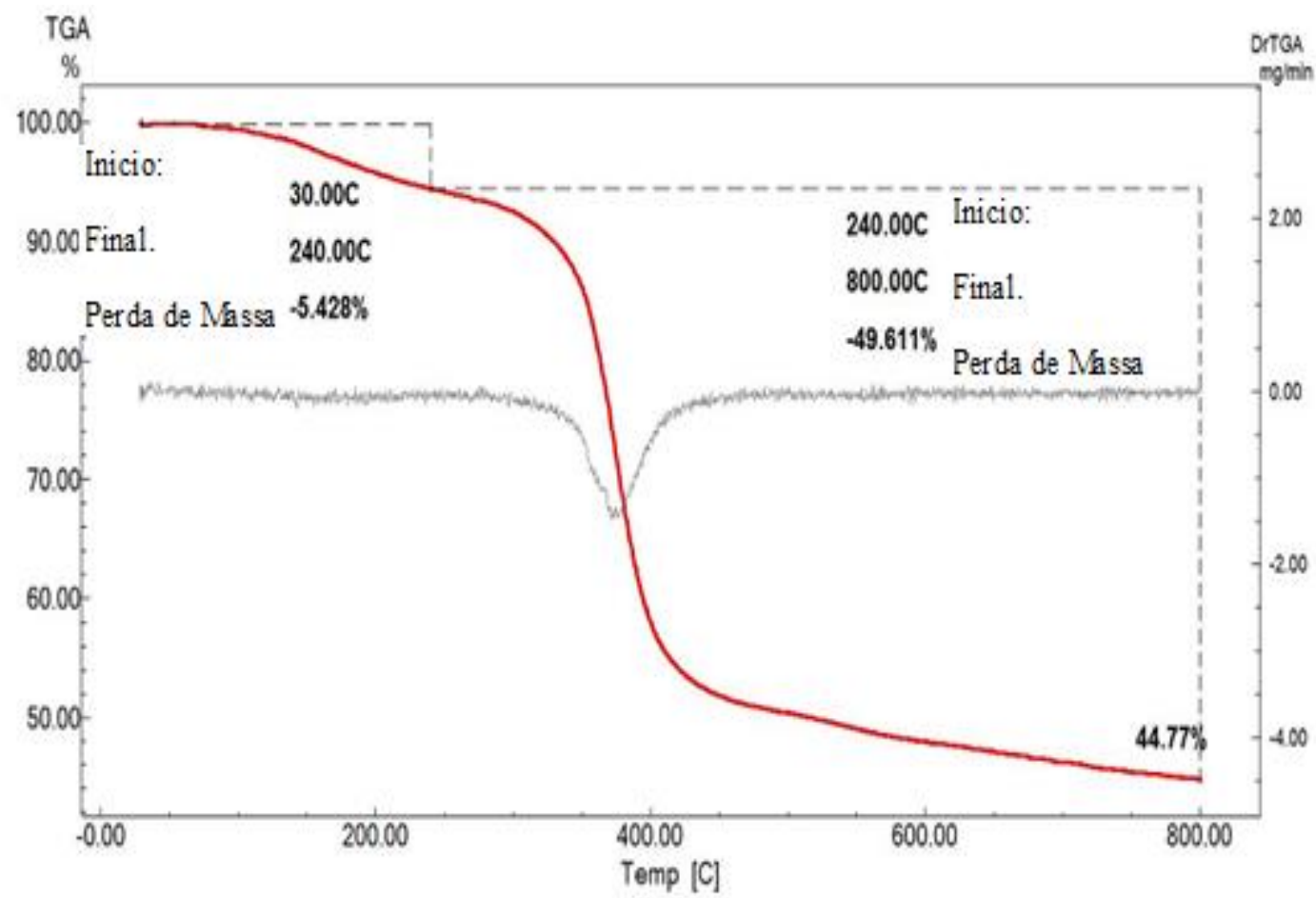

Fonte: elaborado pelo próprio autor, 2019.

Figura 125 - Comportamento da Perda de Massa Protótipo HNIPUcom IPDA e mica sililada (HNIPU 2).

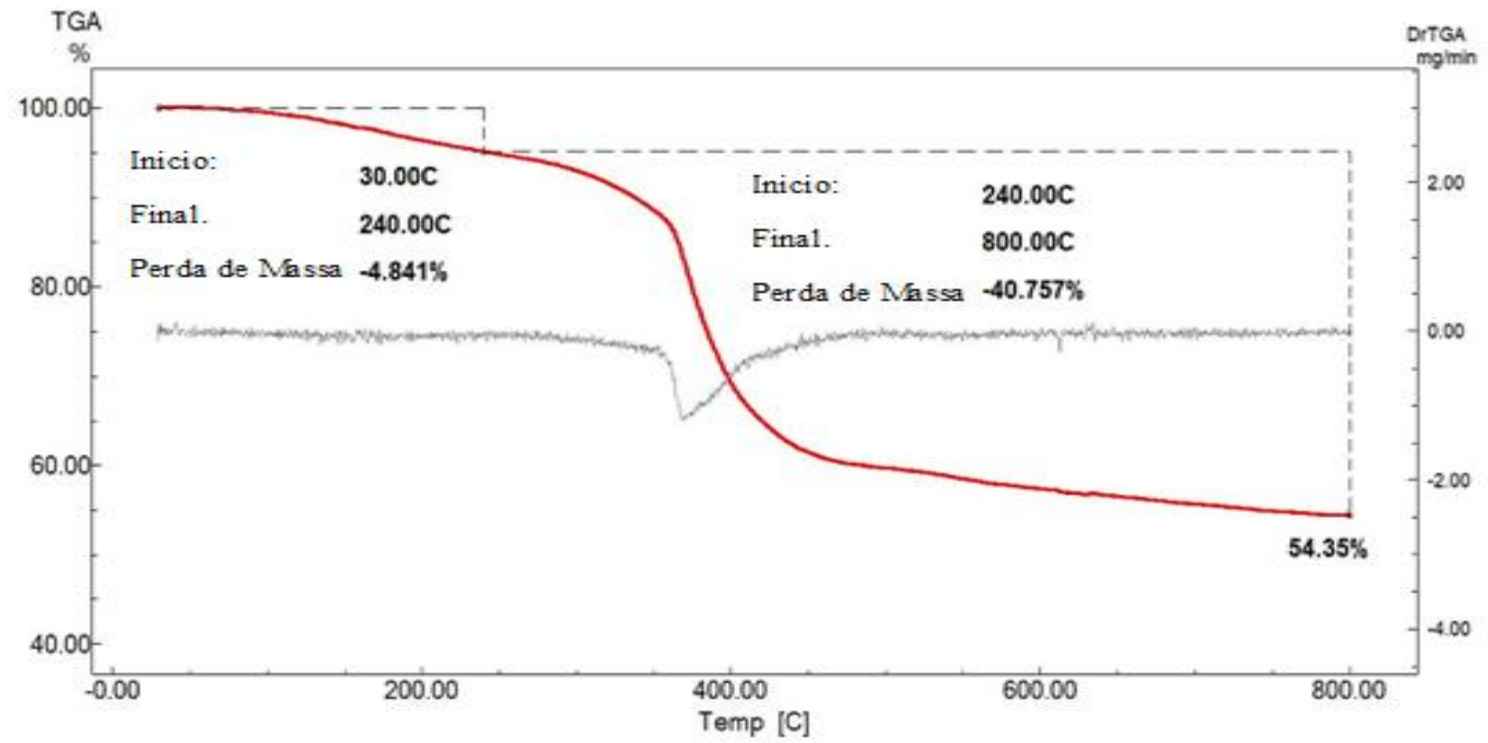

Fonte: elaborado pelo próprio autor, 2019. 
Figura 126 - Comportamento da Perda de Massa Protótipo HNIPU com IPDA e sem mica (HNIPU 1).

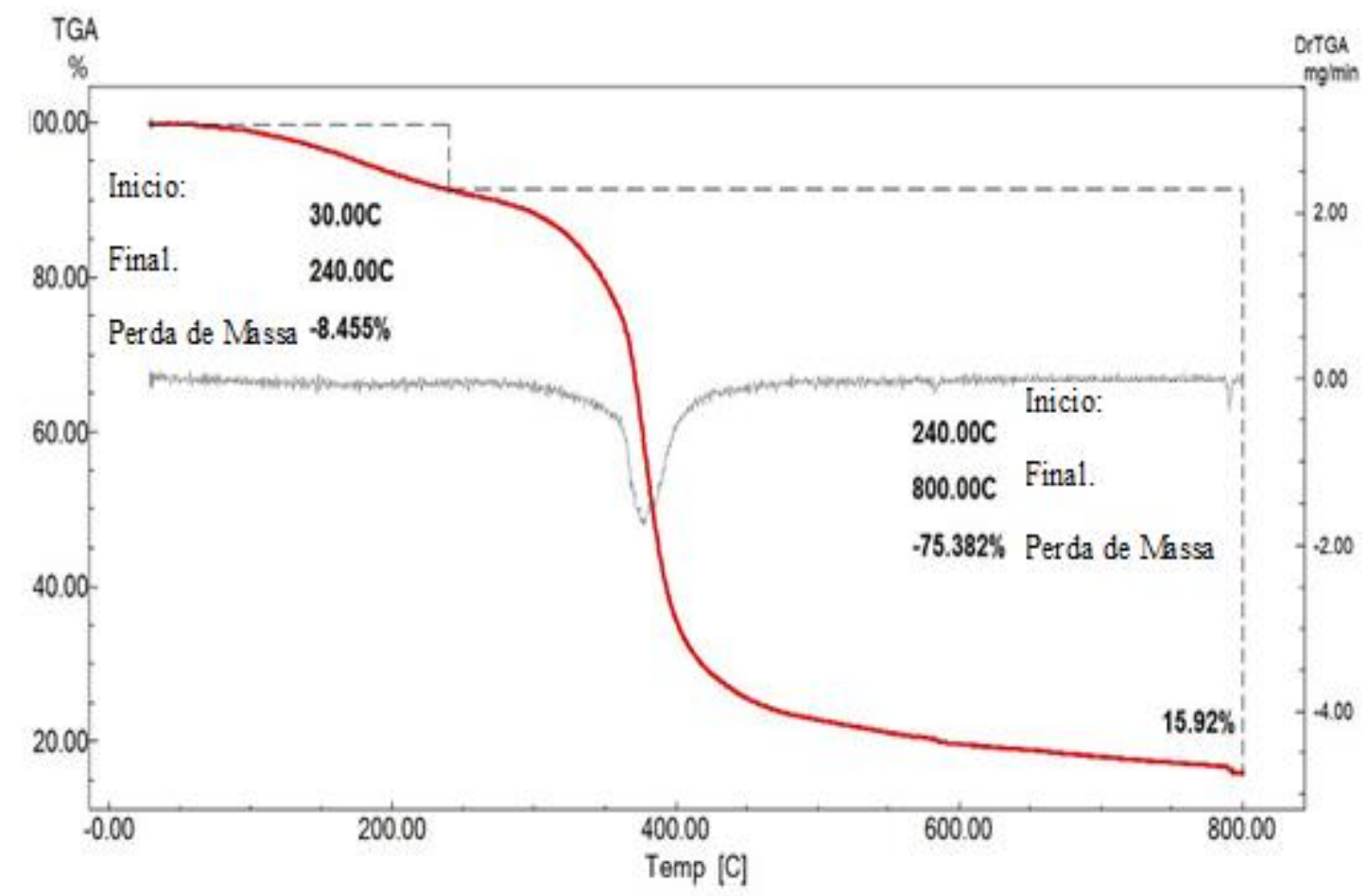

Fonte: elaborado pelo próprio autor, 2019.

Nas formulações HNIPU, assim como nos materiais base NIPU, há o impacto positivo da adição da mica sililada, e também o tipo de amina utilizada.

Tabela 36 - Resumo da \% de Perdas de Massa das HNIPU em faixa de temperatura.

\begin{tabular}{c|r|r|r|r}
\hline $\begin{array}{c}\text { Temperatura } \\
\left({ }^{\circ} \mathrm{C}\right)\end{array}$ & HNIPU 1 & HNIPU 2 & HNIPU 3 & HNIPU 4 \\
\hline até 240 & 8,45 & 5,43 & 4,84 & 8,45 \\
\hline 240 a 800 & 75,38 & 49,61 & 40,76 & 48,68 \\
\hline \multicolumn{4}{r}{} \\
\hline \multicolumn{4}{r|}{ Fonte: elaborado pelo próprio autor, 2019. }
\end{tabular}


Figura 127 - Representação Gráfica das Perdas de Massa nas HNIPUs

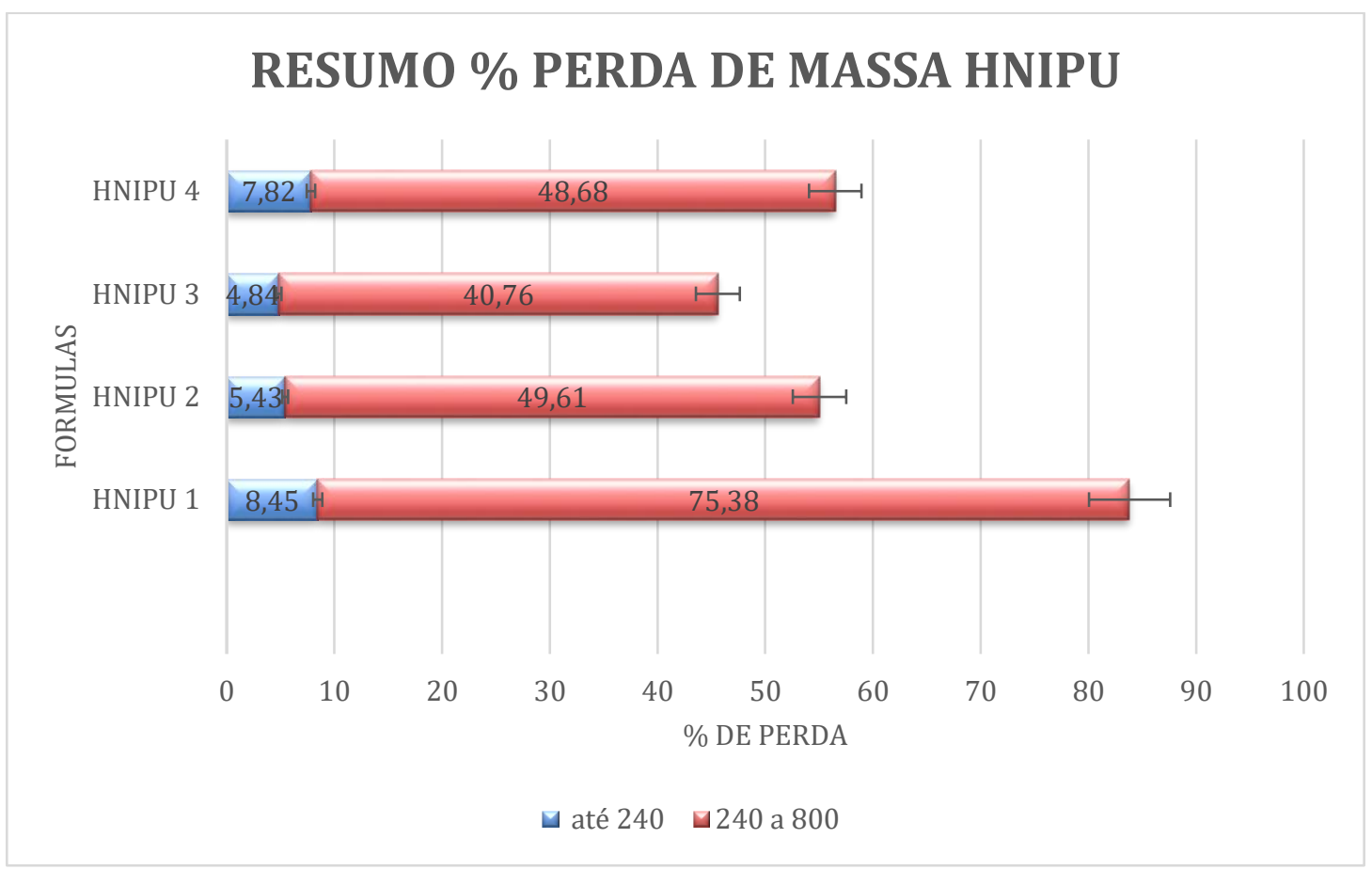

Fonte: elaborado pelo próprio autor, 2019.

Comentários Iniciais: A técnica de avaliação Térmica via TGA mostra que o sistema epoxido é superior aos sistemas HNIPU e NIPU. Os dados desse projeto mostram que há uma necessidade de verificar se a maior perda de massa na faixa até $240{ }^{\circ} \mathrm{C}$ foi causada pelo uso do meio solvente na diluição e preparação dos protótipos e principalmente checar se as amostras avaliadas por TGA sem a pós cura podem ter influenciado esse dado de perda de massa. Analisando os dados de Ke (2017) et al [184] vemos que a perda de massa acima de $5 \%$ ocorre no patamar superior a $260{ }^{\circ} \mathrm{C}$, evidenciando que a perda de massa se deve ao processo de não pós cura antes do teste de TGA.

Em relação a técnica de TGA e as premissas do projeto de isolação em Hidrogerador, a HNIPU pela similaridade de comportamento na faixa de operação do equipamento e da sobrecarga térmica, pode se afirmar que a HNIPU é uma opção, deste que se entenda o efeito do solvente residual e principalmente o mecanismo de pós cura desse sistema. 


\subsection{Avaliação DSC para os Protótipos}

As amostras utilizadas para o DSC são as mesmas do teste de TGA e provenientes da mesma placa curada. Devido ao resultado do TGA, foi realizada uma seleção dos sistemas dentro do escopo do projeto como um sistema alternativo ao epóxi (Tabela 37).

Tabela 37- Composição dos protótipos avaliados via DSC.

\begin{tabular}{|c|c|}
\hline Formulações & Composição Química dos Protótipos. \\
\hline NIPU 2 & CCGEBA/IPDA/mica sililada razão equivalente $1: 1$ \\
NIPU 4 & CCGEBA/IPDA/mica não-sililada razão equivalente $1: 1$ \\
Epóxi 2 & DGEBA/IPDA/MICA sililada \\
Epóxi '3 & DGEBA/IPDA/mica não-sililada \\
HNIPU 2 & CCGEBA/IPDA/ DGEBA) mica não-sililada razão equivalentes $1: 1$ \\
HNIPU 3 & CCGEBA/IPDA/DGEBA) /mica sililida razão equivalente $1: 1$ \\
HNIPU 4 & CCGEBA/TETA/DGEBA)/mica sililada razão equivalentes $1: 1$ \\
\hline
\end{tabular}

Fonte: elaborado pelo próprio autor, 2019.

Sistema NIPU: Nas curvas DSC das Figuras 128 e 129 fica muito clara a influência da presença da mica sililada com aminossilano, a $\mathrm{T}_{\mathrm{g}}$ sai de cerca de $7^{\circ} \mathrm{C}$ na amostra com mica não-sililada, NIPU 4, e vai para $41^{\circ} \mathrm{C}$ na NIPU 2. Tal deslocamento evidencia que o grupamento amino da superfície da mica participa da reticulação, em consonância com o que havia sido observado nos resultados de percentagem de gel. O valor de $7^{\circ} \mathrm{C}$ está dentro do encontrado para hidroxiuretanas de baixo grau de entrecruzamento como aquelas estudadas por Maisonneuve (2015) et al [155], assim como o valor de $41{ }^{\circ} \mathrm{C}$ é condizente com sistemas de hidroxiuretanas com alto grau de entrecruzamento como as derivadas de lignina obtida por Zhao (2015) et al [213]. 
Figura 128 - Curva de DSC para NIPU 4 após cura. (Segundo aquecimento).

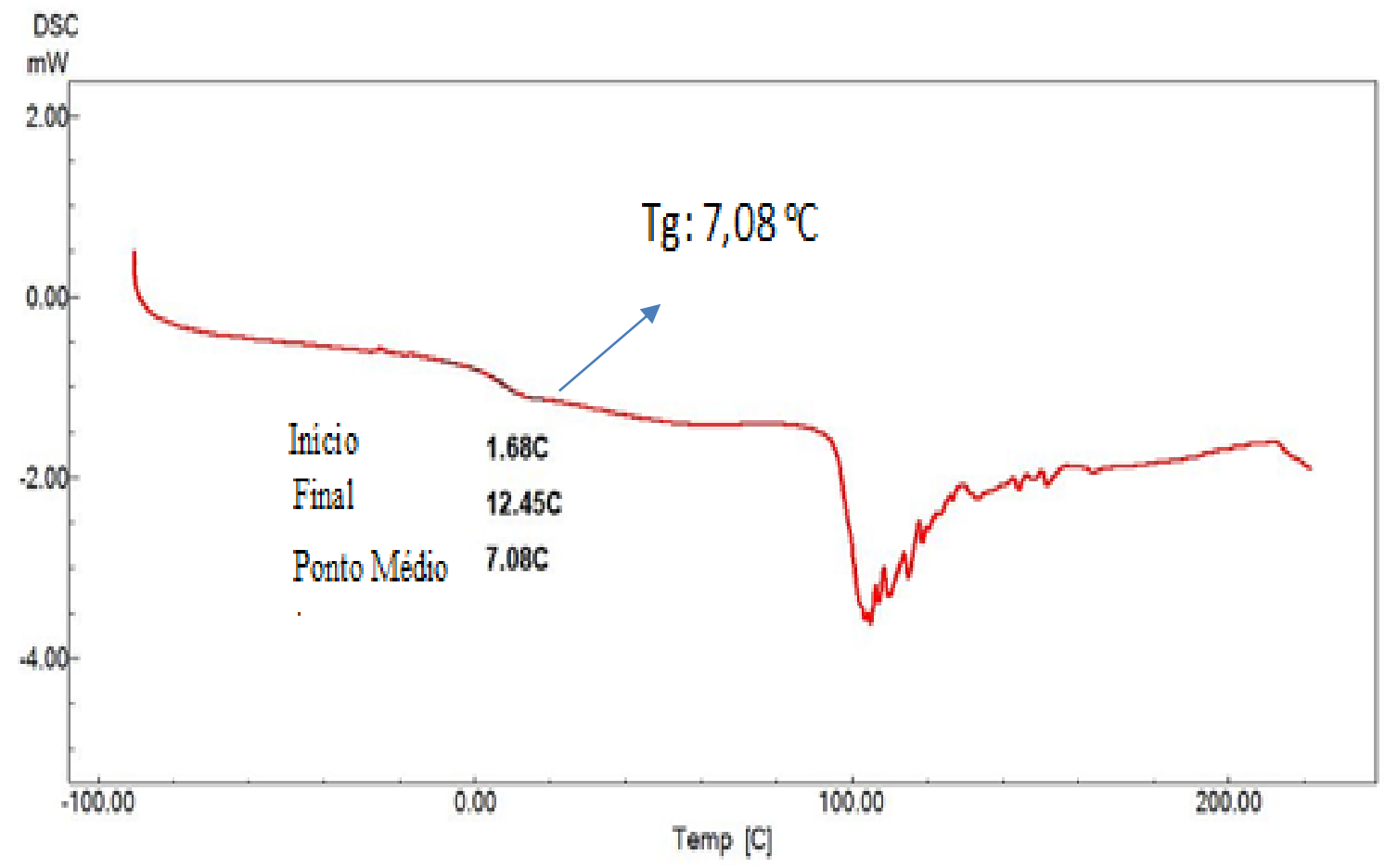

Fonte: elaborado pelo próprio autor, 2019.

Figura 129 - Curva de DSC para amostra NIPU 2 após cura. (Segundo aquecimento).

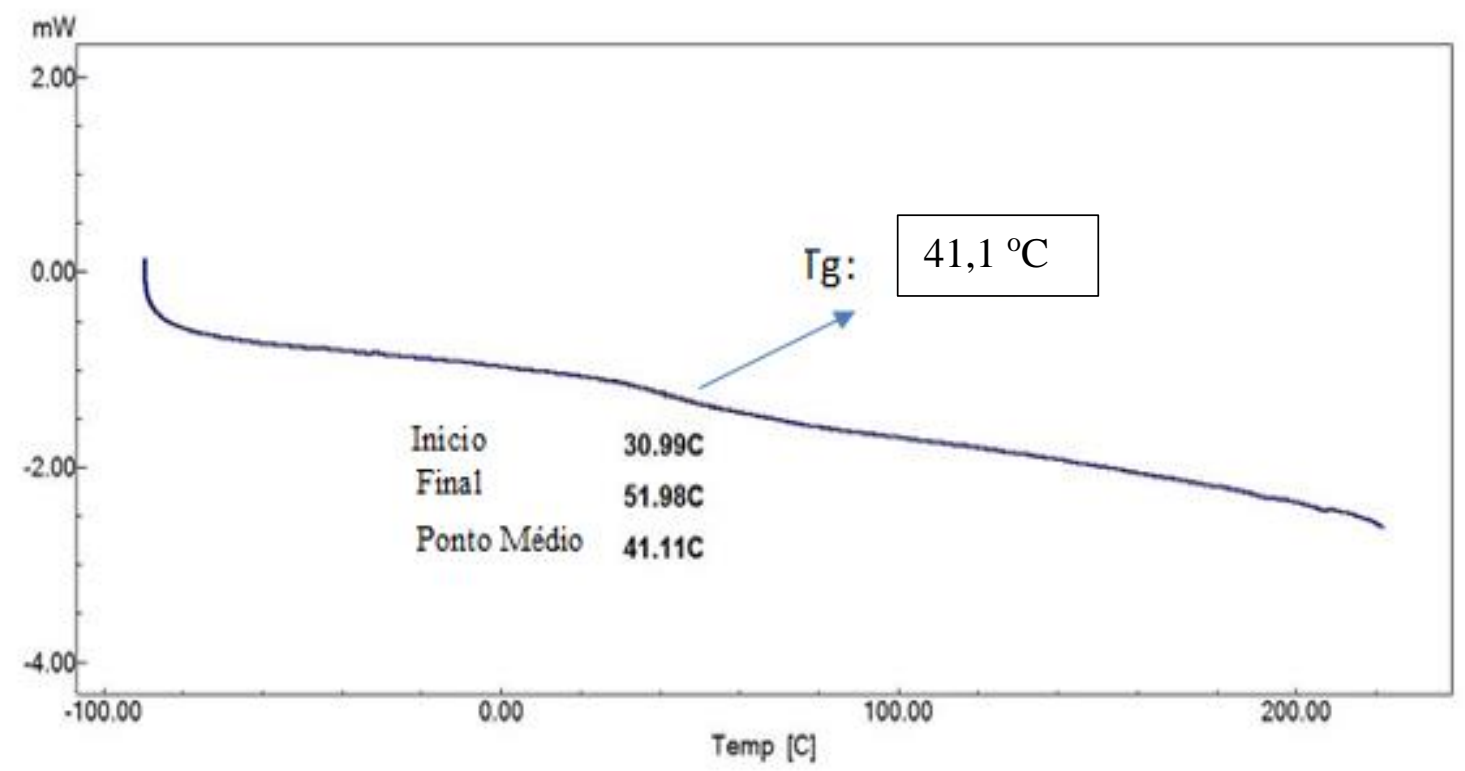

Fonte: elaborado pelo próprio autor, 2019. 
Sistema Epóxi: Nas curvas de DSC do sistema epóxi, Figuras 130 e 131, a imagem do que aconteceu com as NIPUs a presença de mica sililada com aminossilano leva a um aumento de $\mathrm{T}_{\mathrm{g}}$. Contudo esse aumento foi menos importante nos sistemas epóxi, $+16^{\circ} \mathrm{C}$, do que nas NIPUs, $+34{ }^{\circ} \mathrm{C}$. Sem dúvida esse maior aumento nas NIPUs se deve ao maior grau de liberdade gozado pelas NIPUs com mica não-sililada do que o sistema Epóxi com mica não-sililada. Para efeito de comparação, podemos olhar o trabalho de Novaes (2015), [7] utilizando um sistema de DGEBA/Anidrido, sistema epóxi de alta temperatura, com Nanopartícula de sílica há uma similaridade nos valores de Tg. Novaes encontrou entre 104 e $110^{\circ} \mathrm{C}$, mostrando que os valores encontrados com o sistema com a carga tratada impactam positivamente como alternativo ao uso do anidrido.

Figura 130 - Curva de DSC para epóxi 2 (Segundo aquecimento).

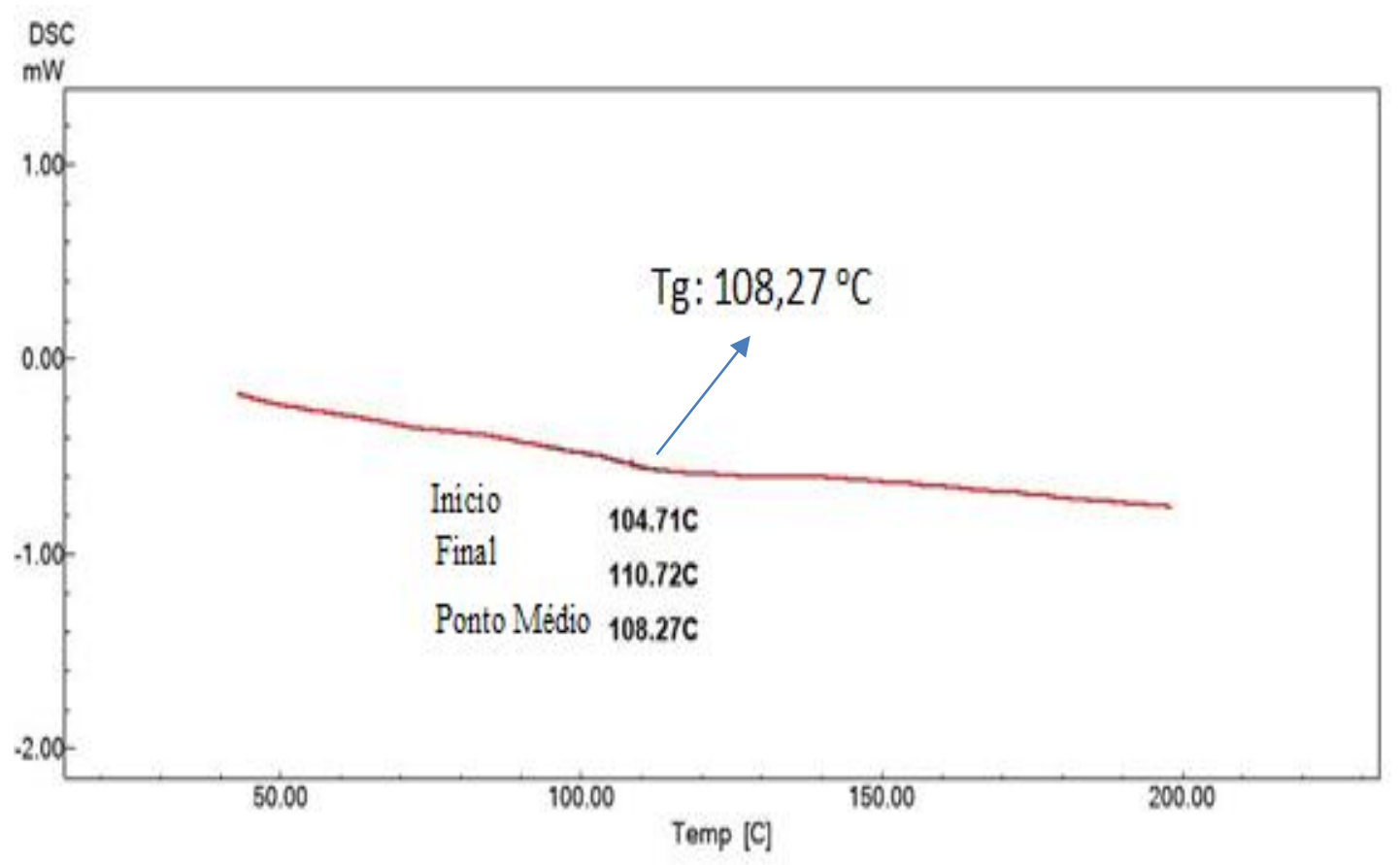

Fonte: elaborado pelo próprio autor, 2019. 
Figura 131 - Curva de DSC para epóxi3 (Segundo aquecimento).

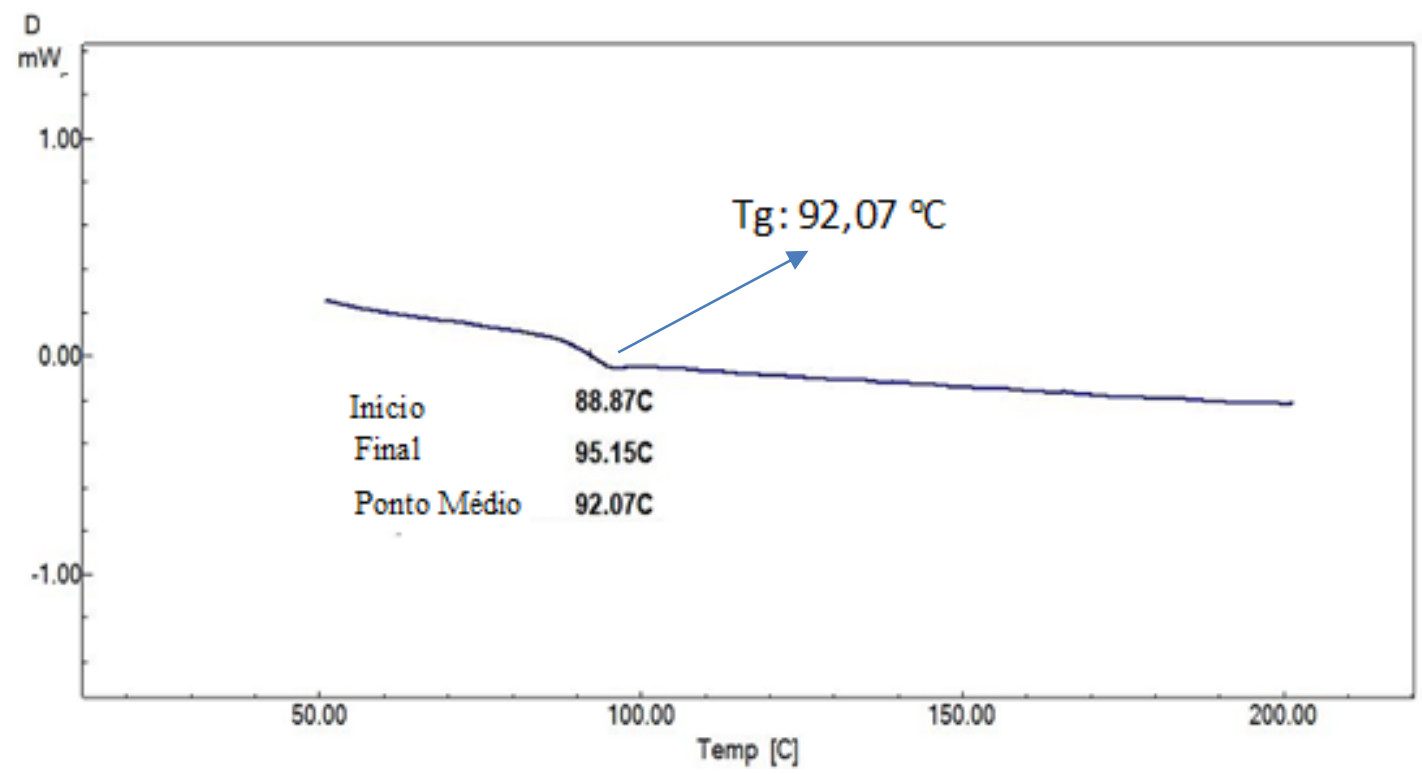

Fonte: elaborado pelo próprio autor, 2019.

Sistemas HNIPU: Nas curvas de DSC do sistema HNIPU, Figuras 132 a 135, ocorre o aumento de $\mathrm{T}_{\mathrm{g}}$ sendo que o aumento de $+14,5^{\circ} \mathrm{C}$ é intermediário entre aquele encontrado para a NIPU e o sistema Epóxi. Assim, a HNIPU seria um sistema de graus de liberdade igualmente intermediário entre esses dois sistemas.

Figura 132 - Curva de DSC para amostra HNIPU 4 (Segundo aquecimento).

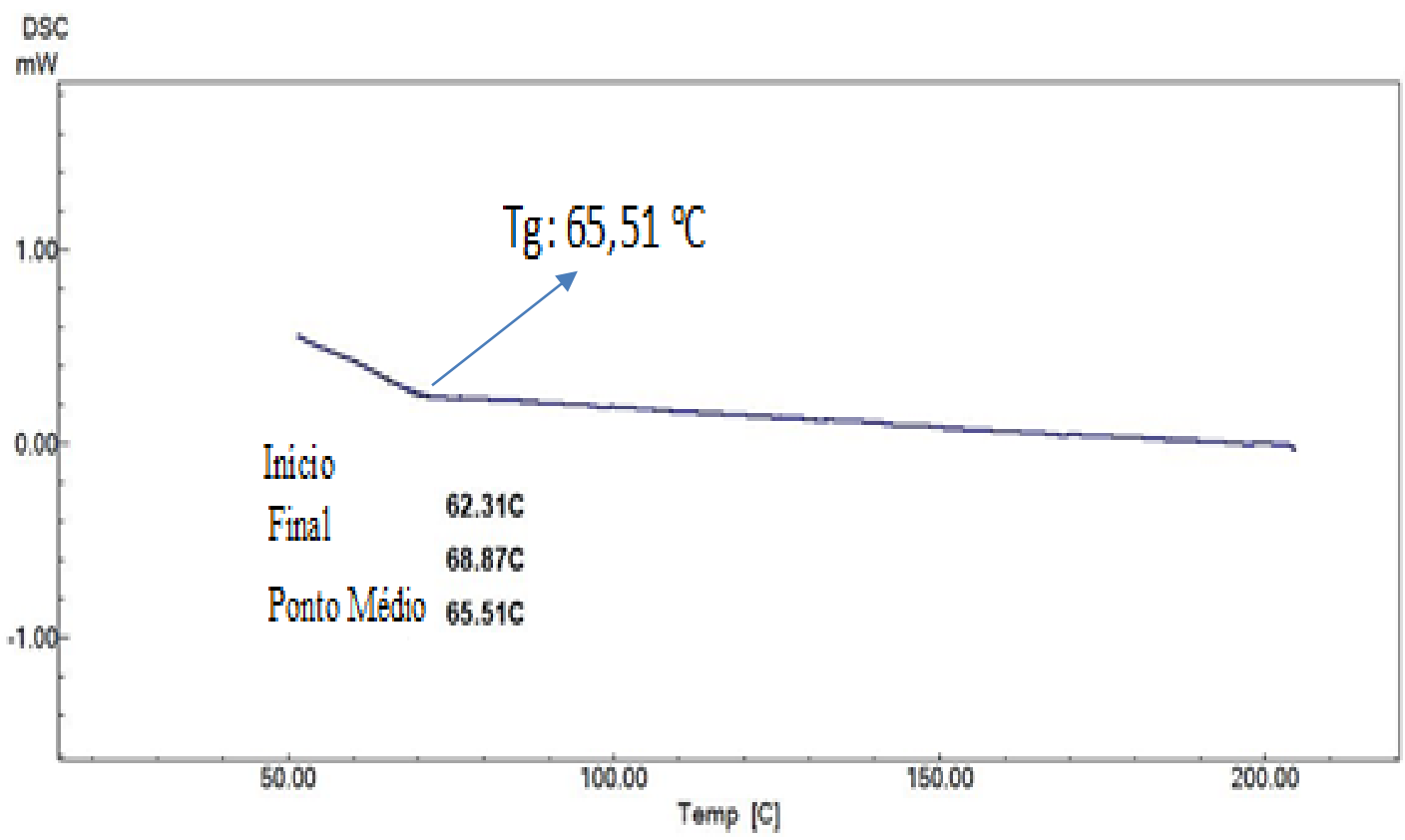

Fonte: elaborado pelo próprio autor, 2019. 
Figura 133- . Curva de DSC para amostra HNIPU 2 (Segundo aquecimento).

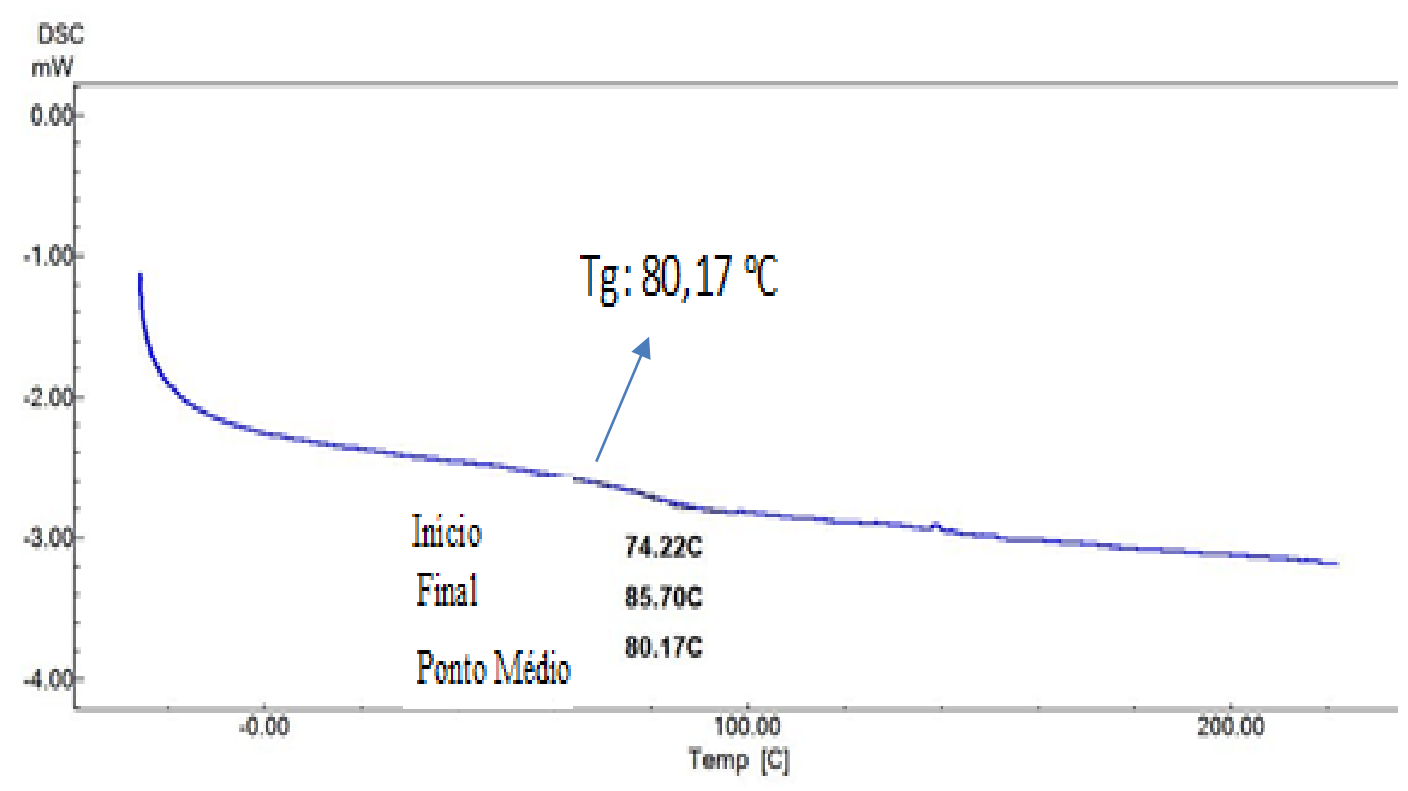

Fonte: elaborado pelo próprio autor, 2019.

Figura 134 - Curva de DSC para amostra HNIPU 3. (Segundo aquecimento).

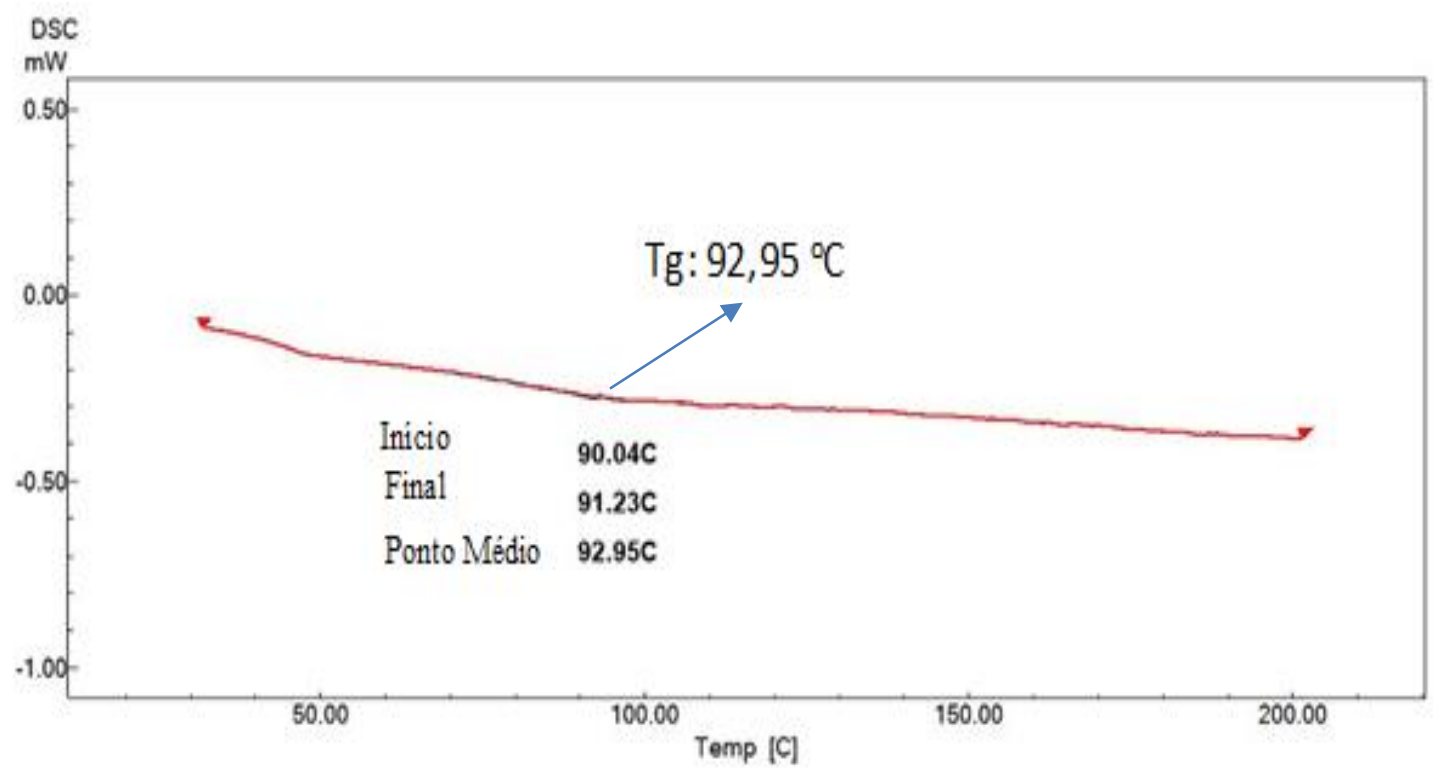

Fonte: elaborado pelo próprio autor, 2019. 
Tabela 38- Resumo dos valores de Tg, das amostras testadas.

\begin{tabular}{|c|c|}
\hline Formulações & $\begin{array}{c}\text { Tg }\left({ }^{\circ} \mathrm{C}\right) \text { obtida por } \\
\text { DSC }\end{array}$ \\
\hline NIPU 4 & 7,08 \\
\hline NIPU 2 & 41,11 \\
\hline Epóxi 1 & 108,3 \\
\hline Epóxi 2 & 92,07 \\
\hline HNIPU 4 & 65,51 \\
\hline HNIPU 2 & 80,17 \\
\hline HNIPU 3 & 92,95 \\
\hline
\end{tabular}

Fonte: elaborado pelo próprio autor, 2019.

Figura 135 - Representação Gráfica dos Dados de Tg (medidas de segundo aquecimento).

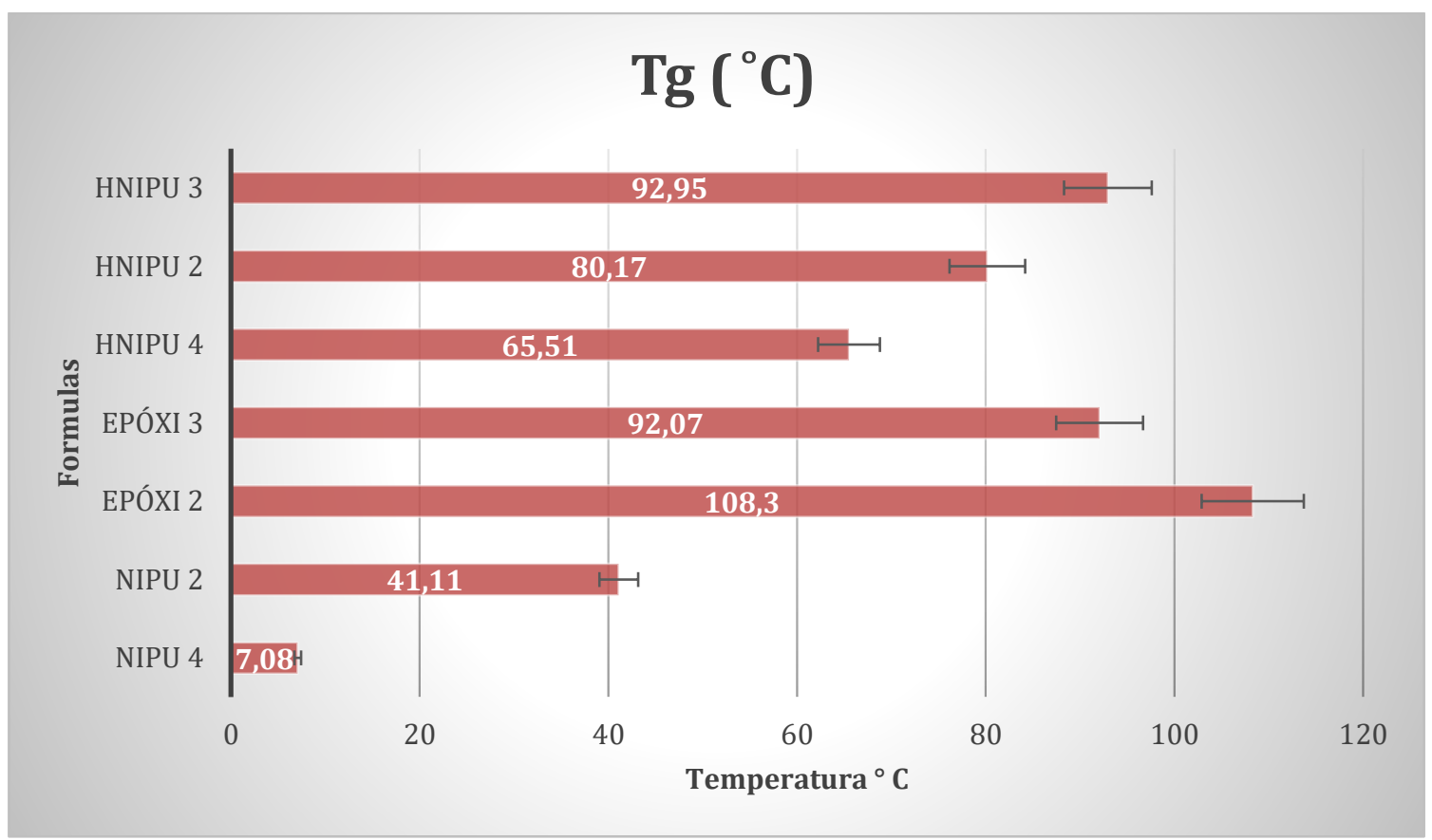

Fonte: elaborado pelo próprio autor, 2019. 
Comentários Iniciais: Analisando os dados de DSC temos que os protótipos epóxi ainda se mostra superior termicamente aos protótipos NIPU e HNIPU. Em todos os sistemas, o uso da mica sililada com aminossilano leva a uma melhoria das propriedades térmicas no que diz respeito à $\mathrm{T}_{\mathrm{g}}$.

Quanto a estratégia para uso no Hidrogerador, considerando a temperatura média de utilização até $70{ }^{\circ} \mathrm{C}$, pode se concluir que as HNIPUS, com exceção da HNIPU 4, em que se usou uma amina linear (TETA), com mica tratada e sem tratamento atendem esse requisito. Considerando a temperatura de pico até $130^{\circ} \mathrm{C}$ pode se concluir que nenhuma amostra atenderia, inclusive os protótipos epóxi de referência. Em trabalho similar de Novaes (2015) et al [7], onde se usou nano partículas de sílica, o valor de Tg foi similar ao encontrado nesse projeto, $116{ }^{\circ} \mathrm{C}$,mesmo usando anidrido como endurecedor. Quando se fez a cura sem a presença da fração inorgânica, o valor de $\mathrm{Tg}$ foi acima de $143^{\circ} \mathrm{C}$. Aqui existe um ponto para se ressaltar, a presença da fração do híbrido como premissa desse projeto, na concentração usada (40\% em peso) terá que ser revista.

A conclusão de Nelson (2002) et al., [215] de Sun (2004) et al., [216] e Singha (2006) et al.[217] é que o uso de material particulado acima de $10 \%$ em peso pode causar um aumento no volume livre entre as cadeias poliméricas, com isso impactando diretamente na densidade de reticulação do sistema DGEBA e endurecedor. A Figura 136, ilustra bem como seria o modelo de ocorrência desse fator.

No caso da HNIPU em que temos grupamentos reativos que participam da reticulação, essa teoria precisa ser melhor entendida, uma ação futura será analisar o impacto da Tg em função do teor de mica tratada com aminossilano. Nesse ponto poderá se ter uma visão mais clara do porquê o sistema com particulados apresenta menor Tg que o sistema livre de fração inorgânica.

Nem todos os pesquisadores concordam com essa explicação do volume livre, por exemplo Zou (2008) et. al., [218], atribui esses valores de aumento ou redução da $T_{g}$ à dispersão das partículas no compósito e tamanho médio das partículas. 
Figura 136 - Ilustração da formação de volume livre devido a introdução de partículas inorgânicas no sistema. [7].

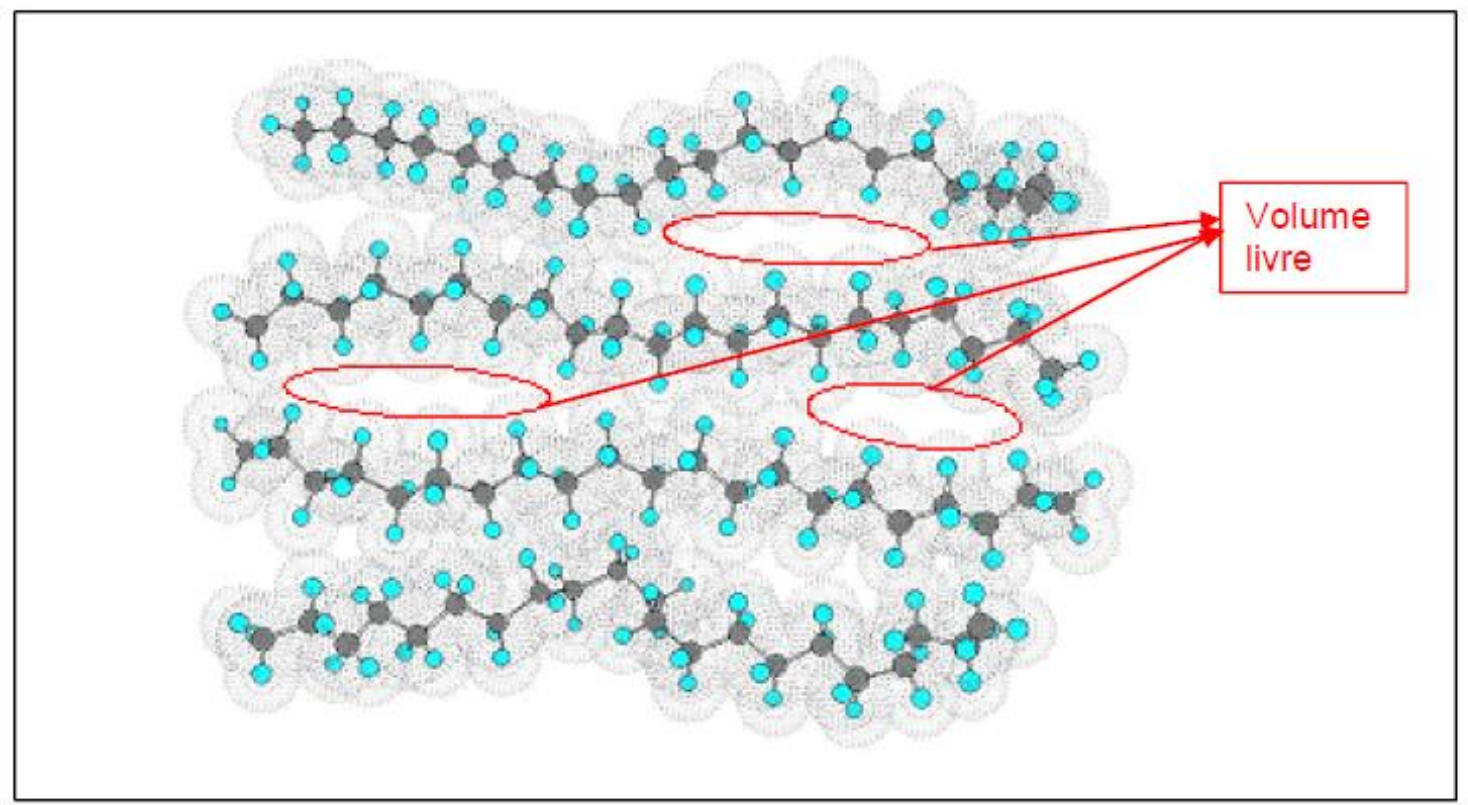

Fonte: Figura extraída de NOVAES, R. D.; et al, Avaliação das propriedades elétricas de barras estatóricas fabricadas com resina do tipo éter diglicidílico do bisfenol F (DGEBF) contendo nano partículas de sílica; Faculdade de Engenharia Química, Universidade Estadual de Campinas - UNICAMP, Campinas, SP, Brasil.

\subsection{Avaliação DMA Protótipos Sem Pós Cura}

Para a análise dinâmico-mecânica foram selecionados aqueles compósitos que mostraram características similares ao sistema epóxi nos experimentos de DSC. (Tabela 39 e 40)

Tabela 39 - Fórmulas dos Protótipos Usados para DMA.

\begin{tabular}{|c|c|}
\hline Formulas & Composição Química dos Protótipos. \\
\hline Epóxi 2 & DGEBA/IPDA/MICA sililada com aminossilano \\
Epóxi 3 & DGEBA/IPDA/Mica sililada com aminossilano \\
HNIPU 2 & CCGEBA-IPDA e Mica sem tratamento \\
HNIPU 3 & CCGEBA-IPDA/ DGEBA) Mica sililada com aminossilano \\
HNIPU 4 & CCGEBA/TETA / DGEBA) Mica Sililada aminossilano \\
\hline
\end{tabular}

Fonte: elaborado pelo próprio autor, 2019. 
Tabela 40 - Medidas das amostras avaliadas no DMA.

\begin{tabular}{|c|r|r|r|}
\hline Formulas & Comprimento $(\mathrm{mm})$ & Largura $(\mathrm{mm})$ & espessura $(\mathrm{mm})$ \\
\hline Epóxi 2 & 20,0 & 10,8 & 1,5 \\
Epóxi 3 & 22,5 & 9,2 & 2,7 \\
HNIPU 2 & 20,3 & 10,8 & 1,2 \\
HNIPU 3 & 20,3 & 11,1 & 2,1 \\
HNIPU 4 & 20,0 & 10,9 & 1,3 \\
\hline
\end{tabular}

Fonte: elaborado pelo próprio autor, 2019.

Figura 137 - Curvas de módulo de armazenamento (E') em função da temperatura para cada amostra em estudo.

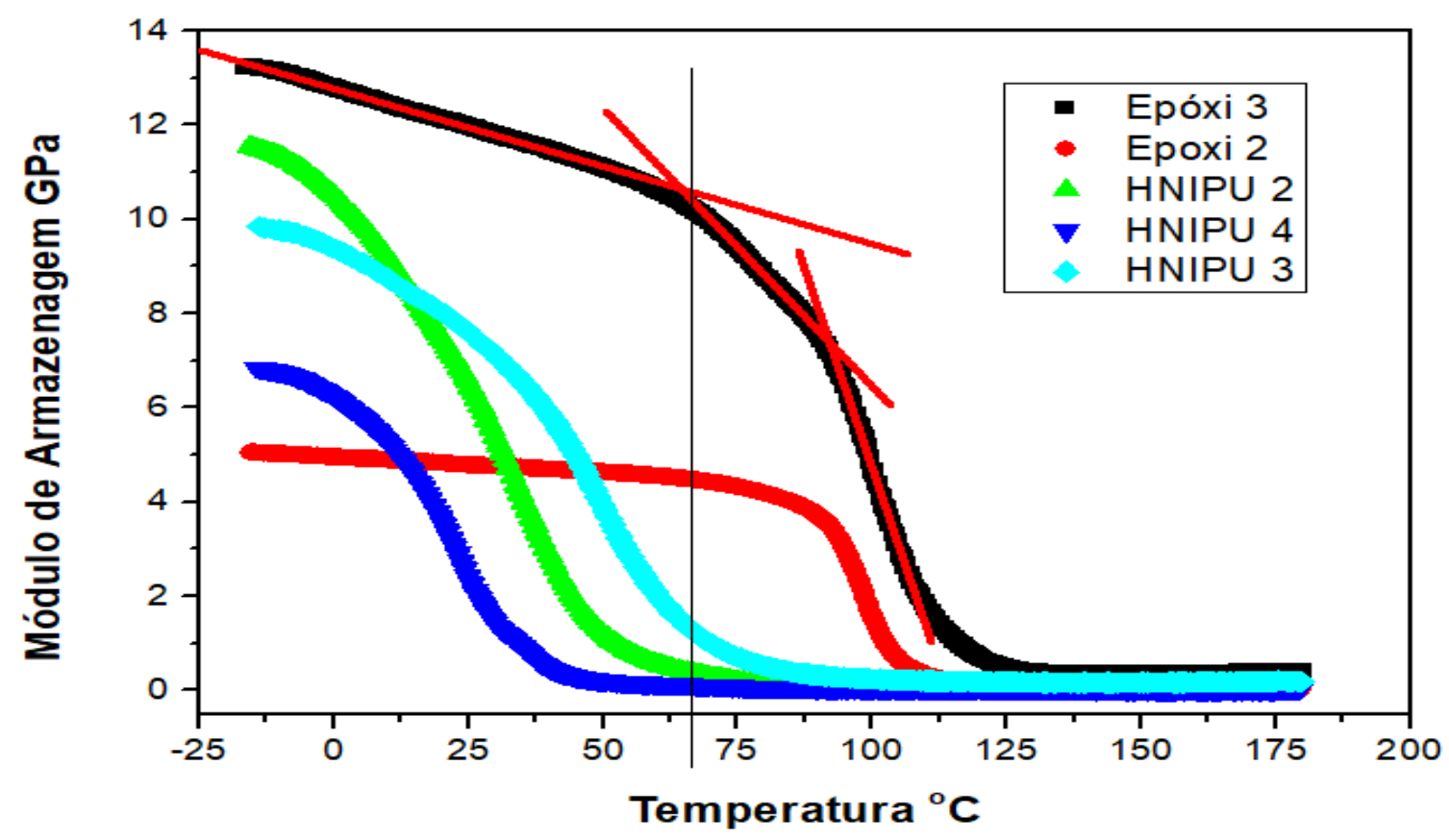

Nota: a linha tracejada em vermelho mostra o modelo para cálculo do Tan delta da amostra,

Fonte: elaborado pelo próprio autor, 2019.

Na Figura 137 observa-se que a amostra Epóxi 3 (com mica não sililada) apresenta o maior valor de módulo E', na temperatura de início do ensaio, sendo mais rígida que as HNIPUs, enquanto que a amostra Epóxi 2 com mica sililada apresenta módulo de armazenagem similar às HNIPUs. A amostra menos rígida entre todas é a HNIPU 4, produzida com amina linear (TETA). 
O maior grau de liberdade dos grupos amina alifáticos e saturados formados quando da reação entre aminas e epóxidos, Figura 11, em relação aos grupos uretana formados pela reação de aminólise dos ciclocarbonatos, Figura 47, explica o fato das amostras contendo NIPU apresentarem um valor de E’ inferior ao da amostra Epóxi 3. Dentre as amostras NIPUs a amostra com TETA apresenta o menor valor de E' portanto é aquela que possui maior grau de liberdade, ou seja, a cadeia alifática linear da TETA leva a um maior número de graus de liberdade do que a cadeia alifática cíclica da IPDA permitindo assim maior acomodação do estímulo mecânico. Em tempo, a presença de TETA livre como evidenciado pela análise termogravimétrica, Figura 122, também é um fator que poderia explicar este comportamento.

Inesperadamente, o uso da mica sililada para ambos os compósitos, HNIPU e Epóxi, levou a um material com uma capacidade de armazenamento e recuperação reversível de energia menor, menor E', portanto, mecanicamente mais flexível. Hailin (2016) et al [83] relataram a mesma situação, sendo que concluíram se tratar da formação de uma estrutura tipo borrachosa na vizinhança entre o epóxi e a mica funcionalizada. Essa nova condição de uma ligação química acaba eliminando a restrição de movimentação quando da aplicação do esforço de deformação no DMA.

Figura 138 - Dependência do módulo de perda (E’') em função da temperatura para as diferentes amostras em estudo.

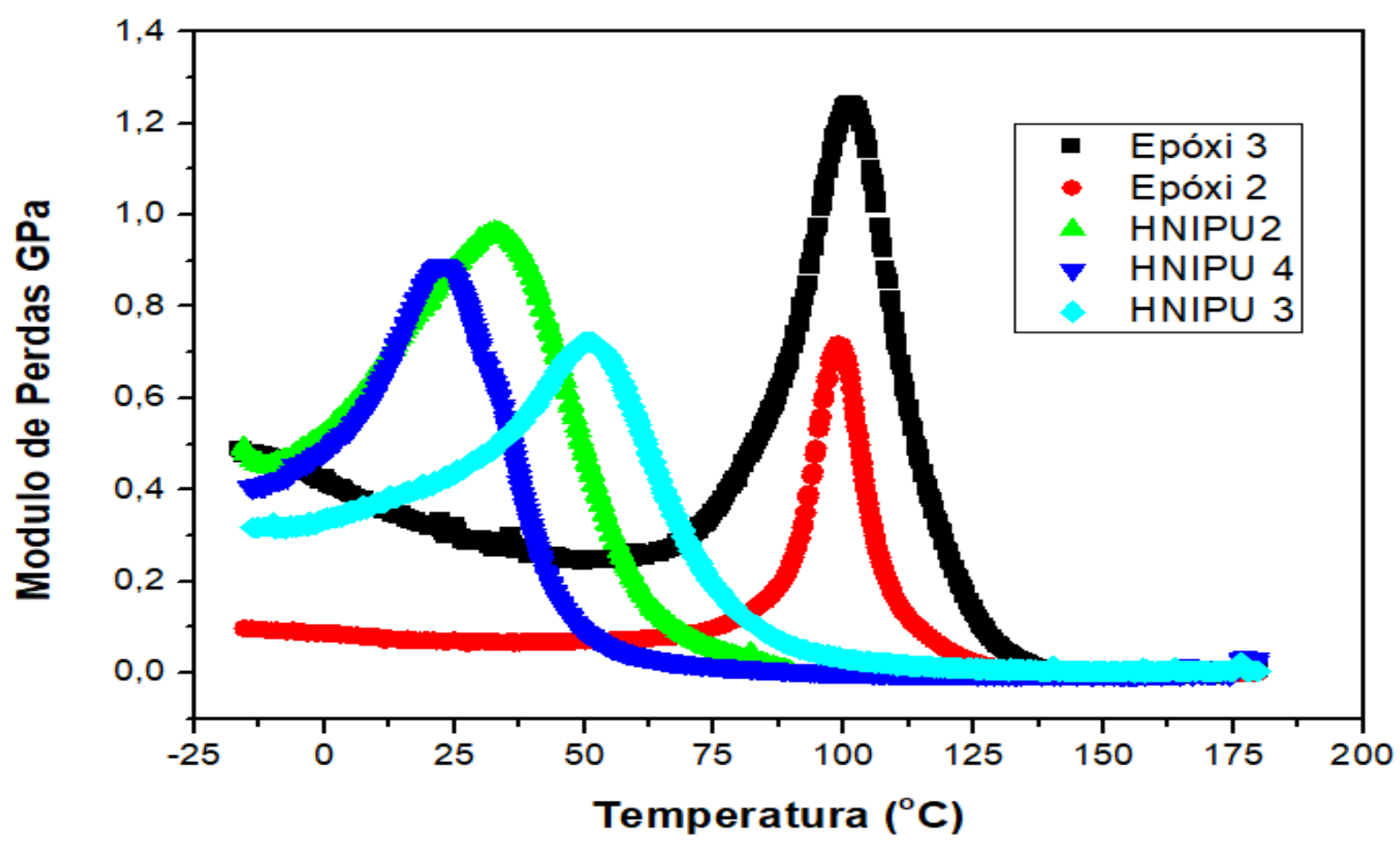

Fonte: elaborado pelo próprio autor, 2019. 
Conforme observado na Figura 138, todas as composições em estudo apresentam picos assimétricos para o módulo de perda, que caracterizam a presença de mais de um mecanismo contribuindo para o incremento significativo nas perdas mecânicas. Tais resultados se comportam de modo similar aos observados para as curvas de módulo de armazenamento, onde o incremento da parte viscosa se revela em maiores temperaturas para as amostras de epóxi do que para as HNIPU.

Figura 139 - Comparação das curvas de $\operatorname{tg} \delta$ em função da temperatura para estudos diversos compósitos.

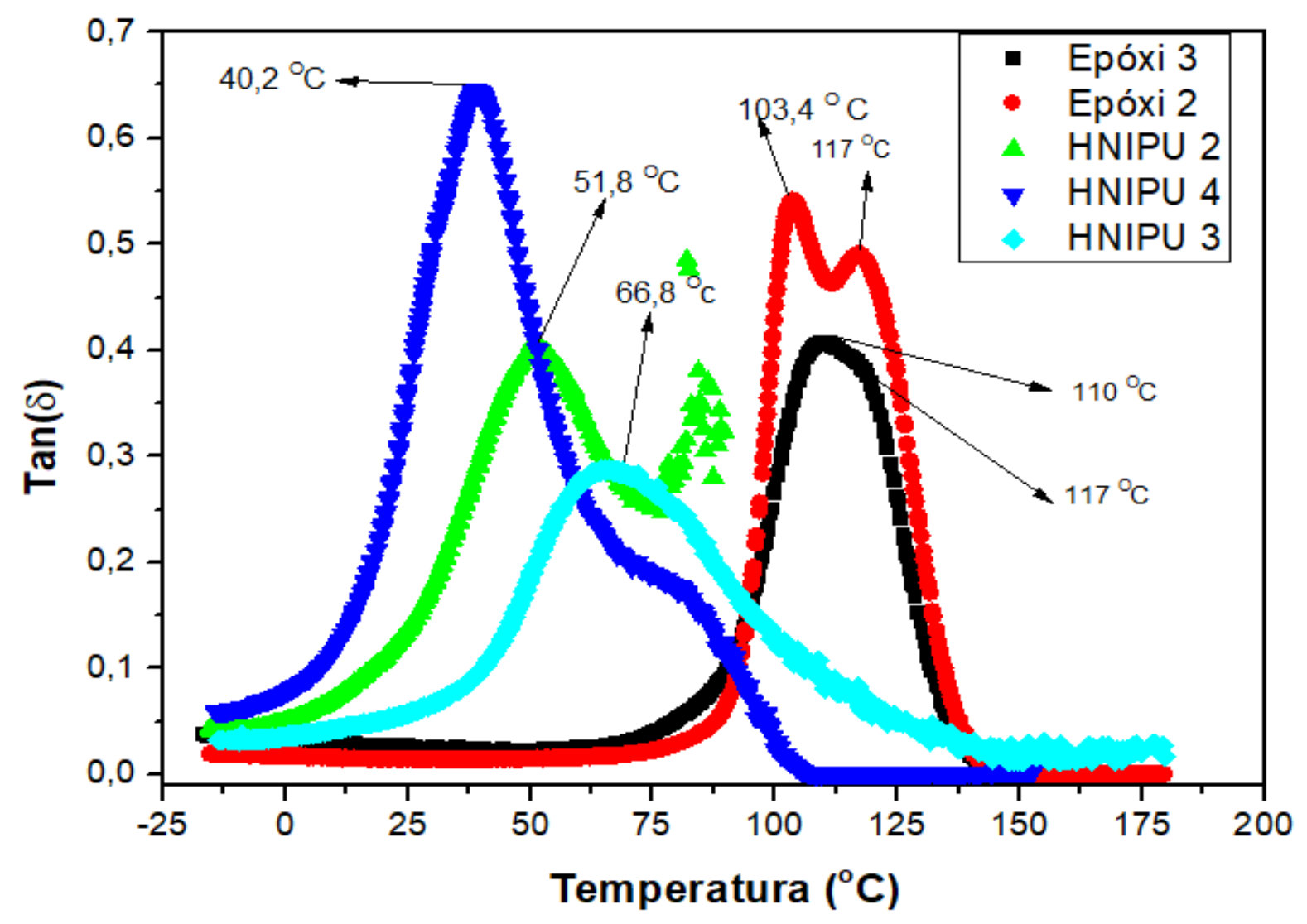

Fonte: elaborado pelo próprio autor, 2019.

As curvas de dissipação de energia elástica (tg $\delta$ ) obtidas, Figura 139, apresentam picos que ocorrem em temperaturas compatíveis com as temperaturas de transição vítrea dos materiais em estudo. Outro parâmetro relevante a ser destacado é que a temperatura de pico de $\operatorname{tg} \delta$ para as caracterizações termomecânicas não são claramente definidas como a Tg do material, assim assumindo-se que o onset das curvas obtidas por DMA, observa-se uma boa concordância entre os resultados obtidos e os dados de DSC. Para todas os compósitos pode- 
se observar a presença de mais de um pico para cada amostra, o que denota a resposta independente de cada parcela composicional do material com a temperatura. No sistema epóxi, vemos que existem duas Tg's, podendo tal comportamento ser atribuído a presença de fases com e sem carga mineral ou com diferentes teores de carga mineral. No sistema epóxi, os picos estão mais convoluídos quando foi usado a mica não sililada com centroides em 110 e $117^{\circ} \mathrm{C}$, indicativos dos valores de $\mathrm{T}_{\mathrm{g}}$. Enquanto para a Epóxi 3, contendo mica sililada há melhor separação dos componentes do pico assimétrico com centroides em $103,7^{\circ} \mathrm{C}$ e $117^{\circ} \mathrm{C}$.

A descontinuidade na curva do HNIPU 2 é indicativa de fratura da amostra, indicando que a amostra com IPDA com mica não-sililada é a mecanicamente mais frágil.

As HNIPU 3 e 4 apresentam picos ainda mais assimétricos com máximos (centroides) em temperaturas mais baixas. As curvas sofrem tanto a influência do tipo de amina utilizado quanto da sililação ou não da mica. O menor valor de transição, mesmo usando uma mica sililada foi com o uso do TETA (HNIPU 4). Em tempo, este compósito usa uma amina linear que, portanto, confere maior grau de liberdade e leva a uma $\mathrm{T}_{\mathrm{g}}$ menor, em torno $40,2{ }^{\circ} \mathrm{C}$. Nos compósitos com HNIPUs, quando utilizou-se IPDA, ocorreu um aumento na $\mathrm{T}_{\mathrm{g}}$, e ao contrário do HNIPU 2 (com mica não-sililada) não há descontinuidade. No compósito HNIPU 3 (com IPDA e mica sililada) temos a maior assimetria de pico com a presença de um terceiro evento térmico além do centroide de menor temperatura estar deslocado para maiores valores. Este primeiro centroide se situa em torno de $66,8{ }^{\circ} \mathrm{C}$ enquanto a HNIPU 2, um compósito similar, de IPDA com mica não-sililada apresentou uma $\mathrm{T}_{\mathrm{g}}$ de $51,8{ }^{\circ} \mathrm{C}$.

Analisando com mais detalhes as curvas de $\operatorname{tg} \delta$ para as HNIPUs, pode-se notar também a presença de picos alargados e assimétricos na curva da HNIPU 3, enquanto para o compósito HNIPU 2 ocorre um único pico seguido de uma descontinuidade e para a HNIPU 4 ocorre a presença de dois picos bem separados termicamente. A presença de dois picos denota a existência de dois materiais distintos nas amostras intimamente misturados. Atribuiu-se os picos de maiores temperaturas à presença da formação de compósito com a carga mineral, com ou sem tratamento da mica. A inexistência de dois eventos térmicos de segunda ordem, transições vítreas, nas curvas calorimétricas destes dois últimos materiais

Comparando-se os valores de Tg obtidos por DMA com aqueles obtidos por DSC, Figura 138, observam-se as mesmas tendências para os valores do conjunto de compósitos. Observa-se que não existem grandes diferenças. Contudo os valores obtidos por DMA para 
as amostras HNIPU são invariavelmente menores que aqueles obtidos por DSC como pode ser visto na Figura 140 e na Tabela 41.

Figura 140 - Gráfico mostrando a comparação entre os valores de $\mathrm{T}_{\mathrm{g}}$ obtidos por DMA com aqueles obtidos por DSC.

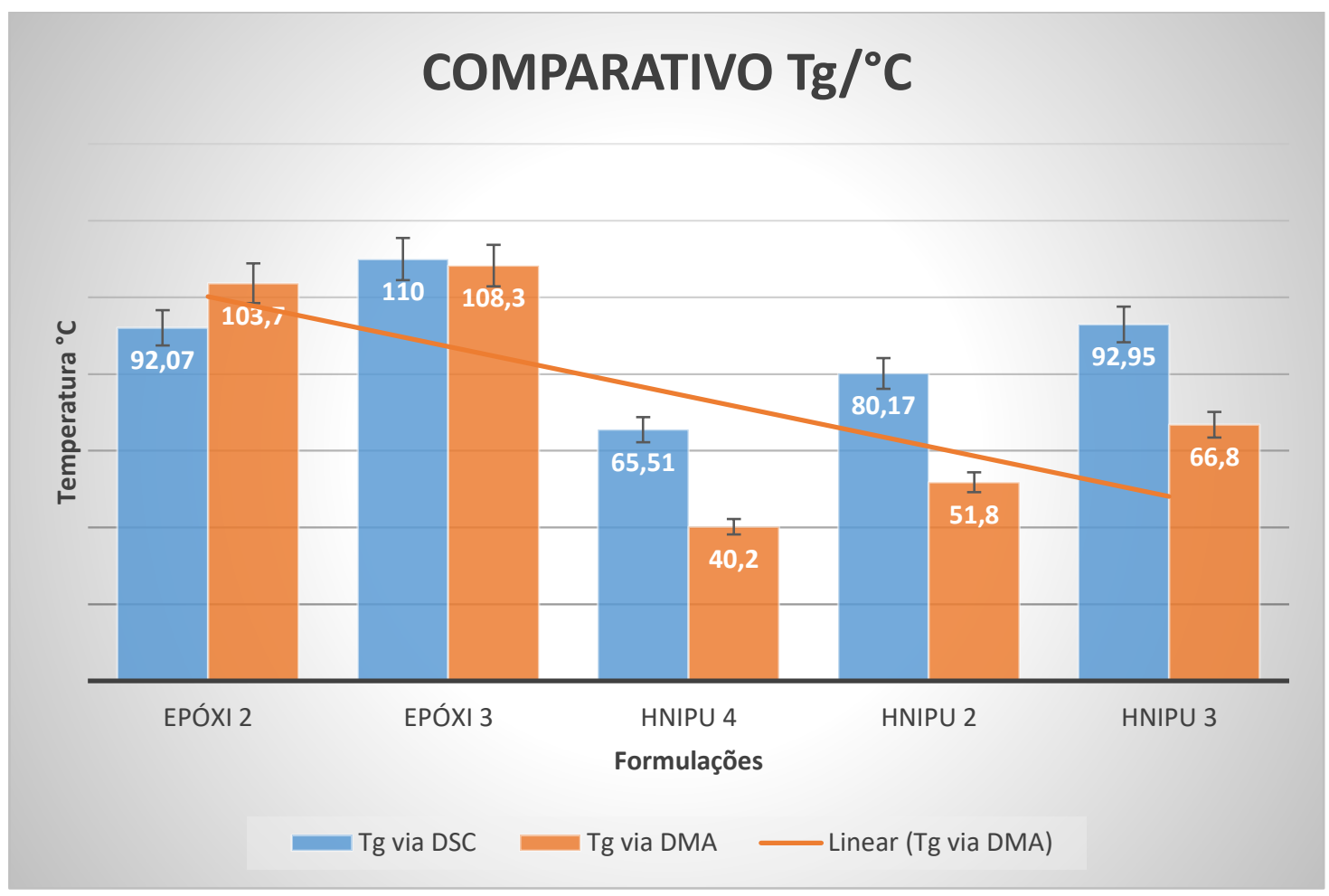

Fonte: elaborado pelo próprio autor, 2019.

Tabela 41 - Dados de Tg obtidos por DMA com aqueles obtidos por DSC.

\begin{tabular}{|c|c|c|}
\hline Amostra & Tg via DSC & Tg via DMA \\
\hline Epóxi 2 & 92,07 & 103,70 \\
Epóxi 3 & 110 & 108,30 \\
HNIPU 4 & 65,51 & 40,20 \\
HNIPU 2 & 80,17 & 51,80 \\
HNIPU 3 & 92,95 & 66,80 \\
\hline
\end{tabular}

Fonte: elaborado pelo próprio autor, 2019.

\subsection{Avaliação DMA Protótipos Com Pós Cura}

Nesta seção é descrita a avaliação termomecânica da HNIPU (NIPU com terminação amina/ DGEBA) após cura em temperatura acima de $70^{\circ} \mathrm{C}$ à semelhança do processo de cura similar ao HNIPU como reportado por Ke (2017) et al. [184]. No trabalho de Ke et al foi feita a cura a $90^{\circ} \mathrm{C}$ por 24 horas, enquanto, as amostras de HNIPUs desse projeto que haviam 
sido curadas em temperatura ambiente foram submetidas a uma pós cura de 24 horas a $80^{\circ} \mathrm{C}$ para que posteriormente fossem testadas por DMA. Os materiais usados para essa etapa estão na Tabela 42.

Tabela 42 - Protótipos de HNIPU (Blenda) que sofreram tratamento térmico a $80^{\circ} \mathrm{C}$ por 24h, dito pós-cura.

\begin{tabular}{|l|l|}
\hline HNIPU $2 \mathrm{t}$ & CCGEBA-IPDA e Mica sem tratamento \\
HNIPU $4 \mathrm{t}$ & CCGEBA/TETA/ DGEBA Mica sililada \\
HNIPU $3 \mathrm{t}$ & CCGEBA/IPDA/ DGEBA) Mica sililada \\
\hline
\end{tabular}

Fonte: elaborado pelo próprio autor, 2019.

Na Figura 139, para a HNIPU 4 a pós-cura não alterou significativamente a curva de $\operatorname{tg} \delta$ para esse compósito. As curvas para as amostras HNIPU 4 e HNIPU 4t (com e sem póscura) são igualmente assimétricas e possuem centroides na mesma faixa de temperatura, isso leva a uma evidência que existe um pequeno impacto da pós cura, não ocorreu alteração significativa nos valores de máxima Tg (Tan. Delta) como a própria figura 141 ilustra. Sendo assim, o tratamento realizado anterior a esta etapa já levou a e reação de todos os grupos epóxi e amina, quer da diamina TETA quer da HNIPU com terminação amina.

Figura 141 - Comparação entre as curvas de tg $\delta$ em função da temperatura para os compósitos pós-cura. HNIPU 4 normal (curva vermelha), HNIPU 4t (curva verde).

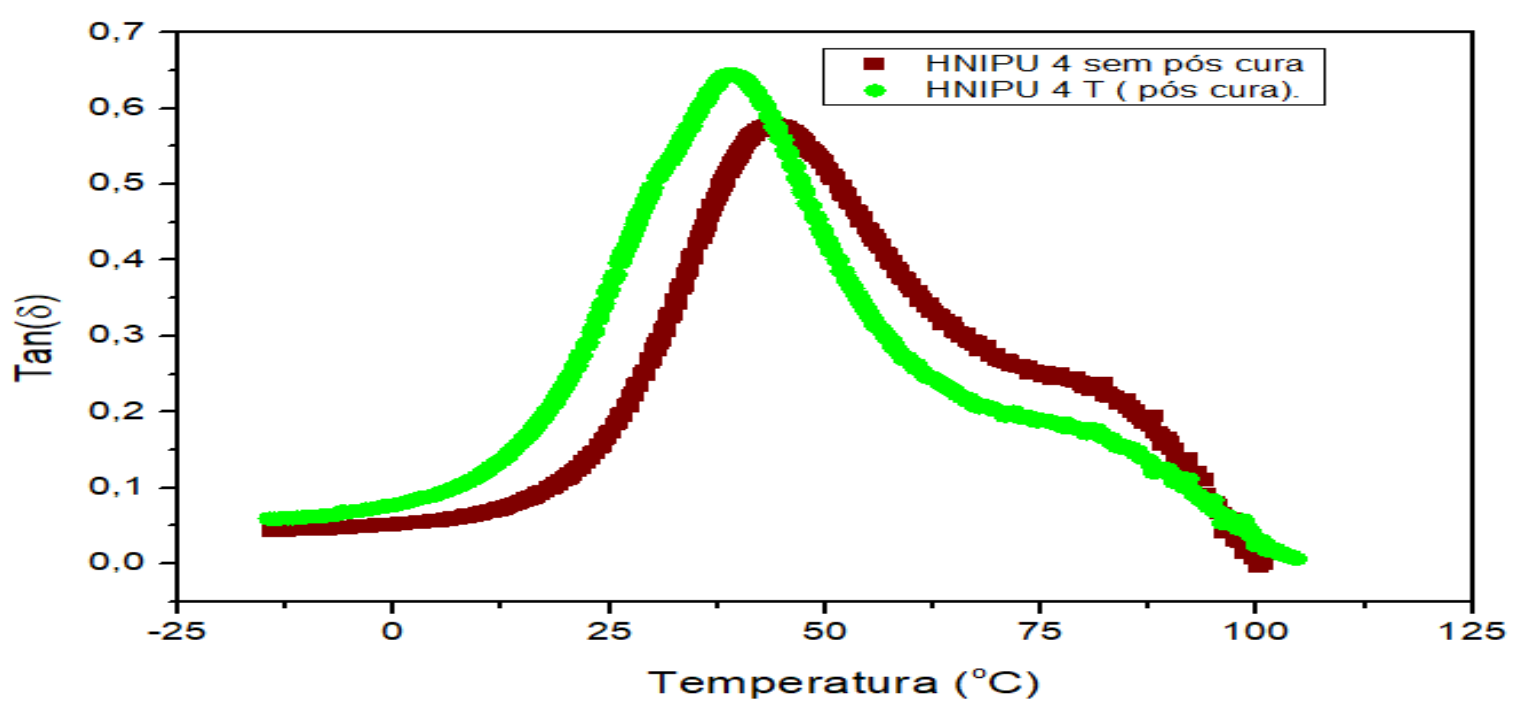

Fonte: elaborado pelo próprio autor, 2019 
Na Figura 142, HNIPU 3, pode-se observar que a pós cura levou ao deslocamento do centroide da curva e reduziu levemente a assimetria nesse compósito. O ganho do valor de Tg pode ser atribuído a reação de grupos funcionais residuais.

Figura 142 - Comparação entre as curvas de $\operatorname{Tg} \delta$ em função da temperatura para os compósitos pós-cura. HNIPU 3 normal (curva vermelha), HNIPU 3t (curva preta).

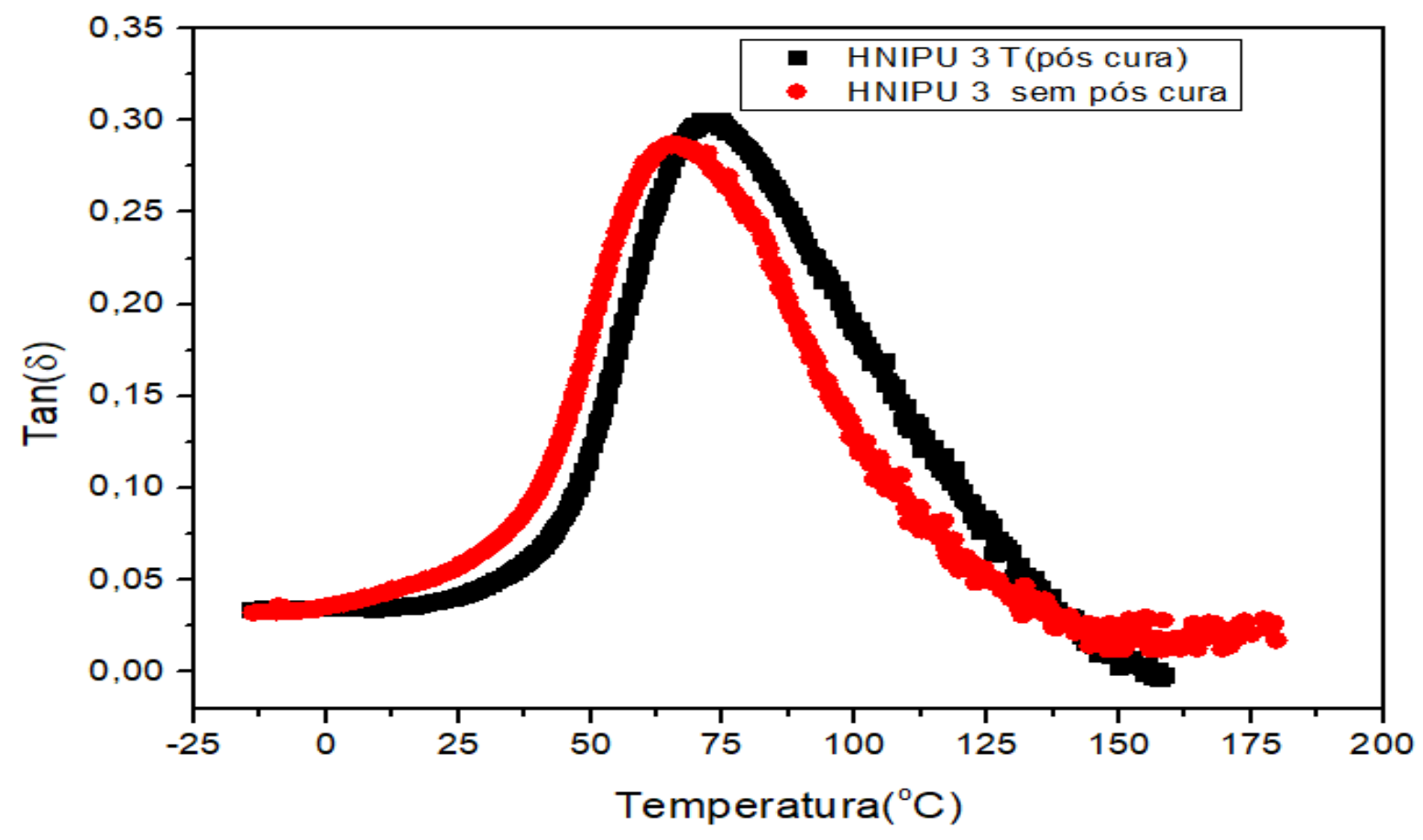

Fonte: elaborado pelo próprio autor, 2019.

Na Figura 143 pode-se observar que o tratamento pós-cura da curva de tg $\delta$ para o compósito HNIPU 2, a descontinuidade em maiores temperaturas desaparece na amostra com a pós-cura comprovando que a descontinuidade estava relacionada a uma cura parcial desta amostra. 
Figura 143 - Comparação entre as curvas de $\operatorname{Tg} \delta$ em função da temperatura para os compósitos pós-cura. Amostra HNIPU 2 normal (curva azul), amostra HNIPU 2 t (curva vermelha).

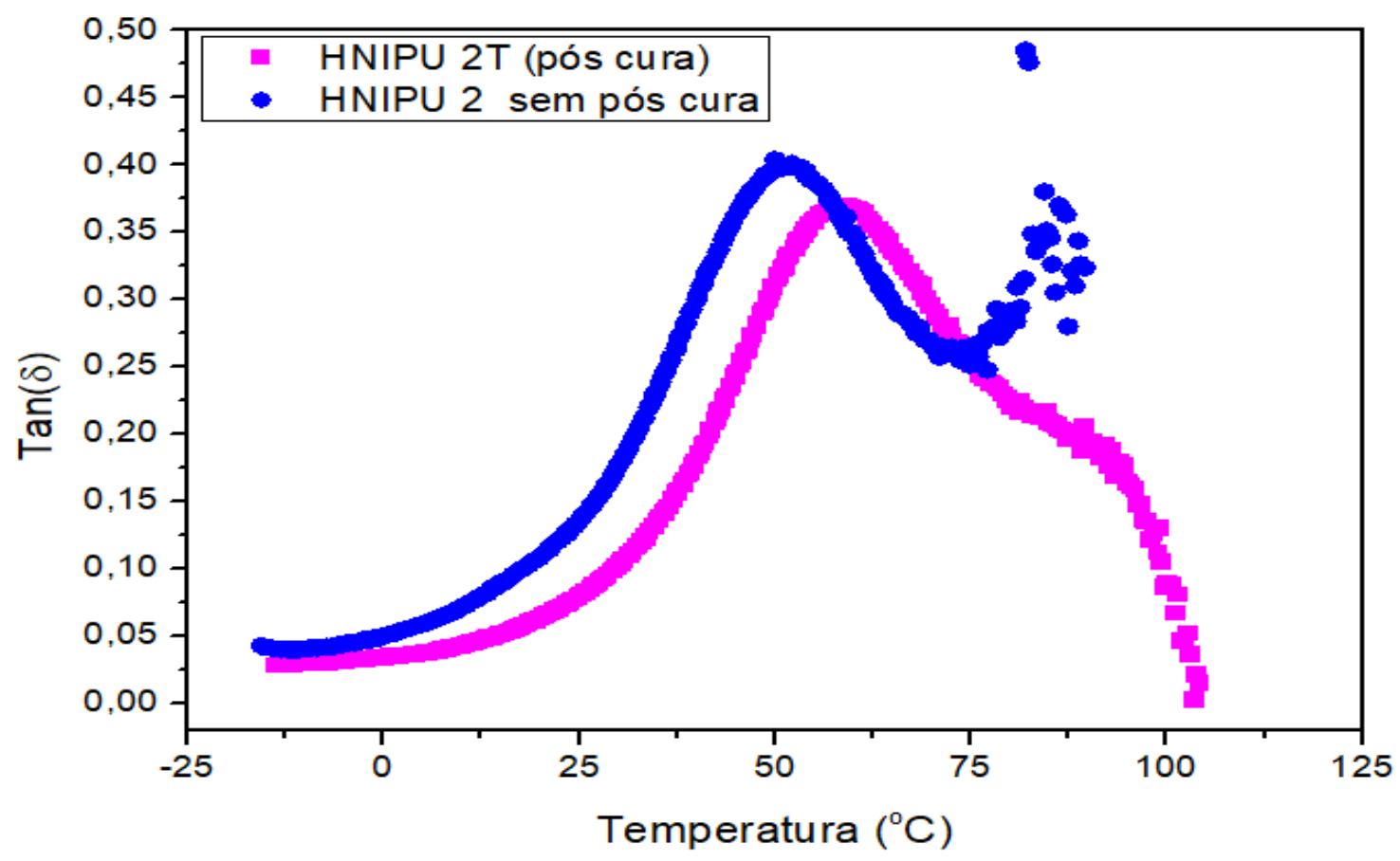

Fonte: elaborado pelo próprio autor, 2019.

Na Figura 144 tem se os dados das três amostras após o processo de pós cura ilustrando os dados da Tabela 43 de comparativo entre as amostras analisadas.

Figura 144 - Comparação entre as curvas de $\operatorname{Tg} \delta$ em função da temperatura para os compósitos pós-cura. Amostra 3t (curva preta), amostra 4t (curva vermelha) e amostra 5t(curva azul).

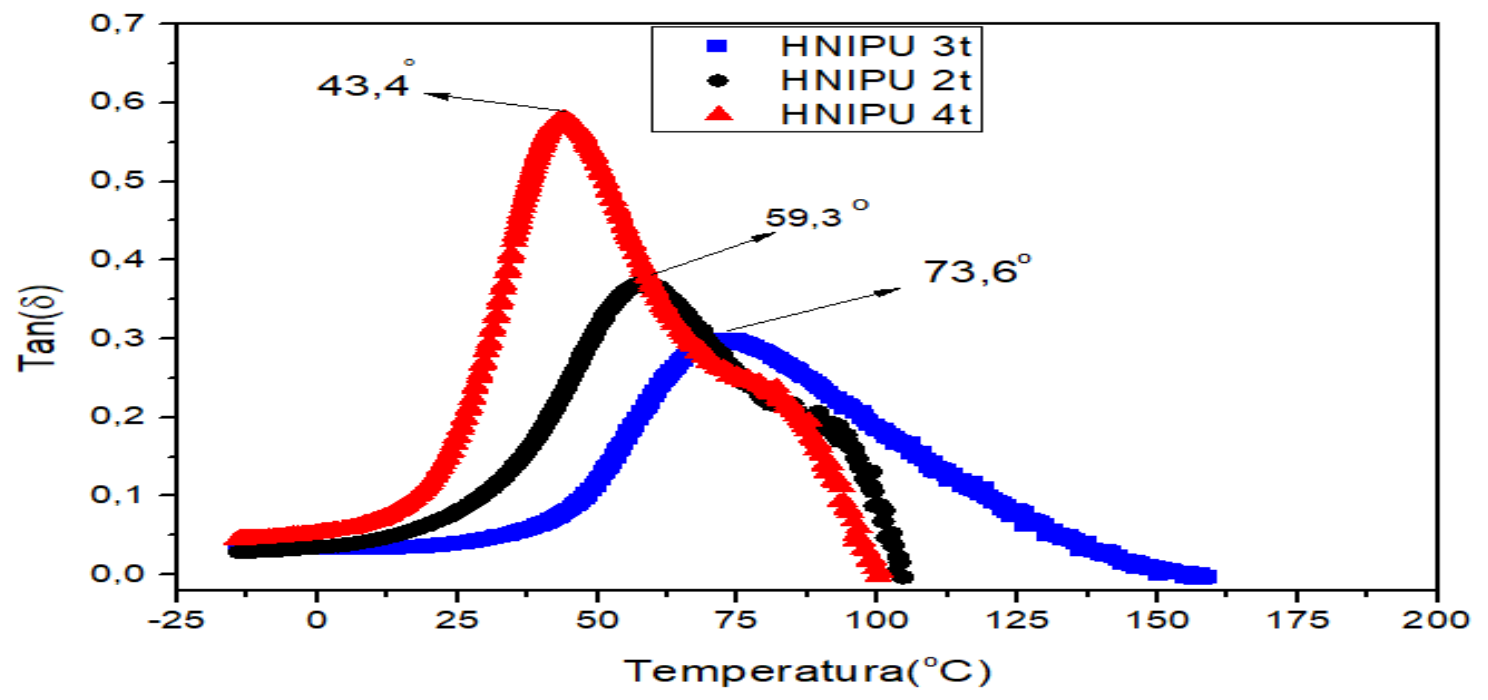

Fonte: elaborado pelo próprio autor, 2019. 
Tabela 43 - Valores de $\mathrm{T}_{\mathrm{g}}$ obtidos dos primeiros centroides das curvas de tg $\delta$ para os compósitos HNIPU pós-cura.

\begin{tabular}{|l|r|r|r|}
\hline Amostra & Tg via DSC ${ }^{\circ} \mathrm{C}$ & $\operatorname{Tg}$ via DMA ${ }^{\circ}{ }^{\circ} \mathrm{C}$ & Tg via DMA com pós-cura ${ }^{\circ} \mathrm{C}$ \\
\hline HNIPU 4 & 65,51 & 40,20 & 43,40 \\
\hline HNIPU 2 & 80,17 & 51,80 & 59,30 \\
\hline HNIPU 3 & 92,95 & 66,80 & 73,60 \\
\hline
\end{tabular}

${ }^{1}$ Centroide do pico em temperatura mais baixa da curva tg $\delta$

Fonte: elaborado pelo próprio autor, 2019.

A pós cura afetou diretamente a $T_{g}$, mostrando que para a HNIPU é necessário realizar uma pós cura e dessa forma ter uma melhor reticulação. Os dados são coerentes com o encontrado por Ke (2017) et al [184], onde usando sistema similar ao deste projeto encontrou valores médios de Tg, para um sistema usando TETA como amina e uma razão de equivalência de 1,3/1,0 um valor médio de $45^{\circ} \mathrm{C}$.

Na avaliação do Módulo de armazenamento, conforme pode se ver nas Figuras 145, 146 e 147, percebe-se o efeito da pós cura principalmente nas amostras que usam a mica sililada, como exemplo a HNIPU 3. Pode se concluir que os grupamentos amina presentes na mica, tem um comportamento de velocidade de reação diferente dos grupamentos amina do pré polímero com terminação amina (CCGEBA com Terminação Amina). Isso até pode explicar, porque Ke et al [184], mesmo não usando mica sililada encontrou valores de $\mathrm{Tg}$ similares ao desse projeto.

Figura 145 - Módulo de armazenamento (E’) em função da temperatura para amostra HNIPU 3 com pós cura (curva preta) e comparativo a HNIPU 3 sem pós cura (curva vermelha) .

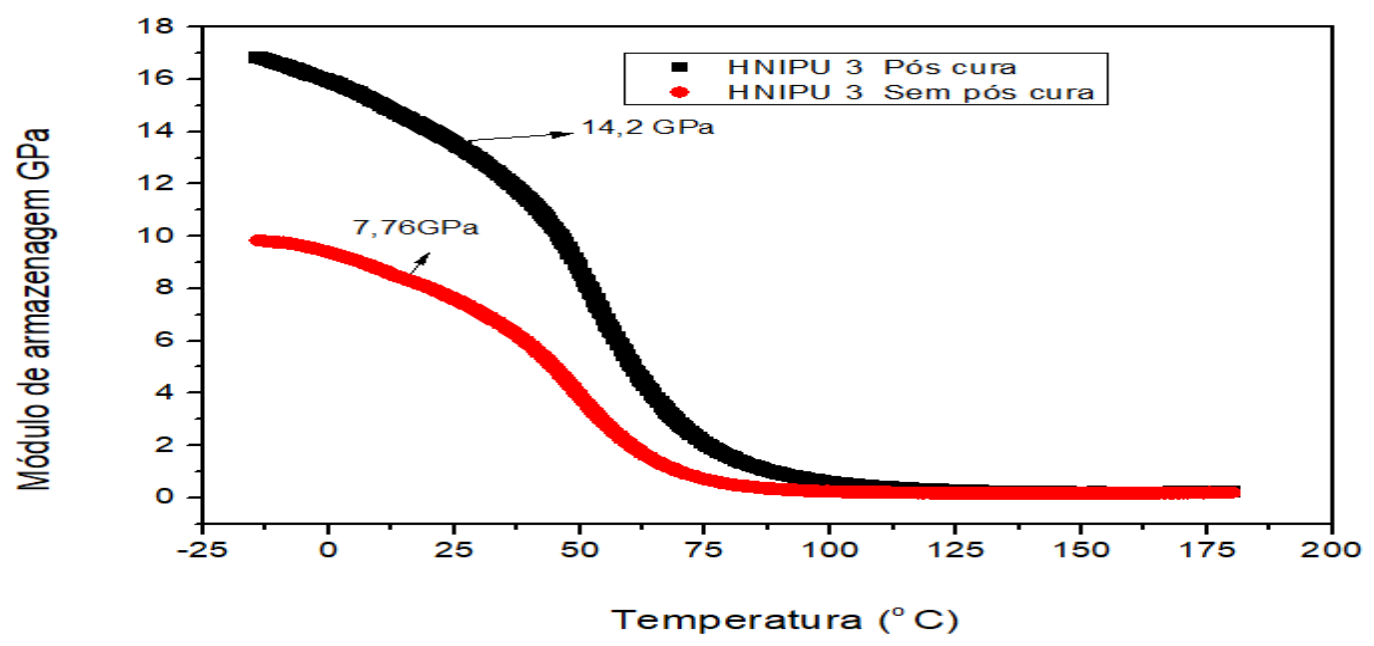

Fonte: elaborado pelo próprio autor, 2019. 
Figura 146 - Módulo de armazenamento (E') em função da temperatura para amostra HNIPU 2 tratamento com pós cura (curva vermelha) e HNIPU 2 sem pós cura (curva azul).

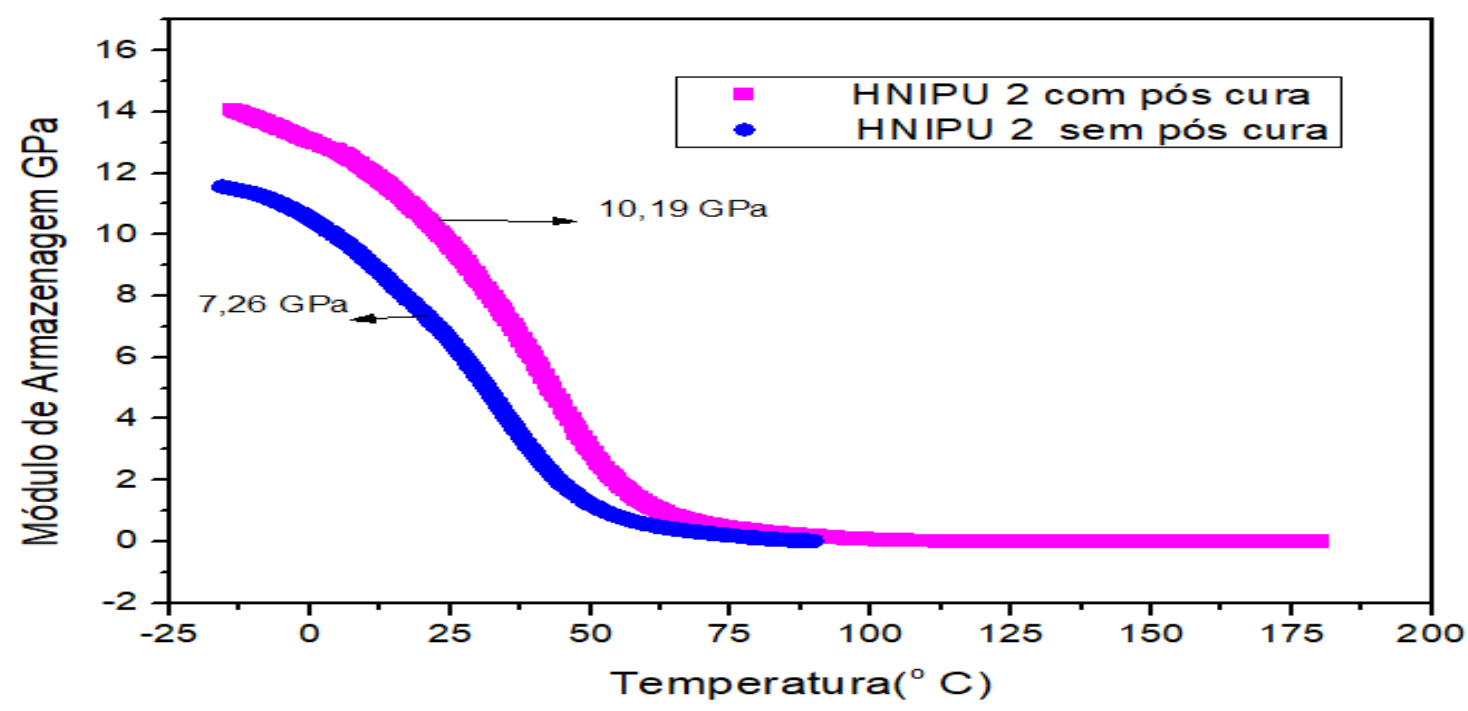

Fonte: elaborado pelo próprio autor, 2019.

Figura 147 - Comparação entre as curvas de módulo de armazenamento (E') em função da temperatura para amostra HNIPU 4 sem pós cura (verde) e com pós-cura (marrom).

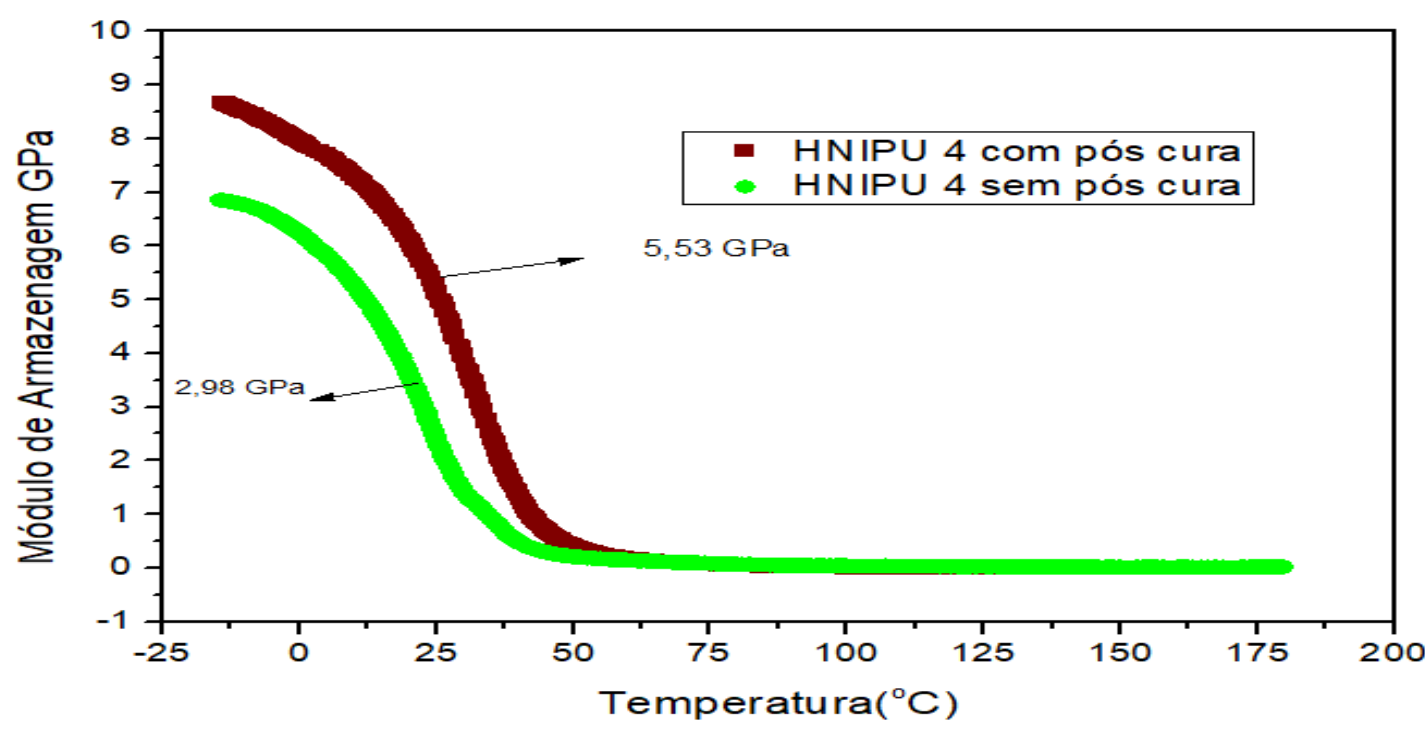

Fonte: elaborado pelo próprio autor, 2019.

Na avaliação do Módulo de Perda (E') como pode ser visto nas Figuras 148, 149 e 150, vê se da mesma forma que no Módulo de Armazenagem a influência dos pós cura nas amostras com mica sililada. Essa informação reforça a necessidade de pós cura para a obtenção de HNIPU. 
Figura 148 - Comparação da resposta do módulo de perda (E’') em função da temperatura para HNIPU 3t (com pós cura, curva preta) e HNIPU 3 (sem pós cura) curva vermelha

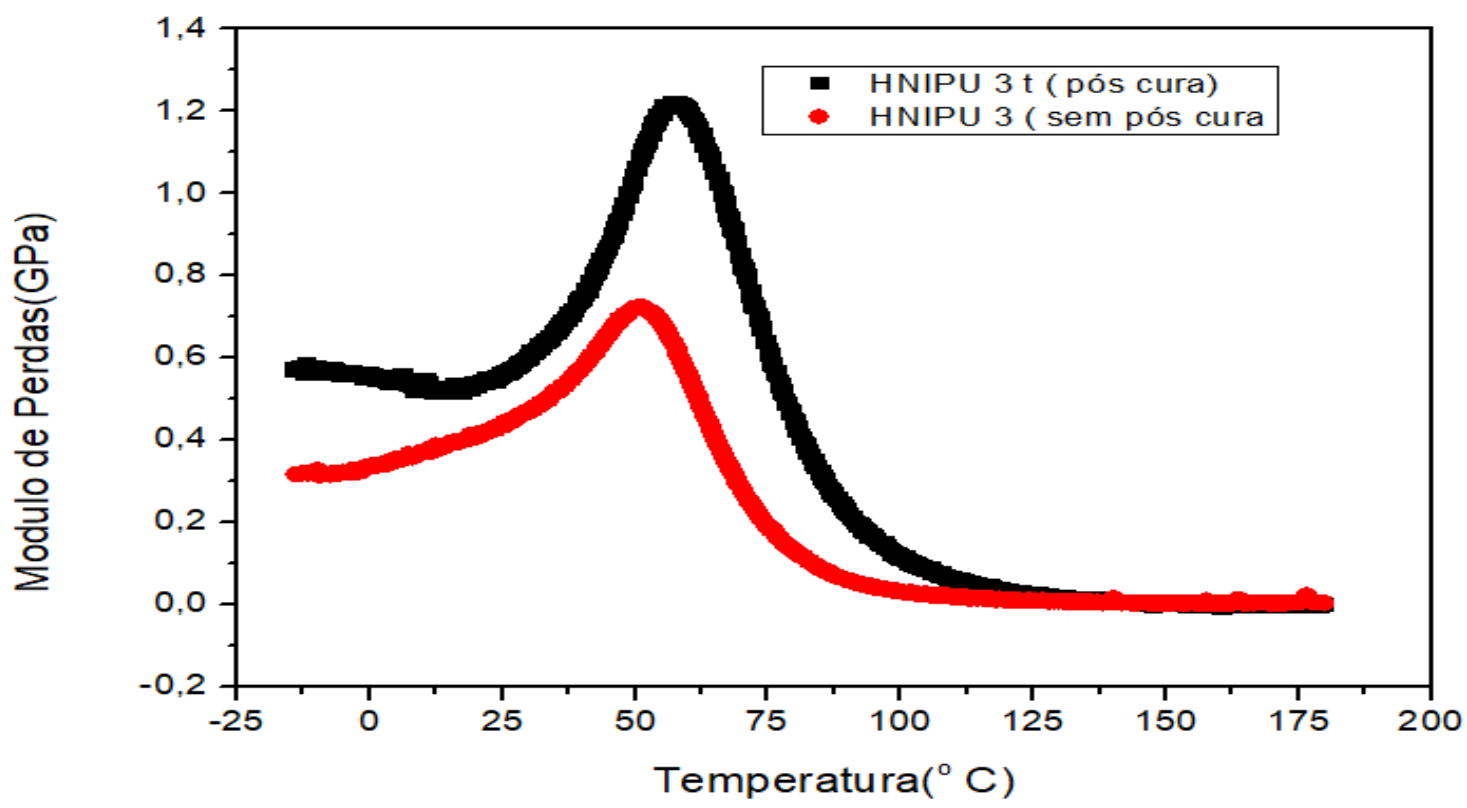

Fonte: elaborado pelo próprio autor, 2019.

Figura 149 - Dependência do módulo de perda (E') em função da temperatura para HNIPU IPDA com mica sem tratamento, amostra 3 (curva azul) e amostra 3t (curva vermelha).

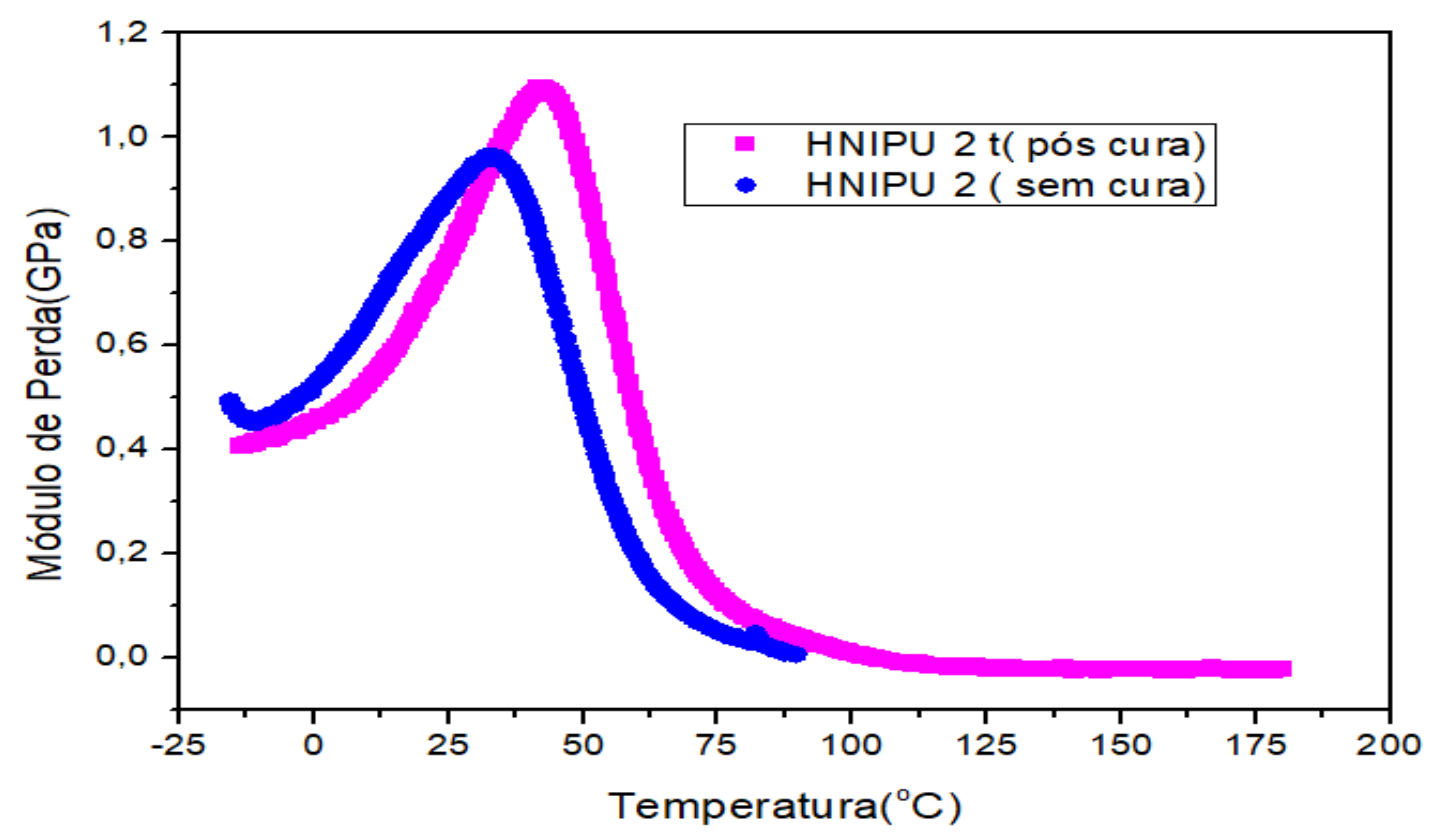

Fonte: elaborado pelo próprio autor, 2019. 
Figura 150 - Dependência do módulo de perda (E’) em função da temperatura para HNIPU 4 t com pós cura curva marrom) e HNIPU 4 sem pós cura, curva verde.

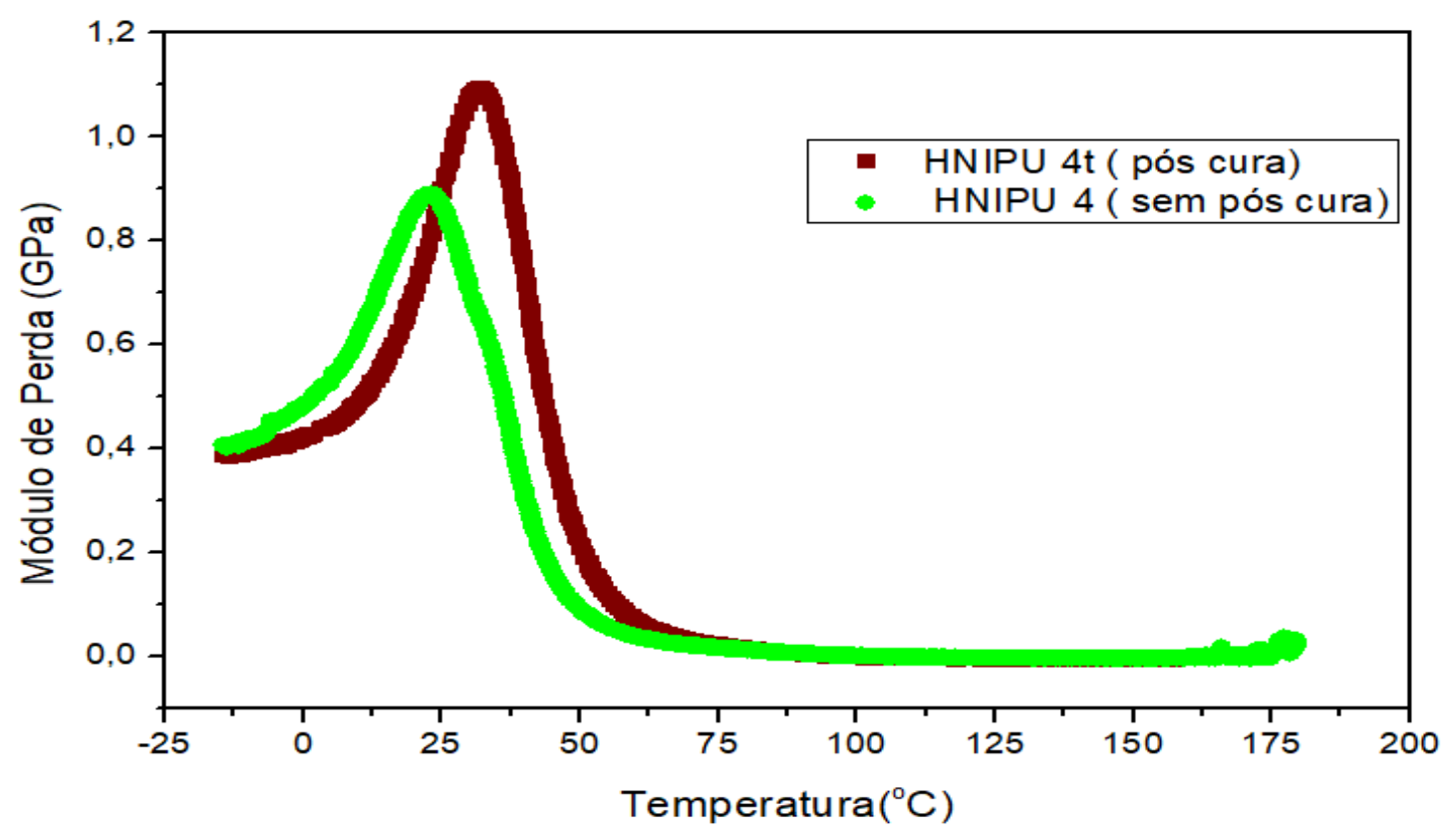

Fonte: elaborado pelo próprio autor, 2019.

Comentários Iniciais: Na avaliação usando DMA, quando se compara com as premissas básicas do projeto, ter se um sistema de isolamento para um Hidrogerador com uma componente elástica que possa evitar a degradação aos estresses térmicos e mecânicos sofridos por esse equipamento, tem já uma evidência extremamente positiva da melhoria da componente elástica quando se compara com um sistema epóxi sem o uso da mica tratada com aminossilano (Epóxi 2). Importante citar que inclusive quando se usa o conceito da mica sililada em um sistema Epóxi (protótipo Epóxi 3), já percebe se o efeito dessa abordagem o que pode ser positivo inclusive para melhorar a componente elástica dos sistemas atualmente usados nos Hidrogeradores, é um fato novo e que deve merecer uma avaliação futura.

Quanto a componente térmica, assim como no DSC, a Tg medida por DMA, mostra que o composto HNIPU3, atende à aplicação para uso continuo a $70{ }^{\circ} \mathrm{C}$, mas não suportaria a sobrecarga dos picos que ocorrem na utilização desse equipamento, em torno de $130{ }^{\circ} \mathrm{C}$. Faz-se necessário melhorar a resistência térmica para a condição desenhada de uma alternativa ao sistema epóxi em hidrogeradores. 


\subsection{Avaliação Propriedades Elétricas}

Devido ao modelo de utilidade desenhado para esse projeto, ou seja, ter um sistema alternativo para o sistema de isolamento de um Hidrogerador, as propriedades elétricas têm uma importância vital no escopo das premissas de direcionamento dos resultados. Devido ao tipo do corpo de prova, fez-se avaliação das propriedades de Rigidez dielétrica, propriedade definida na própria especificação do equipamento e mediu-se também via Espectroscopia de impedância, os valores de constante dielétrica (permissividade) e fator de perda $(\operatorname{Tg} \delta)$. (Tabela 44)

\subsubsection{Avaliação da Rigidez Dielétrica}

Tabela 44 - Formulação usada nos testes Elétricos.

\begin{tabular}{|r|l|}
\hline \multicolumn{1}{|l|}{ Amostra } & Formulação da Síntese. \\
\hline Epóxi 1 & DGEBA/IPDA Sem Mica \\
\hline Epóxi 2 & DGEBA/IPDA/ Mica Sililada \\
\hline Epóxi 3 & DGEBA/IPDA/ Mica não Sililada \\
\hline NIPU 2 & CCGEBA/IPDA razão equiv. 1/1 com Mica Sililada \\
\hline NIPU 3 & CCGEBA/IPDA) razão equiv. 1,5/1 com Mica Sililada \\
\hline NIPU 4 & CCGEBA/IPDA) razão equiv. 1/1 com Mica não Sililada \\
\hline HNIPU 1 & (CCGEBA/IPDA)/DGEBA sem Mica \\
\hline HNIPU 2 & (CCGEBA/IPDA)/DGEBA com Mica não Sililada \\
\hline HNIPU 3 & ( CCGEBA/IPDA)/DGEBA com Mica Sililada \\
\hline HNIPU 4 & ( CCGEBA/TETA)/DGEBA com Mica Sililada \\
\hline
\end{tabular}

Fonte: elaborado pelo próprio autor, 2019.

Tabela 45 - Dados Obtidos nos Testes de Rigidez Dielétrica.

\begin{tabular}{|l|c|c|}
\hline Amostra & Rigidez Dielétrica $(+-1 \%) *$ & $\begin{array}{c}\text { Variação em relação a } \\
\text { amostra padrão da série }\end{array}$ \\
\hline Unidade de medida & V.mm ${ }^{-1}$ & $\%$ \\
\hline \multicolumn{3}{|c|}{ Série Epóxi } \\
Epóxi 1 & 31121 & 0 \\
Epóxi 3 & 27423 & -11 \\
\hline \multicolumn{2}{|c|}{ Série NIPU } \\
\hline NIPU 2 & 20156 & $-6,6$ \\
NIPU 3 & 16544 & 0 \\
NIPU 4 & 18989 & $-17,9$ \\
\hline \multicolumn{2}{|c|}{ Série HNIPU } \\
\hline HNIPU 1 & 28346 & $-5,8$ \\
HNIPU 2 & 26707 & $-5,7$ \\
HNIPU 3 & 27786 & $-1,9$ \\
HNIPU 4 & 25190 & -11 \\
\hline
\end{tabular}

Fonte: elaborado pelo próprio autor, 2019. 
- O teste de Rigidez dielétrica por ser destrutivo, portanto, na série de 3 amostras é escolhido o menor valor.

Com os resultados da Tabela 45 e da Figura 151 pode-se observar que há um maior valor de rigidez dielétrica dos materiais sem mica, isso pode ser explicado pelo maior isolamento elétrico do sistema polimérico que o da Mica [2,152]. Esse dado deverá ser melhor explicado nos testes de impedância onde haverá a determinação dos mecanismos de polarização. Também, é possível perceber claramente que o sistema epóxi e HNIPU apresentam resultados superiores de Rigidez Dielétrica ao sistema NIPU, provavelmente devido maior reticulação destas amostras como demonstrado nos ensaios de teor de gel e inchamento em THF.

Figura 151 - Gráfico com Valores de Rigidez Dielétrica.

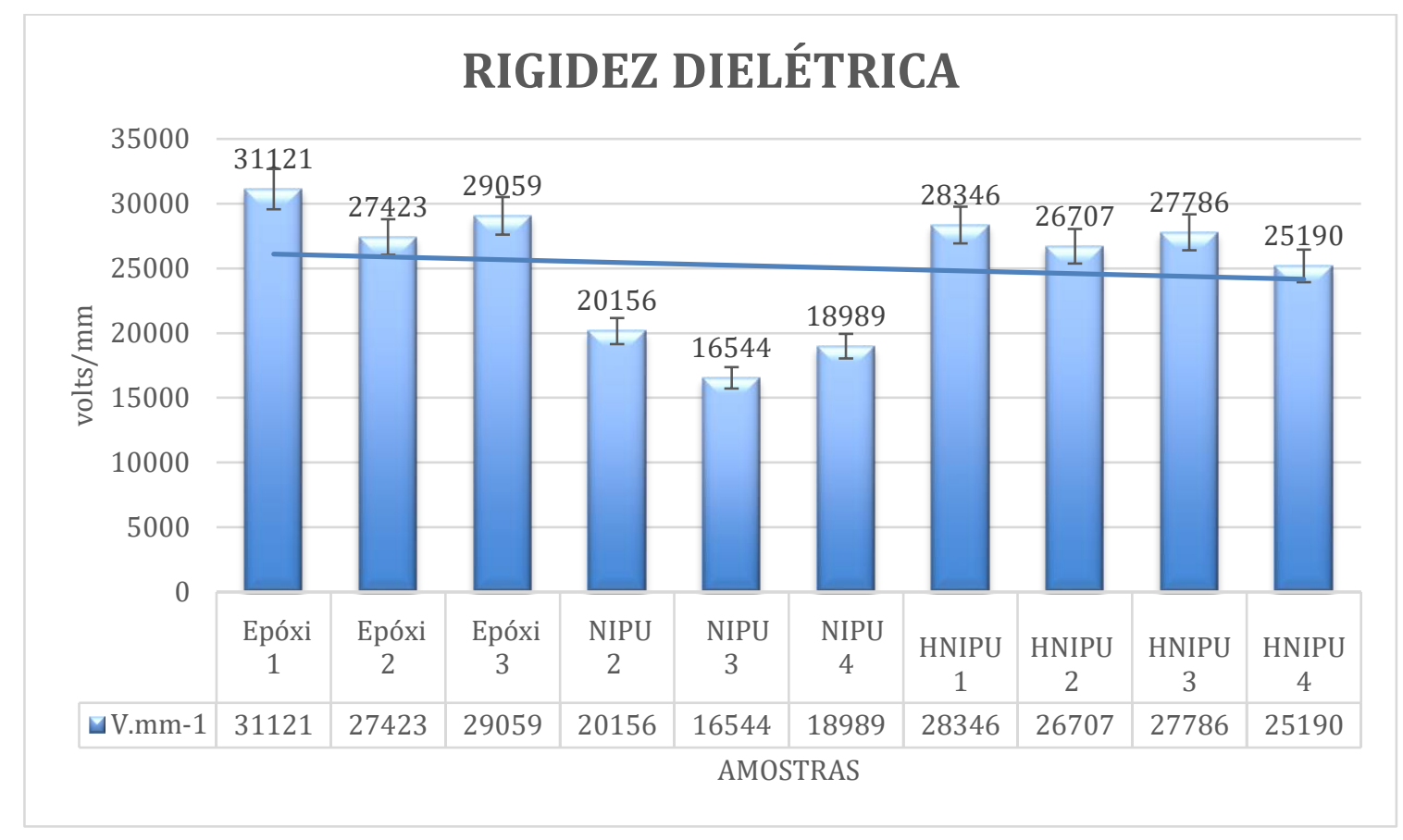

Fonte: elaborado pelo próprio autor, 2019.

Comentários Iniciais: os resultados de Rigidez Dielétrica, para a premissa dos protótipos desenhados serem para uso como elemento de isolação, são extremamente positivos. No Hidrogerador se requer como mínimo de Rigidez Dielétrica de 3000 volts/mm., com isso todas as amostras, Epóxi, NIPU e HNIPU atenderiam esse requisito. A Mica com tratamento, como já era esperado, apresenta valores superiores a mesma base de síntese onde se usou a Mica sem tratamento. Isso também poderá ser mais bem ilustrado nos testes de Constante Dielétrica e Fator de Dissipação. Os dados são coerentes com o trabalho feito por 
Hailin (2016) et al [83] que em sistemas epóxi usando mica tratada obteve melhores propriedades dielétricas.

\subsubsection{Comportamento Dielétrico por Espectroscopia de Impedância}

Para avaliação do comportamento dielétrico dos materiais também foram realizados ensaios de espectroscopia de impedância, onde se utilizou os corpos de prova da mesma placa que produziu os protótipos para a rigidez dielétrica, revestidos com tinta condutiva de carbono/platina para formação do capacitor. As amostras usadas na espectroscopia de Impedância têm a mesma codificação dos testes de Rigidez Dielétrica e estão identificadas na Tabela 44.

Tabela 46 - Medidas dos Corpos de Prova usados na Impedância.

\begin{tabular}{|r|r|r|}
\hline $\begin{array}{c}\text { Amostra } \\
\text { (unidade) }\end{array}$ & $\begin{array}{c}\text { Espessura } \\
\text { (metro) }\end{array}$ & \multicolumn{1}{c|}{$\begin{array}{c}\text { Área } \\
\left(\mathrm{m}^{2}\right)\end{array}$} \\
\hline Epóxi 1 & 0,00321 & $9,03448 \mathrm{E}-05$ \\
Epóxi 2 & 0,00388 & $8,74224 \mathrm{E}-05$ \\
Epóxi 3 & 0,00192 & $9,33147 \mathrm{E}-05$ \\
NIPU 2 & 0,00145 & 0,00011025 \\
NIPU 3 & 0,00186 & 0,000108619 \\
NIPU 4 & 0,00328 & $8,74224 \mathrm{E}-05$ \\
HNIPU 1 & 0,00176 & 0,00010769 \\
HNIPU 2 & 0,00025 & $7,71325 \mathrm{E}-05$ \\
HNIPU 3 & 0,00119 & $7,98015 \mathrm{E}-05$ \\
1HNIPU 4 & 0,00117 & 0,00013396 \\
\hline
\end{tabular}

Fonte: elaborado pelo próprio autor, 2019.

A partir dos dados da Tabela 46 de medidas dos corpos de prova e capacitância obtidos no teste de impedância, Tabela 47, usando as equações para cálculo da Constante Dielétrica (equação 18) e para cálculo do Fator de Dissipação ou perda (equação 19) obtevese os dados de Constante Dielétrica e Fator de Dissipação (Fator de Perda). 
Tabela 47 - Dados de Capacitância Real e imaginária obtida no teste de Impedância. (PicoFarad)

\begin{tabular}{|c|c|c|c|c|c|c|c|c|}
\hline Amostral Frequencia & $0,1 \mathrm{~K}$ & $1 \mathrm{k}$ & $10 \mathrm{~K}$ & $100 \mathrm{~K}$ & $0,1 \mathrm{~K}$ & $1 \mathrm{k}$ & $10 \mathrm{~K}$ & $100 \mathrm{~K}$ \\
\hline Epóxi 1 a $25^{\circ} \mathrm{C}$ & 1,76 & 1,75 & 1,69 & 1,59 & 0,047 & 0,034 & 0,0472 & 0,0854 \\
\hline Epóxi 2 a $25^{\circ} \mathrm{C}$ & 3,97 & 3,75 & 3,56 & 3,36 & 0,162 & 0,014 & 0,124 & 0,154 \\
\hline Epóxi 2 Loop $50^{\circ} \mathrm{C}$ & 3,29 & 3,12 & 2,96 & 2,78 & 0,157 & 0,012 & 0,11 & 0,139 \\
\hline Epóxi 3 a $25^{\circ} \mathrm{C}$ & 2,15 & 1,98 & 1,82 & 1,64 & 0,017 & 0,012 & 0,109 & 0,134 \\
\hline Epóxi 3 a $50^{\circ} \mathrm{C}$ & 2,72 & 2,49 & 2,28 & 2,1 & 0,0236 & 0,018 & 0,124 & 0,143 \\
\hline NIPU 4 a $25^{\circ} \mathrm{C}$ & 8,74 & 5,74 & 4,62 & 4,03 & 5,67 & 1,61 & 0,613 & 0,389 \\
\hline 3 a $25^{\circ} \mathrm{C}$ & 16,2 & 9,26 & 6,53 & 5,28 & 18,5 & 4,35 & 1,44 & 0,803 \\
\hline NIPU 2 a $25^{\circ} \mathrm{C}$ & 22,95 & 2,45 & 2,18 & 1,98 & 0,085 & 0,029 & 0,156 & 0,143 \\
\hline NIPU 2 a $50{ }^{\circ} \mathrm{C}$ & 3,32 & 2,71 & 2,42 & 2,21 & 1,07 & 0,023 & 0,165 & 0,147 \\
\hline $\mathrm{J} 4 \mathrm{a}$ a $25^{\circ} \mathrm{C}$ & 12,4 & 6,79 & 5,15 & 4,45 & 7,46 & 2,45 & 0,818 & 0,437 \\
\hline $\mathrm{U} 1$ a $25^{\circ} \mathrm{C}$ & 18 & 17,1 & 16,28 & 1,54 & 1,44 & 0,81 & 0,578 & 0,75 \\
\hline $\mathrm{U} 1$ a $50^{\circ} \mathrm{C}$ & 20,5 & 17,7 & 16,3 & 15,5 & 3,86 & 1,5 & 0,763 & 0,69 \\
\hline 3 a $25^{\circ} \mathrm{C}$ & 9,32 & 7,11 & 6,02 & 5,34 & 3,11 & 0,012 & 0,608 & 0,443 \\
\hline HNIPU 3 a $50^{\circ} \mathrm{C}$ & 21,9 & 10,4 & 6,68 & 5,33 & 13,3 & 5,09 & 1,73 & 0,751 \\
\hline HNIPU 2 a a $25^{\circ} \mathrm{C}$ & 12,8 & 10,2 & 8,9 & 8,02 & 4,11 & 1,43 & 7,61 & 0,622 \\
\hline HNIPU 2 a $50{ }^{\circ} \mathrm{C}$ & 39,3 & 17,5 & 11,11 & 9,07 & 23,7 & 9,22 & 2,85 & 0,114 \\
\hline
\end{tabular}

Fonte: elaborado pelo próprio autor, 2019.

\subsubsection{Obtenção dos dados de Constante Dielétrica a partir da Impedância}

Utilizando a equação da constante dielétrica obteve-se os resultados mostrados na Tabela 48.

Tabela 48 - Constante Dielétrica das amostras $(\mathcal{E})$.

\begin{tabular}{|l|r|r|r|r|}
\hline Amostra\Frequência & \multicolumn{1}{|l|}{$0,1 \mathrm{KHz}$} & \multicolumn{1}{l|}{$1 \mathrm{KHz}$} & \multicolumn{1}{l|}{$10 \mathrm{KHz}$} & $100 \mathrm{KHz}$ \\
\hline Epóxi 1 a $25^{\circ} \mathrm{C}$ & 7,074 & 7,033 & 6,79 & 6,39 \\
Epóxi 2 a $25{ }^{\circ} \mathrm{C}$ & 10,79 & 9,94 & 9,14 & 8,23 \\
Epóxi 2 Loop $50^{\circ} \mathrm{C}$ & 13,66 & 12,5 & 11,45 & 10,54 \\
Epóxi 3 a $25^{\circ} \mathrm{C}$ & 9,24 & 8,73 & 8,29 & 7,82 \\
Epóxi 3 a $50^{\circ} \mathrm{C}$ & 7,66 & 7,26 & 6,89 & 6,47 \\
\hline NIPU 4 a a $25{ }^{\circ} \mathrm{C}$ & 13,0076 & 8,54 & 6,87 & 5,99 \\
NIPU 3 a $25{ }^{\circ} \mathrm{C}$ & 31,38 & 17,94 & 12,65 & 10,23 \\
NIPU 2 a $25^{\circ} \mathrm{C}$ & 12,52 & 10,41 & 9,25 & 8,41 \\
NIPU 2 a $50^{\circ} \mathrm{C}$ & 14,091 & 11,52 & 10,27 & 9,38 \\
\hline HNIPU 4 a $25{ }^{\circ} \mathrm{C}$ & 22,92 & 12,55 & 9,52 & 8,23 \\
HNIPU 1 a $25{ }^{\circ} \mathrm{C}$ & 3,96 & 6,27 & 5,98 & 5,65 \\
HNIPU 1 a $50^{\circ} \mathrm{C}$ & 7,52 & 6,49 & 5,98 & 5,68 \\
HNIPU 3 a $25{ }^{\circ} \mathrm{C}$ & 15,72 & 11,99 & 10,16 & 9,0079 \\
HNIPU 3 a $50^{\circ} \mathrm{C}$ & 36,94 & 17,54 & 11,27 & 8,99 \\
HNIPU 2 a $25^{\circ} \mathrm{C}$ & 12,64 & 10,078 & 8,79 & 7,92 \\
HNIPU 2 a $50^{\circ} \mathrm{C}$ & 38,83 & 17,29 & 10,97 & 8,96 \\
\hline
\end{tabular}

Fonte: elaborado pelo próprio autor, 2019. 
Como são 03 sistemas diferentes de protótipos, as avaliações foram separadas por grupos e são mostradas a seguir.

Figura 152 - Comportamento Protótipos Epóxi Constante Dielétrica ASTM D 150.

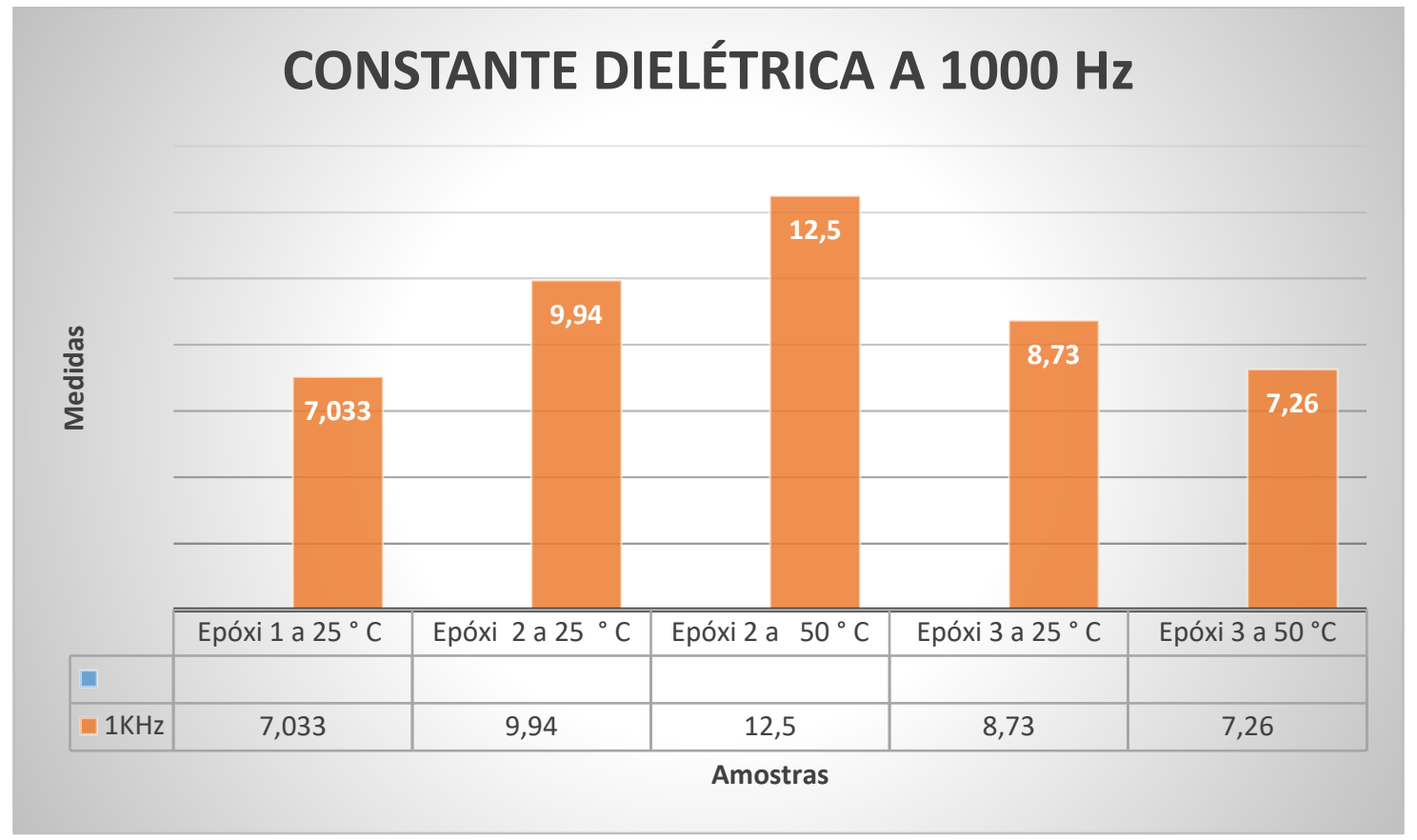

Fonte: elaborado pelo próprio autor, 2019.

Podemos observar na Figura 152 que o melhor valor é obtido com a amostra Epóxi 1, onde utilizou-se apenas a resina epóxi curada com IPDA, coerente com o valor de constante dielétrica para sistemas sem carga mineral o qual tem um valor médio de 5 a 6. [2]

Comparando a Epóxi 3 (mica sililada) com Epóxi 2 (mica não-sililada), observa-se o impacto positivo da sililação da mica. Esses dados são coerentes com os obtidos por Halin (2016) et al [83] onde com o uso do epóxi com mica funcionalizada verificou a mesma tendência aqui encontrada. De maneira geral, todas as amostras se comportaram como um excelente isolante elétrico, obtendo valores abaixo de 30 na propriedade de Constante Dielétrica [199]. 
Figura 153- Comportamento Protótipos NIPU.

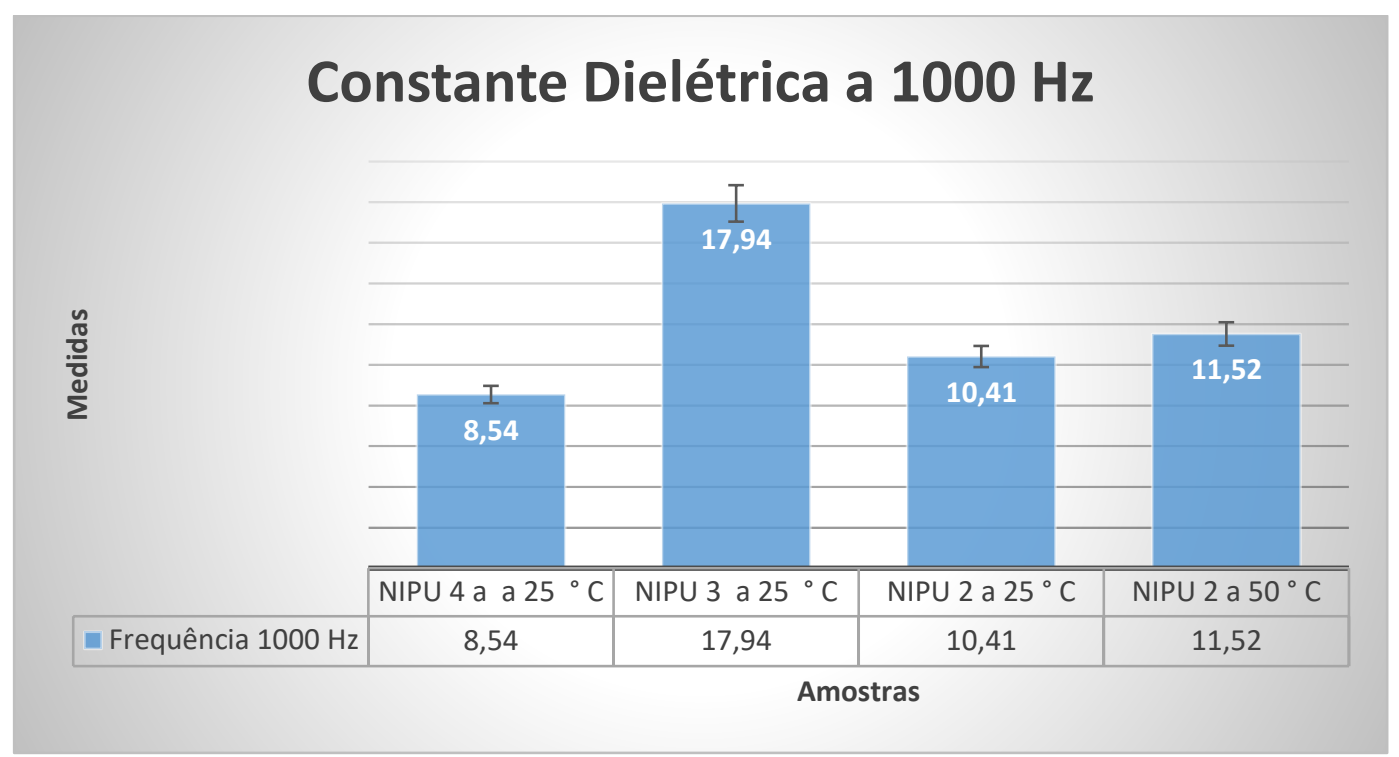

Fonte: elaborado pelo próprio autor, 2019.

No gráfico da Figura 153 verifica-se que a NIPU 3 (com razão de equivalentes 1,5:1,0 entre o ciclocarbonato e a IPDA), apresenta o pior comportamento. O excesso de ciclocarbonato, já comprovado nos dados de rigidez dielétrica deve estar impactando nessa propriedade. Segundo Figovsky (2013) et al [134] os mecanismos de fuga em NIPU são afetados em baixa frequência por fatores de orientação dipolar, enquanto em alta frequência associados com mecanismos iônicos e eletrônicos dos compósitos. Essa condição pode explicar que o excesso de ciclocarbonato pode estar impactando na polaridade desse compósito o que explica esse comportamento inferior às outras amostras.

Comparando o comportamento da NIPU 4 (razão equivalente 1:1 com mica não sililada) com a NIPU 3 (razão equivalente 1:1 com mica sililada) percebe-se pouca diferença, não se vê o efeito do tratamento mica e dos dados já encontrados de aumento da reticulação visto no DSC. Devido ao valor encontrado, os dados da constante dielétrica estão refletindo a propriedade da mica pura, não da parte orgânica ou da reticulação promovida pelo uso da mica sililada, o impacto de $40 \%$ em peso de mica, pode não estar permitindo a visualização do efeito nessa propriedade.

Nota-se que o sistema NIPU, apesar de apresentar características de um excelente isolante, tem um comportamento inferior ao sistema epóxi, possivelmente pela maior reticulação do segundo. 
Figura 154 - Comportamento Protótipos HNIPU (NIPU/DGEBA).

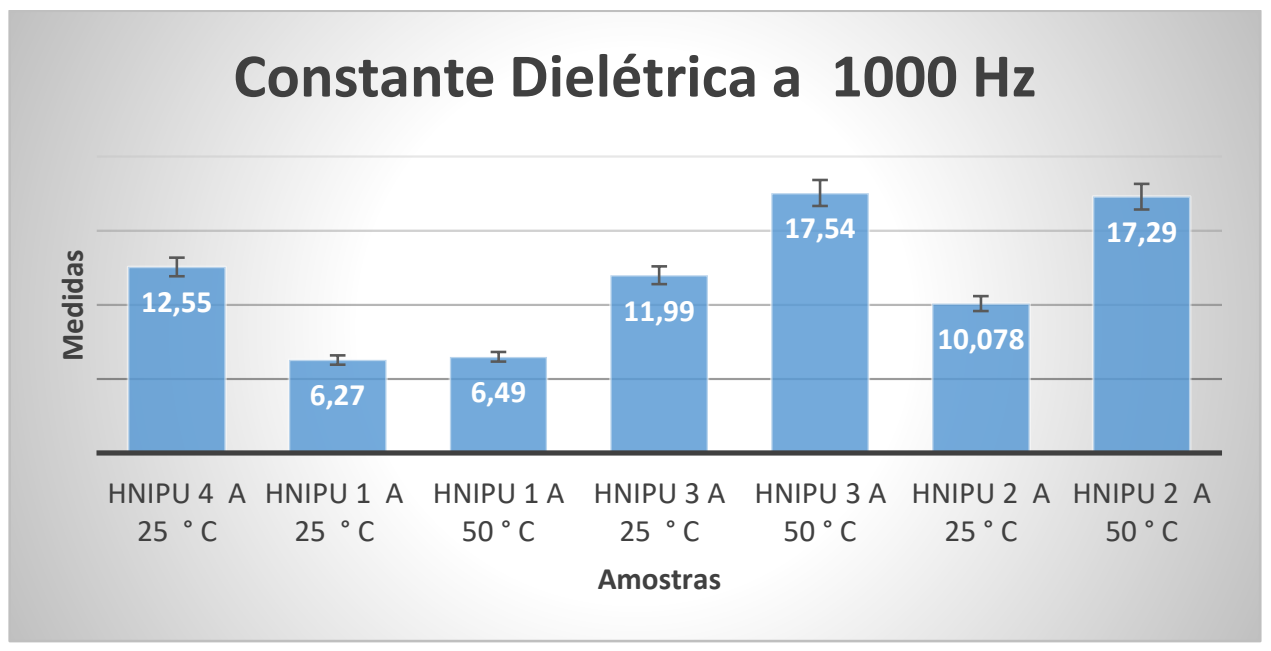

Fonte: elaborado pelo próprio autor, 2019.

Assim como nos protótipos epóxi, nos sistemas HNIPU, Figura 154, o melhor comportamento está na amostra sem a presença da mica, HNIPU 1, pois, mesmo a uma temperatura maior $\left(50^{\circ} \mathrm{C}\right)$ apresenta um melhor valor de constante dielétrica. [2].

Assim como na NIPU, vemos que uso da mica sililada ou não (HNIPU 2 e HNIPU 3) não leva a diferenças significativas nos valores de Constante Dielétrica, provavelmente em função da HNIPU apresentar uma maior reticulação e o próprio percentual de mica, $40 \%$ ter impacto que não permite observar o comportamento isoladamente da reticulação que o grupamento amina da mica sililada pode oferecer. De maneira geral, todas apresentam bons valores de constante dielétrica, comprovando-se serem eletricamente isolantes.

De maneira geral em todos os protótipos podemos observar o impacto da presença da mica como fator determinante para o valor da constante dielétrica. Como percebido nos testes, existe valores de impedância como em duas fases independentes, considerando que a mica apresenta um valor nominal de constante dielétrica de 8 , os valores estão coerentes com esse dado $[30,82]$.

Comentários Iniciais: No caso da propriedade de Constante Dielétrica, como uma propriedade que mede a capacidade de um isolante armazenar carga sem haver sua dissipação, no caso do modo de utilidade de um Hidrogerador, essa medida pode ser associada ao principal requisito que é do isolamento do Hidrogerador suportar as descargas parciais, ou seja, a perda dielétrica causada por mecanismos internos de dissipação. 
Indiretamente as medidas de Constante Dielétrica podem mostrar a capacidade do isolante de suportar uma tensão aplicada sem que haja sua perda. Pode se inclusive deduzir que o isolamento das barras do hidrogerador se comportam como um grande capacitor e diante disso, os dados excelentes principalmente do sistema epóxi e HNIPU são um bom indicativo da capacidade isolante desses sistemas para esse tipo de equipamento e requisitos.

\subsubsection{Medidas de Fator de Dissipação (Tangente de Perda)}

O Fator de Dissipação ou Tangente de Perda, é uma das principais propriedades de um isolamento para hidrogeradores. Sendo que o aumento das perdas está diretamente relacionado com o nível de descargas parciais internas do sistema isolante, podendo ser causado por inclusões gasosas, impurezas e até falha na estrutura do sistema [219].

Utilizando os dados obtidos na impedância via capacitância na fase imaginária (C' '), obteve-se os dados de fator de Dissipação. (Tabela 49)

Tabela 49 - Dados Obtidos do Fator de Dissipação ou Tangente de perda.

\begin{tabular}{|c|c|c|c|c|}
\hline AmostralFrequência & $0,1 \mathrm{KHz}$ & $1 \mathrm{KHz}$ & $10 \mathrm{KHz}$ & $100 \mathrm{KHz}$ \\
\hline Epóxi 1 a $25^{\circ} \mathrm{C}$ & 0,026 & 0,019 & 0,028 & 0,053 \\
\hline Epóxi 2 a $25^{\circ} \mathrm{C}$ & 0,079 & 0,061 & 0,059 & 0,082 \\
\hline Epóxi 2 Loop $50^{\circ} \mathrm{C}$ & 0,086 & 0,071 & 0,054 & 0,068 \\
\hline Epóxi 3 a $25^{\circ} \mathrm{C}$ & 0,041 & 0,036 & 0,034 & 0,045 \\
\hline Epóxi 3 a $50^{\circ} \mathrm{C}$ & 0,047 & 0,038 & 0,037 & 0,051 \\
\hline NIPU 4 a a $25^{\circ} \mathrm{C}$ & 0,64 & 0,28 & 0,13 & 0,096 \\
\hline NIPU 3 a $25^{\circ} \mathrm{C}$ & 0,11 & 0,47 & 0,22 & 0,15 \\
\hline NIPU 2 a $25^{\circ} \mathrm{C}$ & 0,29 & 0,12 & 0,072 & 0,072 \\
\hline NIPU 2 a $50^{\circ} \mathrm{C}$ & 0,32 & 0,12 & 0,068 & 0,066 \\
\hline HNIPU 4 a $25^{\circ} \mathrm{C}$ & 0,61 & 0,36 & 0,16 & 0,098 \\
\hline HNIPU 1 a $25^{\circ} \mathrm{C}$ & 0,13 & 0,047 & 0,036 & 1,58 \\
\hline HNIPU 1 a $50^{\circ} \mathrm{C}$ & 0,19 & 0,084 & 0,046 & 0,044 \\
\hline HNIPU 3 a $25^{\circ} \mathrm{C}$ & 0,33 & 0,17 & 0,11 & 0,083 \\
\hline HNIPU 3 a $50{ }^{\circ} \mathrm{C}$ & 0,61 & 0,49 & 0,26 & 0,14 \\
\hline HNIPU 2 a $25^{\circ} \mathrm{C}$ & 0,32 & 0,14 & 0,086 & 0,078 \\
\hline HNIPU 2 a $50{ }^{\circ} \mathrm{C}$ & 0,61 & 0,53 & 0,26 & 0,12 \\
\hline
\end{tabular}


Figura 155 - Comportamento Protótipos Epóxi Fator de Dissipação ASTM D 150.

\section{$1000 \mathrm{~Hz}$}

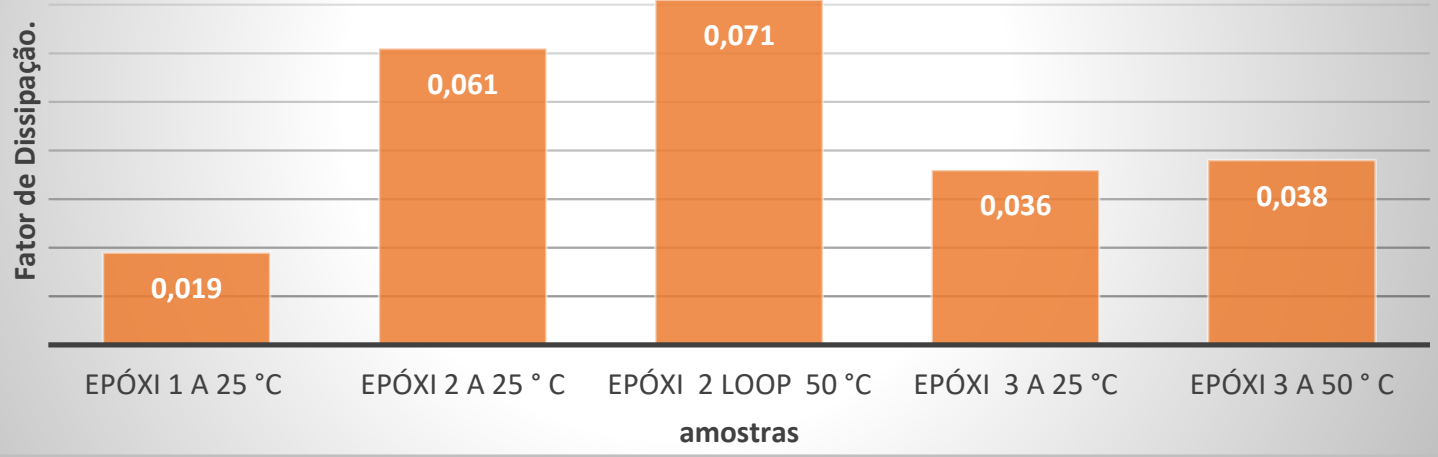

Fonte: elaborado pelo próprio autor, 2019.

Os resultados obtidos do sistema epóxi, Figura 155, corroboram com os valores de constante dielétrica, pois, a amostra sem a mica (Epóxi 1) apresenta um fator de perda extremamente baixo, nota-se na comparação entre Epóxi 3 (com mica sililada) e Epóxi 2 (mica sem tratamento) o impacto positivo da presença do aminossilano. Considerando que na aplicação utilizamos a fita de Mica temos um valor médio de fator de perda entre 0,5 e 0,6 , os protótipos com o uso da mica dispersa na matriz polimérica apresentam excelente característica de perda dielétrica [7].

Figura 156 - Comportamento Protótipos NIPU Fator de Perda ASTM D 150.

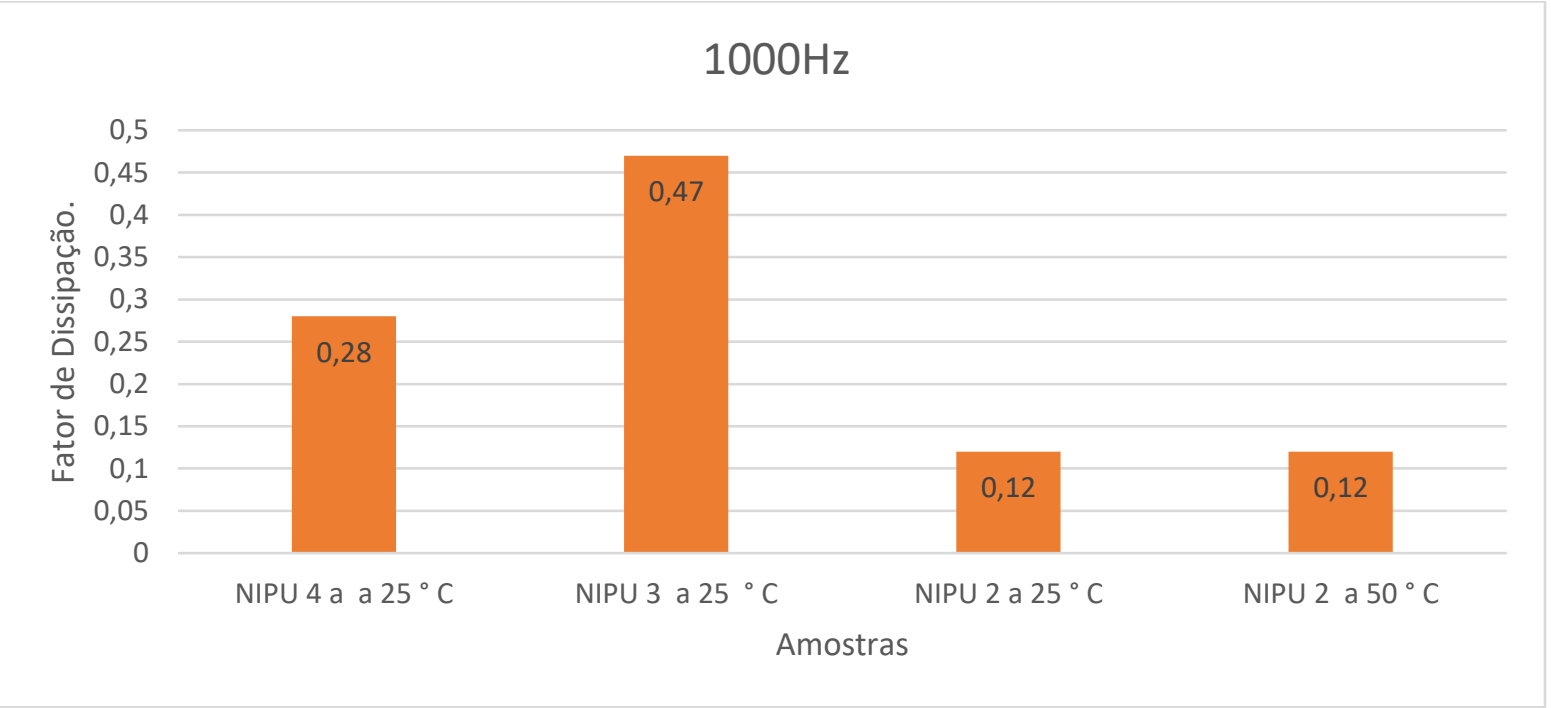

Fonte: elaborado pelo próprio autor, 2019. 
O comportamento do Fator de Dissipação da NIPU, conforme a Figura 156, se reproduz no caso da NIPU 3, onde existe o excesso de ciclocarbonato, têm se um mecanismo de perda agindo nesse material, dado coerente com o encontrado na Constante Dielétrica. Entre NIPU 4 (mica sem tratamento) e NIPU 2 (mica sililada), vemos que a diferença no fator de dissipação entre as duas amostras é bem significativa. Mesmo a $50^{\circ} \mathrm{C}$ os valores são melhores que na condição ambiente da NIPU 4.

Figura 157 - Comportamento Protótipos HNIPU Fator de Dissipação ASTM D 150.

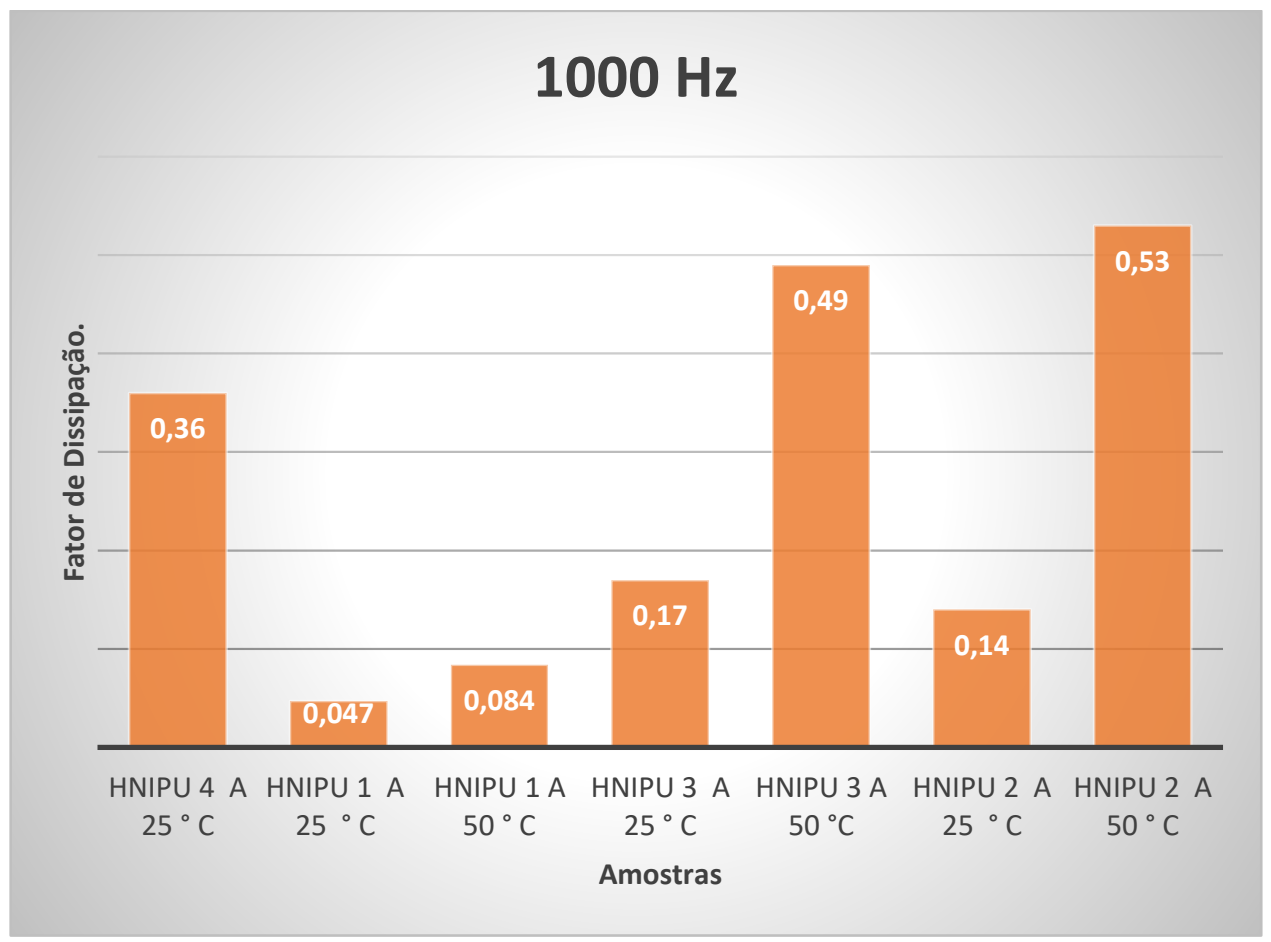

Fonte: elaborado pelo próprio autor, 2019.

Assim como no sistema epóxi, nas HNIPUs observa-se pela Figura 157, que a mica tem um impacto direto nos valores de fator de perda, HNIPU 1 (sem a mica) apresenta valores extremamente baixos quando comparados aos demais. No caso da amostra HNIPU 2 e HNIPU 3, o tratamento da mica não mostra um impacto nos valores do fator de perda. Em termos de comparação com o sistema utilizando a fita de mica, todas as amostras a $25^{\circ} \mathrm{C}$ apresentam valores abaixo de 0,5. No caso da HNIPU 4 (amostra usando TETA), mesmo usando mica sililada, vemos uma característica de inferioridade em relação aos compósitos com IPDA, mostrando o impacto da reticulação. 
Comentários Iniciais: No caso do fator de Dissipação pode se concluir que o uso da mica no formato de partículas incorporadas à matriz polimérica possui valores extremamente positivos em substituição ao uso da fita de mica. Como visto por Novaes Da Conceição (2015), [7], a obtenção de barras estatoras para gerador com o uso do conceito de proteger os condutores com fita de Mica leva a um fator de Dissipação em torno de 0,5 a 0,6 , no projeto em questão, se avaliou nanopartículas em sistemas diferentes de resina epóxi, porém se manteve o uso da fita de Mica. Conforme visto na Figura 158, independentemente do tipo da resina epóxi usada, se mantem o fator de perda de 0,5 a 0,6. [7 ]. Viu se também no fator de Dissipação, a influência do tratamento da mica com aminossilano como algo positivo para a propriedades elétricas, confirmando o visto por Halin (2016) et al [83].

Figura 158 - Comportamento do Fator de Perda em Sistema usando Fita de Mica. [7]

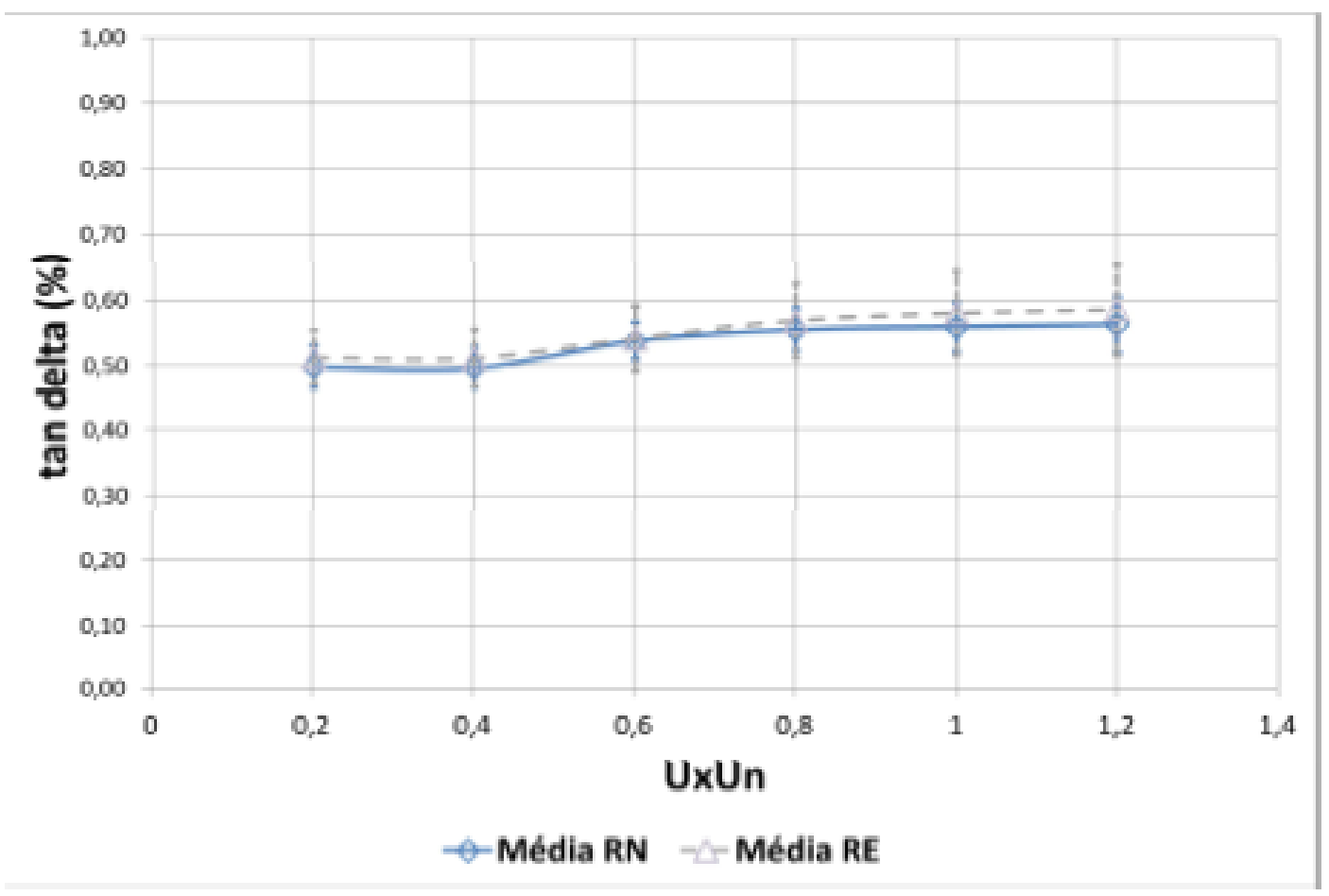

Fonte: Figura extraída de Polímeros, Conceição, R. N., \& Campos, J. S. C. 26(3), 262-268, 2016.

De uma maneira positiva, pode se concluir nesse ponto que a probabilidade de uso da mica em forma de pó, até para sistemas convencionais do tipo epóxi pode ser uma medida importante que associada com a questão elástica já vista no DMA, pode atuar nos dois modos de falha encontrados atualmente nos hidrogeradores. 
Uma informação importante que atesta a melhoria que se tem com a incorporação da mica em pó em sistemas poliméricos, foi dada por Henk (1999) et al, [220], o qual coloca que as partículas inorgânicas se comportam como escudos térmicos redutores de calor e por consequência retardando o efeito de degradação gerados pelas descargas parciais.

\subsection{Propriedades Mecânicas, via Nanoindentação}

Para o teste de Nanoindentação, as amostras foram escolhidas para obter uma coerência em relação às premissas do projeto. Amostras com o uso da Mica sililada com aminossilano e as três rotas trabalhadas, Epóxi (IPDA/Mica Sililada), NIPU (ciclocarbonato/IPDA e Mica sililada) e HNIPU com Mica sililada com aminossilano conforme a Tabela 50.

Tabela 50 - Identificação dos Protótipos avaliados na Nanoindentação.

\begin{tabular}{|r|l|}
\hline Formulas & Formulação dos Protótipos. \\
\hline Epóxi 2 & DGEBA/IPDA/Mica sililada \\
HNIPU 4 & $\begin{array}{l}\text { (CCGEBA/TETA/ DGEBA)/ Mica sililada } \\
\text { HNIPU 3 }\end{array}$ \\
NIPU 2 & $\begin{array}{l}\text { (CCGEBA-IPDA)/Mica sililada } \\
\text { (CCGEBA/IPDA) Mica sililada (razão equivalente } 1: 1)\end{array}$ \\
\hline
\end{tabular}

Fonte: elaborado pelo próprio autor, 2019.

As medidas dos protótipos avaliados estão no Apêndice P, página 263 enquanto as tabelas com todas as propriedades obtidas estão no Apêndice Q da página 264.

As médias dos valores obtidos por Nanoindentação nos ensaios estão apresentados na Tabela 51. 
Tabela 51 - Lista das Propriedades Mecânicas obtidas por Nanoindentação.

\begin{tabular}{|l|r|r|r|}
\hline Protótipo & Dureza ( GPa) & Dureza Hv & Módulos \\
\hline Epóxi 2 & 0,30899 & 29,1976 & 10,64 \\
HNIPU 3 & 0,40784 & 38,53 & 5,04 \\
HNIPU 4 & 0,1611 & 15,129 & 1,89 \\
NIPU & 0,1208 & 2,93 & 2,75 \\
\hline \multicolumn{4}{|c|}{ Fonte: elaborado pelo próprio autor, 2019. }
\end{tabular}

Os dados de Nanoindentação, Figura 159 e Tabela 51, permitem verificar que a HNIPU 3 tem uma dureza maior que o todos os materiais, inclusive o compósito base epóxi (amostra 1). Este fato é inesperado, tendo em vista o maior grau de reticulação do sistema epóxi, contudo pode estar associado a alguns fatores:

1 - Maior rigidez das ligações uretânica em relação a formação de grupos éter ou amina secundárias no sistema epóxi [221].

2 - Segregação de mica para a superfície.

3 - Presença de microbolhas no sistema epóxi, por se tratar de um material viscoso e que foi curado em temperatura ambiente, podemos ainda ter presença de bolhas que não foram eliminadas.

A segregação ocasionaria um aumento na energia de superfície média e, portanto, menor ângulo de contato com a água em relação às outras amostras. Entretanto, a HNIPU com IPDA e mica sililada, HNIPU 3, apresenta o segundo maior valor de ângulo de contato, muito próximo ao do compósito com epóxi. Sendo assim, a hipótese 3 parece ter maior validade, muito embora estudos de mapeamento químico sejam mais adequados para descartar a hipótese 2 que as medidas de molhabilidade. Nos testes de MEV, vimos que em algumas regiões havia sim a presença de microbolhas, o que pode ter impactado no teste de Nanoindentação. 
Figura 159 - Comportamento da Dureza obtida via Nanoindentação para as amostras de compósitos estudados.

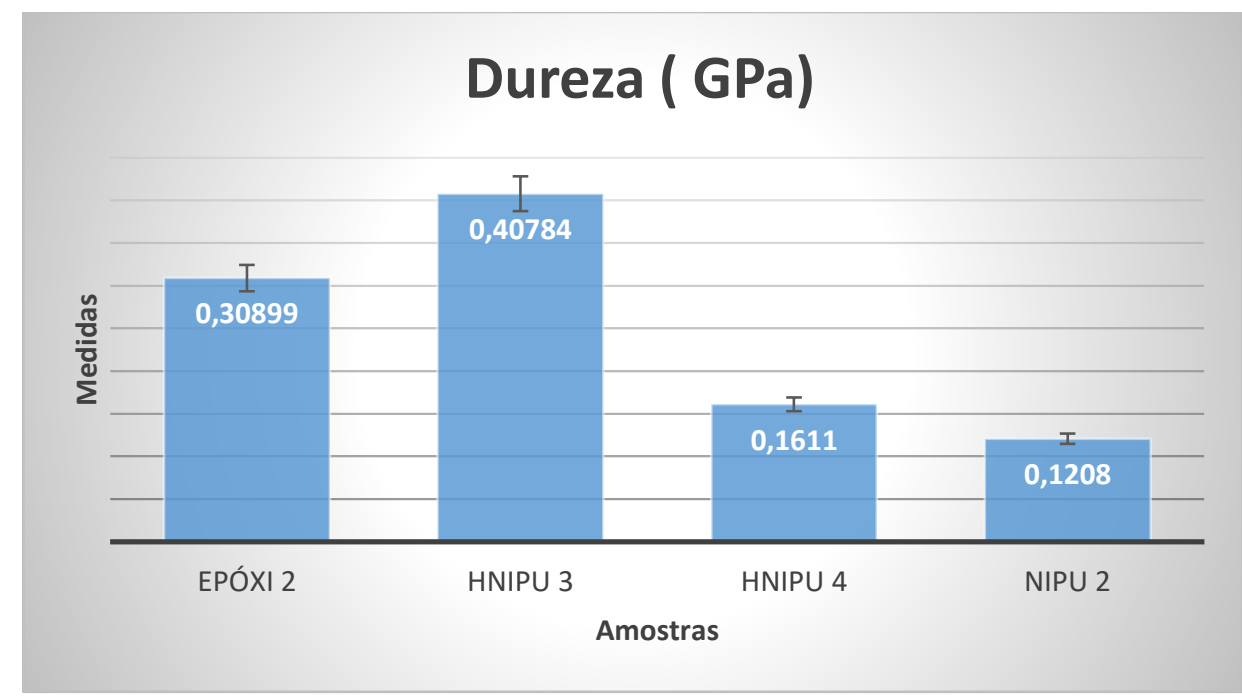

Fonte: elaborado pelo próprio autor, 2019.

Figura 160- Valores de Módulo Elástico (GPa) obtidos via Nanoindentação para os compósitos estudados.

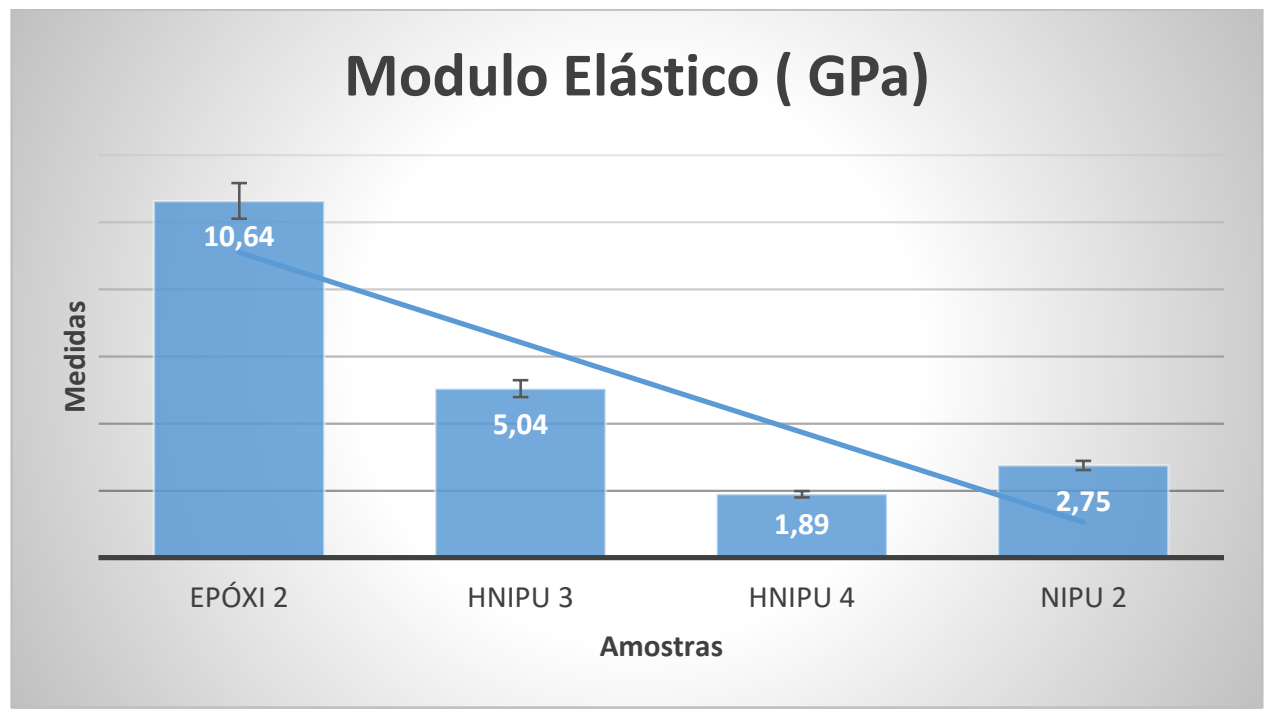

Fonte: elaborado pelo próprio autor, 2019.

Comentários Iniciais: No que diz respeito ao módulo elástico, Figura 160, o sistema epóxi apresenta o maior módulo elástico, condizente com o alto grau de reticulação e maior E', obtido por DMA. Em contrapartida, nos dados de módulo elástico, vemos que realmente o uso da NIPU, ou a obtenção da HNIPU afeta diretamente, com isso podemos concluir que a componente elástica da HNIPU interferiu diretamente na característica do módulo, sendo uma das premissas que se buscou nesse projeto. No caso da HNIPU, o uso da amina linear (TETA), teve um impacto significante na componente elástica, causando um menor valor de 
módulo. Em relação a NIPU, nos gráficos Carga/Deformação, observou-se um comportamento não esperado, pelo perfil do gráfico percebe-se que a ponta fratura o corpo de prova e altera todo o comportamento do teste. Esse dado comprova o que manualmente havia sido observado, a NIPU obtida pela rota desenhada nessa tese é um material muito frágil que se quebra com muita facilidade.

Analisando do ponto de vista das premissas desenhadas para o uso do sistema isolante no Hidrogerador, os dados de Nanoindentação confirmam o que já havia sido visto no DMA, temos uma componente elástica favorecida quando se usa a HNIPU.

\subsection{Fractografia por Microscopia Eletrônica de Varredura}

As imagens das fraturas obtidas pelo ensaio de tração das amostras são mostradas na Figuras 162 a 167. Foram utilizados os materiais descritos na Tabela 52 e o corpo de prova teve como parâmetro o esquema da Figura 161.

Tabela 52 - Identificação dos materiais avaliados por fractografia.

\begin{tabular}{|c|l|}
\hline Formulas & Formulação dos Protótipos. \\
\hline Epóxi 3 & DGEBA/IPDA/MICA não sililada ( $40 \%$ em peso) \\
Epóxi 2 & DGEBA/IPDA/MICA sililada ( $40 \%$ em peso) \\
HNIPU2 & CCGEBA/IPDA/DGEBA e Mica não sililada ( $40 \%$ em peso) \\
HNIPU 3 & CGEBA/IPDA/ DGEBA) Mica sililada (40\% em peso). \\
\hline
\end{tabular}

Fonte: elaborado pelo próprio autor, 2019.

Figura 161- Esquema do protótipo para teste de imagem.

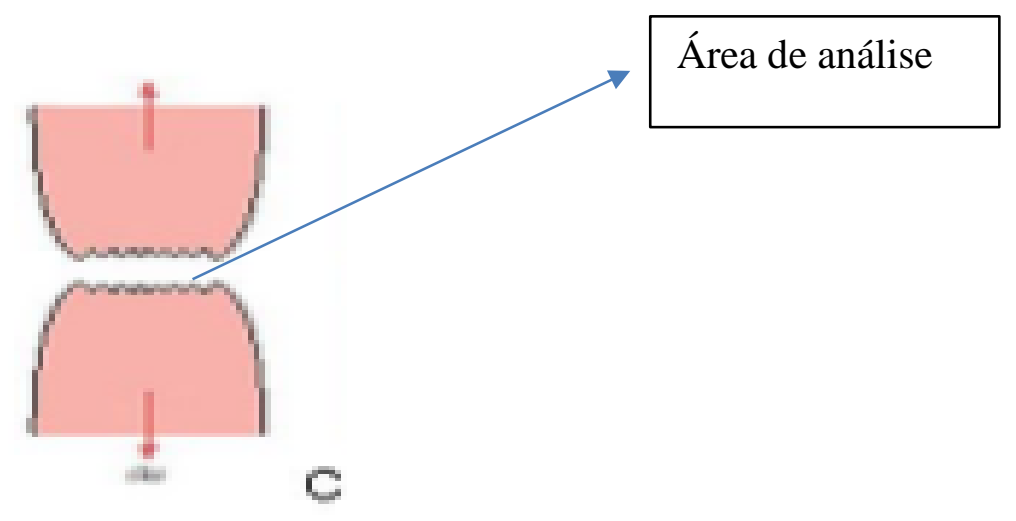

Fonte: Extraída do site www.slideplayer.com.br em 02/06/2019. 
Nestes ensaios de fractografia buscou-se entender como o uso de mica sililada afeta o padrão de fratura dos materiais. Na Figura 162 temos a superfície do epóxi com mica sem tratamento, Epóxi 3, e na Figura 163 a superfície do epóxi com mica sililada, Epóxi 2.

Figura 162 - Imagem fractográfica da superfície fraturada Epóxi 3. (2000 X).

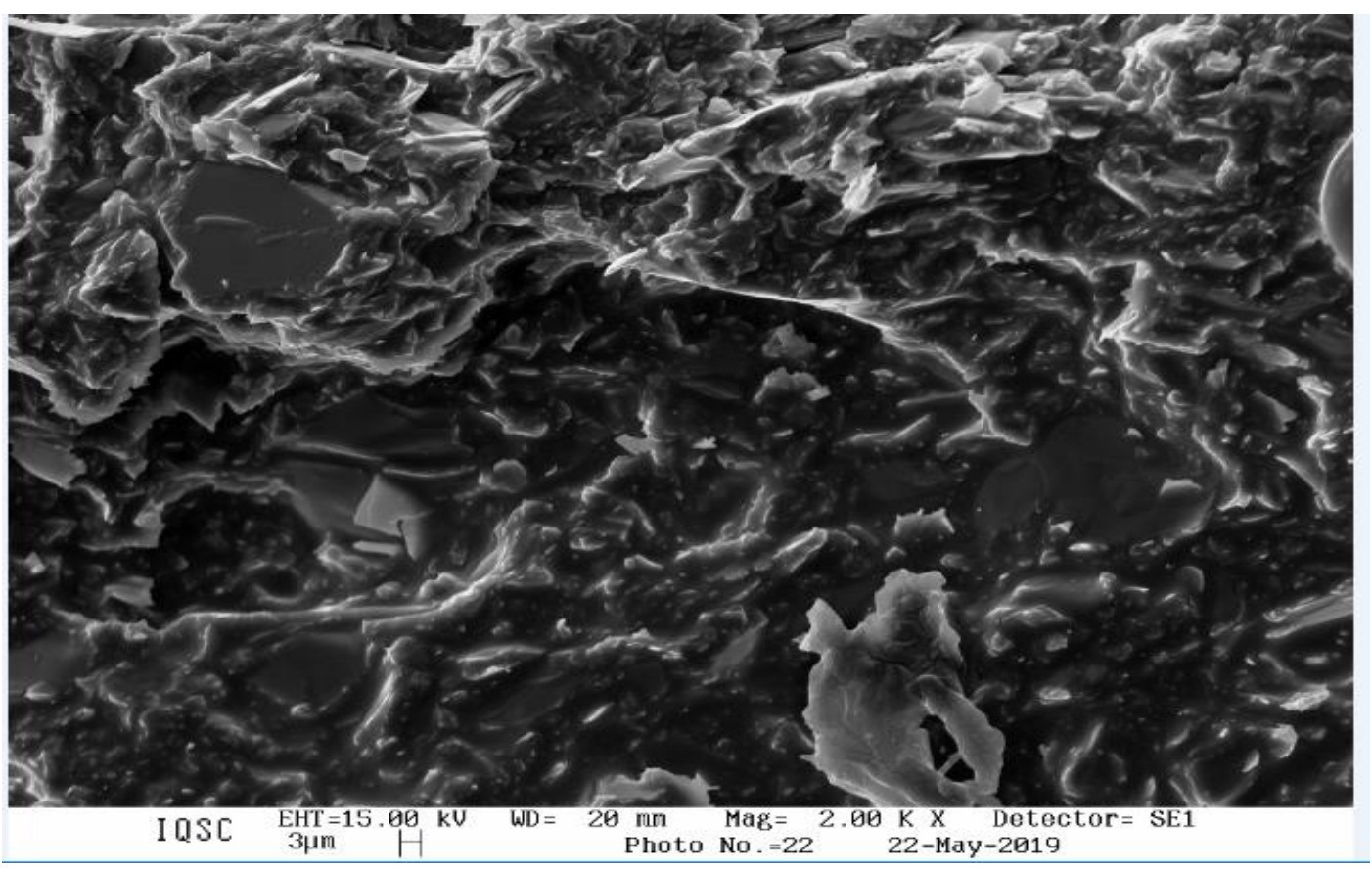

Fonte: elaborado pelo próprio autor, 2019.

Figura 163 - Imagem fractográfica da superfície fraturada Epóxi 2. (2000 X).

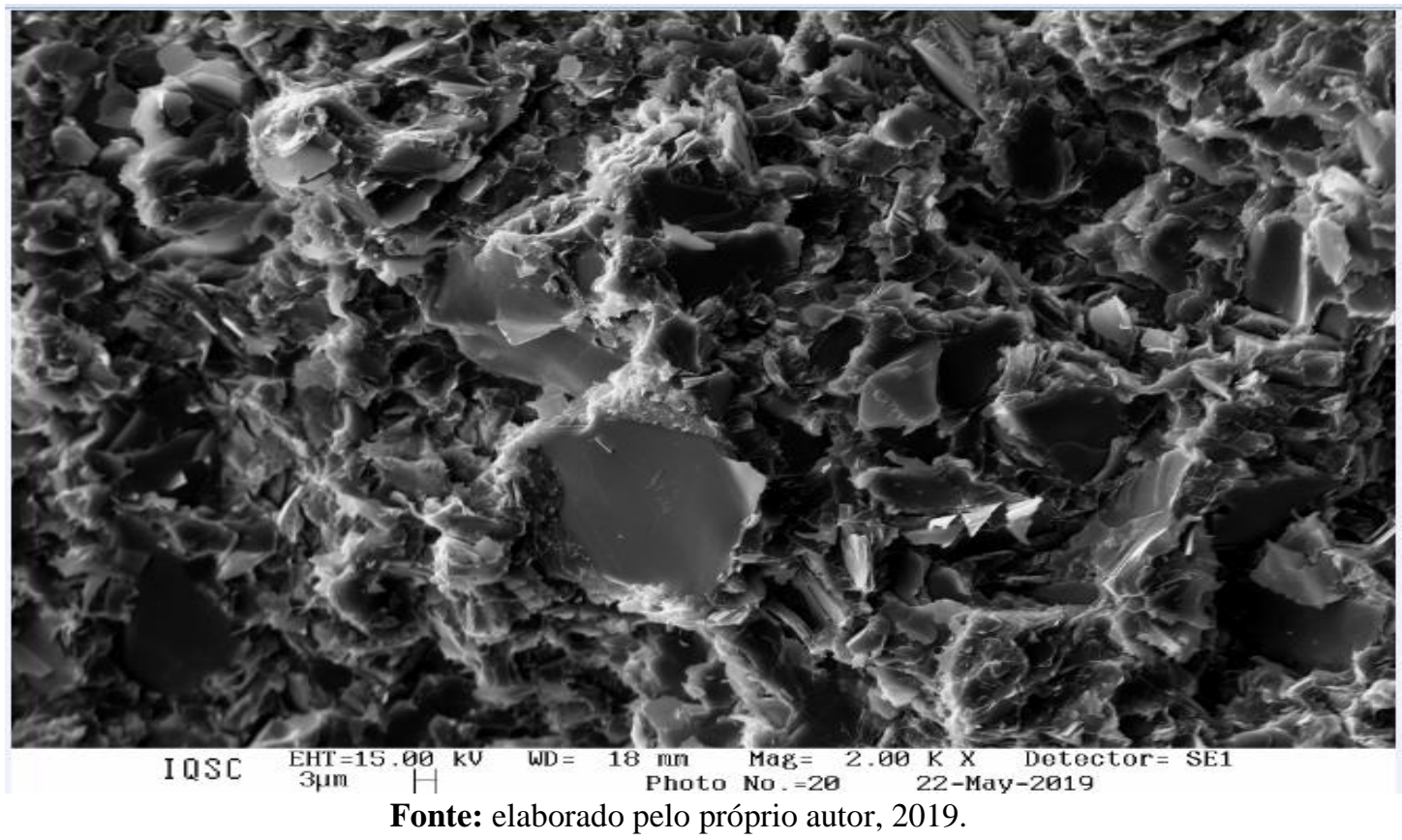


Analisando as duas imagens não é possível dizer que o uso da mica sililada afetou significativamente o padrão de fratura.

Da mesma forma, com a fractografia se pretendia verificar se a adição de mica sililada no lugar de mica não-sililada na HNIPU levava a uma mudança significativa no padrão de fratura, principalmente pelo fato do sistema ter sido feito via solvente. Na Figura $164 \mathrm{com}$ uma amplificação de 200 vezes, temos uma visão geral da fratura para a HNIPU 2(mica sem tratamento) e na Figura 165 com a mesma amplificação para a fratura da HNIPU 3 (mica com tratamento).

Figura 164 - Imagem fractográfica da superfície fraturada HNIPU 2. (200 X).

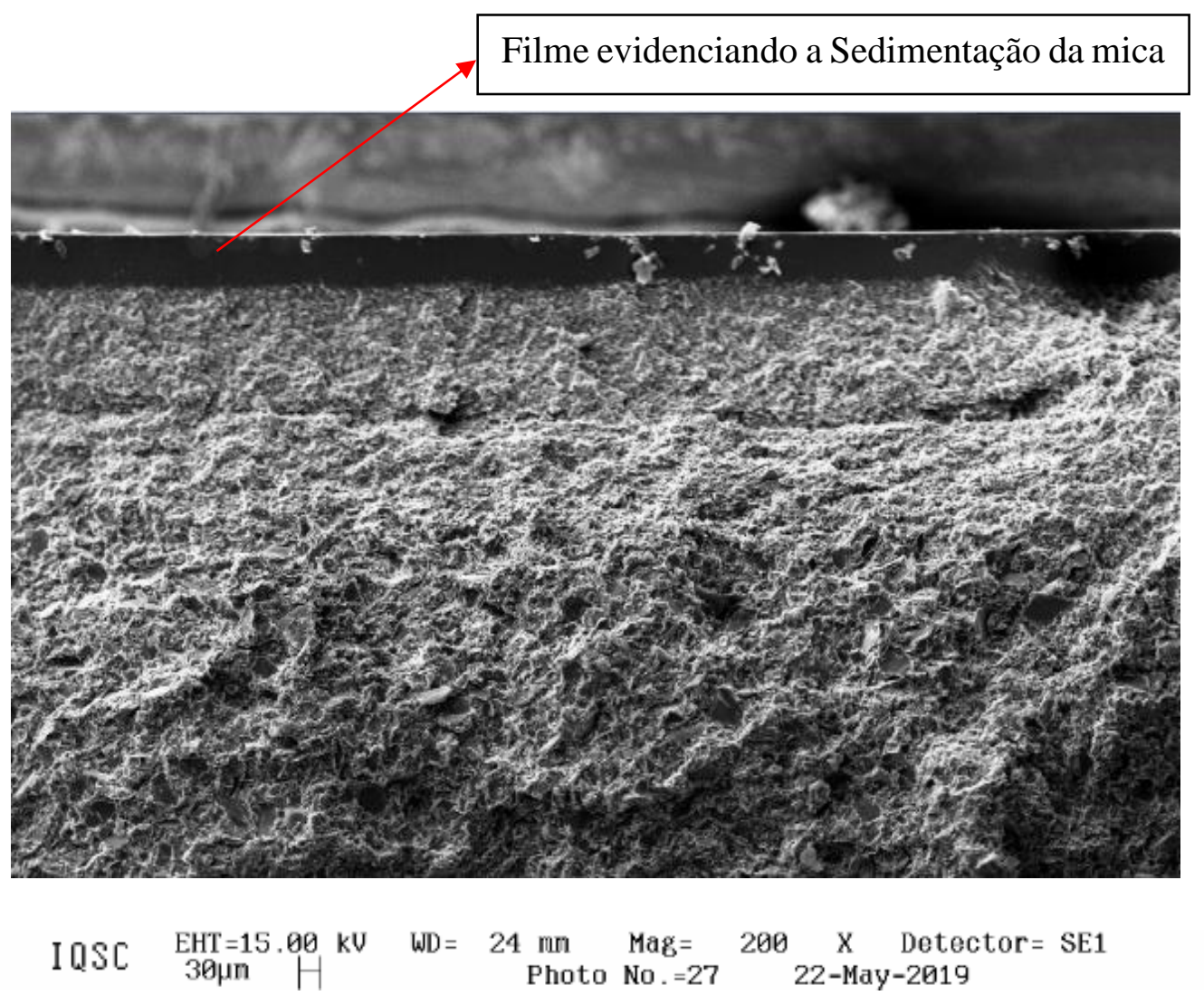

Fonte: elaborado pelo próprio autor, 2019. 
Figura 165- Imagem fractográfica da superfície fraturada HNIPU 3 (200 X).

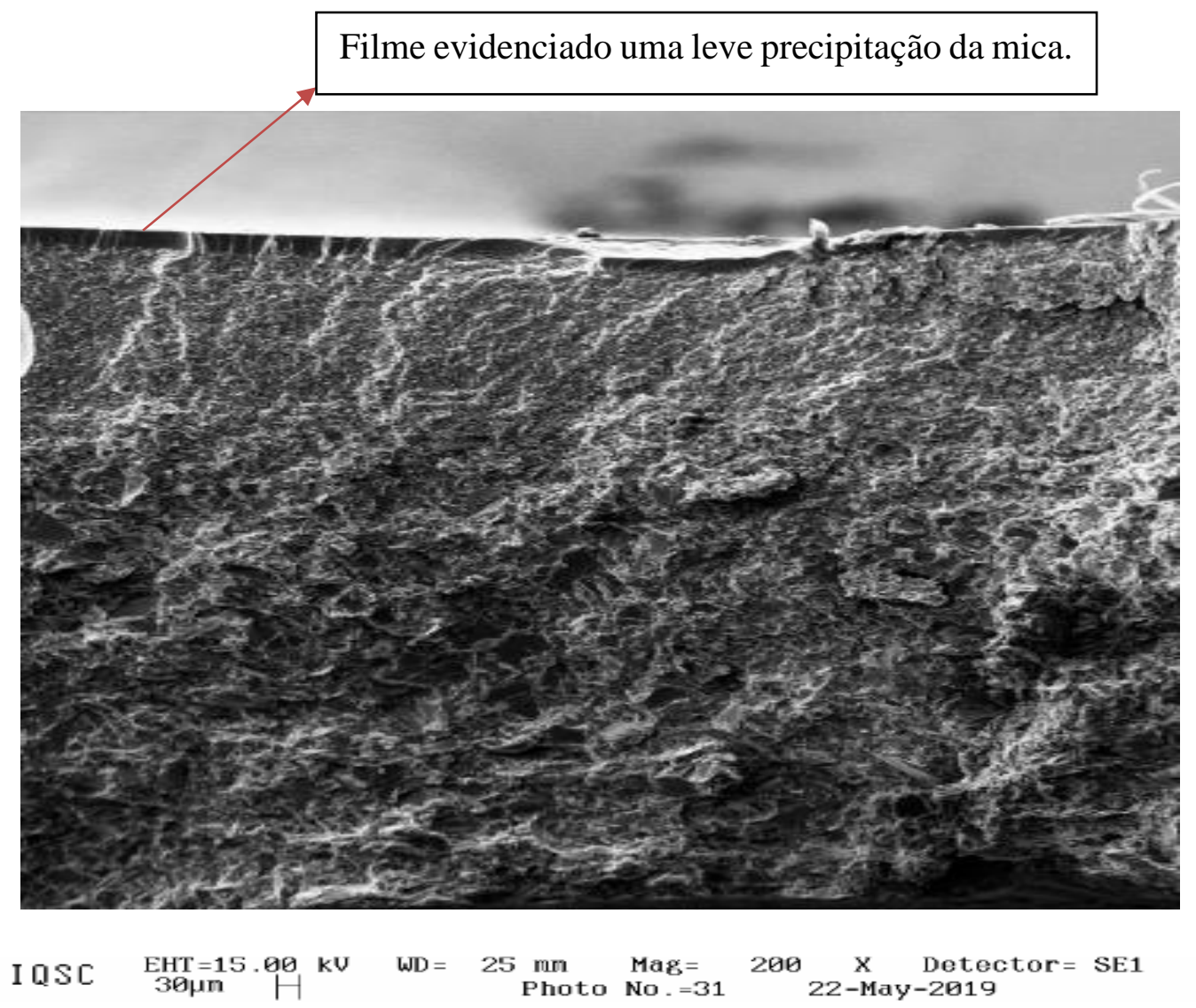

Fonte: elaborado pelo próprio autor, 2019.

As Figuras 164 e 165 ilustram bem o impacto do uso da mica com tratamento a base de aminossilano. Nota-se claramente na Figura 163 uma menor compatibilidade da fase polimérica pois temos devido ao processo de obtenção do protótipo, uso em sistema líquido, uma grande sedimentação da mica e formação de um filme polimérico na superfície. $\mathrm{Na}$ Figura 164 onde utilizou-se a mica com tratamento temos uma menor formação desse filme polimérico.

Dando continuidade na investigação da influência do uso de mica sililada no mecanismo de fratura, novas micrografias foram obtidas em maior ampliação e são mostradas nas Figuras 166 e 167, amplificação de 2000 vezes. 
Figura 166 - Micrografia representativas da superfície fraturada HNIPU 2. (2000 X).

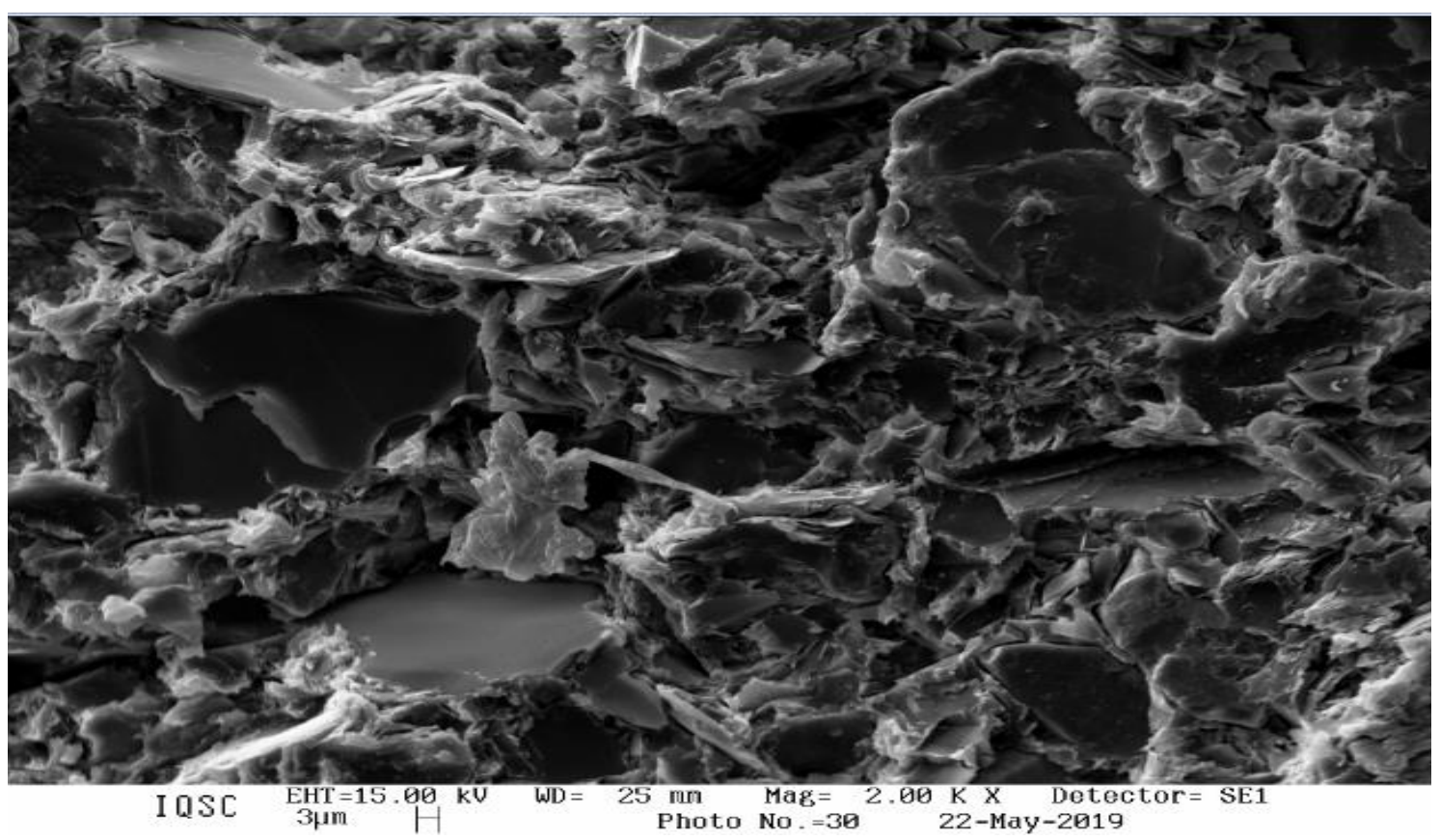

Fonte: elaborado pelo próprio autor, 2019.

Figura 167 - Micrografias representativas da superfície fraturada HNIPU 3. (2160 X).

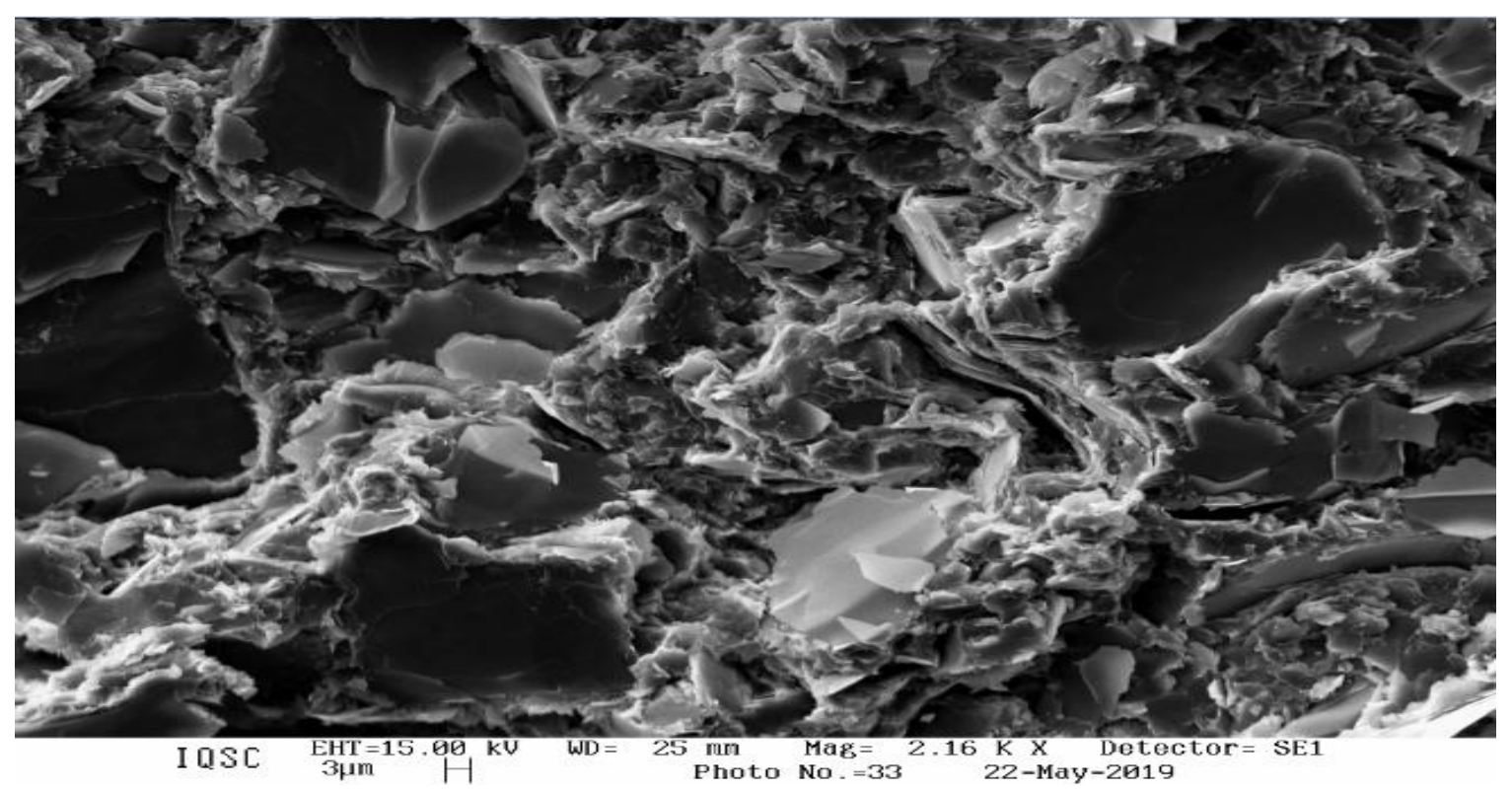

Fonte: elaborado pelo próprio autor, 2019.

Muito embora as imagens em maior ampliação (2000 vezes) permitam uma melhor visualização da microestrutura dos compósitos, não é possível concluir que hajam diferentes padrões de fratura, ambas as imagens apresentam morfologias similares. Esse dado nos mostra que por MEV dado a composição com $40 \%$ de mica presente não se pode medir a diferenciação do tratamento com aminossilano. 


\subsection{Espectroscopia de energia dispersiva (EDS)}

Para avaliar qualitativamente o grau de distribuição da mica dentro da matriz polimérica, fez-se o mapeamento elementar ao longo da fratura. É importante ressaltar neste ponto, todas as amostras possuem a mesma porcentagem de mica, cerca de $40 \%$ em peso. $\mathrm{Na}$ Figura 168 temos o mapeamento do protótipo Epóxi 3 (mica não-sililada), na Figura 169 observa-se o protótipo Epóxi 2 (mica sililada), na Figura 170 é apresentada a fratura da HNIPU 2 e finalmente na Figura 171 a HNIPU 3 (mica sililada).

Uma das ideias iniciais foi o protótipo após o ensaio térmico de DMA, ter uma fratura e esse material ser usado para caracterização de imagem via MEV e EDS. Não houve a fratura no DMA, com isso o material que sofreu o estresse térmico, foi colocado em uma máquina Universal de Ensaios Mecânicos (INSTRON) e fez-se o esforço até que houvesse sua ruptura, sendo esse protótipo que foi usado para análise de imagem. A presença da mica pode ser evidenciada pelo mapeamento dos elementos $\mathrm{K}, \mathrm{Al}$ e $\mathrm{Si}$, enquanto a matriz orgânica é evidenciada pelos elementos $\mathrm{C}$ e $\mathrm{O}$. $\mathrm{Na}$ imagem os pontos brancos indicam a emissão de raios $\mathrm{X}$ característico do elemento selecionado, assim a imagem CKa indica a linha de emissão $\mathrm{K} \alpha$ do $\mathrm{C}$ evidenciando a presença do elemento na amostra e assim por diante.

O mapeamento elementar por EDS dos sistemas epóxi confirmam a presença da mica no interior destes materiais, contudo, a julgar pela comparação destas e outras imagens e tomando como verdadeiro que as imagens são representativas das respectivas amostras o uso da mica sililada não leva a uma maior dispersão da mica. 
Figura 168 - Mapeamento EDS da superfície do epóxi 2 (2000 X).

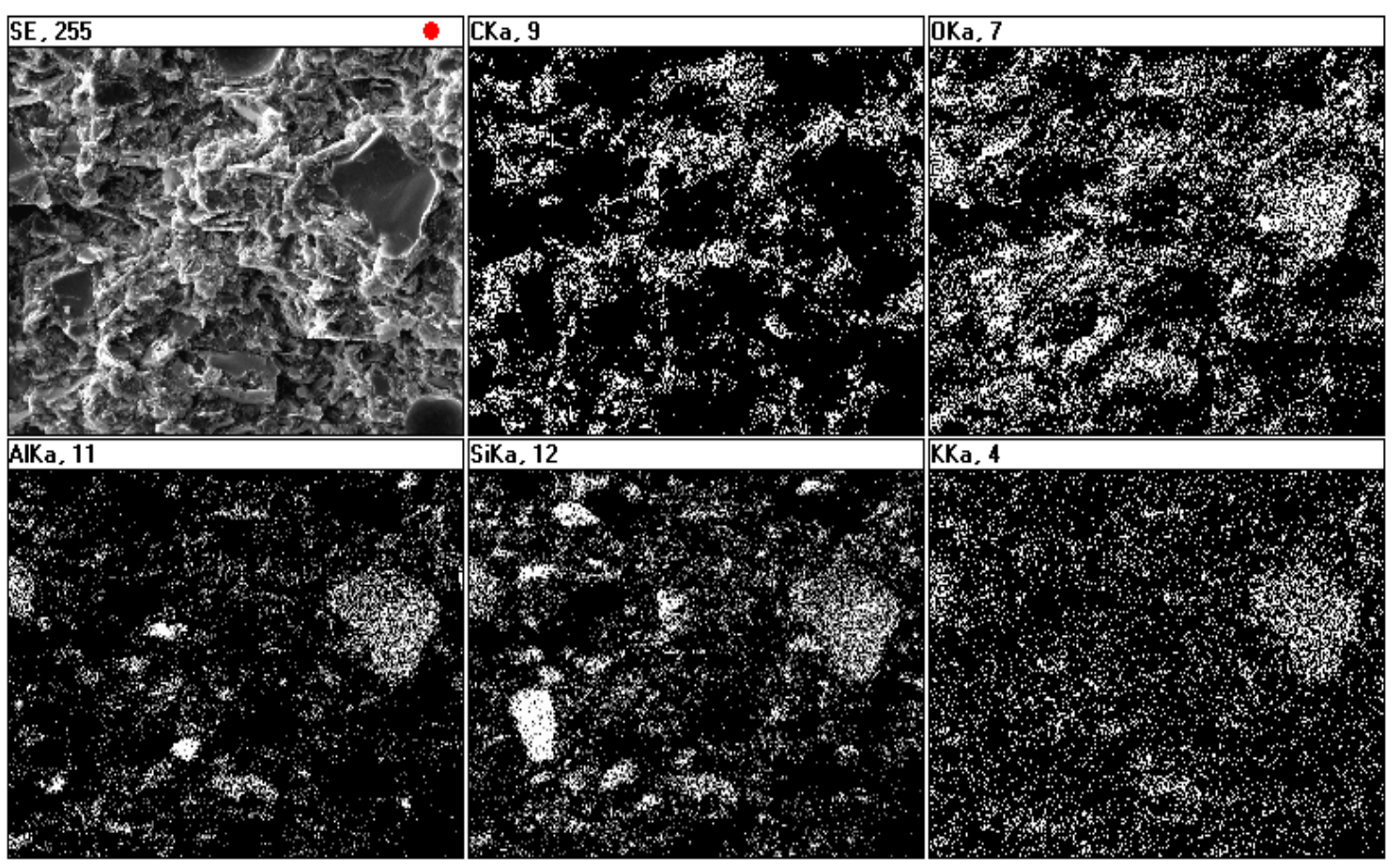

Fonte: elaborado pelo próprio autor, 2019.

Figura 169- Mapeamento EDS da superfície do epóxi 3 (2000 X).

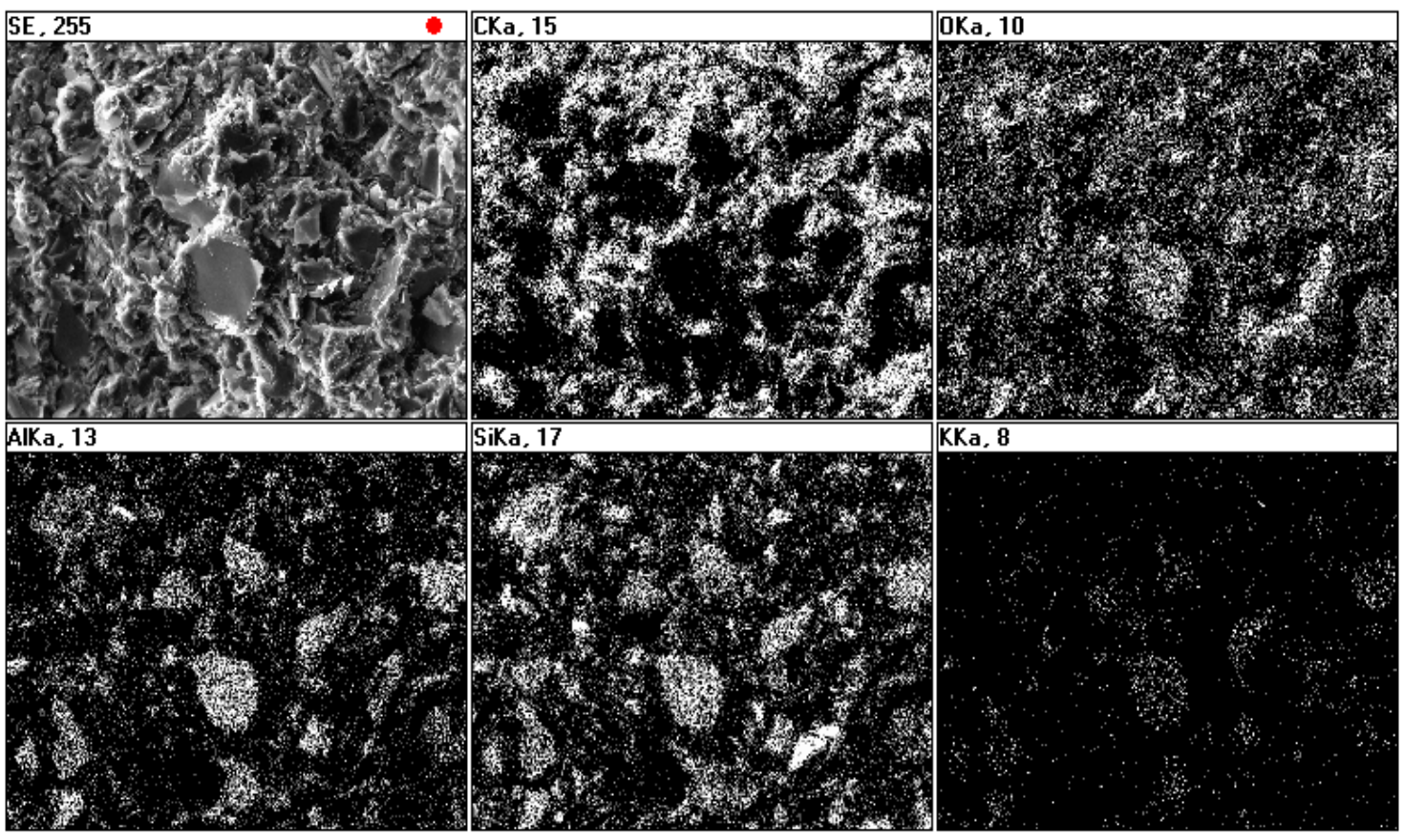

Fonte: elaborado pelo próprio autor, 2019. 
Figura 170 - Mapeamento EDS da superfície da HNIPU 2 (2000 X).

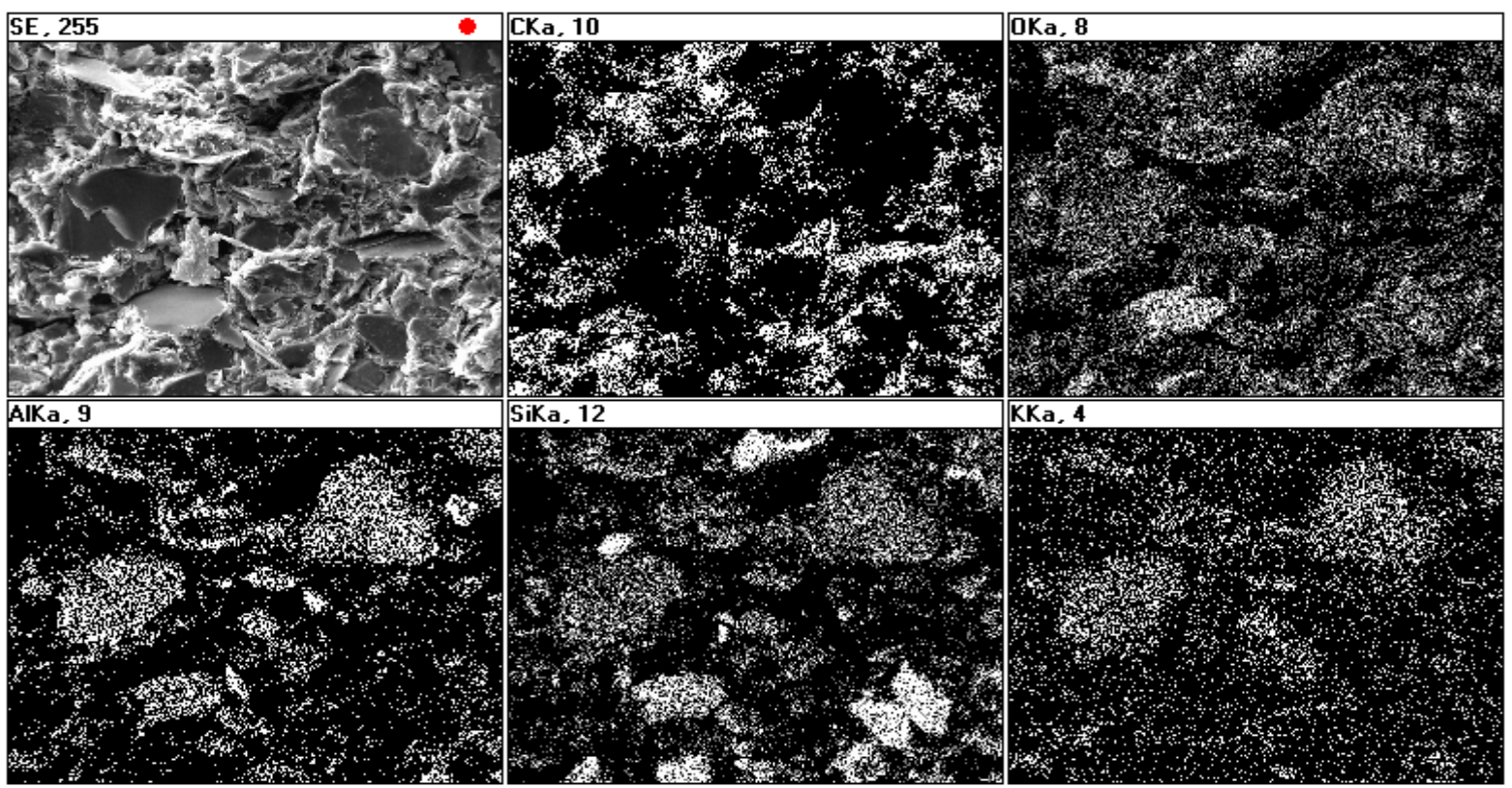

Fonte: elaborado pelo próprio autor, 2019.

Figura 171- Mapeamento EDS da superfície da HNIPU 3 (2000 X).

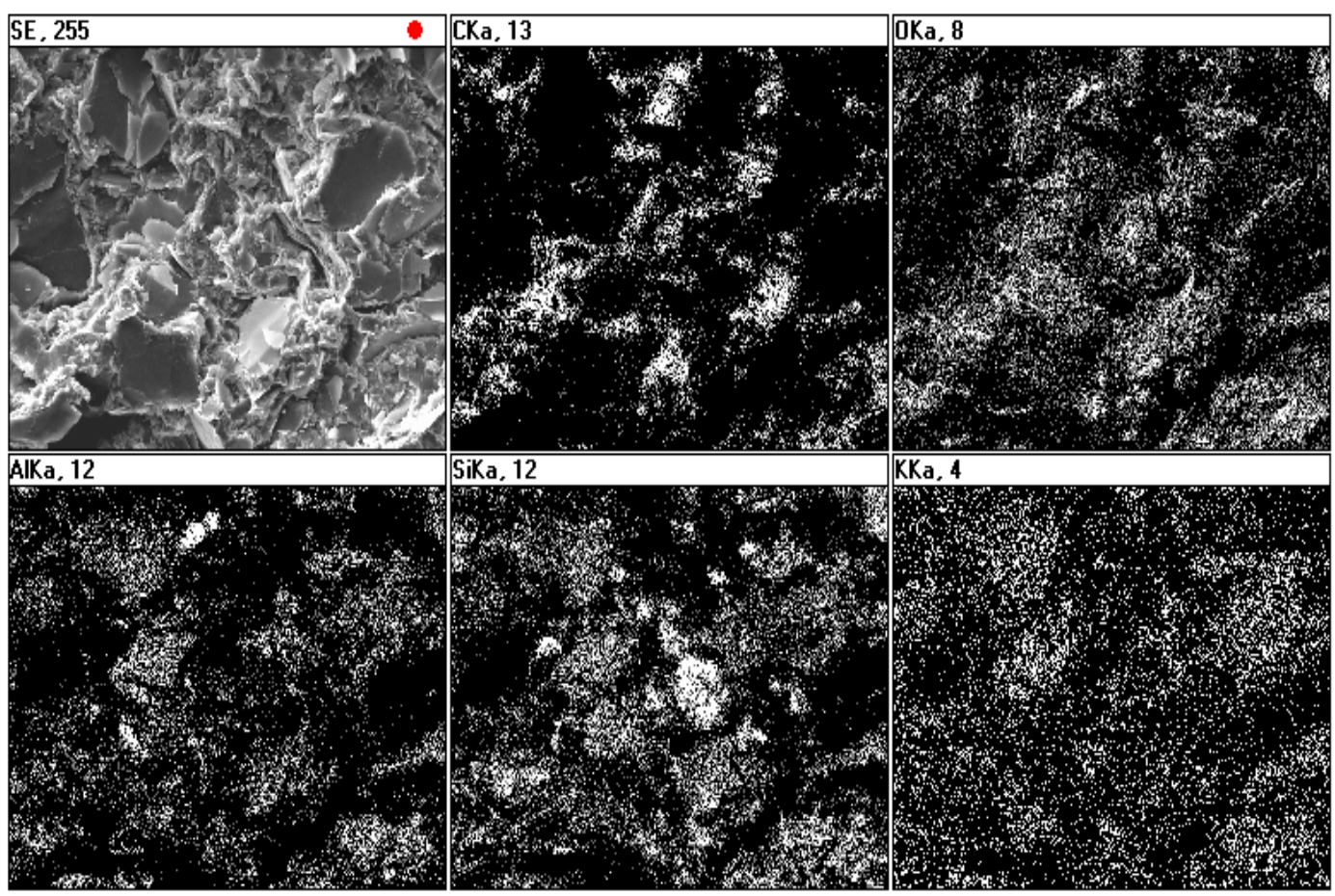

Fonte: elaborado pelo próprio autor, 2019.

No caso do mapeamento das HNIPUs, Figuras 170 e 171, da mesma forma que no sistema epóxi, não pode ser afirmar que existe diferença na dispersão da mica pelo fato da mesma ser sililada. 


\section{CONCLUSÕES FINAIS}

Para facilitar o entendimento, será avaliado o escopo desse projeto dentro da premissa básica de ser um alternativo ao sistema epóxi/fita de mica em um hidrogerador, tendo respostas positivas aos dois modos de falha principal que afeta a questão da isolação do equipamento, a componente elástica do sistema polimérico e a descontinuidade gerando descargas parciais no sistema atual com fita de mica.

\section{Obtenção do Sistema Polimérico Isolante}

O processo de síntese apresentado e a obtenção de uma poliuretana sem o uso de isocianato, segue uma direção de grande importância e extensivamente explorada: o uso ou reciclagem do $\mathrm{CO}_{2}$. Reagindo esse precursor ciclocarbonatos com aminas, obteve-se hidroxiuretanas com um rendimento extremamente satisfatório, propiciando protótipos confiáveis de NIPUs e também das HNIPUs. Qualquer trabalho futuro de NIPUs e HNIPUs já tem uma base técnica consistente para obtenção de protótipos com excelente rendimento na síntese e na conversão de oxirano em ciclocarbonato.

\section{Uso do Híbrido de Mica}

Um dos grandes avanços desse projeto foi a introdução do conceito de usar um hibrido (mica tratada com aminossilano) para reforço mecânico de NIPUs e HNIPUs, trata-se de um avanço inédito, uma nova abordagem para a tecnologia de NIPUs, conseguir o ganho mecânico usando um conceito de reforço via utilização de um híbrido. Os ganhos de propriedades mecânicas foi significativo e abre-se uma nova fronteira de oportunidades para essa tecnologia. Até o momento todo o esforço em NIPUs e HNIPUs se deu para materiais elástoméricos, essa nova possibilidade pode abrir outras perspectivas para destinação desse polímero.

\section{Substituição da Fita de Mica pelo Conceito de Mica em Pó.}

Um avanço obtido por essa TESE se refere ao uso da mica sililada com aminossilano dispersa na matriz polimérica. Neste caso, observou-se que do ponto de vista da constante dielétrica e do fator de dissipação, o uso desse material pode dar resultados melhores que o uso da fita de papel de mica, pois podemos eliminar a interface causadora das descargas parciais, a interface existente entre a matriz polimérica (resina epóxi) e a fita de mica aplicada sobre os condutores metálicos. Inclusive esse avanço tecnológico, propicia dentro até do 
sistema convencional epóxi, seu funcionamento. Essa abordagem pode e deve ser explorada até no sistema atual de epóxi com anidrido, os ganhos elétricos são muito positivos.

Componente Elástica: Outro avanço dessa TESE foi a obtenção de protótipos com um módulo elástico favorável a evitar a degradação causada pelo esforço mecânico de vibração e envelhecimento. Os protótipos NIPUs e HNIPUs apresentam um módulo elástico que mostra os ganhos de flexibilidade e por consequência, podem suportar os danos causados pelo uso do equipamento. Um ponto positivo a ser trazido se refere a um ganho obtido inclusive no próprio conceito epóxi, o uso do híbrido de mica tratada com aminossilano, quando usado no epóxi convencional deu a característica elástica similar aos compostos de NIPU e HNIPU, sendo um fato novo e que pode ser avaliado inclusive nos compostos atuais de epóxi com anidridos e aminas.

4. Características para uso no Hidrogerador: as NIPUs do ponto de vista elétrico e químico atenderiam os requisitos da aplicação, porém não atenderiam os requisitos de temperatura de uso $\left(70{ }^{\circ} \mathrm{C}\right)$ e de sobrecarga na utilização $\left(130^{\circ} \mathrm{C}\right)$.

Quanto as HNIPUS, com exceção da HNIPU com amina linear (TETA) e com o uso da mica sem tratamento, a HNIPU 3, onde se usou IPDA e Mica sililada, a mesma atende todos os requisitos da aplicação, sendo necessário apenas a melhoria na característica térmica para suportar os estresses térmicos na sobrecarga $\left(130{ }^{\circ} \mathrm{C}\right)$. A HNIPU 3, tem uma Tg (Transição vítrea) de $73,6{ }^{\circ} \mathrm{C}$, sendo necessário atingir acima de $130{ }^{\circ} \mathrm{C}$. Aqui se faz necessário uma ação futura, sem comprometer o ganho nas propriedades gerais, aumentar a Tg para um patamar que possa ser usado em equipamentos com esse requisito.

Aqui uma observação, para aplicações elétricas com patamares de menores requisitos térmicos, as NIPUs e HNIPUs obtidas nesse projeto podem ser destinados com total segurança.

Contribuição ao Estado da Arte: essa TESE traz para o Grupo de Materiais Híbridos da USP -São Carlos a obtenção da HNIPU, uma nova fronteira que ainda não havia sido explorada e principalmente a possibilidade de via uso de um híbrido ter-se o reforço mecânico de NIPUS e HNIPUs. No caso da aplicação em hidrogerador, traz-se a evidência que o uso do híbrido de mica sililada, pode ser uma alternativa inteligente e viável para substituição do uso da fita de Mica até nos sistemas convencionais de epóxi atual. Tem se o ganho no fator de dissipação e principalmente pode dar a componente elástica ao sistema, contribuindo para evitar o modo de falha causado pelo excesso de rigidez do sistema atual. 


\section{PRÓXIMOS PASSOS}

A premissa principal para a sequência deste trabalho é a necessidade de correção da questão térmica. Para tal será fixado o trabalho com a HNIPU 3, híbrido com mica sililada. De uma forma inicial, já vemos como abordar os seguintes pontos:

a) Dentro do que já foi visto no DSC, onde a Tg reduzida pode ter sido causado pelo aumento de volume livre em função do teor de híbrido, uma avaliação preliminar será entender o comportamento do teor de híbrido nas propriedades térmicas. Fixamos nessa TESE o percentual de 40\%, o ideal entender sua influência.

b) Ainda dentro do conceito atual, outra possibilidade será usar o híbrido não como terminação amina, mas sim com terminação epóxi, hoje o processo de incorporação do híbrido junto a NIPU, pode estar levando a formação de uma estrutura mais frágil pois reagiria apenas as aminas primárias e por consequência levar a um efeito de menor reticulação. O híbrido epóxi reagiria com as terminações amina do pré-polímero e não com o ciclocarbonato da NIPU.

Após essa etapa, caso o caminho desenhado não seja favorável, as outras abordagens serão:

a) Aumentar a reticulação substituindo o Di-epóxi usado (DGEBA) por um tri-epóxi, dessa forma a NIPU obtida terá uma maior reticulação e com isso sem perda na estrutura central da cadeia para se obter uma maior densidade de reticulação conforme representado graficamente na Figura 172.

Figura 172 - Representação da estrutura atual com diciclocarbonato e futura de tri-ciclocarbonatos.
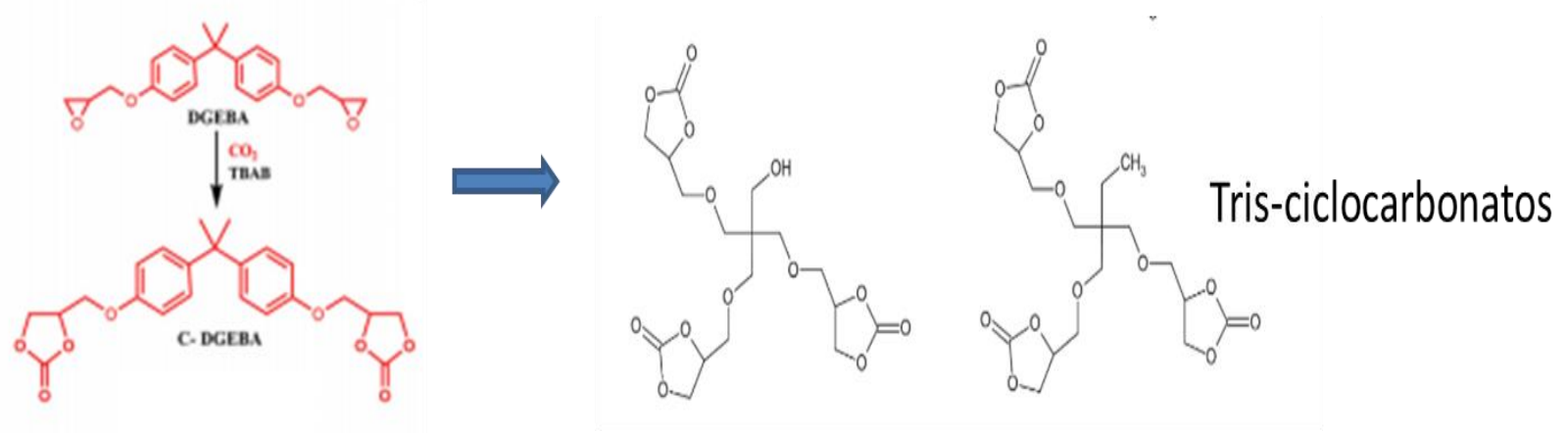

Fonte: Autoria própria 2020.

b) Dentro da premissa de aumento da reticulação, uma possibilidade que pode ser feita e usando os mesmos parâmetros atuais de síntese e processo, na obtenção do HNIPU, substituir a diamina IPDA por uma triamina, dessa forma pode se levar também a 
uma maior reticulação e dessa forma aumentar a Tg do sistema sem perder a parte central do DGEBA usado na síntese da NIPU e HNIPU. Na Figura. 173, pode se ver a estrutura usada nessa TESE e na Figura.174 a nova proposta com as funcionalidades aminas que irão reagir com o DGEBA. Com o IPDA tem-se uma funcionalidade 6, com a Triamina irá para 10, o que pode aumentar a densidade da reticulação.

Figura 173: Representação Gráfica do prepolímero de NIPU com terminação vinda do IPDA (Diamina).

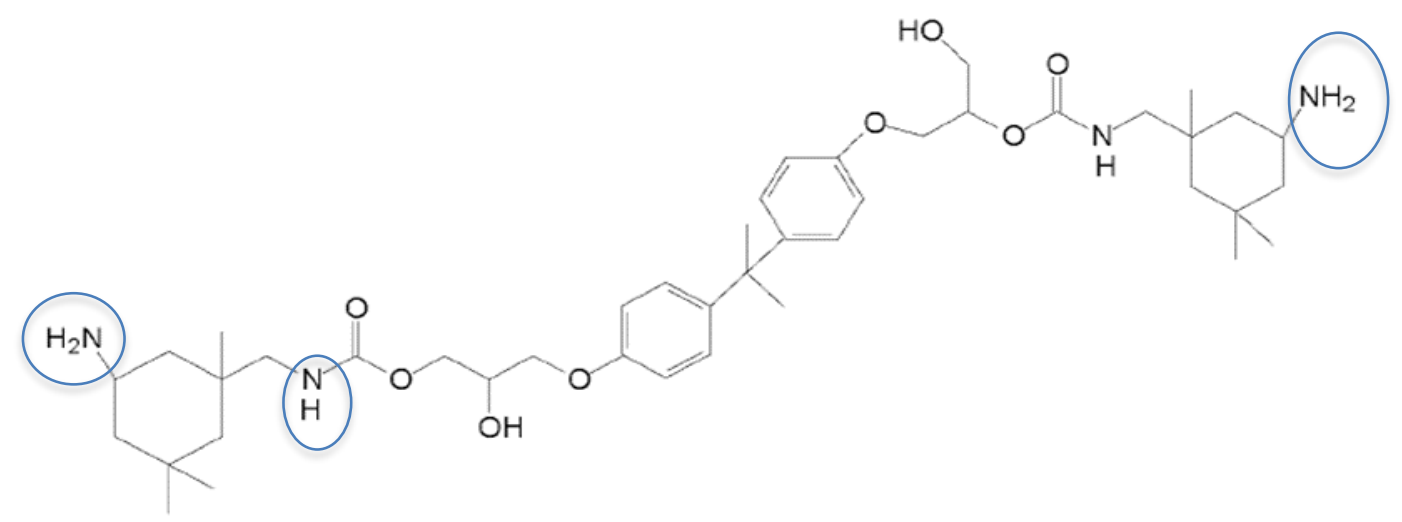

Fonte: Autoria própria 2019.

Figura.174. Representação Gráfica do novo Pre-polimero com Terminação usando Triamina.

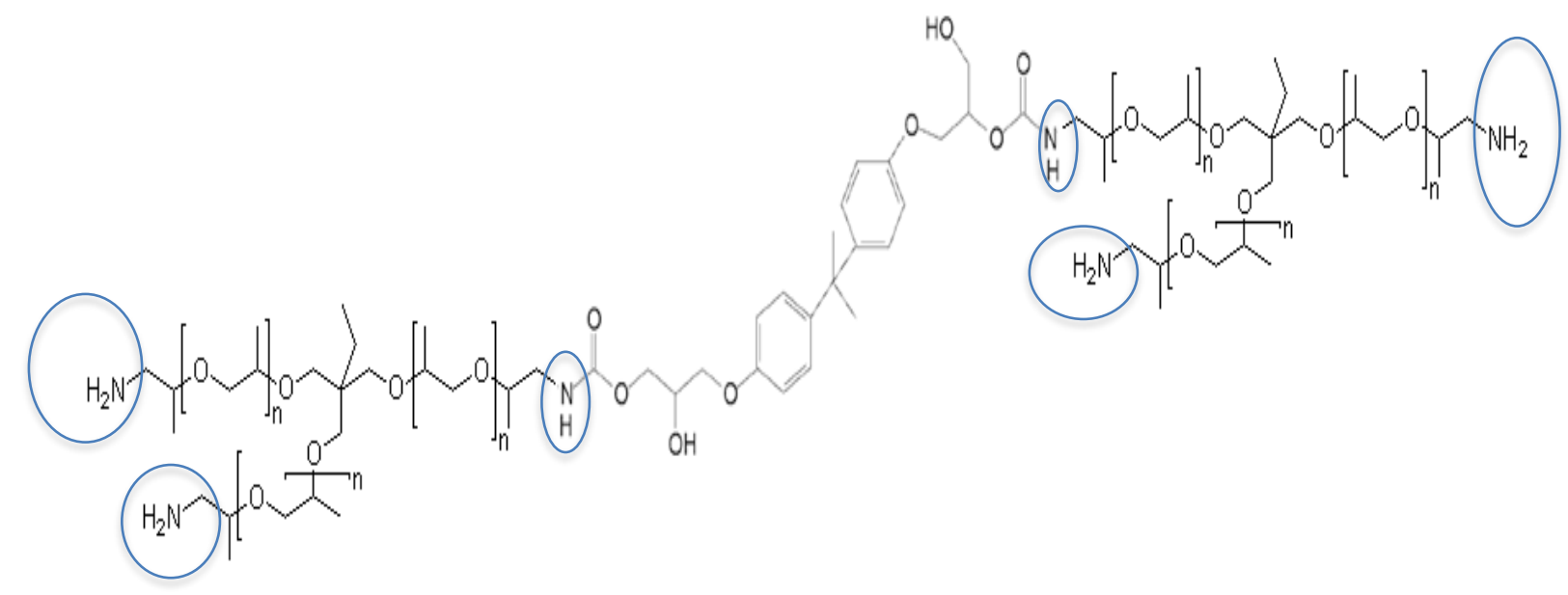

Fonte: Autoria Própria 2020.

c) Para obter a HNIPU usa-se o próprio material de partida da obtenção da NIPU (DGEBA), pode se simplificar a rota de obtenção da HNIPU, fazendo uma síntese de NIPU, diferente do usado neste projeto. Nesse projeto foi obtido uma conversão 
acima de $90 \%$ em estrutura ciclocarbonato, o que se leva a formação de um material sólido o que força a ter que ser feito um processo de solubilização via fusão ou solvente. Ao reduzir a conversão de oxirano em ciclocarbonato para um patamar de no máximo 50\%, o monômero obtido será liquido, dessa forma favorece o processo de manuseio e também por possuir os dois grupamentos alvo, pode se ter a formação de HNIPU de maneira diferente. Seria uma forma inédita de obter esse polímero em rota única. Essa nova abordagem proposta está representada na Figura 175, onde pode se ver o desenho dos dois grupamentos nas extremidades do monômero.

Figura 175. Representação do novo monômero proposto com terminação ciclocarbonato e oxirano na mesma cadeia molecular.

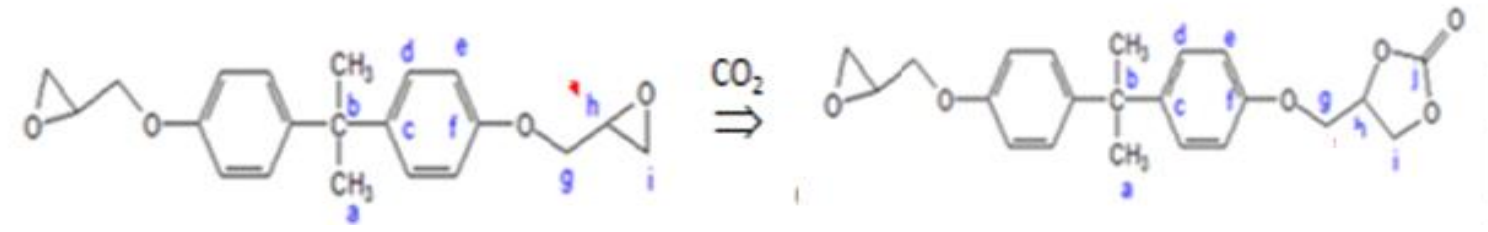

Fonte: Autoria Própria 2020. 


\section{REFERÊNCIAS}

[1] TOLMASQUIM, M. T.; Perspectivas e planejamento do setor energético no Brasil. Estud. av. [online]. 2012, vol.26, n.74, pp. 247-260.

[2] ROCHA, J. E; MAURO, M.A.S; BORTONI, E.C.; GUSMÃO, G.; Avaliação de Sistemas de Isolação em Alta Tensão-Significado Eletrodinâmico Dos Testes Tipicamente especificados; XXV Seminário Nacional de Produção e Transmissão de Energia Elétrica, Belo Horizonte, novembro 2019.

[3] BRUETSCH, R., TARI, M., FROHLICH, K., WEIERS, T., VOGELSANG, R.; Insulation Failure Mechanisms of Power Generators. Electrical Insulation Magazine, v. 24, n.4, p. 17-25. July-August 2008.

[4] DE VILHENA, P.R. M.; Sistema Para Detecção, Localização e Monitoramento de Descargas Parciais em Estatores de Hidrogeradores, TESE Submetida ao Programa de PósGraduação em Engenharia Elétrica da Universidade Federal do Pará, TD 16/2015.

[5] MAY CA. Epoxy resins. Second Ed. New York: Marcel Dekker Inc.; 1988.

[6] PASCAL, T.; BONNEAU J.L.; BIOLlEY N.; MERCIER R.; SILlLION B.; Approach to Improving the Toughness of TGMDA / DDS Epoxy Resin by Blending with Thermoplastic Polymer Powders, Polymer. Adv. Tecnol. 6 (1995) 219-229.

[7] NOVAES, R. D.; Avaliação das propriedades elétricas de barras estatóricas fabricadas com resina do tipo éter diglicidílico do bisfenol $\mathrm{F}$ (DGEBF) contendo nano partículas de sílica; Dissertação de Mestrado apresentada na Faculdade de Engenharia Química, Universidade Estadual de Campinas - UNICAMP, Campinas, SP, Brasil. 2015.

[8] ADRIANOV, K.A; FROMBERG, M.B.; SOROKINA, L, Y.; Vysokomol. Soed. 3, 1692 (1961).

[9] PATTISON, D, B; U.S. Pat. 2830038 (1958) (to E. I. DuPont de Nemours).

[10] LOPES, J.H.; Obtenção de Ciclocarbonato Oligomérico via reação de $\mathrm{CO}_{2}$ e seu uso na preparação de NIPU, Dissertação de Mestrado Engenharia de Materiais, USP-São Carlos, Maio 2004. 
[11] AGUIAR, K.R; SANTOS V.G; EBERLIN M.N; RISCHKA M.; NOESKE M.; TREMILIOSI-FILHO G.; RODRIGUES FILHO U.P.; Efficient Green Synthesis of Bis (cyclic carbonate) polydimethylsiloxane derivative using $\mathrm{CO}_{2}$ addition: a novel precursor for synthesis of urethanes, RSC Advances 2014, 4, 24334-24343

[12] SZYCHER M.; Structure- Property Relations in Polyurethanes, Szycher's Handbook of Polyurethane, DOI 10.1201/b12343-4, online publication date: July 2012

[13] GUAN,J.; SONG Y. ;LIN Y.; ZUO M.;ZHAO Y.;ZHENG Q.; Progress in Study of Non Isocyanate Polyurethane, Industrial Engineering Chemistry Research, 2011 - 50, $6517-6527$.

[14] PARZUCHOWSKI, P, G.; KIZLINSKA, M.; ROKICKI, G.; Science Direct Polymer, 48, 1857-1865, 2007.

[15] DIAKOUMAKOS C.D.; KOTZEV D.L.; "Non-isocyanate-based polyurethanes derived upon the reaction of amines with cyclocarbonate resins," Macromol. Symp. 216, No. 1, 37 46 (2004).

[16] STONE, G. C., BOULTER, E. A., CULBERT, I. DHIRANI, H. Electrical insulation for rotating machines: design, evolution, aging testing, and repair. Piscataway: IEEE Press Series on Power Engineering \& Wiley-Interscience, 2004, 392.

[17] VOGELSANG, R. Time to breakdown of high voltage winding insulations with respect to microscopic properties and manufacturing qualities. Dissertation ETH 15656 HartungGore Verlag Konstanz, Germany, 2004.

[18] ANDRASCHEK N.; WANNER,A.J.;EBNER,C.; RIESS,G.; Mica/Epoxy-Composites in the electrical industry application, Composites for Insulation, and Investigation on Failure Mechanism for Prospective Optimization, Polymers 2016, 8,201; DOI: 10.3390/polym8050201

[19] GLADSTONE, J.H.; Michael Faraday (McMillian, London 1872).

[20] AlEXANDER, G.; WAllaCE, G.A.; Eletrotécnica- Princípios e Aplicações, Ao Livro Técnico S.A, Rio de Janeiro ,1964.

[21] DICIONÁRIO BRASILEIRO DE ELETRICIDADE. Editora ABNT-Cobei, 1986. 
[22] MARQUES, A.P.; SÁ, L.C.R..; Avaliação de Envelhecimento em Barras de Estator de Hidrogeradores, XV SNPTEE Grupo de Geração Hidráulica, Foz do Iguaçu 1999.

[23] HADAD, D. K. Physical and chemical characterization of epoxy resins. Epoxy Resins: chemistry and technology. 2nd Ed. New York: Marcel Dekker, p. 1089-1172, 1988.

[24] HANCU, L.; PAUNESCU, D.; BORZAN, M.; Considerations about filling Materials influence upon deflection of epoxy resin, Revista Materiale Plastice, vol 44 (2007).

[25] URBAN, M. W.; Fourier Transform Infrared and Fourier Transform Raman Spectroscopy of Polymers in Structure-Property Relations in Polymers: Spectroscopy and Performance, American Chemical Society, p. 3-40. 1993.

[26] FROHLICH H; Dielectric breakdown in Solids, Rep. Prog. Phys, 6 (1939) 411-43.

[27] GRANATO, R. C.; LEVY, N. M.; TULIO, L. Apostila: Manutenção de transformadores baseada em ensaios físico-químicos e cromatográficos no sistema isolante. Instituto de Tecnologia para o Desenvolvimento, agosto, 2001, 25p

[28] TOMMASINI, D.; Dielectric Insulation and High Voltage Issues, CERN, 2011, Geneva, Switzerland.

[29] TANAKA, K.; KOJIMA, H.; ONODA, M.; SUSUKI, K.; Prediction of Residual Breakdown Electrical Field Strength of Epoxy-Mica Paper Insulation Systems, IEEE Transactions on Dielectrics and Electrical Insulation Vol. 22, April 2015, 1118-1123. [30] NOTINGHER, PV 2002, Insulation Systems, PRINTECH House Ltd., Bucharest.

[31] NOTINGHER, PV 2005, Materials for Electrotechnics. Structure. Properties, Vol. I, POLITEHNICA PRESS, Bucharest.

[32] SHIM, S.B.; SEFERIS, J.C.; EOM, Y, S. Thermochimica Acta, 291, p.73-79, 1997.

[33] NOTINGHER, PV \& Plopeanu, M 2009, “Accelerated Development of Electrical Trees. Part I: Initiation of Trees”, EEA - Electrical Engineering, Electronics, Automatics, Vol. 57, No. 4, pp. 11-19.

[34] SILVA, R, F.D.; Trilhamento Elétrico Sobre Materiais Poliméricos Pela Análise Da Energia Absorvida Devido As Descargas Elétricas Superficiais. Tese de Doutorado, Engenharia e Ciência dos Materiais, Programa de Pós-Graduação em Engenharia e Ciência 
dos Materiais - PIPE. Setor de Tecnologia, Universidade Federal do Paraná, Curitiba, Paraná, 2014]

[35] GREGÓRIO F ${ }^{\circ}$ R.; Permissividade elétrica e índice de perdas em CANEVAROLO Jr., S. V. Técnicas de caracterização de polímeros. Artliber Editora, 2004, p. 313-32

[36] MARK, H.F.; BIKALES, N.M.; OVERBERTER, C.G.; Encyclopedia of polymer science and engineering. Emulsion polymerization to fibers, Manufacture, v.6, John Wiley \& sons, New York (1986).

[37] MORALES, A. R. Morfologia e propriedades dinâmicas e mecânicas de resina epóxi/elastômero reativo. 1989. 204f. Dissertação (Mestrado em Ciência e Engenharia de Materiais) - Faculdade de Engenharia de Materiais, Universidade Federal de São Carlos, São Carlos, 1989.

[38] PEREIRA, D.S; Propriedades de Materiais Nanoestruturados de Sistemas epóxidicos DGEBA/TETA modificado com um éster de silsesquioxano; Dissertação de Mestrado em Ciência dos Materiais, UNESP-Ilha Solteira, 2006.

[39] SAUNDERS, J.K. Epoxies in Organic Polymer Chemistry: an introduction to the organic chemistry of adhesives, fibers, paints, plastics, and rubbers. $2^{a}$ edition. Cap. 18, p.412-417, 1988.

[40] UGLEA, C. V. Epoxy resins in Oligomer technology and applications. New York: Marcel Dekker, p. 393-456, 1998.

[41] DOUGLAS, A.; MARTIN, J.E.; WILCOXON, J.P.; Evolution of Structure and Viscoelasticity in an Epoxy near the Sol-Gel Transition, Macromolecules, 23, 2, 527-531, 1990.

[42] HIRATSUKA, R.S.; SANTILLI, C.V.; PULCINELLI, S.H.; O Processo Sol-Gel: Uma Visão Físico-Química; Química Nova, 18(2), 171-180, 1995.

[43] SIDEBOTTOM, D. L.; Ultrasonic measurements of an epoxy resin near its sol-gel transition, Physical Review E, 48(1), 391-399, 1993.

[44] DAKIN, TW, "Application of Epoxy Resins in Electrical Apparatus," IEEE transactions on electrical insulation, vol. ei-9, no. 4, pp. 121-128, Dec. 1974.

[45] MASTERBOND, Technical paper for Evaluation electrically insulating epoxies materials (www.masterbond.com). 
[46] LEE, H and NEVILLE, K., Handbook of Epoxy Resins, South El Monte: Mc Graw Hill inc. 1967.

[47] BAR-LONG.D.;YU.S.H.;CHEN,L.W.;CHIU,W.Y.;WU,T.R.; The Curing Reaction and Physical Proprieties of DGEBA/DETA Epoxy Resin Blended with Propyl Ester Phosphazene, Journal Applied Polymer 74 pp. 229-237, 1999.

[48] VECCHIA, D.G, DIAS FILHO, N.L., Pedido de patente junto ao INPI, 2003.

[49] SALIM Y., YOUNG, R. J; The Mechanical Proprieties of Epoxy Resins. Journal Mechanical Science, pp. 1823-1831, 1980.

[50] MENCZEL J.D., PRIME R.B., Thermal analysis of polymers, fundamentals and applications, 1 ed., New York, Wiley, 2009.

[51] MIKA, T, F.; BAUER, R, S.; Epoxy Resins: chemistry and technology. 2nd Ed. New York: Marcel Dekker, pp 465-550, 1988.

[52] ALMEIDA, J. R. M.; PEREIRA, A.A.C.; The influence of the amount of hardener on the tensile mechanical behavior of an epoxy system. Polymers for Advanced Technologies, v. 9, p. 216- 221 (1998).

[53] KAR, S.; BANTHIA, A. K.; Synthesis evaluation of liquid amine-terminated polybutadiene rubber and its role in epoxy toughening. Journal Applied Polymer Science, v. 96 , p. $2446-2453(2005)$.

[54] ALCÂNTARA, R. M.; PIRES, A. T. N.; BARROS, G. G.; BELFIORE, L. A. Pseudo interpenetrating polymer networks based on tetra functional epoxy resins and poly (methyl methacrylate). Journal of Applied Polymer Science, v. 89, p. 1859-1868 (2003).

[55] LEE, A.; LICHTENHAN, J. D. Viscoelastic responses of oligosilsesquioxane reforced epoxy systems. Macromolecules, v. 31, p. 4970-4974 (1998).

[56] STROGANOV, V.; STOYANOV, O.; STROGANOV, I.; KRAUS, E.; Functional Modification Effect of Epoxy Oligomers on the Structure and Properties of Epoxy Hydroxyurethane Polymers; Advances in Material Science and Engineering, volume 2018. [57] YU, J.; HUO, H.; WU, C.; WU, X.; WANG, W.; JIANG, P.; Macromol. Res. 20 (2012) $816-826$.

[58] YU, X; Epoxy Resin Electric Insulating Materials, Chemical Industry Press, Beijing, 2007. 
[59] DOnG, Y., CHAUdhary, D.; PlOUMis, C; LAU, K.T.; Compos. Part A, Appl. Sci. Manuf. 42 (2011) 1483-1492.

[60] TRIANTAFYlliDiS, K.S.; LE BARON, P.C.; PINNAVAIA, T.J.; Chem. Mater. 14 (2002) 4088-4095.

[61] BORTZ, D.; MERINO, C.; GULLON, I.M.; Composites. Sci. Technol. 71 (2011) 3138.

[62] GURUSIDESWAR, S.; VELMURUGAN, R.; Mater. Des. 60 (2014) 468-478.

[63] KOBAYASHI, M.; SAITO, H.; MATSUKAWA, K.; SUGAHARA, Y.; Appl. Organomet. Chem. 27 (2013) 673-677.

[64]KRITYSIS,A.;VIKELIS,G.;MAROULAS,P.;PISSIS,P.;MILOSHEVA,B.;KOTISILK OVA,R.; TOPliSJSKA,A.;SIlVESTRE,C.;DURACCIO, D.; J. Appl. Polym. Sci. 121 (2011) 3613-3627.

[65] FENG, M.; ZHAN, H.; Facile preparation of transparent and dense CdS-silica gel glass nanocomposites for optical limiting applications. Nanoscale, 2014, 6, 3972.

[66] NELSON J.K., FOTHERGIL, J.; Nanotechnology 15 (2004) 586-595.

[67] LEE, H and NEVILLE, K., Handbook of Epoxy Resins, South El Monte: Mc Graw Hill inc. 1967.

[68] MAITY P., S.; BASU, V.; PARAMESWARAN; IEEE Trans. Dielectric. Electr. Insul. 15 (2008) 52-61.

[69] TANAKA T., IEEE Trans. Dielectric. Electr. Insul. 12 (2005) 914-928.

[70] SHENGTAO,L.;YIN G.;BAI,S.;JIANYING L.; A New Potential Barrier Model in Epoxy Resin Nanodielectrics; IEEE Transactions on Dieletricts and electrical Insulation Vol. 18, No 5; October 2011.

[71] MCINTYRE, S.; LIGGAT, J.; PETHRICK, R.; Influence of the epoxy structure on the physical properties of epoxy resin nanocomposites; Industrial and Engineering Chemistry Research, 2004.

[72] BROWN, J; RHONEY, I.; PETHRICK, R.; Epoxy resin based nanocomposites: 1. Diglycidylether of bisphenol A (DGEBA) with triethylenetetramine (TETA). Polymer International, v. 53, n. 2130-2137 (2004).

[73] LAINE, R. M.; CHOI, J.; YEE, A.F; Organic/Inorganic hybrid composites from cubic silsesquioxanos. Journal of American Chemical Society, v. 123, p. 11420- 11430 (2001). 
[74] HARTMANN, M.; Über die Bauwürdigkeit von Pegmatitvorkommen auf Glimmer; Montan-Verlag: Düsseldorf, Germany, 1954; pp. 84-86

[75] GAINES R.V; New Mineralogy, $8^{\text {a }}$ ed, John Wiley \& Sons, Nova Iorque, p. 1444$1447,1997$.

[76] RIEDER, M.; CAVAZZINI, G.; VSEGEI, Y.S.; KOVA, P.V.; Nomenclature of the Micas; The Canadian Mineralogist: Vancouver, BC, Canada, 1998; Volume 36.

[77] LIEBEAU, F.; Structural Chemistry of Silicates; Springer Verlag-Berlin Heidelberg, 1985.

[78] LAGALY G. ; Ullman`s Encyclopedia of Industrial Chemistry, 2012 Wiley-VCH Verlag GmbH \& Co. KGaA, Weinheim, vol 32, p.509-572; 23,76.

[79] ROTTER, H, W.; Glimmer \& Glimmererzeugnisse: Eigenschaften, Entwicklungen, Anwendungen; Siemens Aktiengesellschaft: Berlin, Germany, 1985.

[80] KLEIN, H. H. Some thoughts regarding mica and mica paper. Von Roll Isola course information, 2012.

[81] SAXÉN, C; A $\mu$ - CT Investigation of the electrical breakdown mechanisms in Mica/Epoxy Machine Insulation; Examensarbete 30 Hp; Uppsala Universitet; July 2017.

[82] ABU, M.H; RAMADEEN, Y.A.; ZIHLIF, A.; The Electrical Behavior of MicaPolystyrene Composite; Physics Department, University of Jordan, Amman, Jordan Published online: 23 Oct 2006.

[83] HAILIN M.; WANG, G.; LIU, F.; JIANG, P.; The influence of the interface between mica and epoxy matrix on properties of epoxy-based dielectric materials with high thermal conductivity and low dielectric loss, RSC Advances, Issue 86, 2016.

[84] TRIPATHI, A.; TRIPATHI, A.K.; PILLAI, P.K.C.; Journal of Mtl Sci. letters 9, pg. 443-45, (1990).

[85] GUPta V. B.; BRahatheeswaran B.; J. Appl. Polym. Sci. vol 52, 107- 118 (1994).

[86] SAHAI R.S.N and PAWAR N.; Studies on Mechanical Properties of Mica filled Polyphenylene Oxide Composite with coupling Agent, Asian Journal of Applied Science and Technology (AJAST) Volume1, Issue 7, pages 153-157, August 2017. 
[87] VOGELSANG, R., FARR, T., FRÖHLICH, K. The effect of barriers on electrical tree propagation in composite insulation materials. IEEE Transactions on Dielectrics and Electrical Insulation v. 13, n. 1, p. 373-382, February 2006.

[88] ROTHON, R, N.; Surface modification and surface modifiers.in: Particulate-Filled Polymer composites. Longman, Harlow, p125.

[89] CAneVarolo JR, S, V.; Ciência dos Polímeros-Texto Básico para Tecnólogos e Engenheiros, Artiber Editora, São Paulo (2002).

[90] DIAZ, F, R, V.; Obtenção de argilas organofílicas partindo-se de argilas esmectíticas e sal quaternário de amônio. Congresso Brasileiro de Cerâmica, 43,1999, Florianópolis.

[91] SIQUEIRA, M, A.; Análise de Vida útil de Isolamento de Geradores elétricos, Programa de Pós-Graduação em Engenharia Elétrica na Universidade Federal de Itajubá, julho 2015.

[92] MACIEL G. E.; CHUANG, S.I.; Detailed Model of Local Structure and Silanol Hydrogen Bonding of Silica Gel Surfaces. J. Phys. Chem. B 1997, 101, 3052-3064.

[93] YOSOMIYA, R.; MORIMOTO, K.; NAKAJIMA, Y.; IKAKA, I.; SUZUKI, T.; Adhesion and bonding in composites. New York M. Dekker, 1990.

[94] XANTHOS, M.; Functional fillers for plastics.2. ed. [: WILEY-VCH Verlag, 2005.

[95] PLUEDDEMANN E.P.; Adhesion through Silane Coupling Agents, The Journal of Adhesion, 2:3,184-201, 2008, DOI: 10.1080/0021846708544592.

[96] PLUEDDEMANN, E, P.; Interfaces in polymer matrix composites. In: Broutman, L, J, Krock, R, H, (Ed). Composite Materials. New York Academic Press, 1974. v.6.

[97] MICHALSKA, Z. M.; Silica-Supported Rhodium Complexes. Relation between Catalyst Structure and Activity. Journal of Molecular Catalysis 11 (1981) 323 - 330.

[98] KANG, H.J.; BLUM, F.D.; J. Am. Chemical Society, 1991,95,9391.

[99] ISHIDA, H.; CHIANG, C.; KOENING, J. L.; J. Colloid Interface Sci.; 1980, 74, 396. [100] OKABAYASHI, H.; SHIMIZU, I.; NISHIO, E..; CONNOR, C. J. O.; Colloid Polymer Science, 1997, 275, 744.

[101] DE HAAN J.W.; BOGAERT, V.D.H.M; PONJEE, P.P.; J. Colloid Interface Sci.; 1986, 110, 591.

[102] CARAVAJAL G.S.; LEYDEN, D.E.; QUINTING, G.R.; MACIEL, G.E.; Anal. Chem. 1988, 60, 1776. 
[103] ONDRUS D.J.; BOERIO F. J.; J. Colloid Interface Sci.; 1988,124,349.

[104] HYACINTH, L.,C.;PHAM.V.;LOZANO.J.;CELIO.H.;WINTER.R.;Self-Organized Fibrous Nanostructures on Poly (aminopropyl) siloxane Films Studied by Atomic Force Microscopy. Langmuir 2000, 16, 10471-10481.

[105] WONG C.P.; Solid Surface Mount Technol.; 1999, 11, 33.

[106] DHARMALINGAM U.; DHANASEKARAN, M.; BALASBRAMANIA M.; KOTHANDARAMAN K.; Surface Treated fly ash filled modified epoxy composites, Polímeros vol.25 no.6 São Carlos Nov./Dec. 2015.

[107] TORKILDSEN A, N.; Impact of fillers on physical and mechanical properties of an epoxy matrix, and the effect of surface modification using a silane coupling agent, Thesis in Materials, Energy and Nanotechnology, Department of Chemistry, University of Oslo, May 2018.

[108] CHIANG C.H.; KOENIG J.L.; Chemical Reactions Occurring at the Interface of Epoxy Matrix and Aminosilane Coupling Agents in Fiber-Reinforced Composites; Polymer Composites, December 1980, Vol. 1, No. 2.

[109] TIANHAO L.; the investigation of interface effect on the properties of nanosilica-based underfill; 2017 18th International Conference on Electronic Packing Technology.

[110] ARROYO, M.; SUAREZ, R, V.; HERRERO, B; LOPEZ-MANCHADO, M, A. Optimization of nanocomposites based on polypropylene/polyethylene blends and organobentonite. Journal of Materials Chemistry 2003, 13, 2915-2921.

[111] MANO E., B.; Polímeros como Materiais de Engenharia. Editora Edgard Blücher Ltda., cap. 2, pág. 124-125.

[112] SANCHEZ, C.; MARTIN.I. Molecular design of alkoxide precursors for the synthesis of hybrid organic-inorganic gels. Journal of Non-Crystalline Solids 147-148 (1992) 1-12.

[113] ALMEIDA C.J.; WACHA A.; GOMES P.G.; FERNANDES M.H.R.; SALVADO I.M.M.;PDMS-SiO2-TiO2-CaO hybrid materials Cytocompatibility and nanoscale surface features. Materials Science and Engineering C 64 (2016) 74-86.

[114] KARTAL, I.; Toughening of Epoxy Resin via Silane terminated urethane including Pre-Hydrolyzed Tetraethoxysilane, Asian Journal of Chemistry, Vol.26, No.18 (2014) 6018-6022. 
[115] MACAN J.; IVANKOVIC H.; MENCER H.J.; Synthesis and Characterization of Organic-Inorganic Hybrids Based on Epoxy Resin and 3Glycidyloxypropyltrimethoxysilane, Journal of Applied Polymer Science 2004, 498-505. [116] GONZALEZ M.G.; CABANELAS J.C.; POZUELO J.; BASELGA J.; Preparation of cycloaliphatic epoxy hybrids with non-conventional amine-curing agents, J. Therm Anal Calorim. (2011) 103:717-72.

[117] PREZZI L.; MASCIA L.; Network Density Control in Epoxy-Silica Hybrids by Selective Silane Functionalization of Precursors; Advances in Polymer Technology, Vol. 24, No. 2, 91-102 (2005) C 2005 Wiley Periodicals, Inc.

[118] SELIMOV A.; JAHAN S.A.; BARKER E.; DACKUS P.; CAROLAN D.; Silane functionalization effects on dispersion of alumina nanoparticles in hybrid carbon fiber composites; Applied Optics, Vol. 57, No. 23 August 2018.

[119] AICHA S.; PASCAULT J.P.; LAM T.M.; Reactions in Aminosilane-Epoxy Prepolymer Systems. Kinetics of Epoxy-Amine Reactions ; Laboratoire des Matkriaux Macromolkculaires, URA CNRS n O 507, Institut National des Sciences Appliqukes de Lyon, France.1991.

[120] HASSANEIN J.; Evaluation of Curing Reaction Kinetics of Epoxy Siloxane Hybrid Polymers; Helsinki Metropolia University of Applied Sciences, Chemical Engineering Thesis 5 May 2015.

[121] PISCITELI F.; Epoxy-Based Organic-Inorganic Hybrid Materials By Sol-Gel Method: Chemical Tailoring And Multi-Scale Characterization, Tese de Doutorado, Programa De Ingegneria Dei Materiali E Delle Strutture, Dipartimento Di Ingegneria Dei Materiali E Della Produzione, Facoltà Di Ingegneria, Università Degli Studi Di Napoli "Federico II", 2010. p.286.

[122] OLEKSY M.; RZEPKA K.S.; HENECZKOWSKY M.; OLIWA R.; Epoxy Resin Composite Based on Functional Hybrid Fillers; Materials 2014, 7, 6064-6091.

[123] ABDOLLAHI, A.; MAMAGANI, H.R.; KALAJAHI, M.S.; RASAVI, B.; Preparation of Hybrid Composites Based on Epoxy Novolac, and Epoxidized Novolac Resins and Silica Nanoparticles with High Char Residue by Sol-Gel Method; Polymer Composites, 2018.

[124] BRINCKERHOF, P.; The Global CCS Institute. Accelerating the Uptake of CCS: Industrial Use of Captured Carbon Dioxide; 2011. 
[125] BUSTAMANTE M.M.C.; SILVA J.S.O.; ZHIMBO J.Z.; OLIVEIRA P.V.C.; SANTOS M.M.O.; Engagement of Scientific Community and Transparency in C Accounting: The Brazilian Case for Anthropogenic Greenhouse Gas Emissions from Land Use, Land-Use Change and Forestry. Environ. Res. Lett. 2018, 13, 055005.

[126] RANDALL D.A.; WOOD R.A. ; BONY S. ; COLMAN R. ; FICHEFET T.; FYFE J. ; KATTSOV V.; PITMAN A. ; SHUKLA J. ; SRINIVASAN J.; STOUFFER R.J.;; SUMI A. ; TAYLOR K.E.; Climate Models and Their Evaluation. Evaluation 2007, 323, 589-662. [127] ROCKSTROM J.;SHCELLNHUBER H.J.;HOSKINS B.;RAMANATHAN V.; SCHOLOSSER P.;BRASSEUR G.P.; GAFFNEY O; Earth's Future The World's Biggest Gamble Earth's Future. Earth's Future. 2016, 4, 465-470.

[128] RUSSEL G.L.; LACIS A.A.; RIND D.H.; COLOSE C.; OPSTBAUM R.F.; Fast Atmosphere-Ocean Model Runs with Large Changes in $\mathrm{CO}_{2}$. Geophysics. Res. Lett. 2013, 40 (21), 5787-5792.

[129] WANG L.; YANG Y.; SHEN W.; KONG Y.; Capture from Flue Gas in an Existing Coal-Fired Power Plant by Two Successive Pilot-Scale VPSA Units. Ind. Eng. Chem. Res. 2013, 52 (23), 7947-7955.

[130] ARESTA M.; Carbon dioxide as Chemical Feedstock, 2010 Willey-VCH Verlag $\mathrm{GmbH}$.

[131] NORTH M.; Synthesis of Cyclic carbonates from epoxides and carbon dioxide using bimetallic aluminum (salen) complex; Reviews ARKIVOC 2012, page 610-628.

[132] CARRILO V.C; CALEIRO L.C.; AGUIAR K.R.; JOSWIG J.O.; RODRIGUES FILHO U.P.; RISCHKA K.; Molecular Simulation on Carbon Dioxide Fixation Routes towards Synthesis of Precursors for Innovative Urethanes. Appl. Adhes. Sci. 2015, 1-11. [133] DARENSBOURG D.; YEUNG A. D.; Concise Review of Computational Studies of the Carbon Dioxide-epoxide Copolymerization Reactions. Polymer. Chem. 2014, 5, 39493962.

[134] FIGOVSKY 0.; SHAPOVALOV L.; LEYKIN A.; BIRUKOVA O.; POTASHNIKOVA R.; Recent of Non-Isocyanate Polyurethanes Based on Cyclic Carbonates. PU Magazine. 2013, pp 1-9.

[135] CHISHOLM M.H.; CLARK R.J.H.; GALlUCCI J.; HADDAD C.; J. Am. Chem. Soc. 2004.

[136] INOUE, H.K; TSURUTA, T.; Polymer Letter, 7, 287 (1969). 
[137] KURAN W.; PASYNKIEWICZ S.; SKUPINSKA J.; ROKICKI A.; Makromol. Chem. 1976, 177, 11-20.

[138] JACOBSEN E.N.; NIELSEN L.P.C.; STEVENSON C.P.; BLACKMOND D.G.; J. Am. Chem. Soc. 2004, 126, 1360-1362.

[139] DARENSBOURG, D.J, HOLTCAMP, M. W:" Catalysts for Reactions of Epoxides and Carbon Dioxide” Coordination Chemistry Reviews, Page 155-174, 1996.

[140] COATES G.W.; Allen S.D.; LOBKOvSKY E.B.; MOORE D.R.; J. Am. Chem. Soc. 2002 , 124, 14284-14285.

[141] COATES G.W.; ALLEN S.D.; LOBKOVSKY E.B.; MOORE D.R.; BYRNE C.M.;

J. Am. Chem. Soc. 2004, 126, 11404-11405.

[142] DELEBECQ E.; PASCAULT J.P.; BOUTEVIN B.; GANACHAUD F.; On the versatility of urethane/urea bonds: reversibility, blocked isocyanate, and non-isocyanate polyurethane, Chemical Review; 113, 2013, 80-118.

[143] DARENSBOURG D.J.; YARBROUGH J.C.; ORTIZ C.; FANG C.C.;J. Am. Chem. Soc. $2003,125,7586-7591$.

[144] SAKAKURA, T., Choi, J.-C., and Yasuda, H. 2007. Transformation of Carbon Dioxide. Chem. Rev. 107, 6, 2365-2387.

[145] TOMiTA H., F. Sanda, T. Endo; J. Polym. Sci., Part A: Polym. Chem. 39 (2001) $3678-3685$.

[146] NOGUEIRA, R, N.; Obtenção é caracterização de poliuretanos sem uso de isocianato (NIPU) e com fixação de $\mathrm{CO}_{2}$, Tese de Doutorado no Instituto de Química, USP-São Carlos, novembro 2010.

[147] LEITE, D, F, Estudo Teórico experimental do catalisador P-Dabco para ciclo adição catalítica do CO2 aos epoxidos, Dissertação de Mestrado em Química IQSC, 2015.

[148] SAUNDERS, M.; polyurethane Chemistry and Technology, Interscience (1962/1964).

[149] VILLAR, W. D; “Química e Tecnologia de Poliuretanos”, Manual Pronor 2002.

[150] MERENYL, S.; REACH Regulation (EC). No 1907/2006: Consolidated version (June 2012) with an introduction and future prospects regarding the area of Chemicals legislation, GRIN Verlag, 2012. 
[151] RAPPORT, L, Y.; PETROV, G, N.; TRSOSTYANSKAYA, I, I.; GAVRILOVA, O, P.; Inter. Polymer Sci. Technol. 8 (5), (1981) T/68-T/70.

[152] BENYAHYA S.; HABAS J.P.; AUVERGNE R.; LAPINTE V.; CAILLOL S.; Structure-property relationships in polyhydroxyurethanes produced from terephthaloyl dicyclocarbonate with various polyamines; Wiley Online Library: (wileyonlinelibrary.com) 2012.

[153] KIM M.R.; KIM H.S.; HA.C.S. PARK D.W.; LEE J.K.; Syntheses and Thermal Properties of Poly (hydroxyl) urethanes by Polyaddition Reaction of Bis (cyclic carbonate) and Diamines; Department of Polymer Science and Engineering, Pusan National University, Pusan 609-735, 2001, Korea.

[154] GUAN J.; SON. Y.; LIN Y.; YIN X.; ZUO, M.; ZHAO, Y.; TAO, O.; ZHENG, Q.; Ind. Eng. Chem. Res. 50 (2011) 6517-6527.

[155] MAISONNEUVE, L. ; LAMARZELLE O. ; RIX E. ; GRAU E. ; CRAMAIL H. ; Chem. Rev. 115 (2015) 12407-12439 [Washington, DC, US].

[156] ARGYROPOUlOS J. N.,BHATTACHARJEE D., Ambient temperature curable isocyanate-free compositions for preparing cross-linked polyurethanes, EP2397506A1, 2011.

[157] ISHIDA H.; CHIANG C.H.; KOENIG J.L.; et al; J. Colloid Interface Sci.; 1980, 74, 396.

[158] IHATA O.; KAYAKI Y.; IKARIYA T.; Synthesis of thermoresponsive polyurethane from 2-methylaziridine and supercritical carbon dioxide, Angewandte Chemie, Int Ed; 43, 2004.

[159] LUNDBERG R. D., Montgomery D. R., Carbon dioxide polymers, US3523924 A, 1970.

[160] KATHALEWAR M. S., JOSHI P. B., SABNIS A. S.,MALSHE V. C., Non-isocyanate polyurethanes: from chemistry to applications, RSC Adv.; 3, 2013, 4110-4129.

[161] Http:// br.investing.com/commodities/carbon-emissions.

[162] FIGOVSKY O...; Patent WO9965969A1, 1999.

[163] WHELAN J.M. Jr., HILL M.; COTTER R.J.; US Patent 3072613 A. 1963

[164] RIED W., MERKEL W.; Angewandte Chemie, Int. Ed. Engl. 8 (1969) 379-380. 
[165] TOMITA H., SANDA F.; ENDO T.; J. Polym. Sci., Part A: Polym. Chem. 39 (2001) 851-859.

[166] BHANAGE B.M.; FUJITA S.; IKUSHIMA Y.; ARAI M.; Green Chemistry. 5 (2003) 429-432.

[167] CRAMAIL H.;BOYER A.;BOYER E.;CLOUTET B.; GAUDENNE C.; Patent WO2011061452A2, 2011.

[168] ENDO T.; KIHARA N.; J. Polym. Sci., Part A: Polymer. Chem. 31 (1993) 27652773 .

[169] TOMITA H., SANDA F.; ENDO T.; J. Polym. Sci., Part A: Polymer. Chem. 39 (2001) $860-867$.

[170] ROKICKI G.; PARZUCHOWSKY P. G.; MAZUREK M.; Non-isocyanate polyurethanes: synthesis, properties, and applications, Polymers for Advanced Technologies, vol.26, issue.7, pp.707-761, 2015.

[171] CARRE, C. ; BONNET, L. ; AVEROUS L. ; RSC Adv. 5 (2015) 100390-100400.

[172] BESSE, V. ; AUVERGNE, R. ; CARLOTTI, S. ; BOUTEVIN, G. ; CAILlOL, S. ; PASCAULTJ.P. React. Funct. Polymer. 73 (2013) 588-594.

[173] BOYER, A.; ClOUTET, E. ; TASSAING, T. ; GADENNE, B. ; ALFOS, C. ; CRAMAIL, H. ; Green Chemistry. 12 (2010) 2205-2213.

[174] STEBLYANKO, A. ; CHOI, W. ; SANDA, F. ; ENDO, T. ; J. Polym. Sci., Part A: Polymer. Chem. 38 (2000) 2375-2380.

[175] FATOUMATA C.; BESSE V.; BENYAHYA S.; BOUTEVIN G.; Reactivity of Secondary Amines for synthesis of Non-Isocyanate Polyurethane; European Polymer Journal (55) -2014.

[176] FLEISCHER M.; BLATTMANN H.; MULHAUPT R.; Green Chemistry. (15) (2013) 934-942.

[177] HELOU M.; CARPENTIER J.F.; GUILAUME S.M.; Green Chemistry. 13 (2011) $266-271$.

[178] HE Y.; KEUL H.; MOLLER M.; React. Funct. Polymer. (71) 2011 175-186.

[179] FIGOVSKY O.; SHAPOVALOV L.; Patent WO2003028644A2, 2003.

[180] LAMBETH R.H.; HENDERSON T.J.; Polymer 54 (2013) 5568-5573. 
[181] GARIPOV R.M.; SYSOEV V.A.; MIKHEEV V.V.; SAGIDULLIN A.I.; DEBERDEEV R.Y.; IRZHAK V.I.; Reactivity of Cyclic Carbonate Groups in Modified Epoxy- Amine Compositions, Doklady Physical Chemistry; 393, 2003, 289-292.

[182] CORNILLE A.;GUILHET C.;BENYAHIA S.;NEGRELL C.;BOUTEVIN B.;CAILLOL S.; Room temperature flexible isocyanate-free polyurethane foams, European Polymers Journal; 2016, Accepted manuscript.

[183] CORNILLE A.;MICHAUD G.;GUILAUME S.;FOUQUAI F.;AUVERGNE S.; BOUTEVIN R.;CAILLOL S.;Promising Mechanical and Adhesive properties of isocyanatefree poly (hydroxyurethane; European Polymer Journal 84 (2016) 404-420.

[184] KE J.;XIAOYUN L.;WANG F.;SHUAI J.;MAOGING K.;JUNWEI W.; RSC Adv., $2017,7,28841$.

[185] ROKICKI G., WOJCIECHOWSKI C.; Epoxy Resin Modified by Aliphatic Cyclic Carbonates, Journal of Applied Polymer Science, Vol. 41, 647-659 (1990).

[186] FIGOVSKY 0.;SHAPOVALOV L.;LEYKIN A.; Synthesis and application of Non isocyanate polyurethanes, Chemistry \&Chemical Technology, Vol. 10, No. 4(s), 2016.

[187] KATHALEWAR M.; ANAGHA S.; GULZAR W.; Effect of incorporation of surface treated zinc oxide on non-isocyanate polyurethane based Nano-composite coatings.; Progress in Organic Coatings 76 (2013) 1215-1229.

[188] ISO 3001-1978; Determinação de Grupos epóxi com ácido perclorico Vantico LTDA - Taboão da Serra Brasil. 1983.

[189] AKITT J. W.; MANN B. E.; NMR and Chemistry. Cheltenham, UK: Stanley Thornes. Akitt \& Mann, p. 287 (2000).

[190] KEELER J.; (2010). Understanding NMR Spectroscopy (second Ed.). Wiley. pp. 184187; 190-191. ISBN 978-0-470-74608.

[191] DOBLER D.; OSWALD S., WETZIG K.; Calibration of XPS - energy scale for determination of the oxidation states of doping elements in $\mathrm{SnO}_{2}$ powders. Anal Bioanal Chem (2002) 374:646-649. Pag 97.

[192] WAGNER C. D.; Journal of Electron Spectroscopy and Related Phenomena, 32 (1983) 99-102.

[193] AMERICAN SOCIETY FOR TESTING AND MATERIALS, ASTM D 570-98, 2000. 
[194] ALVAREZ, V. A., VALDEZ, M. E., \& VÁZQUEZ, A. Dynamic mechanical properties and interphase fiber/matrix evaluation of unidirectional glass fiber/epoxy composites. Polymer Testing, v. 22, p. 611-615, 2003.

[195] PINEDA, F.A.E; Propriedades Mecânicas, adesivas e absorção de água de polímeros epoxídicos, Dissertação de Mestrado, Universidade Federal de Itajubá. 2014.

[196] MACDONALD, J.R; Impedance Spectroscopy - Emphasizing Solid Material and Systems, John Wiley \& Sons, Canada (1987).

[197] MACDONALD J.R; Impedance Spectroscopy, Annals of Biomedical Engineering, Vol. 20, pp. 289-305 (1992).

[198] AMERICAN SOCIETY FOR TESTING AND MATERIALS, ASTM D 150 -1987, Standard Test Methods for A-C Loss Characteristics and Permittivity (Dielectric Constant) of Solid Electrical Insulating Materials.

[199] CHINELATTO. A. L.; SOUZA D.P.F.; et al, Porcelanas Elétricas Aluminosas: Parte 1, Revisão de Literatura. Cerâmica, V50, no 313. 2004.

[200] YEE, R, Y.; STEPHENS, T, S.; A TGA technique for determining graphite fiber content in epoxy composites, Thermochimica Acta, Volume 272, 20 January 1996, Pages 191-199.

[201] CANEVAROLO JR, S.V.; Técnicas de Caracterização de Polímeros. São Carlos Artiber, 2004.

[202] CRESPI M. S.; RIBEIRO C.; OLIVEIRA S.; SILVIO A.R.; Composting of urban solid residues by different dispositions: kinetics of thermal decomposition. Journal of Thermal Analysis and Calorimetry, v. 72, n. 3, p. 1049-1056, 2003.

[203] GOERTZEN W.K.; KESSLER M. R.; Dynamic mechanical analysis of carbon/epoxy composites for structural pipeline repair. Composites: Part B, v. 38, p. 1-9, 2007.

[204] WULLS, G, M, P.; THEODORA, W.; Greene’s Protective Groups in Organic Synthesis.4 $4^{\text {a }}$ ed. John Wiley \& Sons. page 428-429, cap. 3, 2007, NJ, EUA.

[205] DUNCAN, J.; Principles and application of mechanical thermal analysis. Oxford Blackwell Publishing Ltd. 2008. page 119-163. 
[206] MENARD. K. P.; Dynamics Mechanical Analysis: a practical introduction. Boca Raton: CRC Press Taylor \&Francis Group 2008.

[207] URBANIAK M.; GRUDZINSKI, K.; Time-temperature-transformation (TTT) cure diagram for EPY® epoxy system, Polymer -Warsaw- · February 2007, 52, nr 2.

[208] OLIVER, W.C and PHARR G.M.; J. Mat. Res. 7(4) (1992) 1564.

[209] TIWARI A.; Nanomechanical analysis of Hybrid silicones and Hybrid epoxy coatings, Advances in Chemical Engineering and Science, 2012, 2, 34-44.

[210] PEDROSO M.S.C.; Desenvolvimento de método analítico para determinação da composição de aminoácidos em proteína de soja utilizando sistema SAI com pervaporação; Dissertação de Mestrado apresentada ao Programa de Pós-Graduação em Química na Universidade Estadual de Maringá, 2014.

[211] WULLS, G, M, P.; THEODORA, W.; Greene’s Protective Groups in Organic Synthesis. $4^{\text {a }}$ ed. John Wiley \& Sons. $p$ 428-429, cap. 3, 2007, NJ, EUA.

[212] DUTTA, S.S.; Water Absorption and Dielectric Properties of Epoxy Insulation; Master of Science in Energy and Environment; Norwegian University of Science and Technology, 2008.

[213] ZHAO Z.K.; CHEN Q.; GAO K.; PENG C.; XIE H.; BAO.; Preparation of lignin/glycerol-based bis (cyclic carbonate) Synthesis of polyurethanes. Green Chemistry. $2015,17,4546-4551$.

[214] CLAY, R.M.; CORR S.; KEENAN S.; STEELE G.; Standard enthalpies of sublimation and vaporization of 1, 4, 8,11-tetraazacyclotetradecane and 1,4,8,11-tetraazaundecane. Gasphase macrocyclic enthalpy, J. Am. Chem. Soc., 1983, 105, 7, 2070-2071, https://doi.org/10.1021/ja00345a069.

[215] NELSON J. K., FOTHERGILL, J. C., DISSADO L.A., PEASGOOD W.; Towards an understanding of nanometric dielectrics. Annual Report Conference on Electrical Insulation and Dielectric Phenomena, p. 295-298, October 2002.

[216] SUN, Y., ZHANG, Z., MOON, K. S., WONG, C. P. Glass Transition and Relaxation Behavior of Epoxy Nanocomposites. Journal of Polymer Science Part B: Polymer Physics, v. 42, n. 21, p. 3849-3858, November 2004. 
[217] SINGHA, S., THOMAS, M.J. Polymer composite/nanocomposite processing and its effect on the electrical properties. Annual Report Conference on Electrical Insulation and Dielectric Phenomena 2006, p. 557-560.

[218] ZOU H., WU S., SHEN J. Polymer/Silica Nanocomposites: Preparation, Characterization, Properties, and Applications. Chem. Rev., v.108, n.9, p.3893-3957, August 2008.

[219] EMERY, F. T.; Partial Discharge, Dissipation Factor, and Corona Aspects for High Voltage Electric Generator Stator Bars and Windings. IEEE Transactions on Dielectrics and Electrical Insulation, Charlotte, v. 12, n. 2, p.347-361; Abril 2005.

[220] HENK, P. O., KORTSEN T. W., Increasing the electrical discharge endurance of acid anhydride cured DGEBA epoxy resin by dispersion of nanoparticle silica High Perform; Polymers v. 11, n.3, p. 281-296, September 1999.

[221] KARAMI Z.; KABIRI K., ZOHURIAN M.J.M.; Non Isocyanate polyurethane based on a bio resourced star-shaped epoxy macromonomer in comparison with a cyclocarbonate fossil based epoxy resin: A Preliminary study on thermos-mechanical and antibacterial properties; Journal of $\mathrm{CO}_{2}$ Utilization ,34, (2019) 558-567. 


\section{APÊNDICE}

Apêndice A - Espectro de RMN de ${ }^{1} \mathrm{H}$ do pré-polímero PHU

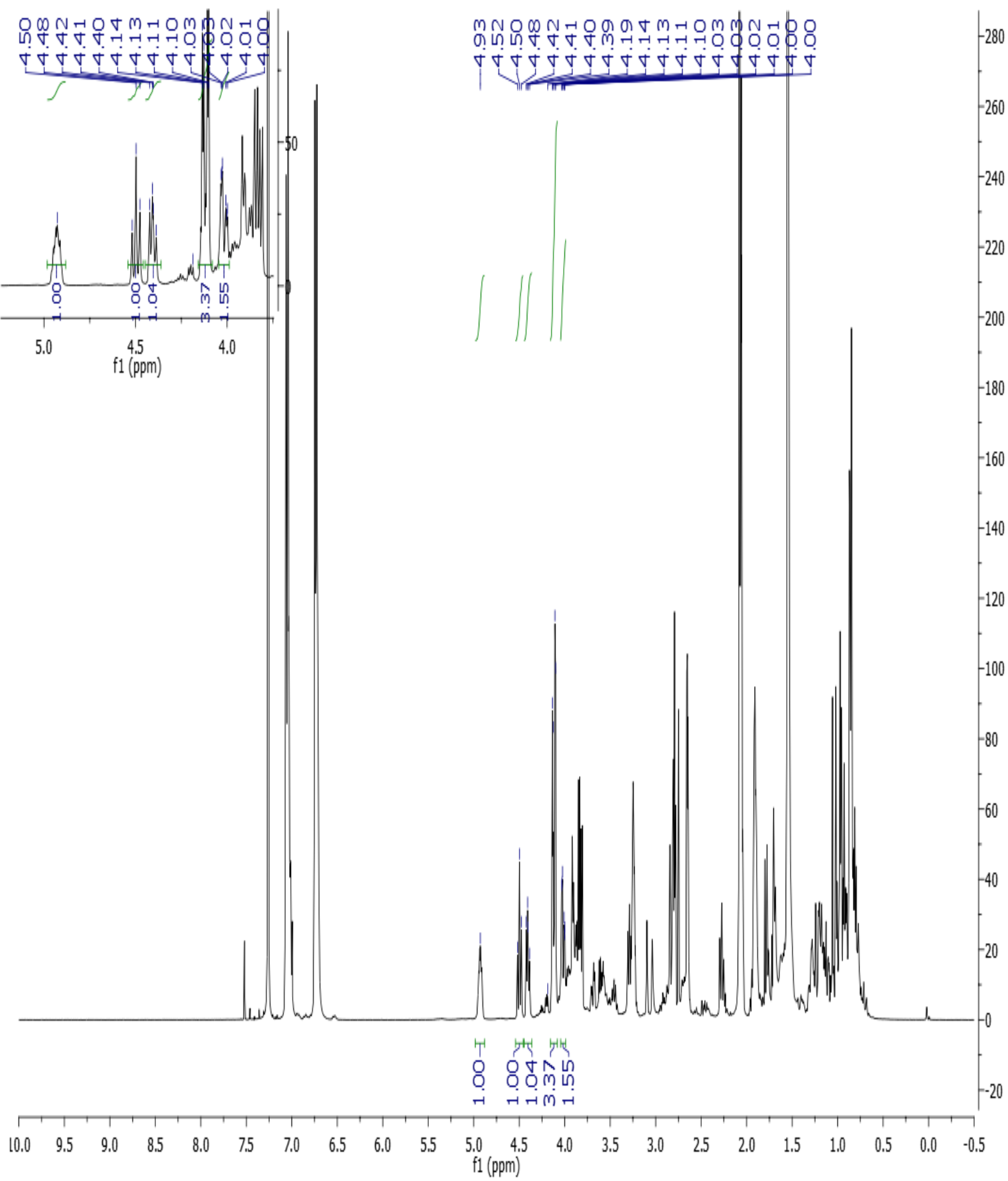

Fonte: elaborado pelo próprio autor, 2019. 
Apêndice B - RMN com a sequência do pulso COSY.

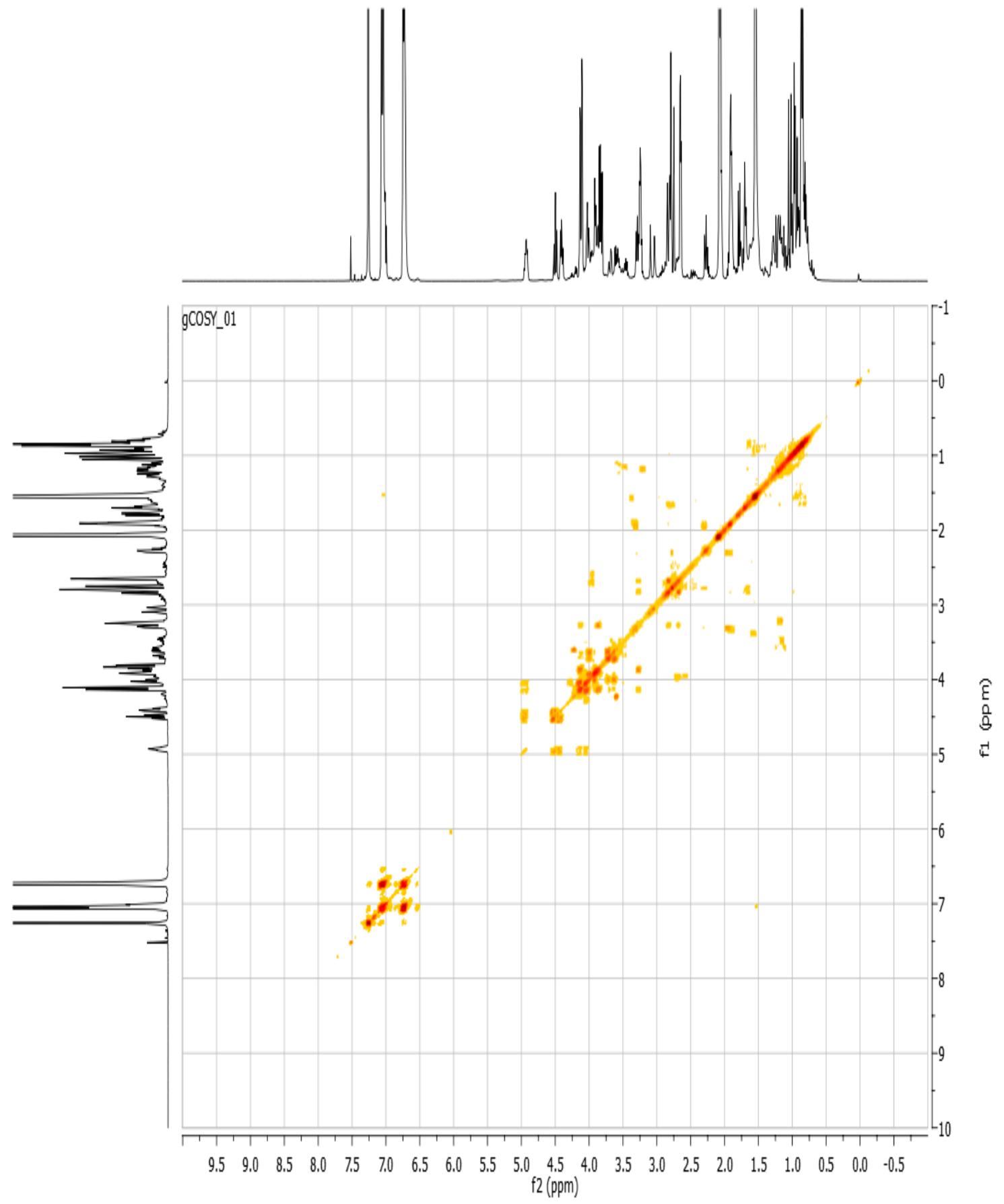

Fonte: elaborado pelo próprio autor, 2019. 


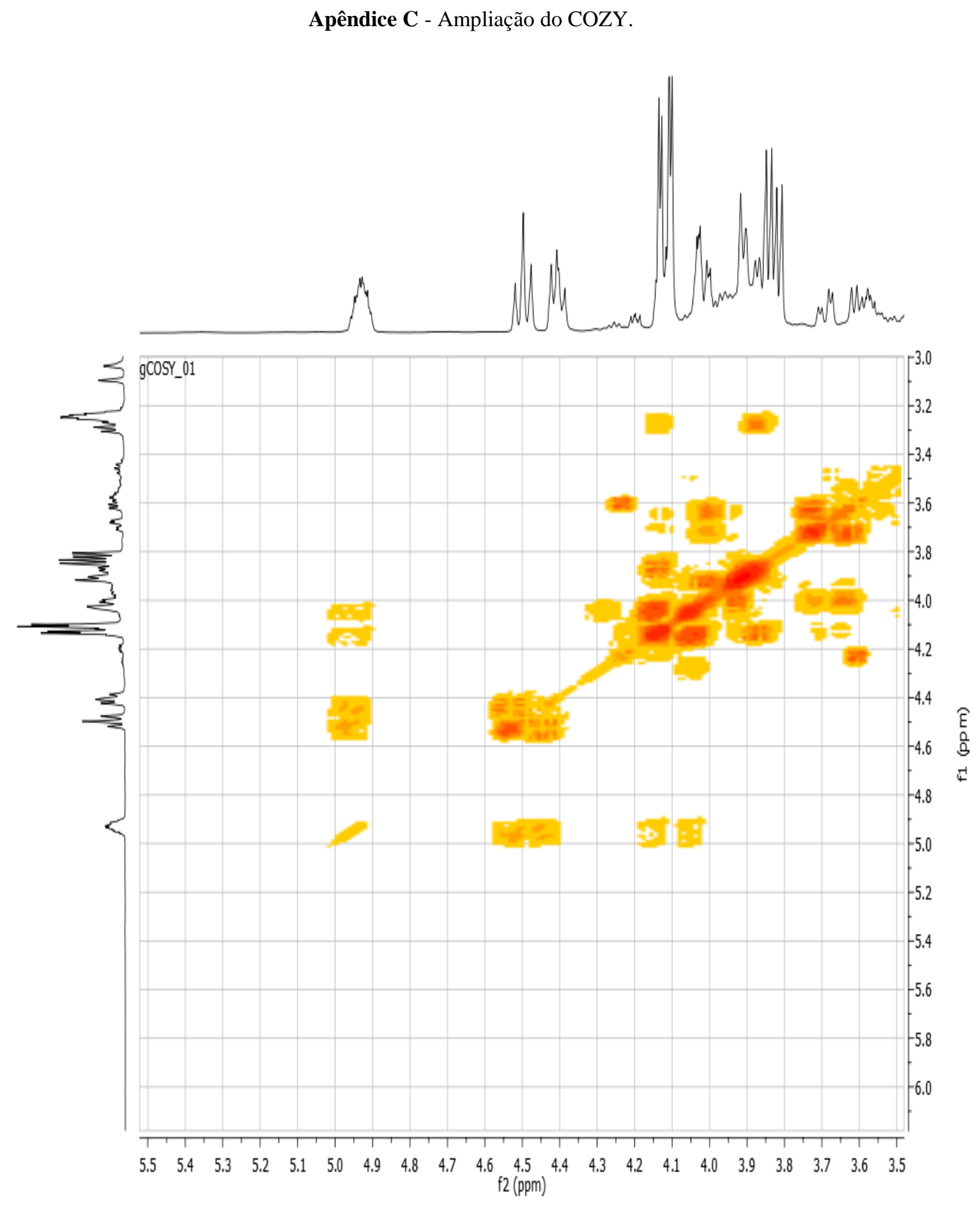

Fonte: elaborado pelo próprio autor, 2019. 
Apêndice D - Uso da Técnica de HSQC.

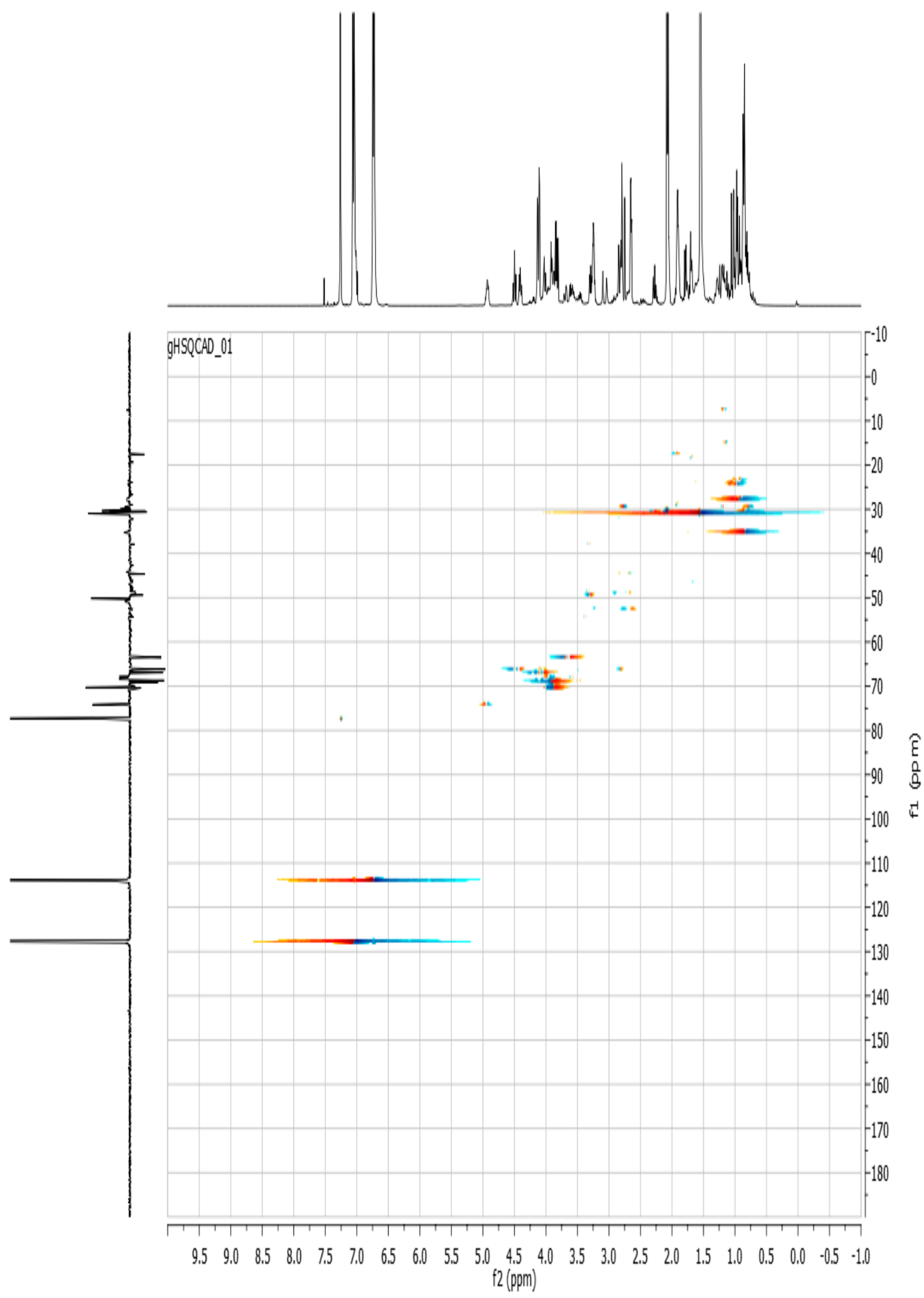

Fonte: elaborado pelo próprio autor, 2019. 
Apêndice E Ampliação do HSQC.

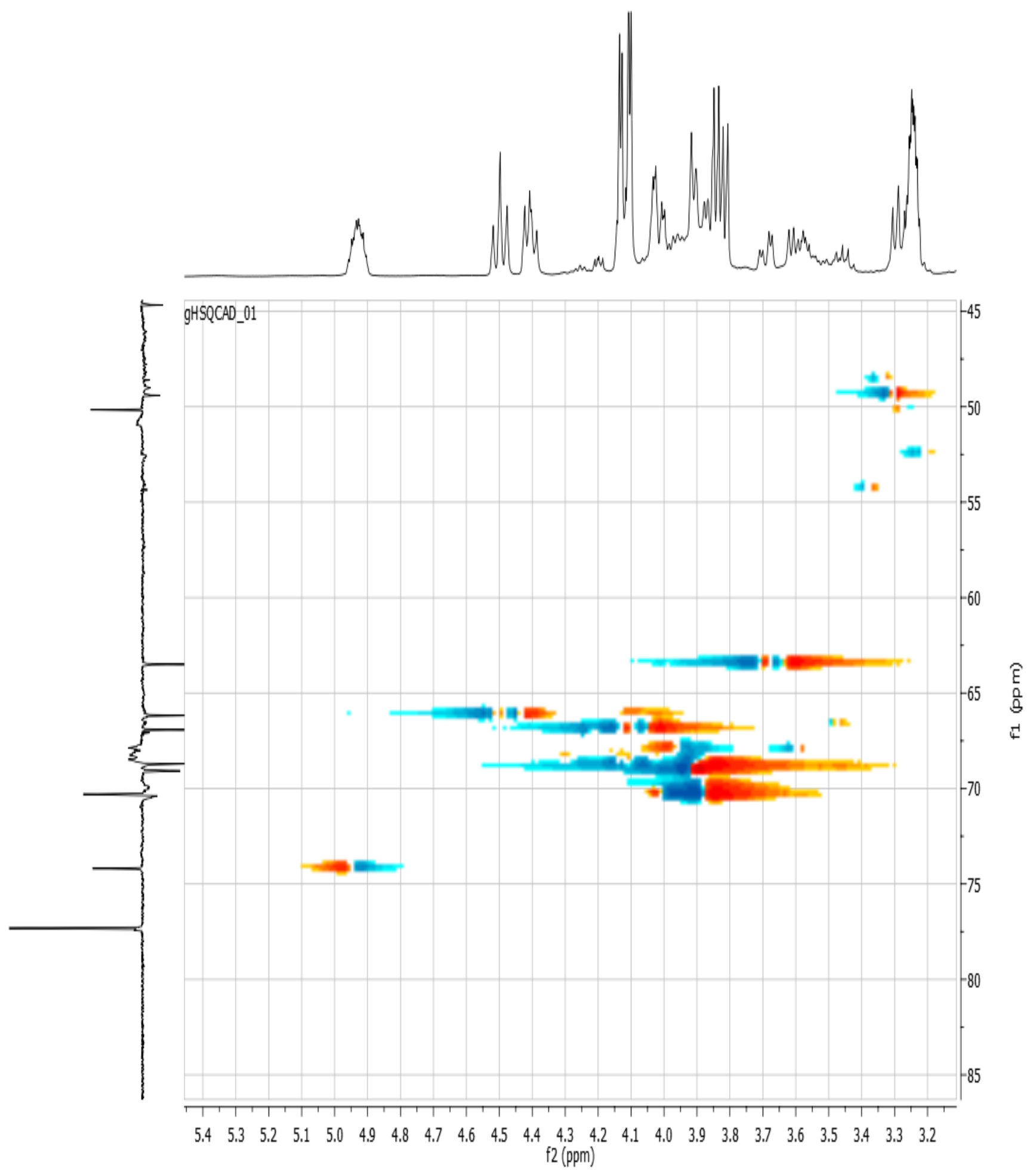

Fonte: elaborado pelo próprio autor, 2019. 
Apêndice F - Ressonância de Carbono 13.

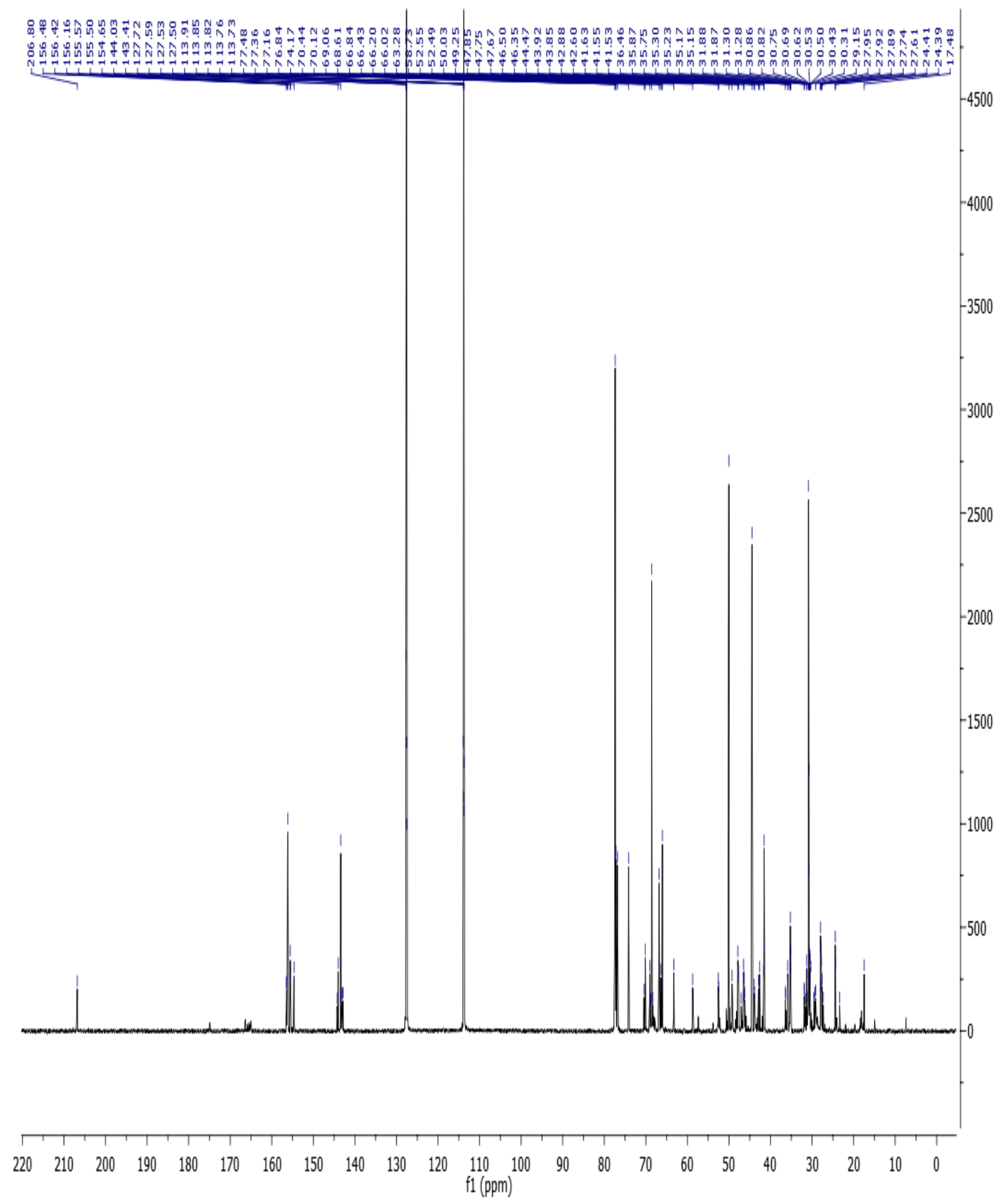

Fonte: elaborado pelo próprio autor, 2019. 
Apêndice G- Avaliação DEPT 135.

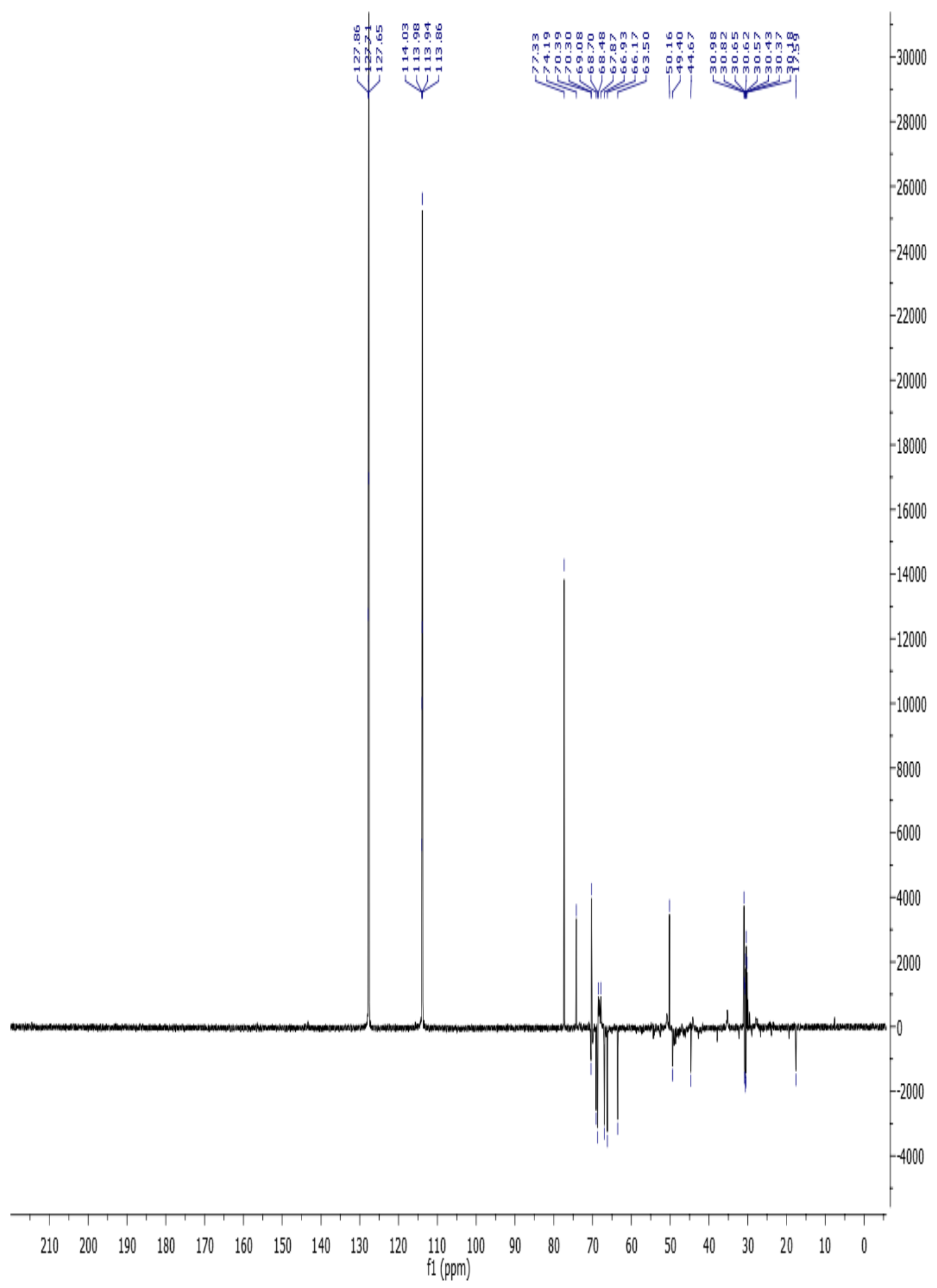

Fonte: elaborado pelo próprio autor, 2019. 
Apêndice H. Pesagem inicial $\left(\mathrm{m}_{0}\right)$ em gramas referentes ao teste de \% Absorção de Água (página 164)

\begin{tabular}{|l|c|c|c|ll|}
\hline Síntese & amostra 1 & amostra 2 & amostra 3 & média \\
\hline Epóxi 1 & 0,565 & 0,557 & 0,569 & $0,564 \pm 0,006$ \\
\hline Epóxi 2 & 0,618 & 0,598 & 0,620 & $0,612 \pm 0,012$ \\
\hline Epóxi 3 & 0,518 & 0,534 & 0,535 & $0,529 \pm 0,009$ \\
\hline NIPU 1 & 0,616 & 0,598 & 0,608 & $0,607 \pm 0,009$ \\
\hline NIPU 2 & 0,697 & 0,703 & 0,697 & $0,699 \pm 0,003$ \\
\hline NIPU 3 & 0,592 & 0,612 & 0,608 & $0,604 \quad \pm 0,010$ \\
\hline NIPU 4 & 0,573 & 0,587 & 0,584 & $0,581 \quad \pm 0,007$ \\
\hline HNIPU 1 & 0,579 & 0,572 & 0,584 & $0,578 \pm 0,006$ \\
\hline HNIPU 2 & 0,579 & 0,583 & 0,588 & $0,583 \pm 0,004$ \\
\hline HNIPU 3 & 0,535 & 0,548 & 0,537 & $0,543 \pm 0,007$ \\
\hline HNIPU 4 & 0,546 & 0,553 & 0,549 & $0,549 \pm 0,004$ \\
\hline
\end{tabular}

Fonte: elaborado pelo próprio autor, 2019.

Apêndice I. Pesagem final $\left(\mathrm{m}_{1}\right)$ em gramas referentes ao teste de \% Absorção de Água (página 164)

\begin{tabular}{|l|c|c|c|c|}
\hline Síntese & Final 1 & Final 2 & Final 3 & Média \\
\hline Epóxi 1 & 0,572 & 0,563 & 0,574 & $0,570 \pm 0,006$ \\
\hline Epóxi 2 & 0,630 & 0,607 & 0,632 & $0,623 \pm 0,012$ \\
\hline Epóxi 3 & 0,535 & 0,552 & 0,552 & $0,546 \pm 0,009$ \\
\hline NIPU 1 & 0,631 & 0,614 & 0,623 & $0,623 \pm 0,008$ \\
\hline NIPU 2 & 0,711 & 0,718 & 0,712 & $0,713 \pm 0,003$ \\
\hline NIPU 3 & 0,705 & 0,728 & 0,723 & $0,719 \pm 0,124$ \\
\hline NIPU 4 & 0,627 & 0,643 & 0,639 & $0,636 \pm 0,008$ \\
\hline HNIPU 1 & 0,587 & 0,576 & 0,588 & $0,583 \pm 0,007$ \\
\hline HNIPU 2 & 0,589 & 0,593 & 0,598 & $0,593 \pm 0,005$ \\
\hline HNIPU 3 & 0,542 & 0,555 & 0,543 & $0,546 \pm 0,007$ \\
\hline HNIPU 4 & 0,553 & 0,560 & 0,556 & $0,556 \pm 0,003$ \\
\hline
\end{tabular}

Fonte: elaborado pelo próprio autor, 2019. 
Apêndice J - Dados da Pesagem inicial $\left(\mathrm{m}_{0}\right)$ em gramas dos protótipos do teste de \% de Gelificação (página 167).

\begin{tabular}{|l|c|c|c|c|}
\hline \multicolumn{5}{|c|}{ Amostra Inicial $\left(\mathrm{m}_{0}\right)$ gramas } \\
\cline { 1 - 3 } Formulas & amostra 1 & amostra 2 & amostra 3 & média \\
\hline Epóxi 1 & 0,546 & 0,573 & 0,565 & $0,561 \pm 0,014$ \\
\hline Epóxi 2 & 0,535 & 0,497 & 0,543 & $0,525 \pm 0,024$ \\
\hline Epóxi 3 & 0,519 & 0,536 & 0,498 & $0,517 \pm 0,019$ \\
\hline NIPU 1 & 0,508 & 0,526 & 0,536 & $0,523 \pm 0,014$ \\
\hline NIPU 2 & 0,530 & 0,498 & 0,574 & $0,534 \pm 0,038$ \\
\hline NIPU 3 & 0,582 & 0,556 & 0,567 & $0,568 \pm 0,013$ \\
\hline NIPU 4 & 0,504 & 0,543 & 0,549 & $0,532 \pm 0,024$ \\
\hline HNIPU 1 & 0,560 & 0,587 & 0,559 & $0,568 \pm 0,016$ \\
\hline HNIPU 2 & 0,549 & 0,523 & 0,568 & $0,546 \pm 0,023$ \\
\hline HNIPU 3 & 0,515 & 0,546 & 0,543 & $0,534 \pm 0,017$ \\
\hline HNIPU 4 & 0,529 & 0,556 & 0,528 & $0,537 \pm 0,016$ \\
\hline
\end{tabular}

Fonte: elaborado pelo próprio autor, 2019.

Apêndice K - Pesagem após 24 horas em gramas dos protótipos em THF m1 da página 167.

\begin{tabular}{|r|c|c|c|c|}
\hline \multicolumn{6}{|l|}{ Amostra Após 24 horas em THF $\left(\mathrm{m}_{1}\right)$ gramas } \\
\hline Formulas & amostra 1 & amostra2 & amostra 3 & média \\
\hline Epóxi 1 & 0,971 & 1,130 & 1,030 & $1,043 \pm 0,080$ \\
\hline Epóxi 2 & 0,806 & 0,885 & 0,958 & $0,883 \pm 0,076$ \\
\hline Epóxi 3 & 0,812 & 0,783 & 0,752 & $0,782 \pm 0,030$ \\
\hline NIPU 1 & 0 & 0 & 0 & 0 \\
\hline NIPU 2 & 0 & 0 & 0 & 0 \\
\hline NIPU 3 & 1,119 & 1,069 & 1,093 & $1,094 \pm 0,025$ \\
\hline NIPU 4 & 0 & 0 & 0 & 0 \\
\hline HNIPU 1 & 0,577 & 0,605 & 0,575 & $0,585 \pm 0,016$ \\
\hline HNIPU 2 & 0,593 & 0,565 & 0,613 & $0,590 \pm 0,024$ \\
\hline HNIPU 3 & 0,547 & 0,580 & 0,577 & $0,568 \pm 0,018$ \\
\hline HNIPU 4 & 0,614 & 0,645 & 0,612 & $0,624 \pm 0,018$ \\
\hline
\end{tabular}

Fonte: elaborado pelo próprio autor, 2019. 
Apêndice $\mathbf{L}$ - Pesagem dos protótipos que foram removidos do THF após 24 horas em estufa a $80{ }^{\circ} \mathrm{C}\left(\mathrm{m}_{2}\right)$.

\begin{tabular}{|c|c|c|c|l|}
\hline \multicolumn{5}{|c|}{ Amostras 24 horas em estufa a $80^{\circ} \mathrm{C}\left(\mathrm{m}_{2}\right)$} \\
\hline Formulas & amostra 1 & amostra 2 & amostra 3 & Media \\
\hline Epóxi 1 & 0,230 & 0,241 & 0,238 & $0,236 \pm 0,005$ \\
\hline Epóxi 2 & 0,432 & 0,443 & 0,462 & $0,446 \pm 0,015$ \\
\hline Epóxi 3 & 0,411 & 0,431 & 0,407 & $0,416 \pm 0,013$ \\
\hline NIPU 1 & 0 & 0 & 0 & 0 \\
\hline NIPU 2 & 0 & 0 & 0 & 0 \\
\hline NIPU 3 & 0,139 & 0,133 & 0,136 & $0,136 \pm 0,003$ \\
\hline NIPU 4 & 0 & 0 & 0 & 0 \\
\hline HNIPU 1 & 0,448 & 0,470 & 0,447 & $0,455 \pm 0,013$ \\
\hline HNIPU 2 & 0,497 & 0,473 & 0,514 & $0,495 \pm 0,020$ \\
\hline HNIPU 3 & 0,477 & 0,505 & 0,502 & $0,513 \pm 0,016$ \\
\hline HNIPU 4 & 0,495 & 0,479 & 0,488 & $0,465 \pm 0,008$ \\
\hline
\end{tabular}

Fonte: elaborado pelo próprio autor, 2019.

Apêndice M - Fotografia da gota d'água sobre as amostras HNIPU 2 e HNIPU 3)

a) HNIPU 2 (mica não sililada)

b) HNIPU 3 mica sililada.

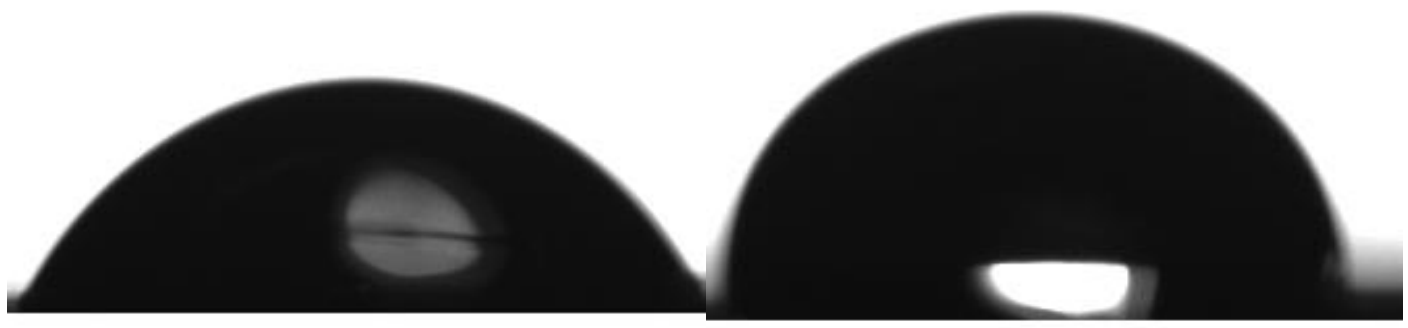

Fonte: elaborado pelo próprio autor, 2019 
Apêndice N - Fotografia da gota d'água sobre as amostras Epóxi.

a) Epóxi 2 (com mica sililada) $\quad$ b) Epóxi 3 (com mica não sililada)

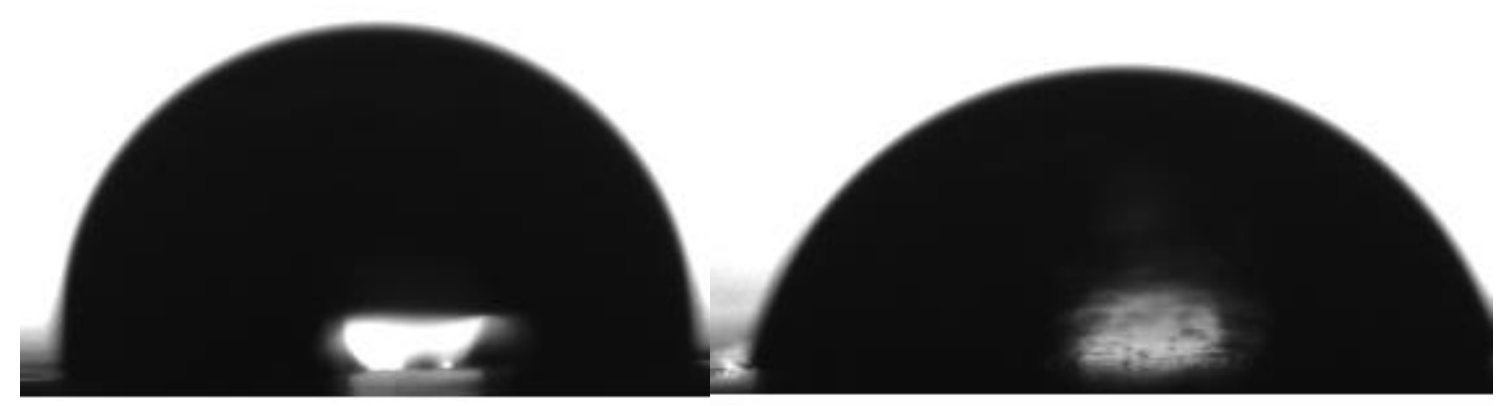

Fonte: elaborado pelo próprio autor, 2019.

Apêndice O - Fotografia da gota d'água sobre a NIPU 2(com Mica Sililada).

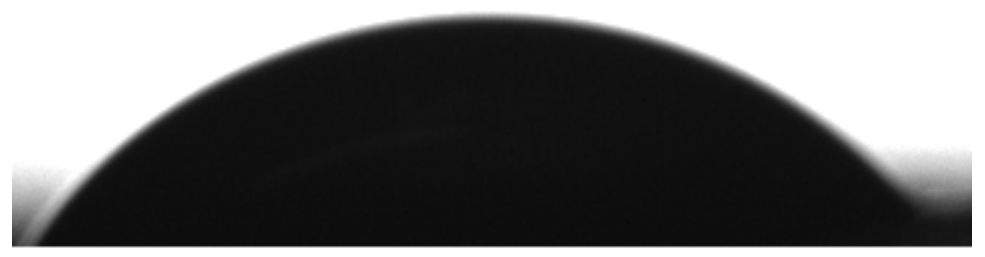

Fonte: elaborado pelo próprio autor, 2019.

Apêndice P - Parâmetros de indentação para as amostras avaliadas via Nanoindentação.

\begin{tabular}{|l|c|c|}
\hline Formulações & Largura $(\mathrm{mm})$ & espessura $(\mathrm{mm})$ \\
\hline Epóxi 2 & 10,80 & 2,51 \\
HNIPU 4 & 9,26 & 1,30 \\
HNIPU 3 & 10,80 & 1,65 \\
NIPU 2 & 11,05 & 1,75 \\
\hline
\end{tabular}

Fonte: elaborado pelo próprio autor, 2019. 
Apêndice Q- Dados Obtidos na avaliação de Nanoindentação.

\begin{tabular}{|c|c|c|c|c|c|c|c|}
\hline Epoxi 2 & Teste & Carga Máx & Penetração Máx & Dureza(GPa) & \begin{tabular}{|l|}
$\operatorname{Dureza}(\mathbf{H V})$ \\
\end{tabular} & Modulus & Dureza Martens \\
\hline & Teste 2 & 26,13 & 1813,37 & 0,4 & 37,88 & 11,36 & 0,3 \\
\hline & Teste 3 & 25,68 & 2359,89 & 0,21 & 20,07 & 13,36 & 0,17 \\
\hline & Teste 4 & 28,72 & 2332,96 & 0,27 & 25,15 & 8,14 & 0,19 \\
\hline & Teste 5 & 26,75 & 1957,87 & 0,36 & 33,69 & 9,7 & 0,26 \\
\hline & Média & 26,82 & 2116,02 & 0,31 & 29,2 & 10,64 & 0,23 \\
\hline & Desvio Padrão & 1,16 & 236,19 & 0,07 & 6,98 & 1,94 & 0,05 \\
\hline \multirow[t]{7}{*}{ HNIPU 3} & Teste & Carga Máx. & Penetração Máx & Hardness (GP & Dureza(HV) & Modulus & Martens \\
\hline & Teste 1 & 29,09 & 1870,84 & 0,6 & 56,51 & 5,46 & 0,31 \\
\hline & Teste 2 & 28,91 & 2339,81 & 0,32 & 30,47 & 4,56 & 0,2 \\
\hline & Teste 3 & 26,02 & 1946,06 & 0,41 & 39,12 & 5,92 & 0,26 \\
\hline & Teste 4 & 28,9 & 2437,55 & 0,3 & 28,04 & 4,23 & 0,18 \\
\hline & Média & 28,23 & 2148,57 & 0,41 & 38,54 & 5,04 & 0,24 \\
\hline & Desvio Padrão & 1,27 & 244,04 & 0,12 & 11,17 & 0,68 & 0,05 \\
\hline \multirow[t]{6}{*}{ HNIPU 4} & Teste & Carga Máx. & Penetração Máx & Dureza(GPa) & Dureza(HV) & Modulus & Martens \\
\hline & Teste 2 & 22,86 & 3094,43 & 0,14 & 13,23 & 2,31 & 0,09 \\
\hline & Teste 3 & 29,1 & 3824,71 & 0,13 & 12,76 & 1,49 & 0,07 \\
\hline & Teste 4 & 29,12 & 3236,6 & 0,2 & 19,4 & 1,87 & 0,1 \\
\hline & Média & 27,03 & 3385,25 & 0,16 & 15,13 & 1,89 & 0,09 \\
\hline & Desvio Padrão & 2,94 & 316,12 & 0,032 & 3,02 & 0,33 & 0,01 \\
\hline \multirow[t]{5}{*}{ NIPU 2} & Teste & Carga Máx. & Penetração Máx & Dureza(GPa) & Dureza(HV) & Modulus & Martens \\
\hline & Teste 1 & 26,71 & 2898,54 & 0,16 & 15,02 & 4,48 & 0,12 \\
\hline & Teste 3 & 27,31 & 2501,85 & 0,1 & 9,15 & $-1,02$ & 0,17 \\
\hline & Média & 27,01 & 2700,19 & 0,13 & 12,09 & 1,72 & 0,15 \\
\hline & Desvio Padrão & 0,3 & 198,34 & 0,03 & 2,93 & 2,76 & 0,02 \\
\hline
\end{tabular}

Fonte: elaborado pelo próprio autor, 2019. 